\title{
200-BP-5 Operable Unit Treatability Test Report
}

\author{
RECEIVED
$A U_{6} 081996$ \\ OSTI
}


TRADEMARK DISCLAIMER

Reference herein to any specific commercial product, process, or service by trade name, trademark, manufacturer, or otherwise, does not necessarily constitute or imply its endorsement, recommendation, or favoring by the United States Government or any agency thereof or its contractors or subcontractors.

This report has been reproduced from the best avallable copy. Available in paper copy and microfiche.

Available to the U.S. Department of Energy

and its contractors from

Office of Scientific and Technical Information

P.O. Box 62

Oak Ridge, TN 37831

(615) $576-8401$

Available to the public from the U.S. Department of Commerce

National Technical Information Service

5285 Port Royal Road

Springfield, VA 22161

(703) 487-4650

Printed in the United States of America

DISCLM-5.CHP (8-91) 


\section{0-BP-5 Operable Unit Treatability Test Report}

Date Published

April 1996

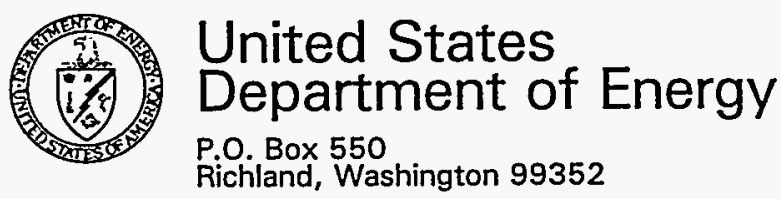

Richland, Washington 99352 


\section{DISCLAIMER}

Portions of this document may be illegible in electronic image products. Images are produced from the best available original document. 


\section{CONTENTS}

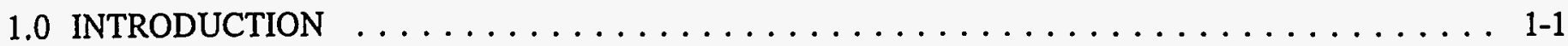

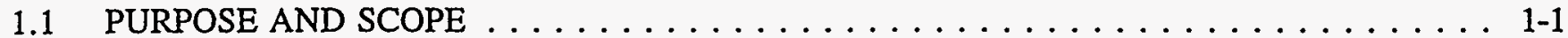

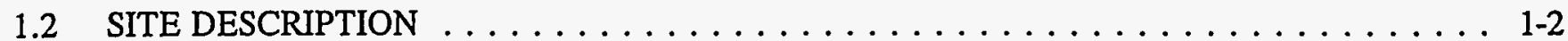

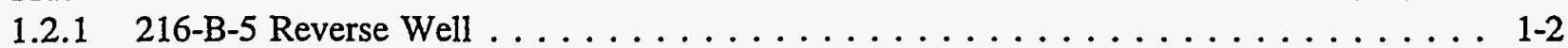

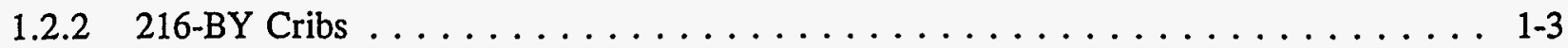

1.3 TREATMENT TECHNOLOGY DESCRIPTION $\ldots \ldots \ldots \ldots \ldots \ldots \ldots \ldots \ldots \ldots \ldots \ldots$

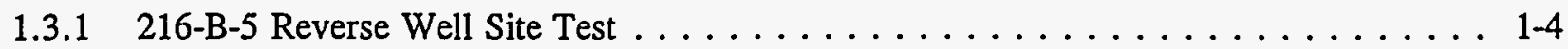

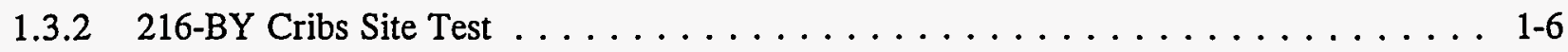

1.4 GENERAL GEOLOGY AND HYDROGEOLOGY $\ldots \ldots \ldots \ldots \ldots \ldots \ldots \ldots \ldots \ldots \ldots$

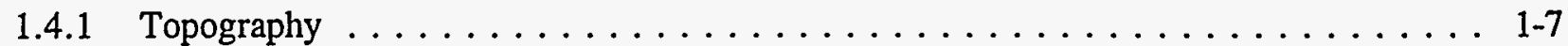

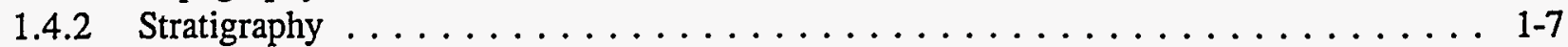

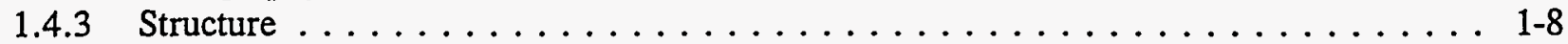

1.4 .4 Hydrogeology . . . . . . . . . . . . . . . . . . .

1.5 REPORT ORGANIZATION $\ldots \ldots \ldots \ldots \ldots \ldots \ldots \ldots \ldots \ldots \ldots \ldots \ldots \ldots \ldots \ldots$

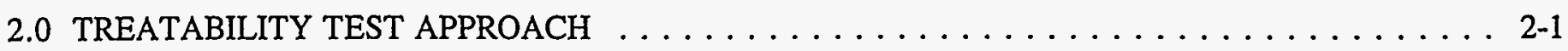

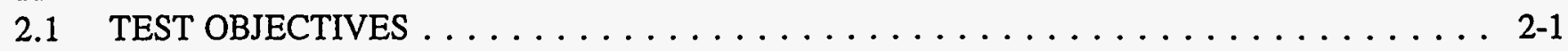

2.1.1 Test Performance Objectives ..................... 2-1

2.1.2 Data Quality Objectives ..................... 2-3

2.2 EXPERIMENTAL DESIGN AND PROCEDURE $\ldots \ldots \ldots \ldots \ldots \ldots \ldots \ldots \ldots \ldots$

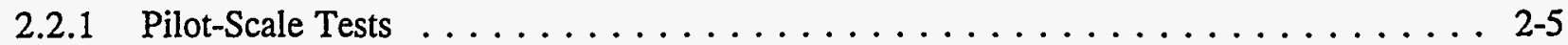

2.2.2 Laboratory-Scale Tests . . . . . . . . . . . . . . . . . . 2-8

2.2.3 Groundwater Monitoring/Hydrogeologic Assessment Activities . . . . . . . 2-12

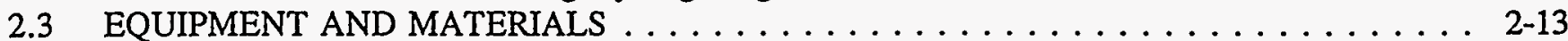

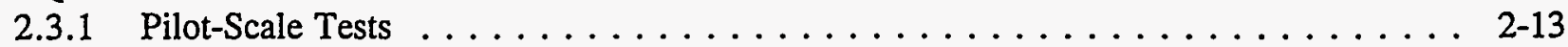

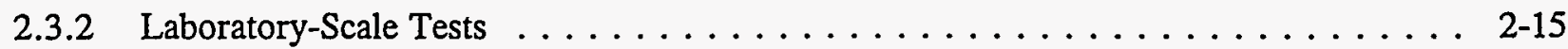

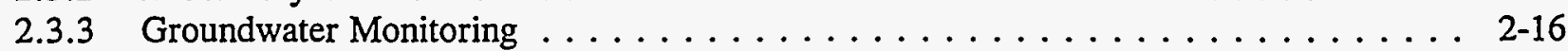

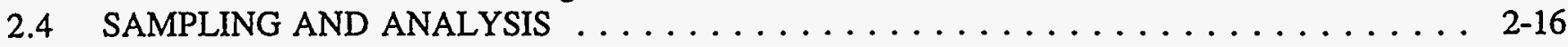

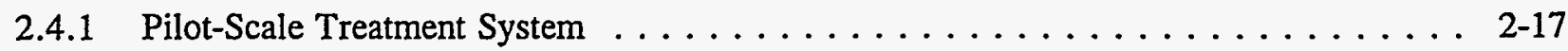

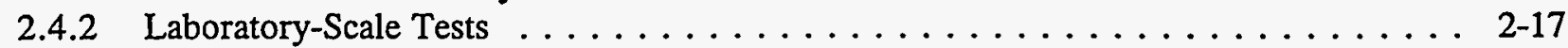

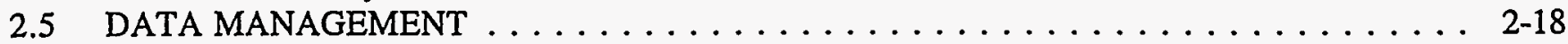

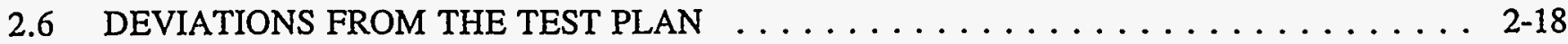

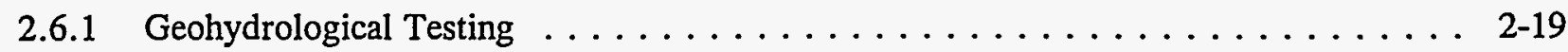

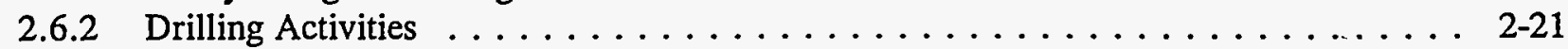

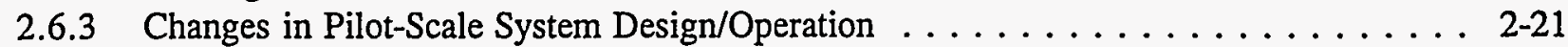

2.6.4 Preliminary Engineering Assessment of Treatment Alternatives $\ldots \ldots \ldots \ldots \ldots$ 2-23

2.6.5 Addition of the 216-A-25 Gable Mountain Pond to the Risk Assessment . . . . . . . 2-23

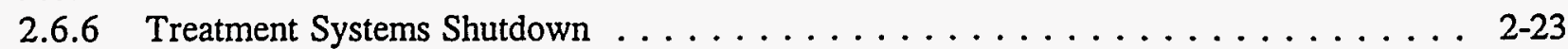

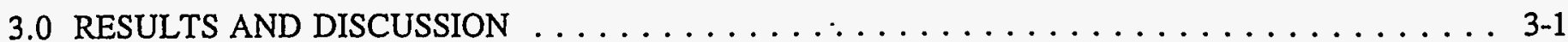

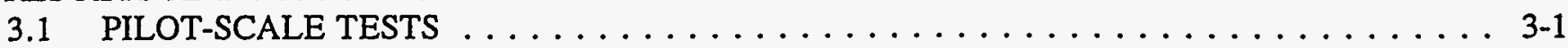

3.1.1 Pilot-Scale Treatment System Effectiveness . . . . . . . . . . . . . . 3-1

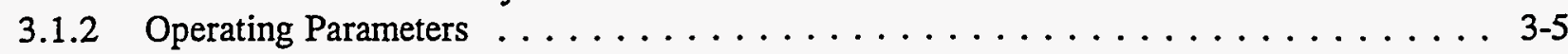

3.1.3 Resource Requirements . . . . . . . . . . . . . . . . . . . 3-8

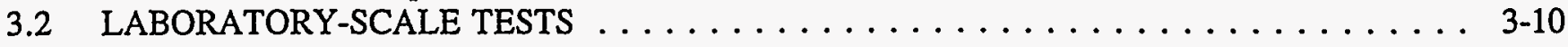

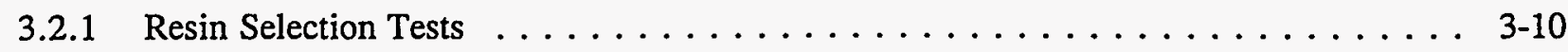


DOE/RL-95-59

Rev. 0

\section{CONTENTS (Continued)}

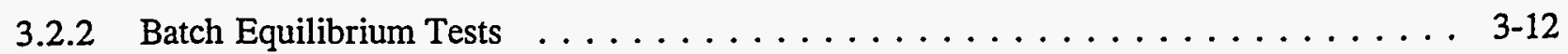

3.2.3 Flow-Through Column Tests (Mini-Columns) . . . . . . . . . . . . . . . . 3-15

3.2 .4 Strontium-85 Data for $100-\mathrm{N}$ Area $\ldots \ldots \ldots \ldots \ldots \ldots \ldots \ldots$. . . . . . . . . . . . . . .

4.0 GROUNDWATER MONITORING AND ASSESSMENT ACTIVITIES . . . . . . . . . . . . . 4-1

4.1 WELL SUITABILITY INVESTIGATION $\ldots \ldots \ldots \ldots \ldots \ldots \ldots \ldots \ldots \ldots \ldots$

4.2 WATER-LEVEL MONITORING IN SUPPORT OF TREATABILITY TESTING $\ldots \ldots \ldots$. . . . 4-2

4.2.1 Pre-Treatability Test Water-Level Monitoring at the 216-B-5 Reverse Well Site . . . . . 4-2

4.2.2 Water-Level Monitoring During Operation at the 216-B-5 Reverse Well Site . . . . . . 4-2

4.2.3 Post-Treatability Test Water-Level Data at the 216-B-5 Reverse Well Site . . . . . . . . 4-3

4.2.4 Pre-Treatability Test Water-Level Monitoring at the 216-BY Cribs . . . . . . . . . . 4-3

4.2.5 Water-Level Monitoring During Operation at the 216-BY Cribs . . . . . . . . . . . 4-3

4.2.6 Post-Treatability Test Water-Level Monitoring at 216-BY Cribs . . . . . . . . . . . . 4-4

4.3 CONTAMINANT CONCENTRATION RESPONSE . . . . . . . . . . . . . . . . . . 4-4

4.3.1 Baseline Groundwater Quality in the 216-B-5 Reverse Well Plume . . . . . . . . . . . . 4-4

4.3.2 Contaminant Response to Pumping at Extraction Well 299-E28-23 . . . . . . . . . . . 4-4

4.3 .3 Review of Data . . . . . . . . . . . . . . . . . . . . . 4-7

4.3.4 Post-Treatability Test Water Quality . . . . . . . . . . . . . . . . . . . . 4-9

4.3.5 Baseline Groundwater Quality at the 216-BY Cribs Plume . . . . . . . . . . . . . 4-9

4.3 .6 Post-Treatability Test Water Quality . . . . . . . . . . . . . . . . . . . 4-10

4.4 DESCRIPTION OF OTHER HYDROGEOLOGIC ASSESSMENT ACTIVITIES . . . . . . . . . 4-10

4.4.1 Sonic Push Groundwater Sampling for 216-BY-Cribs Plume Definition . . . . . . . . 4-10

4.4 .2 Production Testing During Treatability Testing . . . . . . . . . . . . . 4-11

4.4 .3 Groundwater In Situ Flow Survey . . . . . . . . . . . . . . . . . . . 4-12 . . . . . . . . . . . .

4.4 .4 216-B-5 Reverse Well Tracer Tests . . . . . . . . . . . . . . . 4-13

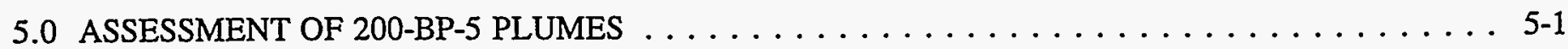

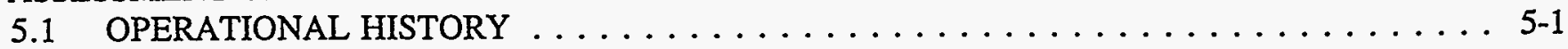

5.1 .1200 Area Facility Operational Histories . . . . . . . . . . . . . . . . 5-2

$5.1 .2 \quad 200-$ BP-5 Contaminant and Effluent Sources . . . . . . . . . . . . . . . 5-5

5.1 .3200 West Area Groundwater Movement . . . . . . . . . . . . . . . . . . . . 5-9

5.2 HISTORICAL GEOSCIENCES INFORMATION . . . . . . . . . . . . . . . . . . 5-10

5.2 .1 Water Levels . . . . . . . . . . . . . . . . . . . . . . . . 5-10

5.2.2 Groundwater Contamination Concentrations and Plume Migration . . . . . . . . . . 5-12

5.3 CONTAMINANT CONCEPTUAL MODELS . . . . . . . . . . . . . . . . . 5 5 15

$5.3 .1 \quad 216-\mathrm{B}-5$ Reverse Well $\ldots \ldots \ldots \ldots \ldots \ldots \ldots \ldots \ldots \ldots \ldots \ldots \ldots \ldots \ldots$

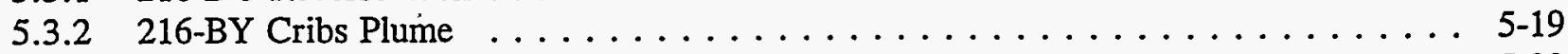

$5.3 .3216-\mathrm{A}-25$ Gable Mountain Pond Plume . . . . . . . . . . . . . . . . 5-22

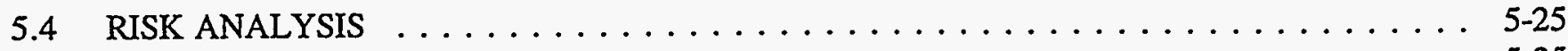

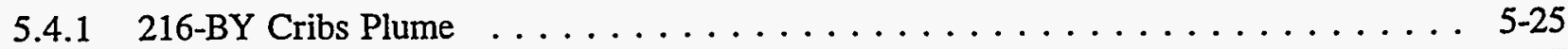

$5.4 .2 \quad 216-\mathrm{B}-5$ Reverse Well Plume $\ldots \ldots \ldots \ldots \ldots \ldots \ldots \ldots \ldots \ldots \ldots \ldots \ldots \ldots$

5.4 .3 Gable Mountain Pond Plume . . . . . . . . . . . . . . . . . . . . . . . 5-29

5.5 UNCERTAINTIES AND DATA NEEDS . . . . . . . . . . . . . . . . . . . . . . . . . . . . 5-29

$5.5 .1 \quad 216-\mathrm{B}-5$ Reverse Well Plume $\ldots \ldots \ldots \ldots \ldots \ldots \ldots \ldots \ldots \ldots \ldots$

$5.5 .2 \quad 216-\mathrm{BY}$ Cribs Contaminant Plume $\ldots \ldots \ldots \ldots \ldots \ldots \ldots \ldots \ldots \ldots$

$5.5 .3 \quad 216-\mathrm{A}-25$ Gable Mountain Pond Plume $\ldots \ldots \ldots \ldots \ldots \ldots \ldots \ldots$ 
DOE/RL-95-59

Rev. 0

CONTENTS (Continued)

6.0216 -BY CRIBS TREATMENT SYSTEM $\ldots \ldots \ldots \ldots \ldots \ldots \ldots \ldots \ldots \ldots \ldots \ldots \ldots \ldots \ldots$

6.1 CONTAMINANT EXTRACTION SYSTEM CONCEPTUAL DESIGN . . . . . . . . 6-1

6.2 TREATMENT SYSTEM DESIGN PARAMETERS FOR THE 216-BY CRIB PLUME . . . . 6-2

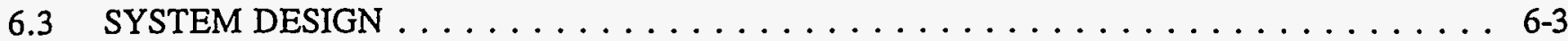

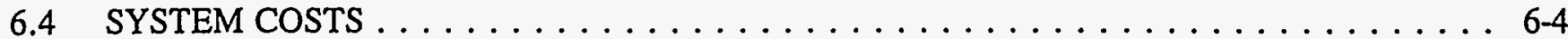

7.0 CONCLUSIONS AND RECOMMENDATIONS $\ldots \ldots \ldots \ldots \ldots \ldots \ldots \ldots \ldots \ldots \ldots \ldots$

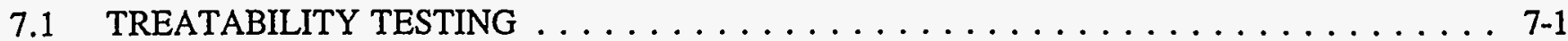

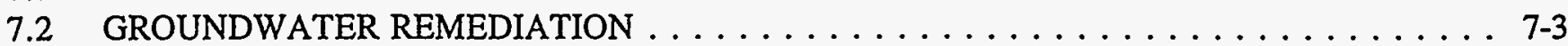

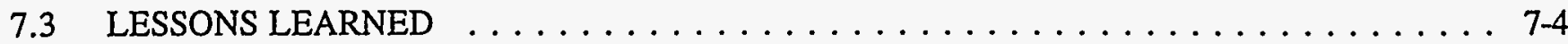

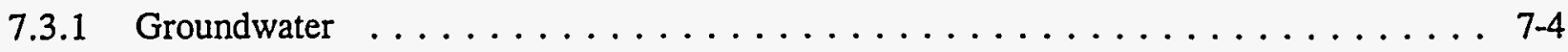

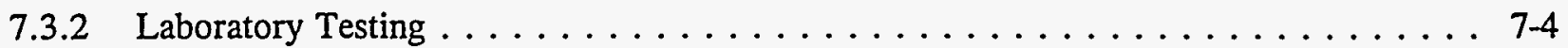

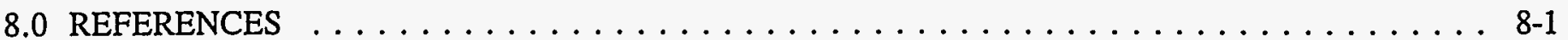

\section{APPENDICES:}

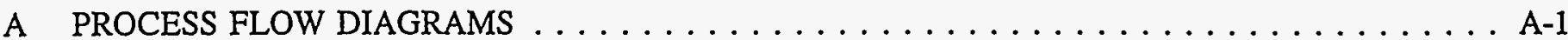

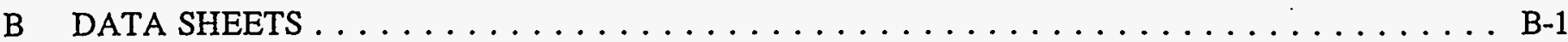

C DATA TABLES, DATABASE, AND SECONDARY CONTAMINANTS $\ldots \ldots \ldots \ldots \ldots \ldots$ C-1

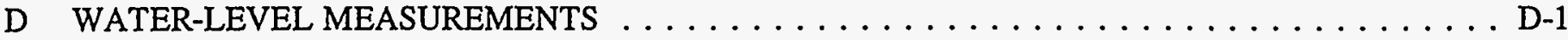

E REPORT ON IN SITU FLOW VELOCITY MEASUREMENTS AT THE 200-BP-5 OPERABLE UNIT . . . . . . . . . . . . . . . . . . . . . . E-1

F AS-BUILT AND SITE MAPS FOR 200-BP-5 PUMP-AND-TREAT SITES $\ldots \ldots \ldots \ldots \ldots \ldots$ F-1

\section{FIGURES:}

1-1. Hanford Site Map . . . . . . . . . . . . . . . .

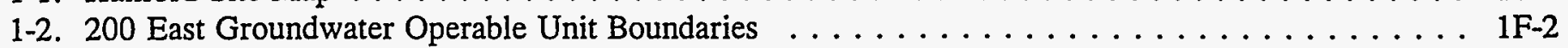

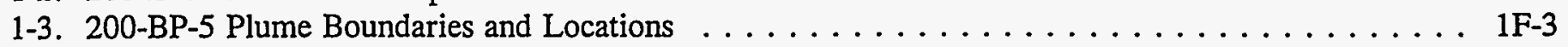

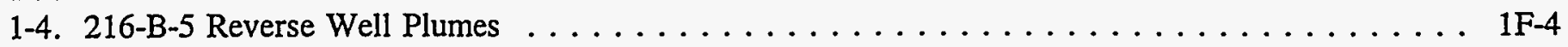

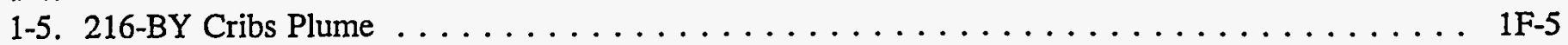

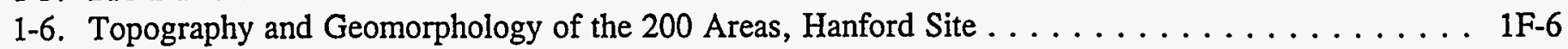

1-7. Generalized Stratigraphy of the Hanford Site $\ldots \ldots \ldots \ldots \ldots \ldots \ldots \ldots \ldots \ldots \ldots \ldots \ldots \ldots \ldots$

1-8. Generalized Stratigraphy of the Suprabasalt Sediments Beneath the Hanford Site $\ldots \ldots \ldots \ldots \ldots$ 1F-8

1-9. Conceptual Hydrogeologic Column for the 200 East Area. . . . . . . . . . . . . . . . 1F-9

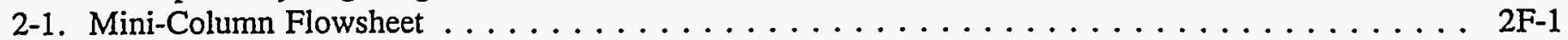

2-2. 216-B-5 Reverse Well Treatment System Equipment Arrangement $\ldots \ldots \ldots \ldots \ldots \ldots \ldots \ldots$ 2F-2

2-3. 216-BY Cribs Treatment System Equipment Arrangement . . . . . . . . . . . . 2F-3

3-1. Pilot-Scale System Lead Column Strontium-90 Effluent Versus Bed Volumes Treated, Run $1 \ldots \ldots$ 3F-1

3-2. Pilot-Scale System Overall Strontium-90 Effluent Versus Bed Volumes Treated, Run $1 \ldots \ldots$. . . 3F-2

3-3. Pilot-Scale System Lead Column Cesium-137 Effluent Versus Bed Volumes Treated, Run $1 \ldots \ldots$ 3F-3

3-4. Pilot-Scale System Plutonium-239/240 Effluent Versus Bed Volumes Treated, Run $1 \ldots \ldots$. . . 3F-4

3-5. Pilot-Scale System Lead Column Strontium-90 Effluent Versus Bed Volumes Treated, Run $2 \ldots$. . 3F-5 
DOE/RL-95-59

Rev. 0

\section{CONTENTS (Continued)}

3-6. Pilot-Scale System Overall Strontium-90 Effluent Versus Bed Volumes Treated, Run 2 . . . . . . . 3F-6

3-7. Pilot-Scale System Lead Column Technetium-99 Effluent Versus Bed Volumes Treated . . . . . . . . 3F-7

3-8. Pilot-Scale System Lead Column Cobalt-60 Effluent Versus Bed Volumes Treated . . . . . . . . . . 3F-8

3-9. IRC-718 Isotherm for Strontium-90 . . . . . . . . . . . . . . . . . . . . . . . . . . 3F-9

3-10. Hanford Bone Char Isotherm for Plutonium $\ldots \ldots \ldots \ldots \ldots \ldots \ldots \ldots \ldots \ldots$

3-11. Resintech Bone Char Isotherm for Plutonium . . . . . . . . . . . . . . . . . 3F-11

3-12. Resintech Bone Char Isotherm for Strontium $-90 \ldots \ldots \ldots \ldots \ldots \ldots \ldots \ldots$. . . . . . . . . . 3F-12

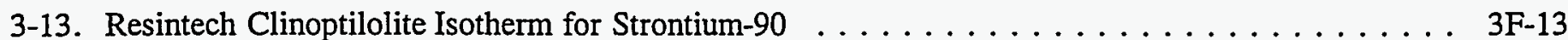

3-14. Resintech Clinoptilolite Isotherm for Cesium-137 . . . . . . . . . . . . . . . . . . 3F-14

3-15. American Resources Corporation Clinoptilolite Isotherm for Strontium-90 . . . . . . . . . . . . 3F-15

3-16. American Resources Corporation Clinoptilolite Isotherm for Cesium-137 . . . . . . . . . . . 3F-16

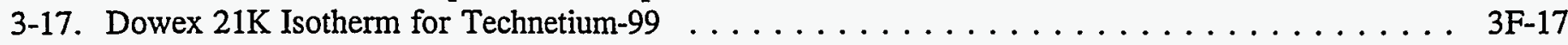

3-18. Clinoptilolite Flow-Through Column Test Plot (Resin Selection Tests) . . . . . . . . . . . . 3F-18

3-19. UOP A-51 Adsorption Isotherm . . . . . . . . . . . . . . . . . . . . . . . . . 3F-19

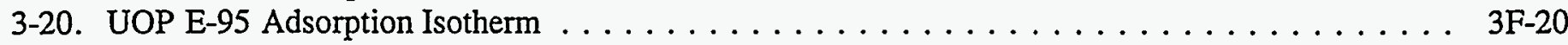

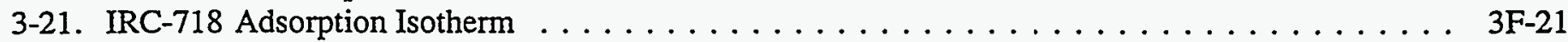

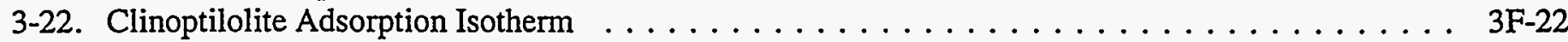

3-23. Third Group Clinoptilolite Adsorption Isotherms $\ldots \ldots \ldots \ldots \ldots \ldots \ldots \ldots$. . . . . . . . . 3F-23

3-24. MCT-1 Lead Clinoptilolite Column Strontium-90 Removal Versus Bed Volumes Treated . . . . 3F-24

3-25. MCT-1 Overall System Strontium-90 Removal Versus Bed Volumes Treated . . . . . . . . . . . 3F-25

3-26. MCT-1 Lead Clinoptilolite Column Cesium-137 Removal Versus Bed Volumes Treated . . . . . 3F-26

3-27. MCT-1 Bone Char Column Plutonium-239/240 Removal Versus Bed Volumes Treated . . . . . . . 3F-27

3-28. MCT-1 and MCT-2 Lead Column Strontium-90 Removal Versus Bed Volumes Treated . . . . . . 3F-28

3-29. MCT-1 and MCT-2 Overall Strontium-90 Removal Versus Bed Volumes Treated . . . . . . . . . 3F-29

3-30. 2MCT-2 Lead Clinoptilolite Column Strontium-90 Removal Versus Bed Volumes Treated . . . . . 3F-30

3-31. 2MCT-2 Overall System Effluent Strontium-90 Removal Versus Bed Volumes Treated . . . . . . 3F-31

3-32. 2MCT-3 Lead Clino Column Strontium-90 Removal Versus Bed Volumes Treated . . . . . . . . 3F-32

3-33. 2MCT-3 Overall System Strontium-90 Removal Versus Bed Volumes Treated . . . . . . . . . . 3F-33

3-34. Lead Mini-Column Technetium-99 Effluent Versus Bed Volumes Treated, Test 1 . . . . . . . . . 3F-34

3-35. Overall Mini-Column Technetium-99 Effluent Versus Bed Volumes Treated, Test $1 \ldots \ldots$. . . . . 3F-35

3-36. Lead Mini-Column Technetium-99 Effluent Versus Bed Volumes Treated, Test $2 \ldots \ldots$. . . . . . 3F-36

3-37. Overall Mini-Column Technetium-99 Effluent Versus Bed Volumes Treated, Test $2 \ldots \ldots$. . . . 3F-37

3-38. Lead Mini-Column Cobalt-60 Effluent Versus Bed Volumes Treated, Test $1 \ldots \ldots$. . . . . . . 3F-38

3-39. Lead Mini-Column Cobalt-60 Effluent Versus Bed Volumes Treated, Test $2 \ldots \ldots$. . . . . . . . 3F-39

4-1. Water-Table Map at 216-B-5 Reverse Well Plumes . . . . . . . . . . . . . . . . . . . . 4F-1

4-2. Water-Table Map at 216-BY Cribs Plume . . . . . . . . . . . . . . . . . . . . 4F-2

4-3. 216-B-5 Reverse Well Baseline Contamination Distribution Map . . . . . . . . . . . . . . . 4F-3

4-4. Plutonium-239/240 Extraction at 216-B-5 Reverse Well Site . . . . . . . . . . . . . . . . . . . . 4F-4

4-5. Cesium-137 Extraction at the 216-B-5 Reverse Well Site . . . . . . . . . . . . . . . . . . 4F-5

4-6. Strontium-90 Extraction at the 216-B-5 Reverse Well Site . . . . . . . . . . . . . . . . 4F-6

4-7. 216-BY Cribs Baseline Contamination Distribution Map . . . . . . . . . . . . . . . . 4F-7

4-8. Cobalt-60 Extraction at the 216-BY Cribs Site . . . . . . . . . . . . . . . . . 4F-8

4-9. Technetium-99 Extraction at the 216-BY Cribs Plume Site . . . . . . . . . . . . . . . . . 4F-9

4-10. Sonic Push Well Location Map at the 216-BY Cribs Site . . . . . . . . . . . . . . . . . . . 4F-10

4-11. Groundwater Sampling Map for Sonic Push Testing at 216-BY Cribs . . . . . . . . . . . . . . 4F-11

4-12. In Situ Velocity Flowmeter Test Wells in the 216-BY Cribs Plume . . . . . . . . . . . . . . . 4F-12 
DOE/RL-95-59

Rev. 0

\section{CONTENTS (Continued)}

4-13. Comparison of the Analytical Solution Output to the Measured Bromide Concentration at Well 299-E28-23 . . . . . . . . . . . . . . . . . . . . . .

4-14. Sensitivity Analysis of the Analytical Solution Output to the Porosity Term Varied by $17 \%$. . . .

4-15. Sensitivity Analysis of the Analytical Solution Output to the Dispersivity Term Varied by $27 \%$. . .

4-16. Comparison of the Analytical Solution Output to the Measured

Bromide Concentration at Well 299-E28-23 . . . . . . . . . . . . . . . . . . . . . 4F-16

4-17. Sensitivity Analysis of the Analytical Solution Output to the Porosity Term Varied by $27 \%$. . . . 4F-17

4-18. Sensitivity Analysis of the Analytical Solution Output to the Dispersivity Term Varied by 25\% . . 4F-18

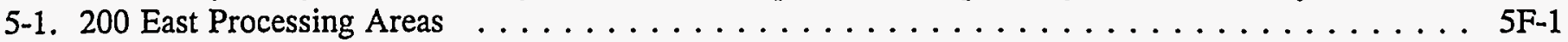

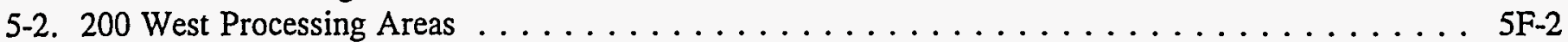

5-3. The 216-BY Cribs, 200-BP-1 Operable Unit $\ldots \ldots \ldots \ldots \ldots \ldots \ldots \ldots \ldots \ldots$

5-4. Estimated Annual Discharge (in liters) to Gable Mountain Pond (216-A-25), and B Pond System (216-B-3 Ponds), 200 East Area, 1945 to 1994 . . . . . . . . . . . . . . . 5F-4

5-5. Ditches and Pipelines Used For Effluent Transport to the 216-B-3 Pond System . . . . . . . . . 5F-5

5-6. Estimated Annual Discharges (in liters) to S Ponds, T Pond, and U Pond, 200 West Area,

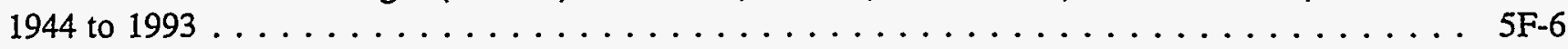

5-7. Estimated Annual Discharge (in liters) to S Plant, T Plant, U Plant, and Z Plant, 1944 to 1993 . . . 5F-7

5-8. Estimated Effluent Discharge Volumes to 216-B-3 Pond, 216-A-25 Gable Mountain Pond,

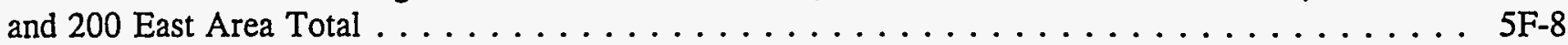

5-9. Historic Water-Table Maps for 200-BP-5 Operable Unit, 1944 to $1995 \ldots \ldots$. . . . . . . . . . . . 5F-9

5-10. Historic Groundwater Elevation Changes for 200-BP-5 Operable Unit

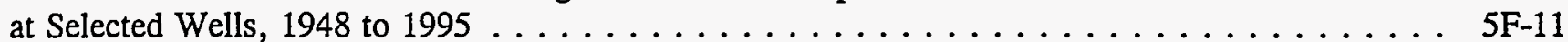

5-11. Streamline Analysis for 200 East Area, $1993 \ldots \ldots \ldots \ldots \ldots \ldots \ldots \ldots \ldots$. . . . . . . . . . 5F-12

5-12. Historic Gross Beta Distribution Maps in 200 Areas, 1956 to $1992 \ldots \ldots \ldots$. . . . . . . . . . 5F-13

5-13. Well and Facility Locations, 216-B-5 Reverse Well . . . . . . . . . . . . . . . . . . . . 5F-17

5-14. Estimated Radionuclide Distributions at 216-B-5 Reverse Well, 1947 to $1949 \ldots \ldots$. . . . . . . 5F-18

5-15. Strontium-90 Concentrations in Wells about the 216-B-5 Reverse Well, 1985 to 1994 . . . . . . . 5F-20

5-16. Cesium-137 Concentrations in Wells at the 216-B-5 Reverse Well, 1985 to 1994 . . . . . . . . . 5F-21

5-17. Plutonium-239/240 Concentrations in Wells at the 216-B-5 Reverse Well, 1985 to 1994 . . . . . 5F-22

5-18. Gross Beta Time History at 299-E33-4 216-BY Cribs, 1952 to 1993 . . . . . . . . . . . . . . 5F-22

5-19. Gross Beta Time History for Wells within 216-BY Cribs Plumes, 1952 to 1995 . . . . . . . . . 5F-23

5-20. Cyanide Distribution in Wells at the 216-BY Cribs Plumes, 1985 to $1995 \ldots \ldots \ldots \ldots$. . . . . . 5F-25

5-21. Cobalt-60 Distribution in Wells at the 216-BY Cribs Plumes, 1985 to $1995 \ldots \ldots$. . . . . . . . 5F-26

5-22. Technetium-99 Distribution in Wells at the 216-BY Cribs Plumes, 1985 to $1995 \ldots \ldots$. . . . . . 5F-27

5-23. Gross Beta Time History at Well 699-55-50A, 215-A-25 Gable Mountain Pond, 1952 to 1990 . . . 5F-27

5-24. Strontium-90 Time History at Wells in the 216-A-25 Gable Mountain Pond Plume, 1980 to 1995 . 5F-28

5-25. Gable Mountain Pond Strontium-90 Plume: Data are from $1994 \ldots \ldots$. . . . . . . . . . . . . . 5F-29

5-26. Site Map of the Deactivated 216-A-25 Gable Mountain Pond Showing Well Locations . . . . . . 5F-30

5-27. History of Strontium-90 Concentrations in Groundwater and Water-Table Elevations in Wells 699-53-47B and 699-53-48B, Gable Mountain Pond . . . . . . . . . . . . . . . 5F-31

5-28. History of Strontium-90 Concentrations in Groundwater at Gable Mountain Pond . . . . . . . . . 5F-32

5-29. History of Cesium-137 Concentrations in Groundwater at Gable Mountain Pond . . . . . . . . . . 5F-33

5-30. 216-BY Cribs Plume Incremental Lifetime Cancer Risk for Reasonable Maximum Exposure to Technetium-99 in Groundwater, Existing and Future Conditions . . . . . . . . . . 5F-34

5-31. 215-B-5 Reverse Well Plume Incremental Lifetime Cancer Risk for Reasonable Maximum Exposure to Technetium-99 in Groundwater, Existing and Future Conditions . . . . . . . . . . 
DOE/RL-95-59

Rev. 0

\section{CONTENTS (Continued)}

5-32. Gable Mountain Pond Plume Incremental Lifetime Cancer Risk for Reasonable Maximum

Exposure to Strontium-90 in Groundwater, Existing and Future Conditions

6-1. Preliminary Capture-Zone Analysis $\ldots \ldots \ldots \ldots \ldots \ldots \ldots \ldots \ldots \ldots \ldots \ldots \ldots \ldots \ldots$

\section{TABLES:}

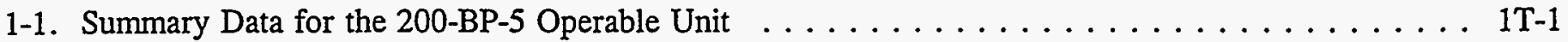

2-1. Data Quality Objectives for Laboratory-Scale Testing . . . . . . . . . . . . . . . 2T-1

2-2. Data Quality Objectives for 200-BP-5 Operable Unit Plumes Pilot-Scale Treatment Testing . . . . . 2T-2

2-3. 200-BP-5 Treatability Test Objectives and Approach . . . . . . . . . . . . . . 2T-4

2-4. Data Quality Objectives for 200-BP-5 Operable Unit Plumes Contaminant Extraction Testing . . . . 2T-5

2-5. Data Quality Objectives for Hydrogeologic Assessment . . . . . . . . . . . . . 2T-7

2-6. Data Quality Objectives for Groundwater Monitoring $\ldots \ldots \ldots \ldots \ldots \ldots \ldots \ldots \ldots \ldots \ldots \ldots \ldots \ldots$

2-7. Mini-Column Tests at the $216-\mathrm{B}-5$ Reverse Well $\ldots \ldots \ldots \ldots \ldots \ldots \ldots \ldots \ldots \ldots \ldots$. . . . . . . . . . .

3-1. Lead Column Removal Performance, Quantities of Radionuclides . . . . . . . . . . . . . . . 3T-1

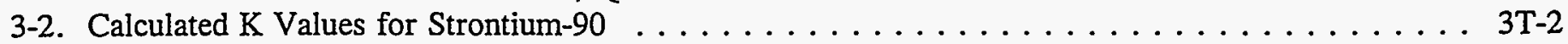

3-3. System Removal Performance, Quantities of Radionuclides . . . . . . . . . . . . . . . 3T-3

3-4. Cost/Resource Requirements . . . . . . . . . . . . . . . . . . . . . 3T-4

3-5. N-Springs Groundwater Test Conditions and Breakthrough of Strontium-85 in Clinoptilolite

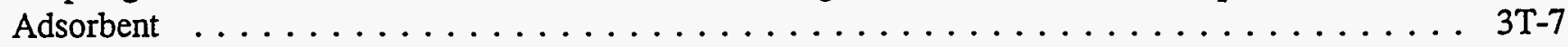

4-1. Summary of Well Suitability Activities and Production Data $\ldots \ldots \ldots \ldots \ldots \ldots \ldots \ldots$ 4T-1

4-2. 216-B-5 Reverse Well Baseline Water Quality Data . . . . . . . . . . . . . . . . 4T-2

4-3. Summary of the Average Concentration of Contaminants in Groundwater During Pumping . . . . 4T 4 -4

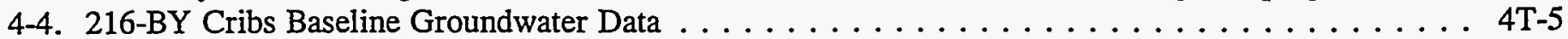

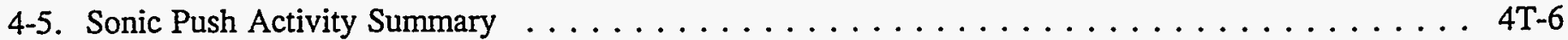

4-6. Measurement Results from Sonic Push . . . . . . . . . . . . . . . . . . . . 4T-7

4-7. Groundwater Data Collected Over Time at Well 699-55-57 During Production Testing . . . . . . . 4T-7

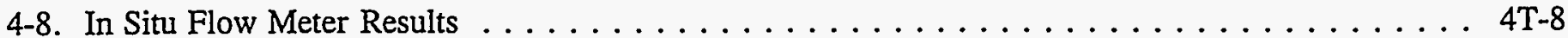

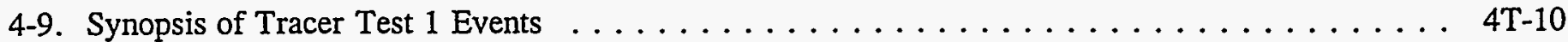

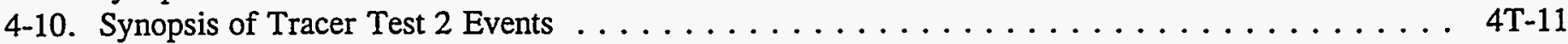

5-1. Summary of Waste Management Units Pertinent to 200-BP-5 Treatability Test . . . . . . . . T5-1

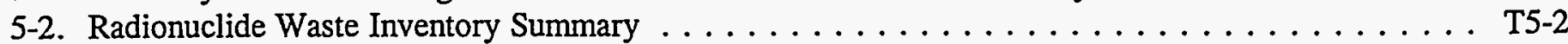

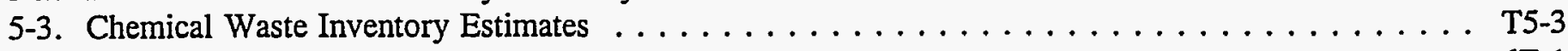

6-1. 216-BY Cribs Treatment System Estimated Cost . . . . . . . . . . . . . . . . 6T-1 


\section{ACRONYMS}

AmReC

B-5 Reverse Well

bgs

$\mathrm{BHI}$

$\mathrm{BiPO}_{4}$

BV

BY-Cribs

$\mathrm{C}_{\mathrm{o}}$

COPC

DOE

DOE-RL

DOW

DQO

DWS

Ecology

EIP

EPA

ERA

ERC

FY

GAC

GFAA

HEIS

HSRAM

ILCR

IRM

ITS

$\mathrm{K}_{\mathrm{d}}$

LFI

MCL

MTCA

NPL

PFP

PIF

PNNL

PRF

PUREX

QAPjP

QC

QRA

RBDA

RCA

RCRA

REDOX

$\mathrm{SpA}$

$\mathrm{SrCl}_{2}$
American Resources Corporation

216-B-5 Reverse Well

below ground surface

Bechtel Hanford, Inc.

bismuth phosphate

bed volume

216-BY Cribs

concentration

contaminants of potential concern

U.S. Department of Energy

U.S. Department of Energy, Richland Operations Office

description of work

data quality objectives

drinking water standard

Washington State Department of Ecology

Environmental Investigation Procedure

U.S. Environmental Protection Agency

expedited response action

Environmental Restoration Contractor

fiscal year

granular activated carbon

graphite furnace atomic adsorption

Hanford Environmental Information System

Hanford Site Risk Assessment Methodology

incremental lifetime cancer risk

interim remedial measure

in-tank solidification

distribution coefficient

limited field investigation

maximum contaminant level

Model Toxics Control Act

National Priorities List

Plutonium Finishing Plant

Plutonium Isolation Facility

Pacific Northwest National Laboratory

Plutonium Reclamation Facility

Plutonium/Uranium Extraction

quality assurance project plan

quality control

Qualitative Risk Assessment

Risk-Based Decision Analysis

Radiation Control Area

Resource Conservation and Recovery Act of 1976

reduction-oxidation

specific activity

strontium chloride 
DOE/RL-95-59

Rev. 0

\section{ACRONYMS (Continued)}

TBP

TCLP

TDL

Tri-Party Agreement

UCL

WESF

WHC tributyl phosphate

toxic characteristic leach procedure

Technology Development Laboratory

Hanford Federal Facility Agreement and Consent Order

upper confidence limit

Waste Encapsulation and Storage Facility

Westinghouse Hanford Company 
DOE/RL-95-59

Rev. 0

\subsection{INTRODUCTION}

The 200-BP-5 Operable Unit was established in response to recommendations presented in the 200 East Groundwater Aggregate Area Management Study Report (AAMSR) (DOE-RL 1993a). Recognizing different approaches to remediation, the groundwater AAMSR recommended separating groundwater from source and vadose zone operable units and subdividing 200 East Area groundwater into two operable units. The division between the 200-BP-5 and 200-PO-1 Operable Units was based principally on source operable unit boundaries and distribution of groundwater plumes derived from either B Plant or Plutonium/Uranium Extraction (PUREX) Plant liquid waste disposal sites (Figures 1-1 and 1-2).

Following a rationale outlined in the Hanford Past-Practice Strategy (DOE-RL 1991), the AAMSR (DOE-RL 1993a) also identified two locations in the 200-BP-5 Operable Unit where high-priority candidate plumes were found and recommended accelerated action along either an expedited response action (ERA) or an interim remedial measure (IRM) pathway. At one location at the 216-B-5 Reverse Well (B-5 Reverse Well) site, ${ }^{137} \mathrm{Cs},{ }^{239240} \mathrm{Pu}$, and ${ }^{90} \mathrm{Sr}$ concentrations were identified as the plume contaminants; at the 216-BY Cribs (BY-Cribs) plume site, ${ }^{60} \mathrm{Co},{ }^{99} \mathrm{Tc}$, cyanide, and nitrate were identified as the plume contaminants. Plutonium-239/240 and technetium-99 were considered to be the most important radionuclides because of their long half-lives. By virtue of its higher concentrations, the ${ }^{90} \mathrm{Sr}$ plume was recommended as a candidate for the ERA pathway but was grouped with the IRM-level contaminants, ${ }^{137} \mathrm{Cs}$ and ${ }^{239 / 240} \mathrm{Pu}$, for ease of treatment (DOE-RL 1993a).

An agreement between the U.S. Department of Energy (DOE), the U.S. Environmental Protection Agency (EPA), and the Washington State Department of Ecology (Ecology), as documented in the Hanford Federal Facility Agreement and Consent Order (Tri-Party Agreement) (Change Control Form M-13-93-03) (Ecology et al. 1994), enacted these recommendations. It required the preparation of a treatability test plan by January 1994 and startup of pilot-scale pump-and-treat treatability test systems at each plume site by August 1994. The treatability tests, if successful, were to be the first step toward developing a full-scale IRM treatment system for each plume. The change also specified that ${ }^{60} \mathrm{Co},{ }^{137} \mathrm{Cs},{ }^{239 / 240} \mathrm{Pu},{ }^{90} \mathrm{Sr}$, and ${ }^{99} \mathrm{Tc}$ would be the primary target contaminants. Cyanide and nitrate were considered to be secondary contaminants of concern.

The treatability test plan (DOE-RL 1995c) identified ion exchange as the treatment technology to be evaluated. It also indicated the need for improved understanding of both groundwater contaminant distribution and aquifer property evaluation at each plume. Treatability testing began on August 29, 1994; regular operations started on January 18; 1995, and were halted on May 29, 1995. This report summarizes the results of the treatability tests at the two sites and the aquifer characterization efforts. Additionally, the report provides information related to historic plume migrations that was deemed useful in planning future actions at the 200-BP-5 Operable Unit.

\subsection{PURPOSE AND SCOPE}

The pilot-scale treatability tests were performed to assess the following: (1) the ability of an aboveground pump-and-treat system to extract sufficient volumes of groundwater from the B-5 Reverse Well and BY-Cribs plumes to affect the groundwater contaminant concentrations, and (2) the effectiveness of aboveground ion-exchange treatment systems in removing cesium, cobalt, plutonium, strontium, and technetium contaminants from the extracted groundwater. During the 
course of testing, additional elements were added to the scope. These activities provided data to support decisions on future remedial actions at the plumes.

Treatability tests were also intended to better determine the distribution of the respective contaminants at each plume and improve understanding of aquifer properties. Modifications to Rev. 0 of the treatability test plan specified drilling activities to determine the BY-Cribs plume location. A 200 National Priorities List (NPL) Agreement/Change Control Form (BHI-00203, dated November 9, 1994) detailed a number of specific activities to characterize the aquifer at both sites. Activities included additional well sampling, tracer tests, and in situ flow velocity tests. These activities are described in greater detail in Section 2.6.1.

A qualitative risk analysis (QRA) was proposed for fiscal year (FY) 1995 to assess contaminant risk to human health. An evaluation of the QRA process found it to be overly conservative and relatively costly to prepare. An alternate Risk-Based Decision Analysis (RBDA) approach to the QRA process was proposed by the Environmental Restoration Contractor (ERC) (BHI 1995b) and approved by the U.S. Department of Energy, Richland Operations Office (DOE-RL). The QRA and RBDA differed according to the conventions by which contaminant concentrations were assigned in the plume and how the plume was then rated. The QRA typically assigned the highest concentration of the target contaminant to the entire plume and then calculated the risk. From there the plume was then qualitatively rated as a low, medium, or high risk and applied to the entire area. The RBDA preserved spatial distribution from available well data and then calculated risk values for individual concentration values. The risks were then represented as risk contours on a map. In addition, the RBDA modeled the migration of contaminants to downgradient locations or specified points in time to assess the effects of natural attenuation on risk to potential future users of the ground water.

Per an agreement between the DOE, EPA, and ERC, additional text was developed for the treatability test report to address historical site operational conditions and knowledge and to relate it to the current 200-BP-5 Operable Unit data. Several groundwater reports over the years have indicated plume migrations and behavior that have not been previously analyzed in a coherent fashion.

\subsection{SITE DESCRIPTION}

The two plumes resulted from low-level radioactive liquid waste disposal activities associated with operations at the B Plant complex, located in the northwest corner of the 200 East Area. Waste was discharged to the two sites periodically during the first 30 years of Hanford Site operations. Both source sites are situated on the Separations Area Plateau at elevations of 189 to $207 \mathrm{~m}$ (620 to $680 \mathrm{ft}$ ) above sea level. The ${ }^{137} \mathrm{Cs}$, ${ }^{2391240} \mathrm{Pu}$, and ${ }^{90} \mathrm{Sr}$ plumes remain close to the $\mathrm{B}-5$ Reverse Well, but the ${ }^{60} \mathrm{Co}$ and ${ }^{99} \mathrm{Tc}$ plume from the BY-Cribs has migrated north toward Gable Gap. Consequently, while the B-5 treatment system was set up at the original waste facility, the BY treatment system was set up at the center of the current plume, well 699-50-53A.

\subsubsection{6-B-5 Reverse Well}

The B-5 Reverse Well plume is centered around the B-5 Reverse Well, which is located about $305 \mathrm{~m}$ $(1,000 \mathrm{ft})$ northeast of the 221-B Canyon Building at the B Plant facility (Figures 1-3 and 1-4). The 241-B-361 Settling Tank is located about $15.2 \mathrm{~m}$ (50 ft) southwest of the B-5 Reverse Well and was used to settle-out precipitated solids in the aqueous wastes before they entered the well. The reverse 
well is flanked by a series of four wells that lie along a northwest-southeast line within $20 \mathrm{~m}$ (65 ft) of the B-5 Reverse Well. These wells were drilled or deepened in 1979 to 1980 . The wells encounter the water table $85 \mathrm{~m}(280 \mathrm{ft})$ below the ground surface and extend to the bottom of the $15-\mathrm{m}(48-\mathrm{ft})$ thick aquifer. The next nearest wells are 155 to $168 \mathrm{~m}(510$ to $550 \mathrm{ft})$ northwest and $152 \mathrm{~m}(500 \mathrm{ft})$ east of the B-5 Reverse Well.

The pilot-scale treatability test system was set up in close proximity to the B-5 Reverse Well because the plumes were believed to be confined around the reverse well. As described in Section 4.1, based

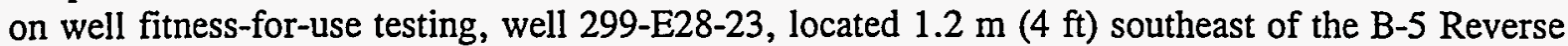
Well, was chosen to be the extraction well. Well 299-E28-7 was chosen to be the return well after an ERC regulatory analysis determined that the originally selected return well, 299-E28-1, was outside the plume boundary. The treatment system was not designed to remove ${ }^{90} \mathrm{Sr}$ to below drinking water standards (DWS) (8 pCi/L or $5.67 \times 10^{-8} \mathrm{ppb}$ ), and therefore reinjection at the well 299-E28-1 could spread contamination to an otherwise uncontaminated part of the 200 East Area aquifer [for comparison, the $1.2 \mathrm{pCi} / \mathrm{L}$ maximum contaminant level $(\mathrm{MCL})$ for ${ }^{239240} \mathrm{Pu}$ is $1.96 \times 10^{-6} \mathrm{ppb}$ and the $120 \mathrm{pCi} / \mathrm{L} \mathrm{MCL}$ for ${ }^{137} \mathrm{Cs}$ is $1.38 \times 10^{-6} \mathrm{ppb}$. A site map and well as-builts are included in Appendix F.

\subsubsection{6-BY Cribs}

The BY-Cribs plume is centered at well 699-50-53A, located $914 \mathrm{~m}(3,000 \mathrm{ft})$ north of the source BY-Cribs and 241-BY Tank Farm (Figure 1-5). From well fitness-for-use testing (see Section 4.1), it was determined that well 699-50-53A was the only candidate for the extraction well. This site was selected based on available groundwater chemistry data from local wells that indicated that the area of greatest contaminant concentration was centered at that location. The pilot-scale system was set up around well 699-50-53A. Well 699-49-55A, approximately $610 \mathrm{~m}(2,000 \mathrm{ft})$ to the west-southwest, was chosen for reinjection when fitness-for-use testing proved its suitability as a return well. Other nearby wells were 1,067 to $1,219 \mathrm{~m}(3,500$ to $4,000 \mathrm{ft})$ away. More distant wells defining the plume are scattered irregularly on $457-$ to $610-\mathrm{m}(1,500-$ to $2,000-\mathrm{ft})$ centers. The distance between wells was not considered optimal, but efforts to site and drill a well closer to the extraction well (see Section 2.6.2) were unsuccessful. A map location and well as-builts are included in Appendix F.

\subsection{TREATMENT TECHNOLOGY DESCRIPTION}

Ion exchange was selected as the treatment technology for both 200-BP-5 Operable Unit pilot-scale treatability tests. Ion exchange as a unit process is commonly applied in chemical processing, hydrometallurgy, and water and waste treatment as a technique for sorbing soluble metal species from solution. Cesium, cobalt, plutonium, strontium, and technetium are transition metals that are amenable for removal by ion exchange. This treatment technology is a proven process that does not require major technological development and is easily implemented. It has been evaluated at radioactively contaminated Superfund sites (EPA 1990) and the Oak Ridge National Laboratory (Robinson 1990). Ion exchange has been used in previous treatment studies and systems at the Hanford Site (Ames 1959, Mercer 1960, Delegard et al. 1986, Barney et al. 1992) and numerous municipal and industrial water treatment applications (Baker et al.. 1988; Sorg 1989, 1991; Jelinek and Sorg 1988; Del Cul et al. 1992). These applications demonstrate that ion exchange is an effective treatment process for removing radionuclides from both water and groundwater. 
Ion-exchange technology removes ions from solution by adsorption onto a solid medium (e.g., ion-exchange resin). Typically, with groundwater treatment, extracted groundwater is prefiltered and then pumped through a series of two or more beds (ion-exchange columns) of adsorbent where the ionic species in the groundwater exchange with or are adsorbed onto the surface of the adsorbent, thereby removing them from solution.

Generally, ion-exchange treatment systems consist of three columns that are plumbed to provide flow through any two columns at one time in a lead-polish mode, while a third column is offline for resin regeneration or resin replacement. The lead column provides primary removal of the contaminant(s) while the polish column "polishes" the discharge from the lead column to achieve a high-quality effluent. The columns are operated in a rotational basis. This arrangement provides for continuous operation in that when the lead column reaches breakthrough, it is valved out and the polish (or second) column is switched to lead position and the standby column is switched into polish position.

If the objective of ion-exchange treatment is to provide a high-quality effluent (achieve a very low target contaminant level) the lead column is generally run to $30 \%$ to $50 \%$ breakthrough to ensure that the polish column can achieve the overall desired removal. An option is to use a third column in series, then the lead column can be loaded to saturation. However, this increases system pressures and costs. The cost savings for increased loading of the lead column may not be offset by the installed cost of the third column (the overall system would require four columns for continuous operation).

The 200-BP-5 pilot-scale treatment systems used two to three ion-exchange columns in a series-flow arrangement. At the B-5 Reverse Well plume site, two lead columns of different media were required to remove the three contaminants followed by a mixed bed polishing column. At the BY-Cribs plume site, a typical two-column arrangement was used.

Resins can be regenerated, but this requires a large volume of water and regenerant solutions (acids, salt, or caustic solutions) and creates large volumes of spent solutions that require further treatment before disposal. If there were a market or demand for the recovered material, regenerating the resin might be beneficial. The 200-BP-5 Treatability Test Plan (DOE-RI, 1995c) specified that the spent resins would be dewatered, removed, and drummed for disposal (see Sections 2.2.1, 3.1). Resins were sampled and analyzed for waste characterization (Section 3.1.2.3).

To properly select an adsorbent for use in an ion-exchange treatment system, a qualitative prediction of its sorptive behavior must be made. This involves determining the type and ionic species of the contaminants that might be encountered so that an adsorbent with the proper functional group can be identified. A review of the historical processes and waste treatment operations of the facilities contributing the wastes and hydrochemical characteristics of the groundwater is helpful in determining the ionic species. The groundwater in the 200 Areas contains dissolved solids resulting from both natural and man-made processes. It also contains a significant quantity of free, or dissolved, oxygen, thus creating an oxidizing chemical environment.

\subsubsection{6-B-5 Reverse Well Site Test}

The B-5 Reverse Well was used for the disposal of medium-level radioactive wastes from B Plant starting in 1945 and received approximately $303 \times 10^{7} \mathrm{~L}\left(8 \times 10^{6}\right.$ gal) until its abandonment in 1947. Waste liquids were derived from fuel rod dissolution and waste neutralization processes at the 221-B 
Building and from waste neutralization processes at the 224-B Concentrator Building. A precipitate in the waste stream was allowed to settle in the 241-B-361 Settling Tank, located just upstream of the well. The residual waste stream containing reduced levels of cesium, plutonium, and strontium was then allowed to overflow to the ground via the B-5 Reverse Well. Contaminant activities and contaminant plume data are included in Table 1-1.

Plutonium has four oxidation states: (III), (IV), (V), and (VI). Pu(V) is unstable, disproportionating to other valence states. $\mathrm{Pu}(\mathrm{III})$ is readily converted to $\mathrm{Pu}(\mathrm{IV})$ in the presence of oxidants. This processing generally ensured that the plutonium in plant waste discharges was in the $\mathrm{Pu}(\mathrm{IV})$ state. Moreover, when plutonium is in contact with soil sediments, the higher oxidation states are slowly reduced to the $\mathrm{Pu}(\mathrm{IV})$ state (Barney 1988). The plutonyl ion is unstable and, at the $\mathrm{pH}$ ranges encountered in the aquifer ( $\mathrm{pH} 7$ to 8.5), generally combines with carbonates, hydroxides, and sulfates. Therefore, plutonium exists mainly as anions in hydroxyl and carbonate complexes in the form $\mathrm{PuO}_{2}\left(\mathrm{CO}_{3}\right)_{3}{ }^{5 \cdot}$ or $\mathrm{Pu}(\mathrm{OH})_{5}{ }^{-}$(Barney et al. 1992), or in the nitrate form $\mathrm{Pu}\left(\mathrm{NO}_{3}\right)_{6}{ }^{2-}$ (Ryan 1960). Cations and uncharged species may predominate at lower $\mathrm{pH}$ values, but generally because of the cation-exchange capacity of the soil, cations are sorbed/exchanged from groundwater. Based on previous laboratory work (Barney et al. 1992) it was determined that the distribution coefficient $\left(\mathrm{K}_{d}\right)$ for plutonium on bone char (registered trademark of TIGG Corporation/Tate \& Lyle Process Technology Specialty Chemicals, Greenock, Scotland) was about $30,000 \mathrm{~mL} / \mathrm{g}$ of resin (i.e., plutonium was strongly attracted to and held by the bone char). Column tests concluded that bone char could process 83,278 L (22,000.gal) of Plutonium Finishing Plant (PFP) water (with a plutonium concentration of $100 \mathrm{pCi} / \mathrm{L}$ ) per gallon of bone char to break through. Based on these results, bone char was selected for plutonium removal.

Strontium, an alkaline earth element, is an active metal, and is readily soluble in nitric acid, forming bivalent cations. Strontium is not readily extractable from nitrate solutions in solvent extraction processing, and therefore ends up in the raffinate (aqueous waste stream from solvent extraction columns containing the impurities) discharged as waste. Being bivalent, strontium is rather strongly adsorbed by cation-type adsorbents. Clinoptilolite [registered trademark of American Resource Corporation (AmReC)/Ash Meadow Clino] was selected as the adsorbent for ${ }^{90} \mathrm{Sr}$ removal.

Cesium, also an alkaline metal element, forms few water-insoluble compounds and is readily soluble in nitric acid, forming a monovalent cation. Cesium is not appreciably extracted into organic solvents under the conditions of solvent extraction. However, several insoluble metal-ferrocyanide and ferricyanides act to precipitate and/or scavenge cesium from solution. The affinity of cesium for cation-exchange adsorbents is generally low as a result of its low ionic charge. However, one sulfonated cation resin (IR-100) (registered trademark of Rohm and Haas, Philadelphia, Pennsylvania) did indicate an unusually high affinity for cesium (Reactor Handbook 1961). Cesium has been shown to adsorb readily from alkaline solutions by certain complex silicate minerals such as the clay, montmorillonite, and the zeolite, clinoptilolite (Reactor Handbook 1961). Laboratory tests indicated satisfactory cesium removal by the natural zeolite clinoptilolite. Therefore, clinoptilolite was selected as the adsorbent for cesium removal.

The ion-exchange process system for the B-5 Reverse Well pilot-scale treatment test consisted of three ion-exchange columns in a series-flow arrangement: a bone char column followed by a clinoptilolite column followed by a mixed bed column with $50 \%$ bone char, $50 \%$ clinoptilolite. 
DOE/RL-95-59

Rev. 0

\subsubsection{6-BY Cribs Site Test}

During the first years of Hanford Site operations, separation waste containing significant quantities of uranium was stored in the 241-Tank Farms. To reduce tank construction requirements and to recover uranium, the Uranium Recovery Program (URP) was initiated at the 221/244-U Buildings. This process captured most of the uranium but, in the process, concentrated significant quantities of fission products in the waste being returned to the tank farms. In the process, the URP generated waste at a 2:1 ratio for every gallon of tank waste brought in to the URP (Waite 1991). Evaporators in the Uranium Recovery Process and at the $T$ and $B$ tank farms were not able to keep up with the processing rate, and there was net loss in tank space (Anderson 1990). Plans were made to operate the tanks in a cascade and discharge the supernatant to the ground to prevent exhausting tank capacity. However, this was recognized to result in unacceptably high concentrations of radionuclides going to the ground and was not implemented.

An in-plant scavenging process that added potassium ferrocyanide to the waste stream before going to the tank farms was included in post-September 1954 waste treatment operations. Liquid effluents sent to the 241-BY Single-Shell Tank Farms prior to in-plant fission product removal were transferred to the $241-C R$ vault for ferrocyanide scavenging. Upon return, the waste was cascaded through a three-tank system with most of the precipitated cesium dropping out in the first tank. Overflow liquids were then discharged to the soil column at the BY-Cribs through the 216-B-43 to 216-B-49 Cribs between November 1954 and December 1957.

Cobalt-60 was not recognized in the groundwater until January 1956 when it was detected in groundwater samples near the BY-Cribs (Thomas et al. 1956). The presence of ${ }^{60} \mathrm{Co}$ in the groundwater was surprising because it was generally known to readily sorb onto soils and to be significantly retarded in moving through the soil column. Cobalt was assumed to have complexed with a large molecule or to exist in a nonionized form. Cyanide is highly mobile in groundwater and soil and was present in the waste solutions discharged to the BY-Cribs (Thomas et al. 1956). By the time ${ }^{60} \mathrm{Co}$ had been detected, the BY-Cribs had already been closed to further waste discharges because beta activity had been detected in the groundwater under the cribs (Kasza 1993). Regular groundwater sampling and analysis for ${ }^{99} \mathrm{Tc}$ was initiated in 1985 due to improved analytical methods. Contaminant plume data are presented in Table 1-1.

Two in-tank solidification (ITS) processing systems pumped more than $144,000,000 \mathrm{~L}$ (38,000,000 gal) of tank liquor condensate to the 216-B-50 and 216-B-57 Cribs, located about $61 \mathrm{~m}$ (200 ft) north of the 241-BY Tank Farm. With these systems, tank liquids were evaporated, extracted from the tank, and then condensed. The process condensate was sent to the soil column. ITS-1 was used in Tanks 241-BY-101 and 241-BY-102, while ITS-2 was used in Tank 241-BY-112. Tank liquids were received from the Waste Fractionization Process at the $221-\mathrm{B}$ Plant where ${ }^{137} \mathrm{Cs}$ and ${ }^{90} \mathrm{Sr}$ were recovered from existing tank wastes.

Del Cul et al. (1992) and Barney (1994) have reported that technetium is predominantly in the pertechnatate form $\left(\mathrm{TcO}_{4}\right)$ an anion. They assume that this is because of the oxic (oxidizing) conditions of groundwater. Dissolved oxygen concentrations of 5.7 to $10.5 \mathrm{mg} / \mathrm{L}$ are reported in the Hanford Environmental Information System (HEIS) database for groundwater in the 200 Areas. It may also be because of the other conditions that provide a reducing environment in the groundwater at depths beyond $61 \mathrm{~m}$ (200 ft). Cobalt-60 normally exists as a divalent cation in acidic to mildly alkaline conditions and readily sorbs onto soil via cation exchange, much as the contaminants at the B-5 Reverse Well. However, cobalt can form anion or neutral complexes. Since cyanides have a 
strong affinity for forming metal complexes, it is thought that cyanide has complexed with the cobalt. A cobalt-cyanide complex in the anionic form $\mathrm{Co}(\mathrm{CN})_{6}{ }^{4}$ would explain the increased mobility of cobalt.

Because many ion-exchange resin manufacturers have developed adsorbents with functional groups that have an affinity for transition metals and because the cobalt and technetium were thought to be in anionic form, Dowex $21 \mathrm{~K}$ (registered trademark of DOW Chemical Company, Midland, Michigan), a strong base anion ion-exchange resin, was selected for evaluation at the BY-Cribs site. The BY-Cribs ion-exchange treatment system consisted of two ion-exchange columns in a series-flow arrangement.

\subsection{GENERAL GEOLOGY AND HYDROGEOLOGY}

The geology of the Hanford Site and surrounding area has been reported in several documents (Myers et al. 1979, Delaney et al. 1991, Reidel et al. 1992). The 200 East Area geology and hydrology is presented in detail in the AAMSR (DOE-RL 1993a), in Connelly et al. (1992), and Lindsey et al. (1992), among others. For the purposes of this treatability test report, a brief discussion is given to provide a foundation for understanding the geology and hydrologic conditions at the two treatability test sites and to provide a basis for understanding recommendations for future activities. Local geologic features affecting the groundwater flow system are also emphasized.

\subsubsection{Topography}

The 200-BP-5 Operable Unit encompasses the northeastern portion of the 200 Area Plateau located on the Cold Creek Bar (also known as Separations or Central Plateau) and the slope north to Gable

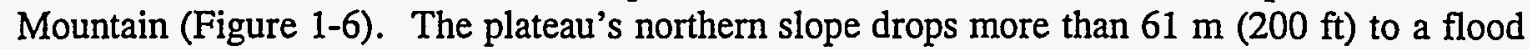
channel and coulee system at the base of Gable Mountain. The B-5 Reverse Well site is located near the center of the plateau; the BY-Cribs site lies on the northern slope between deep flood channel depressions south of Gable Mountain. The presence of the flood channels substantiates some of the bedrock features interpreted from well logs, as discussed in the following section.

\subsubsection{Stratigraphy}

The 200-BP-5 Operable Unit is underlain by a thick sequence of Columbia River basalts that are, in turn, overlain by the Ringold and Hanford Formation sediments. A thin layer of eolian sediments mantel the surface. Figure 1-7 depicts the stratigraphic relationships of the sedimentary units.

The Elephant Mountain Member of the Columbia River Basalt Group forms the base for the upper, unconfined aquifer system throughout most of the 200-BP-5 Operable Unit. The Columbia River Basalt Group, which erupted approximately 17 to 6 million years ago, consists of a number of flood basalt flows typically 30 to $91 \mathrm{~m}$ (100 to $300 \mathrm{ft}$ ) thick that are separated by relatively thin interbeds of sediments belonging to the Ellensburg formation. The interbeds and interflow zones are typically the sites of confined regional aquifers.

Lying unconformably on the basalt under the southern part of the 200-BP-5 Operable Unit is the Ringold Formation (Figure 1-8). This sedimentary sequence is a regionally extensive unit filling the 
Pasco Basin. It consists of river channel-deposited sands and gravels combined with overbank sand and silt deposits. Between the channel deposits are fresh-water lake mud deposits that tend to form less permeable layers for groundwater movement. In general terms, this formation is not found in the area north of the 200 East Area fenceline and south of Gable Mountain. The Ringold Formation tends to thicken to the south and west toward the Cold Creek Syncline, and its disappearance north toward Gable Mountain is attributed to erosion by the Missoula Floods and the ancestral Columbia River. Smith (1980) estimates the Ringold Formation to be approximately 27 to $30 \mathrm{~m}$ (90 to $100 \mathrm{ft}$ ) thick at the B-5 Reverse Well. Connelly et al. (1992) reinterpreted the Ringold Formation to be approximately 9 to $11 \mathrm{~m}$ ( 30 to $35 \mathrm{ft}$ ) thick in the vicinity of the B-5 Reverse Well. The Ringold Formation is not present in the area of the BY-Cribs plume.

The overlying Hanford formation is the result of sediment deposition associated with the cataclysmic Missoula Floods, the last of which occurred approximately 13,000 years ago. The formation consists of coarse gravel layers overlain by upward-fining deposits of gravels, sands, and silts. The sedimentary unit is extensive and fills eroded channels in the underlying Elephant Mountain Basalt and the Ringold Formation with very coarse gravels. Away from the channels, deposits are finer grained. The Hanford formation comprises approximately the upper $76 \mathrm{~m}(250 \mathrm{ft})$ of sediments at the B-5 Reverse Well site. It is the only formation found overlying the BY-Cribs plume site, where its thickness is dependent on the surface topography.

\subsubsection{Structure}

The major structural feature found in the basalts beneath the 200-BP-5 Operable Unit is the subsurface extension of the Umtanum Ridge anticline. The east-west-trending axis of this structure lies to several thousand feet north of the 200 East Area fenceline and is approximated by Gable Mountain and Gable Butte. The basalt surface under most of the operable unit dips gently to the south toward the Cold Creek Syncline, while the north limb dips steeply to the north.

The basalt has been locally eroded by the Missoula Floods and the ancestral Columbia River, leaving erosional scours or channels in the Elephant Mountain basalt. At least one erosional window through the basalt is recognized in the vicinity of well cluster 699-53-55 and well 699-55-55, where sediments up to $76 \mathrm{~m}(250 \mathrm{ft})$ thick are encountered. In the area of Gable Gap, Elephant Mountain basalt has been eroded to expose the older Pomona, Esquatzel, Asotin, and Umatilla Members. East of wells 699-50-53A and 699-52-54, basalt is found above the water table as either an eastward extension of the Gable Butte fold or as a less-eroded portion of the top of the Elephant Mountain flow.

\subsubsection{Hydrogeology}

The unconfined aquifer beneath the 200-BP-5 Operable Unit is a composite aquifer system composed of the sediments resting on the top of the Elephant Mountain basalt and open fractures within basalt flow. The saturated sediments range from $0 \mathrm{~m}$ at the margins of the subsurface basalt high near well 699-50-53A to 3 to $5 \mathrm{~m} \mathrm{(10} \mathrm{to} 15 \mathrm{ft}$ ) thick at wells around the BY-Cribs and to thicknesses of $13.7 \mathrm{~m}$ $(45 \mathrm{ft})$ at the B-5 Reverse Well. The total thickness is undefined due to erosional effects on the basalt. In general, the aquifer thickens to the south in response to the dip of the basalt. Typically, the aquifer is present in gravels of the Hanford formation north of the 200 East Area fenceline and in coarser portions of the Ringold Formation, south of the boundary (Figure 1-9). 
Pre-Hanford groundwater flow was generally west to east. The flow pattern was modified with the start of Separation Area operations by the discharge of significant volumes of cooling water to surface ponds and the soil column. Water-table mounding associated with the 216-B-3 Pond operations was noted as early as 1951 by Bierschenk (1957), who recognized pond operations as a means of retarding radionuclide migration. Water-table rises of 3 to $5 \mathrm{~m}$ (10 to $15 \mathrm{ft}$ ) were reported as resulting from B Plant cooling water discharges of approximately $5,700 \mathrm{~L} / \mathrm{min}(1,500 \mathrm{gal} / \mathrm{min})$ to the B Pond system from 1944 to 1951 . These levels increased by another 1.5 to $3 \mathrm{~m}(5$ to $10 \mathrm{ft}$ ) with the onset of the PUREX Plant operations, during which an average $14,000 \mathrm{~L} / \mathrm{min}(3,600 \mathrm{gal} / \mathrm{min})$ was discharged to the $216-\mathrm{B}-3$ and $216-\mathrm{A}-25$ pond systems. The influence of pond discharges was noted at the B-5 Reverse Well in 1947 and is attributed to be the driving force for the BY-Cribs plume's northward migration. Water-table elevations fluctuated over time in response to changes in plant operations but remained at elevated levels until the recent termination of the PUREX Plant operations. Due to the reduced quantities of water discharged to the ponds, groundwater levels have declined at rates of 0.15 to $0.30 \mathrm{~m} / \mathrm{yr}(0.5$ to $1.0 \mathrm{ft} / \mathrm{yr})$, and several wells are being affected. Because of the interference of numerous local and regional groundwater influences and the low hydraulic gradient over much of the 200 East Area, actual groundwater movement over time in and through the 200-BP-5 Operable Unit is not well documented.

Before the treatability test, aquifer properties were not well known at either of the extraction wells, and large variations were recognized for the two plumes. The best data available, as reported in the 200-BP-5 Treatability Test Plan (DOE-RL 1995c), indicated that tests performed near the 241-BY Tank Farm yielded an aquifer transmissivity value of $4,459 \mathrm{~m}^{2} /$ day $\left(48,000 \mathrm{ft}^{2} /\right.$ day $)$ and hydraulic conductivity values of 1,524 to $3,048 \mathrm{~m} /$ day $(5,000$ to $10,000 \mathrm{ft} /$ day). Groundwater level measurements indicate gradients of 0.00006 . Based on an assumed effective porosity of $20 \%$, an average linear flow velocity of $0.45 \mathrm{~m} /$ day $(1.5 \mathrm{ft} /$ day) was calculated. Newcomer et al. (1992) reported a transmissivity value of $186 \mathrm{~m}^{2} /$ day $\left(2,000 \mathrm{ft}^{2} /\right.$ day) and an equivalent hydraulic conductivity of $122 \mathrm{~m} /$ day (400 ft/day) for well $699-52-54$ near the BY-Cribs plume.

The generally poor understanding of groundwater conditions and uncertainties expressed in the test plan conceptual models for the two plumes prompted a greater emphasis on characterizing * groundwater conditions at the 200-BP-5 Operable Unit. Several contemplated characterization activities were discussed in the 200-BP-5 Treatability Test Plan (DOE-RL 1995c), while others were approved in a 200 NPL Agreement/Change Control Form (BHI-00203). Results of these activities are presented in Chapters 4.0 and 5.0.

\subsection{REPORT ORGANIZATION}

This report follows EPA's general recommendations for content and organization of treatability test reports, but incorporates modifications developed in the 200-UP-1 Test Report (DOE-RL 1995c). The document also includes significant additions and changes in scope to address and support the data requested by the DOE, EPA, and Ecology. Chapter 2.0 discusses the test goals and data quality objectives (DQOs) in the 200-BP-5 Treatability Test Report that drove the design, operations, sampling requirements, and equipment requirements for the treatability test and test requirements for groundwater and contaminant distributions. It also includes those changes produced through agreements, unforeseen/unexpected conditions, and redirections from improved understandings of test facets. 
The results of treatability testing and the associated laboratory and field test programs for both systems are reported in Chapter 3.0. Chapter 4.0 reports on the contaminant extraction and groundwater properties related to pumping during the treatment test. Chapter 5.0 summarizes historical data related to plume movement and presents revised conceptual models of the two plumes. It also estimates the risk associated with three 200-BP-5 Operable Unit plumes as reported in the Risk Based Decision Analysis for the 200-BP-5 Groundwater Operable Unit (BHI 1995c). Chapter 5.0 concludes with a discussion of the data gaps and data needs for potential future work. Chapter 7.0 provides conclusions and recommendations for potential future work for the 200-BP-5 Operable Unit. Appendices include tabulations of the raw data used in support of the discussions in Chapters 3.0 and 4.0 .

NOTE: Throughout the text, the term MCLs is described as the concentration of a radionuclide in groundwater that is considered as the DWS. The concentrations used $\left({ }^{60} \mathrm{Co}=100 \mathrm{pCi} / \mathrm{L},{ }^{137} \mathrm{Cs}=\right.$ $120 \mathrm{pCi} / \mathrm{L},{ }^{239240} \mathrm{Pu}=1.2 \mathrm{pCi} / \mathrm{L},{ }^{90} \mathrm{Sr}=8 \mathrm{pCi} / \mathrm{L},{ }^{99} \mathrm{Tc}=900 \mathrm{pCi} / \mathrm{L}$ ) were first delineated as a standard in Price (1986). Table C-2 of Appendix C in Price (1986) presents most of these values and references Table IV-2A of EPA (1976) as the source. The method of calculation has been changed, and the proposed new MCL values are not presented in this document. Thus, for project consistency, neither the terminology nor the cited MCL concentrations will be changed. 


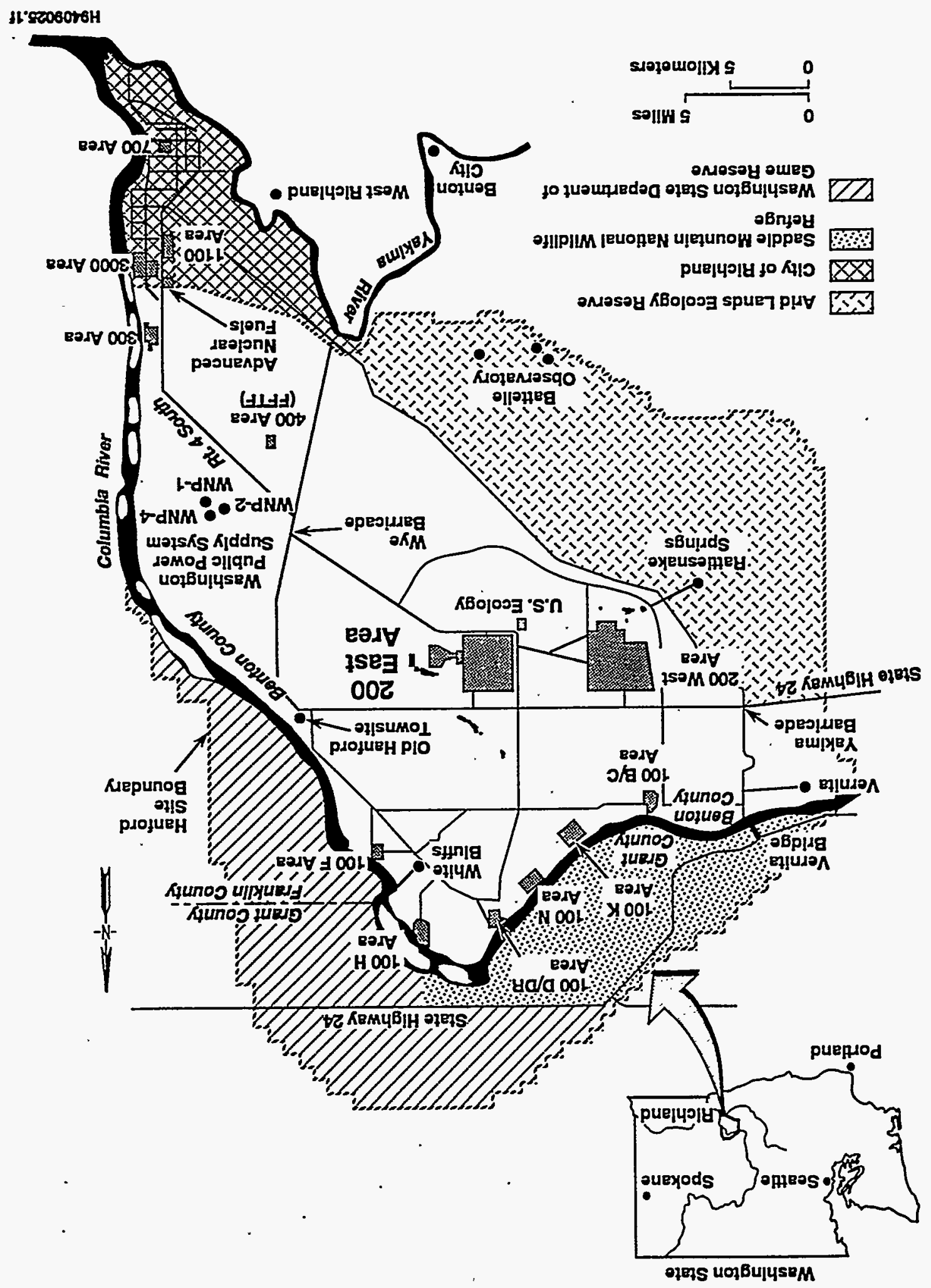

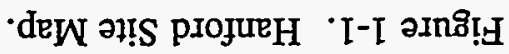




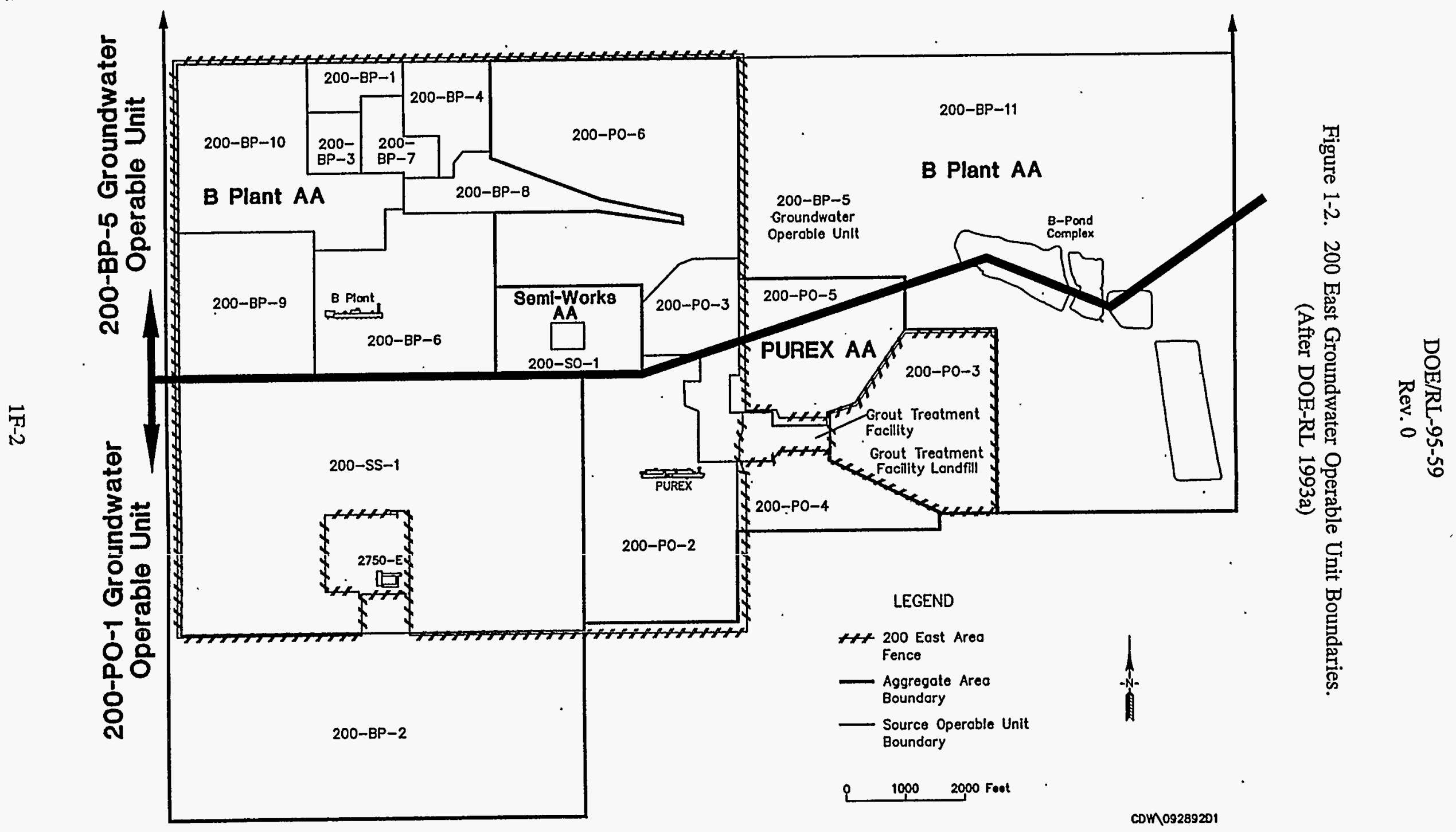


Figure 1-3. 200-BP-5 Plume Boundaries and Locations.

(1993)

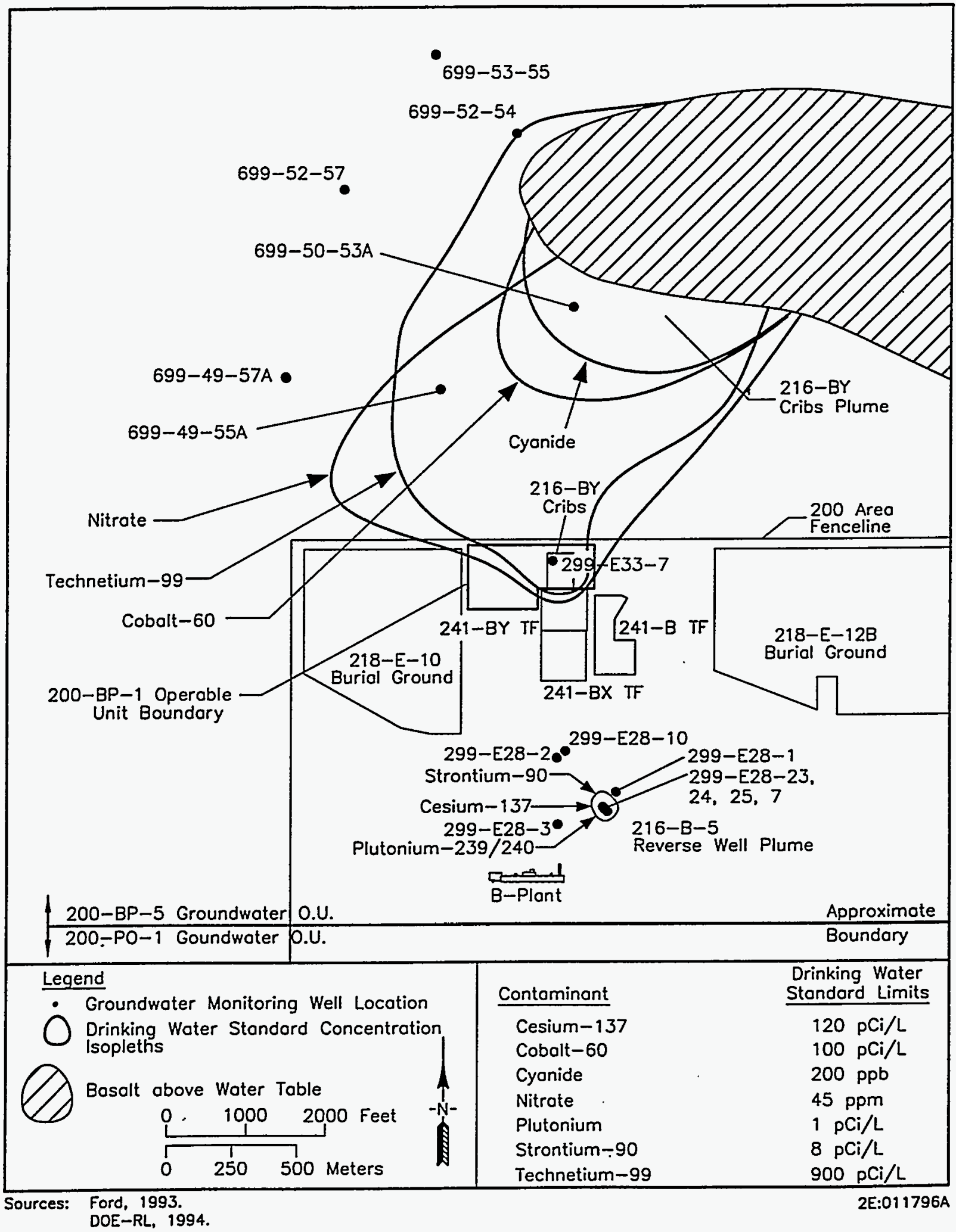


DOE/RL-95-59

Rev. 0

Figure 1-4. 216-B-5 Reverse Well Plumes.

(1995)

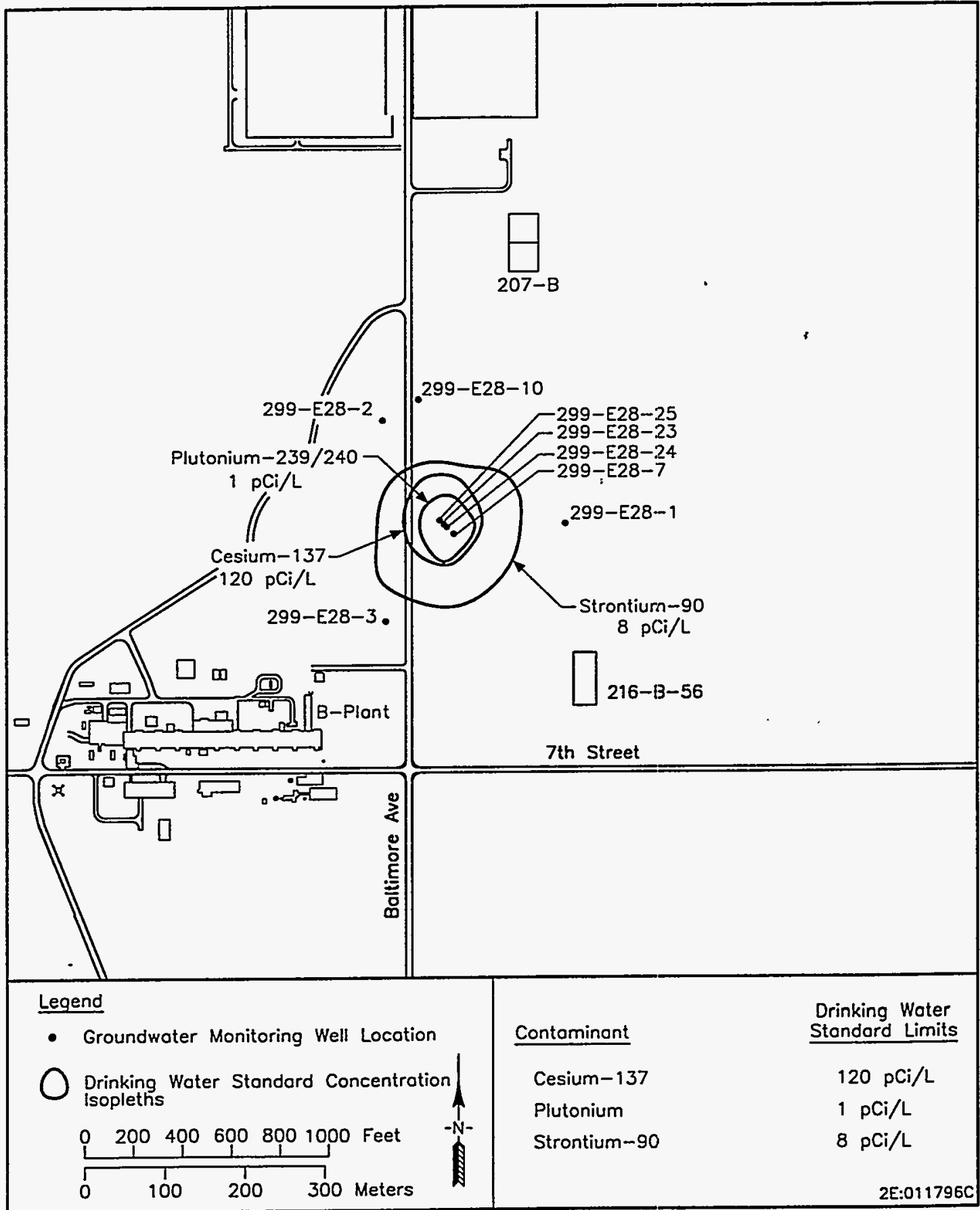

Sources: Ford, 1993.

DOE-RL. 1994. 
DOE/RL-95-59

Rev. 0

Figure 1-5. 216-BY Cribs Plume.

(1995)

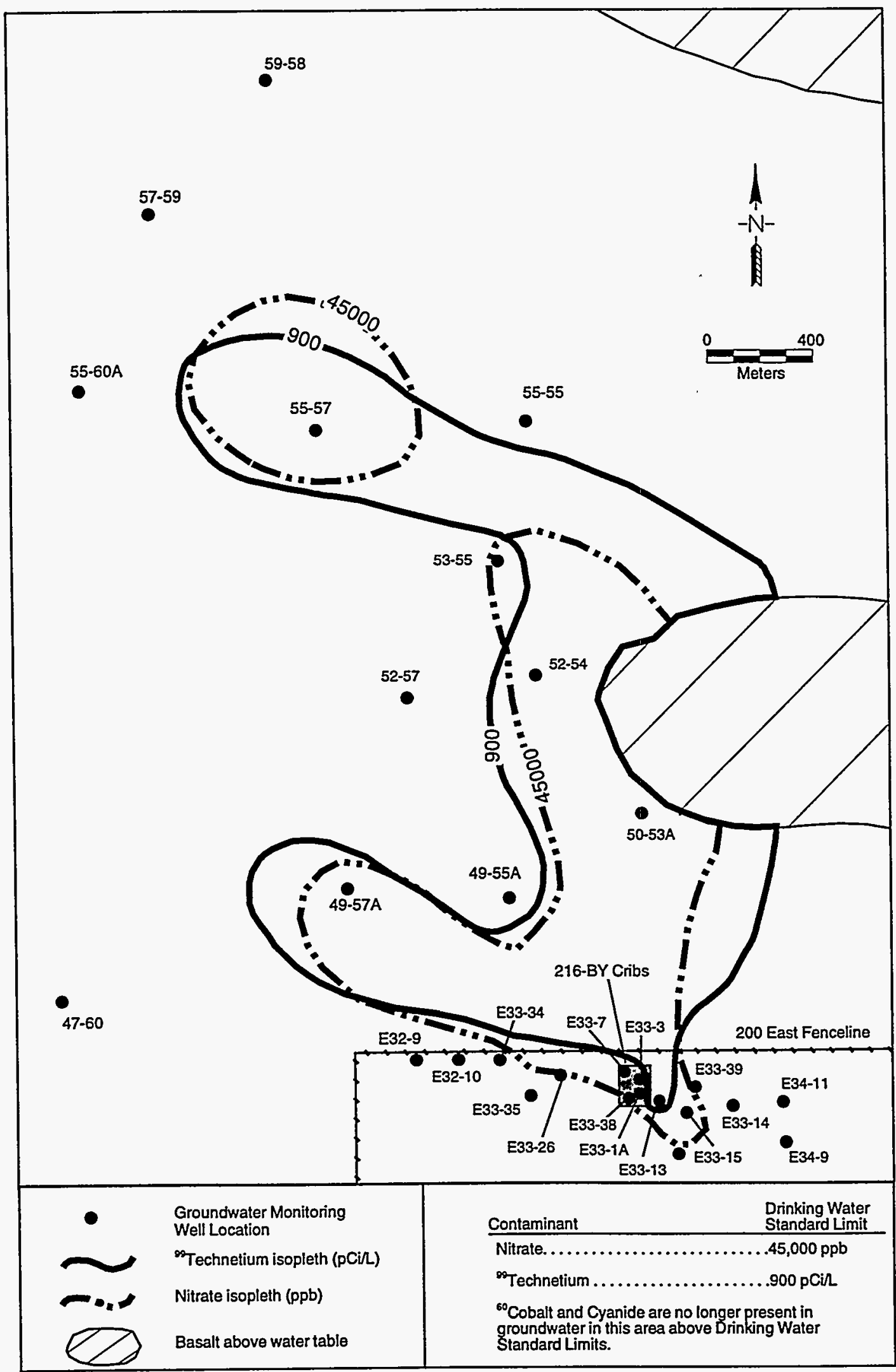


Figure 1-6. Topography and Geomorphology of the 200 Areas, Hanford Site. (Last et al. 1989)

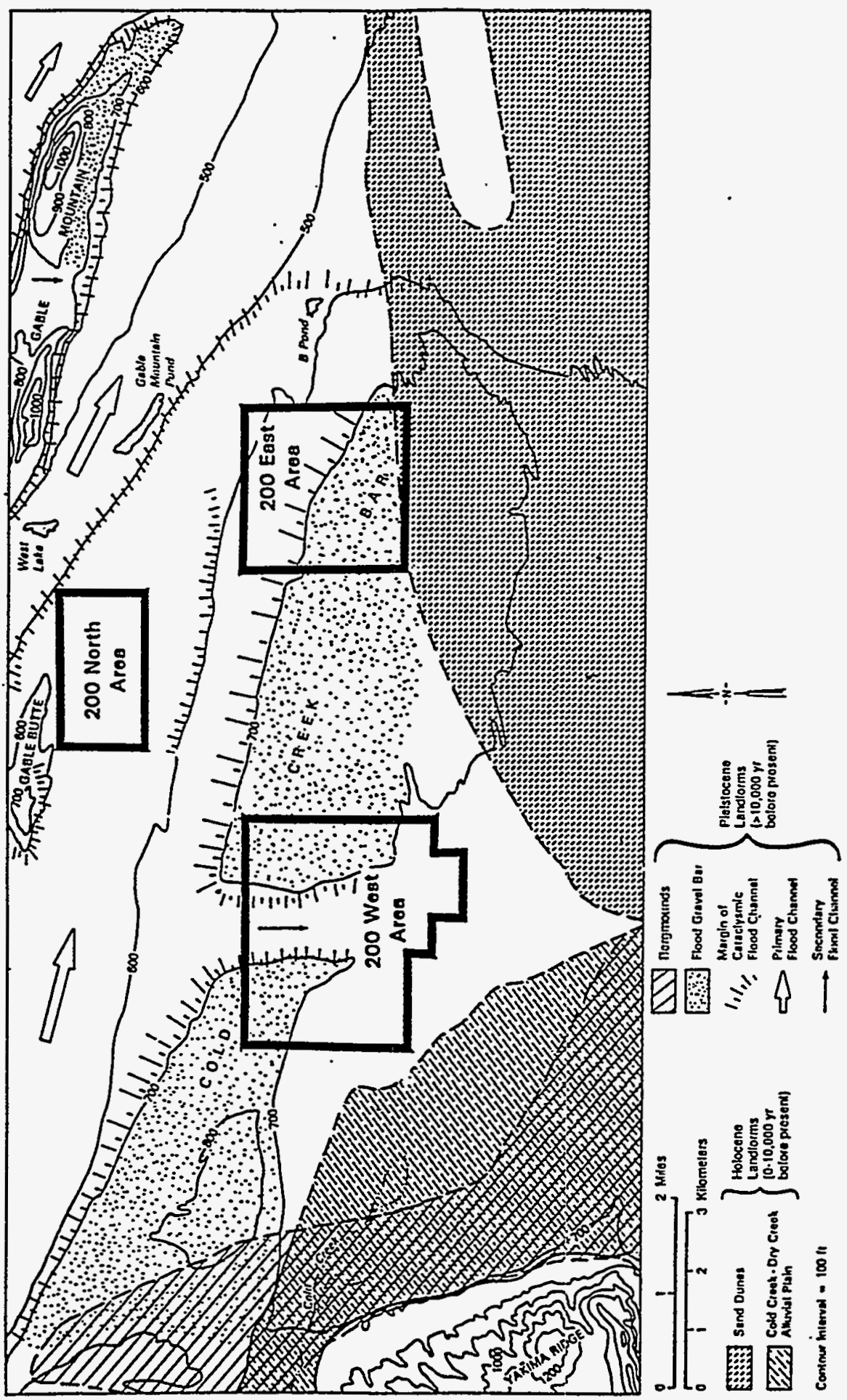


DOE/RL-95-59

Rev. 0

Figure 1-7. Generalized Stratigraphy of the Hanford Site.

(DOE 1989)

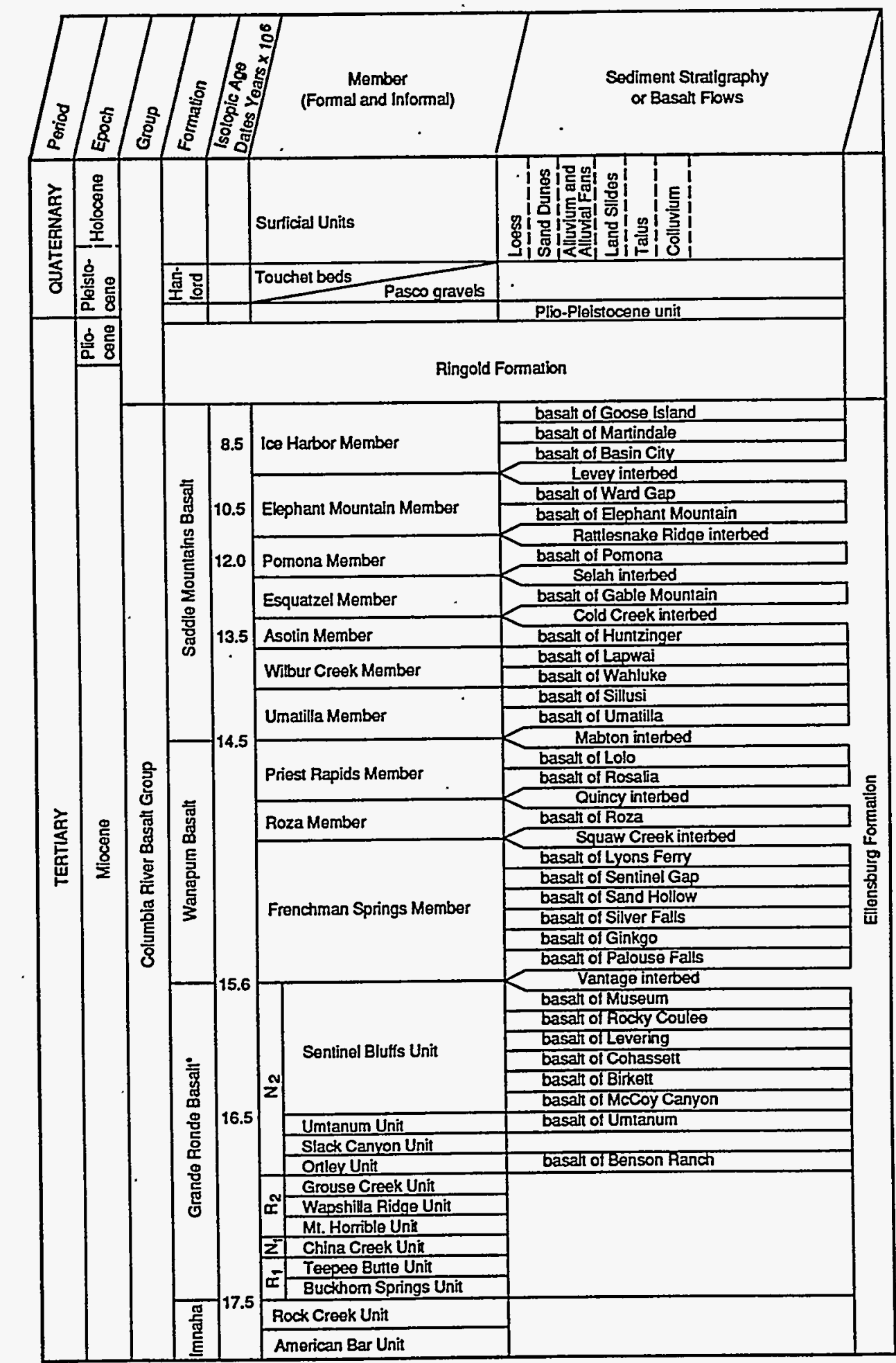

- The Grande Ronde Basaht consists of at least 120 major basak flows. Only a few flows have been named.

$N_{2}, R_{2}, N_{1}$ and $R_{1}$ are magnetostratigraphle units.

Ho102020.6 
DOE/RL-95-59

Rev. 0

Figure 1-8. Generalized Stratigraphy of the Suprabasalt Sediments Beneath the Hanford Site.

(Delaney et al. 1991)

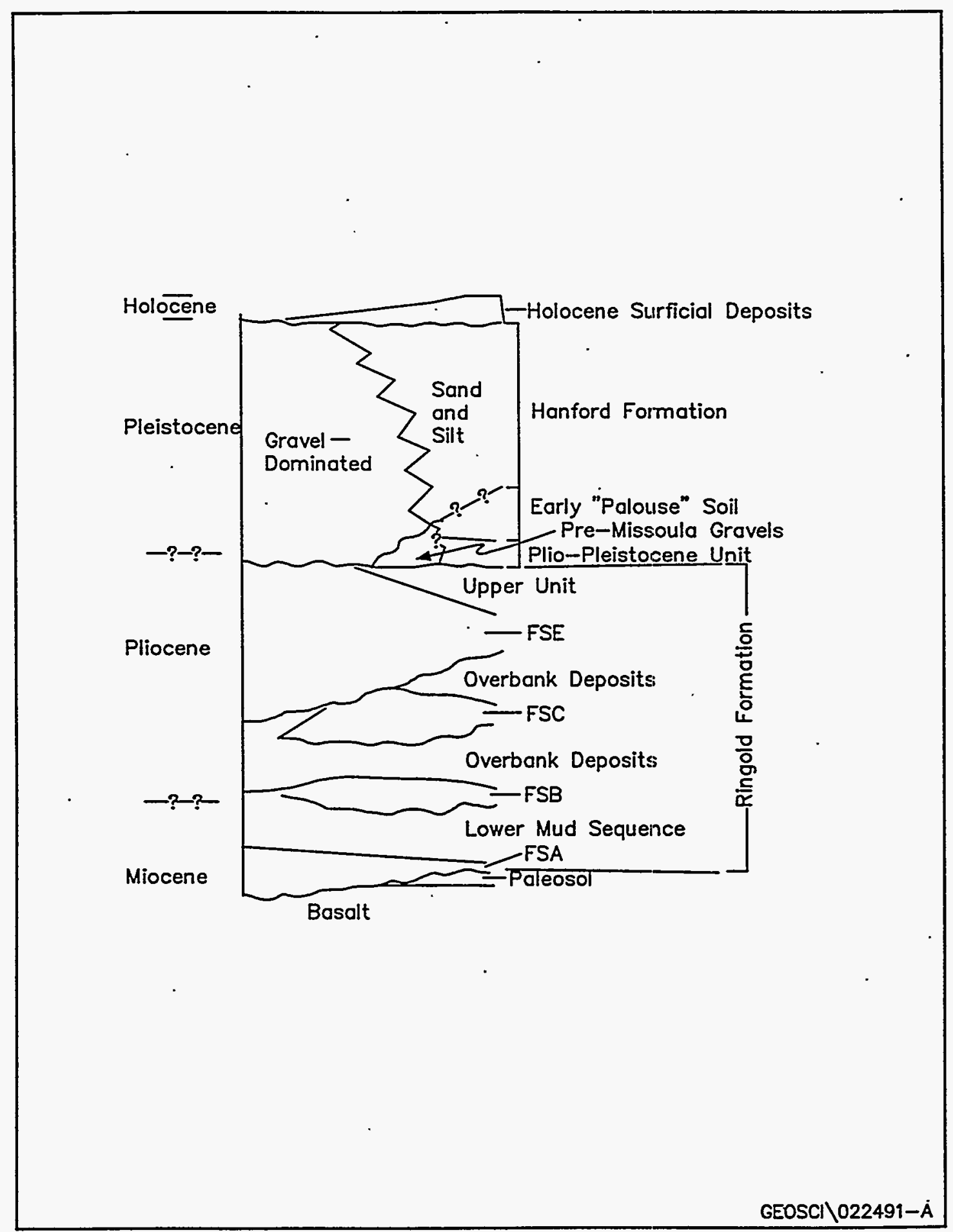




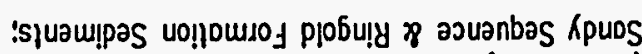

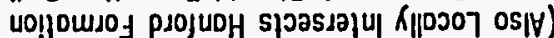
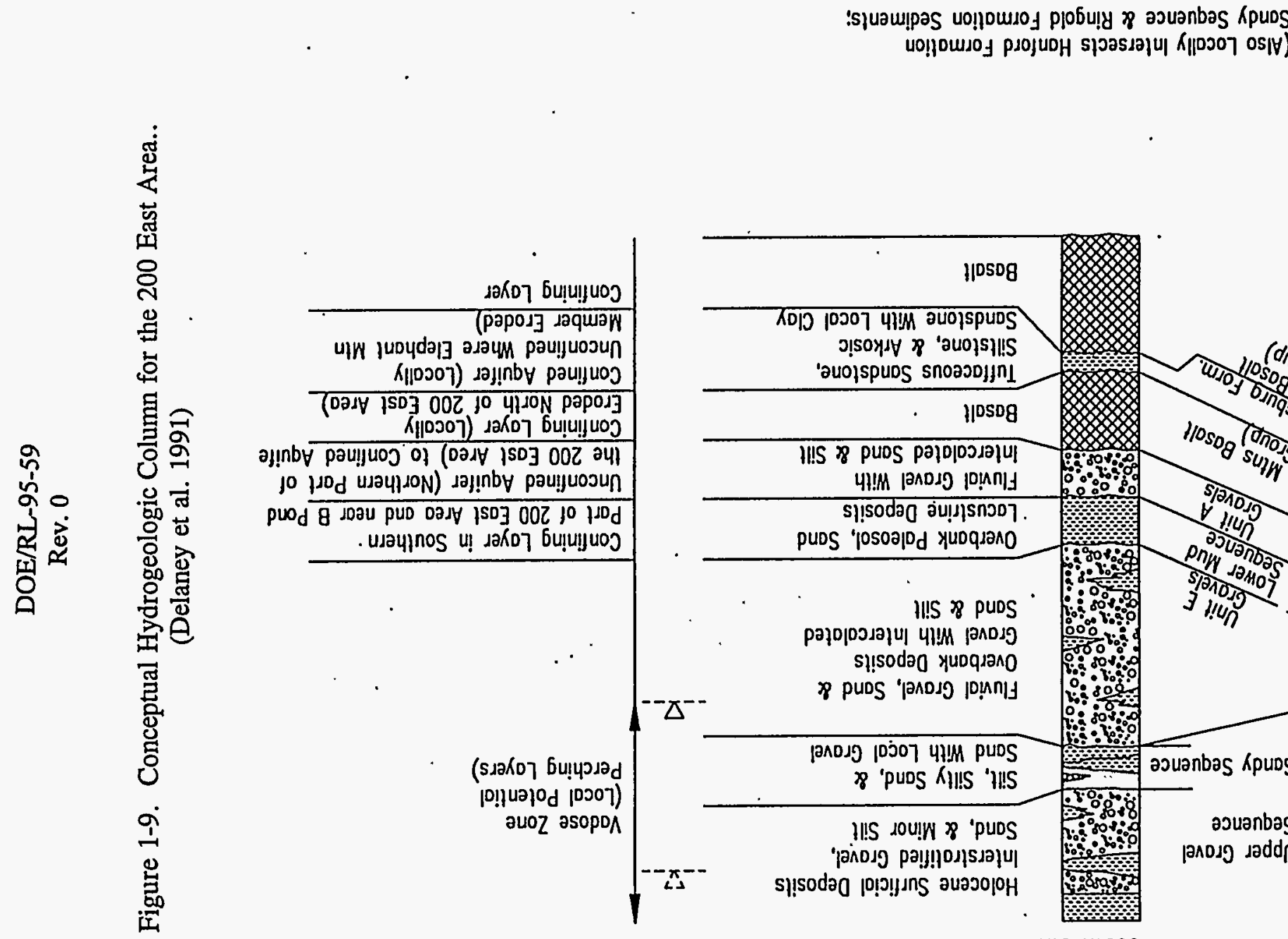

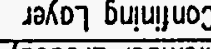

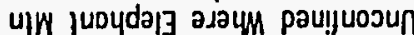

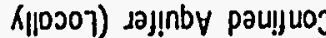

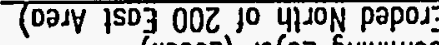

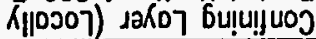

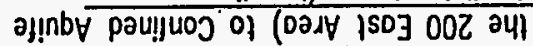

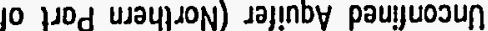

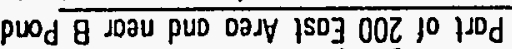
uJauknos u! daKoך bu!ujuoj

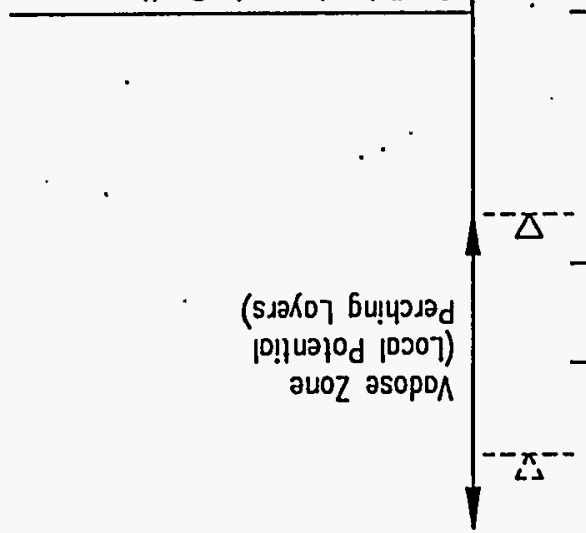

SIINก JHHdYQILYYISOYOH uo!̣oussof PsojuoH uा

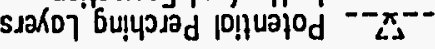

pNo19 5..5\%

IIIS 垶

puos ?

HoSOg

0N 3037

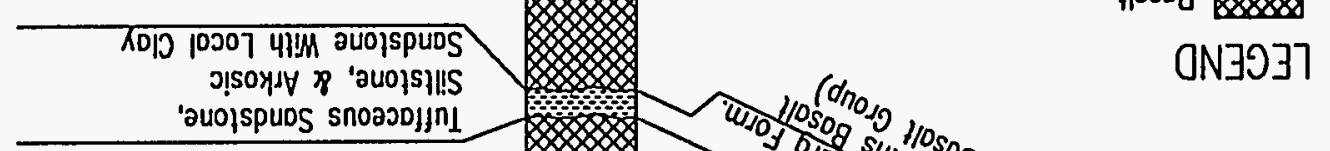

Uud snozsoljn!

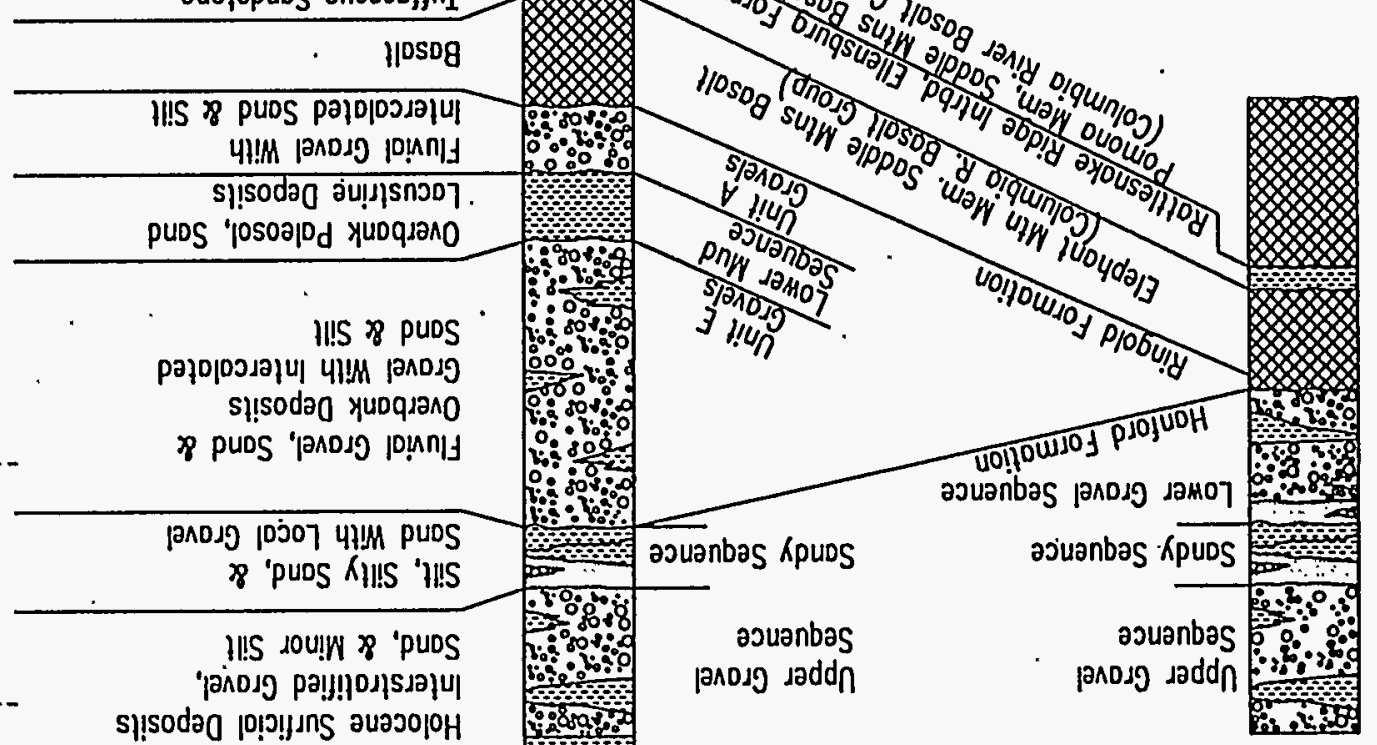

(Woinowos Propwor) AHdYYILYYIS HLYON 
DOE/RL-95-59

Rev. 0 
Rev. 0

Table 1-1. Summary Data for the 200-BP-5 Operable Unit.

\begin{tabular}{|c|c|c|c|c|c|c|c|}
\hline Plume & Contaminant & $\begin{array}{l}\text { Quantity } \\
\text { disposed }^{2}\end{array}$ & $\begin{array}{l}\text { Dissolved } \\
\text { Plume } \\
\text { Quantity }^{\mathrm{b}}\end{array}$ & $\begin{array}{c}\text { Plume Area, } \\
1992\end{array}$ & $\begin{array}{c}\text { Half life } \\
(y r)^{b}\end{array}$ & $\begin{array}{l}\text { Drinking } \\
\text { Water } \\
\text { Standard }\end{array}$ & $\begin{array}{c}\text { Mobility } \\
\left(k_{d} \text { in } \mathrm{mL} / \mathrm{g}\right)^{b}\end{array}$ \\
\hline \multirow{4}{*}{$\begin{array}{l}\text { 216-BY Cribs } \\
\text { Plume }\end{array}$} & ${ }^{60} \mathrm{Co}$ & $0.45 \mathrm{Ci}$ & $0.43 \mathrm{Ci}$ & $750,000 \mathrm{~m}^{3}$ & 5.3 & $100 \mathrm{pCi} / \mathrm{L}$ & Low (2000) \\
\hline & ${ }^{99} \mathrm{Tc}$ & [unknown] & $21.9 \mathrm{Ci}$ & $1,500,000 \mathrm{~m}^{2}$ & 213,000 & $4,000 \mathrm{pCi} / \mathrm{L}$ & High (0) \\
\hline & Cyanide & $13,900 \mathrm{~kg}$ & $985 \mathrm{~kg}$ & $850,000 \mathrm{~m}^{2}$ & - & $200 \mathrm{ppb}$ & High (0.1) \\
\hline & Nitrate & $5,650,500 \mathrm{~kg}$ & $740,000 \mathrm{~kg}$ & $?$ & -- & $45 \mathrm{ppm}$ & High (0) \\
\hline \multirow{3}{*}{$\begin{array}{c}216-B-5 \\
\text { Reverse Well } \\
\text { Plume }\end{array}$} & ${ }^{90} \mathrm{Sr}$ & $76 \mathrm{Ci}$ & $0.17 \mathrm{Ci}$ & $66,000 \mathrm{~m}^{2}$ & 28.5 & $8 \mathrm{pCi} / \mathrm{L}$ & Moderate (20) \\
\hline & ${ }^{137} \mathrm{Cs}$ & $81 \mathrm{Ci}$ & $0.014 \mathrm{Ci}$ & $22,000 \mathrm{~m}^{2}$ & 30 & $120 \mathrm{pCi} / \mathrm{L}$ & Low (500) \\
\hline & ${ }^{239240} \mathrm{Pu}$ & $\begin{array}{c}2,000 \mathrm{~g} \\
\text { (ca. } 300 \mathrm{Ci})\end{array}$ & $0.0006 \mathrm{Ci}$ & $19,000 \mathrm{~m}^{3}$ & $\begin{array}{c}24,400 / \\
6,560\end{array}$ & $1 \mathrm{pCi} / \mathrm{L}$ & Low (2000) \\
\hline \multicolumn{8}{|c|}{$\begin{array}{l}{ }^{2} \text { Data on quantity disposal from Maxfield (1979), Smith (1980), and Phase I Remedial Investigation Report for } \\
200-B P-1 \text { Operable Unit (DOE-RL 1993d). Plutonium converted from mass to activity according to average specific } \\
\text { activity for }{ }^{239} \mathrm{Pu} \text { and }{ }^{240} \mathrm{Pu} \text {; cyanide data converted from ferrocyanide data. } \\
\text { 'Data on plume quantity, half life, mobility, and primary decay mode from } 200 \text { East Groundwater Aggregate Area } \\
\text { Management Study Report (DOE-RL 1993a). }\end{array}$} \\
\hline
\end{tabular}


DOE/RL-95-59

Rev. 0 
DOE/RL-95-59

Rev. 0

\subsection{TREATABILITY TEST APPROACH}

This chapter describes how the treatability test implemented the requirements of the 200-BP-5 Treatability Test Plan (DOE-RL 1995c). The treatability test objectives, presented in Chapter 3.0 of the test plan, are restated in Section 2.1. Section 2.2 discusses the experimental approach and methods used to meet these objectives. Section 2.3 provides a description of the equipment used in the tests. The sampling and analysis program is described in Section 2.4, and data management is discussed in Section 2.5. Significant deviations from the test plan are discussed in Section 2.6.

\subsection{TEST OBJECTIVES}

\subsubsection{Test Performance Objectives}

Test performance objectives and DQOs are used to clarify and guide the testing process and to outline the quality and quantity of data needed for this treatability test program. Test performance objectives identify information needs required to evaluate the pilot-scale pump-and-treat alternatives. The DQOs link the information requirements with the intended data uses to define the level of quality required for the measured variables. Test objectives were prepared for the pilot-scale treatment systems and groundwater extraction activities.

2.1.1.1 Treatment Test Performance Objectives. The primary test performance objective for the pilot-scale treatment systems was to determine the removal efficiency that could be achieved for the primary contaminants ${ }^{137} \mathrm{Cs},{ }^{239240} \mathrm{Pu}$, and ${ }^{90} \mathrm{Sr}$ in groundwater pumped from the B-5 Reverse Well plume, and ${ }^{60} \mathrm{Co}$ and ${ }^{99} \mathrm{Tc}$ in groundwater pumped from the BY-Cribs plume. Test performance objectives for the pilot-scale treatment system were grouped into three categories: (1) measurement of the effectiveness of ion-exchange treatment, (2) assessment of parameters or factors influencing the ion-exchange operation, and (3) determination of the resource needs associated with the test. Specific objectives under each of the three categories included the following.

- Effectiveness:

-- Determine the effectiveness of the ion-exchange system to consistently remove the following from the groundwater: ${ }^{60} \mathrm{Co}$ and ${ }^{99} \mathrm{Tc}$ at the $\mathrm{BY}$-Cribs system and ${ }^{137} \mathrm{Cs}$, ${ }^{239 / 240} \mathrm{Pu}$ at the B-5 Reverse Well system. Based on previous Hanford Site experience and general expectations for ion-exchange technology and consistent with the Guide for Conducting Treatability Studies Under CERCLA (EPA 1992), removal effectiveness should be at least $90 \%$ of the influent concentration.

-- Identify optimum/preferred ion-exchange resin(s) for removing ${ }^{60} \mathrm{Co},{ }^{137} \mathrm{Cs},{ }^{239240} \mathrm{Pu}$, ${ }^{90} \mathrm{Sr}$, and ${ }^{99} \mathrm{Tc}$.

-- Assess the impact and removal of secondary contaminants (e.g., cyanide, nitrate) in both plumes. 
- $\quad$ Assess the impact and removal of the radionuclides of interest that may be present as solids. Solids may contain radionuclides that will be removed by the prefilters and/or the resin beds. Ultrafine solids may pass through both the filter and the resin bed.

Although not an original objective of the test plan, it became important to assess the capability of the treatment system to remove ${ }^{137} \mathrm{Cs},{ }^{239240} \mathrm{Pu}$, and ${ }^{90} \mathrm{Sr}$ at the B-5 Reverse Well site to the MCL as defined by the Safe Drinking Water Act to enable reinjecting treated groundwater outside the contaminant plume(s).

\section{Operating Parameters:}

-- Refine operational configurations, requirements, and procedures.

-- Assess impacts of groundwater constituents on operational efficiency.

-- $\quad$ Assess operating parameters (e.g., flow rates, residence times, $\mathrm{pH}$ ) to optimize treatment efficiency.

-- Demonstrate operational reliability and safety of an ion-exchange-based treatment system at a scale sufficient to allow scaleup to a full-size remedial system.

\section{- $\quad$ Resource Requirements:}

-- Develop estimates of significant cost components, including equipment and material costs; resin contaminant exchange capacity, exhaustion rate, and cost; electrical power and utility costs; chemical costs and use rates; process residue and secondary waste management costs; maintenance requirements; and operator and personnel requirements.

- $\quad$ Refine health and safety requirements.

2.1.1.2 Contaminant Extraction Test Performance Objectives. At the time of test plan preparation, the ability to provide the B-5 treatment system with quantities of significantly contaminated groundwater was anticipated to be a problem. In general, the radionuclide concentrations from groundwater monitoring that prompted rating the B-5 Reverse Well plume as a significant hazard were not regarded as being sustainable for the life of the treatability test. This concern resulted from the expectation that radionuclides attached to the aquifer sediment would not reach an equilibrium condition with the groundwater at a rapid enough rate as less contaminated groundwater was drawn through the sediments to the extraction well. This would result in sending less contaminated water to the treatment system, making treatment a much less successful process. At the BY-Cribs plume, the highly mobile nature of the contaminants was not thought to present a similar problem.

Initially, contaminant extraction testing was intended to be performed only at the B-5 Reverse Well plume and not at the BY-Cribs plume. However, when April 1994 groundwater monitoring data showed significantly reduced concentrations of the target constituents, the requirement was applied to the BY-Cribs system. Specific contaminant extraction test procedures and results are described in Section 4.2 . 
The primary test performance objective for the contaminant extraction portion of the treatability test in the $\mathrm{B}-5$ and $\mathrm{BY}$-Cribs plumes then was to assess the potential for recovering the primary contaminants, ${ }^{137} \mathrm{Cs},{ }^{239} / 240 \mathrm{Pu},{ }^{90} \mathrm{Sr},{ }^{60} \mathrm{Co}$, and ${ }^{99} \mathrm{Tc}$, that are associated with groundwater plume. If the contaminant recovery was satisfactory, an estimate of the long-term rate at which primary contaminants could be extracted from the aquifer was to be developed. This primary objective involved a number of ancillary objectives that were grouped into three categories: (1) measurement of the effectiveness of the contaminant extraction process, (2) assessment of aquifer parameters or operational procedures to allow optimization of the contaminant extraction process, and (3) determination of resource needs. Specific objectives under each of the three categories included the following.

- Effectiveness:

-- Determine the effectiveness of contaminant recovery for the primary contaminants from the aquifer matrix during operation of a pilot-scale pump-and-treat system (i.e., measure the amount of material extracted from aquifer).

\section{- Operating Parameters:}

- $\quad$ Refine knowledge of aquifer hydraulic properties, primary contaminant distribution properties, and estimates of total contaminant quantities to allow prediction of long-term recovery effectiveness.

-- If needed, optimize extraction pump cycling (pumping rates, aquifer reequilibration times, and the effect of changing extraction wells) to maximize recovery.

- If testing is successful and treatment continues, develop a computer model of local groundwater flow and primary contaminant phase transformation and transport to estimate aquifer and geochemical parameters and predict long-term system performance.

\section{- Resource Requirements:}

-- Develop estimates of significant cost contributors, including electrical costs of pumping, installation of additional wells, technical personnel time to interpret process effectiveness, and analytical costs.

As described in Section 2.6, not all test performance objectives were met.

\subsubsection{Data Quality Objectives}

To ensure that data collected were sufficient to meet test objectives, appropriate DQOs were developed.

2.1.2.1 Treatment Test Data Quality Objectives. DQOs and critical data requirements specific to laboratory-scale and pilot-scale treatability testing are provided in Tables 2-1, 2-2, and 2-3, respectively (tables and appendices referenced therein are based on DOE-RL 1995c). In general, data to assess treatment effectiveness and costs were considered most critical to meet test objectives and 
required quantification through the use of quality control $(\mathrm{QC})$ checks. Less critical was the assessment of operating parameters, which were intended primarily to support design optimization. As a result, only a qualitative engineering evaluation of operating parameters was performed.

Sampling and analytical requirements initially specified both lower level (Levels I and II) and higher level (Levels III and V) analyses. Field screening and field analysis techniques (Levels I and II) were originally planned for daily monitoring requirements and measurements. However, there are no on-line detection or field tests for radionuclides at the very low concentrations found at the two sites. Instead, Level V analyses at the 222-S Laboratory were relied on for process control. Confirmatory (Levels III and V) analyses were performed occasionally for critical parameters such as pre- and post-treatment contaminant concentrations to check the 222-S Laboratory results and to analyze for specific groundwater constituents.

2.1.2.2 Contaminant Extraction and Hydrogeologic Assessment Data Quality Objectives. Data collected during the contaminant extraction tests performed at both sites were initially intended to support developing a numerical model of aquifer and primary contaminant response to groundwater removal, if successful testing favored continued operations. With changes to the program, the DQOs for hydrogeologic assessment and groundwater monitoring in Tables 2-4, 2-5, and 2-6 were used. Data collected during contaminant extraction tests performed at the two sites were the same as those used to assess contaminant treatment effectiveness. Thus, they were considered critical to meet test objectives. These data were submitted for QC checks (confirmatory sampling) by Level III or V analyses. Specific DQOs for contaminant extraction testing at both sites are identified in Table 2-4.

The primary objectives of the hydrogeologic assessment of the two plumes were to further define the nature and lateral extent of contamination and further define the aquifer thickness. To achieve these primary objectives at the BY-Cribs plumes site, drilling activities proceeded in two phases. Phase 1 was a limited exploratory drilling and sampling program in the vicinity of well 699-50-53A. Upon a successful conclusion of Phase 1, Phase 2 was proposed to include installation of one extraction well, one return well, and up to eight additional observation wells, along with necessary aquifer testing and sampling. To avoid random well siting, a high-resolution seismic reflection survey was proposed to provide additional information regarding the placement of wells.

Phase 1 exploratory sampling consisted of drilling up to eight borehole/probes to the bottom of the unconfined aquifer (top of basalt) in a grid pattern around well 699-50-53A. Groundwater samples were collected at the bottom of the borehole/probe. The two main objectives of this exploratory program were to further define both the nature and extent of contaminants around well 699-50-53A and the aquifer thickness. The second objective of this exploratory program was to generate data that would guide the placement of additional observation, extraction, or return wells to support the treatability test.

\subsection{EXPERIMENTAL DESIGN AND PROCEDURE}

The test performance objectives outlined in Section 2.1.1 were met at each plume by conducting the following tests: a preliminary laboratory test suite to identify the most appropriate resins, a pilot-scale test of an ion-exchange-based treatment system, and field-based bench-scale testing of adsorbents. The laboratory and field bench-scale testing typically consisted of batch equilibrium and small-scale flow-through (mini-column) tests. The pilot-scale tests are large-scale flow-through column tests that are used to determine treatment system effectiveness, define parameters necessary 
DOE/RL-95-59

Rev. 0

for system optimization, and provide information about resource needs and costs for operating adsorbent-based (e.g., ion exchange) treatment systems on the Hanford Site. They are normally used to test a proposed design and only after all test variables and treatment aiternatives have been worked out by laboratory tests. Table 2-3 summarizes the approach used to meet the test performance objectives for the pilot-scale treatment systems.

Pre-treatment laboratory studies, including batch equilibrium and mini-column tests, designated as resin selection tests, were performed at the IT Corporation's Knoxville, Tennessee, Technology Development Laboratory (TDL). Based on those tests, clinoptilolite, a natural zeolite, was selected for ${ }^{137} \mathrm{Cs}$ and ${ }^{90} \mathrm{Sr}$ removal at the B-5 Reverse Well pilot-scale test and bone char was selected for plutonium removal. Section 2.2.3.1 discusses those tests and procedures, and results are described in Chapter 3.0. At the BY-Cribs site, Dowex $21 \mathrm{~K}$ was identified for ${ }^{60} \mathrm{Co}$ and ${ }^{99} \mathrm{Tc}$ removal and was evaluated in both mini-column tests and in the pilot-scale system.

Extensive field-based laboratory-scale tests were conducted at both sites. At the B-5 Reverse Well, batch equilibrium tests were used to help select a specific adsorbent(s) for removal of target contaminants. Batch equilibrium tests for the BY-Cribs site were not conducted because previous experience at the 200-UP-1 treatment system (DOE-RL 1995a) indicated that Dowex 21K would successfully remove the target contaminants $\left({ }^{99} \mathrm{Tc}\right)$. Small-scale flow-through (mini-column) tests were conducted at both sites to provide additional data to supplement the data obtained from pilot-scale treatment system in order to more fully determine the treatment effectiveness of the treatment systems.

\subsubsection{Pilot-Scale Tests}

The pilot-scale treatment systems were operated to (1) collect data necessary to demonstrate treatment system effectiveness and define the operating parameters necessary for system optimization in the design of systems for a potential IRM Proposed Plan and (2) determine resource needs and costs for operating an adsorbent/ion-exchange groundwater treatment system at the Hanford Site.

Treatment system effectiveness is determined by comparing the influent versus the effluent concentrations of contaminants of concern, then determining the percent removal of the contaminants.

$$
\text { Percent Contaminant Removal }=\frac{\text { Concentration In }- \text { Concentration Out }}{\text { Concentration In }} \times 100
$$

By plotting the removal efficiencies for the various sampling points versus the volumes of water treated, a graphical representation of system performance, called a breakthrough curve, can be developed. Volume of water treated is commonly reported as bed volumes (BVs), which is equal to the volume of resin in a column, without regard to porosity.

The removal efficiency is commonly calculated for both the lead column and total system and graphed. When the removal efficiency drops below a specified level for a column $(90 \%$ for the 200-BP-5 systems), the system is said to have reached breakthrough. At this point, the polishing column then is relied on to remove the target contaminant to agreed-to levels, such as MCLs. Typically, the system is run until the first column has reached $90 \%$ to $100 \%$ saturation, which provides input into the cost of adsorbent for future treatment. If the effluent from the polishing column has also begun to exceed established standards, either another column needs to be added to 
the system or changeout of the adsorbent in the first column needs to occur before it reaches saturation.

Groundwater parameters were also monitored to determine whether they might impact removal efficiencies, in case the treatment system removal efficiencies were not as expected. In some cases, interfering ions may competitively load on the adsorbent(s), thereby shortening adsorbent life or reducing removal of the primary contaminants of concern and the ability to achieve a high-quality effluent. Parameters that were monitored included anions $\left(\mathrm{Cl}, \mathrm{F}, \mathrm{NO}_{3}\right.$, and $\mathrm{SO}_{4}$ ), cations (calcium, iron, magnesium, potassium, sodium, and zinc), and alkalinity. In addition, the operating parameters that were monitored included flow rate and totalized flow, $\mathrm{pH}$, temperature, pressure, dissolved oxygen, and turbidity. Residence/contact time is also an important factor that relates to flow rate.

Resource requirements for the pilot-scale tests were tracked and accounted for by the following categories. Some overlap between the categories exists and accounts for the differences between the sum of costs versus the budget. There is insufficient detail to break out the overlaps.

- Engineering/Design/Construction: Design and construction expenditures included labor and materials for design, well evaluation and remediation, procured equipment, fabrication, construction and construction supplies, and mobilization. Much of the construction work and site preparation was performed by other onsite contractors.

- Operations: Operations expenditures included labor and material costs for operation of the pilot-scale treatment systems. Items in this category included preparation of operating documents, site preparations, operations personnel, site health and safety monitoring, field supervision, and radiation monitoring. Operating materials included ion-exchange adsorbents, fuel, operating supplies, and safety equipment and support facilities (trailers, office equipment, etc.). In addition, field bench-scale testing is considered here.

- Analytical Support for Operations: Analytical support expenditures included analytical costs for both onsite and offsite laboratories. Analytical costs for process control, field bench-scale tests, waste classification, and groundwater are reported here.

- Waste Management: Waste management expenditures included costs for waste management and waste management plan preparation, disposal of regulated and nonregulated wastes, and costs for waste storage supplies and containers (drums, plastic liners, and materials).

- Maintenance and System Standby: Maintenance expenditures included equipment calibrations, equipment repair and replacement, well maintenance, and maintenance management. In addition, tank cleanout and winterization activities are also considered here.

- Project Management: Project management expenditures included labor and material costs associated with project oversight and support, preparation of regulatory and planning documents, safety assessments, and cost account management and support.

- Project Support: Technical labor and associated costs are tracked here in support of all phases of treatability testing. Exempt labor is the dominant expense item.

Other costs included are subcontractor support charges, general site services, indirects and overheads, and other miscellaneous costs not associated with the above categories. 
- Groundwater Characterization: Groundwater characterization activities including drilling, groundwater sampling, and hydrologic testing are considered here. Subheadings include labor and material subcontracts and sampling analytical costs.

2.2.1.1 Treatment System Operation. The two pilot-scale treatment systems were designed according to nearly identical process flowsheets, except that the B-5 Reverse Well treatment system required two different adsorbents for the three contaminants. Process flow diagrams for the treatment systems are provided in Appendix A. The physical arrangement differed from the design in the treatability test plan because of the proximity of extraction and return wells to the treatment systems. Only one adsorbent for removal of the cobalt and technetium was required for the BY-Cribs treatment system.

Each system consisted of an extraction well, a 31,000-L (8,200-gal) influent storage tank, a skid-mounted influent pumping station (with filtration), a skid-mounted adsorbent/ion-exchange treatment system, a 31,000-L (8,200-gal) effluent storage tank, a skid-mounted effluent pumping station (with filtration), and a return well. The extraction systems were designed to operate $24 \mathrm{~h} /$ day to fill the influent storage tank and were provided with both automatic level-sensing shutoff switches and overflow return lines back to the extraction wells. The treatment systems' design processing rates of 95 to $189 \mathrm{~L} / \mathrm{min}$ ( 25 to $50 \mathrm{gal} / \mathrm{min}$ ) were chosen because it was a good size from which to scale-up a larger system and because it would provide appropriate cost data. The systems were typically operated only during day shift to process the water accumulated in the influent storage tank. Smaller systems were considered for both sites but lacked sufficient capacity for efficient use at other potential treatment sites. A granular activated carbon (GAC) adsorber was added to each system after the ionexchange system to remove organic constituents suspected to have originated in the storage tanks (see Section 2.6.3.1). Each system used a programmable logic controller and annunciator panels for monitoring system status and safety interlocks.

- $\quad$ B-5 Reverse Well Site: Groundwater was pumped from well 299-E28-23 to the 31,000-L $(8,200$-gal) influent storage tank. The well was capable of producing at least $132 \mathrm{~L} / \mathrm{min}$ ( $35 \mathrm{gal} / \mathrm{min}$ ), but the well pump was capable of delivering only $106 \mathrm{~L} / \mathrm{min}(28 \mathrm{gal} / \mathrm{min})$. Groundwater was pumped from the influent storage tank via the influent pumping station through filters to the ion-exchange treatment system. The treatment system consisted of four downflow columns: three were used as cation adsorber columns for removal of primary contaminants and the fourth for the GAC. Filtered groundwater was pumped to the first column containing bone char for plutonium removal; to the second column containing clinoptilolite for ${ }^{137} \mathrm{Cs}$ and ${ }^{90} \mathrm{Sr}$ removal; then to the third column containing $50 \%$ clinoptilolite and $50 \%$ bone char as a backup polishing column for all contaminants. The three columns were filled with $1.7 \mathrm{~m}^{2}\left(18 \mathrm{ft}^{3}\right)$ of adsorbent, which resulted in a contact time of $5.4 \mathrm{~min}$ and a hydraulic surface loading rate of $1.9 \mathrm{~L} / \mathrm{min} / \mathrm{m}^{2}\left(5.4 \mathrm{gal} / \mathrm{min} / \mathrm{ft}^{2}\right)$ in each column at a flow rate of $95 \mathrm{~L} / \mathrm{min}(25 \mathrm{gal} / \mathrm{min})$. (Bed volume is defined as the volume of adsorbent, $18 \mathrm{ft}^{3}$; contact time is the bed volume divided by volumetric flow rate.) Treated groundwater was transferred to the $31,000-\mathrm{L}(8,200$-gal) effluent storage tank. The effluent pumping station consisted of a set of pumps and a set of filters to filter the treated water before disposal via the return well.

After processing approximately 4,000 BVs at the B- 5 Reverse Well, the clinoptilolite column and the clinoptilolite-bone char column media were changed. The initial run was designated as "Run 1." Both columns were recharged with clinoptilolite, and the flow was reduced to 
$56.8 \mathrm{~L} / \mathrm{min}$ (15 gal/min) to provide a contact time of 8 minutes for another run, designated as "Run 2."

- BY-Cribs Site: Groundwater was pumped from well 699-50-53A to the 31,000-L $(8,200$-gal) influent storage tank. Because the aquifer at the BY-Cribs site is so thin, well 699-50-53A was only capable of producing 3 to $4 \mathrm{gal} / \mathrm{min}$. Groundwater was pumped from the influent storage tank via the influent pumping station through filters to the ion-exchange treatment system. The ion-exchange treatment system consisted of three downflow columns: two were used as ion-exchange columns and the third was used as a GAC column. Both ion-exchange columns used Dowex $21 \mathrm{~K}$ for the removal of ${ }^{60} \mathrm{Co}$ and ${ }^{99} \mathrm{Tc}$. The ion-exchange columns were filled with $16 \mathrm{ft}^{3}$ of Dowex $21 \mathrm{~K}$, which resulted in a 5-minute contact at $95 \mathrm{~L} / \mathrm{min}(25 \mathrm{gal} / \mathrm{min})$.

Treated groundwater was transferred from the ion-exchange treatment system to the $31,000-\mathrm{L}(8,200$-gal) effluent storage tank. The effluent pumping station consisted of a set of pumps and a set of filters to remove particulates before disposal to the return well.

\subsubsection{Laboratory-Scale Tests}

Laboratory-scale tests were conducted to evaluate the performance of adsorbents that were selected for the B-5 Reverse Well and the BY-Cribs pilot-scale systems. Candidate adsorbents were selected based on experience and a review of the chemistry of groundwater constituents. Data were generated by both batch equilibrium and small-scale flow-through (mini-column) tests. In addition, because the pilot-scale treatment systems would not be run long enough to reach saturation of the media, the mini-column tests would provide supplemental data to satisfactorily determine treatment effectiveness and adsorbent loading data (see Section 2.6.4).

Three different groups of batch equilibrium tests were conducted at the B-5 Reverse Well site, primarily to evaluate adsorbents for strontium removal. The resin selection tests were performed by the IT Corporation on groundwater shipped to the IT Laboratory in Knoxville, Tennessee. These tests are described in Section 2.2.3.1, 2.2.3.2, and the results are presented in Chapter 3.0. The remaining two groups of tests were conducted at the Hanford Site for the B-5 Reverse Well site and were performed according to the Workplan and Procedures for Bench-Scale Testing of Potential Adsorbents for the 200-BP-5 Groundwater Operable Unit (BHI 199.5e). The laboratory-scale tests conducted at the Hanford Site are designated as batch equilibrium tests.

Batch equilibrium tests can be of two types; both involve placing a known amount of adsorbent into a known volume of groundwater. One type determines the $\mathrm{K}_{d}$, or adsorption, of an adsorbent. The $\mathrm{K}_{\mathrm{d}}$ is a single-point expression of the equilibrium, or maximum capacity of an adsorbent for a particular contaminant, expressed in grams of contaminant removed or adsorbed/grams of adsorbent. The $K_{d}$ is represented as follows:

$$
\mathrm{K}_{\mathrm{d}}(\mathrm{mL} / \mathrm{g})=\frac{\text { Contaminant Mass/g of Adsorbent }}{\text { Contaminant Mass } / \mathrm{mL} \text { of Solution }}
$$

The test uses a single dose of adsorbent that is allowed to equilibrate in the solution for $24 \mathrm{~h}$. It may be repeated several times and at various conditions of temperature and/or $\mathrm{pH}$ of the solution.

Statistical techniques are applied to the data to arrive at a significant $K_{d}$ value. 
An adsorption isotherm test is a version of the batch equilibrium test in which several different amounts of adsorbent are allowed to equilibrate at a constant temperature, hence, the term isotherm. In both cases, the residual solution is sampled (filtered if not clear) for the contaminants of interest, and then the amount of contaminant loaded/adsorbed on the adsorbent is calculated. The $\mathrm{K}_{d}$ yields a single value. The numerous values of an adsorption isotherm test provide several data points that may be plotted, as isotherms (amount of contaminant removed per gram of adsorbent versus the residual concentration from each dose batch). The slope of the isotherm plots and comparison of the adsorbent dose versus amount of contaminant removed provides an indication of the potential capacity and kinetics of the adsorbent and the ability to meet a specific effluent discharge requirement.

Lastly, small-scale flow-through mini-column tests were conducted to evaluate the adsorbents in dynamic flow conditions similar to the pilot-scale systems to obtain loading data similar to those obtained in the pilot-scale tests.

Flow-through mini-column tests provide dynamic testing of adsorbents that have been selected or screened by the batch equilibrium tests previously described. Mini-column tests provide additional data regarding the performance of a particular adsorbent in a flow-through column operation. By adjusting test conditions (flow, $\mathrm{pH}$, column size) the loading data obtained provide a better definition of loading capacity, breakthrough characteristics, and kinetics of an adsorbent than that obtained from batch equilibrium tests. Ideally, the adsorbent in flow-through column tests is run to saturation, and samples of the adsorbent are removed to elute the contaminant and perform a mass balance to obtain the ultimate capacity of the adsorbent for the contaminants. Because of schedule constraints, this was not done in the mini-column tests, but adsorbent samples were analyzed from the pilot-scale system.

These tests collectively provide the following:

- An optimum adsorbent for the site-specific conditions and contaminants of interest at the 200-BP-5 treatability test sites

- The volume of groundwater that may be processed by a given amount of adsorbent

- The loading capacities of the adsorbent(s), in milligrams per gram (picocuries per gram), thus providing adsorbent volume requirements

- The ability of an adsorbent to achieve a certain quality of effluent.

In the course of treatability test at the B- 5 Reverse Well site, it became apparent that ${ }^{90} \mathrm{Sr}$ removal by clinoptilolite was not effective at the residence times being used. The failure to remove ${ }^{90} \mathrm{Sr}$ was attributed to its trace concentration in the groundwater. The extremely low concentrations were insufficient to establish a kinetic driving force to remove the ${ }^{90} \mathrm{Sr}$. The maximum ${ }^{90} \mathrm{Sr}$ influent concentration reported for the treatability tests, $6,410 \mathrm{pCi} / \mathrm{L}$, is equivalent to $4.5 \times 10^{-5} \mathrm{ppb}$. Likewise, the maximum concentrations for ${ }^{239240} \mathrm{Pu}(45 \mathrm{pCi} / \mathrm{L})$ and ${ }^{137} \mathrm{Cs}(1,820 \mathrm{pCi} / \mathrm{L})$ are equivalent to $7.3 \times 10^{-5} \mathrm{ppb}$ and $2.1 \times 10^{-5} \mathrm{ppb}$, respectively.

A technique known as isotopic dilution or spiking was investigated as a means of improving ${ }^{90} \mathrm{Sr}$ removal. The addition of nonradioactive strontium, in the form $\mathrm{SrCl}_{2}$, was proposed as a means of increasing the driving force to the clinoptilolite. An addition of a quantity of $\mathrm{SrCl}_{2}$ sufficient to increase total strontium to $2 \mathrm{ppm}$ was tested in field batch-equilibrium and mini-column tests. Results are presented in Section 3.2.2.1. 
2.2.2.1 Resin Selection Tests. Samples of groundwater from the prospective extraction wells in the BY-Cribs and B-5 Reverse Well plumes were tested.The test program consisted of the following:

- Homogeneity/characterization analyses

- Batch equilibrium test for screening of ion-exchange media and adsorbents

- Column tests for process confirmation.

The homogeneity analyses were performed to ensure that the groundwater in each sample container was similar in contaminant concentration.

The groundwater from the B-5 Reverse Well plume (well 299-E28-33) contained representative concentrations of the radionuclides ${ }^{137} \mathrm{Cs}$, ${ }^{239240} \mathrm{Pu}$, and ${ }^{90} \mathrm{Sr}$. Batch equilibrium and column studies were performed on this sample. IRC-718 (a chelating ion-exchange resin) (registered trademark of Rohm and Haas, Philadelphia, Pennsylvania), clinoptilolite (a natural zeolite mineral), and bone char. were tested.

The groundwater from the BY-Cribs plume (well 699-50-53A) contained representative concentrations of the radionuclides ${ }^{60} \mathrm{Co}$ and ${ }^{99} \mathrm{TC}$ as well as cyanide and nitrates. Batch equilibrium studies were performed on the groundwater sample to evaluate the removal of ${ }^{99} \mathrm{Tc}$ and to determine whether the cobalt was in a cyanide complex. Two anion-exchange resins, Dowex 21 and Reillex HPQ (registered trademark of Reilly Industries, Indianapolis, Indiana), were tested. Column tests were not run.

2.2.2.2 Batch Equilibrium Tests. Because of previous work at the 200-UP-1 Operable Unit using Dowex $21 \mathrm{~K}$ for technetium removal, no batch equilibrium tests were performed for the BY-Cribs site. Two groups of batch equilibrium tests were conducted for the B-5 Reverse Well system. The purpose of the first group of B-5 batch tests was to reevaluate different adsorbents for their ability to reduce the levels of cesium, plutonium, and strontium. In the second group of tests, the purpose was to further evaluate clinoptilolite for enhanced strontium removal. Other resins were considered for the second batch equilibrium tests, but the generally good removal efficiency of clinoptilolite coupled with its great economy favored focusing attention on improving its performance.

Batch equilibrium tests were performed by weighing gram amounts of adsorbent that were added to known volumes of groundwater to give varying gram/liter doses. The different amounts of adsorbent were added to filtered groundwater samples taken from the pilot-scale system and stirred for $24 \mathrm{~h}$ to equilibrate. The solution was allowed to settle and then sampled and analyzed for ${ }^{137} \mathrm{Cs},{ }^{239 / 240} \mathrm{Pu}$, and ${ }^{90} \mathrm{Sr}$ in the first group of batch tests. Strontium-90 and total strontium were the only analytes in the second group of tests. $\mathrm{pH}$ measurements were taken before the adsorbent was added to the groundwater and again at the conclusion of the test. The first group of Hanford Site batch equilibrium tests used $0.4-, 4.0-$, and $20.0-\mathrm{g} / \mathrm{L}$ doses of different aclsorbents and varying doses of nonradioactive strontium chloride $\left(\mathrm{SrCl}_{2}\right)(0.2,2$, and $5 \mathrm{ppm}$, as strontium) added to increase the total strontium concentrations. The second group of batch equilibrium tests used $0.2-, 2.0-$, and 20.0-g/L adsorbent doses.

Adsorbents evaluated in the first group of onsite batch equilibrium tests are as follows. Data sheets for the adsorbents are given in Appendix B.

- Bone Char: An absorbent made from cattle bones that have been activated as is activated carbon (Tate \& Lyle, Greenock, Scotland: Tigg Corp., Pittsburgh, Pennsylvania) 
- Clinoptilolite: A natural zeolite (American Resource Corp., Greenbrae, California)

- Durasil 230: An inorganic oxide-based cation ion-exchange media (registered trademark of GTS Duratek, Inc., Columbia, Maryland)

- IRC-718: A chelating resin (Rohm \& Haas, Philadelphia, Pennsylvania)

- UOP A-51: A synthetic zeolite/molecular sieve (registered trademark of UOP Molecular Sieve Adsorbents, Mt. Laurel, New Jersey)

- UOP E-95: A synthetic zeolite/molecular sieve (registered trademark of UOP Molecular Sieve Adsorbents, Mt. Laurel, New Jersey).

Clinoptilolite was the only adsorbent evaluated in the second group of batch equilibrium tests. In addition, the Phipps \& Bird Jar Test (registered trademark of Phipps \& Bird, Richmond, Virginia) apparatus was the only device used for stirring the solution.

The second group of batch equilibrium tests consisted of the following:

- Test 1 evaluated the effect of $\mathrm{pH}$ on adsorption. Two batch tests (in duplicate) were run, one at the normal pH of the groundwater (Test 1a) and one at a lower pH (Test 1b). The pH was lowered by two points (from 8.3 to 6.3) with hydrochloric acid to evaluate whether $\mathrm{pH}$ had an effect on adsorption. Clinoptilolite doses of $0.2,2.0$, and $20.0 \mathrm{~g} / \mathrm{L}$ were added to $1,000 \mathrm{~mL}$ of groundwater; no $\mathrm{SrCl}_{2}$ was added.

- Test 2 evaluated longer contact times and the addition of $\mathrm{SrCl}_{2}$ after the initial contact. In Test $2 \mathrm{a}$, four batch tests were run at clinoptilolite doses of 2.0 and $20.0 \mathrm{~g} / \mathrm{L}$. Duplicates of the $2.0-\mathrm{g} / \mathrm{L}$ (at normal pH) and $20.0-\mathrm{g} / \mathrm{L}$ (at lower $\mathrm{pH}$ ) dose from the first test were also run in this test. In Test $2 \mathrm{~b}$, after the initial $24-\mathrm{h}$ contact of Test $2 \mathrm{a}$ and after sampling, the residual solutions were combined, and fresh clinoptilolite doses of 2.0 and $20.0 \mathrm{~g} / \mathrm{L}$ were added together with $165 \mathrm{ppb}$ of $\mathrm{SrCl}_{2}$ (165 ppb as strontium).

2.2.2.3 Flow-Through Column Tests (Mini-Columns). Flow-through column tests were conducted at different contact times, nominally 5 and 12 minutes, to evaluate the kinetics (rate of uptake), the effect of various flow rates (synonymous with contact times), and the shape of the breakthrough curve. Five mini-column tests in two groups were performed at the B-5 Reverse Well site, and two mini-column tests were performed at the BY-Cribs site to obtain the loading data described above. Dowex $21 \mathrm{~K}$ was the adsorbent tested in the mini-columns at the BY-Cribs. The data sheet for Dowex $21 \mathrm{~K}$ is presented in Appendix B. The adsorbents tested at the B-5 Reverse Well included bone char, clinoptilolite, and UOP A-51.

At the B-5 Reverse Well, two groups of mini-column tests were conducted, coincident with the two runs of the B-5 pilot-scale test. The first group consisted of two sets of columns using a bone char column followed by two clinoptilolite columns in a series flow arrangement (i.e., bone char-clinoptilolite-clinoptilolite) that simulated the pilot-scale system. Both sets of columns were run at the same contact time as the pilot-scale treatment system (5 to 6 minutes). The first set of columns (MCT-1) was run to duplicate Run 1 of the pilot-scale system. In the second set (MCT-2), $\mathrm{SrCl}_{2}$ was added to each of the clinoptilolite columns to evaluate a strontium spike addition as a method for enhancing ${ }^{9} \mathrm{Sr}$ removal, but all other conditions duplicated the first set (and the pilot-scale system). 
The second group of tests was conducted after the pilot-scale system's first run was terminated and the resin replaced for Run 2. Test MCT-1 was continued under the same designation and at the same 5- to 6-minute contact time, as the lead column had not reached saturation for ${ }^{90} \mathrm{Sr}$ or breakthrough of ${ }^{137} \mathrm{Cs}$. The second test, designated "2MCT-2," consisted of one bone char column followed by two clinoptilolite columns, run at a 12-minute contact time. The third test (2MCT-3) consisted of a bone char column followed by a clinoptilolite column followed by a UOP-51 column and was run at a 12-minute contact time. Table 2-7 defines the test parameters/conditions with regard to test number (i.e., 2MCT-3 consisted of bone char, clinoptilolite, and UOP A-51 resins with a 12-minute contact time.

At the BY-Cribs site, two mini-column tests were conducted, each consisting of two mini-columns filled with Dowex $21 \mathrm{~K}$ and each run at a nominal 5-minute contact time to duplicate the pilot-scale system. The purpose of these tests was to obtain supplemental loading and breakthrough data because it was assumed that the BY-Cribs pilot-scale test would conclude before reaching breakthrough. For these tests, a storage tank was filled with prefiltered groundwater from the pilot-scale system that fed the mini-columns (Figure 2-1). The treated effluent was collected in an effluent storage tank and returned batch-wise to the pilot-scale treatment system.

For both sites, those mini-column tests were run until the effluent concentrations from the lead column at each site were $30 \%$ to $50 \%$ of the feed concentration (breakthrough). After breakthrough the lead columns were run to saturation monitoring ${ }^{90} \mathrm{Sr}$ at the B-5 Reverse Well site and ${ }^{99} \mathrm{Tc}$ at the BY-Cribs site at increased sampling frequencies to provide data for plotting the breakthrough curve. To determine each treatment system's removal effectiveness for the other contaminants, ${ }^{60} \mathrm{Co},{ }^{137} \mathrm{Cs}$, and ${ }^{239240} \mathrm{Pu}$ concentrations were monitored periodically at the respective sites.

The mini-columns at the B-5 Reverse Well site were operated and sampled in accordance with the Workplan and Procedures for Bench-Scale Testing of Potential Adsorbents for the 200-BP-5 Groundwater Operable Unit (BHI 1995e). The mini-columns were operated and sampled at the BY-Cribs site according to the Workplan and Procedures for Bench-Scale Testing for the 200-BP-5, Unit \#2 Groundwater Operable Unit (BHI 1995d).

\subsubsection{Groundwater Monitoring/Hydrogeologic Assessment Activities}

Groundwater monitoring activities, including water-level measurements and groundwater sampling, were conducted to assess hydrologic impacts and the contaminant response to pumping on the local aquifer system. Sample collection and water-level measurements were performed in accordance with BHI-EE-01, Environmental Investigation Procedures (BHI 1994). At the B-5 Reverse Well site, water-level pressure transducers connected to a remote datalogger recorded water-level fluctuations in wells 299-E28-7, 299-E28-23, 299-E28-24, and 299-E28-25. Water levels were typically recorded every 60 minutes during periods of normal operation. Water-level measurements were collected at shorter time intervals during the period of system startup and continuous operation. Water levels were also measured with steel tapes in selected wells in the vicinity of the test to support characterization of groundwater flow.

At the BY-Cribs plume site, water-level pressure transducers were installed in both the extraction well 699-50-53A and the adjacent well 699-50-53B, which monitors the upper confined aquifer. Because of the distance between the injection and the return wells, a separate water-level data logging system was used to monitor the return well (699-49-55A) and the upper confined monitoring well 
699-49-55B. Water levels were also measured with steel tapes in selected wells in the vicinity of the BY-Cribs site to support characterization of groundwater flow.

Groundwater samples were collected before the treatability test to baseline the concentration of contaminant in the groundwater. Baseline samples were then analyzed at an offsite laboratory. Groundwater samples were also collected at regular intervals during the operation to determine the concentrations of the contaminants of concern. Samples were collected at the wellhead to serve as time-specific representations of the groundwater quality. These samples were analyzed with the process samples at the 222-S Laboratory. Samples were collected for Level V confirmatory analyses before the start of the process operations and near the end of the operating cycle.

Additional hydrogeologic assessment activities were conducted at both sites. Details of these activities are presented in Section 4.4.

\subsection{EQUIPMENT AND MATERIALS}

Major components of testing equipment and materials are described in the following sections.

\subsubsection{Pilot-Scale Tests}

The major pilot-scale treatment system components, such as pumps/filters and treatment vessels, were mounted on skids for ease of transportation to each test site. Each treatment system consisted of an extraction well, an influent storage tank, an influent pumping station, an ion-exchange treatment system, an effluent storage tank, an effluent pumping station, and a groundwater return well to dispose of treated groundwater (Figures 2-2 and 2-3). High-pressure hoses with quick-disconnect fittings were used to connect the components and to transfer the groundwater through the system. The following sections discuss the pilot-scale system in more detail.

Power for the well pumps, process pumps, and other equipment requirements was furnished by portable diesel-powered generators. A process water tank filled with raw water was used for backwashing requirements, and bottled water was used for sanitary water requirements. Trailers were provided for field test personnel. Tents provided protection for the treatment system from weather. Parts were stored in onsite CONEX boxes.

2.3.1.1 Extraction Wells. The extraction wells were fitted with $480-V$, three-phase submersible pumps. At the B-5 Reverse Well site a 3-hp pump was used, and at the BY-Cribs site a 11/2-hp pump was used. The pumping rate from the well was monitored by a paddle-type flowmeter with remote indication. The groundwater was monitored for temperature, $\mathrm{pH}$, dissolved oxygen, and turbidity. A carbon steel manifold was mounted to a flange welded to the extraction well casing, and an air release valve was mounted in the manifold to vent air back into the well casing until groundwater flow was established. A low-level interlock was installed in the extraction well to shut off the well pump on low level. 
2.3.1.2 Storage Tanks. To store the influent and treated effluent, 31,000-L (8,200-gal) storage tanks were used. The tanks were fitted with level indicators and control interlocks to shut off the following pumps:

- The well pump on high level in the influent tank

- The feed pump(s) to the treatment system on influent tank low level and effluent tank high level

- The effluent pumps on effluent tank low level or disposal well high level.

The tanks were also fitted with a clear polyvinyl chloride sight gauges as backup for the level indicators. The sight gauge was also used to perform pump flow calibrations by measuring the rate of rise. In addition to the level interlocks, each tank used secondary overflow control involving the installation of overflow piping back to either the extraction or disposal well, as appropriate.

2.3.1.3 Influent Pumping Station. The skid-mounted influent pumping station was used to transfer groundwater from the influent storage tank through prefilters, through the ion-exchange treatment system, and into the effluent storage tank. The influent pumping station consisted of two centrifugal pumps, a filter system, a pipe manifold connecting the pumps and filter system together, and a locally mounted control panel. One pump was operated at a time; the other was redundant. The pumping station included a flow meter to measure the instantaneous flow rate and provide totalized volume of water treated. The flow rate was manually adjusted. Flowswitch interlocks were used to protect the pumps from loss of flow, and differential pressure instrumentation was used to indicate differential pressure across the filters. Flowswitches were also used to monitor breaching of the hoses and were interlocked to stop the pumps and thus mitigate potential spills. Valving and quick-disconnect fittings for an air hose were available to blow down the system from several locations in the piping.

The filter system was used to remove suspended solids from the groundwater before the adsorbent/ion-exchange treatment system. The filter system used polypropylene bag filters with 2.5 to $5-\mu \mathrm{m}$ rating housed in a stainless steel housing with a basket filter support. Four filters were manifolded together with individual valves on the inlets and outlets such that one or all four filters could be online.

2.3.1.4 Process Treatment System. The treatment system consisted of fiberglass adsorbent/ionexchange columns that were $76 \mathrm{~cm}$ (30 in.) diameter by $183 \mathrm{~cm}$ (72 in.) high, each having a volume of $0.74 \mathrm{~m}^{3}\left(26 \mathrm{ft}^{3}\right)$ (738 L or $\left.195 \mathrm{gal}\right)$. The B-5 Reverse Well system used three ion-exchange columns, and the BY-Cribs system used two ion-exchange columns. The B-5 Reverse Well system consisted of a bone char column followed by a clinoptilolite column followed by a mixed bed column of bone char and clinoptilolite, in series flow. The BY-Cribs system consisted of two columns with Dowex $21 \mathrm{~K}$ resin, in series flow. A GAC column was added to each treatment system shortly after startup to remove trace organic constituents found in the used $31,000-\mathrm{L}(8,200$-gal) tanks. The GAC columns were added to the end of each treatment train. The adsorbent/ion-exchange system(s) was plumbed to allow for series or parallel flow but operated only in series flow. Hoses connected the influent pumping station to the process treatment system. Two stainless steel process manifolds were used for mounting instrumentation and were located next to the ion-exchange columns. The inlet manifold contained instruments for monitoring process $\mathrm{pH}$, flow, and pressure before the adsorbent/ion-exchange columns. Differential pressure transmitters were used to monitor the pressure drop across each adsorbent/ion-exchange column. After passing through the adsorbent/ion-exchange 
columns, the groundwater went through the second stainless steel pipe manifold mounted beneath the inlet manifold to monitor the outlet $\mathrm{pH}$. The treated groundwater exited the outlet manifold through a 5-cm (2-in.) high-pressure hose to the effluent tank(s).

2.3.1.5 Effluent Pumping Station. The effluent pumping station was used to pump treated water from the effluent storage tank through a set of cartridge filters to the disposal well through a 2-in. hose. The effluent pumping station was fabricated similar to the influent pumping station, except the centrifugal pumps required less head to deliver the flow to the well, and the effluent filters were cartridge type. A flowswitch located in the pump suction piping was interlocked to stop the pump on loss of flow. Differential pressure transmitters monitored the differential pressure across the filters, and a dissolved oxygen analyzer and a thermocouple with a temperature indicator monitored the treated water discharged to the disposal well.

2.3.1.6 Disposal Well. A flange was welded to the protective casing of the disposal well to mount the disposal manifold, like the extraction well. An air release valve was also used to vent air. The turbidity of the treated water was monitored. A level probe was installed in the disposal well and interlocked to shut off the effluent pump on high level.

\subsubsection{Laboratory-Scale Tests}

Laboratory-scale tests consisted of resin selection tests, batch equilibrium tests, and small-scale flow-through tests (mini-column tests).

2.3.2.1 Resin Selection Tests. Before initiation of laboratory-scale tests, the groundwater samples received by the TDL from the Hanford Site were tested for homogeneity and characterization. Samples were submitted to Quanterra Laboratory in St. Louis, Missouri, for initial characterization analysis. Resin selection tests consisted of batch equilibrium and small-scale flow-through tests.

Batch equilibrium tests were performed by weighing gram $( \pm 0.001 \mathrm{~g})$ quantities of different ionexchange media/adsorbents into $2,000-\mathrm{mL}$ polyethylene bottles. Resin/adsorbent doses were typically $0.2,0.5,2.0$, and $20.0 \mathrm{~g} / \mathrm{L}$ of groundwater. Two thousand grams of groundwater was added to each bottle. The bottles were then sealed and agitated by shaker table or magnetic stirrer for $24 \mathrm{~h}$. When the studies were complete, the processed groundwater was decanted or filtered from the ion-exchange medium/adsorbent. The liquid was aliquoted and sent to the Quanterra Laboratory in Richland, Washington, for analysis. Some of the liquid was also used to perform in-house analyses for preliminary results.

The small-column test used a 1.3-cm- (0.5-in.) diameter glass column fed by a variable-speed tubing pump. The column was packed with $20 \mathrm{~mL}$ of clinoptilolite and backwashed with approximately 13 BV of deionized water until the deionized water coming off the top of the column was clear. The column was then allowed to repack before the feed, at $3 \mathrm{~mL} / \mathrm{min}$, was introduced downflow to the column. The duration of the column study was $1,000 \mathrm{BV}$. During the run, grab and composite samples were taken for analysis to determine effluent quality. These samples were analyzed for total strontium.

2.3.2.2 Batch Equilibrium Tests. The Hanford Site batch equilibrium tests were performed by weighing gram $( \pm 0.01)$ quantities of adsorbent into 1-L glass beakers. Next, $750 \mathrm{~mL}$ of sample groundwater was added to the beakers used in the first test group and $1,000 \mathrm{~mL}$ was added to the 
beakers used in the second test group. The test samples were then stirred in a Phipps \& Bird Jar Test device or a toxic characteristic leach procedure (TCLP) tumbler for $24 \mathrm{~h}$. After $24 \mathrm{~h}$, the stirrers were stopped and the contents allowed to settle. The supernatant was filtered via a $1-\mu \mathrm{m}$ filter, sampled, and analyzed for the specific contaminants of interest. Because of the low concentrations of the radionuclides in the residual liquid, a large volume $(750$ to $1,000 \mathrm{~mL})$ of sample was required to obtain an adequate analysis. The feed was filtered groundwater from the pilot-scale treatment system just before the first adsorbent/ion-exchange column. The feed was drawn into a 757-L (200-gal) polyethylene storage tank for dissemination to the test containers.

2.3.2.3 Mini-Column Tests. The mini-column test apparatus at each site consisted of a 200-gal influent feed storage tank, a 1- $\mu \mathrm{m}$ prefilter, two (BY-Cribs site) or three (B-5 Reverse Well site) 2.54-cm- (1-in.) diameter by $1.52-\mathrm{m}-(60$-in.) long glass columns, and a 757-L (200-gal) effluent collection/storage tank (see Figure 2-1). The filter, columns, pumps, and other components were connected with plastic tubing and tubing fittings. Variable-speed tubing pumps were used to provide flow of groundwater through the columns. Teflon three-way valves were installed in the plastic tubing to provide sampling valves at the inlets and outlets of each column. A pressure gauge was installed in the inlet to the first column of each test setup to monitor backpressure of the system and indicate the potential for plugging. The columns were mounted to a fabricated wood structure with laboratory hardware and clamps.

The columns were constructed of heavy wall glass with ground spherical ball joint ends. Glass spherical ball joint (ground joint) adapters were fitted to both ends to allow installation of stainless steel tubing with which to connect the plastic tubing. High-vacuum silicone grease was used to seal the spherical ball joint adapters to the glass column ends. A support media was installed in the bottom of the columns over which 5 to $8 \mathrm{~cm}$ ( 2 to 3 in.) of 3-mm-diameter glass beads were placed. The adsorbent was added from the top to a depth of approximately $91 \mathrm{~cm}(36 \mathrm{in}$.) (bed volume $-460 \mathrm{~mL}$ ).

\subsubsection{Groundwater Monitoring}

Continuous water-level measurements were made by installing an in situ water-level transducer in selected monitoring wells Each transducer was lowered to a predetermined level (top of pump in extraction wells and 0.30 to $0.61 \mathrm{~m}$ ( 1 to $2 \mathrm{ft}$ ) below static water level in injection and observation wells) and secured to the top of the wellhead. The transducers were then connected via signal cable to a central datalogger, which recorded and stored water-level readings at programmed levels. Data were downloaded to a lap-top computer every 2 weeks via an RS-232 port and brought into the office for analysis.

Groundwater samples were collected at a sampling valve on the pump column immediately adjacent to the wellhead. The valve and sampling port were purged before collection to ensure that representative sampling was obtained.

\subsection{SAMPLING AND ANALYSIS}

Sampling and analysis were performed in accordance with the Pilor-Scale Treatability Test Plan for the 200-BP-5 Operable Unit (DOE-RL 1995c), the Workplan and Procedures for Bench-Scale Testing for the 200-BP-5, Unit \#2 Groundwater Operable Unit (BHI 1995d), the Workplan and Procedures 
for Bench-Scale Testing of Potential Absorbents for the 200-BP-Groundwater Operable Unit (BHI 1995e), the Environmental Investigation Procedures (BHI 1994) noted below, and the existing IT TDL procedures. Analyses were performed at the 222-S Laboratory in the 200 Areas of the Hanford Site and at the Quanterra Laboratories in Richland, Washington and St. Louis, Missouri, in accordance with laboratory procedures.

\subsubsection{Pilot-Scale Treatment System}

Pilot-scale treatment system sampling and analysis focused on providing data to demonstrate treatment system effectiveness and to monitor the impacts, if any, of normal groundwater constituents (i.e., anions and cations) on the effectiveness of the treatment system.

Sample valve arrangements had been provided at appropriate locations during construction of the treatment system to allow sampling during system operation (see Figure 2-2 for locations). Before samples were taken, the sample valves and tubing were purged to ensure that a representative sample was obtained. Purgewater was collected and recycled back into the influent storage tank for reprocessing. Treatment system effectiveness was determined by sampling the influent and effluent and calculating the overall removal efficiency as shown in Section 2.2.3.1. In addition, samples were taken of the inlet and outlet of the prefilters and the first ion-exchange column to determine solids removal efficiency and to monitor breakthrough of the lead adsorbent/ion-exchange column.

Samples were generally taken every other day when processing and were analyzed at the $222-S$ Laboratory for ${ }^{17} \mathrm{Cs},{ }^{239240} \mathrm{Pu}$, and ${ }^{90} \mathrm{Sr}$ at the B-5 Reverse Well site and ${ }^{60} \mathrm{Co}$ and ${ }^{99} \mathrm{Tc}$ at the BY-Cribs site. After the adsorbent was changed, more emphasis was placed on monitoring for ${ }^{90} \mathrm{Sr}$ because of the interest in getting the effluent to the $\mathrm{MCL}$ of $8 \mathrm{pCi} / \mathrm{L}$. Moreover, as a cost reduction measure at the BY-Cribs site, the sampling frequency was altered to a rotating frequency of three samples every other day from five possible locations.

Periodically, duplicate samples were sent to an offsite laboratory for a QC check of the analysis. In addition, samples were taken periodically from the treatment system to monitor typical groundwater parameters through the treatment system to determine whether any particular ion was being preferentially removed, thereby interfering with the removal of the radionuclides of interest.

Spent adsorbents taken from the ion-exchange columns were also sampled and analyzed for waste designation. These data also provided a check on the amount of target contaminants removed by the adsorbents.

Samples were handled in accordance with BHI-EE-01, Volume 1, Environmental Investigations Procedures, EIP 5.1, "Chain of Custody," EIP 5.4, "Field Cleaning and/or Decontamination of Equipment," and EIP 5.11, "Sample Packaging and Shipping" (BHI 1994).

\subsubsection{Laboratory-Scale Tests}

2.4.2.1 Resin Selection Test. Two groundwater samples were used in the bench-scale study. Approximately $2,000 \mathrm{~mL}$ of each sample was required for characterization. Each sample was split into equal portions; one portion was submitted to Quanterra Laboratories for analyses "as received" and the other portion was filtered through a $0.45-\mu \mathrm{m}$ glass fiber filter before analysis. All samples 
were collected and analyzed in accordance with approved Quanterra laboratory procedures. The untreated groundwater from the BY-Cribs and B-5 Reverse Well plumes was analyzed by the Quanterra-St. Louis Laboratory. the samples of the groundwater resulting from the batch equilibrium, or isotherm, tests were sent to the Quanterra-Richland Laboratory for radionuclide analyses (e.g., ${ }^{60} \mathrm{Co},{ }^{137} \mathrm{Cs},{ }^{238 / 239 / 240} \mathrm{Pu},{ }^{89 / 90} \mathrm{Sr}$, and ${ }^{99} \mathrm{Tc}$ ). These results were used to verify in-house screening data. Samples of effluent from the column study were collected and analyzed in-house at TDL for ${ }^{137} \mathrm{Cs}$ by gamma spectroscopy and total strontium by GFAA. Selected samples were sent to the Quanterra-Richland Laboratory for isotopic plutonium analysis.

2.4.2.2 Batch Equilibrium Tests. As mentioned previously, two groups of batch equilibrium tests were conducted at the B-5 Reverse Well site. All tests were done in duplicate and analyzed at the 222-S Laboratory. During the first group of batch equilibrium tests, duplicate samples of feed water were also placed on the agitating test apparatus as controls and analyzed with the rest of the post-contact solutions. In addition, a field blank was also processed like the other samples. Samples were analyzed for ${ }^{137} \mathrm{Cs},{ }^{239240} \mathrm{Pu}$, and ${ }^{90} \mathrm{Sr}$ in the first group of batch equilibrium tests. During the second group of batch equilibrium tests, duplicate feed samples were placed on the jar test apparatus for each set as a control. Samples were analyzed for ${ }^{90} \mathrm{Sr}$ and total strontium. Duplicate samples were taken for performing total strontium analyses.

2.4.2.3 Mini-Column Tests. Mini-column test samples were taken from the feed and after each column after processing approximately $250 \mathrm{BV}$ (which occurred approximately every $24 \mathrm{~h}$ ) until $1,500 \mathrm{BV}$ had been processed. The sampling frequency was then increased to every 100 to $150 \mathrm{BV}$ processed, or on a 12-h frequency. The samples were sent to the 222-S Laboratory for analyses, and every fifth sample was sampled for duplicate analyses at an offsite laboratory as a QC check. Samples were analyzed at the $222-\mathrm{S}$ Laboratory for ${ }^{137} \mathrm{Cs}$, ${ }^{239 / 240} \mathrm{Pu}$, and ${ }^{90} \mathrm{Sr}$ from the B-5 Reverse Well site and for ${ }^{60} \mathrm{Co}$ and ${ }^{99} \mathrm{Tc}$ from the BY-Cribs site.

\subsection{DATA MANAGEMENT}

Pilot-scale system operational data were recorded on log sheets and in the field log book specifically assigned to this task. The $\log$ book(s) are part of the project file and are preserved according to EIP 1.5, "Field Logbooks" (BHI 1994). Field screening data were handled as operational data. Analytical data for both the pilot-scale and laboratory-scale tests from the 222-S Laboratory and the offsite laboratories were managed in accordance with EIP 2.0, "Sample Event Coordination" (BHI 1994). Analytical results were entered into the HEIS database.

\subsection{DEVIATIONS FROM THE TEST PLAN}

A number of deviations to the treatability test plan (DOE-RL 1995c) occurred following its implementation. The deviations and resulting impact on test objectives are described below. The most notable deviations from the treatability test plan included changes to the treatment system design and approaches to drilling. The treatability test plan (Rev. 0) submitted to meet the milestone represented the expected state of conditions that guided treatment system design. Production tests performed during the spring of 1995 revealed an unexpectedly thin zone of saturated sediments at the BY-Cribs site and diminished projections of extraction rates. A project review by the Environmental Restoration Contractor (ERC) produced several major changes to system design. The project review and important changes are defined in Appendix A of the treatability test plan (DOE-RL 1995c). 


\subsubsection{Geohydrological Testing}

Lower than expected production from wells in the BY-Cribs plume was demonstrated during production tests in the spring of 1994. Well 699-50-53A, which was most capable of supplying high concentrations of contaminated water, was ultimately selected as the extraction well but did not produce water at rates exceeding $15 \mathrm{~L} / \mathrm{min}$ (4 gal $/ \mathrm{min})$. Continued low flow led to a recommendation for further evaluations of the BY-Cribs aquifer and a cost benefit analysis of moving the treatment system versus piping or trucking water to the existing location. Changes to the original test plan were detailed in a 200 NPL Agreement/Change Control Form (BHI-00203), dated November 9, 1994, that specified hydrogeologic investigations at the BY-Cribs site and also at the B-5 Reverse Well contaminant plume. Specific items included (1) pump test and groundwater analysis at well 699-55-57, (2) groundwater contaminant analysis at well 699-55-60A, (3) in situ groundwater velocity flow measurements, and (4) tracer tests at the B-5 site injection well. Results are detailed in Chapter 4.0 of this test report.

In addition, several activities proposed in the 200-BP-5 treatability test plan were not performed. Specifically not performed/developed were (1) a computer model of the local groundwater flow and primary contaminant distributions, (2) optimized extraction well cycling data, and (3) refined knowledge of the aquifer contaminant distributions. As explained in Section 2.1.1.2, a computer model was to be developed if the test data warranted continued pump-and-treat activities. Extraction well pumping/cycling data were not required due to successful contaminant extraction at both sites. A refined understanding of aquifer contaminant distribution was not acquired due to difficulties with the drilling program explained in Section 2.6.2.

2.6.1.1 Well 699-55-57 Tests. Groundwater monitoring data from the April 1994 200-BP-5 Operable Unit sampling event indicated that well $699-55-57$ had relatively high levels of ${ }^{99} \mathrm{Tc}$ $(2,100 \mathrm{pCi} / \mathrm{L})$ and also penetrated a 1.5 to $2.1-\mathrm{m}(5-$ to $7-\mathrm{ft})$ thickness of unconfined aquifer. This well was initially regarded as the most suitable alternative if the system were moved, and tests were proposed to ascertain the amount of water it could produce. Initial reviews of information provided in Ledgerwood (1993) indicated that well construction did not favor high pumping rates because the casing had been perforated using saw cuts. A preliminary pump test indicated a $8-\mathrm{L} / \mathrm{min}$ (2-gal $/ \mathrm{min}$ ) extraction rate.

It was proposed that aquifer communications could be improved, and a shot perforation technique, available through onsite sources, was procured. The shot perforation system was overcharged and destroyed most of the casing in the aquifer. Following this, running sand conditions were encountered. A 10-cm (4-in.) telescoping screen was installed and the well jetted free of sand several times. An 8-h production test was performed in late February 1995, and five samples were taken to measure the concentration of the primary contaminants of concern. Test results are discussed in Section 4.3.2.

2.6.1.2 Well 699-55-60A Testing. Wells 699-55-60A and 699-55-60B were identified as two of only a few wells lying west of the expected BY-Cribs plume location near the Gable Gap area. Further, no samples had ever been taken from these locations. The wells were both constructed as 36-cm (14-in.) completions for cooling water supply to the 200 North Area in 1944. Both wells were considered for sampling, but a site inspection showed that the amount of debris in well 699-55-60B would not permit reliable sampling. Well 699-55-60A was sampled in early March, in a cooperative 
Rev. 0

venture with Pacific Northwest National Laboratory (PNNL). Results are presented in Section 4.4.2.2.

2.6.1.3 In Situ Flow Velocity Measurements. In situ flow velocity measurements were proposed to determine the rate and direction of groundwater flow in the BY-Cribs plume region, in and north of the 200 East Area. The technique used the KV Engineering Company's In Situ Flow Meter device owned by Westinghouse Hanford Company's (WHC) Groundwater Data Services organization. The device has been modified by WHC to use stouter rods, which ensure accurate north-south directional alignment. The device emits a heat pulse in the groundwater and measures voltage change at eight thermistors because of temperature changes. The device is accurate down to $0.012-\mathrm{m} /$ day (0.04- $\mathrm{ft} /$ day) groundwater flow velocities.

A series of 14 wells, the construction specifications of which met the instrument's requirements, were identified and tested in late May/July timeframe. The wells were tested to determine groundwater directions and velocities and the data used to verify previous plume migration directions. Tests were also considered at the B-5 Reverse Well, but radionuclide contamination raised concerns that the device might become contaminated. Additional test information and results are given in Section 4.3.3.

2.6.1.4 B-5 Reverse Well Injection Well Change. The reinjection well proposed in Section 4.1.2 of the 200-BP-5 treatability test plan (DOE-RL 1995c) was questioned before startup of the system. An ERC regulatory analysis interpretation required that treated water could not be reinjected outside the existing contaminant plume unless the contaminant concentrations were less than the MCLs. For the BY-Cribs plume, the nearby wells were within the plume; therefore, no problems existed with the proposed return well.

At the B-5 Reverse Well site, the plume was much smaller in area and did not include the preselected injection well 299-E28-1. The injection piping was pulled from this well and relocated to well 299-E28-7, $18 \mathrm{~m}$ (60 ft) upgradient from the extraction well. Concerns were raised regarding recirculating treated water and treating it again with much lower radionuclide concentrations through the system; tracer tests described in the next section were performed.

2.6.1.5 Tracer Tests at the B-5 Reverse Well. Two tracer tests were conducted around the B-5 Reverse Well during the course of system operations to test for recirculation of treated groundwater. In both cases, a bromide tracer was mixed into treated effluent water and reinjected at the start of 5 days of continuous extraction/treatment operations. Hourly samples were taken from the extraction well and analyzed with a bromide detector. Extraction rates during both tests were $95 \mathrm{~L} / \mathrm{min}$ (25 gal/min).

The first test was run using well 299-E28-23 as the extraction well and well 299-E28-7 as the injection well. These wells are approximately $18 \mathrm{~m}(60 \mathrm{ft})$ apart. This arrangement provided a measure of flow between an injection well upgradient from the extraction well. The second test was run with the same extraction well location but with the injection well moved to well 299-E28-25, located approximately $8 \mathrm{~m}(25 \mathrm{ft})$ northwest and downgradient from the injection well. Test results are described in Section 4.3.4.

2.6.1.6 Cyclic Pumping at the B-5 Reverse Well System. Section 4.2.1 of the 200-BP-5 treatability test plan proposed cyclic pumping and testing of the B-5 Reverse Well. It was expected that, per the conceptual model, rapid declines in the extraction concentrations of ${ }^{137} \mathrm{Cs},{ }^{239 / 240} \mathrm{Pu}$, and 


\begin{abstract}
${ }^{90} \mathrm{Sr}$ would occur shortly after test startup. It was also expected that after 1 to 2 months of operation, the extracted water would be depleted of high concentrations of contaminant, the system would be turned off, and the groundwater would be allowed to reequilibrate to pretest levels. Testing would then resume 3 to 4 months later. However, because of the continuously high extraction concentrations of ${ }^{137} \mathrm{Cs}$ and ${ }^{90} \mathrm{Sr}$, this approach to groundwater extraction and operations was not needed.
\end{abstract}

\title{
2.6.2 Drilling Activities
}

The recognition of a thin aquifer and poor extraction rates at well 699-50-53A and adjacent wells initiated a program to drill several wells between it and the likely injection well at 699-49-55A. The goal was to locate greater thicknesses of groundwater and greater contaminant concentrations. Two wells were to be evenly spaced between the existing wells and would serve as either extraction, injection, or monitoring wells depending on production testing and groundwater analysis results. Additionally, the use of a heavyweight cone penetrometer exploration system was proposed to ascertain depth to, and thickness of, groundwater, and to then guide drilling accordingly.

Following the ERC project review, revision 0 of the 200-BP-5 treatability test plan proposed the use of a sonic drilling technique using heavy cone penetrometer rods to investigate aquifer thickness and contaminant distribution between the BY-Cribs and well 699-50-53A. Results of this activity would then support drilling a network of eight extraction/injection/monitoring wells around the most productive location found. The sonic drilling system was used in August 1994 and successfully provided aquifer information at three of eight locations. At three other locations holes were drilled, but hard drilling conditions were encountered and groundwater was not reached (see Section 4.4.1). The drilling confirmed a limited ${ }^{99} \mathrm{Tc}$ plume south of the extraction well and did not support pursuing drilling activities in FY 1994.

A second set of wells was proposed for FY 1995 in the area northwest of well 699-50-53A. In an effort to better direct the drilling program, a proposal was made to use high-resolution seismic reflection techniques to locate suitable drilling locations. The seismic reflection program was to be used to locate erosion channels in the basalt that were regarded as possibly providing both a thicker aquifer with high concentrations of the target contaminants. To be effective, this proposal relied on downhole seismic velocity data not then available. The overall expense of the seismic reflection program would have severely limited the resulting drilling program and was not assured of providing the needed data. Plans for drilling were dropped for FY 1995. A monitoring well was then proposed at the B-5 Reverse Well plume site. This well was intended for characterization but was not regarded as essential to the treatability test.

\subsubsection{Changes in Pilot-Scale System Design/Operation}

Design changes and several incidents led to either decreased system effectiveness or delays in operations of both systems.

2.6.3.1 Tank Contamination. System operations began on August 29, 1994, with extraction of groundwater, but after repeated low $\mathrm{pH}$ readings at the BY-Cribs system, operations were shut down to allow investigation of the problem. The 31,000-L (8,200-gal) tanks obtained from B Plant and that were being used as influent and effluent storage tanks were found to contain residual material that had 
not been removed before installation. This was detected during startup and acceptance testing activities when unusually low $\mathrm{pH}$ readings were noted during calibration of $\mathrm{pH}$ instruments at the BY-Cribs site. A review of B Plant history indicated the tanks had been used for storage of aluminum nitrate nonhydrate, ethyldiaminetetracetic acid, and nitric acid. The tanks had not been properly cleaned before transfer from B Plant. Cleaning the tanks and disposing of the cleaning solutions for both sites caused a 3-month delay.

Initial samples taken from the tanks also indicated organic contamination. Therefore, to mitigate the potential for organics being entrained into the treated water that would be discharged into the disposal wells, GAC systems were designed and installed for removal of organics. In addition, during tank cleaning a small quantity of elemental mercury was discovered in one tank and mercury vapor was detected in another tank. The elemental mercury was cleaned up and properly disposed of. Tank cleanup and verification sampling were completed, and the treatment systems started again on November 28, 1994.

2.6.3.2 Winterization. After approximately 1 week of operations in early December 1994, testing was shut down for 6 weeks on December 6,1994, to complete winterization activities. This resulted from an ERC management order following an incident resulting from frozen piping in the 100 Areas. System operations at the B-5 Reverse Well site resumed on January 17, 1995, and at the BY-Cribs site on January 18, 1995.

2.6.3.3 Change in Resin for Strontium-90 Removal. Resin for the B-5 Reverse Well system was changed from Rohm \& Haas IRC-718 to clinoptilolite after laboratory test results indicated that the clinoptilolite appeared to have a higher removal efficiency for ${ }^{90} \mathrm{Sr}$ than the IRC-718. The resin change caused several operational problems because the treatment systems were not designed for the higher operating pressures and flows that clinoptilolite, by virtue of its higher specific gravity and smaller size, required. In addition, the finer grain size of the material required finer mesh screens in the columns and refabrication of screens at either end of the columns. The higher specific gravity limited sufficient backwashing of the clinoptilolite, since the original system design did not anticipate the 1,300 to $1,500 \mathrm{~L} / \mathrm{min}$ ( 350 to $400 \mathrm{gal} / \mathrm{min}$ ) flow rates and associated pressure required to achieve the manufacturer's recommended $50 \%$ bed expansion for the clinoptilolite. The fines also caused a corresponding increase in system pressures. During backwash, the backwash flow rate could achieve only 57 to $76 \mathrm{~L} / \mathrm{min}$ ( 15 to $20 \mathrm{gal} / \mathrm{min}$ ), which was insufficient to remove the fines. The backwash solutions were passed through filters for removal of the fines. This operation took several days to complete. In addition, because of insufficient backwashing, significant quantities of fines tended to clog downstream in-line filters during the first several weeks of processing operation.

2.6.3.4 Ion-Exchange Column Changes. The ion-exchange columns originally selected were thought to have a pressure rating that was too low to meet the requirements of the B-5 Reverse Well system. It also appeared that their delivery would not meet scheduled startup; therefore, procurement of other, higher pressure-rated vessels was initiated. Smaller volume fiberglass vessels were located and ordered. Tradeoffs on the column sizes and resins resulted in operating the systems at $95 \mathrm{~L} / \mathrm{min}$ ( $25 \mathrm{gal} / \mathrm{min}$ ) to provide the minimum 5 -minute residence time per column for the contaminants of concern. This was one-half the originally estimated process rate of $189 \mathrm{~L} / \mathrm{min}(50 \mathrm{gal} / \mathrm{min})$. 
DOE/RL-95-59

Rev. 0

\subsubsection{Preliminary Engineering Assessment of Treatment Alternatives}

A preliminary engineering assessment of treatment alternatives study was conducted to identify and evaluate alternate technologies that might be more effective or less costly than ion exchange. The document is being released as a Bechtel Hanford, Inc. (BHI) report.

\subsubsection{Addition of the 216-A-25 Gable Mountain Pond to the Risk Assessment}

As part of the RBDA and per agreement between DOE, EPA, and ERC, the ${ }^{90} \mathrm{Sr}$ plume at the 216-A-25 Gable Mountain Pond was examined for hazard to offsite personnel. As explained in more detail in Section 5.1.2.4, Gable Mountain Pond received a large portion of the cooling waters generated at the 200 East facilities, primarily the PUREX Plant, over the years. In the course of operations, a ${ }^{90} \mathrm{Sr}$ plume built up under the pond following an accidental release at the PUREX Plant in 1964. Based on the relative risk assessment performed in the 200 East Groundwater Aggregate Area Management Study Report (DOE-RL 1993a), it was considered to be the third most significant plume in the 200-BP-5 Operable Unit for risk to human health, following the B-5 Reverse Well and BY-Cribs plumes. The risk assessment discussion is presented in Section 5.4.

\subsubsection{Treatment Systems Shutdown}

The proposed 6-month test period specified in the 200-BP-5 treatability test plan (DOE-RL 1995c) was reduced to 4.5 months following delays resulting from tank cleanout and winterization. In anticipation of the reduced testing program, the field-based mini-column tests were proposed as a means of gathering breakthrough data for the initially selected resins. Modifications were later made to the B-5 mini-column tests to examine several options for enhanced ${ }^{90} \mathrm{Sr}$ removal. A $200 \mathrm{NPL}$ Agreement/Change Control Form (BHI-00334) was approved by DOE, EPA, and Ecology on May 15, 1995, and implemented a May 30, 1995 date by which to cease all operations. The BY-Cribs pilot system was shut down on May 22, 1995, and the B-5 Reverse Well system was shut down on May 29, 1995. 
DOE/RL-95-59

Rev. 0 
DOE/RL-95-59

Rev. 0

Figure 2-1. Mini-Column Flowsheet.

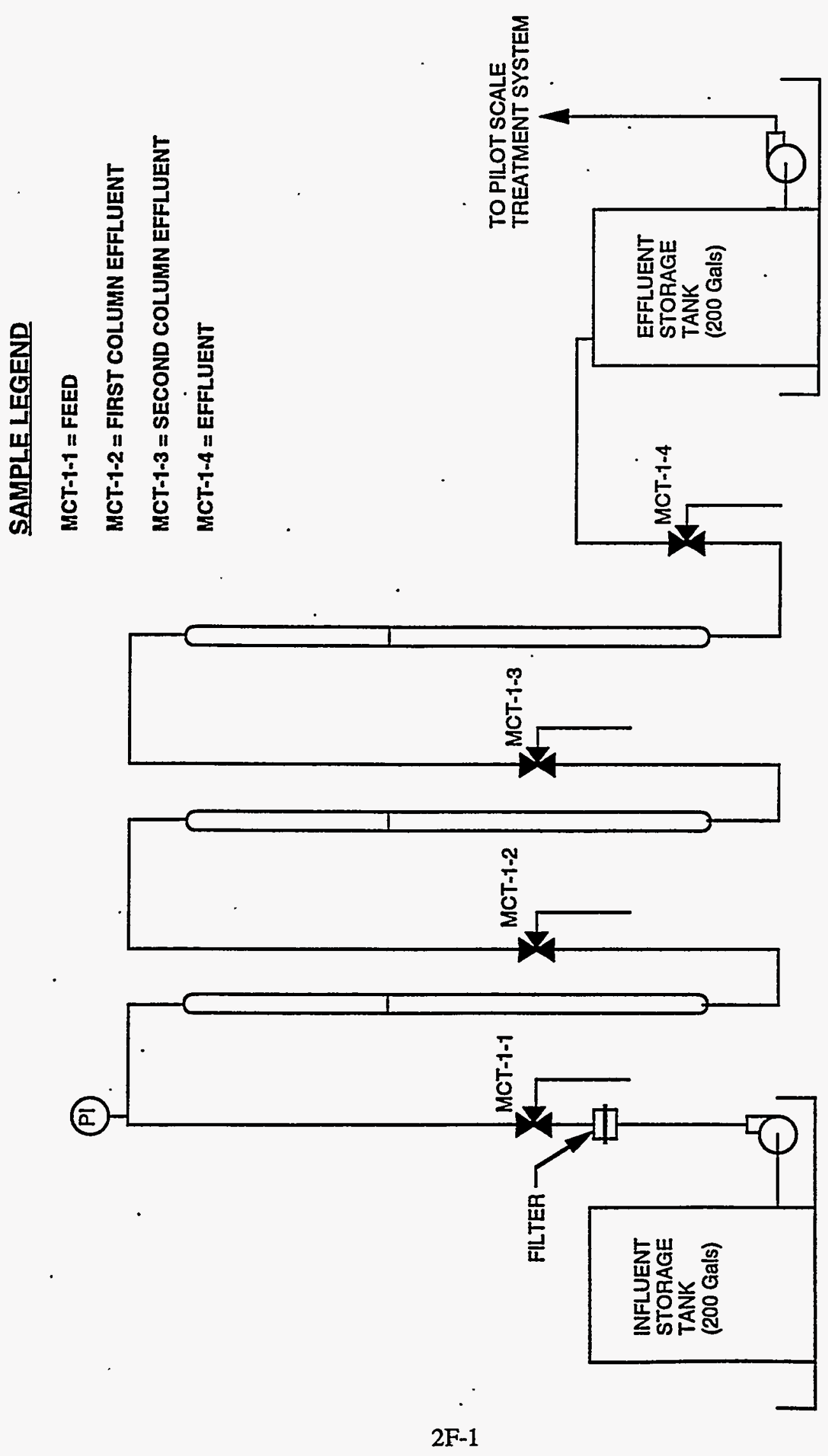




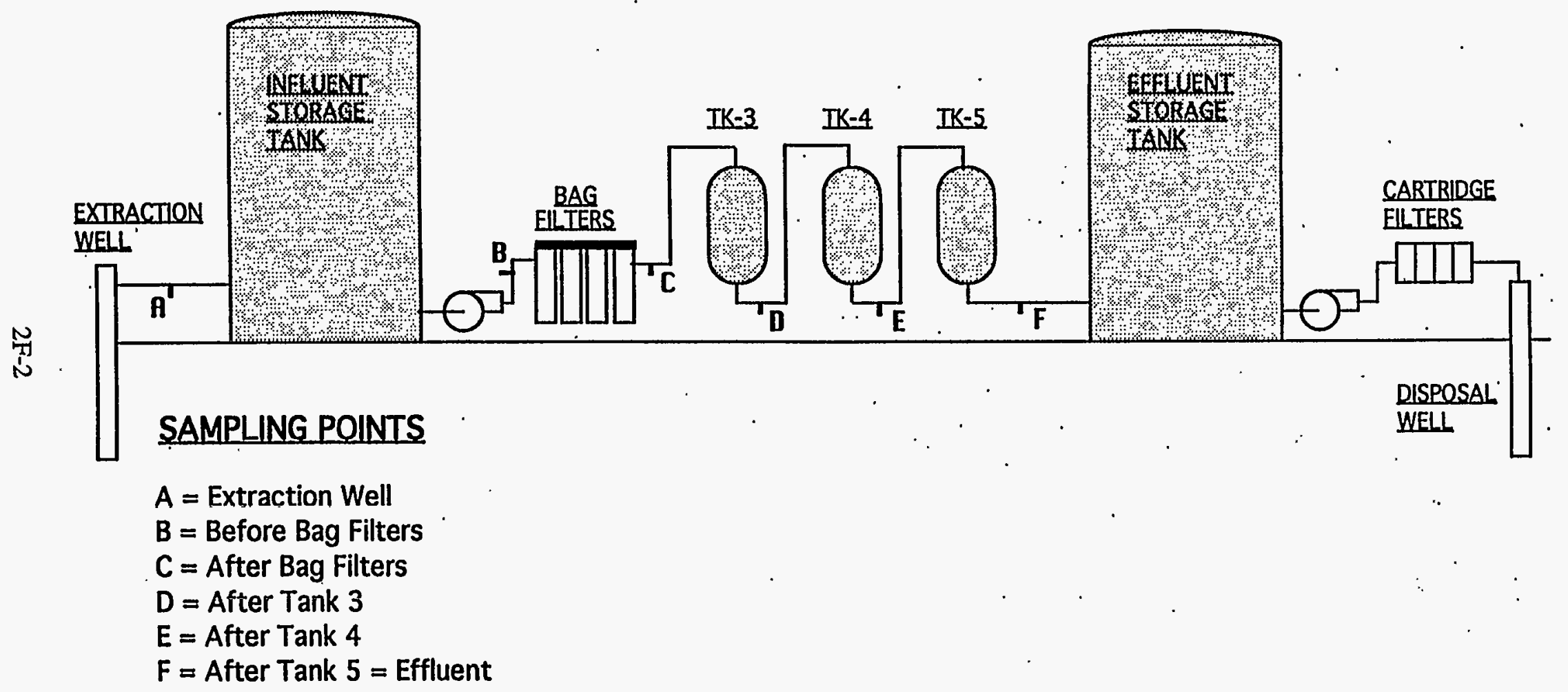


DOE/RL-95-59

Rev. 0

Figure 2-3. 216-BY Cribs Treatment System Equipment Arrangement.

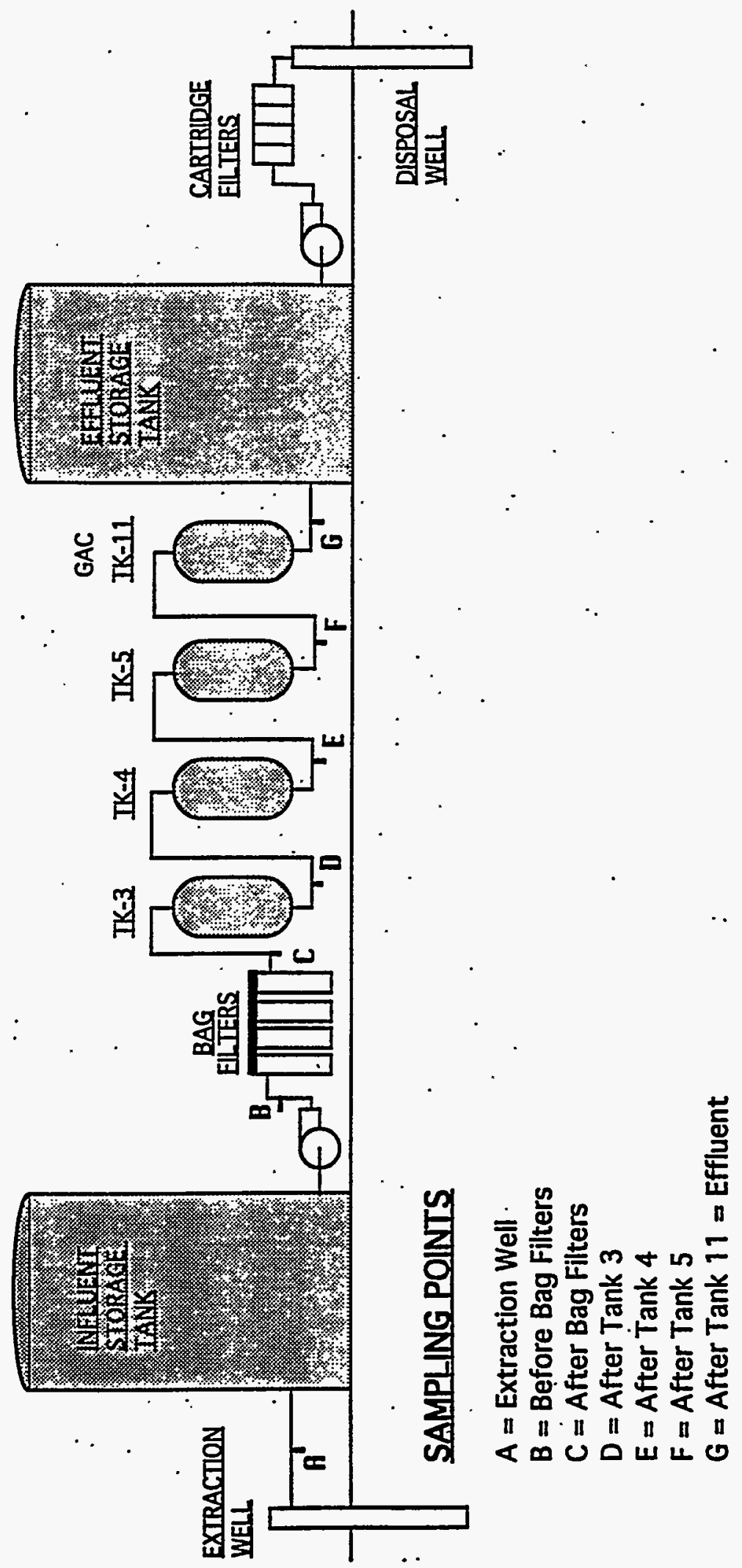


DOE/RL-95-59

Rev. 0 
Rev. 0

Table 2-1. Data Quality Objectives for Laboratory-Scale Testing.

\begin{tabular}{|c|c|}
\hline Activity & $\begin{array}{l}\text { Conduct chemistry tests of ion-exchange resin(s), coupled with } \\
\text { pre-treatment system chemistry, if necessary, that is suitable for } \\
\text { removing }{ }^{60} \mathrm{Co} \text { and }{ }^{99} \mathrm{Tc} \text { or }{ }^{137} \mathrm{Cs},{ }^{239 / 240} \mathrm{Pu} \text {, and }{ }^{90} \mathrm{Sr} \text { from groundwater. }\end{array}$ \\
\hline Objectives & $\begin{array}{l}\text { Identify the preferred ion-exchange resin(s) effective at capturing }{ }^{60} \mathrm{Co} \\
\text { and }{ }^{99} \mathrm{Tc} \text { (or }{ }^{137} \mathrm{Cs},{ }^{239 / 240} \mathrm{Pu} \text {, and }{ }^{90} \mathrm{Sr} \text { ) from groundwater samples. }\end{array}$ \\
\hline Prioritized Data Uses & $\begin{array}{l}\text { Support pilot-scale treatment system design (i.e., resin selection and } \\
\text { pre-treatment requirements). }\end{array}$ \\
\hline $\begin{array}{l}\text { Appropriate Analytical } \\
\text { Level or Implementation } \\
\text { Guidelines }\end{array}$ & $\begin{array}{l}\text { Protocols follow established industrial standards or U.S. Environmental } \\
\text { Protection Agency methods. Some analyses may require method } \\
\text { modification and/or development (Level V). }\end{array}$ \\
\hline \multirow[t]{3}{*}{$\begin{array}{l}\text { Parameters to be } \\
\text { Obtained }\end{array}$} & $\begin{array}{l}\text { Because of the limited scope of the laboratory testing program, the } \\
\text { parameters to be obtained focus on the effectiveness of the treatment } \\
\text { system as determined by sampling the influent and effluent } \\
\text { concentrations of contaminants of concern from the ion-exchange resin } \\
\text { columns and potential pre-treatment processes as follows: }\end{array}$ \\
\hline & $\begin{array}{l}\text { Resin Selection: } \\
\text { - } \quad \text { Concentrations of primary and secondary contaminants } \\
\text { - } \quad \text { pH, temperature, oxidation/reduction potential } \\
\text { - } \quad \text { Katch equilibria } \\
\text { Kinetics, rate of uptake. }\end{array}$ \\
\hline & $\begin{array}{l}\text { Pre-treatment: } \\
\text { - } \quad \text { Effect of } \mathrm{pH} \text { adjustment on removal efficiency } \\
\text { - } \quad \text { Resin capacity and effectiveness in removing }{ }^{60} \mathrm{Co} .\end{array}$ \\
\hline $\begin{array}{l}\text { Required Detection or } \\
\text { Measurement Limits }\end{array}$ & $\begin{array}{l}\text { Analytical detection limits and data quality objective (DQO) } \\
\text { requirements (precision, accuracy, representativeness, completeness, } \\
\text { comparability parameters) will be identified in the sampling and analysis } \\
\text { plan (Appendix C) and the quality assurance project plan (QAPjP) } \\
\text { (Appendix B). These requirements will focus on the effectiveness of } \\
\text { the processes being tested. The DQOs for Level III analyses are listed } \\
\text { in the QAPjP (Appendix B). }\end{array}$ \\
\hline $\begin{array}{l}\text { Critical Samples or } \\
\text { Values }\end{array}$ & $\begin{array}{l}{ }^{60} \mathrm{Co} \text { and }{ }^{99} \mathrm{Tc} \text { or }{ }^{137} \mathrm{Cs},{ }^{239 / 240} \mathrm{Pu} \text {, and }{ }^{90} \mathrm{Sr} \text { concentrations in pre- and } \\
\text { post-treatment samples. }\end{array}$ \\
\hline Constraints & $\begin{array}{l}\text { Representative samples of groundwater are required from each of the } \\
\text { two plumes. }\end{array}$ \\
\hline
\end{tabular}


Table 2-2. Data Quality Objectives for 200-BP-5 Operable Unit Plumes Pilot-Scale Treatment Testing. (2 Sheets)

\begin{tabular}{|c|c|}
\hline Activity & Pilot-scale treatability test. \\
\hline Objectives & $\begin{array}{l}\text { Assess effectiveness, operating parameters, and cost of using ion } \\
\text { exchange to remove }{ }^{137} \mathrm{Cs},{ }^{239240} \mathrm{Pu} \text {, and }{ }^{90} \mathrm{Sr} \text {; or }{ }^{60} \mathrm{Co} \text { and }{ }^{99} \mathrm{Tc} \text { from } \\
\text { extracted groundwater. }\end{array}$ \\
\hline Prioritized Data Uses & $\begin{array}{l}\text { Support the selection of a preferred interim action alternative for the } \\
\text { plume. }\end{array}$ \\
\hline $\begin{array}{l}\text { Appropriate Analytical } \\
\text { Level or Implementation } \\
\text { Guidelines }\end{array}$ & $\begin{array}{l}\text { Level I and II screening analyses will be used for process monitoring. } \\
\text { As a minimum, }{ }^{137} \mathrm{Cs},{ }^{239240} \mathrm{Pu} \text {, and }{ }^{90} \mathrm{Sr} \text {; or }{ }^{60} \mathrm{Co} \text { and }{ }^{99} \mathrm{Tc} \\
\text { concentrations will be verified by limited Level III or V analyses. No } \\
\text { validation (Level IV) data will be required because only interim action } \\
\text { decisions are being supported. Requirements will be refined in the } \\
\text { process monitoring sampling and analysis plan (Appendix C) and the } \\
\text { quality assurance project plan (QAPjP) (Appendix B). }\end{array}$ \\
\hline \multirow[t]{3}{*}{ Parameters to be Obtained } & $\begin{array}{l}\text { Effectiveness: Influent and effluent concentrations of }{ }^{137} \mathrm{Cs},{ }^{239 / 240} \mathrm{Pu} \text {, } \\
\text { and }{ }^{90} \mathrm{Sr} \text {; or }{ }^{60} \mathrm{Co} \text { and }{ }^{99} \mathrm{Tc} \text {. Develop breakthrough curves for } \\
\text { adsorbents. }\end{array}$ \\
\hline & $\begin{array}{l}\text { Operating Parameters: } \\
\text { - } \quad \text { Flow rate } \\
\text { - } \quad \text { Op, temperature, turbidity, dissolved oxygen } \\
\quad \text { Operating pressures, both differential and point. }\end{array}$ \\
\hline & 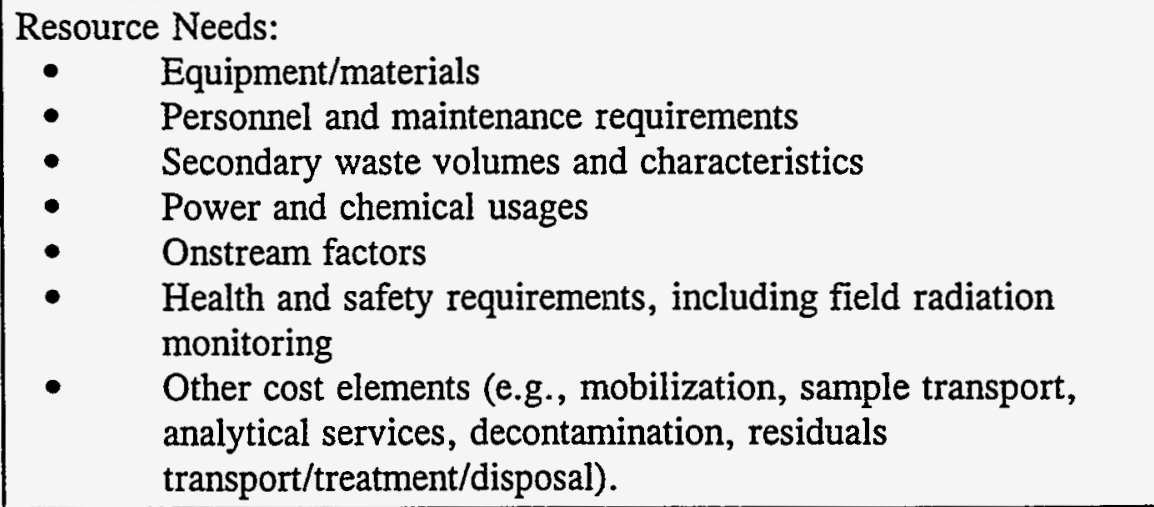 \\
\hline $\begin{array}{l}\text { Required Detection or } \\
\text { Measurement Limits }\end{array}$ & $\begin{array}{l}\text { Effectiveness: Analytical detection limits for }{ }^{137} \mathrm{Cs},{ }^{239240} \mathrm{Pu},{ }^{90} \mathrm{Sr} \text {, and } \\
\text { nitrate; or }{ }^{60} \mathrm{Co} \text { and }{ }^{99} \mathrm{Tc} \text { must be able to detect expected effluent } \\
\text { concentrations after } 90 \% \text { removal. A.ccuracy should be sufficient to } \\
\text { support calculation of removal efficiency to } \pm 1 \% \text {. Other supporting } \\
\text { documentation such as equipment data sheets may also affect final data } \\
\text { quality objectives (DQOs). The DQOs and other precision, accuracy, } \\
\text { representativeness, completeness, comparability parameters are } \\
\text { specified in the QAPjP (Appendix B). }\end{array}$ \\
\hline
\end{tabular}


Table 2-2. Data Quality Objectives for 200-BP-5 Operable Unit Plumes Pilot-Scale Treatment Testing. (2 Sheets)

\begin{tabular}{|c|c|c|c|c|}
\hline \multirow[t]{9}{*}{$\begin{array}{l}\text { Required Detection or } \\
\text { Measurement Limits } \\
\text { (Continued) }\end{array}$} & \multicolumn{4}{|c|}{$\begin{array}{l}\text { Operating Parameters: Process chemistry will be measured primarily } \\
\text { to detect significant and/or unanticipated secondary impacts on system } \\
\text { operation and efficiency. Analytical protocols will follow established } \\
\text { vendor standards, industrial standards, or EPA practices. Other } \\
\text { operating parameters will be measured as follows: }\end{array}$} \\
\hline & Parameter & Instrument & Range & Accuracy \\
\hline & Flow rate & meter & 10 to $60 \mathrm{gal} / \mathrm{min}$ & $\pm 1 \mathrm{gal} / \mathrm{min}$ \\
\hline & $\mathrm{pH}$ & probe & 0 to 14 & \pm 0.1 \\
\hline & Temperature & $\begin{array}{l}\text { thremocouple or } \\
\text { thermometer }\end{array}$ & 0 to $100{ }^{\circ} \mathrm{C}$ & $\pm 1{ }^{\circ} \mathrm{C}$ \\
\hline & Turbidity & meter & 0 to $100 \mathrm{NTU}^{2}$ & $\pm 5.0 \mathrm{NTU}$ \\
\hline & $\begin{array}{l}\text { Differential } \\
\text { Pressure }\end{array}$ & $\begin{array}{l}\text { transmitter or } \\
\text { gauge }\end{array}$ & 0 to $30 \mathrm{lb} / \mathrm{in}^{2}$ & $\pm 0.5 \mathrm{lb} / \mathrm{in}^{2}$ \\
\hline & Point Pressure & $\begin{array}{l}\text { transmitter or } \\
\text { gauge }\end{array}$ & 0 to $100 \mathrm{lb} / \mathrm{in}^{2}$ & $\pm 1 \mathrm{lb} / \mathrm{in}^{2}$ \\
\hline & \multicolumn{4}{|c|}{$\begin{array}{l}\text { Resource Needs: Resources will be monitored in accordance with } \\
\text { normal recordkeeping practices (e.g., inventory, workhours) specific to } \\
\text { each resource type. U.S. Environmental Protection Agency (EPA) } \\
\text { guidance (EPA 1992) calls for an accuracy of }+50 \% \text { to }-30 \% \text { in } \\
\text { estimating implementation costs. }\end{array}$} \\
\hline Critical Samples or Values & \multicolumn{4}{|c|}{$\begin{array}{l}\text { Cesium- } 137,{ }^{239240} \mathrm{Pu} \text {, and }{ }^{90} \mathrm{Sr} \text {; or }{ }^{60} \mathrm{Co} \text { and }{ }^{99} \mathrm{Tc} \\
\text { concentrations in influent and effluent streams at a frequency } \\
\text { proportional to the rate of change in the primary contaminants } \\
\text { Chemical and radiological concentrations in spent resins and } \\
\text { discarded filter cartridges } \\
\text { Operating costs (e.g., materials, personnel) } \\
\text { - Secondary waste disposal costs. }\end{array}$} \\
\hline Constraints & \multicolumn{4}{|c|}{$\begin{array}{l}\text { It is necessary that resin breakthrough be measured in a } \\
\text { timely manner for }{ }^{137} \mathrm{Cs}, 239240 \mathrm{Pu} \text {, and }{ }^{90} \mathrm{Sr} \text {; or }{ }^{60} \mathrm{Co} \text { and }{ }^{99} \mathrm{Tc} \text {. } \\
\text { Representative samples are required of process water streams, } \\
\text { discarded filter cartridges, and spent resin. } \\
\text { Groundwater monitoring is required to assess transport of } \\
\text { contaminants in response to pumping. } \\
\text { Some resin and filter cartridge samples may have high } \\
\text { radionuclide content that requires special sampling and } \\
\text { handling methods. }\end{array}$} \\
\hline
\end{tabular}

${ }^{\mathrm{a} N T U}=$ nephelometric turbidity unit(s). 
Table 2-3. 200-BP-5 Treatability Test Objectives and Approach.

\begin{tabular}{|c|c|}
\hline Test Objective & Approach \\
\hline \multicolumn{2}{|r|}{ Effectiveness } \\
\hline $\begin{array}{l}\text { Identify optimum ion- } \\
\text { exchange resin }\end{array}$ & $\begin{array}{l}\text { Conduct laboratory-scale batch equilibrium tests of various resins to } \\
\text { select the best candidate based on performance and cost. }\end{array}$ \\
\hline $\begin{array}{l}\text { Determine ion-exchange } \\
\text { system effectiveness for } \\
\text { removal of }{ }^{137} \mathrm{Cs},{ }^{239 / 240} \mathrm{Pu} \text {, } \\
\text { and }{ }^{90} \mathrm{Sr} \text { at } \mathrm{B}-5 \text { Reverse } \\
\text { Well and }{ }^{60} \mathrm{Co} \text { and }{ }^{99} \mathrm{Tc} \text { at } \\
\text { BY-Cribs from extracted } \\
\text { groundwater }\end{array}$ & $\begin{array}{l}\text { Monitor pilot-scale ion-exchange column influents versus effluents for } \\
\text { concentrations of }{ }^{137} \mathrm{Cs},{ }^{239240} \mathrm{Pu} \text {, and }{ }^{90} \mathrm{Sr} \text { at } \mathrm{B}-5 \text { Reverse Well and } \\
{ }^{60} \mathrm{Co} \text { and }{ }^{99} \mathrm{Tc} \text { at } \mathrm{BY}-\mathrm{Cribs} \text { using field screening and laboratory } \\
\text { analyses. Conduct laboratory-scale mini-column tests to provide } \\
\text { additional resin breakthrough data and evaluation of resin kinetics } \\
\text { (effectiveness at different flow rates). }\end{array}$ \\
\hline \multicolumn{2}{|r|}{ Operating Parameters } \\
\hline $\begin{array}{l}\text { Refine operational } \\
\text { requirements/procedures }\end{array}$ & $\begin{array}{l}\text { Use observational approach during pilot-scale testing to refine } \\
\text { operating requirements. Conduct dry-run ion-exchange resin } \\
\text { changeout. Revise operating procedures based on observations. }\end{array}$ \\
\hline $\begin{array}{l}\text { Assess impacts of "other" } \\
\text { groundwater constituents } \\
\text { on operational efficiency }\end{array}$ & $\begin{array}{l}\text { Monitor pilot-scale process chemistry including suspended solids, } \\
\text { calcium carbonate, chloride, nitrate, phosphate, and sulfate. Use } \\
\text { observational approach to detect significant impacts on system } \\
\text { operation and efficiency. Revise operations accordingly. }\end{array}$ \\
\hline $\begin{array}{l}\text { Assess operating } \\
\text { parameters to optimize } \\
\text { treatment efficiency }\end{array}$ & $\begin{array}{l}\text { Monitor pilot-scale system flow rate, } \mathrm{pH} \text {, temperature, turbidity, and } \\
\text { pressures. Use observational approach to optimize treatment } \\
\text { efficiency. Use laboratory-scale flow-through column tests to perform } \\
\text { kinetic studies to evaluate removal efficiencies at various flow rates } \\
\text { (residence times), and to provide supplemental resin loading data. } \\
\text { Conduct laboratory-scale batch equilibrium tests of resins at various } \\
\text { pHs to assess impact of pH on loading effectiveness. }\end{array}$ \\
\hline $\begin{array}{l}\text { Demonstrate operational } \\
\text { reliability and safety }\end{array}$ & $\begin{array}{l}\text { Operate pilot-scale system for approximately } 5 \text { months. Identify and } \\
\text { allocate needed resources. Conduct site safety inspections and } \\
\text { meetings to ensure health and safety of personnel. }\end{array}$ \\
\hline \multicolumn{2}{|r|}{ Resource Needs } \\
\hline $\begin{array}{l}\text { Develop cost estimates of } \\
\text { significant cost components }\end{array}$ & $\begin{array}{l}\text { Track significant' expenditures by the following categories: } \\
\text { engineering, construction, and startup; operations; maintenance; } \\
\text { analytical; waste management; and project management through the } \\
\text { Financial Data System. }\end{array}$ \\
\hline $\begin{array}{l}\text { Refine health and safety } \\
\text { requirements }\end{array}$ & $\begin{array}{l}\text { Refine Site Safety Plans and Radiation Work Permits based on lessons } \\
\text { learned during operations, safety inspections and meetings, and } \\
\text { monitoring the work environment as needed. Establish hazardous and } \\
\text { radiological control zones as required. }\end{array}$ \\
\hline
\end{tabular}


Table 2-4. Data Quality Objectives for 200-BP-5 Operable Unit Plumes Contaminant Extraction Testing. (2 Sheets)

\begin{tabular}{|c|c|}
\hline Activity & Pilot-scale contaminant extraction testing. \\
\hline Objectives & $\begin{array}{l}\text { Develop a pumping schedule in terms of time pumping is on, time } \\
\text { pumping is off for reequilibration or partitioning of primary } \\
\text { contaminants, pumping locations, and return locations. Estimate total } \\
\text { (dissolved and adsorbed) contaminant mass that can interact with } \\
\text { groundwater to reestablish a plume after completion of interim action. } \\
\text { Develop estimate of primary contaminants. }\end{array}$ \\
\hline Prioritized Data Uses & $\begin{array}{l}\text { Determine contaminant recovery effectiveness and system efficiency of } \\
\text { pump-and-treat alternative. Develop numerical model of aquifer and } \\
\text { primary contaminant response to pumping. }\end{array}$ \\
\hline $\begin{array}{l}\text { Appropriate Analytical } \\
\text { Level or Implementation } \\
\text { Guidelines }\end{array}$ & $\begin{array}{l}\text { Level I and II screening analyses (gross alpha, beta, or spectral gamma } \\
\text { radiation) will be used for preliminary determination of pumping } \\
\text { schedule, to be confirmed by limited Level III and V analyses for } \\
\text { specific radionuclides. }\end{array}$ \\
\hline \multirow[t]{3}{*}{$\begin{array}{l}\text { Parameters to be } \\
\text { Obtained }\end{array}$} & $\begin{array}{l}\text { Effectiveness: } \\
\text { - } \quad \text { Concentrations of }{ }^{137} \mathrm{Cs},{ }^{239240} \mathrm{Pu} \text {, and }{ }^{90} \mathrm{Sr} \text { in extracted } \\
\text { groundwater } \\
\text { - } \quad \text { Pumping rates and locations, times for pumpage on and off } \\
\text { - } \quad \text { Estimates of dissolved and adsorbed }{ }^{137} \mathrm{Cs},{ }^{239240} \mathrm{Pu} \text {, and }{ }^{90} \mathrm{Sr} \text { in } \\
\text { aquifer and on aquifer materials. }\end{array}$ \\
\hline & $\begin{array}{l}\text { Operating Parameters: } \\
\text { - } \quad \text { Aquifer hydraulic properties and contaminant distribution } \\
\text { properties } \\
\text { - } \quad \text { Ostimates of total primary contaminant quantities } \\
\text { Optimized pumpage cycling (pumping rates, aquifer. } \\
\text { reequilibration times, and moving pumping among available } \\
\text { wells) to maximize recovery } \\
\text { Computer model input parameters for local groundwater flow } \\
\text { and contaminant phase transformation and transport. }\end{array}$ \\
\hline & $\begin{array}{ll}\text { Resource Requirements: } \\
\text { - } & \text { Electrical costs of pumping } \\
\text { - } & \text { Installation of additional wells } \\
\text { - } & \text { Technical personnel time to interpret process effectiveness } \\
\text { - } & \text { Onalytical costs } \\
\end{array}$ \\
\hline
\end{tabular}


Rev. 0

Table 2-4. Data Quality Objectives for 200-BP-5 Operable Unit Plumes Contaminant Extraction Testing. (2 Sheets)

\begin{tabular}{|l|l|}
\hline $\begin{array}{l}\text { Required Detection or } \\
\text { Measurement Limits }\end{array}$ & $\begin{array}{l}\text { Parameters for field or mobile laboratory screening methods will be } \\
\text { developed in the test sampling and analysis plan (Appendix C). } \\
\text { Parameters for all analytical measurements will be based on usual limits } \\
\text { of normal analytical services as expressed in Table 3-3 and the quality } \\
\text { assurance project plan (Appendix B). Screening methods are used } \\
\text { because of the need for fast turnaround time to interpret analytical data. } \\
\text { Costs will be monitored in accordance with normal recordkeeping } \\
\text { practices. Estimates of total (adsorbed and dissolved) primary } \\
\text { contaminant mass in aquifer matrix and groundwater will be made } \\
\text { through a calibrated computer model and are likely to be accurate to } \\
\text { about a half an order of magnitude. }\end{array}$ \\
\hline $\begin{array}{l}\text { Critical Samples or } \\
\text { Values }\end{array}$ & $\begin{array}{l}\text { Primary contaminant concentrations during pumpage and after } \\
\text { reequilibration. }\end{array}$ \\
\hline Constraints & $\begin{array}{l}\text { Timing of extraction testing, pumping rates, and pumping procedures } \\
\text { cannot be estimated beyond first cycle. Remainder of extraction testing } \\
\text { will depend on observed response of groundwater system during initial } \\
\text { testing. }\end{array}$ \\
\hline
\end{tabular}


Table 2-5. Data Quality Objectives for Hydrogeologic Assessment.

\begin{tabular}{|c|c|}
\hline Activity & $\begin{array}{l}\text { Install new wells. Complete aquifer properties testing in the aquifers } \\
\text { utilizing pumping and slug tests. Obtain water level measurements } \\
\text { from existing and new wells. }\end{array}$ \\
\hline Objectives & $\begin{array}{l}\text { New wells will help define aquifer properties, groundwater flow, nature } \\
\text { and extent of contamination, and groundwater geochemistry, and will } \\
\text { provide additional wells for groundwater extraction and return. Aquifer } \\
\text { testing results address general data needs for identifying aquifer } \\
\text { properties necessary to evaluate groundwater flow and contaminant } \\
\text { mobility. Water level measurements are needed to calculate horizontal } \\
\text { and vertical hydraulic gradients required to evaluate groundwater flow. }\end{array}$ \\
\hline Prioritized Data Uses & $\begin{array}{l}\text { Support groundwater flow characterization and contaminant transport } \\
\text { evaluation needed to refine the operable unit conceptual model and } \\
\text { support project treatability test operations. }\end{array}$ \\
\hline $\begin{array}{l}\text { Appropriate Analytical } \\
\text { Level or Implementation } \\
\text { Guidelines }\end{array}$ & $\begin{array}{l}\text { Wells will be installed according to procedures outlined in the } \\
\text { Environmental Investigations and Site Characterization Manual, EII } 6.8 \\
\text { (WHC 1988) and Washington Administrative Code (WAC) 173-160 and } \\
\text { following description of work (DOWs). Aquifer tests will be completed } \\
\text { according to procedures outlined in the Environmental Investigation } \\
\text { Procedures, EIP 7.1, "Aquifer Testing" (BHI 1994) and follow-on } \\
\text { DOWs. Water level measurements and related tape calibration will be } \\
\text { completed according to procedures outlined in the Environmental } \\
\text { Investigation Procedures, EIP 7.1, "Aquifer Testing" (BHI 1994). }\end{array}$ \\
\hline $\begin{array}{l}\text { Parameters to be } \\
\text { Obtained }\end{array}$ & $\begin{array}{l}\text { Hydraulic conductivity, transmissivity, and depth-to-water } \\
\text { measurements for existing and new wells. }\end{array}$ \\
\hline $\begin{array}{l}\text { Required Detection or } \\
\text { Measurement Limits }\end{array}$ & None. \\
\hline $\begin{array}{l}\text { Critical Samples or } \\
\text { Values }\end{array}$ & $\begin{array}{l}\text { Wells must be completed in the aquifer to allow sample } \\
\text { collection for analysis and to allow aquifer testing. } \\
\text { Wells need to show maximum contaminant values and the } \\
\text { extent of contaminant plumes. } \\
\text { - Single-well slug tests should be supplemented by limited } \\
\text { numbers of slug interference and/or pumping tests with } \\
\text { observation wells to characterize test results variability. } \\
\text { Periodic water level measurements to assess aquifer gradient } \\
\text { and response to pumping and changes in B Pond disposal } \\
\text { practices. }\end{array}$ \\
\hline Constraints & $\begin{array}{l}\text { Well design should consider contingencies for multiple use } \\
\text { (i.e., pump-and-treat systems). } \\
\text { Emphasize slug tests in contaminated areas. } \\
\text { - } \quad \text { Accurate surveys of measurement points are required. }\end{array}$ \\
\hline
\end{tabular}


Rev. 0

Table 2-6. Data Quality Objectives for Groundwater Monitoring.

\begin{tabular}{|c|c|}
\hline Activity & Groundwater sampling and analysis. \\
\hline Objectives & $\begin{array}{l}\text { Establish a baseline on major contaminants and } \\
\text { co-contaminants before the start of treatability testing. } \\
\text { Determine the effect of groundwater extraction and return on } \\
\text { concentration of primary contaminants and co-contaminants } \\
\text { within the plume and in the vicinity of the return well. } \\
\text { - } \\
\text { Determine hydraulic impacts in the area influenced by the test. } \\
\text { Provide remedial design input. }\end{array}$ \\
\hline Prioritized Data Uses & $\begin{array}{l}\text { Support treatability test feed water requirements and provide input } \\
\text { parameters for numeric model calibration and remedial action design. }\end{array}$ \\
\hline $\begin{array}{l}\text { Appropriate Analytical } \\
\text { Level or Implementation } \\
\text { Guidelines }\end{array}$ & $\begin{array}{l}\text { Field screening (Level II) will be used as a quick indicator of test } \\
\text { effectiveness. Data from an offsite laboratory (Level IV) will be used } \\
\text { to make final decisions regarding the test. See the quality assurance } \\
\text { project plan (Appendix B) for required detection or measurement limits. }\end{array}$ \\
\hline $\begin{array}{l}\text { Parameters to be } \\
\text { Obtained }\end{array}$ & $\begin{array}{l}\text { Concentration of primary contaminants }\left({ }^{60} \mathrm{Co} \text { and }{ }^{99} \mathrm{Tc} \text { for the }\right. \\
\text { BY-Cribs plume, }{ }^{337} \mathrm{Cs},{ }^{239,}{ }^{240} \mathrm{Pu} \text {, and }{ }^{90} \mathrm{Sr} \text { for the B-5 Reverse } \\
\text { Well plume). } \\
\text { Interfering nontarget groundwater constituents (anions) before, } \\
\text { during, and/or after test(s). } \\
\text { General groundwater quality parameters to include gross alpha, } \\
\text { gross beta, pH, temperature, conductivity, and oxidation/ } \\
\text { reduction potential. } \\
\text { Groundwater flow direction before, during, and/or after testing } \\
\text { within the network. }\end{array}$ \\
\hline $\begin{array}{l}\text { Required Detection or } \\
\text { Measurement Limits }\end{array}$ & None. \\
\hline $\begin{array}{l}\text { Critical Samples or } \\
\text { Values }\end{array}$ & $\begin{array}{l}\text { Groundwater should be sampled before the test begins, as needed } \\
\text { during the test (e.g., pore volume removed, pumping cycle completed, } \\
\text { significant contaminant reduction), and at completion of the treatability } \\
\text { test to evaluate test effectiveness. }\end{array}$ \\
\hline Constraints & $\begin{array}{l}\text { - } \quad \text { Representative groundwater samples are required. } \\
\text { - } \quad \text { Accurate water level measurements are required. }\end{array}$ \\
\hline
\end{tabular}


Rev. 0

Table 2-7. Mini-Column Tests at the 216-B-5 Reverse Well.

\begin{tabular}{|c|c|c|c|}
\hline Test 1 & MCT-1 & MCT-2 & \\
\hline Columns & $\begin{array}{l}\text { Bone char-clinoptilolite- } \\
\text { clinoptilolite, run at 5- to } \\
6 \text {-minute contact }\end{array}$ & $\begin{array}{l}\text { Bone char-clinoptilolite- } \\
\text { clinoptilolite (with } \\
\text { strontium chloride } \\
\text { addition), run at 5- to } \\
6 \text {-minute contact }\end{array}$ & \\
\hline Test 2 & $2 \mathrm{MCT}-1$ & 2MCT-2 & $2 \mathrm{MCT}-3$ \\
\hline Columns & $\begin{array}{l}\text { Continuance of Test } 1 \\
\text { MCT-1 (Bone } \\
\text { char-clinoptilolite-clinoptilo } \\
\text { lite) }\end{array}$ & $\begin{array}{l}\text { Bone char-clinoptilolite- } \\
\text { clinoptilolite, run at } \\
\text { 12-minute contact }\end{array}$ & $\begin{array}{l}\text { Bone char-clinoptilolite- } \\
\text { UOP A-51, run at } \\
\text { 12-minute contact }\end{array}$ \\
\hline
\end{tabular}


DOE/RL-95-59

Rev. 0 


\subsection{RESULTS AND DISCUSSION}

\subsection{PILOT-SCALE TESTS}

\subsubsection{Pilot-Scale Treatment System Effectiveness}

3.1.1.1 216-B-5 Reverse Well. Two tests were conducted with the pilot-scale treatment system at the B-5 Reverse Well site, designated as "Run 1" and "Run 2". Tables C-1, C-2, and C-3 (Appendix C) present the ${ }^{137} \mathrm{Cs},{ }^{2391240} \mathrm{Pu}$, and ${ }^{90} \mathrm{Sr}$ analytical results for the ion-exchange treatment system for Run 1. Figure 3-1 is a plot of the lead column results for ${ }^{90} \mathrm{Sr}$ removal, and Figure 3-2 is a plot of the overall system results for ${ }^{90} \mathrm{Sr}$ removal. Figure 3-3 is a plot of the lead column results for ${ }^{137} \mathrm{Cs}$ removal. Figure 3-4 is a plot of the overall system results for the removal of ${ }^{239240} \mathrm{Pu}$. Because the system was not able to achieve the target ${ }^{90} \mathrm{Sr}$ level after 2 months of operations, testing was terminated and the clinoptilolite and mixed-bed (clinoptilolite and bone char) media removed.

Run 1 average inlet concentrations (see Tables C-1, C-2, and C-3, Appendix C) were 1,354 pCi/L for ${ }^{137} \mathrm{Cs}, 19.4 \mathrm{pCi} / \mathrm{L}$ for ${ }^{239 / 240} \mathrm{Pu}$, and $3,937 \mathrm{pCi} / \mathrm{L}$ for ${ }^{90} \mathrm{Sr}$. The average effluent concentrations from the lead column(s) were less than $59.2 \mathrm{pCi} / \mathrm{L}{ }^{137} \mathrm{Cs}$, less than $5.6 \mathrm{pCi} / \mathrm{L}{ }^{239 / 240} \mathrm{Pu}$, and $1,785 \mathrm{pCi} / \mathrm{L}$ ${ }^{90} \mathrm{Sr}$. This results in average removal efficiencies of greater than $95.6 \%$ for ${ }^{137} \mathrm{Cs}$, greater than $77 \%$ for ${ }^{239240} \mathrm{Pu}$, and $54.7 \%$ for ${ }^{90} \mathrm{Sr}$.

The ${ }^{137} \mathrm{Cs}$ and ${ }^{239240} \mathrm{Pu}$ effluent results reported are actually an average of the detection limits together with actual values from the 222-S Laboratory. Most of the reported effluent cesium and plutonium values are the detection limits for the 222-S Laboratory, reported as "less than" values. The 222-S Laboratory has high background levels that affect analytical results for some radionuclides in that the detection limits vary and may be quite high. For example, in the tables in Appendix $\mathrm{C}$ if a value is an actual value, there is either no "less than" $(<)$ symbol or there is a "Y" in the column for detectable. If the value is at or below the detection limit, there is a $<$ or $\mathrm{N}$ in the detectable column. As can be seen, there are times that effluent values are higher than influent values because of higher background yielding a high detection limit at the time the analysis was run, whereas the detection limit may have been lower (lower background) when the influent sample was analyzed and reported as an actual value. Because of this, the data and resulting curve plots appear sporadic. For this reason, it is more important to look at trends rather than the actual values and to interpret results accordingly. If the treatment system can achieve an effluent lower than detection limits of the laboratory, the removal efficiencies reported herein underestimate actual removal efficiencies.

Offsite laboratory detection limits are somewhat lower, indicating that actual effluent values for ${ }^{137} \mathrm{Cs}$ may be approximately $8 \mathrm{pCi} / \mathrm{L}$ and approximately $1.6 \mathrm{pCi} / \mathrm{L}$ for ${ }^{239 / 240} \mathrm{Pu}$ (the detection limit for two samples was 11 and $4.8 \mathrm{pCi} / \mathrm{L}$ for ${ }^{137} \mathrm{Cs}$ and 1.5 and $1.6 \mathrm{pCi} / \mathrm{L}$ for ${ }^{239} / 240 \mathrm{Pu}$ ). Based on these values, the ${ }^{137} \mathrm{Cs}$ and ${ }^{239240} \mathrm{Pu}$ removal efficiencies would be $99.5 \%$ and $92 \%$, respectively, and would indicate that the treatment system may be capable of meeting the 1.2-pCi/L MCL for drinking water for ${ }^{2391240} \mathrm{Pu}$. In any case, the treatment system appears capable of easily meeting the $120-\mathrm{pCi} / \mathrm{L} \mathrm{MCL}$ for ${ }^{137} \mathrm{Cs}$.

It should be noted that the lead column for plutonium removal is the first column in line (the bone char column), and the lead column for strontium and cesium removal is the second column in line (the first clinoptilolite column). Thus, referring to the "lead" column for strontium and cesium 
removal actually includes the bone char and the first clinoptilolite column. It can be seen (see Table C-1, Appendix C) that for the first $500 \mathrm{BV}$, bone char removed significant amounts of ${ }^{90} \mathrm{Sr}$ $(-20 \%)$. Figure 3-1 is a plot of ${ }^{90} \mathrm{Sr}$ removals versus bed volumes treated for the "lead column" and shows that for the first $500 \mathrm{BV},{ }^{90} \mathrm{Sr}$ removal through the bone char and clinoptilolite columns averaged $47 \mathrm{pCi} / \mathrm{L}$. However, after $500 \mathrm{BV}$, a sharp increase in effluent concentration is seen, which over the course of Run 1 yielded an average effluent of $1,785 \mathrm{pCi} / \mathrm{L}$. This resulted in an average lead column removal efficiency for ${ }^{90} \mathrm{Sr}$ removal of $54.7 \%$.

System removal efficiency for ${ }^{90} \mathrm{Sr}$ is shown in Figure 3-2 where the average effluent concentration averaged $936 \mathrm{pCi} / \mathrm{L}$. Table $\mathrm{C}-1$ (Appendix C) shows that the mixed-bone char-clinoptilolite column reduced the average ${ }^{90} \mathrm{Sr}$ concentration from $1,785 \mathrm{pCi} / \mathrm{L}$ to $936 \mathrm{pCi} / \mathrm{L}$, resulting in an overall removal efficiency of $76.2 \%$. Figure 3-3 presents removal results for the lead column versus bed volumes treated for ${ }^{137} \mathrm{Cs}$, and Figure $3-4$ presents the ${ }^{239 / 240} \mathrm{Pu}$ removal results for the treatment system versus bed volumes treated.

A total volume of $2,284,000 \mathrm{~L}(603,362 \mathrm{gal})$, or 4,033 BV, of groundwater was processed in Run 1 . The mass amount removed by the lead columns is determined by the definition of Specific Activity $(\mathrm{SpA})$ of a radionuclide, in the following relationship:

$$
\operatorname{SpA}=\frac{(\ln 2) \times N=\mathrm{Ci} / \mathrm{g}}{\mathrm{T}_{1 / 2}}
$$

where $\mathrm{N}$ is the number of radioactive atoms per unit mass $\left(6.0225 \times 10^{23}\right.$ /atomic mass) and $\mathrm{T}_{\mathrm{I} / 2}$ is half-life of the radionuclide.

For ${ }^{90} \mathrm{Sr}$, the specific gravity is $141 \mathrm{Ci} / \mathrm{g}$ or $141 \times 10^{14} \mathrm{pCi} / \mathrm{g}$. For ${ }^{137} \mathrm{Cs}$, the specific activity is $87 \mathrm{Ci} / \mathrm{g}$ and for ${ }^{239240} \mathrm{Pu}$ the specific activity is taken as $0.0886 \mathrm{Ci} / \mathrm{g}$.

For a radionuclide, calculating the grams removed by the adsorbent is determined by the formula:

$$
\text { (Influent Concentration - Effluent Concentration) } \mathrm{x} \text { (Volume of Water)/(SpA) }
$$

The results for lead column removal are presented in Table 3-1.

At the conclusion of Run 1, the clinoptilolite and clinoptilolite-bone char were removed from tanks 4 and 5, and both were recharged with clinoptilolite. The bone char was not changed because it was still demonstrating good ${ }^{239 / 240} \mathrm{Pu}$ removal. Thus, Run 2 commenced with the original bone char column followed by two columns with new clinoptilolite. The GAC column remained online at the end of the treatment train, but was not regularly monitored. The process flow rate was reduced from approximately $95 \mathrm{~L} / \mathrm{min}$ ( $25 \mathrm{gal} / \mathrm{min}$ ) in Run 1 to $57 \mathrm{~L} / \mathrm{min}$ (15 gal $/ \mathrm{min}$ ) to increase the contact time to 8 minutes per column (versus the 5 to 6 min of Run 1 ).

Run 2 analytical results are presented in Tables C-4 and C-5 (Appendix C) for ${ }^{137} \mathrm{Cs}$ and ${ }^{90} \mathrm{Sr}$. Because the emphasis of Run 2 was ${ }^{90} \mathrm{Sr}$ removal, no plutonium and only limited ${ }^{137} \mathrm{Cs}$ data were obtained. The ${ }^{137} \mathrm{Cs}$ data were not plotted. Figures 3-5 and 3-6 present the ${ }^{90} \mathrm{Sr}$ results versus bed volumes treated for the lead column and the overall system, respectively. Near the end of Run 2, a tracer test was performed, and the flow was increased to 106 to $114 \mathrm{~L} / \mathrm{min}$ ( 28 to $30 \mathrm{gal} / \mathrm{min}$ ), which reduced contact time to 5 minutes. 
Run 2 concluded after processing approximately 1,448, $559 \mathrm{~L} / \mathrm{min}(382,670 \mathrm{gal})$, or $3,198 \mathrm{BV}$. The system provided an average effluent concentration of $267 \mathrm{pCi} / \mathrm{L}{ }^{90} \mathrm{Sr}$ and $58.5 \mathrm{pCi} / \mathrm{L}{ }^{137} \mathrm{Cs}$. The corresponding removal efficiencies for ${ }^{137} \mathrm{Cs}$ and ${ }^{90} \mathrm{Sr}$ were $96 \%$ and $94.5 \%$, respectively. As previously mentioned, no plutonium data were obtained for Run 2 . It should be noted that there was a significant increase in the influent ${ }^{90} \mathrm{Sr}$ concentration from an average of $3,695 \mathrm{pCi} / \mathrm{L}$ for Run 1 to $4,896 \mathrm{pCi} / \mathrm{L}$ for Run 2. The respective influent ${ }^{137} \mathrm{Cs}$ values were $1,354 \mathrm{pCi} / \mathrm{L}$ for Run 1 and $1,457 \mathrm{pCi} / \mathrm{L}$ for Run 2 .

As shown in Figure 3-5, the longer contact time did improve ${ }^{90} \mathrm{Sr}$ removal. The quality of the effluent from the lead clinoptilolite column decreased over time, with concentrations ranging from a low of $56 \mathrm{pCi} / \mathrm{L}$ at approximately $100 \mathrm{BV}$ to approximately $1,000 \mathrm{pCi} / \mathrm{L}{ }^{90} \mathrm{Sr}$ at $1,850 \mathrm{BV}$. At $2,150 \mathrm{BV}$, coincident with the onset of the tracer test, the effluent concentration increased to $2,200 \mathrm{pCi} / \mathrm{L}{ }^{90} \mathrm{Sr}$. The lead column removed an average of $980 \mathrm{pCi} / \mathrm{L}$ over the course of Run 2 for a removal efficiency of $80 \%$. For ${ }^{137} \mathrm{Cs}$, the removal efficiency was unchanged at $96 \%$ from Run 1. The increase in influent concentration and reduction in residence time during the tracer test probably caused some degradation of removal efficiency for the ${ }^{90} \mathrm{Sr}$.

As shown by the removal efficiency curve in Figure 3-5 (dashed line) before the tracer test, removal efficiencies seem to follow a weekly "stair-step" pattern. For example, after $200 \mathrm{BV}$, the efficiency declined until $570 \mathrm{BV}$ were reached on a Friday. The removal efficiency then appeared to recover on the following Monday. Again, at approximately 970 BV (Friday), the efficiency was $87 \%$, down from $94 \%$ at the beginning of the week (Monday). At approximately 1,000 BV (Monday), the efficiency was back up to $90 \%$. This pattern is seen throughout the test from 350 to $1,850 \mathrm{BV}$ and follows an overall downward trend from week-to-week. This seems to suggest that clinoptilolite may be better suited for batch operations. During the tracer test, a kinetic effect was observed, in that shorter contact times and continuous operation ( $24 \mathrm{~h} /$ day) resulted in increased effluent concentrations, increasing to approximately $2,500 \mathrm{pCi} / \mathrm{L}$ by the end of the test $(3,000$ to $3,200 \mathrm{BV})$. As mentioned above, longer contact times and daily operations seemed to show improved ${ }^{90} \mathrm{Sr}$ removals.

Another observation was that the prefilters (bag filters) periodically demonstrated good ${ }^{90} \mathrm{Sr}$ removal values. It is thought that fines from backwashing the clinoptilolite are responsible. The backwash solutions were sent back to the influent storage tank and processed through the system for removal by the prefilters. The fines are the small-sized clay fraction of the clinoptilolite. Because some clays are known to provide good cation removal, it is thought that the clinoptilolite fines residing in the influent storage tank are able to adsorb the ${ }^{90} \mathrm{Sr}$ and are periodically resuspended, drawn into the system, and removed by the filters. It also seemed that there was a small amount of material periodically released by the filters because the filter effluent ${ }^{90} \mathrm{Sr}$ concentrations are up to $13 \%$ higher than the feed. This may be a sampling or analysis anomaly, but a $13 \%$ difference is significant (see Table $\mathrm{C}-4$, Appendix C, for a comparison of the data).

The removal efficiency of the second clinoptilolite column for ${ }^{90} \mathrm{Sr}$ was $13 \%$ at $94 \mathrm{BV}$, but then increased to $90 \%$ by $425 \mathrm{BV}$ (see Table C-4, Appendix C, and Figure 3-6). The corresponding feed concentrations of ${ }^{90} \mathrm{Sr}$ (effluent from lead column) were $56 \mathrm{pCi} / \mathrm{L}$ and $289 \mathrm{pCi} / \mathrm{L}{ }^{90} \mathrm{Sr}$, and the respective effluent concentrations were $48.6 \mathrm{pCi} / \mathrm{L}$ and $29.3 \mathrm{pCi} / \mathrm{L}$. The effluent from the second clinoptilolite column is the final effluent.

This indicates that the clinoptilolite performs poorly with a dilute feed, and was not capable of meeting the target $\mathrm{MCL}$ of $8 \mathrm{pCi} / \mathrm{L}{ }^{90} \mathrm{Sr}$ effluent concentration at an 8-minute contact time. After the 
tracer test began, the removal efficiency decreased to approximately $56 \%$ at $2,700 \mathrm{BV}$ and was $55 \%$ at the end of the test (see Table C-4, Appendix C).

Considering the overall treatment system effectiveness, the average removal efficiency for ${ }^{90} \mathrm{Sr}$ was approximately $97 \%$, achieving an average effluent ${ }^{90} \mathrm{Sr}$ concentration of $77.8 \mathrm{pCi} / \mathrm{L}$ until $1,850 \mathrm{BV}$; it then decreased to $68 \%$ by the end of the test with an effluent concentration of $1,160 \mathrm{pCi} / \mathrm{L}$. While operating with an 8-minute contact time per column, the effluent concentration ranged from $28 \mathrm{pCi} / \mathrm{L}$ to $134 \mathrm{pCi} / \mathrm{L}{ }^{90} \mathrm{Sr}$. At the end of Run 2 of the pilot-scale test, the effluent had increased to $1,160 \mathrm{pCi} / \mathrm{L}{ }^{90} \mathrm{Sr}$.

First-order rate constants ( $\mathrm{K}$ values) were calculated from the pilot-scale and mini-column test data for ${ }^{90} \mathrm{Sr}$ to separate the effect of residence time from bed performance. The rate constants were calculated from the following equation.

$$
\mathrm{Kt}=-\ln \text { (Effluent }{ }^{90} \mathrm{Sr} \text { conc./Influent }{ }^{90} \mathrm{Sr} \text { conc.) }
$$

where $\mathrm{K}$ is the kinetic constant and $\mathrm{t}$ is the empty bed contact time. The resulting rate constants are tabulated in Table 3-2 for each run.

Inspection of the rate constants shows generally good agreement from the first to second bed. The $\mathrm{K}$ values are generally higher in the mini-columns relative to the pilot plant. This is probably due to the more efficient contacting in small columns produced by the higher length/diameter ratios and the lower tendencies for small-diameter columns to form short-circuiting channels in the resin.

Based on the $\mathrm{K}$ values calculated above, a conservative extrapolation of the data suggests that a three-bed system with approximately 18 minutes of contact time should allow achievement of $8 \mathrm{pCi} / \mathrm{L}$ ${ }^{90} \mathrm{Sr}$ in the effluent.

Run 2 processed a total volume of $1,448,559 \mathrm{~L}(382,670 \mathrm{gal})$, or $3,198 \mathrm{BV}$, of groundwater. The mass amount removed by the lead columns is calculated as described above for Run 1 and is presented in Table 3-1. In addition, the mass removed by the system is presented in Table 3-3.

3.1.1.2 216-BY Cribs. Based on Beck's work (WHC 1994) with Dowex 21K resin on groundwater containing chromate, nitrate, and uranium, Dowex 21K was selected for use for the 200-UP-1 pilot-scale treatability test. From the results of the Treatability Test Report for the 200-UP-1 Operable Unit - Hanford Site (DOE-RL 1995a), Dowex $21 \mathrm{~K}$ demonstrated good removal of ${ }^{99} \mathrm{Tc}$, to saturation of the lead ion-exchange column at approximately $2,600 \mathrm{BV}$. The loading curve demonstrated sharp breakthrough beginning at between 1,800 to $2,000 \mathrm{BV}$. It appeared that the Dowex $21 \mathrm{~K}$ favored uranium over technetium, but there is no uranium at the BY-Cribs. Therefore, it was expected that Dowex $21 \mathrm{~K}$ would process approximately 5,000 BV before saturation/ breakthrough.

Table C-6 (Appendix C) presents ${ }^{60} \mathrm{Co}$ and ${ }^{99} \mathrm{Tc}$ data from the first, or lead, ion-exchange column of the BY-Cribs pilot-scale treatment system. The average inlet ${ }^{60} \mathrm{Co}$ and ${ }^{99} \mathrm{Tc}$ concentrations were $154 \mathrm{pCi} / \mathrm{L}{ }^{60} \mathrm{Co}$ and $9,008 \mathrm{pCi} / \mathrm{L}{ }^{99} \mathrm{Tc}$, respectively. The average treated effluent concentrations from the lead column were less than $38.1 \mathrm{pCi} / \mathrm{L}{ }^{60} \mathrm{Co}$ and $164 \mathrm{pCi} / \mathrm{L}{ }^{99} \mathrm{Tc}$, respectively. This results in an average removal efficiency of greater than $75 \%$ for ${ }^{60} \mathrm{Co}$ and $98 \%$ for ${ }^{99} \mathrm{Tc}$ for the lead ion-exchange column. The offsite ${ }^{60} \mathrm{Co}$ detection limit was $10.5 \mathrm{pCi} / \mathrm{L}$; therefore, ${ }^{60} \mathrm{Co}$ removal efficiency may be on the order of $93.2 \%$. A total volume of $1,426,200 \mathrm{~L}(376,760 \mathrm{gal})$, or $3,014 \mathrm{BV}$, of groundwater 
was processed without reaching saturation or breakthrough, although the data plot (Figure 3-7) indicates some amount of breakthrough. The mass of ${ }^{60} \mathrm{Co}$ and ${ }^{99} \mathrm{Tc}$ removed during the treatability test by the lead column and the whole treatment system is presented in Tables 3-1 and 3-3, respectively. It can be seen that Dowex $21 \mathrm{~K}$ is capable of providing a discharge that meets or is lower than the MCL targets of $200 \mathrm{pCi} / \mathrm{L}^{60} \mathrm{Co}$ and $4,000 \mathrm{pCi} / \mathrm{L}{ }^{99} \mathrm{Tc}$.

As noted, the ${ }^{60} \mathrm{Co}$ results from the lead column effluent (Table C-7, Appendix C and Figure 3-8) were reported as less-than values, below the detection limit of the 222-S Laboratory. Offsite detection limits are between 10 and $20 \mathrm{pCi} / \mathrm{L}$. Using the data in Table C-7 (Appendix C), the ${ }^{60} \mathrm{Co}$ removal effectiveness would be $75.3 \%$; but using the offsite data point of $10.5 \mathrm{pCi} / \mathrm{L},{ }^{60} \mathrm{Co}$ would result in a $93 \%$ removal.

In the treatability test plan (DOE-RL 1995c), it was hypothesized that the cobalt in the groundwater might be complexed with cyanide in a metal-cyanide complex to form an anion rather than the cobalt cation. Because the cobalt was readily adsorbed on the anion resin, Dowex $21 \mathrm{~K}$, it is certain that the cobalt was in anionic form, and most probably in the cobalt-cyanide complex, as was previously hypothesized. However, because no analyses for cyanide were performed as it moved through the treatment system, there is no indication of the complex. Analysis of the resin from the lead ionexchange column at the end of the campaign indicates a cyanide loading of $9.8 \mathrm{mg}$ cyanide per gram of resin. Because this loading is not proportional to the ${ }^{60} \mathrm{Co}$ that was loaded, this indicates other anions were complexed with the cyanide, probably iron, aluminum, and zinc as indicated by somewhat high loadings of these metals on the resin.

\subsubsection{Operating Parameters}

Operating parameters were monitored to refine operational requirements/procedures, assess the impact of "other" (secondary) groundwater constituents on operational efficiency, and assess operating parameters to optimize treatment efficiency. Because the B-5 Reverse Well system and the BY-Cribs system were similar in design, the operating parameters were also comparable, as noted in the following sections.

3.1.2.1 216-B-5 Reverse Well. The results of the secondary contaminants analyses (Appendix C) show that the clinoptilolite adsorbed calcium, magnesium, and potassium, and released sodium and iron until an equilibrium was reached. After this equilibrium was reached, the concentrations remained fairly constant throughout the system. Samples collected around the bag filters indicate the filters removed iron, zinc, and chloride, apparently originating from the feed tank, but released sulfate and nitrate. The sulfate and nitrate were then absorbed by either the bone char or clinoptilolite. Data collected immediately before the tracer test $(1,850 \mathrm{BV})$ showed the bone char was releasing iron and zinc, but the clinoptilolite was readsorbing these concentrations. Alkalinity, fluoride, chloride, and sulfate concentrations (except data around the bag filters) remained fairly constant throughout the test.

With the available data, it is difficult to determine whether the adsorption and/or release of the contaminants discussed could have affected the treatment efficiency. It is possible that the calcium, magnesium, and potassium occupied potential ${ }^{90} \mathrm{Sr}$ sorption sites, thus decreasing the treatment efficiency. However, closer monitoring of the secondary contaminant concentrations is needed for a more definitive conclusion. 
The flow rate, tank levels, differential and point pressures, and $\mathrm{pH}$ were monitored hourly to ensure that the treatment system was operated within its design parameters. The flow rate was monitored from the extraction well, the process treatment system, and the groundwater return (injection) system. Point pressures were measured upstream and downstream of each ion-exchange column, GAC column, and influent (bag) and effluent (cartridge) filter sets. The differential pressure was measured across each of these point pressures. The differential pressure across the post-column filters (in-line between the last ion-exchange column and the GAC column) was estimated by measuring the point pressure downstream of the last ion-exchange column and upstream of the GAC column.

The differential pressure across the filters increased as the filters became loaded with solids. The filters were replaced when the differential pressure reached a specified reading, as follows:

- Bag filters:

$207 \mathrm{kPa}\left(30 \mathrm{lb} / \mathrm{in}^{2}\right)$

- $\quad$ Post-column filters: $138 \mathrm{kPa}\left(20 \mathrm{lb} / \mathrm{in}^{2}\right)$

- Cartridge filters: see below.

The treated groundwater was gravity-fed from the effluent tank back into the aquifer. With clean cartridge filters, an injection flow rate of approximately $170 \mathrm{~L} / \mathrm{min}(45 \mathrm{gal} / \mathrm{min})$ could be maintained. A 57- to $76-\mathrm{L} / \mathrm{min}$ (15- to $20-\mathrm{gal} / \mathrm{min}$ ) decrease in flow rate was an indication that the filters were loaded, and was, therefore, used as the criterion for filter replacement.

Extraction rates averaged approximately $106 \mathrm{~L} / \mathrm{min}$ ( $28 \mathrm{gal} / \mathrm{min})$; therefore, when operating at either $95 \mathrm{~L} / \mathrm{min}$ ( $25 \mathrm{gal} / \mathrm{min}$ ) (Run 1) or $57 \mathrm{~L} / \mathrm{min}$ (15 gal/min) (Run 2), it was necessary to extract groundwater only during operating hours. If circumstances arose that caused the influent tank to be at a low level at the end of an operating day, extraction occurred overnight.

The $\mathrm{pH}$ was noted to increase between the extraction well and the ion-exchange columns, and then to slightly decrease after passing through the ion-exchange columns. The average $\mathrm{pH}$ measured at the extraction wellhead was approximately 7.69 , increasing to approximately 8.13 before the ionexchange columns, and decreasing to approximately 8.04 at the ion-exchange columns effluent, before the GAC column. Sufficient sampling of secondary contaminants was not performed with which to determine the cause of the $\mathrm{pH}$ variations, which could be due to a variety of factors, including the $\mathrm{pH}$ probes. For example, removal of some cations or anions (and even alkalinity) from solution is known to affect the effluent from an ion-exchange column. Additionally, removal of the cations or anions from the resin in the ion-exchange process itself is known to affect the $\mathrm{pH}$ of the discharge.

Various problems were encountered while backwashing the clinoptilolite columns. The problems are detailed in the site logbook, kept while backwashing the columns before starting Run 2 . This $\log$ provides the record for this discussion. Similar problems were experienced when backwashing before Run 1, but a detailed log was not available to support a separate discussion. Backwashing is designed to remove the fines contained within the media and to grade the media with respect to density and/or size. The system was configured so that the backwash water, pumped from the effluent tank, ran through the column (bottom to top), through a portable rotameter, through the influent bag filters, to the feed tank. The bag filters were used to remove the clinoptilolite fines that had been washed from the column so that the feed tank would not be overburdened with solids. A flow rate of approximately $1,893 \mathrm{~L} / \mathrm{min}$ ( $500 \mathrm{gal} / \mathrm{min}$ ) was specified by the clinoptilolite manufacturer for backwashing. The pilot-scale system had not been designed for this high flow rate as it was not designed for using clinoptilolite as the ion-exchange media. Because of high differential pressures across the bag filters, the backwash flow rate had to be maintained at a low level, averaging 
Rev. 0

approximately $30 \mathrm{~L} / \mathrm{min}$ ( $8 \mathrm{gal} / \mathrm{min}$ ) (measured at the rotameter). The bag filters had to be replaced seven times during backwashing of each of the clinoptilolite column to relieve the high differential pressure still induced by the approximately $30-\mathrm{L} / \mathrm{min}$ (8-gal/min) flow rate. Once the water passing through the rotameter appeared to be clear, the backwashing was stopped. Backwashing the two columns took a total of 5 days. Although it was evident that a completely thorough backwash could not be performed given the physical characteristics of clinoptilolite, the job was considered sufficient given the time constraints of Run 2 .

The operational problems experienced after the backwashing of the clinoptilolite were further evidence that fines were not removed during backwashing. The post-column filters had to be replaced ten times, and the bag filters were also replaced once within the first four days of operation because of high differential pressures. The frequency of filter changes then decreased for the remainder of the test.

3.1.2.2 216-BY Cribs. The results of the secondary contaminants analyses (Appendix C) show that the Dowex $21 \mathrm{~K}$ adsorbed iron, zinc, and copper. However, the other contaminant concentrations remained fairly constant throughout the test, indicating that they had little or no effect on treatment efficiency. Although it appears the adsorption of the iron, zinc, and copper did not affect the treatment efficiency, it is difficult to reach a definitive determination with the available data. Closer monitoring of the secondary contaminant concentrations is needed for a definitive conclusion.

The flow rate, tank levels, differential and point pressures, and $\mathrm{pH}$ were monitored hourly to ensure that the treatment system was operated within its design parameters. The flow rate was monitored from the extraction well, the process treatment system, and the groundwater return (injection) system. Point pressures were measured upstream and downstream of each ion-exchange column, GAC column, and bag and cartridge filter sets. The differential pressure was measured across each of these point pressures.

The differential pressure across the filters increased as the filters became loaded with solids. The filters were replaced when the differential pressure reached a specified reading, similar to that at the B-5 Reverse Well bag filters [207 $\mathrm{kPa}\left(30 \mathrm{lb} / \mathrm{in}^{2}\right)$ for cartridge filters]. A 57- to 76- L/min (15- to $20-\mathrm{gal} / \mathrm{min}$ ) decrease in flow rate was used as a criterion for cartridge replacement.

Treated groundwater was originally pumped from the effluent tank into a truck, which then delivered the water to the injection well. A hose was later installed that gravity-fed the treated groundwater from the effluent tank to the injection well. An injection flow rate of approximately $95 \mathrm{~L} / \mathrm{min}$ (25 $\mathrm{gal} / \mathrm{min}$ ) was maintained.

The extraction flow rate was the limiting factor at the BY-Cribs. The flow rate averaged approximately $13.2 \mathrm{~L} / \mathrm{min}(3.5 \mathrm{gal} / \mathrm{min})$, so the system had to be operated on a batch-like processing schedule. Approximately $15,100 \mathrm{~L}$ (4,000 gal) was processed each day with the extraction pump running continuously. Well maintenance activities identified minor biofouling on the well pump. However, the minimal extent of the biofouling was not considered to be a contributing factor to the low extraction rate. No significant increase in production rate was noted following well maintenance.

Water at the extraction wellhead, bag filter effluent, and ion-exchange column effluent was monitored for $\mathrm{pH}$. The $\mathrm{pH}$ averaged approximately 7.7 at the wellhead, approximately 7.8 after the bag filters, and remained relatively constant after passing through the ion-exchange columns. 
DOE/RL-95-59

Rev. 0

No problems were experienced while backwashing the Dowex $21 \mathrm{~K}$. The manufacturer specified a backwash flow rate of approximately $3 \mathrm{gal} / \mathrm{min} / \mathrm{ft}^{2}$, which equated approximately $102 \mathrm{~L} / \mathrm{min}$ (27 gal $/ \mathrm{min}$ ). This flow rate was maintained until the backwash water was clear, which took approximately 30 minutes.

3.1.2.3 Resin Disposal. During the early years of Hanford operations, process waste containing significant quantities of uranium was stored in the existing 241-Tank Farms. To reduce tank construction requirements and to recover this uranium, the Uranium Recovery Program (URP) was initiated at the 221/244-U Buildings. This recovery process extracted most of the contained uranium but also concentrated significant quantities of fission products in the effluent returned to the tank farms. Evaporators in the Uranium Recovery Process and at the $T$ and B Tank Farms were not able to keep up with the processing rate, and there was a net loss in tank space (Anderson 1990). An in-plant scavenging process that added potassium ferrocyanide to waste stream before going to the BY Tank Farms was included in post-September 1954 waste treatment operations.

Liquid effluents sent to the 241-BY Single-Shell Tank Farms prior to in-plant fission product removal were transferred to the 241-CR Vault for ferrocyanide scavenging. Upon return, the waste was cascaded through a three-tank system with most of the precipitated cesium dropping out in the first tank. Overflow liquids were then discharged to the soil column at the BY-Cribs through the 216-B-43 to 216-B-49 Cribs between November 1954 and December 1957. Subsequent discharges were made at the $\mathrm{BC}-\mathrm{Cribs}$

Cobalt-60 was not recognized in the groundwater until January 1956 when it was detected in groundwater samples near the BY-Cribs (Thomas et al. 1956). The presence of ${ }^{60} \mathrm{Co}$ in the groundwater was surprising as it was generally known to readily sorb onto soils and to be significantly retarded in moving through the soil column. Cobalt was assumed to have complexed with a large molecule or to exist in a nonionized form. Cyanide is highly mobile in groundwater, and soil and was present in the waste solutions discharged to the BY-Cribs (Thomas et al. 1956). By the time ${ }^{60} \mathrm{Co}$ had been detected, the BY-Cribs had been closed to further waste discharges because of high ${ }^{137} \mathrm{Cs}$ concentrations reported in the same timeframe. ${ }^{99} \mathrm{Tc}$ was not detected in the groundwater until 1985 (Law et al. 1986). Contaminant plume data are presented in Table 1-1.

Spent resins removed after treatability testing were drummed, sampled, and analyzed for target contaminants, metals, anions, volatile and semivolatile organics, mercury, polychlorinated biphenyls, and radionuclides. Based on the presence of radionuclides, all resins were given waste designations of "low-specific activity" and are suitable for burial onsite. Current plans call for disposal at the Environmental Restoration Disposal Facility when that facility opens in 1996. Cyanide was removed by DOWEX $21 \mathrm{~K}$ and was found to be present at 10 times the concentration expected from the ${ }^{60} \mathrm{Co}$ found in the resins. This suggests that other forms of cyanides are present in the groundwater than the ${ }^{60} \mathrm{Co}$ ferrocyanide complex alone.

\subsubsection{Resource Requirements}

Cost and manhours expended are presented in Table 3-4. The following is a summary of these costs. Total operational costs are $\$ 3,571.5 \mathrm{~K}$ from September 1994 through June 1995 . Total project cost from March 1994 to June 1995 is $\$ 5,555,300$. Indirect charges amounted to $29.3 \%$ of the total budget. Additional expenses were incurred for other 200-BP-5 activities. 
3.1.3.1 Operations. Total operational costs accounted for approximately $44.4 \%$ of the total operational budget expended through June 1995. The major contributors in the operational costs were from exempt employee charges, personnel assigned to operate the system, analytical expenses, and miscellaneous expenses (see "other" in Table 3-4). Actual costs from operations of the systems during the months of mid-January to May 1995 are approximately $30.6 \%$. With mini-column tests included, field activities encompassed $53.6 \%$ of the operational budget. The miscellaneous charges include rental charges for the support trailer and generator, fuel charges, and miscellaneous support from WHC Site Services.

3.1.3.2 Analytical Costs. Analytical costs total only $6.9 \%$ of the total operational budget through June 1995 for pilot system operations. With mini-column testing, analytical costs reached $13.1 \%$ of operational budget. This does not include labor and materials for sample acquisition. Analytical costs related to tank cleanout and geosciences accounted for an additional $1.5 \%$ of operational budget. This reflects the emphasis placed on process control using onsite (222-S Laboratory) analytical . support rather than offsite laboratory analysis. Also, not all analytical cost have been accrued for samples submitted through May. There is a lag time for these charges to be billed by the offsite laboratory and accrued on the cost account.

3.1.3.3 Waste Management. Waste management costs tracked through June 1995 are minor but have not completely accrued. The costs for disposal of some, but not all, spent resins are valued at $1 \%$ of operational budget. Sample costs for waste designation are contained with each system's operational analytical subheading.

3.1.3.4 Engineering, Design, and Construction. The design and construction of the treatment system accounts for 35.7\% of the total FY 1994 and FY 1995 budget expended. The majority of the material costs for construction are actually accrued under the miscellaneous category because the items were purchased by a site contractor tasked with this function, but some materials were purchased by the Design Engineering task.

3.1.3.5 Maintenance and System Standby. Cost breakout between the two categories is difficult to separate due to the funding of craft support by supplemented Work Order for much of FY 1995. Total craft support comprised $4.2 \%$ of the operational budget. This covers the costs of tank cleanout, winterization, and regular maintenance, which is a small portion of this category. Based primarily on labor and indirects, additional costs incurred by delays to the two systems operations amounted to $13.8 \%$ of the operational budget.

3.1.3.6 Project Management. Project management expenditures account for $10.2 \%$ of the total expended budget. The majority of the costs accrued come from exempt labor charges and miscellaneous support charges (see "other").

3.1.3.7 Project Support. Project support covers technical labor support for multiple aspects of the treatment systems' operations in FY 1995. Higher burn rates are noted during months for tank cleanout and winterization. Project support for FY 1994 is contained primarily within the Design Engineering heading. FY 1995 project support accounts for $15.8 \%$ of the operational budget.

3.1.3.8 Groundwater Characterization. Costs associated with performing preoperational and operational geohydrologic tests amount to $3.9 \%$ of the operational budget. This includes FY 1994 fitness-for-use testing, sonic push activities, tracer tests, and additional groundwater sampling/analysis. Labor associated with the tracer tests is included under operations. 


\subsection{LABORATORY-SCALE TESTS}

As discussed in Section 2.2.3, laboratory-scale tests consisted of resin selection tests, batch equilibrium tests, and mini-column tests. The results of these tests are presented in the following sections.

\subsubsection{Resin Selection Tests}

Samples of groundwater were collected in late June 1994 from wells in the B-5 Reverse Well and BY-Cribs plume and sent to the IT Corporation Laboratory in Knoxville, Tennessee. The samples were characterized with the following results:

$\begin{array}{lll}\text { B-5 Reverse Well: } & { }^{90} \mathrm{Sr} & =11,400 \mathrm{pCi} / \mathrm{L} \\ & { }^{137} \mathrm{Cs} & =2,550 \mathrm{pCi} / \mathrm{L} \\ & { }^{239240} \mathrm{Pu} & =20.1 \mathrm{pCi} / \mathrm{L} \\ & & \\ & { }^{99} \mathrm{Tc} & =1,480 \mathrm{pCi} / \mathrm{L} \\ & { }^{60} \mathrm{Co} & =28.3 \mathrm{pCi} / \mathrm{L} \\ & \text { Cyanide } & =149 \mathrm{ppb} \\ & \text { Nitrate } & =20.3 \mathrm{ppm} .\end{array}$

3.2.1.1 216-B-5 Reverse Well Groundwater. A series of batch equilibrium tests was performed to evaluate Rohm and Haas IRC-718 ion-exchange resin: two sources of bone char (Resintech and a sample procured for use in the B-5 pilot-scale treatment system - TIGG Corporation), and two sources of clinoptilolite (Resintech and American Resources Corporation) by IT Corporation on characterized samples of B-5 Reverse Well groundwater. The results of those tests are presented in Table C-10 (Appendix C). Isotherm plots are shown in Figures 3-9 through 3-17.

IRC-718 is a chelant-based cation-exchange resin that was tested on the B-5 Reverse Well groundwater. This resin has a preference for the heavy metal, multivalent cations. Results for cesium, plutonium, and strontium are shown in Table C-10 (Appendix C), and an isotherm plot for ${ }^{90} \mathrm{Sr}$ is shown in Figure 3-9. The isotherm data show that this resin had little affinity for cesium and, at the lower doses, strontium was not removed. Strontium was probably displaced from the resin by other cations (calcium, iron, magnesium, and other metals) that were more strongly adsorbed or present in higher concentrations. Cesium is a monovalent cation that was not expected to adsorb on this resin. Plutonium loading data were not consistent, and the IRC-718 showed no loading capacity at concentrations below $7.7 \mathrm{pCi} / \mathrm{L}$, which indicates that meeting the $\mathrm{MCL}$ criteria of 1 to $2 \mathrm{pCi} / \mathrm{L}$ would be difficult with this resin. No isotherm plots are presented for ${ }^{137} \mathrm{Cs}$ and ${ }^{239240} \mathrm{Pu}$ loading on IRC-718.

Bone char has been used in the 200 Area processing plants to remove plutonium from wastewater and was expected to have some capacity to remove strontium. As shown on the data summary and isotherms, the Resintech bone char did not work very well on strontium or cesium, although it was fairly effective on plutonium. Isotherm tests were also repeated on a sample of the actual bone char (TIGG/Tate \& Lyle) that was to be used in the pilot test. The pilot plant (Hanford Site) bone char was coarser than the Resintech material. The results of these tests are shown in Table C-10 (Appendix C), and isotherm plots for plutonium loading are shown in Figures 3-10 and 3-11. 
Isotherm tests were also conducted on acid-washed bone char to determine if strontium removal could be increased. The purpose of the acid wash was to clean the surface of the bone matrix (calcium hydroxy apatite) and, it was hoped, increase its activity. Results of this testing indicated no improvement in strontium removal.

The plutonium isotherm for the Resintech bone char (see Figure 3-11) showed that the loading at $7 \mathrm{pCi} / \mathrm{L}$ was higher than at $16 \mathrm{pCi} / \mathrm{L}$. This was not expected, and the last data point is suspect. Splitting the difference on the last two points and extrapolating to the inlet groundwater concentration of $20.1 \mathrm{pCi} / \mathrm{L}$ plutonium would yield a saturation loading of $38 \mathrm{pCi} / \mathrm{g}$ of bone char. Based on $75 \%$ of saturation as the effective bed loading capacity, this results in a run length of $1,007 \mathrm{BV}$. A more conservative loading of $26 \mathrm{pCi} / \mathrm{g}$ (actual loading equivalent to a feed concentration of $6.88 \mathrm{pCi} / \mathrm{L}$ ) resulted in an expected run length of $688 \mathrm{BV}$. Extrapolation of the Hanford Site bone char isotherm gives a predicted saturation loading of $42 \mathrm{pCi} / \mathrm{g}$, which translates to a run length of $1,113 \mathrm{BV}$.

Clinoptilolite is a naturally occurring zeolite that removes contaminants by both cation exchange and adsorption because of its molecular sieve properties. It was tested on the B-5 Reverse Well groundwater. The first batch of clinoptilolite, from Resintech, was a high-calcium clinoptilolite. It showed good adsorption for cesium, but tailed off at the high doses and had poor capacity for strontium. A second batch, from $\mathrm{AmReC}$, had a much higher capacity for strontium and better cesium removal at the low concentrations. This is not unusual, because clinoptilolite deposits from different mines vary in their composition and adsorptive capacity. These results are shown in the data summary (see Table C-10, Appendix C), and isotherm plots (Figures 3-13 through 3-16). Because the loading capacity of the bone char for plutonium was not as high as expected, a series of batch equilibrium tests, designed to produce a plutonium isotherm on the AmReC clinoptilolite, were added to the test program. This isotherm showed that the AmReC clinoptilolite has poor loading capacity for plutonium.

At the lowest dose used in the AmReC clinoptilolite isotherm tests $(0.2 \mathrm{~g}$ clinoptilolite/L of reverse well groundwater), cesium loading was $11,195 \mathrm{pCi} / \mathrm{g}$ of clinoptilolite. Extrapolation of the cesium/clinoptilolite isotherm to the inlet concentration $(\mathrm{Co})$ of $2,550 \mathrm{pCi} / \mathrm{L}$ would result in a very high saturation loading ( $-48,000 \mathrm{pCi} / \mathrm{g})$. To be conservative, an effective bed loading of $18,750 \mathrm{pCi} / \mathrm{g}$ was assumed, which was only $50 \%$ higher than test loading at an equilibrium concentration of $232 \mathrm{pCi} / \mathrm{L}$. This resulted in a predicted run length of $6,470 \mathrm{BV}$ for cesium breakthrough. Extrapolating the strontium isotherm gave a bed saturation loading of $47,000 \mathrm{pCi} / \mathrm{g}$ of clinoptilolite or an effective bed capacity of $35,250 \mathrm{pCi} / \mathrm{g}$. This resulted in a predicted run length of $2,700 \mathrm{BV}$ for full loading of strontium. Early breakthrough of low levels of strontium are expected because of low loading at concentrations less than $500 \mathrm{pCi} / \mathrm{L}$. Plutonium was not effectively adsorbed on the clinoptilolite.

3.2.1.2 216-BY Cribs Groundwater. Batch equilibrium tests were performed on characterized samples of BY-Cribs groundwater to evaluate the ability of Dowex $21 \mathrm{~K}$ ion-exchange resin to remove ${ }^{99} \mathrm{Tc}$. The results of those tests are presented in Table C-11 (Appendix C). Isotherm plots are shown in Figure 3-17. Technetium-99 was present in the initial BY-Cribs groundwater at $1,480 \mathrm{pCi} / \mathrm{L}$, which is above the IRM limit of $900 \mathrm{pCi} / \mathrm{L}$. If the isotherm is extrapolated to the inlet groundwater concentration of $1,480 \mathrm{pCi} / \mathrm{L}$, a saturation capacity of $13,500 \mathrm{pCi} / \mathrm{g}$ resin is predicted. Based on achieving $75 \%$ of saturation loading, the expected run length would be $4,400 \mathrm{BV}$.

3.2.1.3 Clinoptilolite Flow-Through Column Tests. In the laboratory-scale flow-through column testing conducted at IT Laboratory in Knoxville, Tennessee, a 1,000 BV column test with a single 
column using clinoptilolite was completed. It confirmed that low levels of strontium rapidly bleed through the column. All strontium analyses for this flow-through column study were conducted as total strontium by GFAA. Removal efficiency for total strontium and ${ }^{90} \mathrm{Sr}$ should be equivalent. Data from this study are shown in Table C-12 (Appendix C) and Figure 3-18. Initial column effluent contained $1 \mathrm{ppb}$ of strontium, which is $99.4 \%$ removal (based on $155 \mathrm{ppb}$ feed). At $500 \mathrm{BV}$, effluent strontium was $10 \mathrm{ppb}(93.5 \%$ removal). At $1,000 \mathrm{BV}$, effluent was $21 \mathrm{ppb}$, which is $86.5 \%$ removal. Average effluent over the $1,000 \mathrm{BV}$ was about $10 \mathrm{ppb}(735 \mathrm{pCi} / \mathrm{L})$. Clinoptilolite (in a single-stage column with a 7.33-minute empty-bed contact time) was not able to get strontium down to the $8-\mathrm{pCi} / \mathrm{L}(0.11-\mathrm{ppb})$ DWS. A two-stage system or column with higher contact time should be more effective. Isotopic dilution may also improve removal in a second-stage column. A two-stage system with isotopic dilution might give 1,200 to $1,500 \mathrm{BV}$ with $98 \%$ removal of strontium (effluent $2.5 \mathrm{ppb}$ or $184 \mathrm{pCi} / \mathrm{L})$.

Cesium in the column effluent was less than $50 \mathrm{pCi} / \mathrm{L}$ after $1,000 \mathrm{BV}$. Samples of the column effluent showed plutonium at $16.8 \mathrm{pCi} / \mathrm{L}$ after $500 \mathrm{BV}$ and at $20.8 \mathrm{pCi} / \mathrm{L}$ after $1,000 \mathrm{BV}$. This shows rapid breakthrough of plutonium and clinoptilolite's lack of affinity for plutonium.

\subsubsection{Batch Equilibrium Tests}

Batch equilibrium tests are performed at varying dose rates of adsorbent (generally two or more) to provide equilibrium loading data with which to predict the adsorption of constituents from solution. The models proposed by Freundlich and Langmuir are commonly used (Freundlich 1926, Langmuir 1918). The most commonly used model is the Freundlich adsorption isotherm:

$$
\frac{\mathrm{x}}{\mathrm{m}}=\mathrm{KC}^{\mathrm{l} / \mathrm{n}}
$$

where:

$$
\begin{aligned}
& \mathrm{x}=\text { mass of constituent adsorbed (adsorbate) on solid phase, } \mathrm{pCi} \\
& \mathrm{m}=\text { mass of solid (adsorbent) being used for adsorption, } \mathrm{g} \\
& \mathrm{C}=\text { equilibrium concentration of residual groundwater sample, } \mathrm{pCi} / \mathrm{L} \\
& 1 / \mathrm{n}=\text { an empirical exponent used to linearize the data (Freundlich 1926) } \\
& \mathrm{K}=\text { a constant, sometimes called the Freundlich adsorption coefficient }
\end{aligned}
$$

In log form the equation becomes:

$$
\log \frac{\mathrm{x}}{\mathrm{m}}=\frac{1}{\mathrm{n}}(\log \mathrm{C})+\log \mathrm{K}
$$

which is in the form: $y=m x+b$.

Plotting the $\log$ of $\mathrm{x} / \mathrm{m}$ versus the $\log$ of $\mathrm{C}$ should provide a straight line with the intercept of $\log \mathrm{K}$ and $1 / n$ the slope of the straight line isotherm curve.

Freundlich (1926) proposed that the amount of a solid, or a gas, adsorbed per gram of adsorbing material would be proportional to the equilibrium concentration (for a solid), or the equilibrium pressure (for a gas), raised to some fractional exponent. The Freundlich isotherm, albeit empirical, is 
used to linearize batch equilibrium data as straight line curves when plotted on log-log graphs. These curves then can be used to compare the results of different adsorbents for the intended use.

In addition to the information discussed in evaluating the results of batch equilibrium test data, isotherm plots provide the following:

- The slope of the straight line gives a general indication of an adsorbent's ability for use in either a batch or column operation. Steeper slopes indicate good adsorption from solutions at higher concentrations, but not at lower ones; they also indicate higher capacity and better suitability for flow-through column operation. More gradual slopes indicate more even adsorption over the entire range of concentration of the solution, and the ability to achieve a high-quality effluent, or low concentration of ion in the effluent, may be better suited for batch operations depending on the requirements.

- The curve can be projected to intersect a vertical line constructed at the initial concentration $\left(\mathrm{C}_{\mathrm{o}}\right)$ of the groundwater sample to give an approximate loading capacity of the adsorbent for the contaminant.

3.2.2.1 Second Group of Batch Equilibrium Tests. The test program for this work is described in Workplan and Procedures for Bench-Scale Testing of Potential Adsorbents for the 200-BP-5 Groundwater Operable Unit (BHI 1995e). Six adsorbents were evaluated in this test. Results of the second group of batch equilibrium tests, performed at the B-5 Reverse Well, are summarized in Table C-13 (Appendix C), and plots of strontium adsorption isotherms are shown in Figures 3-19, $3-20,3-21$, and 3-22. Isotherm plots are presented for only four of the adsorbents showing adequate ${ }^{90}$ Sr removal (UOP A-51, clinoptilolite, IRC-718, and UOP E-95). In addition, cesium and plutonium data were not plotted because the emphasis of this test was to find a strontium removal adsorbent. The six adsorbents in this test included UOP A-51, UOP E-95, IRC-718, Durasil 230, bone char, and clinoptilolite. The batch equilibrium tests were conducted with the addition of varying amounts $(0.2$, 2 , and $5 \mathrm{ppm}$ ) of $\mathrm{SrCl}_{2}$ as a source of nonradioactive strontium. The addition of strontium chloride is an isotopic dilution technique that increases the total strontium levels to increase the driving force for mass removal on an adsorbent. If there is sufficient elemental strontium present in the groundwater, there may be sufficient driving force for adsorption. However, the target end concentration of 8 $\mathrm{pCi} / \mathrm{L}$ of ${ }^{90} \mathrm{Sr}$ only represents a mass concentration of $5.67 \times 10^{-8} \mathrm{ppb}$ of strontium. Addition of nonradioactive strontium greatly increases the mass loading and in theory should promote adsorption of the radioactive as well as the nonradioactive strontium. Clinoptilolite was also evaluated without the addition of $\mathrm{SrCl}_{2}$, and the results are plotted in Figure 3-20 with the other clinoptilolite data. Bone char was evaluated to determine whether it was a good choice for plutonium removal. The plutonium data were not plotted as an adsorption isotherm because the residual ${ }^{239 / 240} \mathrm{Pu}$ concentrations in the batch equilibrium tests were below the detection limit for plutonium and would not provide a representative curve.

The MCL, or $4 \%$ of the derived concentration guides, for ${ }^{137} \mathrm{Cs},{ }^{239240} \mathrm{Pu}$, and ${ }^{90} \mathrm{Sr}$ are $120 \mathrm{pCi} / \mathrm{L}$, $1.2 \mathrm{pCi} / \mathrm{L}$, and $8 \mathrm{pCi} / \mathrm{L}$, respectively. The detection limit for plutonium analysis at the $222-\mathrm{S}$ Laboratory is above the $\mathrm{MCL}$, generally ranging around 4.5 to $8 \mathrm{pCi} / \mathrm{L}$, because of the high background in the laboratory. The detection limit at offsite laboratories is much better (to $<1 \mathrm{pCi} / \mathrm{L}$ ), but the turnaround time (15 to 45 days) did not provide a timely response and costs were prohibitive. 
In the absence of adsorption isotherm plots, batch equilibrium data still provide significant information. In evaluating the results of batch equilibrium tests, the lower dose levels (i.e., 0.2 and $0.4 \mathrm{~g} / \mathrm{L}$ ) give a good approximation of the loading capacity of an adsorbent. The higher dose levels give an indication of the ability of the same adsorbent to achieve a high-quality effluent, assuming kinetics are not a factor (assumes that the adsorbent and the liquid are in equilibrium in the batch test). As can be seen from the plutonium data in Table C-13 (Appendix C) for bone char, the lower dose of $0.4 \mathrm{~g} / \mathrm{L}$ resulted in a range of plutonium loading between 22.2 to $35.7 \mathrm{pCi} / \mathrm{g}$, and the bone char was able to achieve less than 4 to less than $6 \mathrm{pCi} / \mathrm{L}$ residual ${ }^{239 / 240} \mathrm{Pu}$. Two other adsorbents indicated good plutonium removal values. UOP A-51 resulted in a plutonium loading of 11 to $12 \mathrm{pCi} / \mathrm{g}$ and a residual ${ }^{239 / 240} \mathrm{Pu}$ concentration ranging from less than 4.6 to less than $7.3 \mathrm{pCi} / \mathrm{L}$ at the higher doses; IRC-718 resulted in a plutonium loading of 26.9 to $29 \mathrm{pCi} / \mathrm{g}$ and a residual concentration ranging from less than 3.8 to less than $7.3 \mathrm{pCi} / \mathrm{L}$.

From the batch equilibrium data and ${ }^{90} \mathrm{Sr}$ adsorption isotherm plots for UOP A-51 and IRC-718 (see Figures 3-19 and 3-21), it appears both have the ability to achieve a high-quality effluent, resulting in a low average residual ${ }^{90} \mathrm{Sr}$ concentration of 7 and $4.7 \mathrm{pCi} / \mathrm{L}$, respectively, at the higher doses of adsorbent. Interestingly, the IRC-718 achieved an average $4.7 \mathrm{pCi} / \mathrm{L}$ concentration at a $4-\mathrm{g} / \mathrm{L}$ dose as well. This would be an indication that IRC-718 might be capable of achieving low concentrations over a range of concentrations as described previously. The UOP A-51 isotherm has a steeper slope, indicating that it might be better suited for column operation. Strontium chloride addition appeared to depress the loading capacity of the UOP A-51 (see Figure 3-19), as witnessed by a decrease in the slope of the isotherm plot. However, $\mathrm{SrCl}_{2}$ appeared to improve the loading capacity of the IRC-718 (see Figure 3-21). IRC-718 isotherm did have a shallower slope than UOP A-51, indicating that it might be better suited for batch operation. From these data, both IRC-718 and UOP A-51 appear to be good candidates for ${ }^{90} \mathrm{Sr}$ removal.

The UOP E-95 and clinoptilolite results are similar in that both achieve residual ${ }^{90} \mathrm{Sr}$ concentrations between 40 to $60 \mathrm{pCi} / \mathrm{L}$ at the higher doses of adsorbent. The isotherm slopes are similar, and $\mathrm{SrCl}_{2}$ appears to interfere with ${ }^{90} \mathrm{Sr}$ loading. Referring to the isotherms (see Figures 3-20 and 3-22) it can be seen that the lowest strontium chloride dose of $0.2 \mathrm{ppm}$ provided the lowest ${ }^{90} \mathrm{Sr}$ concentrations. Both adsorbents might be good for column operation, but would require some type of polishing step to achieve a low ${ }^{90} \mathrm{Sr}$ concentration. Figure 3-20 also shows the isotherm plot for clinoptilolite where no $\mathrm{SrCl}_{2}$ was added; it falls between the 2- and 5-ppm plot, which seems to indicate that a $\mathrm{SrCl}_{2}$ addition of $0.2 \mathrm{ppm}$ might improve ${ }^{90} \mathrm{Sr}$ removal for clinoptilolite.

Durasil 230 was tested to evaluate its potential for cesium removal. Table C-13 (Appendix C) shows that Durasil 230 is comparable to clinoptilolite for ${ }^{90} \mathrm{Sr}$ and ${ }^{137} \mathrm{Cs}$ removal. The Durasil resulted in an average residual ${ }^{90} \mathrm{Sr}$ concentration of $54 \mathrm{pCi} / \mathrm{L}$ and an average ${ }^{90} \mathrm{Sr}$ loading of $3,075 \mathrm{pCi} / \mathrm{g}$. The results for Durasil regarding ${ }^{137} \mathrm{Cs}$ indicate an average residual ${ }^{137} \mathrm{Cs}$ concentration of $57 \mathrm{pCi} / \mathrm{L}$ and an average ${ }^{137} \mathrm{Cs}$ loading of $3,155 \mathrm{pCi} / \mathrm{g}$. The addition of strontium chloride had little affect on ${ }^{137} \mathrm{Cs}$ removal by Durasil 230.

3.2.2.2 Third Group of Batch Equilibrium Tests. This third group of batch equilibrium tests were conducted to determine the following:

- If lowering the $\mathrm{pH}$ by two points would improve/affect the removal of ${ }^{90} \mathrm{Sr}$ 
Rev. 0

- If the addition of $\mathrm{SrCl}_{2}$ in a test simulating column operation, where the addition of $\mathrm{SrCl}_{2}$ is added to the second column (or in the case of this test, the second part of batch Test $2 \mathrm{~b}$, described below) would improve ${ }^{90} \mathrm{Sr}$ removal.

The results of the third group of batch equilibrium tests are summarized in Table C-14 (Appendix C) and plotted as adsorption isotherms in Figure 3-23.

In Test 1a, the batch equilibrium tests were run at the normal $\mathrm{pH}$ of the feed groundwater, approximately 8.3 . In Test $1 \mathrm{~b}$, the $\mathrm{pH}$ was adjusted to 6.3 with $20 \%$ hydrochloric acid to determine the effects of lower $\mathrm{pH}$ on the adsorption of ${ }^{90} \mathrm{Sr}$. The final $\mathrm{pH}$ of the solutions was measured before sampling. The $\mathrm{pH}$ had increased by approximately $0.5 \mathrm{pH}$ (nominally 8.5 to 9 ) in Test $1 \mathrm{a}$ and 1.5 $\mathrm{pH}$ (nominally 7.5 to 8.0 ) in Test $1 \mathrm{~b}$. It was noted that the higher clinoptilolite doses caused a higher terminal $\mathrm{pH}$, and that the higher doses also required more acid to lower the $\mathrm{pH}$. This is probably due to the highly alkaline nature of the clinoptilolite because of relatively high concentrations of calcium, magnesium, sodium, and potassium oxides. In addition, the groundwater has an alkalinity of approximately $100 \mathrm{ppm}$.

In Test $2 \mathrm{a}$, the batch equilibrium tests were run at two dosages, 2 and $20 \mathrm{~g} / \mathrm{L}$, and then sampled. In Test $2 b$, the residual solutions from Test $2 a$ were combined, and fresh clinoptilolite in doses of 2 and $20 \mathrm{~g} / \mathrm{L}$ were added to the appropriate previous doses of 2 and $20 \mathrm{~g} / \mathrm{L}$. Then, $0.26 \mathrm{ppm}$ (as strontium) $\mathrm{SrCl}_{2}$ was added to each beaker and placed back on the stirrers for another 24-h contact.

The results for Test 1 indicate that lowering the $\mathrm{pH}$ reduced the clinoptilolite's ability to achieve a low effluent concentration. At the $20-\mathrm{g} / \mathrm{L}$ dose, the average residual ${ }^{90} \mathrm{Sr}$ concentration of the normal $\mathrm{pH}$ batch test was $24.4 \mathrm{pCi} / \mathrm{L}$, whereas the average residual concentration at the lower $\mathrm{pH}$ was $46.9 \mathrm{pCi} / \mathrm{L}$. The slopes of the adsorption isotherms, as shown in Figure 3-23, are similar, except the curve for the lowered $\mathrm{pH}$ batch test is depressed. However, the ${ }^{90} \mathrm{Sr}$ loadings at the $0.2-, 2-$, and $20-\mathrm{g} / \mathrm{L}$, doses are very close, averaging $3,012.5 \mathrm{pCi} / \mathrm{g}$ at the $0.2-\mathrm{g} / \mathrm{L}$ dose, $2,061.2 \mathrm{pCi} / \mathrm{g}$ at the $2-\mathrm{g} / \mathrm{L}$ dose, and $237.3 \mathrm{pCi} / \mathrm{g}$ at the $20 \mathrm{~g} / \mathrm{L}$ dose. Projecting the two curves to the initial concentration, $\mathrm{C}_{\mathrm{o}}$ of $4,780 \mathrm{pCi} / \mathrm{L}$, and reading from the $\mathrm{Y}$ axis $\left({ }^{90} \mathrm{Sr}\right.$ loading) would indicate that the equilibrium capacity of approximately $3,000 \mathrm{pCi} / \mathrm{g}$ was reached.

Test 2, at longer contact and with addition of $\mathrm{SrCl}_{2}$, had curious results. Test $2 \mathrm{a}$ was like Test 1a, except only two doses $(2$ and $20 \mathrm{~g} / \mathrm{L})$ were run having similar results $(2,514.5 \mathrm{pCi} / \mathrm{g}$ and $275 \mathrm{pCi} / \mathrm{g}$ at the $2-$ and $20-\mathrm{g} / \mathrm{L}$ doses, respectively). In Test $2 \mathrm{a}$, the feed ${ }^{90} \mathrm{Sr}$ increased to $5,395 \mathrm{pCi} / \mathrm{L}$ with different results from Test 1 a (which was $4,780 \mathrm{pCi} / \mathrm{L}$ ). The $20 \mathrm{~g} / \mathrm{L}$ dose was not able to achieve the low residual concentration of Test 1a (62.4 versus $24.4 \mathrm{pCi} / \mathrm{L})$. Furthermore, the slope of the isotherm plot increased significantly. In Test $2 \mathrm{~b}$, the higher dose $(60 \mathrm{~g} / \mathrm{L})$ indicated the ability to achieve a lower effluent concentration, although not as low as the normal $\mathrm{pH}$ batch of Test la. The curious observation is that the loading for both the 6 - and $60-\mathrm{g} / \mathrm{L}$ doses is nearly the same at approximately $850 \mathrm{pCi} / \mathrm{g}$, which seems to indicate that a longer contact or the addition of $\mathrm{SrCl}_{2}$ does not improve the loading; in fact, some metathesis or desorption may have been occurring.

\subsubsection{Flow-Through Column Tests (Mini-Columns)}

To adequately evaluate the effectiveness of an ion-exchange treatment system, it is desirable to obtain multiple sets of performance data. This can be accomplished in a short period of time by performing small-scale ion-exchange column tests. The objective is to process sufficient volumes of contaminated 
groundwater to load the adsorbent bed to saturation (where the column effluent equals the influent) two or three times to obtain sufficient data. These data then can be used to obtain the shape of the breakthrough curve, the amount of contaminant(s) that can be removed, and the volume of groundwater that can be processed. When the volume of groundwater processed in either pilot-scale or mini-column tests is converted to bed volumes and the flow rate to bed volumes per unit of time, the data can be directly related, compared, and used to scale-up to larger sized systems. For this test, mini-column data were also intended to supplement data collected from the pilot-scale system, since it was anticipated that breakthrough in the pilot-scale system beds would not occur within the desired time frame. To achieve breakthrough data more quickly than with the pilot-scale system, mini-columns were run $24 \mathrm{~h} /$ day.

Small-scale flow-through ion-exchange column, or mini-column, tests were performed at both the B-5 Reverse Well site and the BY-Cribs site. Two groups of mini-column tests were performed at the B-5 Reverse Well site. The first group of tests was intended to perform the following:

- Test MCT-1 was to provide supplemental loading and breakthrough data from a flowsheet comparable (i.e., same contact time) to the pilot-scale treatment system (a bone char column followed by a clinoptilolite column followed by a clinoptilolite column in a series-flow arrangement) for the removal of ${ }^{137} \mathrm{Cs},{ }^{239 / 240} \mathrm{Pu}$, and ${ }^{90} \mathrm{Sr}$

- Test MCT-2 was to evaluate a strontium dilution method for enhancing the removal of ${ }^{90} \mathrm{Sr}$ with the addition of $\mathrm{SrCl}_{2}$.

From the results of the first group of tests, it appeared that the flowsheet was capable of good removals of ${ }^{137} \mathrm{Cs}$ and ${ }^{239 / 240} \mathrm{Pu}$, but ${ }^{90} \mathrm{Sr}$ removals resulted in an effluent that was still higher in concentration than the target MCL of $8 \mathrm{pCi} / \mathrm{L}$. The emphasis of the second group of tests focused primarily on ${ }^{90} \mathrm{Sr}$ removal to accomplish the following:

- Evaluate whether longer contact times on clinoptilolite would improve ${ }^{90} \mathrm{Sr}$ removals (Test 2MCT-2)

- Evaluate an alternate adsorbent (UOP A-51) that had demonstrated good ${ }^{90} \mathrm{Sr}$ removals in the batch equilibrium tests described above (a bone char column followed by a clinoptilolite column followed by a UOP A-51 column) (Test 2MCT-3)

- Continue the non-SrCl${ }_{2}$ addition test from the first group of tests to achieve either saturation with respect to ${ }^{90} \mathrm{Sr}$ or breakthrough of ${ }^{137} \mathrm{Cs}$ (Test MCT-1 continued).

One group of mini-column tests was performed at the BY-Cribs site using Dowex $21 \mathrm{~K}$ ion-exchange resin. Because it appeared that the pilot-scale treatment system would not be able to reach saturation for ${ }^{99} \mathrm{Tc}$ or ${ }^{60} \mathrm{Co}$, supplemental loading data needed to be obtained by performing two mini-column tests. Both mini-column tests were run at the same contact time of the pilot-scale treatment system $(\sim 5 \mathrm{~min}$ per column) in a two-column (lead and polish column series-flow arrangement) configuration.

3.2.3.1 216-B-5 Reverse Well Group 1. Because it appeared that ${ }^{90} \mathrm{Sr}$ would be the most difficult contaminant to remove, the emphasis of both groups of mini-column tests performed at the B-5 Reverse Well site was to evaluate/enhance the effectiveness of clinoptilolite for the removal of ${ }^{90} \mathrm{Sr}$. However, it was also necessary to obtain data to supplement the pilot-scale treatment system on 
effective ${ }^{137} \mathrm{Cs}$ and ${ }^{239 / 240} \mathrm{Pu}$ removals. These data were obtained during the operation of the first group of mini-column tests. In addition, during the second group of mini-column tests, as described above, ${ }^{137} \mathrm{Cs}$ data were collected to look for either breakthrough of ${ }^{137} \mathrm{Cs}$ or saturation of ${ }^{90} \mathrm{Sr}$.

The results of the first group of B-5 Reverse Well site mini-column tests (MCT-1, MCT-2) are shown in Tables C-15 and C-16 (Appendix C) and plotted in Figures 3-24 through 3-29. Tables C-17 and C-18 (Appendix C) and Figures 3-30 through 3-33 give the results for the second group of tests (2MCT-2, 2MCT-3). All mini-column sample analysis results are reported in Appendix C.

Data reported in the tables are organized by bed volume and sample port. Sample ports are distinguished by the first and second numbers in the labels (e.g., "MCT-1-1" means mini-column test one, sample port one) (see Figure 2-1 for locations of sample ports).

Blank spaces in the tables and missing points on the curves are a result of missing or lost data. As previously discussed, some samples analyzed by the 222-S Laboratory were below the laboratory detection limits. The detection limits averaged approximately $60 \mathrm{pCi} / \mathrm{L}$ for ${ }^{137} \mathrm{Cs}$, approximately $10 \mathrm{pCi} / \mathrm{L}$ for ${ }^{239 / 240} \mathrm{Pu}$, and approximately $4 \mathrm{pCi} / \mathrm{L}$ for ${ }^{90} \mathrm{Sr}$. Data below the detection limit are shown with a " $<$ " (less than) in the column to the left of the data in the tables. These data do not present a precise picture of removal effectiveness in that it cannot be determined whether the target treatment goals were met. However, they can be used to demonstrate the general ability of the treatment system to remove the contaminants. Offsite laboratory results, because of lower background, provide the data necessary to show the ability to meet target treatment goals.

Because the influent concentrations of the contaminants varied, the trends of the effluent concentrations do not always represent how the system is performing. Therefore, the results will be presented in terms of removal efficiencies with mention of influent and effluent concentrations. Removal efficiencies are calculated by the following equation:

$$
\frac{\text { (Influent - Effluent) }}{\text { Influent }} \times 100 \%
$$

After processing 3,500 BV, both Tests MCT-1 and MCT-2 were stopped. Review of the data indicated that the addition of $\mathrm{SrCl}_{2}$ (in Test MCT-2) appeared to degrade the performance of clinoptilolite for ${ }^{90} \mathrm{Sr}$ removal. Further, because of the gradually increasing (not sharp) breakthrough curve for both tests (MCT-1 and MCT-2), it could not be determined when breakthrough of the clinoptilolite would occur (see Figure 3-28).

Two new tests were proposed. First, it was decided to perform a kinetic evaluation of clinoptilolite to see if a longer (12-minute) contact time would improve ${ }^{90} \mathrm{Sr}$ removal (Test 2MCT-2). Second, it was decided to evaluate an adsorbent selected from the batch equilibrium tests, UOP A-51, in combination with clinoptilolite in a bone char column, clinoptilolite column, and a UOP A-51 column test (Test 2MCT-3). Third, it was decided to continue the clinoptilolite test (without $\mathrm{SrCl}_{2}$ ) at the previous contact time to see if saturation with respect to ${ }^{90} \mathrm{Sr}$ or breakthrough of ${ }^{137} \mathrm{Cs}$ could be achieved (continued test of MCT-1). These tests are summarized in Table 2-7 and discussed in Sections 2.2.3.4 and 3.2.3, 3.2.4.

Before stopping the tests at 3,500 BV, the columns experienced minor biofouling by algae. While MCT-1 operations were interrupted, algae increased, becoming visible in the standing water above and within the top $10 \mathrm{~cm}$ of the clinoptilolite and in sections approximately $30 \mathrm{~cm}$ from the top of the 
bed in both the lead and second clinoptilolite beds. Once the test was restarted, the algae continued to grow throughout the column, covering the clinoptilolite, column inner walls, and water above the clinoptilolite, with algae in both the lead and second clinoptilolite columns. An increase in growth was noticeable after a weekend, or when the test was stopped for more than a day, and as the weather became warmer. A small (approximately $1 \mathrm{~cm}$ in diameter) growth was visible on the top of the bone char bed. The algae were visible throughout the tubing of the system and continually clogged the precolumn filter. Growth was also visible on the bottom of the mini-column influent tank after restarting MCT-1.

The algae's growth created a back pressure in the columns, which was revealed by the pressure gauge installed before the bone char column (see Figure 2-1). The flow rate was reduced to relieve the back pressure. As discussed in the following paragraphs, it appeared that the only measurable effect the biofouling had on the removal efficiency of the clinoptilolite. However, the resulting reduction in flow rate did influence ${ }^{90} \mathrm{Sr}$ removal. This is also discussed in the following sections.

At the conclusion of the test, a sample of the algae was obtained and dried to check for radioactivity. The algae was found to be emitting beta radiation at about $8,000 \mathrm{dpm}$ and was concluded to be from uptake of ${ }^{90} \mathrm{Sr}$. Biological organisms are known to assimilate strontium as if it were calcium or a calcium substitute. Radiation measurements taken through the glass column in the upper region of the clinoptilolite bed during the test indicated beta radiation levels twice that of the dried algae. To determine if the algal growth interfered with ${ }^{90} \mathrm{Sr}$ removal effectiveness, a comparison of the results between two lead clinoptilolite columns of separate mini-column tests (2MCT-2, which had significant algae growth and $2 \mathrm{MCT}-3$, which had no algae growth) indicated no measurable effect. This is evident by looking at the effluent results from each lead column (see Figures 3-30 and 3-32).

3.2.3.1.1 MCT-1 Results. The results for Test MCT-1 are presented in Table C-15 (Appendix C) and plotted in Figures 3-24, 3-25, 3-26, and 3-27. The data presented in the table and figures include the initial, as well as the continuation of Test MCT-1. As mentioned previously, the initial run was terminated at approximately 3,500 BV, and then continued for another approximately $4,580 \mathrm{BV}$ (total of $\sim 8,100 \mathrm{BV}$ ). Sampling during the continuation run was intended to monitor for ${ }^{90} \mathrm{Sr}$ saturation or ${ }^{137} \mathrm{Cs}$ breakthrough, whichever occurred first. In looking at the lead column effluent curve (see Figure 3-24), immediately after 3,500 BV up to 4,800 BV, it appears that the lead column approached saturation for ${ }^{90} \mathrm{Sr}$. During this time, the test was run $24 \mathrm{~h} /$ day (see Figure 3-24). Additionally, when the test was begun, it ran continuously and was sampled once per day until reaching $1,500 \mathrm{BV}$, at which time operations were reduced to $8 \mathrm{~h} /$ day because the test plan (BHI 1995e) called for increased sampling frequency after 1,500 BV. This could only be accommodated by running 8 -h days and sampling every other day. At approximately $1,000 \mathrm{BV}$, there seemed to be a sharp "breakthrough." When the test was operated discontinuously ( $8 \mathrm{~h} /$ day), a kinetic effect appeared in that removal of ${ }^{90} \mathrm{Sr}$ by clinoptilolite seemed to recover after continuous operations were stopped. In addition, at 4,800 $\mathrm{BV}$ and again at $6,500 \mathrm{BV}$, the algal growth caused a reduction in flow (with attendant increase in contact time of $11.5 \mathrm{~min}$ after $6,500 \mathrm{BV}$ ) and there also was a "recovery." This "stair-step" removal/recovery effect seems to suggest that ${ }^{90} \mathrm{Sr}$ removal by clinoptilolite has a dependence on contact time and/or discontinuous operation, or rather, has a kinetic dependence and may be best suited for batch operation. This also could suggest suitability for continuous operation at a long contact time. The effluent concentration reached a low of $1,820 \mathrm{pCi} / \mathrm{L}$ at 7,500 BV when the flow rate was reduced, resulting in a contact time of approximately 21 minutes. Generally, the results indicate a better quality effluent when the system was run discontinuously, or in a batch-type operation, and when the contact time was increased. 
The bone char column, as a roughing column for ${ }^{90} \mathrm{Sr}$, removed a significant portion of the feed ${ }^{90} \mathrm{Sr}$ for the first $500 \mathrm{BV}$. But after $500 \mathrm{BV}$, the bone char was apparently saturated and started to "leak" small amounts of ${ }^{90} \mathrm{Sr}$, causing somewhat sporadic results in the lead clinoptilolite column's test results. The bone char effluent was not monitored for ${ }^{90} \mathrm{Sr}$ during the mini-column tests because pilot-scale test data indicated that the bone char became loaded after $500 \mathrm{BV}$ and was no longer effective.

The lead clinoptilolite bed (with help from the bone char) removed $95 \%$ of the ${ }^{90} \mathrm{Sr}$ for the first $500 \mathrm{BV}$. After the bone char became saturated, the ${ }^{90} \mathrm{Sr}$ concentration from the lead clinoptilolite column increased to $1,060 \mathrm{pCi} / \mathrm{L}$ at $1,000 \mathrm{BV}$, resulting in a removal efficiency of approximately $75 \%$. The removal efficiency dropped to around $70 \%$ at 1,500 BV and averaged $70 \%$ to 3,500 BV. After 3,500 BV, the removal efficiency of the clinoptilolite again dropped, averaging $40 \%$ to $45 \%$ for the rest of the test. This clearly indicates that clinoptilolite cannot, with any confidence, achieve the MCL target effluent of $8 \mathrm{pCi} / \mathrm{L}$ at short contact times.

The second clinoptilolite bed effluent, or system effluent, was monitored at the same frequency as the lead clinoptilolite effluent during the first $3,500 \mathrm{BV}$. However, because it was determined that adequate data would not be obtained to properly determine the ${ }^{90} \mathrm{Sr}$ breakthrough curve due to the short duration of this test, the objective of the continuation phase of this test was to look for ${ }^{90} \mathrm{Sr}$ saturation (effluent equals effluent) or ${ }^{137} \mathrm{Cs}$ breakthrough. For this reason, overall system removal data was not obtained with any regularity for this portion of this test.

The second clinoptilolite column achieved $90 \%{ }^{90} \mathrm{Sr}$ removal to $500 \mathrm{BV}$, but then dropped to $74 \%$ by $1,500 \mathrm{BV}$ (see Figure 3-25). The removal efficiency averaged about $75 \%$ to 3,500 BV and decreased to between $50 \%$ and $60 \%$ by the end of the test. For the first $500 \mathrm{BV}$, this provided the overall system with fair ${ }^{90} \mathrm{Sr}$ removals, with one data point less than $8 \mathrm{pCi} / \mathrm{L}$. After $500 \mathrm{BV}$, however, the effluent increased sharply to an average $605 \mathrm{pCi} / \mathrm{L}{ }^{90} \mathrm{Sr}$ (a range of 305 to $768 \mathrm{pCi} / \mathrm{L}$ ).

The ${ }^{137} \mathrm{Cs}$ results seen in Table C-16 (Appendix C) show less-than-detectable values $(-60 \mathrm{pCi} / \mathrm{L}$ ) from the lead clinoptilolite column (MCT-1-3 column in table) effluent except for three data points at $4,800,6,900$, and $7,700 \mathrm{BV}$. The influent concentration showed a steadily increasing trend starting at approximately $4,200 \mathrm{BV}$, yet the ${ }^{137} \mathrm{Cs}$ removals held constant (see Figure $3-26$ ). At $7,700 \mathrm{BV}$, there was a sudden increase in influent concentration with a parallel increase in effluent concentration of $230 \mathrm{pCi} / \mathrm{L}$, and the two data points after this were again below the detection limit following the decrease in influent concentration. Regardless, no breakthrough was seen relative to ${ }^{137} \mathrm{Cs}$ after processing $8,100 \mathrm{BV}$ when the test was terminated. It appears from this that clinoptilolite is a good adsorbent for ${ }^{137} \mathrm{Cs}$.

Plutonium-239/240 values were below the $222-\mathrm{S}$ Laboratory detection ( $\sim 10 \mathrm{pCi} / \mathrm{L})$ in the bone char effluent to 3,500 BV. The ${ }^{239240} \mathrm{Pu}$ effluent concentration was not checked again until $8,100 \mathrm{BV}$ had been processed, and the value was still below detection. As discussed in Section 3.1.1.1, because of high background levels at the 222-S Laboratory the detection limits for low-level analyses of plutonium and cesium varied from day-to-day. This produced varying results. For example, referring to Table C-15 (Appendix C) and Figure 3-27, at 3,100 BV, the effluent concentration appears to be greater than the influent. However, the effluent concentration of $35 \mathrm{pCi} / \mathrm{L}$ is below detection limit, whereas the influent concentration of $14.3 \mathrm{pCi} / \mathrm{L}$ is a detectable value. It can be seen that the data plot in Figure 3-27 is sporadic and indicates inconsistent data from which to draw a conclusion. 
A sample was collected at 2,600 BV for analysis at an offsite laboratory as a QC check against the 222-S Laboratory data (these data are shown in Table C-15, Appendix C). The ${ }^{90} \mathrm{Sr}$ concentration from the lead clinoptilolite column effluent from the offsite laboratory was $1,180 \mathrm{pCi} / \mathrm{L}$, and the corresponding value from the $222-\mathrm{S}$ Laboratory was $1,120 \mathrm{pCi} / \mathrm{L}$. The ${ }^{137} \mathrm{Cs}$ value from the $222-\mathrm{S}$ Laboratory from the same location was below detection $(60.5 \mathrm{pCi} / \mathrm{L})$, and the value from the offsite laboratory was $-1.59 \mathrm{pCi} / \mathrm{L}$. The negative value represents a value that is less than the background found at the laboratory. The ${ }^{239 / 240} \mathrm{Pu}$ value from the $222-\mathrm{S}$ Laboratory was less than detection $(10.7 \mathrm{pCi} / \mathrm{L})$ and $0.742 \mathrm{pCi} / \mathrm{L}$ from the offsite laboratory. The lower detection limit of the offsite laboratory shows that the system was capable of treating to values less than the DWS of $1.2 \mathrm{pCi} / \mathrm{L}$ ${ }^{239240} \mathrm{Pu}$ and $120 \mathrm{pCi} / \mathrm{L}{ }^{137} \mathrm{Cs}$. No other offsite laboratory samples were taken for this test.

3.2.3.1.2 MCT-2 Results. This test was done to evaluate the effect of adding a 2-ppm spike of $\mathrm{SrCl}_{2}$ to each of the clinoptilolite columns for the removal of ${ }^{90} \mathrm{Sr}$ (BHI 1995e), and was designated as "MCT-2. Because of an error in making up the strontium solution (it was to be $80 \mathrm{ppm}$ $\mathrm{SrCl}_{2}$ as strontium) plus difficulties with the metering pump, the strontium concentrations were 0.6 to $0.8 \mathrm{ppm}$ instead of $2 \mathrm{ppm}$. After the total strontium was found to be low, the feed rate was adjusted, and at 2,600 BV the feed strontium was up to $1.4 \mathrm{ppm}$. At 3,500 BV it was at $2.12 \mathrm{ppm}$. Comparing the total strontium $(0.167 \mathrm{ppm})$ with the ${ }^{90} \mathrm{Sr}$ concentration $(4,205 \mathrm{pCi} / \mathrm{L}$, or $\left.2.982 \times 10^{-8} \mathrm{ppm}\right)$ in the feed groundwater shows that the ${ }^{90} \mathrm{Sr}$ concentration is an insignificant portion of the measured total strontium. Therefore, the ${ }^{90} \mathrm{Sr}$ removed by the clinoptilolite in the lead column does not affect the value of total strontium measured after the second $\mathrm{SrCl}_{2}$ addition.

The addition of approximately $1 \mathrm{ppm}$ total strontium in the feed streams to the clinoptilolite columns appeared to reduce the effectiveness of the clinoptilolite for ${ }^{90} \mathrm{Sr}$ removal. The MCT-2 lead clinoptilolite column effluent concentrations followed the same trends as that of MCT-1 but were consistently about 300 to $400 \mathrm{pCi} / \mathrm{L}$ higher (see Table C-16, Appendix C, and Figure 3-28). The removal efficiencies of the two tests were similar while the bone char was actively removing ${ }^{90} \mathrm{Sr}$ (to $500 \mathrm{BV}$ ), but the MCT-2 lead clinoptilolite column effluent concentrations increased and stayed consistently higher by approximately 300 to $400 \mathrm{pCi} / \mathrm{L}$. Both tests were otherwise run identically.

Figure 3-29 compares overall system removals of ${ }^{90} \mathrm{Sr}$ for the MCT-1 and MCT-2 tests. Although the second MCT-2 clinoptilolite column removal efficiency was nearly the same as that of MCT-1, the effluent concentration stayed consistently approximately $300 \mathrm{pCi} / \mathrm{L}$ higher than the effluent from MCT-1 because of the higher inlet concentration.

The addition of $\mathrm{SrCl}_{2}$ did not appear to affect the performance of the clinoptilolite for ${ }^{137} \mathrm{Cs}$ or ${ }^{239 / 240} \mathrm{Pu}$ removal. Effluent concentrations for both radionuclides were below the detection limit $(-60 \mathrm{pCi} / \mathrm{L}$ ${ }^{137} \mathrm{Cs}$ and $-10 \mathrm{pCi} / \mathrm{L}^{239 / 240} \mathrm{Pu}$ ) throughout the test.

Offsite laboratory results were consistent with the $222-\mathrm{S}$ Laboratory for feed ${ }^{239240} \mathrm{Pu}$. Offsite laboratory results for a sample and a duplicate for ${ }^{137} \mathrm{Cs}$ were 1.96 and $2.02 \mathrm{pCi} / \mathrm{L}$, respectively; the $222-\mathrm{S}$ Laboratory result was less than $58 \mathrm{pCi} / \mathrm{L}$. The offsite laboratory reported $0.524 \mathrm{pCi} / \mathrm{L}$ and $0.491 \mathrm{pCi} / \mathrm{L}$ for a ${ }^{239240} \mathrm{Pu}$ sample and duplicate. The $222-\mathrm{S}$ Laboratory reported less than $5.24 \mathrm{pCi} / \mathrm{L}$. These results again indicate that the system is capable of treating to less than the target MCLs for ${ }^{137} \mathrm{Cs}$ and ${ }^{239240} \mathrm{Pu}$.

3.2.3.2 216-B-5 Reverse Well Test Group II. After evaluation of the data obtained from mini-column tests MCT-1 and MCT-2, and because of the poor performance of the clinoptilolite for ${ }^{90} \mathrm{Sr}$ removal, it was decided to perform another group of mini-column tests. MCT-1 was to be 
continued to look for saturation of ${ }^{90} \mathrm{Sr}$ or breakthrough of ${ }^{137} \mathrm{Cs}$. The second test, $2 \mathrm{MCT}-2$, was to be a kinetic evaluation of clinoptilolite to see if a longer $(12 \mathrm{~min})$ contact time would improve ${ }^{90} \mathrm{Sr}$ removal. This is equivalent to running the pilot-scale system at $38 \mathrm{~L} / \mathrm{min}(10 \mathrm{gal} / \mathrm{min})$ as compared to the normal processing rate of 95 to $114 \mathrm{~L} / \mathrm{min}$ (25 to $30 \mathrm{gal} / \mathrm{min}$ ). In the third test, another adsorbent, UOP A-51, was selected from the batch equilibrium tests for evaluation in a mini-column test (designated 2MCT-3). These tests were performed simultaneously.

The equipment used for MCT-2 was cleaned and reused for the 2MCT-2 test. However, residual algae from the feed tank or other source apparently entered the 2MCT-2 equipment because it became infested with algae during this test. Test $2 \mathrm{MCT}-3$ consisted of all new equipment and materials. Test 2MCT-2 showed no biological growth until near the end of the test. The growth, appearing on the top of the UOP A-51 bed, did not appear to be algae, but possibly a bacterial growth that was white and slimy in appearance. This contrasted with the definite green color of the algae. There was no discernible difference in the results of either test; therefore, it appears that the growths had no significant impact.

3.2.3.2.1 2MCT-2 Results. 2MCT-2 was run in the same configuration as MCT-1 (bone char, clinoptilolite, clinoptilolite), but at a 12-minute contact time per column. The test was run $24 \mathrm{~h} /$ day for 6 weeks, processing a total of approximately $2,900 \mathrm{BV}$. The test was operated $24 \mathrm{~h} /$ day to process the maximum amount of groundwater possible in the 6 weeks of available testing time.

The lead clinoptilolite column ${ }^{90} \mathrm{Sr}$ effluent concentration followed the same "stair-step" path with an overall downward trend (see Table C-17, Appendix C, and Figure 3-30) as was noted in the pilot-scale system (discussed in Sections 3.1.1.1 and 3.2.4.1.1). The data again indicate the same kinetic dependence as noted in Test MCT-1. The high effluent concentrations occurred at the end of the week (i.e., either a Thursday or Friday) and the low effluent concentrations occurred at the beginning of the week, after recovering over the weekend.

For the first $200 \mathrm{BV}$, the bone char acted as a roughing column for ${ }^{90} \mathrm{Sr}$. After $630 \mathrm{BV}$, the bone char effluent was not monitored for ${ }^{90} \mathrm{Sr}$ because the bone char column was assumed to have reached saturation. At approximately 1,500 BV, the bone char removed approximately $46 \%$ of the ${ }^{90} \mathrm{Sr}$. However, at $1,900 \mathrm{BV}$ it appeared to be releasing some of the ${ }^{90} \mathrm{Sr}$. It appears that after the bone char becomes saturated, some cation is being preferentially loaded, thereby pushing off the ${ }^{90} \mathrm{Sr}$.

The second clinoptilolite column demonstrated a ${ }^{90} \mathrm{Sr}$ removal efficiency greater than $90 \%$ to $1,000 \mathrm{BV}$. Beyond 1,250 BV, it demonstrated an average removal efficiency of $90 \%$. At the 1,250 BV sampling event for both 2MCT-2 and 2MCT-3, the samples were mislabeled when turned in to the laboratory. The laboratory corrected the error; however, these data are suspect and appear anomalous (see Figure 3-31). The overall system achieved a ${ }^{90} \mathrm{Sr}$ removal efficiency that ranged from approximately $99.9 \%$ through $1,000 \mathrm{BV}$ to $96.8 \%$ at $2,900 \mathrm{BV}$. For the first $1,000 \mathrm{BV}$, the effluent concentration was less than the target $\mathrm{MCL}$ of $8 \mathrm{pCi} / \mathrm{L}{ }^{90} \mathrm{Sr}$. It appears that longer contact time improved ${ }^{90} \mathrm{Sr}$ removals.

3.2.3.2.2 2MCT-3 Results. 2MCT-3 was set up similarly to 2MCT-2, except that a UOP A-51 column was added at the end instead of clinoptilolite and consisted of bone char, clinoptilolite, and UOP A-51 (a synthetic zeolite/molecular sieve) columns. 2MCT-3 was run $24 \mathrm{~h} /$ day for 6 weeks. A total of $2,900 \mathrm{BV}$ were processed at a contact time of 12 minutes per column. 
The bone char again removed a significant percentage of the ${ }^{90} \mathrm{Sr}$ to $200 \mathrm{BV}$ and then became saturated. The sample data at $1,250 \mathrm{BV}$ indicate a $99 \%{ }^{90} \mathrm{Sr}$ removal by bone char (see Table C-18, Appendix C, and Figure 3-32). As in the 2MCT-2 results, however, there were some mislabeled samples at this data collection $(1,250 \mathrm{BV})$ that may be considered anomalous.

For the first $200 \mathrm{BV}$, while the bone char bed was actively removing ${ }^{90} \mathrm{Sr}$, the lead clinoptilolite bed was removing $>99 \%$ of its influent (the bone char effluent). Once the bone char became saturated, the lead clinoptilolite bed's efficiency dropped to approximately $90 \%$ until $1,250 \mathrm{BV}$, and then averaged $80 \%$ through the end of the test.

The removal efficiency of the lead column followed the same downward-trending "stair-step" pattern as 2MCT-2 (see Figure 3-30), but was not as pronounced. The removal efficiency curve (dashed line) again indicates low and high removals corresponding with the ends and beginnings of the week, respectively. At 2,500 BV (Monday) the removal efficiency did not recover as in previous weeks. The mini-column tests were restarted on Sunday morning after being shut down Friday afternoon, which allowed only one day to sit idle. This may have contributed to the lower recovery observed on. Monday. The removal efficiency did not increase throughout this week (through 2,900 BV) as in previous weeks. A leak in the line at the feed pump was found Friday morning $(2,900 \mathrm{BV})$ and repaired before sampling. The amount of water lost (all of which was held within the containment structure) indicated that 2MCT-3 had been without a feed stream for 1 to $2 \mathrm{~h}$. Sampling of 2MCT-3 occurred approximately $1.5 \mathrm{~h}$ after the feed stream was reestablished. The pause in operations, which allowed a lengthy contact time within the columns, may have contributed to maintaining the level of removal efficiency.

The UOP A-51 maintained a removal efficiency greater than $90 \%$ to the end of test. A downward trend in the removal efficiency curve after $1,250 \mathrm{BV}$ is illustrated in Figure 3-33. The last data point indicated a removal efficiency of $89.9 \%$.

The system removal efficiency with the UOP A-51 adsorbent was greater than $95 \%$ for the duration of the test. The overall system effluent concentration was less than the target $\mathrm{MCL}$ of $8 \mathrm{pCi} / \mathrm{L}$ for ${ }^{90} \mathrm{Sr}$ for the first $1,000 \mathrm{BV}$, although it was sporadic because of the detection limits.

3.2.3.3 216-BY Cribs Mini-Column Tests. Based on previous batch equilibrium studies by Barney (WHC 1994) and the successful removal of technetium in mini-column and pilot-scale treatment tests at 200-UP-1 Operable Unit, Dowex $21 \mathrm{~K}$, a strong base anion gel-type resin, was selected for testing in the BY-Cribs pilot-scale treatability test. Because it did not appear that sufficient loading data would be provided from the pilot-scale treatment system, mini-column tests were conducted at the $\mathrm{BY}$-Cribs site to provide more data. These used Dowex $21 \mathrm{~K}$ at a contact time simulating the pilot-scale system. The $200-\mathrm{UP}-1$ results for ${ }^{99} \mathrm{Tc}$ indicated that Dowex $21 \mathrm{~K}$ became saturated at approximately $2,600 \mathrm{BV}$ in the presence of uranium. However, because there was little or no uranium in the BY-Cribs groundwater, it was expected that ${ }^{99} \mathrm{Tc}$ would be able to process approximately 4,000 to $5,000 \mathrm{BV}$ before saturation. Additionally, because the geology of the BY-Cribs site was different from that at the 200-UP-1 site, other anions or cations may preferentially load on the Dowex $21 \mathrm{~K}$, thereby reducing or interfering with ${ }^{99} \mathrm{Tc}$ loading.

The two mini-column tests conducted at the BY-Cribs site processed approximately 5,900 BV each (bed volume $=460 \mathrm{~mL}$ ). The results are shown in Tables C-19 and C-20 (Appendix C).

Figures 3-34 through 3-37 are plots of the ${ }^{99} \mathrm{Tc}$ data. Figures 3-34 and 3-36 show the ${ }^{99} \mathrm{Tc}$ results for the lead columns of both tests. Both curves are the typical sharp breakthrough curves normally 
experienced by a resin that performs well. The curves indicate that ${ }^{99} \mathrm{Tc}$ saturation occurred at between 4,500 to $5,000 \mathrm{BV}$. A $30 \%$ breakthrough occurred at between 3,300 to $3,500 \mathrm{BV}$, and $50 \%$ breakthrough occurred at $3,800 \mathrm{BV}$. The average ${ }^{99} \mathrm{Tc}$ removal for both lead columns was $90 \%$ to $30 \%$ breakthrough and $82 \%$ to $84 \%$ to $50 \%$ breakthrough.

Figures 3-38 and 3-39 are plots of the ${ }^{60} \mathrm{Co}$ data for the lead columns of Tests 1 and 2.

Unfortunately, the 222-S Laboratory's detection limit for ${ }^{60} \mathrm{Co}$ averaged approximately $38 \mathrm{pCi} / \mathrm{L}$, but when used for an effluent value, the lead column demonstrated a removal efficiency of greater than $75 \%$. Because the ${ }^{60} \mathrm{Co}$ effluent from the lead column was below the detection limit, the polish column feed and effluent results were expected to be, and were, the same. Thus, these results were not plotted.

The offsite detection limits for both ${ }^{60} \mathrm{Co}$ and ${ }^{99} \mathrm{Tc}$ are 10.5 and $2.5 \mathrm{pCi} / \mathrm{L}$, respectively (with $95 \%$ upper confidence limit [UCL]). Comparing one offsite ${ }^{60} \mathrm{Co}$ sample result with a similar sample result (taken at same time and point) from the 222-S Laboratory shows a detection limit of $10.5 \mathrm{pCi} / \mathrm{L}$ compared to $42.7 \mathrm{pCi} / \mathrm{L}$ at the $222-\mathrm{S}$ Laboratory. It should be noted that the offsite laboratory result was actually $2.93 \mathrm{pCi} / \mathrm{L}$, but this was at a lower confidence level than the minimum detectable activity/amount (which is the $95 \%$ UCL detection limit). In any case, with a feed concentration of $168 \mathrm{pCi} / \mathrm{L}$ and a $10.5 \mathrm{pCi} / \mathrm{L}$ effluent, the resulting removal efficiency would be $93.8 \%$. If the 2.93 value were used, it would be $98.3 \%$ removal:

\subsubsection{Strontium-85 Data for 100-N Area}

An unpublished report by PNNL documents data developed for the 100-N Area ion-exchange pump-and-treat system. Four mini-column, single-bed, flow-through adsorption tests were run using AmReC clinoptilolite. Three tests were run at residence times of $13.4 \mathrm{~min} /$ column with about $30 \mathrm{mg} / \mathrm{L}$ of calcium added to the influent to approximate groundwater quality conditions. Test conditions and breakthrough of ${ }^{85} \mathrm{Sr}$, used as a replacement for ${ }^{90} \mathrm{Sr}$, are given in Table 3-5. The other test was run with the same calcium content and had an even longer residence time. A fifth test was done with 27-minute empty-bed residence time, but with about six times more calcium added. Breakthrough occurred almost immediately. PNNL concluded that clinoptilolite-exchange columns could effectively adsorb ${ }^{90} \mathrm{Sr}$ from groundwater if the groundwater had the lower ionic strengths resulting from the observed calcium content. 
DOE/RL-95-59

Rev. 0 
DOE/RL-95-59

Rev. 0

Figure 3-1. Pilot-Scale System Lead Column Strontium-90 Effluent Versus Bed Volumes Treated, Run 1.

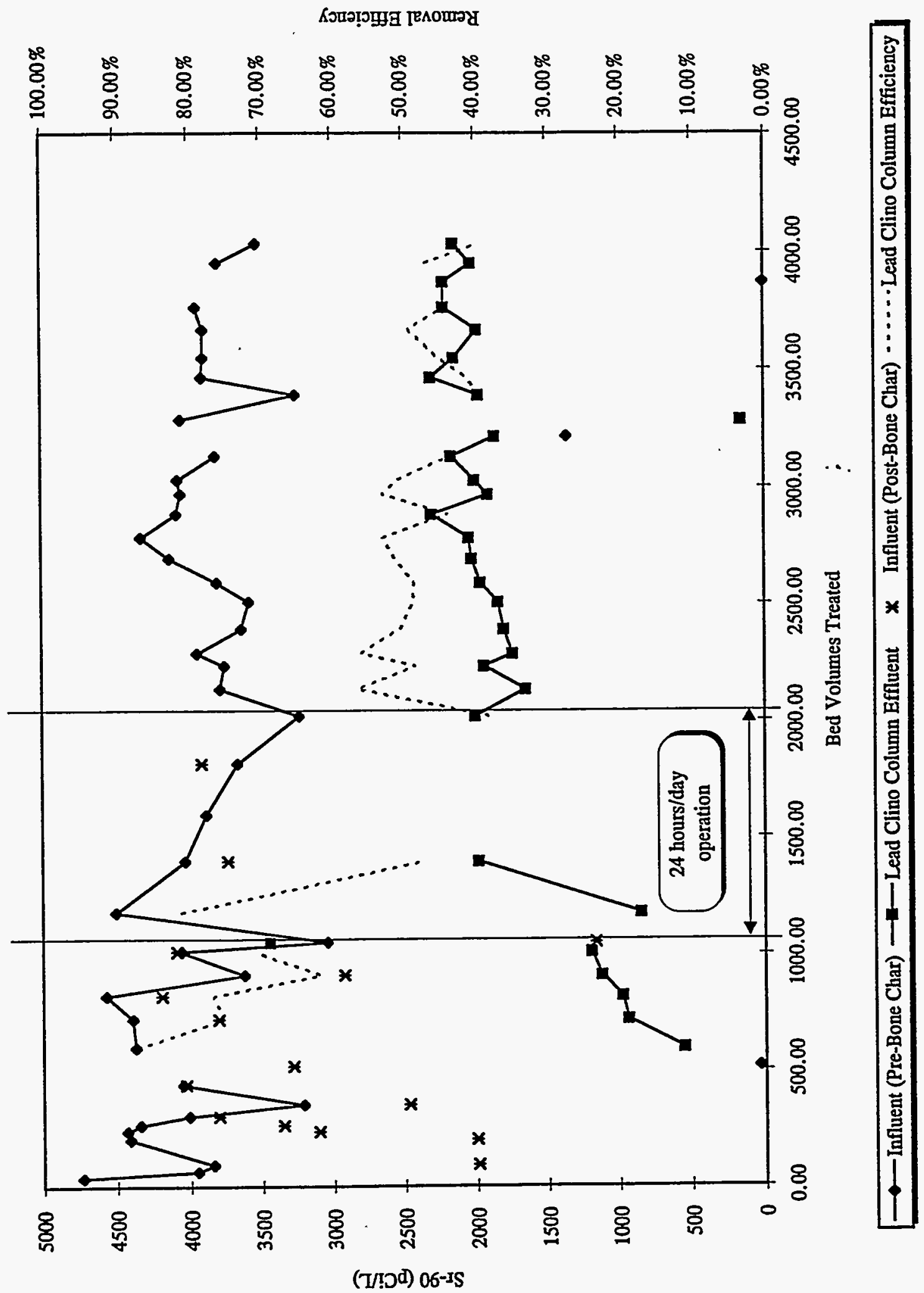


DOE/RL-95- $\overline{59}$

Rev. 0

Figure 3-2. Pilot-Scale System Overall Strontium-90 Effluent Versus Bed Volumes Treated, Run 1.

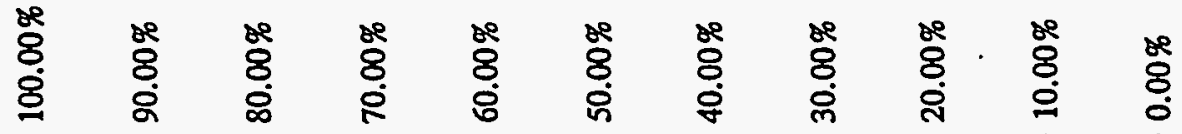

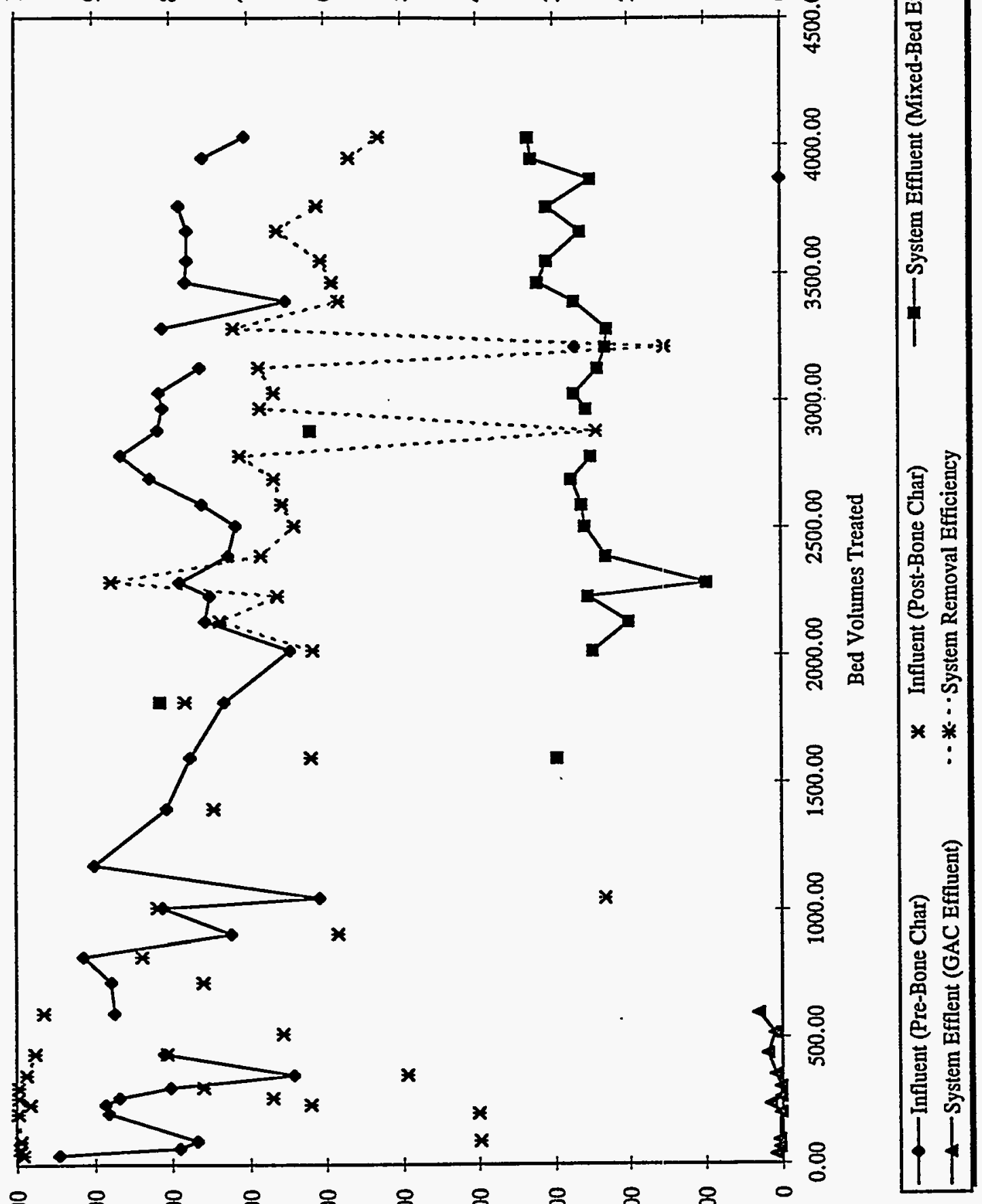

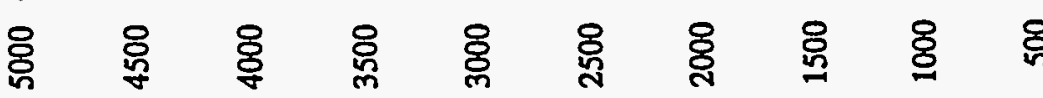

(T/गd) 06-1S 
DOE/RL-95-59

Rev. 0

Figure 3-3. Pilot-Scale System Lead Column Cesium-137 Effluent Versus Bed Volumes Treated, Run 1.

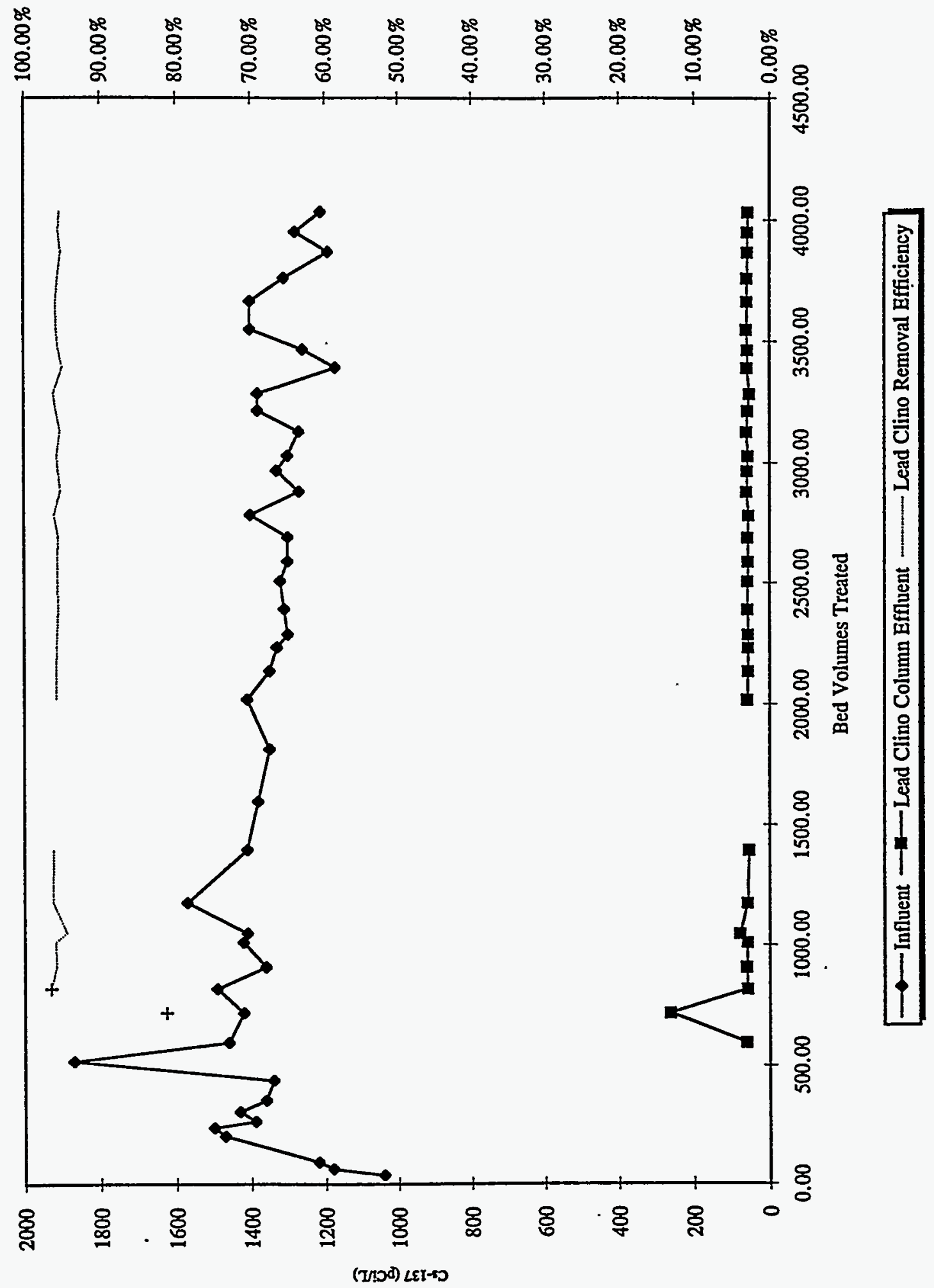


DOE/RL-95-59

Rev. 0

Figure 3-4. Pilot-Scale System Plutonium-239/240 Effluent Versus Bed Volumes Treated, Run 1.

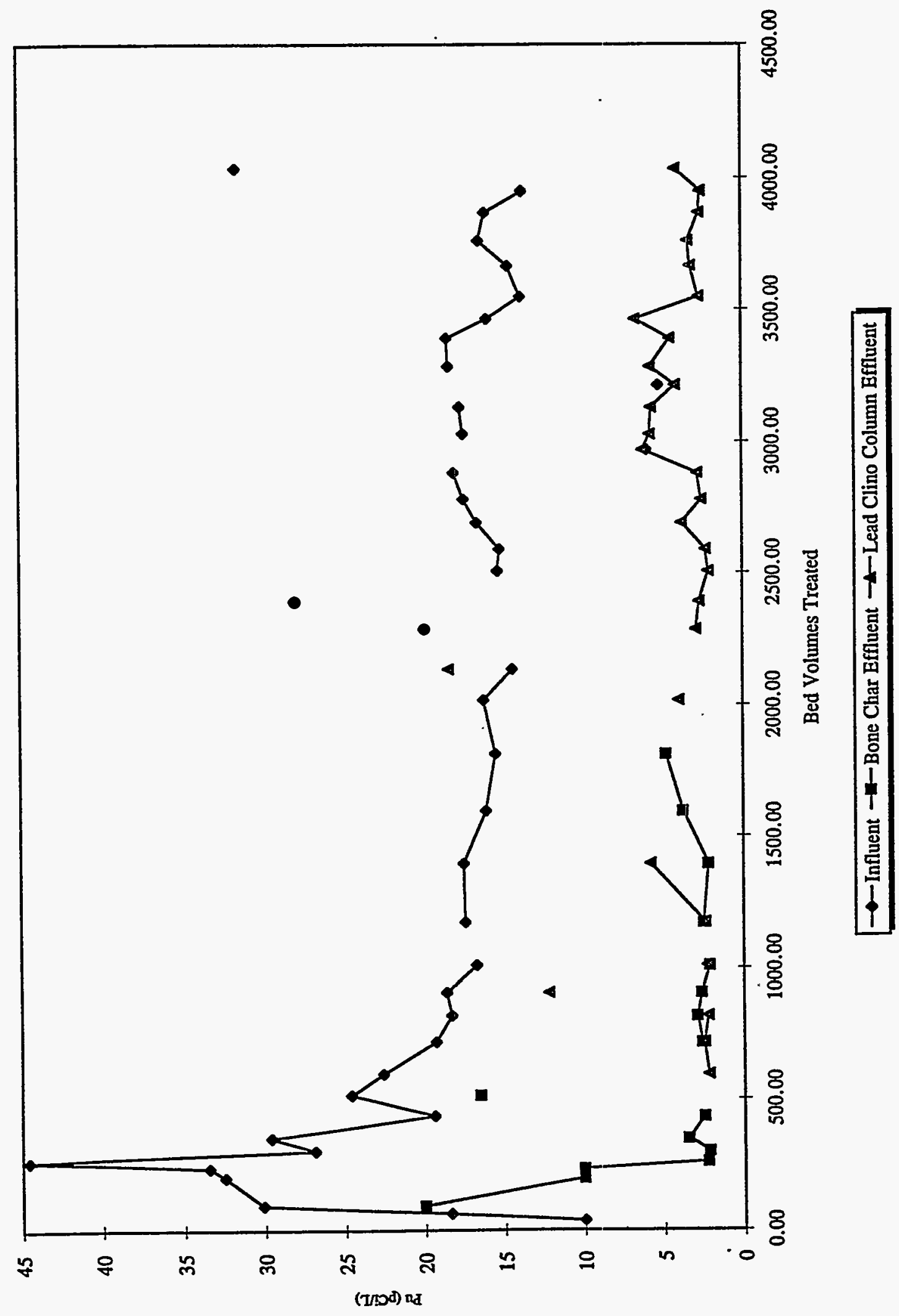


DOE/RL-95-59

Rev. 0

Figure 3-5. Pilot-Scale System Lead Column Strontium-90 Effluent Versus Bed Volumes Treated, Run 2.

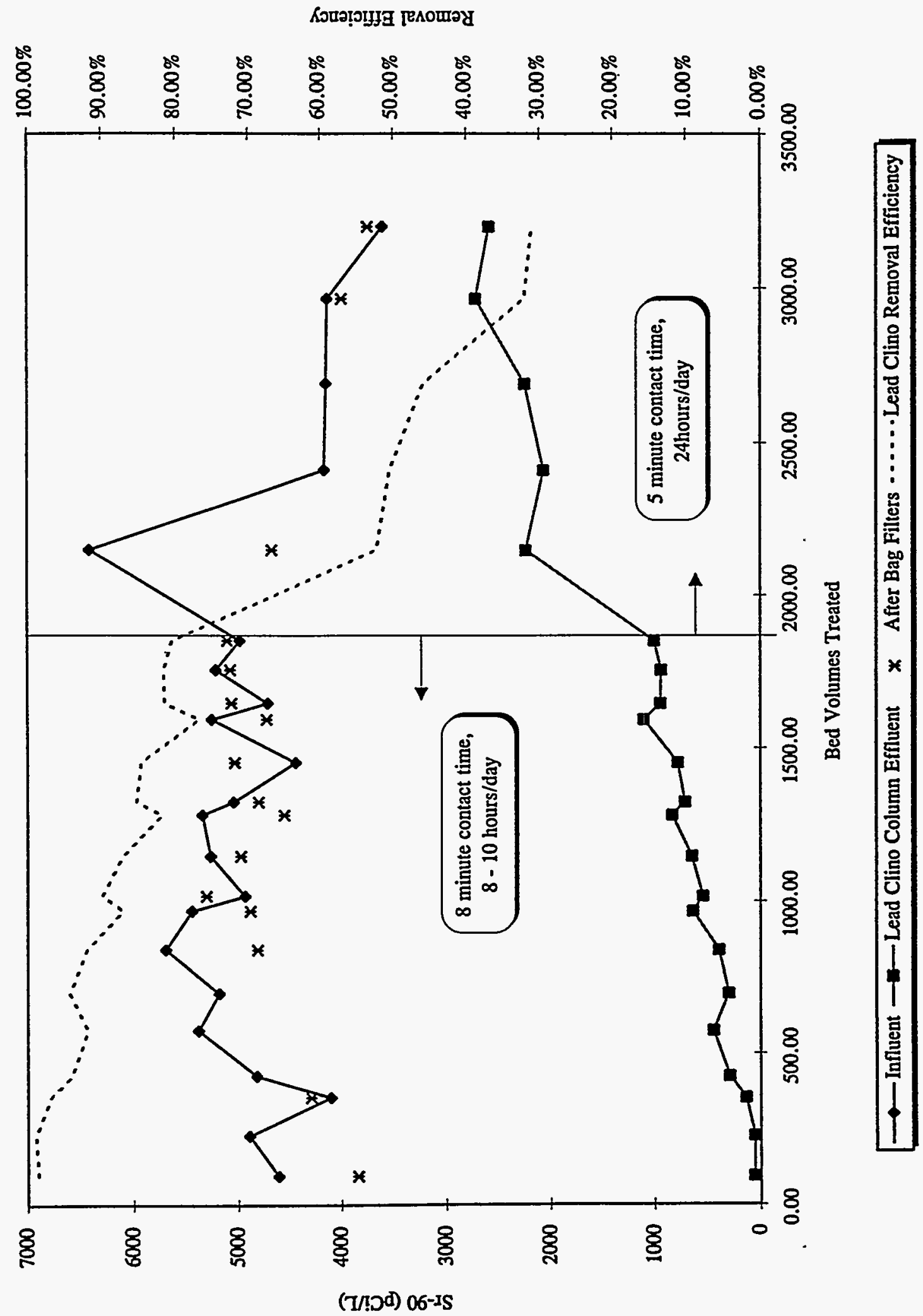




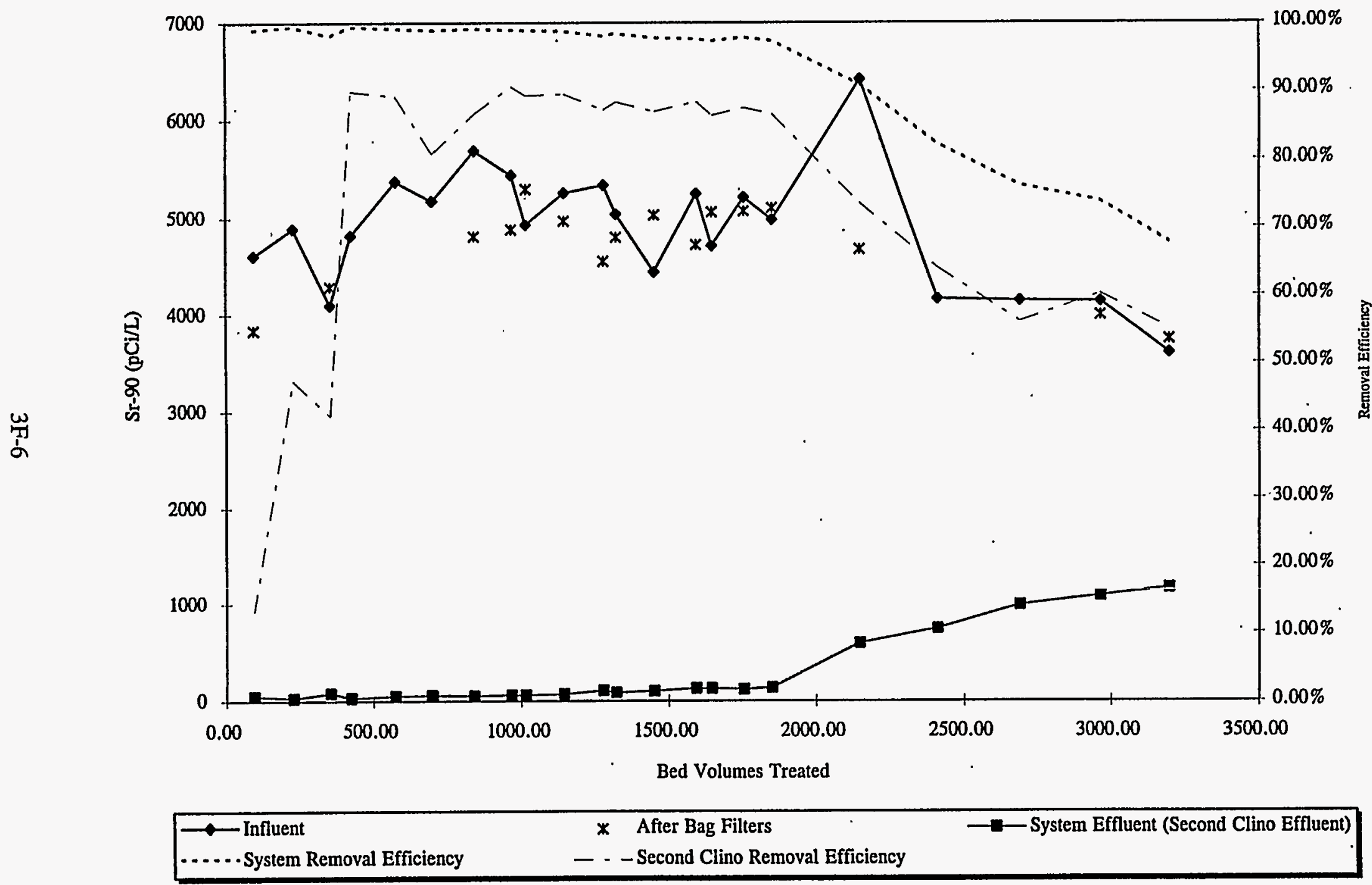


DOE/RL-95-59

Rev. 0

Figure 3-7. Pilot-Scale System Lead Column Technetium-99 Effluent Versus Bed Volumes Treated.

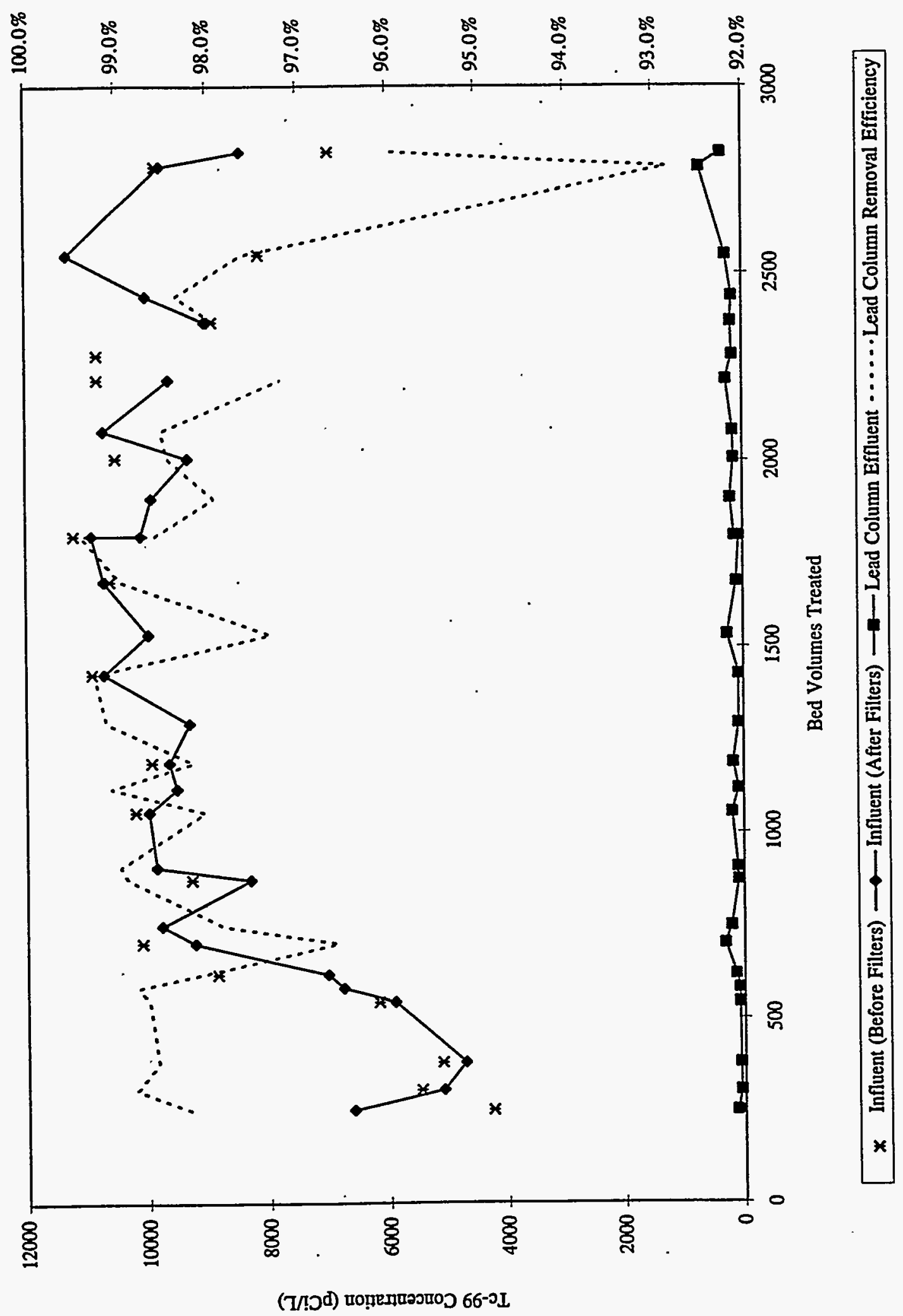


DOE/RL95-59

Rev. 0

Figure 3-8. Pilot-Scale System Lead Column Cobalt-60 Effluent Versus Bed Volumes Treated.

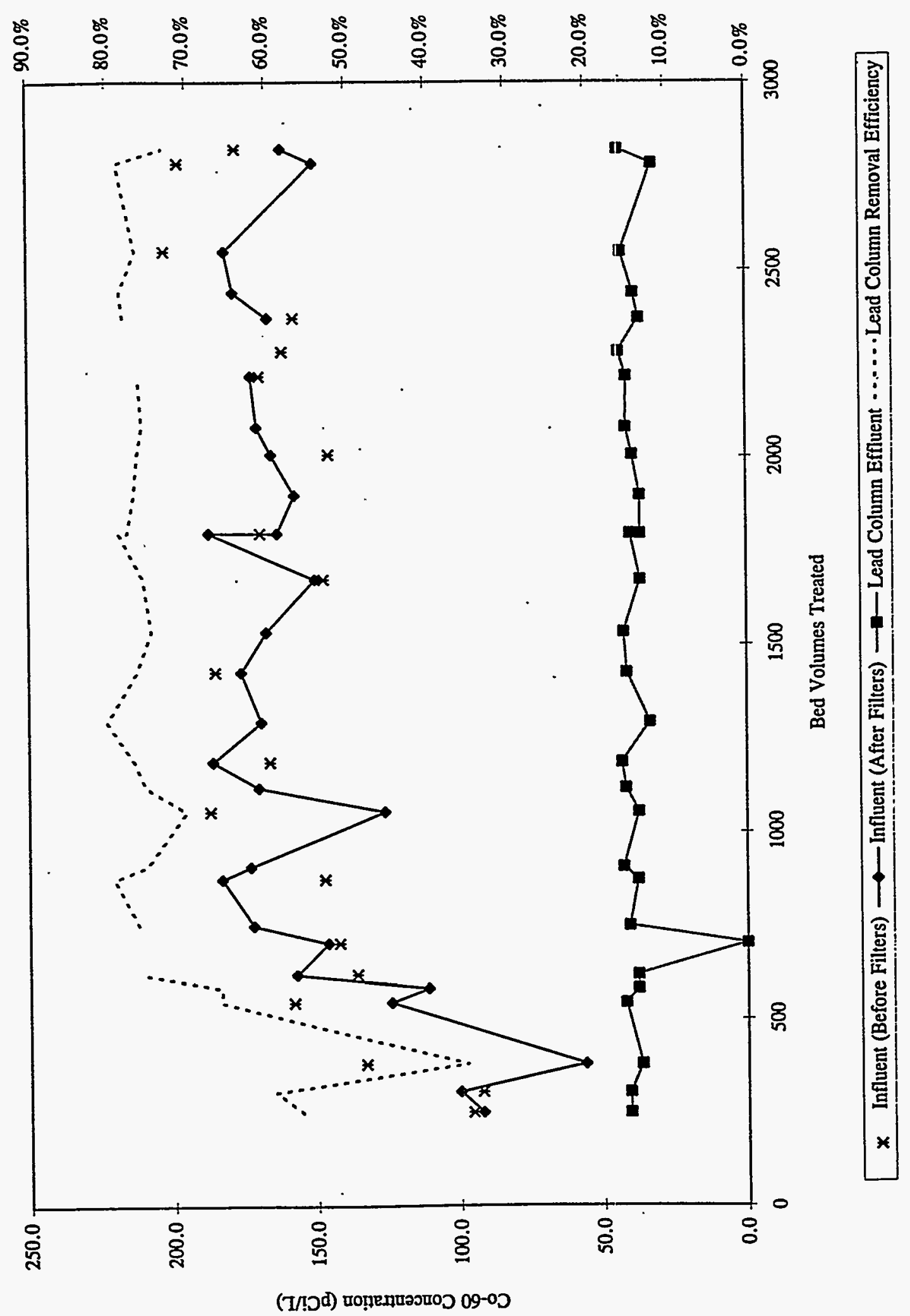


DOE/RL-95-59

Rev. 0 .

Figure 3-9. IRC-718 Isotherm for Strontium-90.

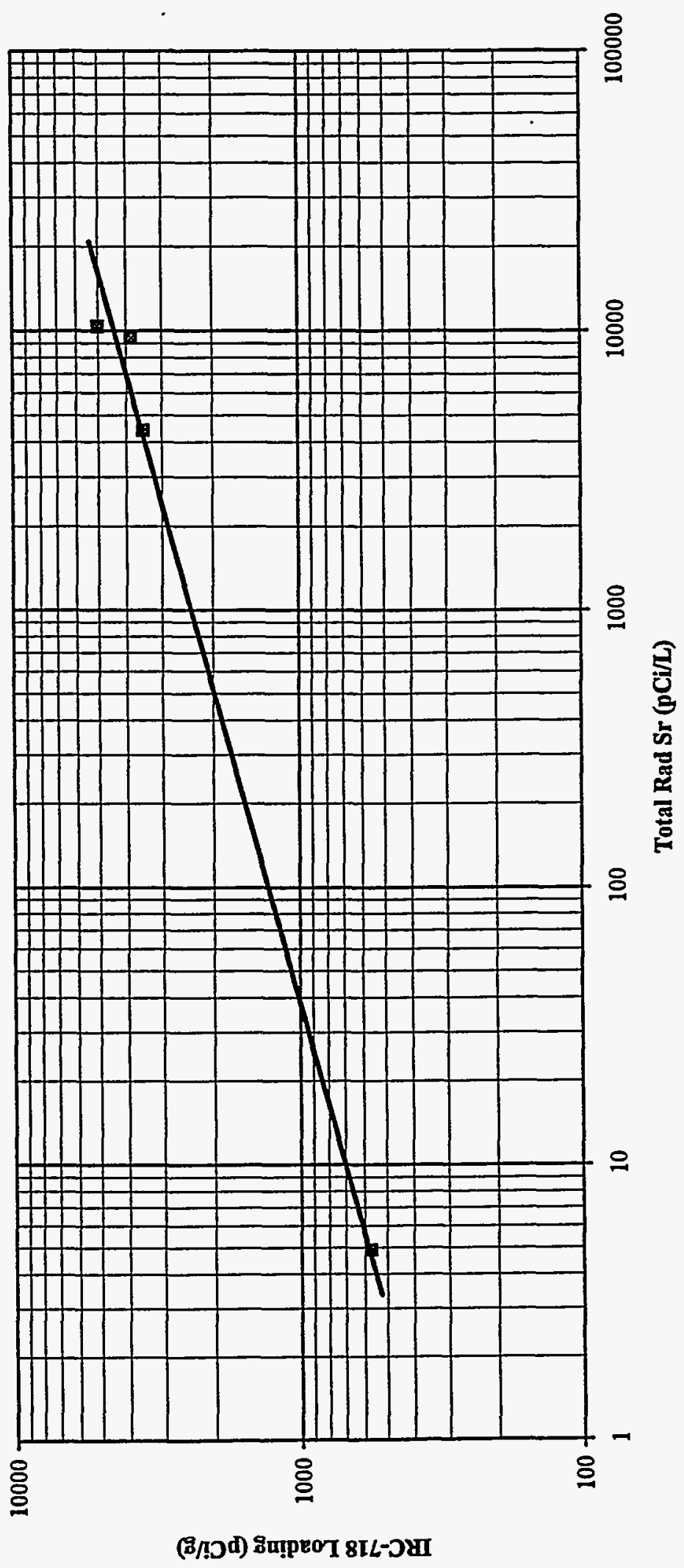


DOE/RL- $9 \overline{5}-\overline{5} 9$

Rev. 0

Figure 3-10. Hanford Bone Char Isotherm for Plutonium.

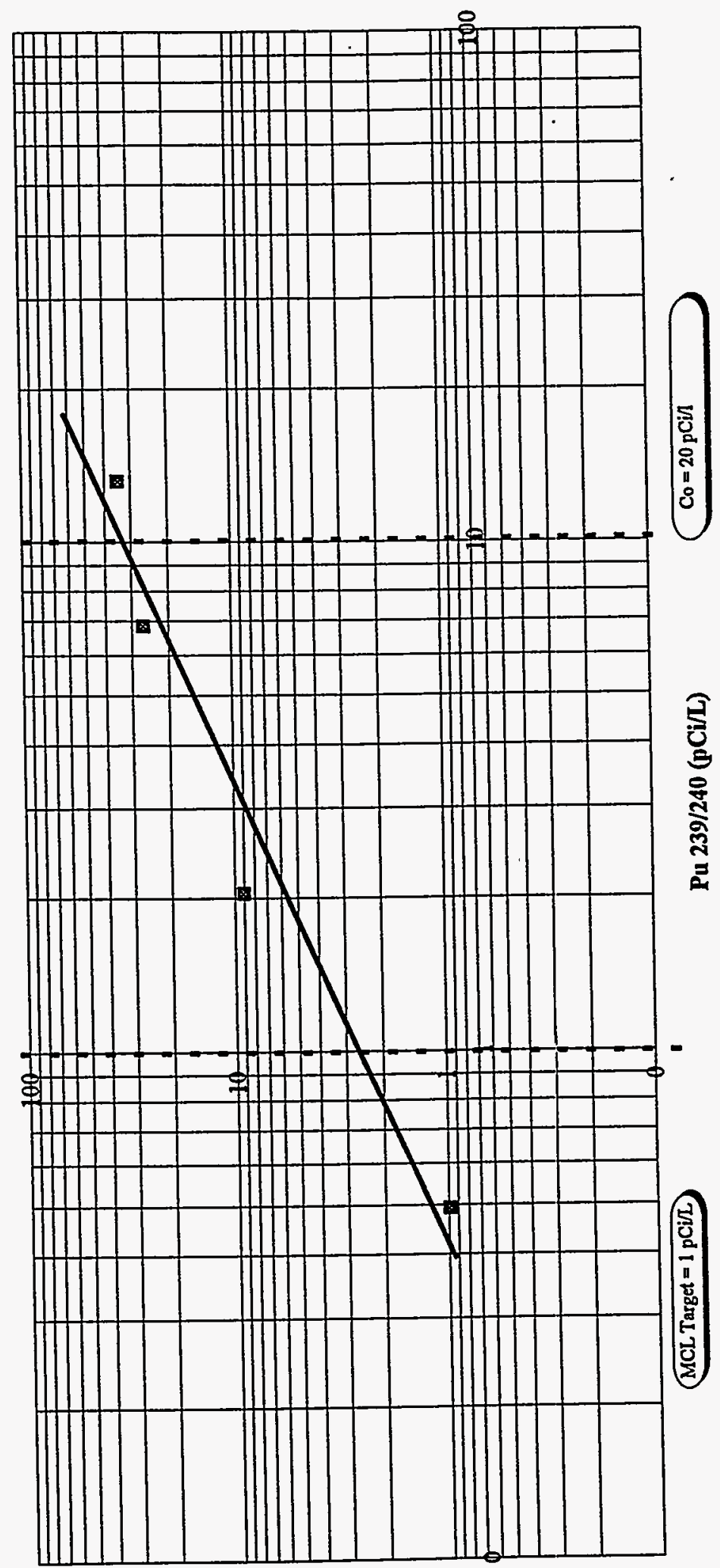

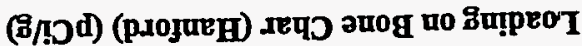


DOE/RL-95-59

Rev. 0

Figure 3-11. Resintech Bone Char Isotherm for Plutonium.

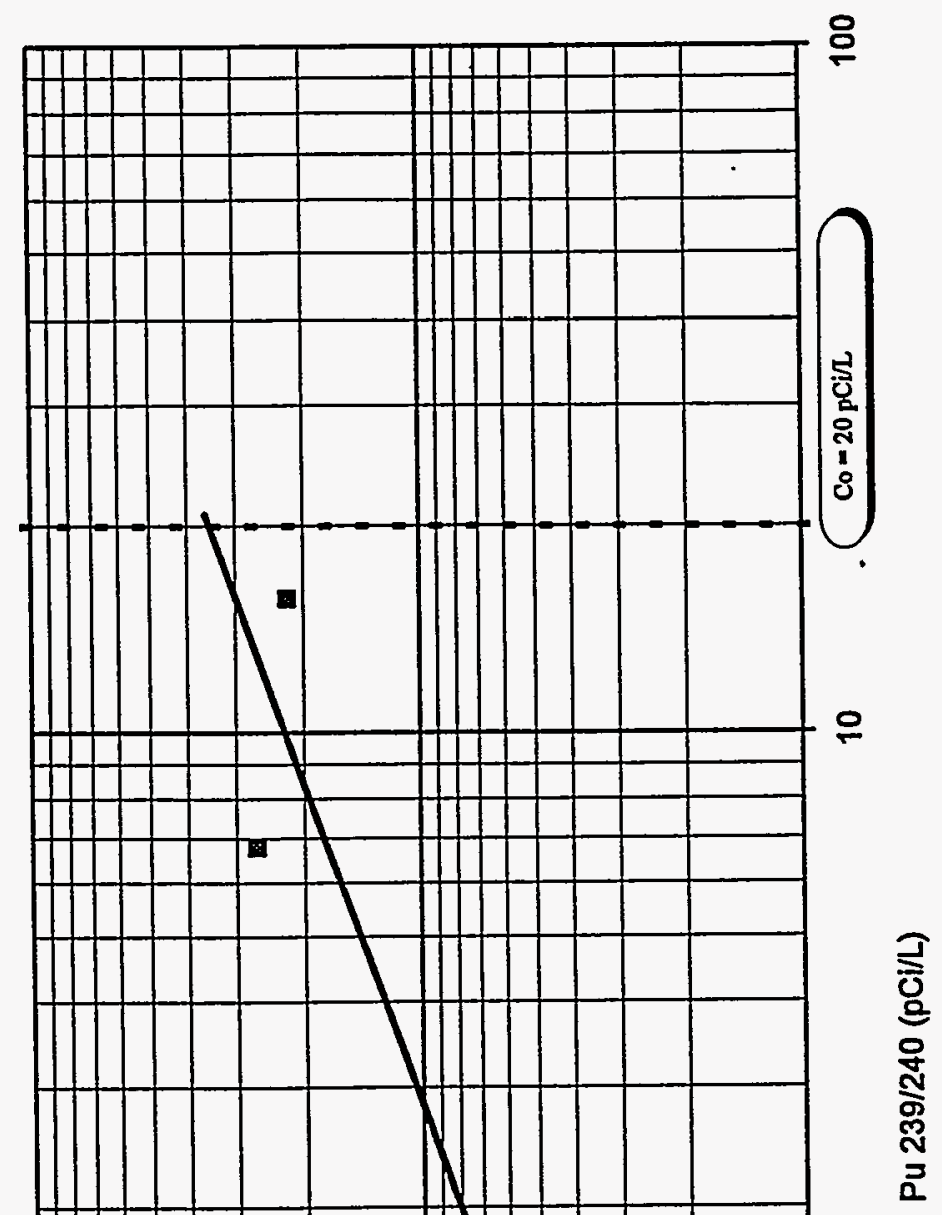


DOE/RL-95-59

Rev. 0

Figure 3-12. Resintech Bone Char Isotherm for Strontium-90.

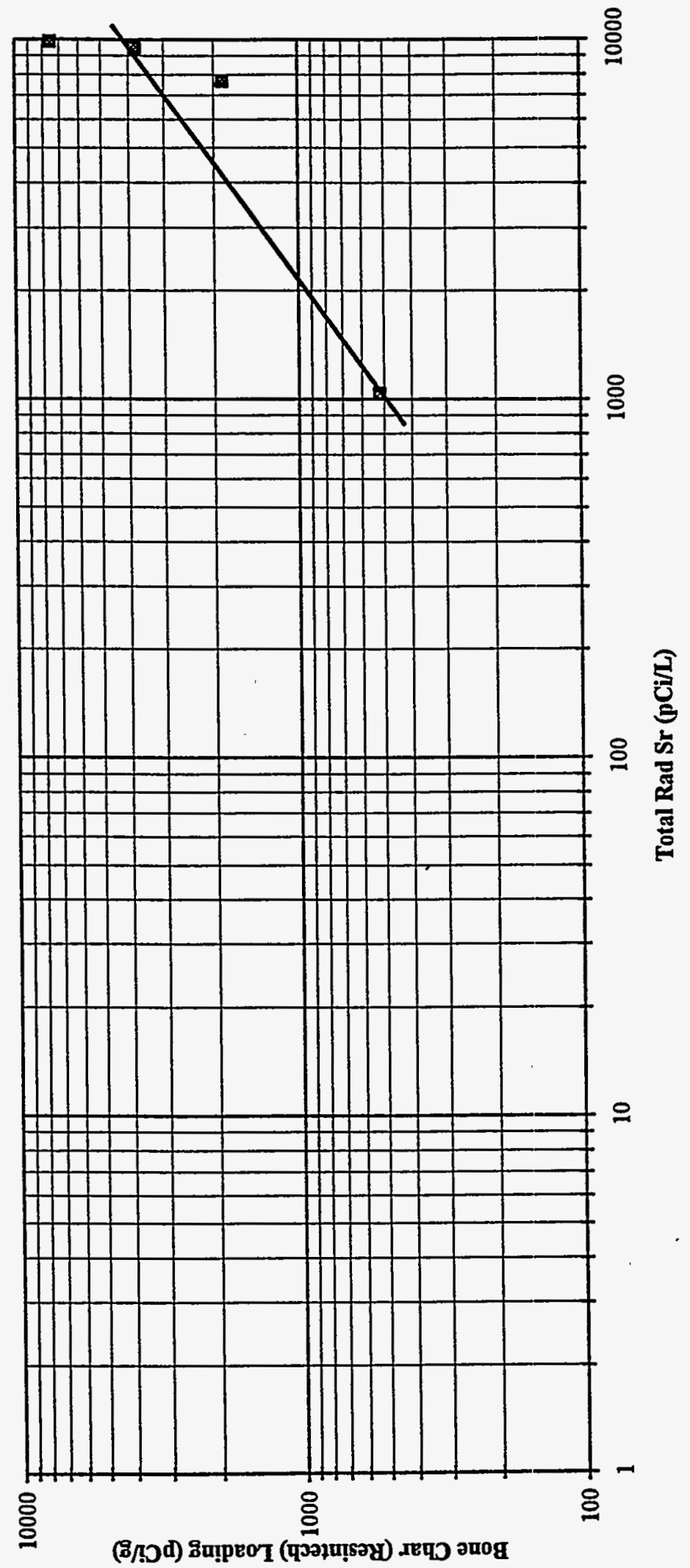


DOE/RL-95-59

Rev. 0

Figure 3-13. Resintech Clinoptilolite Isotherm for Strontium-90.

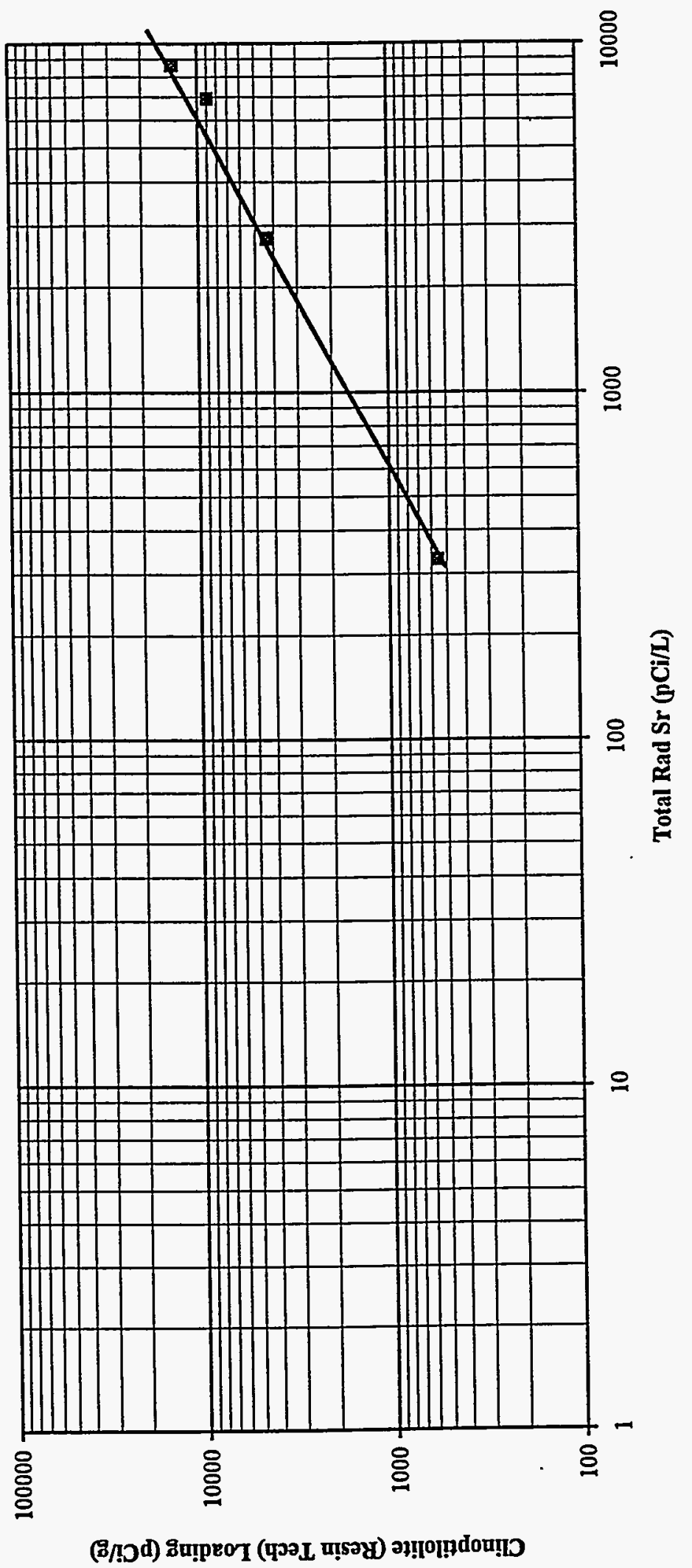


DOE/RL-95-59

Rev. 0

Figure 3-14. Resintech Clinoptilolite Isotherm for Cesium-137.

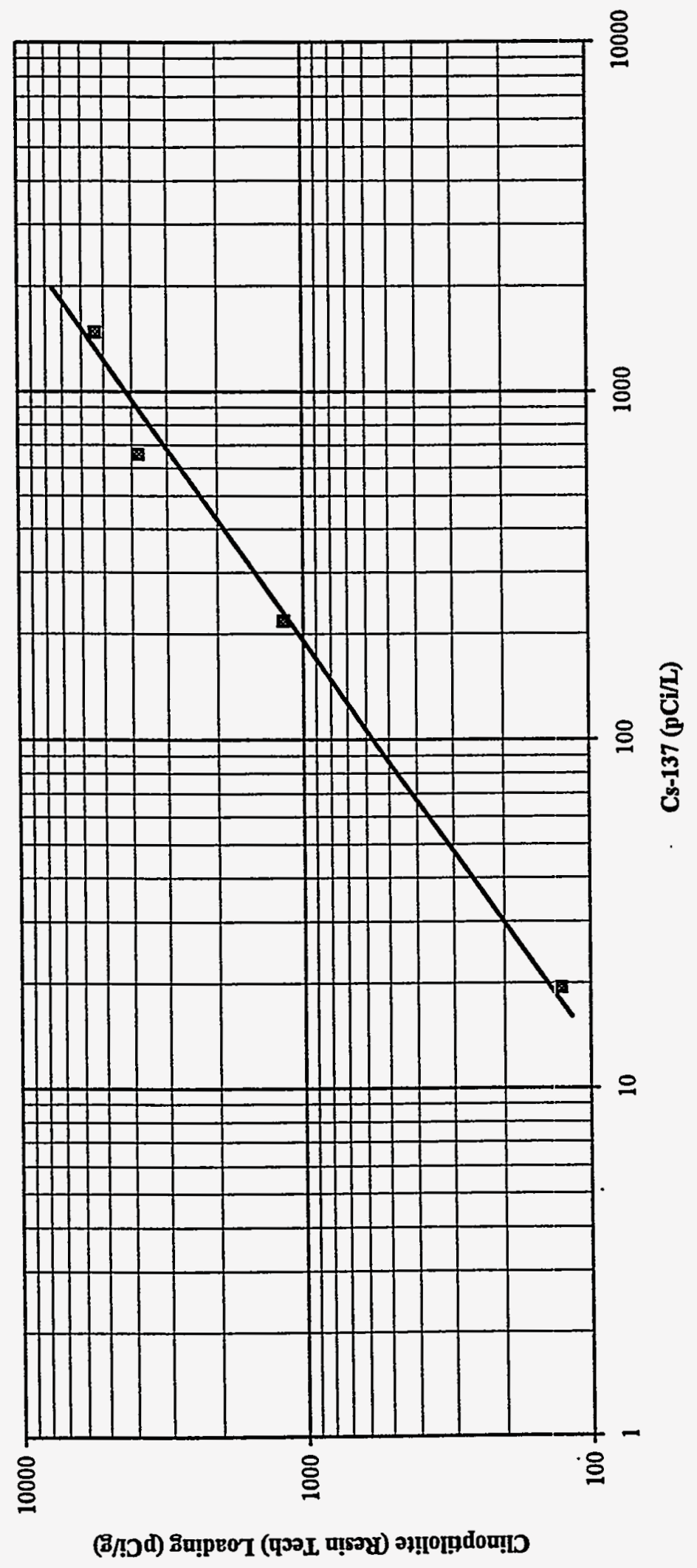


DOE/RL-95-59

Rev. 0

Figure 3-15. American Resources Corporation Clinoptilolite Isotherm for Strontium-90.

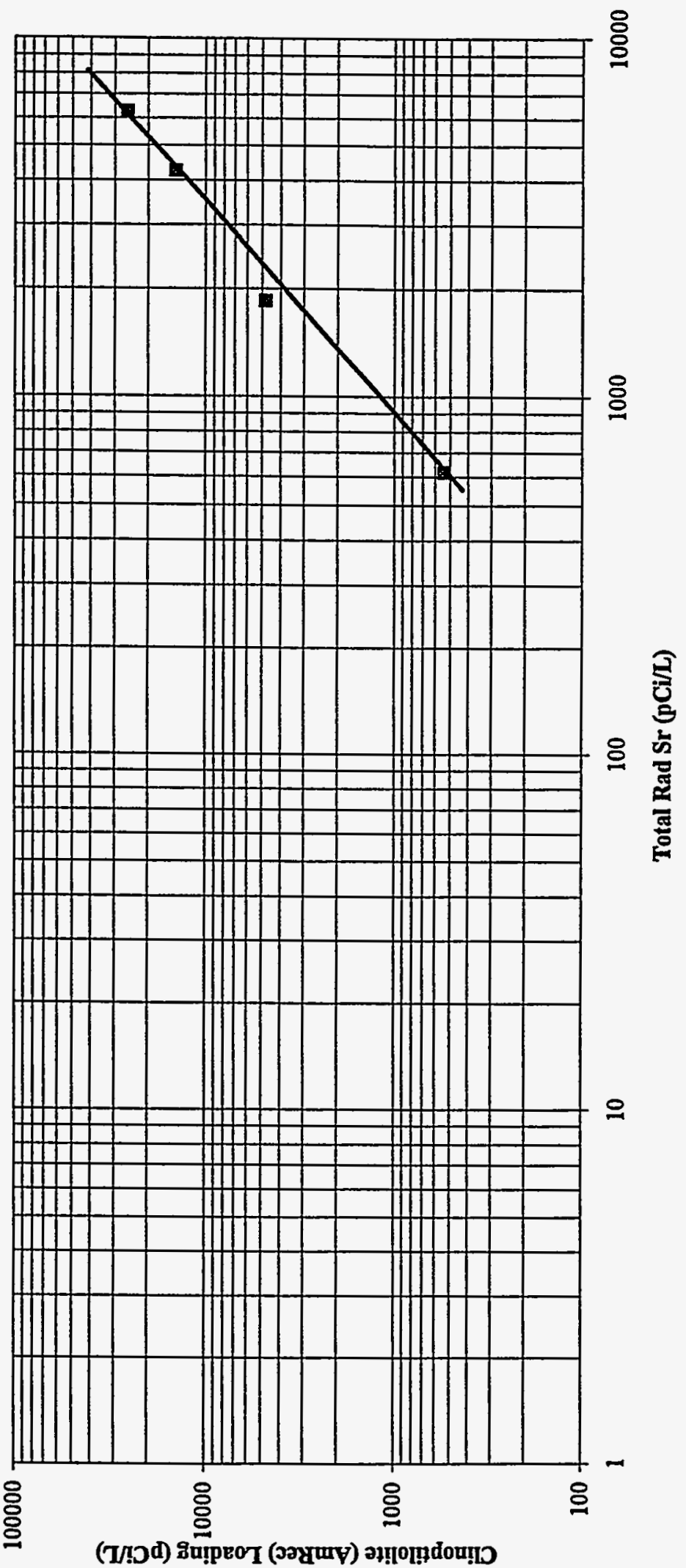


DOE/RL-95-59

Rev. 0

Figure 3-16. American Resources Corporation Clinoptilolite Isotherm for Cesium-137.

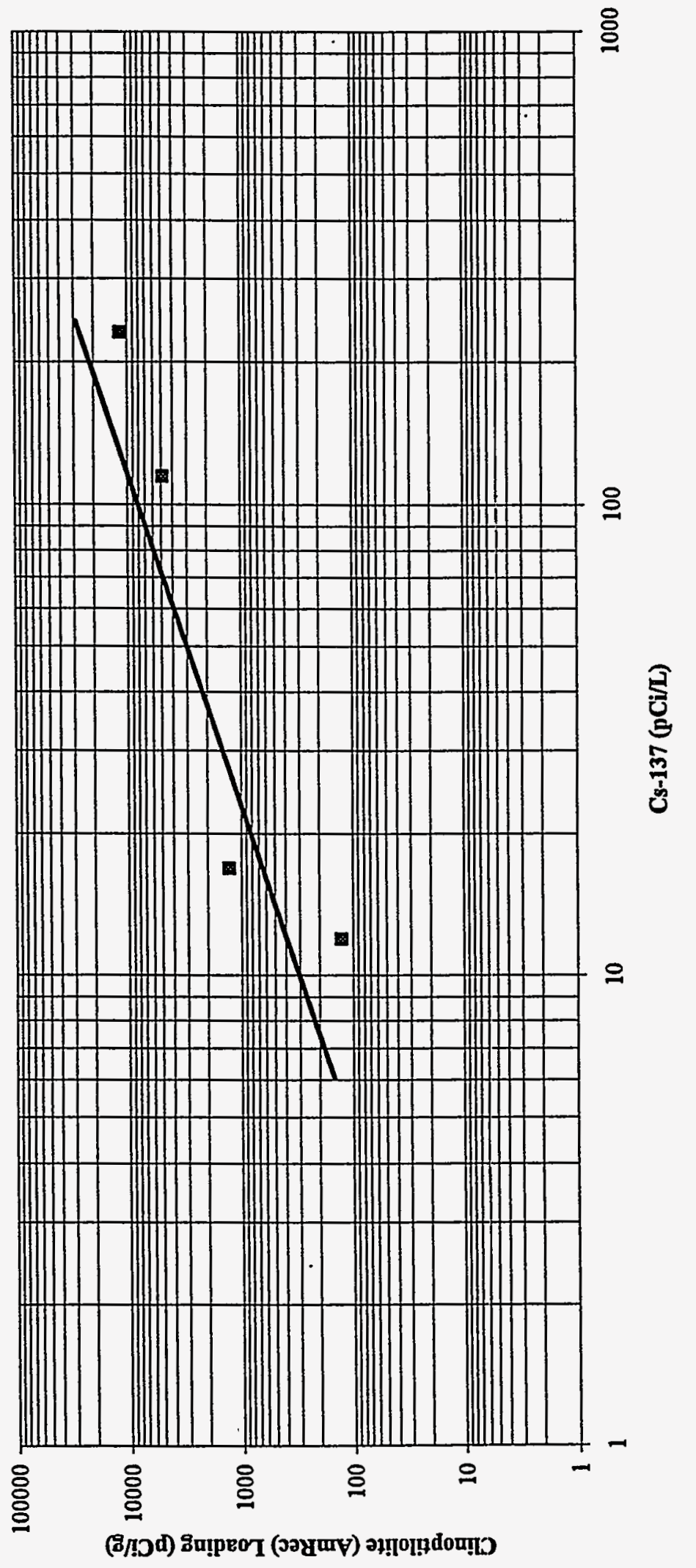


DOE/RL-95-59

Rev. 0

Figure 3-17. Dowex 21K Isotherm for Technetium-99.

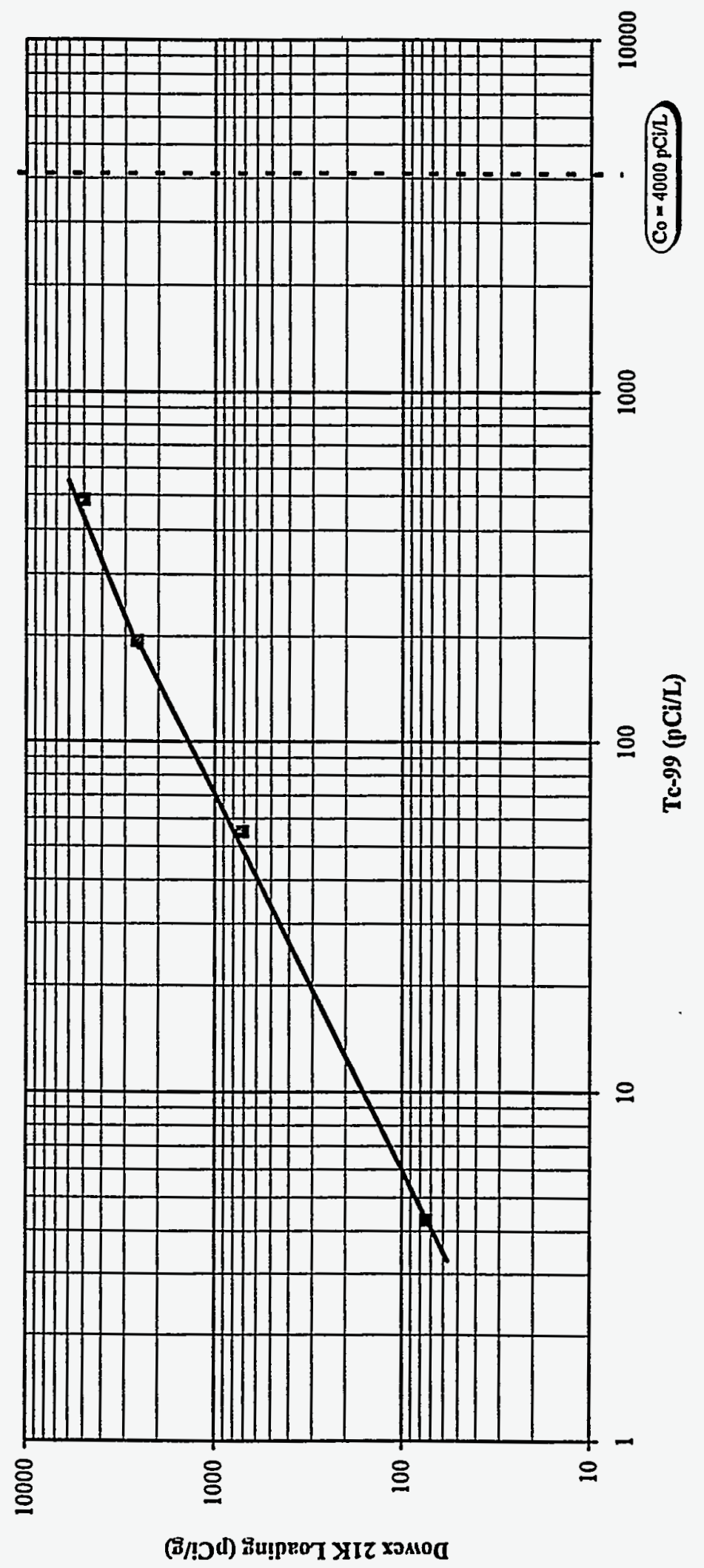


DOE/RL-95-59

Rev. 0

Figure 3-18. Clinoptilolite Flow-Through Column Test Plot (Knoxville Tests).

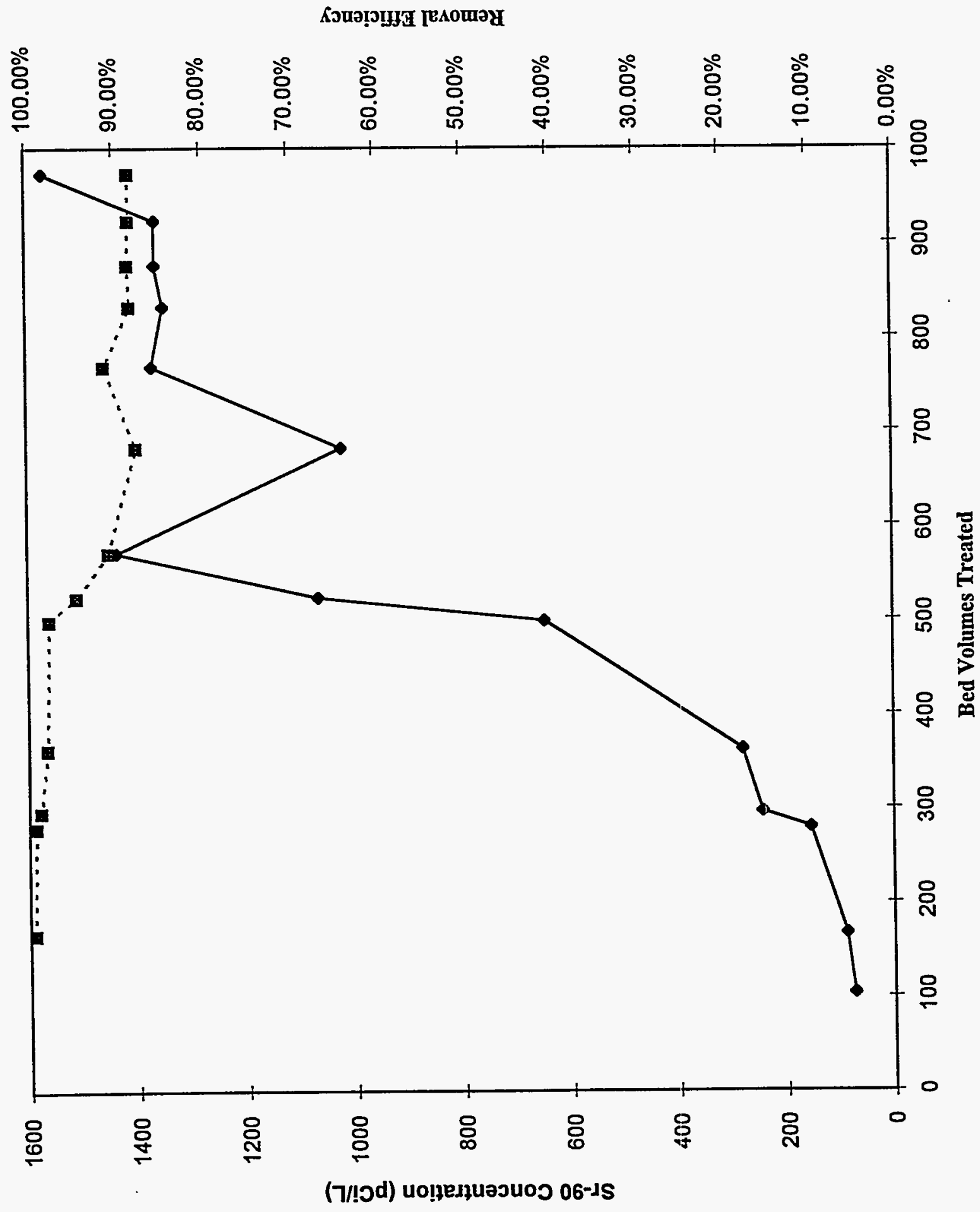




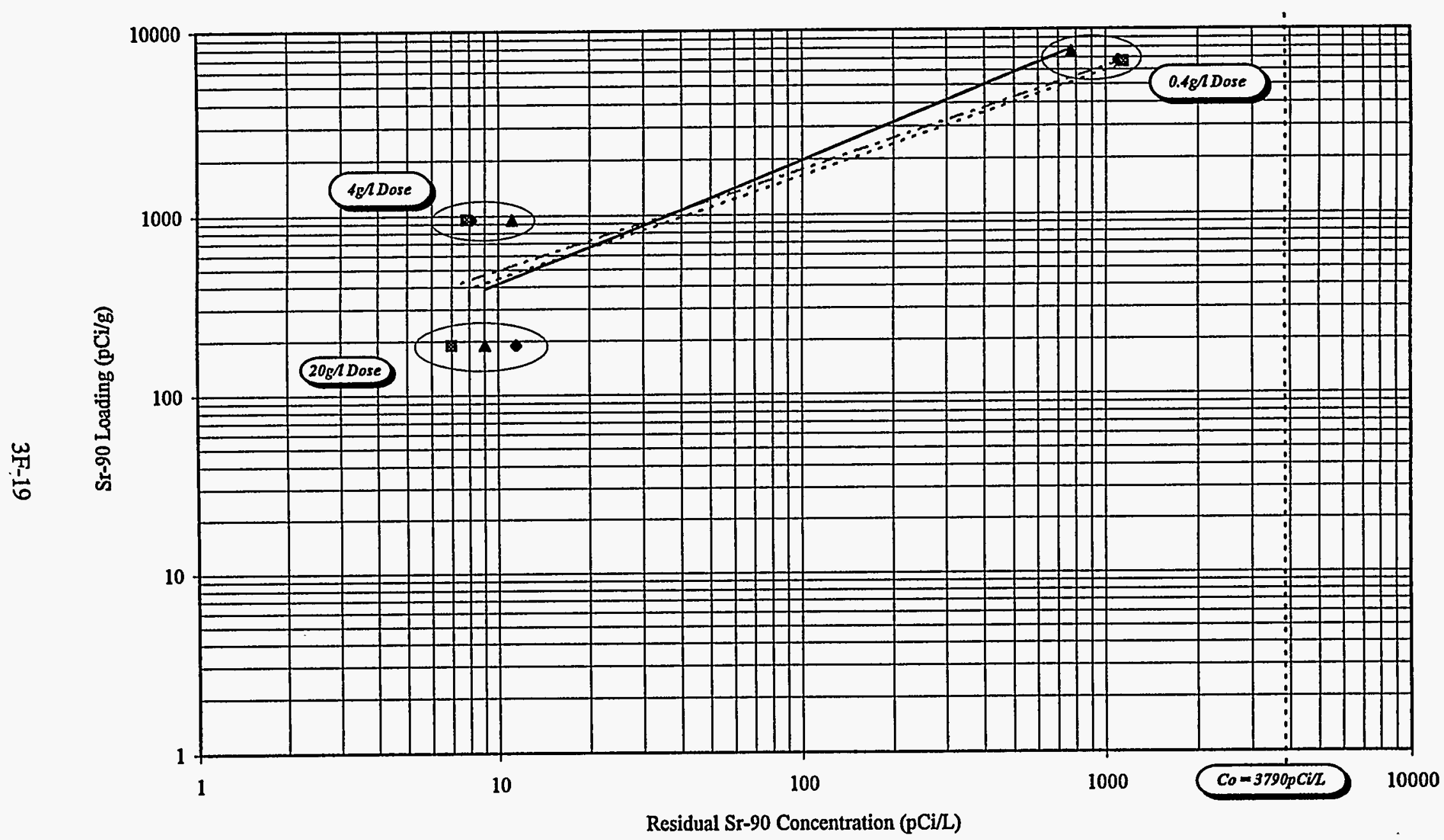


DOE/RL-95-59

Rev. 0

Figure 3-20. UOP E-95 Adsorption Isotherm.

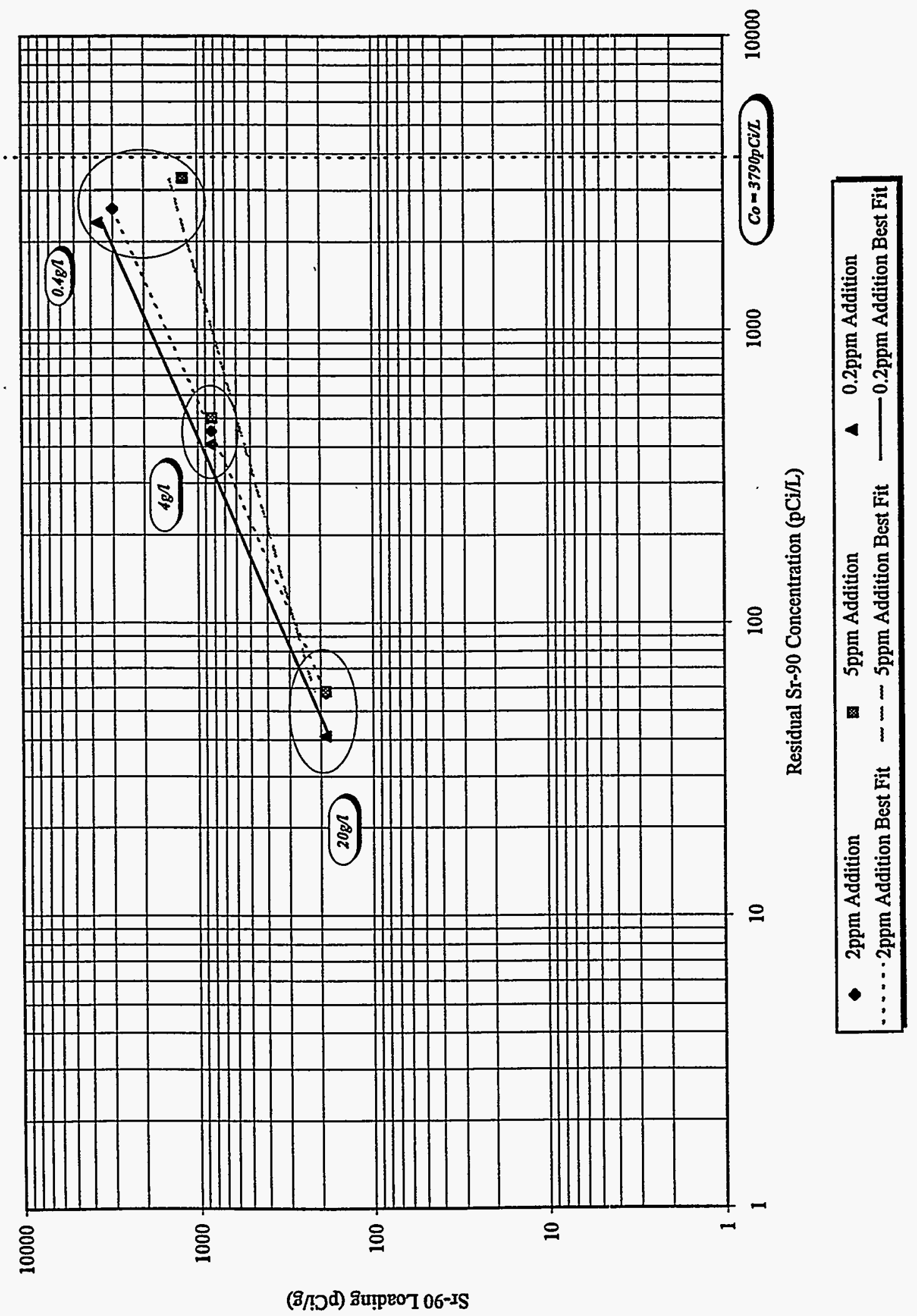




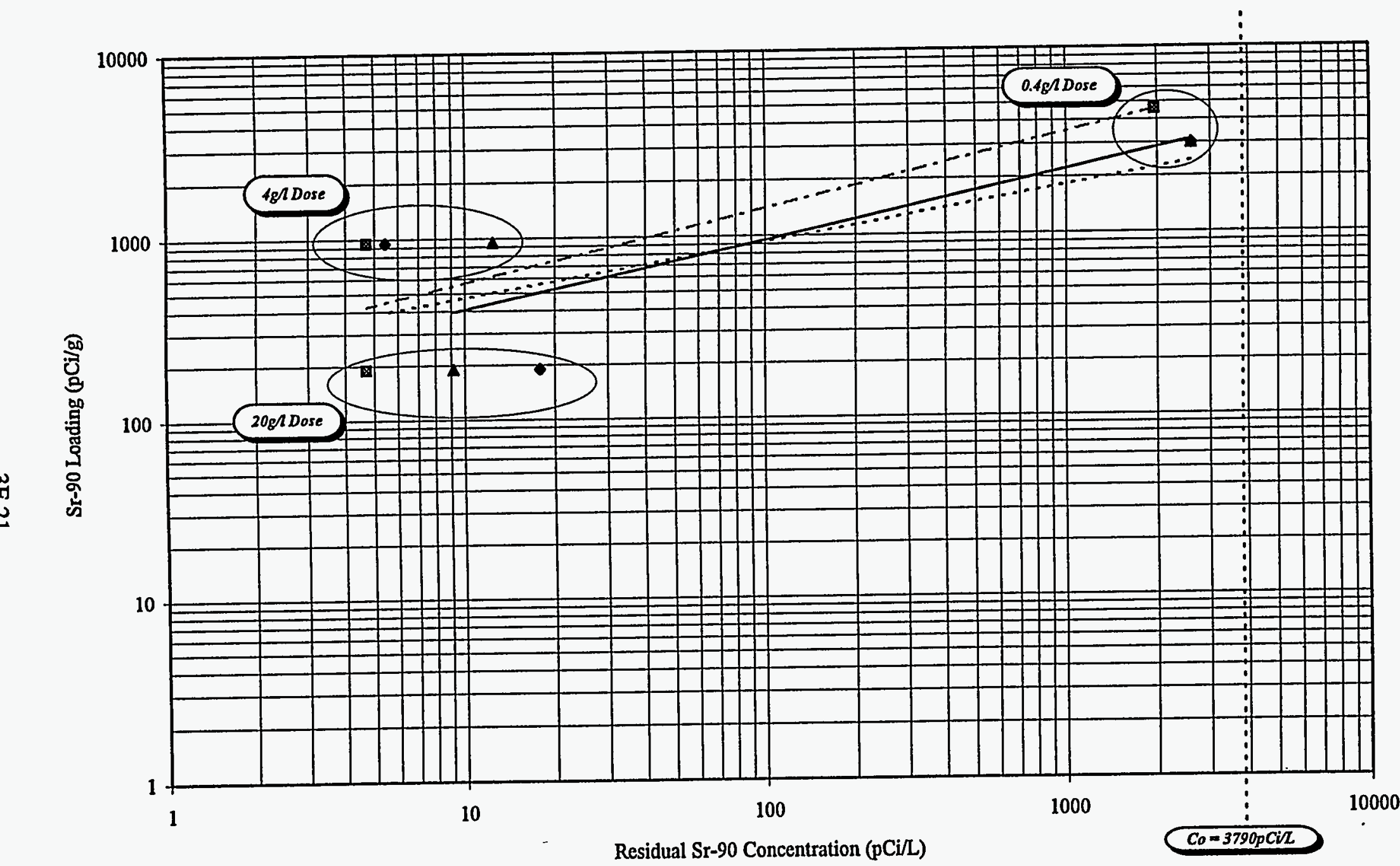




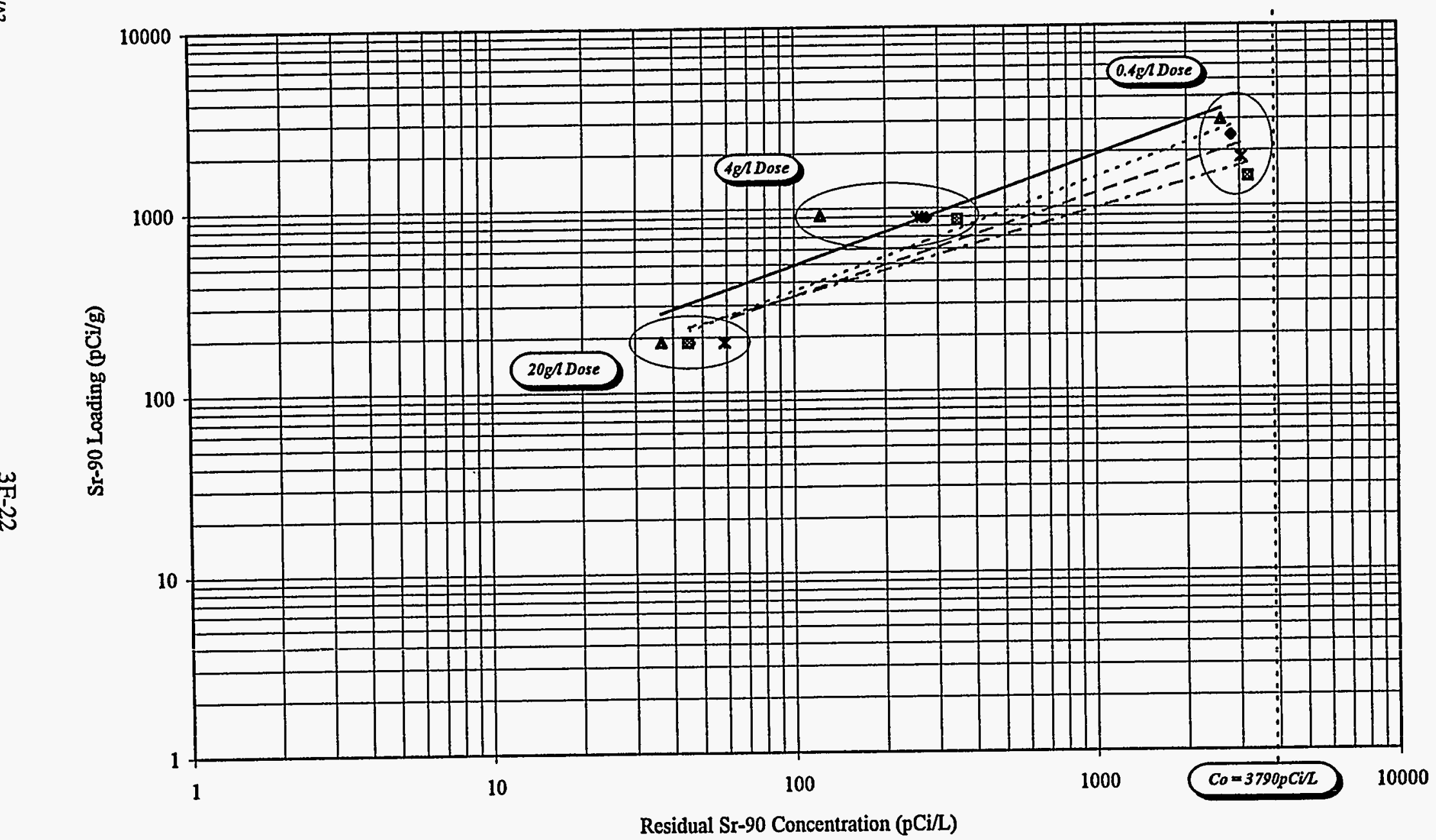




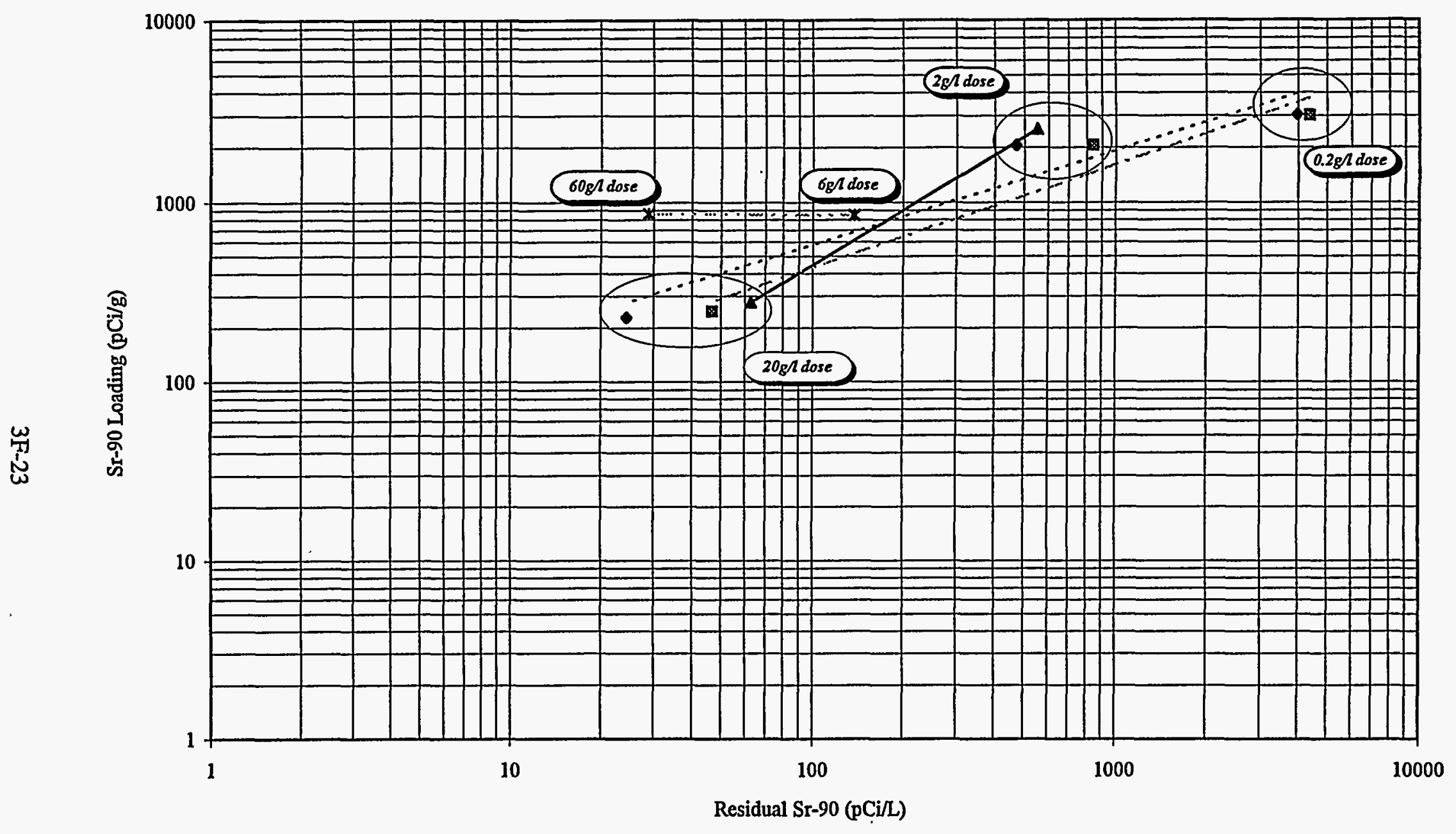

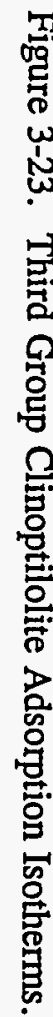

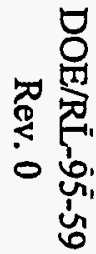

- Test 1a: No pH Adjustment

Test 1b: $\mathrm{pH}$ Adjusted

$\longrightarrow$ Test 2a: Duplicate of 1a ...... Test la Best Fit —... - Test 1b Best Fit

- * - Test 2b: Greater Clino Dose 
Figure 3-24. MCT-1 Lead Clinoptilolite Column Strontium-90 Removal Versus Bed Volumes Treated.

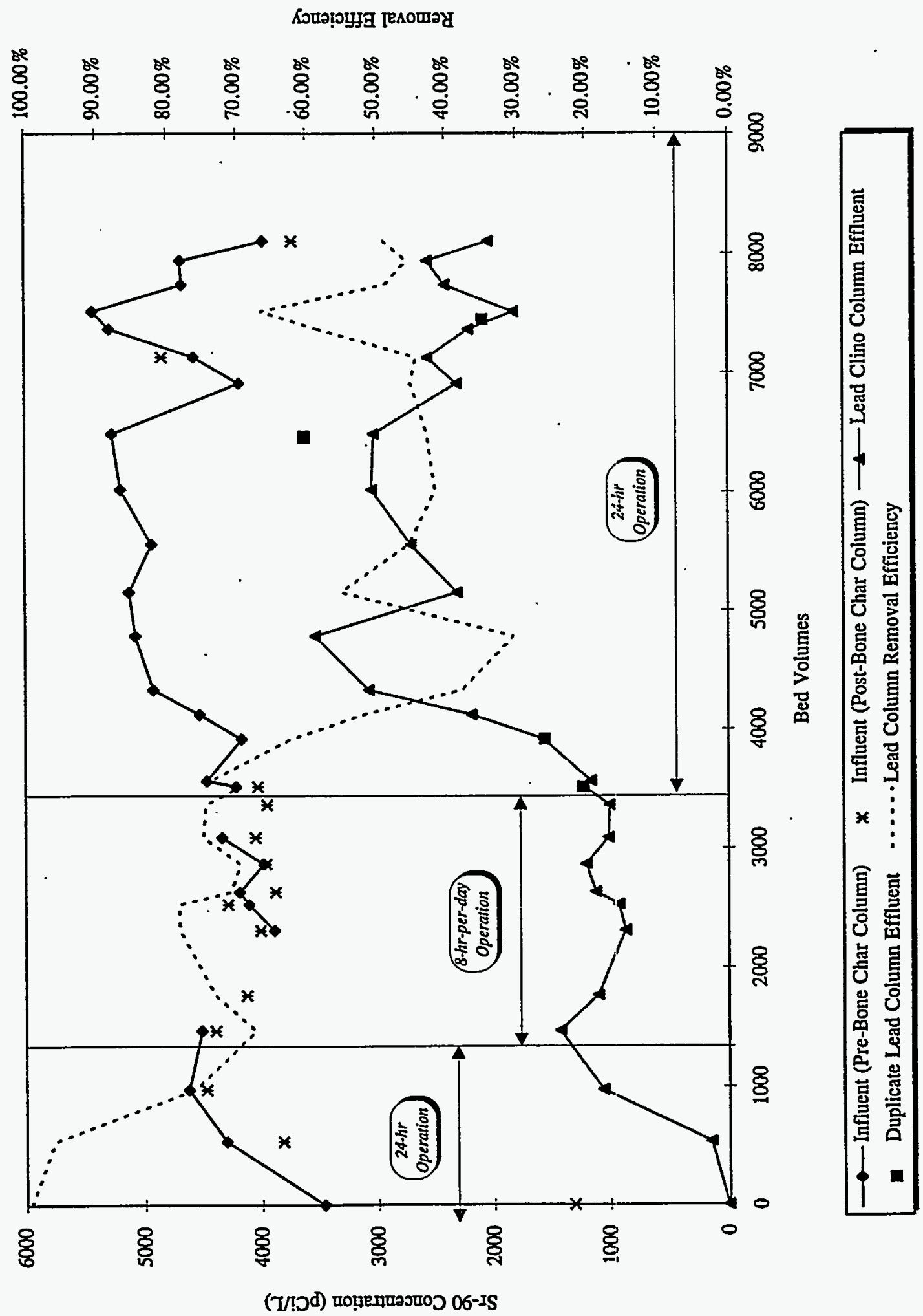


DOE/RL-95-59

Rev. 0

Figure 3-25. MCT-1 Overall System Strontium-90 Removal Versus Bed Volumes Treated.

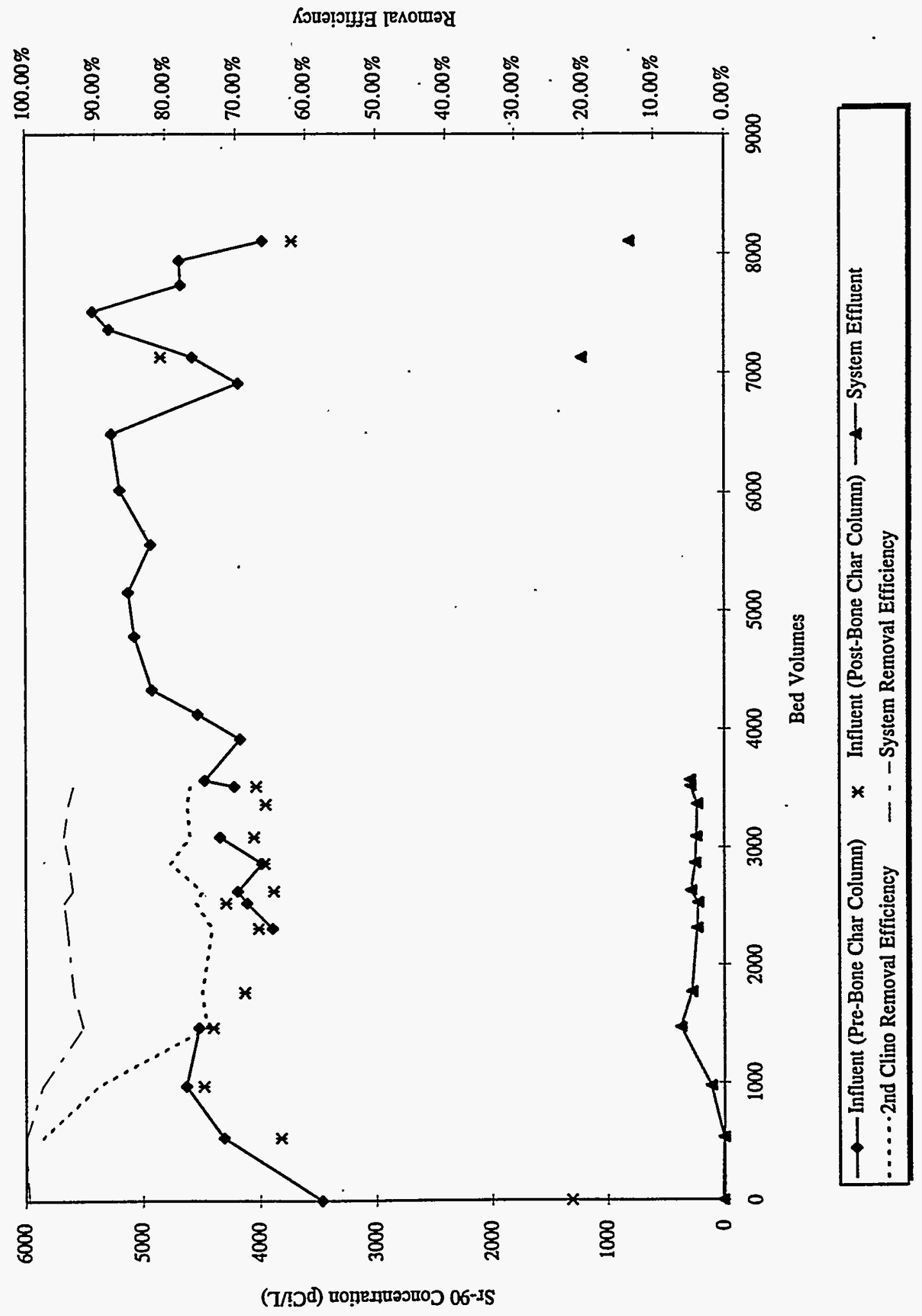


DOE/RL-95-59

Rev. 0

Figure 3-26. MCT-1 Lead Clinoptilolite Column Cesium-137 Removal Versus Bed Volumes Treated.

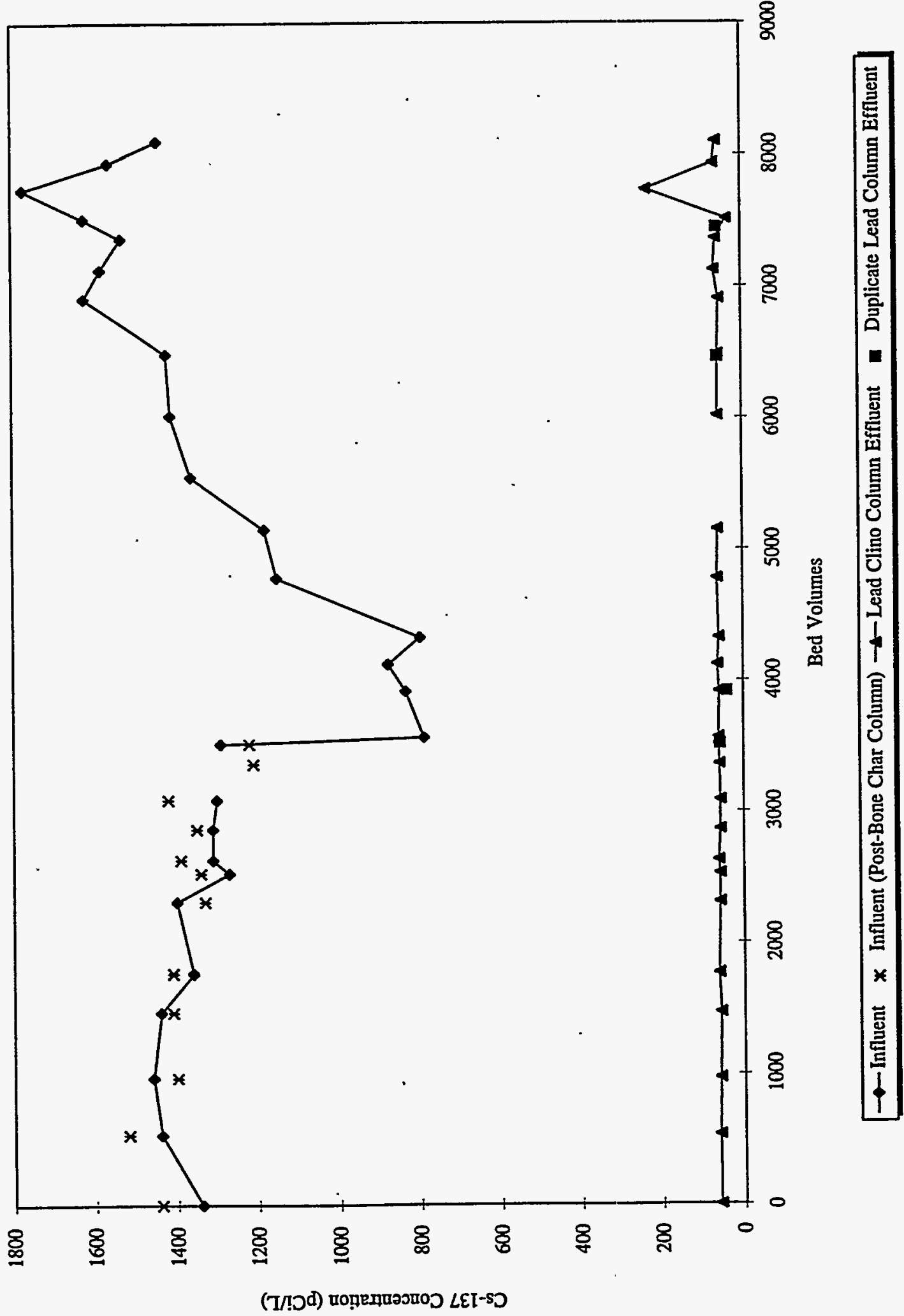


DOE/RL-95-59

Rev. 0

Figure 3-27. MCT-1 Bone Char Column Plutonium-239/240 Removal Versus Bed Volumes Treated.

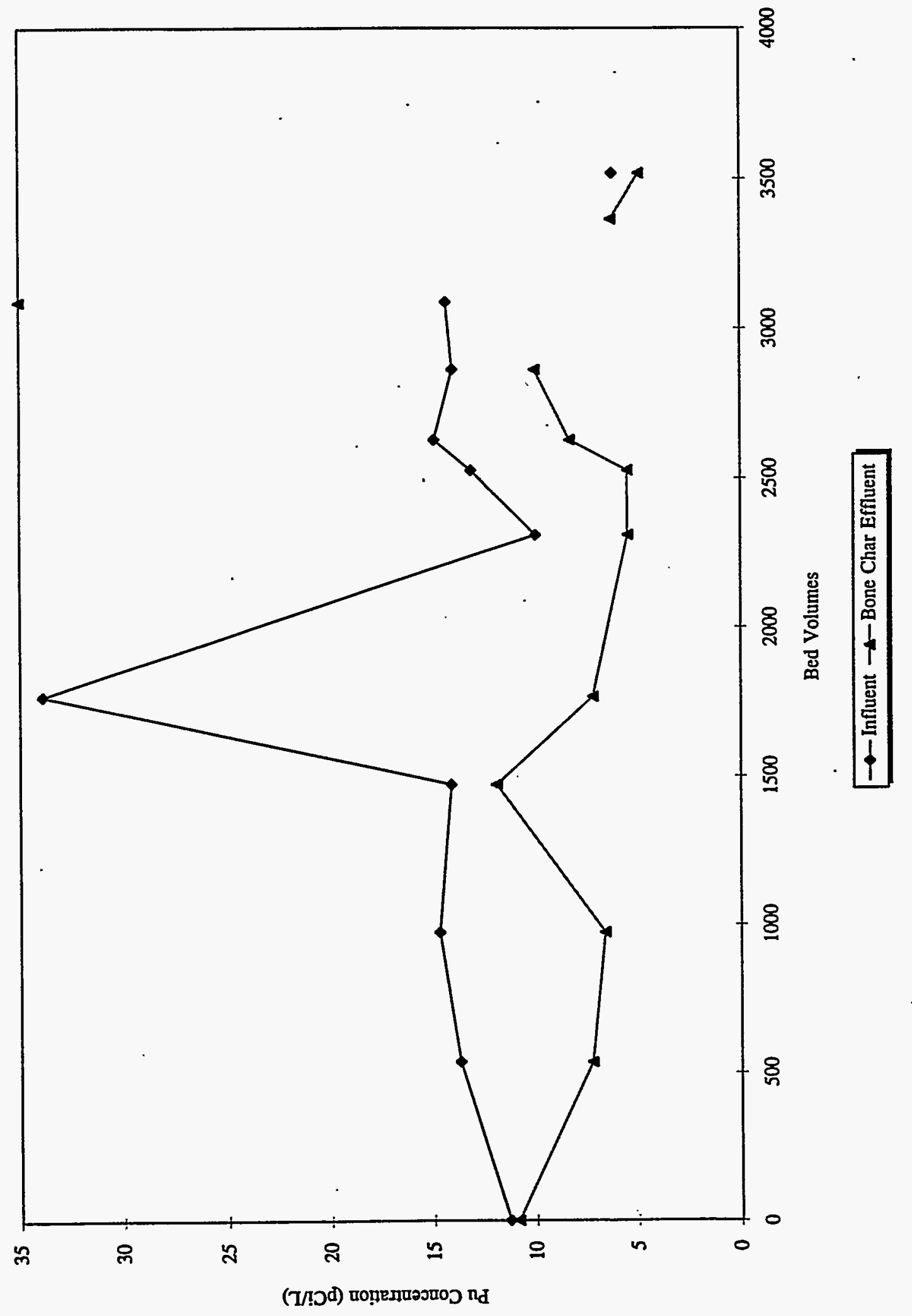




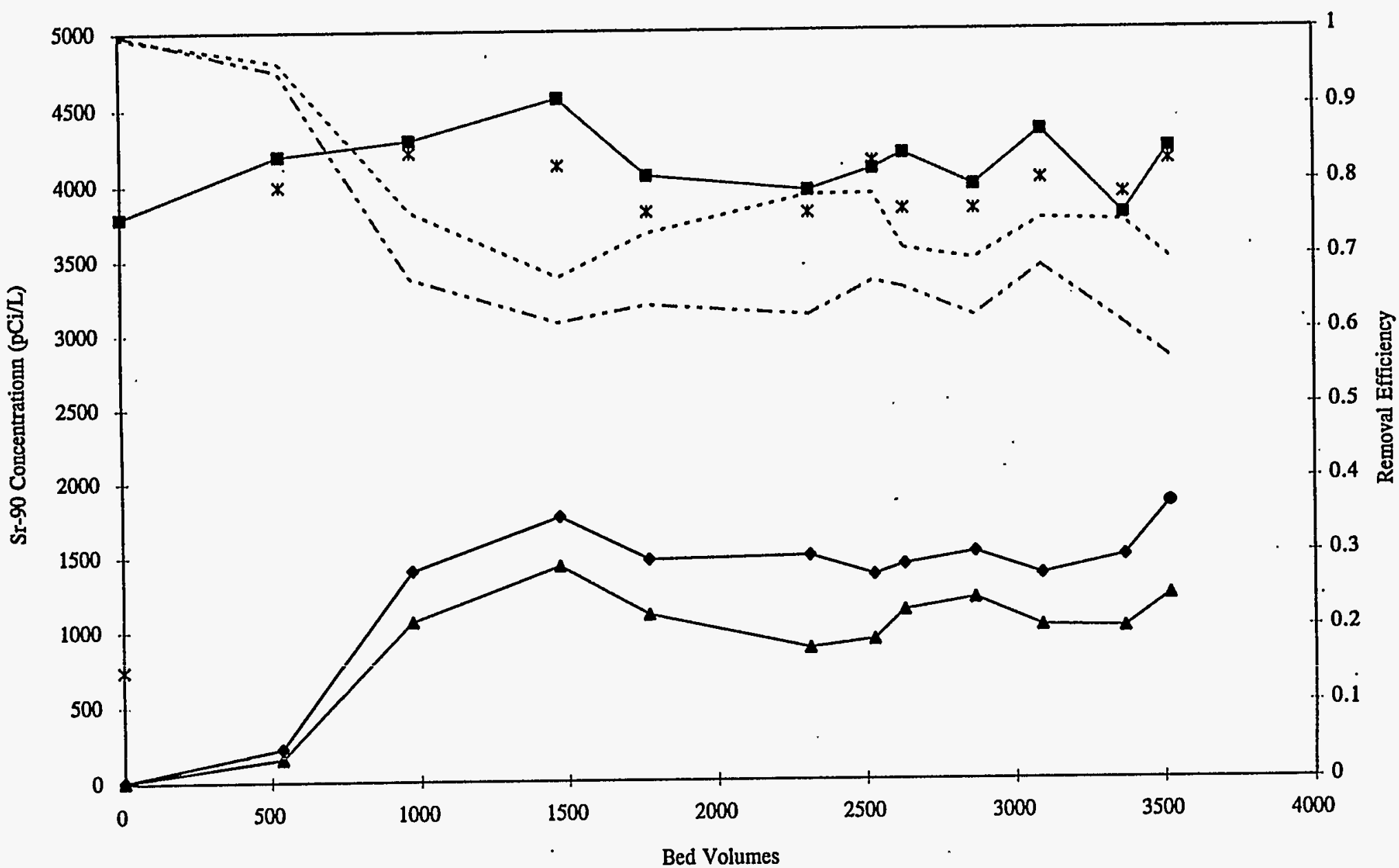

\begin{tabular}{|lll|}
\hline- Influent & $\multimap-$ MCT-1 Lead Column Effluent & $\longrightarrow-$ MCT-2 Lead Column Effluent \\
$* \quad$ Bone Char Effluent & $\ldots \ldots$ MCT-1 Removal Efficiency & $\ldots-$ MCT-2 Lead Column Efficiency \\
\hline
\end{tabular}


Rev. 0

Figure 3-29. MCT-1 and MCT-2 Overall Strontium-90 Removal Versus Bed Volumes Treated.

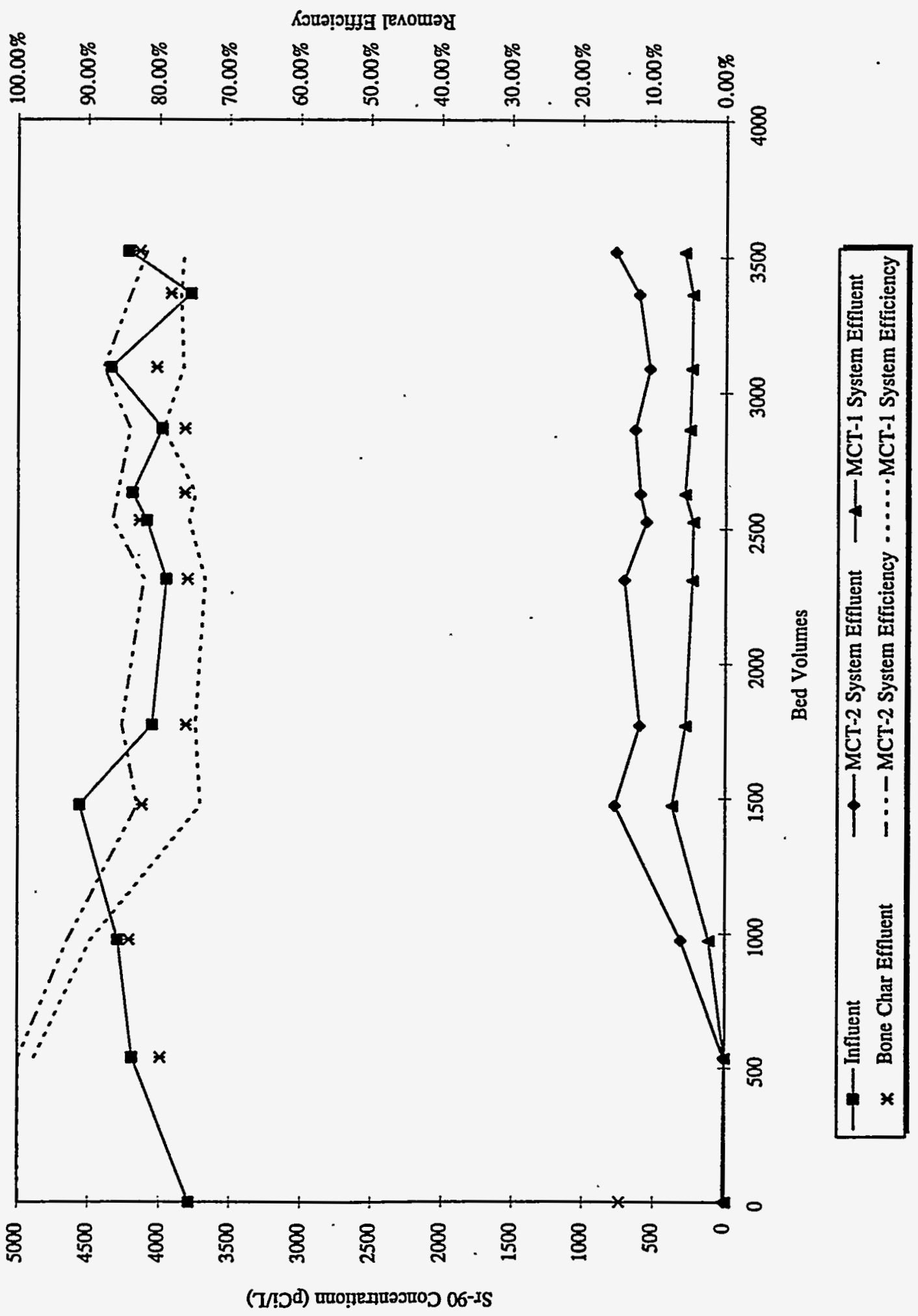


DOE/RL-95-59

Rev. 0

Figure 3-30. 2MCT-2 Lead Clinoptilolite Column Strontium-90 Removal Versus Bed Volumes Treated.

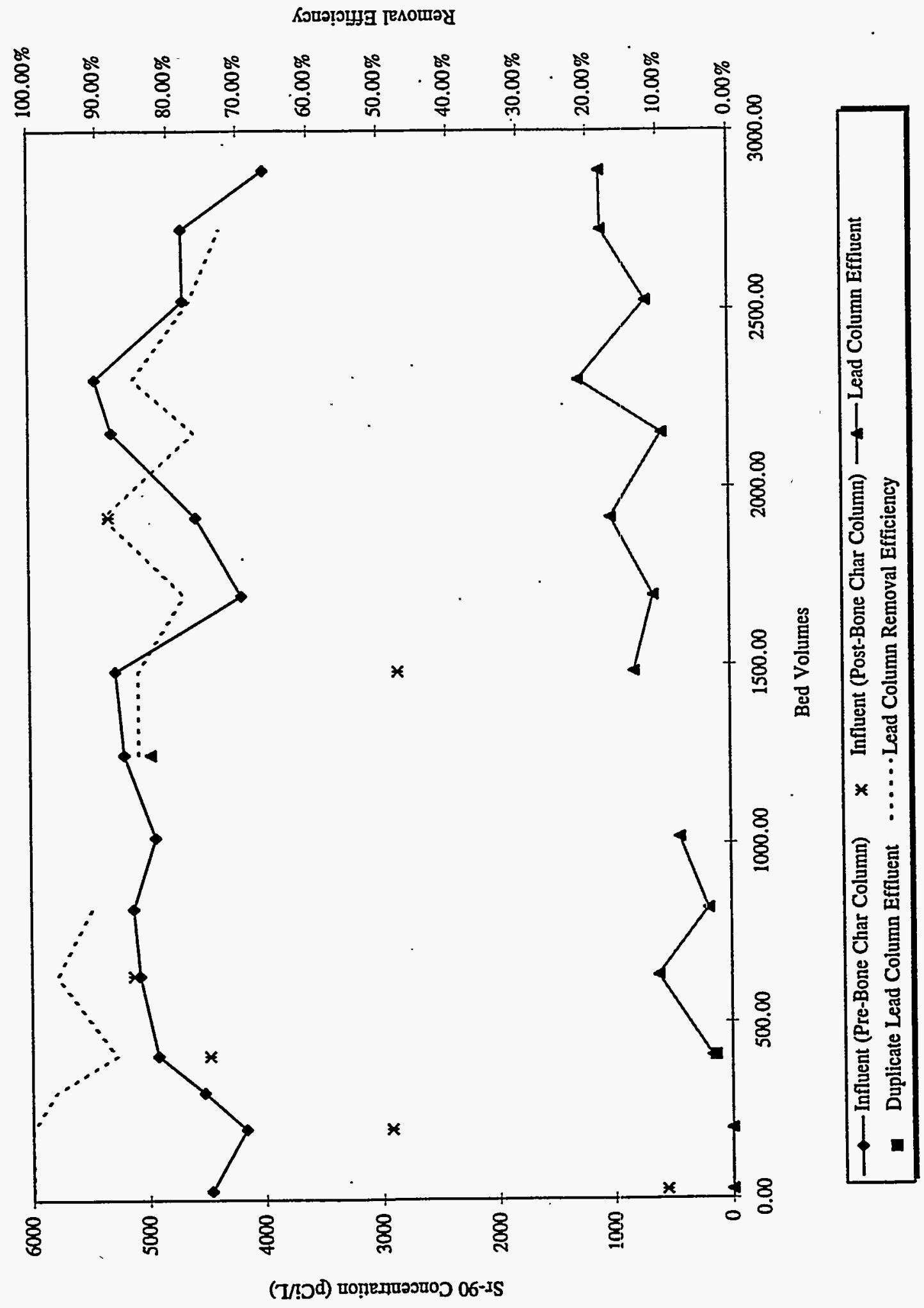


DOE/RL-95-59

Rev. 0

Figure 3-31. 2MCT-2 Overall System Effluent Strontium-90 Removal Versus Bed Volumes Treated.

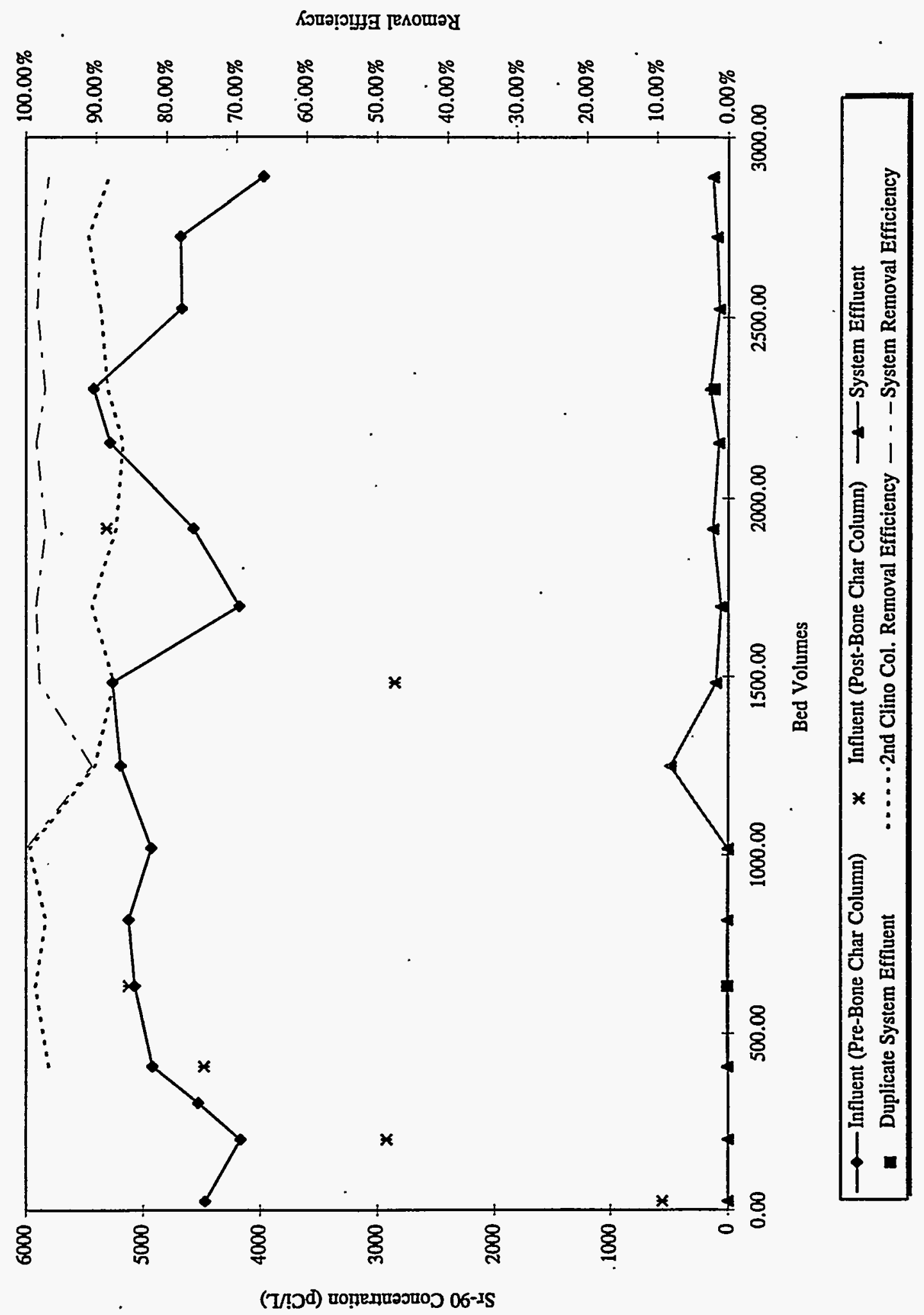


DOE/RL-95-59

Rev. 0

Figure 3-32. 2MCT-3 Lead Clino Column Strontium-90 Removal Versus Bed Volumes Treated.

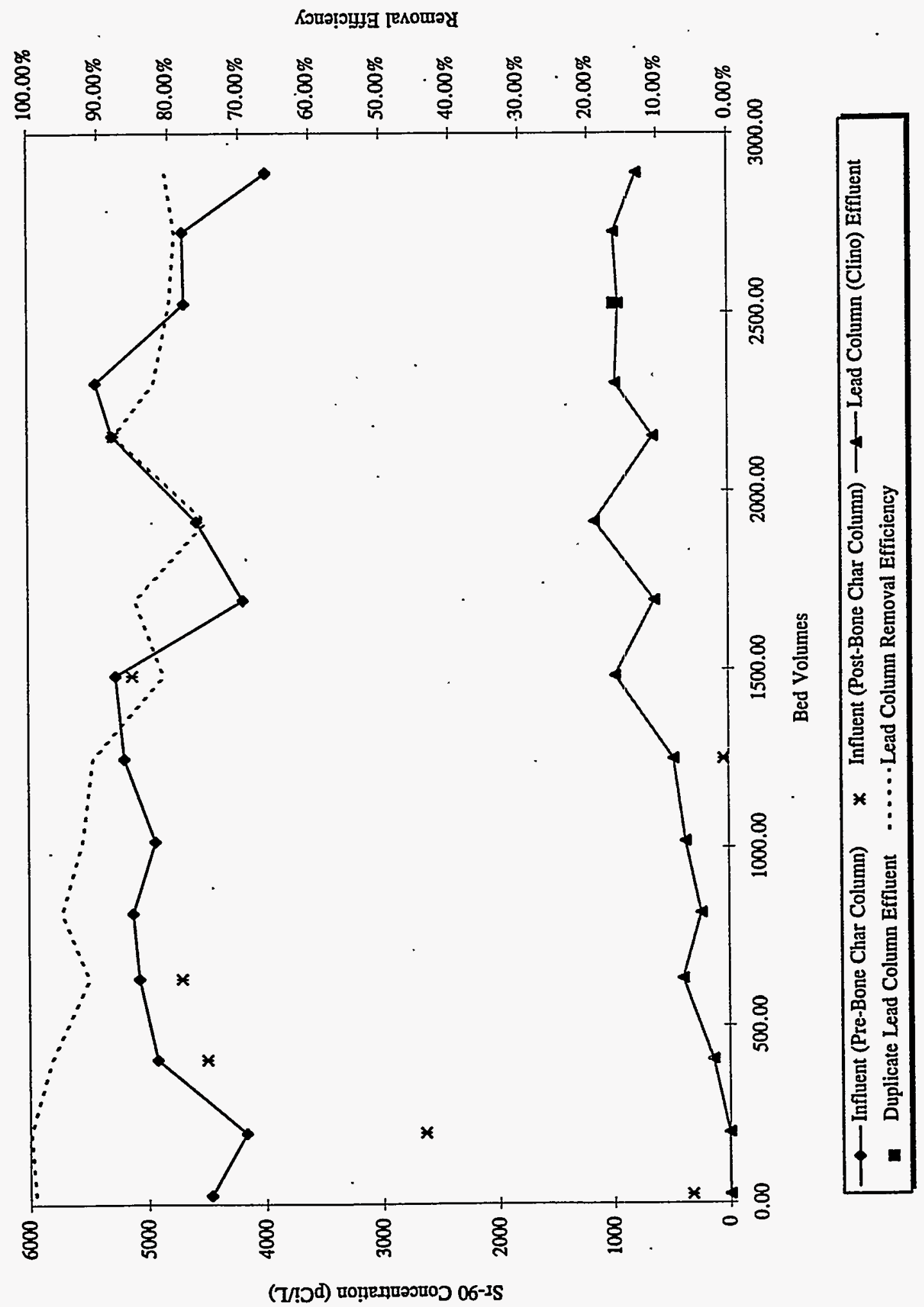


DOE/RL-95-59

Rev. 0

Figure 3-33. 2MCT-3 Overall System Strontium-90 Removal Versus Bed Volumes Treated.

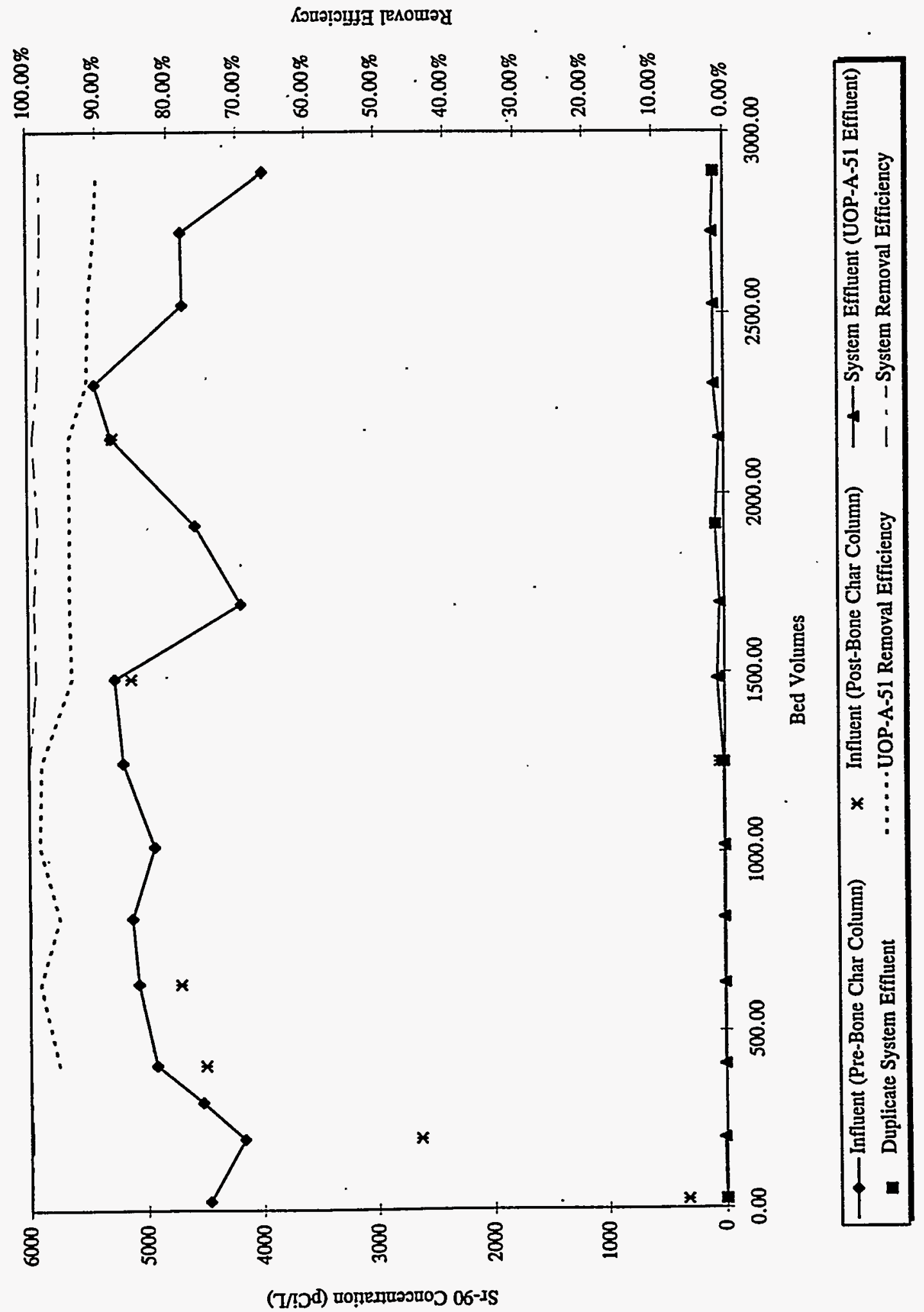


Figure 3-34. Lead Mini-Column Technetium-99 Effluent Versus Bed Volumes Treated, Test 1.
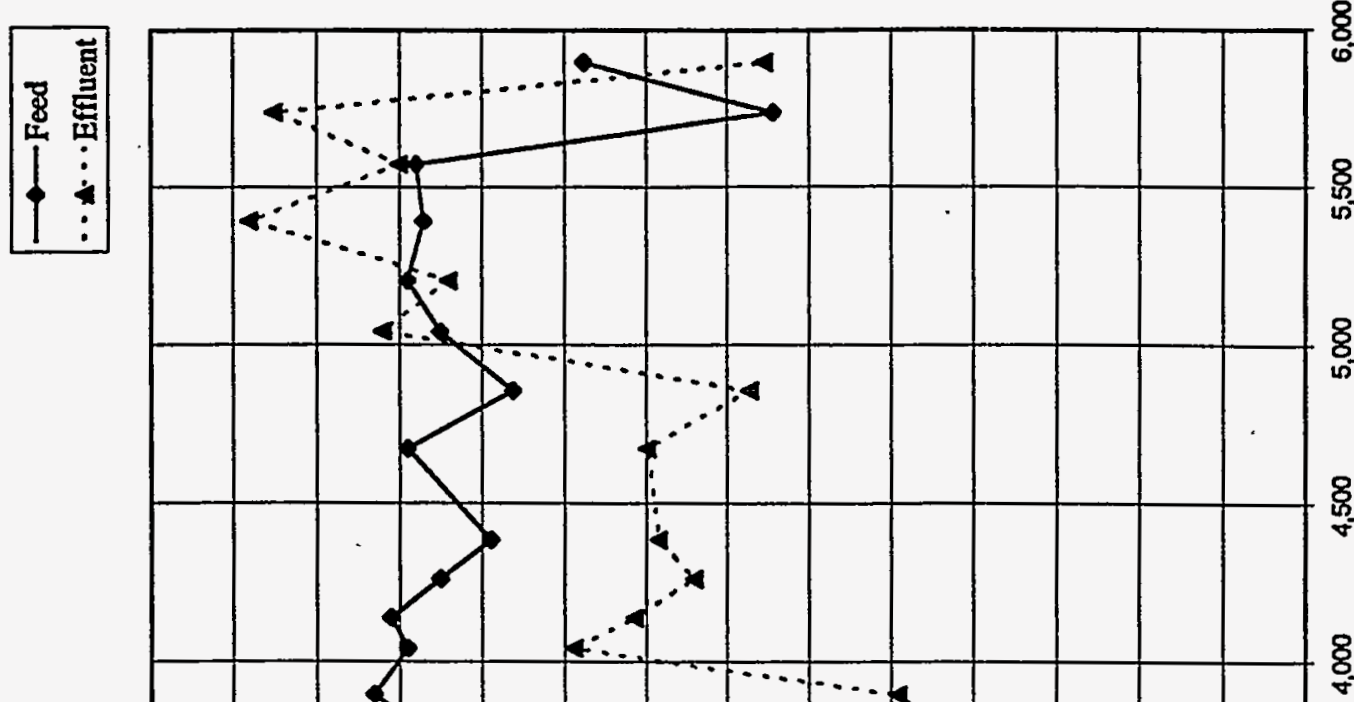

8

8

$\underset{\substack{8 \\ \mathbf{s}^{\circ}}}{8}$

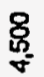

$\underset{8}{+}$
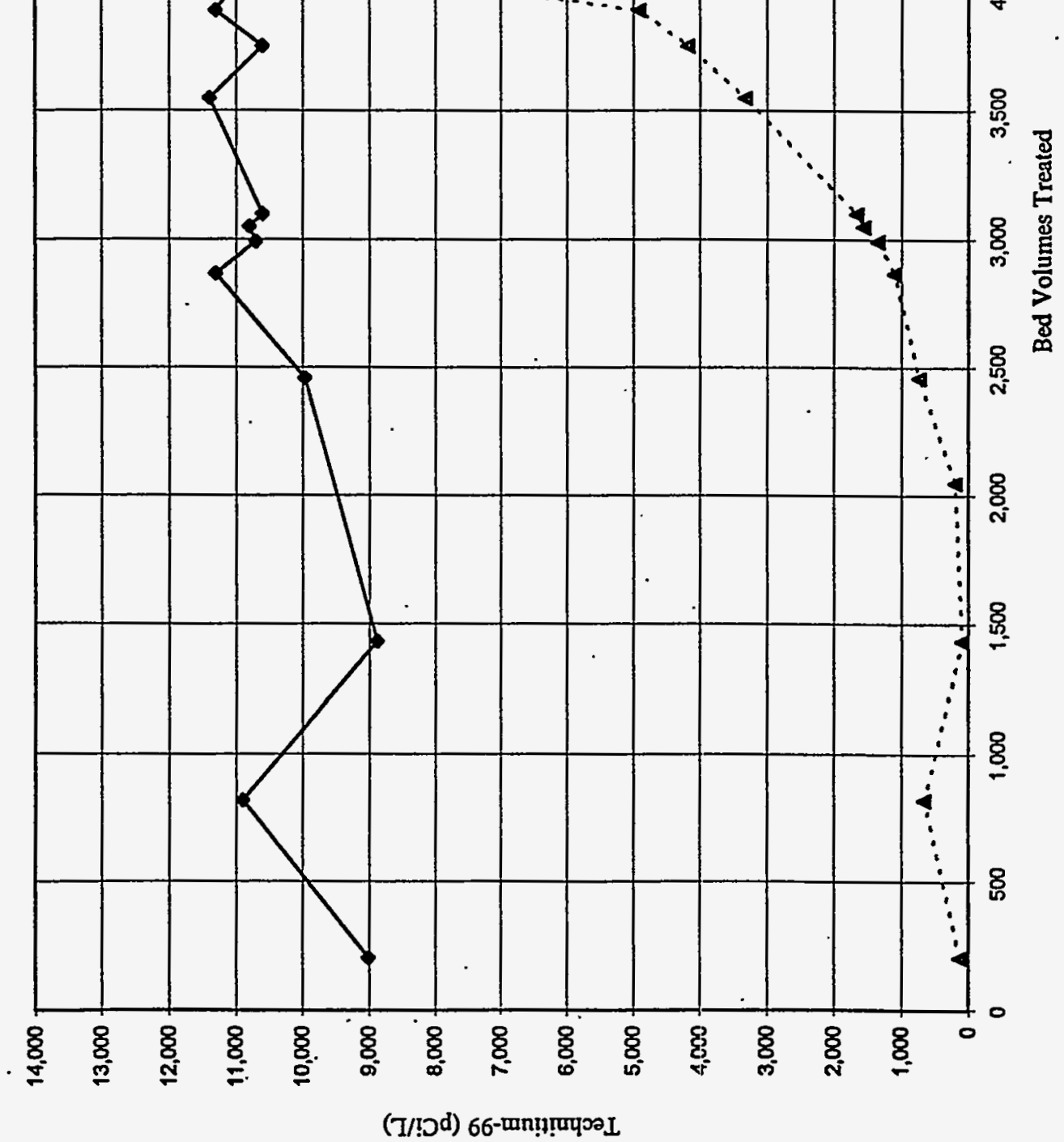
DOE/RL-95-59

Rev. 0

Figure 3-35. Overall Mini-Column Technetium-99 Effluent Versus Bed Volumes Treated, Test 1.
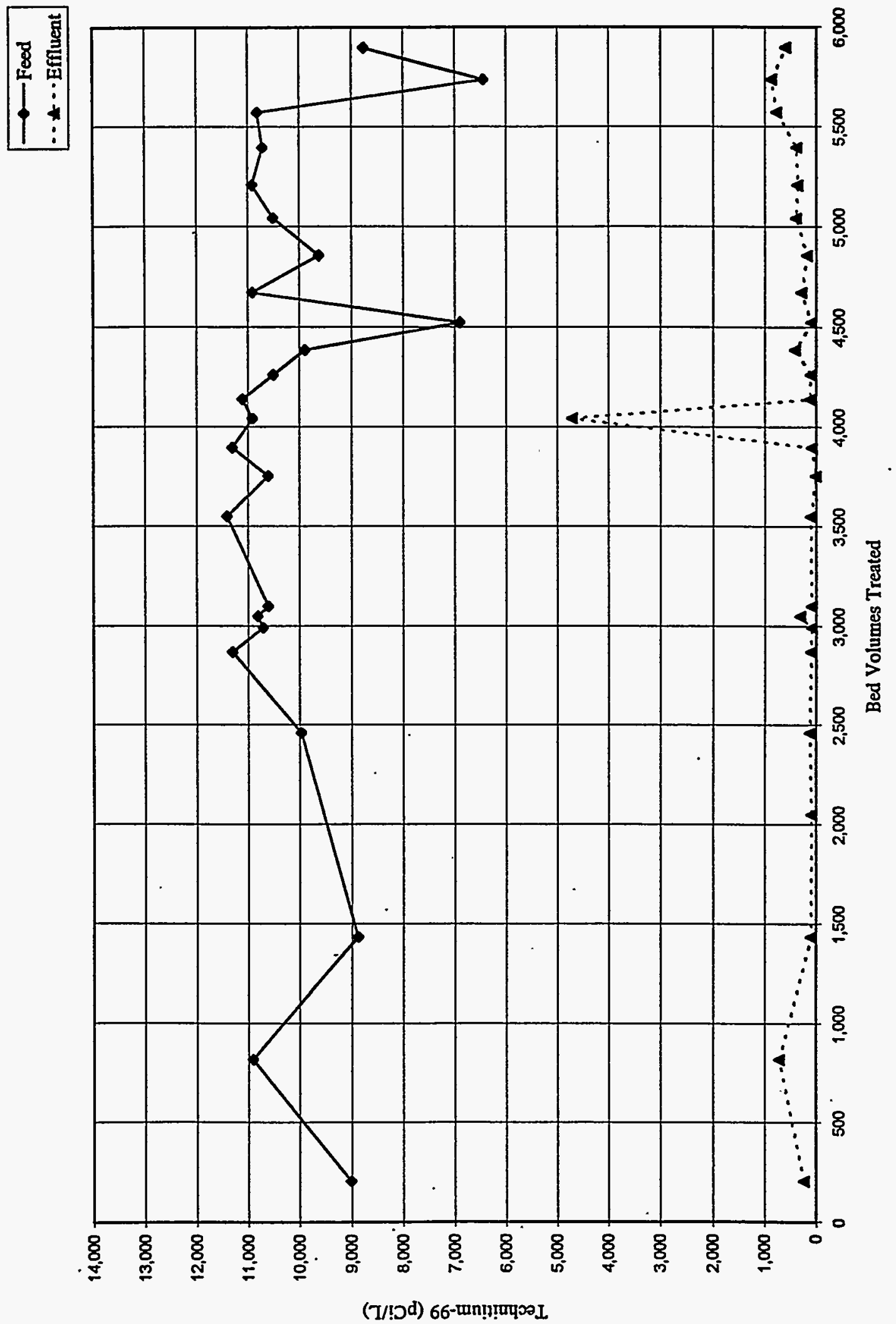
DOE/RL-95-59

Rev. 0

Figure 3-36. Lead Mini-Column Technetium-99 Effluent Versus Bed Volumes Treated, Test 2.
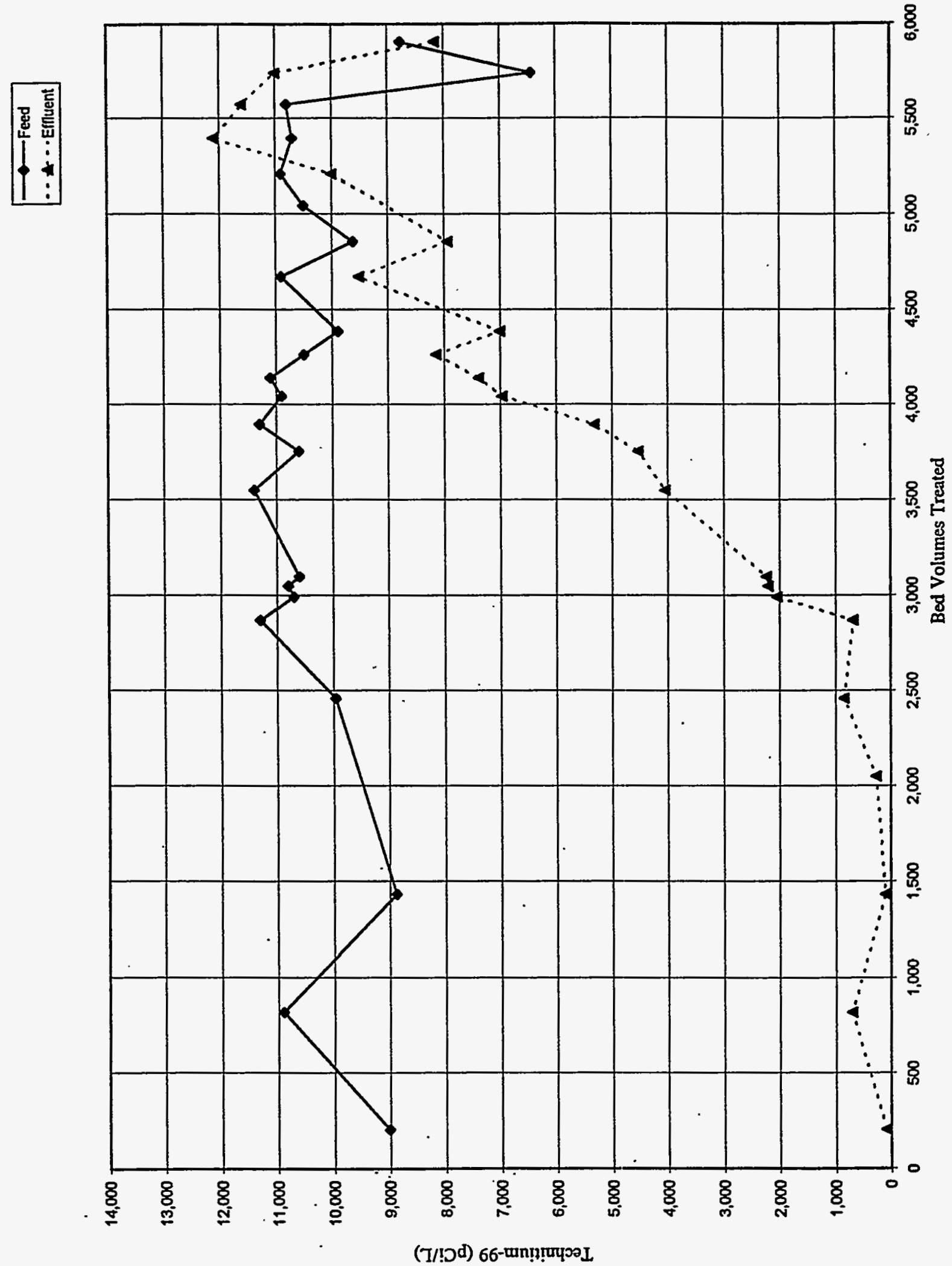
Rev. 0

Figure 3-37. Overall Mini-Column Technetium-99 Effluent Versus Bed Volumes Treated, Test 2.
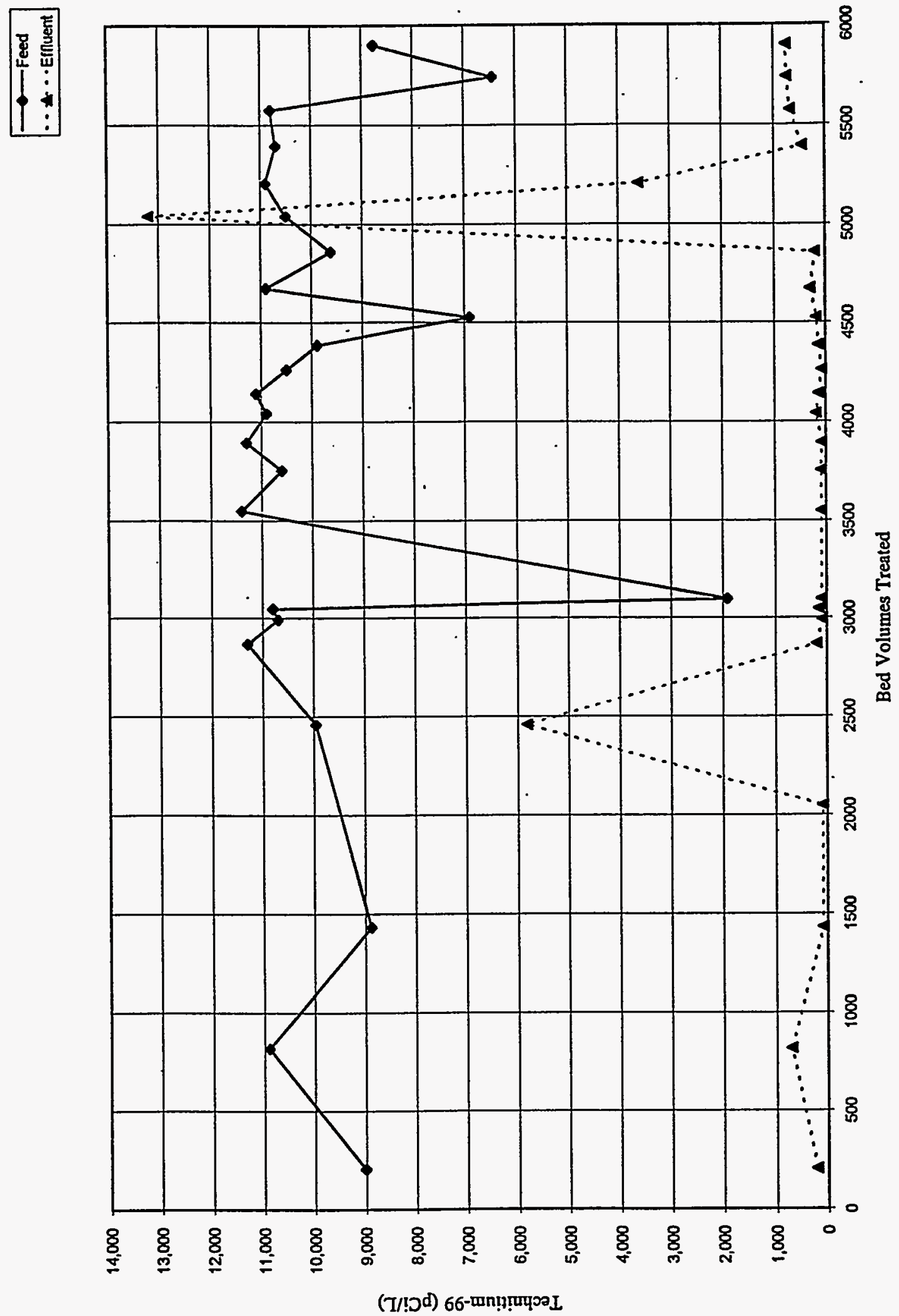
Figure 3-38. Lead Mini-Column Cobalt-60 Effluent Versus Bed Volumes Treated, Test 1.
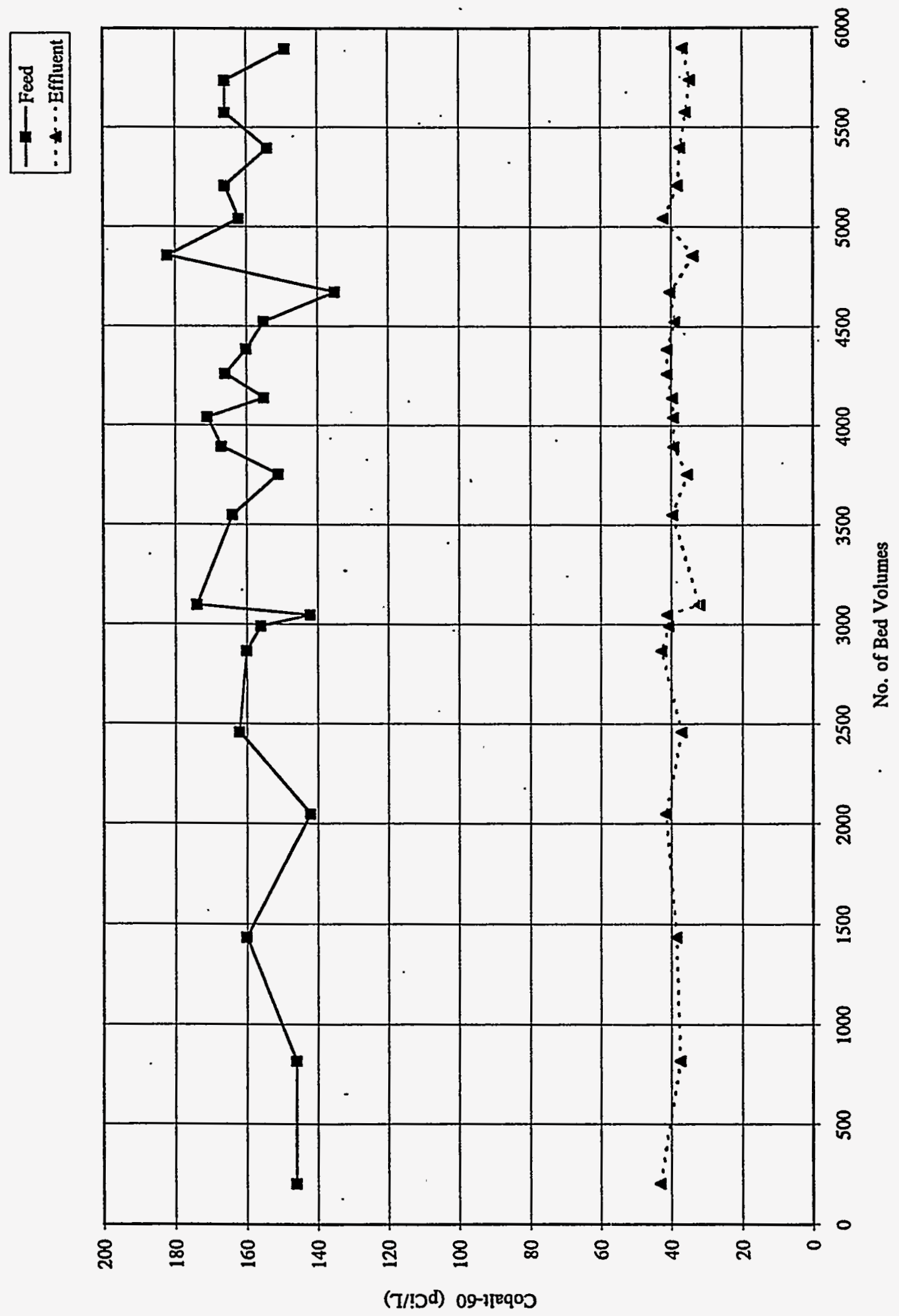
DOE/RL-95-59

Rev. 0

Figure 3-39. Lead Mini-Column Cobalt-60 Effluent Versus Bed Volumes Treated, Test 2.

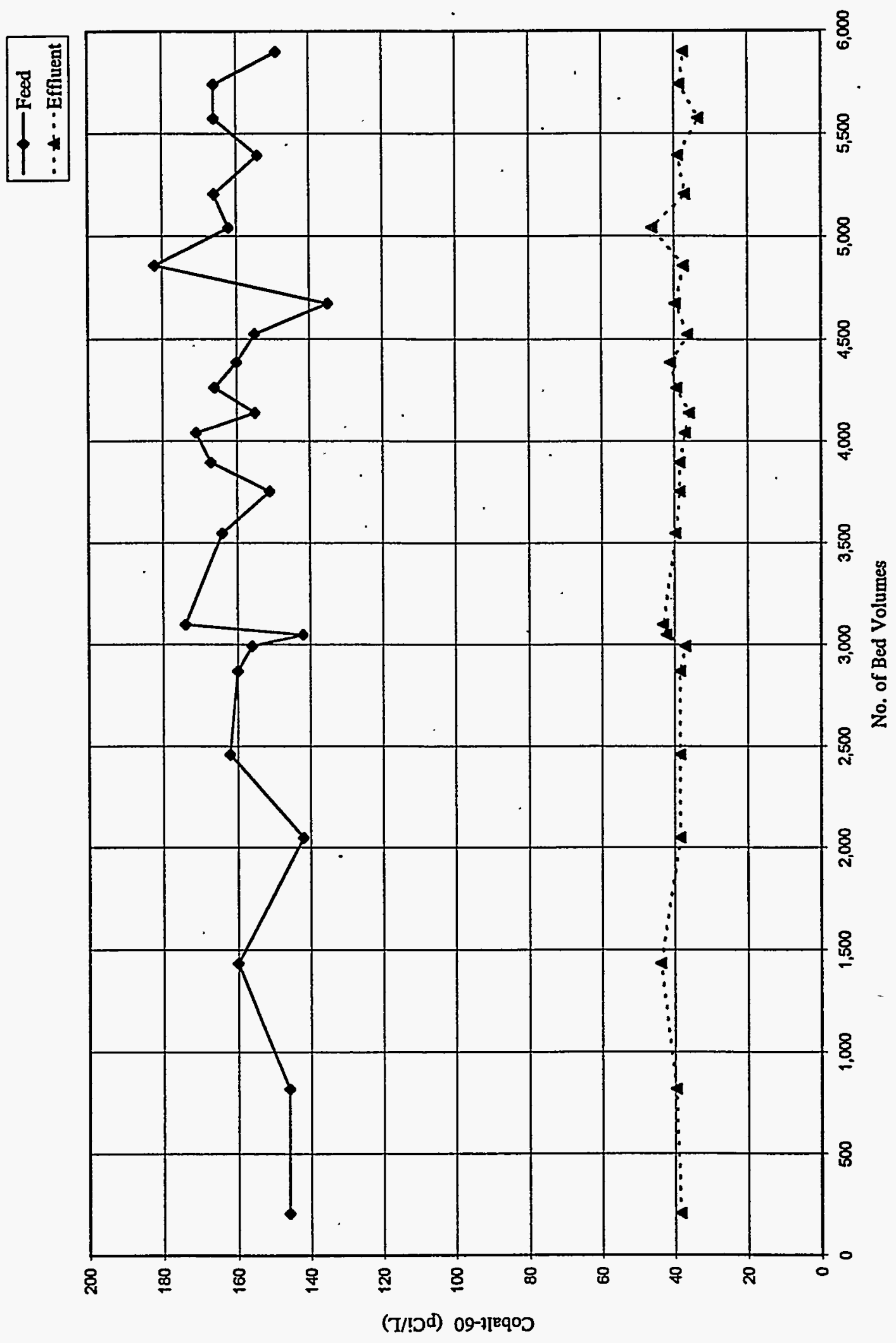


DOE/RL-95-59

Rev. 0 
Table 3-1. Lead Column Removal Performance, Quantities of Radionuclides.

\begin{tabular}{|c|c|c|c|c|c|c|}
\hline Contaminant & $\begin{array}{c}\text { Average } \\
\text { Concentra- } \\
\text { tion of } \\
\text { Well } \\
\text { Influent } \\
\text { (pCi/L) }\end{array}$ & $\begin{array}{c}\text { Average } \\
\text { Concentration } \\
\text { of Lead } \\
\text { Column } \\
\text { Effluent } \\
\text { (pCi/L) }\end{array}$ & $\begin{array}{c}\text { Liters (gal) } \\
\text { treated }\end{array}$ & $\begin{array}{l}\text { Total pico- } \\
\text { Curies } \\
\text { Removed }\end{array}$ & Specific Activity & $\begin{array}{c}\text { Total } \\
\text { Grams } \\
\text { Removed }\end{array}$ \\
\hline \multicolumn{7}{|c|}{ 216-B-5 Reverse Well Plumes } \\
\hline${ }^{90} \mathrm{Sr}-\mathrm{Run} 1$ & 3,937 & 1,785 & $\begin{array}{c}2,283,725 \\
(603,362)\end{array}$ & $4.915 \times 10^{9}$ & $1.41 \times 10^{14} \mathrm{pCi} / \mathrm{g}$ & $3.49 \times 10^{-5}$ \\
\hline${ }^{90} \mathrm{Sr}-$ Run 2 & 4,896 & 980 & $\begin{array}{l}1,448.406 \\
(382,670)\end{array}$ & $5.672 \times 10^{9}$ & "n " " & $4.02 \times 10^{-5}$ \\
\hline${ }^{90} \mathrm{Sr}-$ Total & N/A & N/A & $\begin{array}{l}3,732,131 \\
(986,032)\end{array}$ & $1.059 \times 10^{10}$ & " " " " & $7.51 \times 10^{-5}$ \\
\hline${ }^{137} \mathrm{Cs}-$ Run 1 & 1,354 & $59.2(\mathrm{OS}=8)$ & $\begin{array}{l}2,283,725 \\
(603,362)\end{array}$ & $\begin{array}{c}2.957 \times 10^{9} \\
\left(3.074 \times 10^{9}\right)\end{array}$ & $8.7 \times 10^{13} \mathrm{pCi} / \mathrm{g}$ & $\begin{array}{c}3.40 \times 10^{-5} \\
\left(3.53 \times 10^{-5}\right)\end{array}$ \\
\hline${ }^{137} \mathrm{Cs}-$ Run 2 & 1,457 & $\begin{array}{c}59.1 \\
(O S=5.75)\end{array}$ & $\begin{array}{l}1,448.406 \\
(382,670)\end{array}$ & $\begin{array}{r}2.025 \times 10^{9} \\
\left(2.102 \times 10^{9}\right) \\
\end{array}$ & " " " " & $\begin{array}{c}2.33 \times 10^{-5} \\
\left(2.42 \times 10^{-5}\right)\end{array}$ \\
\hline${ }^{137} \mathrm{Cs}$ - Total & N/A & N/A & $\begin{array}{l}3,732,131 \\
(986,032)\end{array}$ & $\begin{array}{c}4.982 \times 10^{9} \\
\left(5.176 \times 10^{9}\right)\end{array}$ & nn nn & $\begin{array}{r}5.73 \times 10^{-5} \\
\left(5.95 \times 10^{-5}\right) \\
\end{array}$ \\
\hline $\begin{array}{l}{ }^{23924040} \mathrm{Pu}- \\
\text { Run } 1\end{array}$ & 19.4 & $\begin{array}{c}5.6 \\
(\mathrm{OS}=1.55)\end{array}$ & $\begin{array}{l}2,283,725 \\
(603,362)\end{array}$ & $\begin{array}{c}3.153 \times 10^{7} \\
\left(4.065 \times 10^{7}\right)\end{array}$ & $8.86 \times 10^{10} \mathrm{pCi} / \mathrm{g}$ & $\begin{array}{r}3.56 \times 10^{-4} \\
\left(4.59 \times 10^{-4}\right)\end{array}$ \\
\hline $\begin{array}{l}{ }^{239240} \mathrm{Pu} \\
\text { (extrapolated } \\
\text { for total run) }\end{array}$ & 19.4 & $\begin{array}{c}5.6 \\
(\mathrm{OS}=1.55)\end{array}$ & $\begin{array}{l}3,732,131 \\
(986,032)\end{array}$ & $\begin{array}{c}5.150 \times 10^{7} \\
\left(6.662 \times 10^{7}\right)\end{array}$ & $n n n$ & $\begin{array}{c}5.81 \times 10^{-4} \\
\left(7.52 \times 10^{-4}\right)\end{array}$ \\
\hline \multicolumn{7}{|c|}{ 216-BY Cribs Plume } \\
\hline${ }^{99} \mathrm{Tc}$ & 9,007 & 169.5 & $\begin{array}{l}1,426.037 \\
(376,760)\end{array}$ & $1.260 \times 10^{10}$ & $1.7 \times 10^{10} \mathrm{pCi} / \mathrm{g}$ & $0.74 \mathrm{~g}$ \\
\hline${ }^{60} \mathrm{Co}$ & 156 & $\begin{array}{c}39.5 \\
(O S=10.5)\end{array}$ & $\begin{array}{l}1,426.037 \\
(376,760)\end{array}$ & $\begin{array}{c}1.661 \times 10^{8} \\
\left(2.075 \times 10^{8}\right)\end{array}$ & $\begin{array}{c}1.130 \times 10^{15} \\
\mathrm{pCi} / \mathrm{g}\end{array}$ & $\begin{array}{c}1.47 \times 10^{-7} \\
\left(1.84 \times 10^{-7}\right)\end{array}$ \\
\hline
\end{tabular}

NOTES:

1. All data calculated from Appendix $C$ tables.

2. $\quad \mathrm{OS}=\mathrm{X}$ is offsite laboratory analytical results. Bracketed calculations for total curies and total grams are based on using offsite analyses when 222-S Laboratory results were reported as lessthan detection values. 
DOE/RL-95-59

Rev. 0

Table 3-2. Calculated K Values for Strontium-90.

\begin{tabular}{|l|c|c|}
\hline \multirow{2}{*}{ Run ID } & \multicolumn{2}{|c|}{ First-Order K Values } \\
\cline { 2 - 3 } & First Bed & Second Bed \\
\hline Pilot Run 1 & 0.138 & 0.135 \\
\hline 1MCT-1 & 0.268 & 0.263 \\
\hline 1MCT-2 & 0.20 & 0.18 \\
\hline Pilot Run 2 & 0.079 & 0.12 \\
\hline 2MCT-2 & 0.126 & 0.19 \\
\hline 2MCT-3 & 0.136 & 0.20 \\
\hline 2MCT-1 (loaded) & 0.063 & 0.062 \\
\hline
\end{tabular}


Table 3-3. System Removal Performance, Quantities of Radionuclides.

\begin{tabular}{|c|c|c|c|c|c|c|}
\hline Contaminant & $\begin{array}{c}\text { Average } \\
\text { Concentra- } \\
\text { tion of } \\
\text { Well } \\
\text { Influent } \\
\text { (pCi/L) }\end{array}$ & $\begin{array}{c}\text { Average } \\
\text { Concentration } \\
\text { of System } \\
\text { Effuent } \\
\text { (pCi/L) }\end{array}$ & $\begin{array}{c}\text { Liters (gal) } \\
\text { treated }\end{array}$ & $\begin{array}{l}\text { Total pico- } \\
\text { Curies } \\
\text { Removed }\end{array}$ & Specific Activity & $\begin{array}{c}\text { Total } \\
\text { Grams } \\
\text { Removed }\end{array}$ \\
\hline \multicolumn{7}{|c|}{ 216-B-5 Reverse Well Plumes } \\
\hline${ }^{90} \mathrm{Sr}-$ Run 1 & 3,937 & 936 & $\begin{array}{l}2,283,725 \\
(603,362)\end{array}$ & $6.853 \times 10^{9}$ & $1.41 \times 10^{14} \mathrm{pCi} / \mathrm{g}$ & $4.86 \times 10^{-5}$ \\
\hline${ }^{90} \mathrm{Sr}-\operatorname{Run} 2$ & 4,896 & 267 & $\begin{array}{l}1,448,406 \\
(382,670)\end{array}$ & $6.705 \times 10^{9}$ & $n n n$ & $4.76 \times 10^{-5}$ \\
\hline${ }^{90} \mathrm{Sr}$ - Total & N/A & N/A & $\begin{array}{l}3,732,131 \\
(986,032)\end{array}$ & $1.356 \times 10^{10}$ & $n n n$ " n. & $9.62 \times 10^{-5}$ \\
\hline${ }^{137} \mathrm{Cs}$ - Run 1 & 1,354 & $55.6(\mathrm{OS}=8)$ & $\begin{array}{l}2,283,725 \\
(603,362)\end{array}$ & $\begin{array}{c}2.965 \times 10^{9} \\
\left(3.074 \times 10^{9}\right)\end{array}$ & $8.7 \times 10^{13} \mathrm{pCi} / \mathrm{g}$ & $\begin{array}{c}3.41 \times 10^{-5} \\
\left(3.53 \times 10^{-5}\right)\end{array}$ \\
\hline${ }^{137} \mathrm{Cs}$ - Run 2 & 1,457 & $\begin{array}{c}58.5 \\
(O S=5.75)\end{array}$ & $\begin{array}{l}2,283,725 \\
(382,670)\end{array}$ & $\begin{array}{r}2.026 \times 10^{9} \\
\left(2.102 \times 10^{9}\right)\end{array}$ & $n n$ & $\begin{array}{c}2.33 \times 10^{-5} \\
\left(2.42 \times 10^{-5}\right)\end{array}$ \\
\hline${ }^{137} \mathrm{Cs}$ - Total & N/A & N/A & $\begin{array}{l}3,732,131 \\
(986,032) \\
\end{array}$ & $\begin{array}{r}4.991 \times 10^{9} \\
\left(5.176 \times 10^{9}\right)\end{array}$ & $n n n$ & $\begin{array}{c}5.74 \times 10^{-5} \\
\left(5.95 \times 10^{-5}\right)\end{array}$ \\
\hline $\begin{array}{l}{ }^{239 / 240} \mathrm{Pu}- \\
\text { Run } 1\end{array}$ & 19.4 & $\begin{array}{c}5.5 \\
(O S=1.55)\end{array}$ & $\begin{array}{r}2,283,725 \\
(603,362)\end{array}$ & $\begin{array}{c}3.174 \times 10^{7} \\
\left(4.065 \times 10^{7}\right)\end{array}$ & $8.86 \times 10^{10} \mathrm{pCi} / \mathrm{g}$ & $\begin{array}{c}3.58 \times 10^{-4} \\
\left(4.59 \times 10^{-4}\right)\end{array}$ \\
\hline $\begin{array}{l}{ }^{239 / 240} \mathrm{Pu} \\
\text { (extrapolated } \\
\text { for total run) }\end{array}$ & 19.4 & $\begin{array}{c}5.6 \\
(O S=1.55)\end{array}$ & $\begin{array}{l}3,732,131 \\
(986,032)\end{array}$ & $\begin{array}{c}5.188 \times 10^{7} \\
\left(6.662 \times 10^{7}\right)\end{array}$ & $n n$ & $\begin{array}{r}5.86 \times 10^{-4} \\
\left(7.52 \times 10^{-4}\right)\end{array}$ \\
\hline \multicolumn{7}{|c|}{ 216-BY Cribs Plume } \\
\hline${ }^{99} \mathrm{Tc}$ & 9,007 & 164 & $\begin{array}{l}1,426.037 \\
(376,760) \\
\end{array}$ & $1.262 \times 10^{10}$ & $1.7 \times 10^{10} \mathrm{pCi} / \mathrm{g}$ & $0.74 \mathrm{~g}$ \\
\hline${ }^{60} \mathrm{Co}$ & 156 & $\begin{array}{c}38 \\
(O S=10.5)\end{array}$ & $\begin{array}{l}1,426.037 \\
(376,760)\end{array}$ & $\begin{array}{c}1.683 \times 10^{8} \\
\left(2.075 \times 10^{8}\right)\end{array}$ & $\begin{array}{c}1.130 \times 10^{15} \\
\mathrm{pCi} / \mathrm{g}\end{array}$ & $\begin{array}{r}1.49 \times 10^{-7} \\
\left(1.84 \times 10^{-7}\right)\end{array}$ \\
\hline
\end{tabular}

NOTES:

1. All data calculated from Appendix $C$ tables.

2. $\quad \mathrm{OS}=\mathrm{X}$ is offsite laboratory analytical results. Bracketed calculations for total curies and total grams are based on using offsite analyses when 222-S Laboratory results were reported as lessthan detection values. 
Rev. 0

Table 3-4. Cost/Resource Requirements. (3 Sheets)

\begin{tabular}{|c|c|}
\hline Resources & Dollars \\
\hline \multicolumn{2}{|c|}{ Design Engineering and Systems Fabrication/Field Installation (FY 1994 only) } \\
\hline \multicolumn{2}{|c|}{\begin{tabular}{l|l|} 
Design Engineering & \\
\end{tabular}} \\
\hline Exempt & 367.9 \\
\hline Nonexempt & 31.7 \\
\hline Bargaining Unit & 0.1 \\
\hline Materials & 341.2 \\
\hline Other $^{\mathrm{b}}$ & 227.8 \\
\hline Indirect $^{c}$ & 527.0 \\
\hline Subtotal & $1,495.7$ \\
\hline \multicolumn{2}{|l|}{ Systems Fabrication/Field Installation } \\
\hline Exempt & 3.8 \\
\hline Craft & 17.7 \\
\hline Subcontractors & $458.0^{\mathrm{d}}$ \\
\hline Indirects & 8.6 \\
\hline Subtotal & 488.10 \\
\hline Total & $1,983.8$ \\
\hline \multicolumn{2}{|c|}{ 216-B-5 Reverse Well Operations } \\
\hline Exempt & $235.6(115.8)^{\mathrm{e}}$ \\
\hline Nonexempt & $24.8(8.0)^{\mathrm{e}}$ \\
\hline Craft & $16.4(16.4)^{e}$ \\
\hline Materials/Equipment & 36.3 \\
\hline Sample Analysis & $158.9(145.9)^{f}$ \\
\hline Other ${ }^{b}$ & 200.6 \\
\hline Indirect & 232.7 \\
\hline Total & 905.3 \\
\hline \multicolumn{2}{|c|}{ 216-BY-Cribs Operations } \\
\hline Exempt & $178.8(57.3)^{\mathrm{c}}$ \\
\hline Nonexempt & $60.3(45.1)^{\mathrm{c}}$ \\
\hline Craft & $4.0(4.0)^{c}$ \\
\hline Materials & 44.0 \\
\hline Analytical & $99.5(84.5)^{f}$ \\
\hline Other & 98.8 \\
\hline Indirect & 195.6 \\
\hline Total & 681.0 \\
\hline \multicolumn{2}{|c|}{ 216-B-5 Reverse Well Mini-Column Tests } \\
\hline$\overline{\text { Exempt }}$ & 36.3 \\
\hline Materials & 16.4 \\
\hline Sample Analysis & $199.9(198.3)^{f}$ \\
\hline Other & 7.8 \\
\hline Indirect & 43.7 \\
\hline Total & 304.1 \\
\hline
\end{tabular}


Rev. 0

Table 3-4. Cost/Resource Requirements. (3 Sheets)

\begin{tabular}{|c|c|}
\hline Resources & Dollars \\
\hline \multicolumn{2}{|c|}{ 216-BY-Cribs Mini-Column Tests } \\
\hline Exempt & 5.9 \\
\hline Materials & 1.0 \\
\hline Sample Analysis & $10.1(5.1)^{f}$ \\
\hline Indirect & 5.3 \\
\hline Total & 22.3 \\
\hline \multicolumn{2}{|c|}{ Project Support } \\
\hline Exempt & 265.7 \\
\hline Nonexempt & 24.4 \\
\hline Craft & 3.6 \\
\hline Materials & 0.3 \\
\hline Other & 19.1 \\
\hline Indirect & 190.0 \\
\hline Total & 503.1 \\
\hline \multicolumn{2}{|c|}{ Project Management (FY 1994 and 1995) } \\
\hline Exempt & 224.6 \\
\hline Nonexempt & 0.8 \\
\hline Materials & 23.8 \\
\hline Other & 32.0 \\
\hline Indirect & 283.3 \\
\hline Total & 564.5 \\
\hline \multicolumn{2}{|c|}{ Waste Management } \\
\hline Exempt & 3.6 \\
\hline Nonexempt & 1.1 \\
\hline Other & 22.2 \\
\hline Indirect & 7.2 \\
\hline Total & 34.1 \\
\hline \multicolumn{2}{|c|}{ Winterization Activities at 216-B-5 Reverse Well and 216-BY-Cribs } \\
\hline Exempt & 10.2 \\
\hline Craft & 57.3 \\
\hline Materials & 36.7 \\
\hline Indirect & 23.6 \\
\hline Total & 127.8 \\
\hline \multicolumn{2}{|c|}{ Tank Cleanout at 216-B-5 Reverse Well and 216-BY-Cribs } \\
\hline Exempt & 15.2 \\
\hline Craft & 66.1 \\
\hline Other & 1.4 \\
\hline Sample Analysis & 25.1 \\
\hline Indirect & 10.8 \\
\hline Total & 118.6 \\
\hline
\end{tabular}


DOE/RL-95-59

Rev. 0

Table 3-4. Cost/Resource Requirements. (3 Sheets)

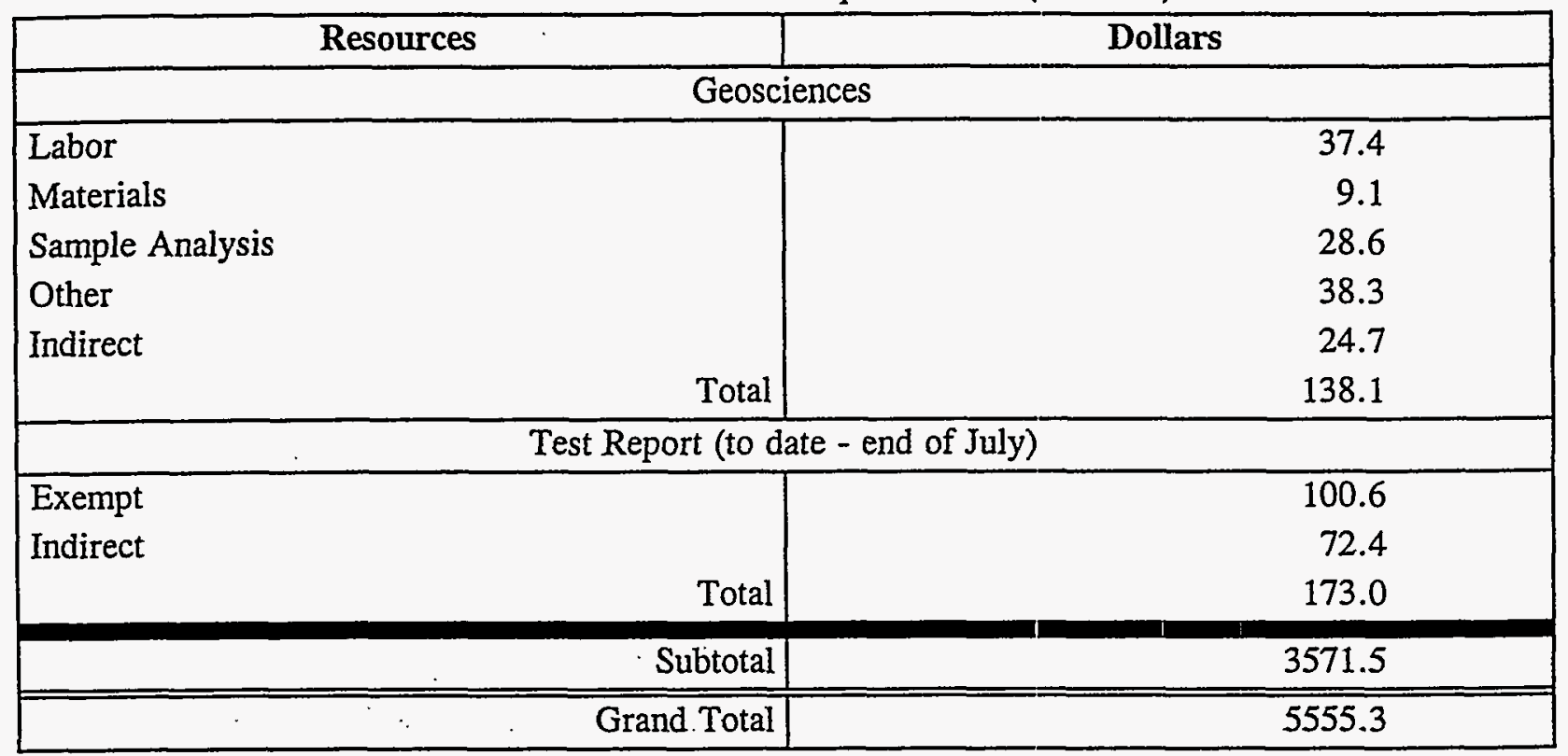

${ }^{2}$ Design Engineering costs are undifferentiated for the two systems. Design Engineering and Systems Fabrication/Field Installation are FY 1994 activities only.

'Other: Costs reported here vary between tasks, but include Purchase Order contracts, subcontractor Westinghouse Hanford Company, subcontractor analytical (when not reported separately), travel and living, heavy equipment, office supplies, miscellaneous purchased services taxed, shop and laboratory supplies, Hanford Site telephone, U.S. postage, etc.

'Indirects include Bechtel Hanford, Inc. (BHI) award fee, BHI direct distributable, BHI general distributable, BHI operating centers, BHI General and Administrative, and organizational overhead.

${ }^{d}$ Subcontractor includes labor, materials, equipment, etc., used for site preparation and field installation of both treatment systems.

¿Numbers in parentheses are labor dollars during months of operation.

Numbers in parenthesis are 222-S Laboratory dollars. 
Rev. 0

Table 3-5. N-Springs Groundwater Test Conditions and Breakthrough of Strontium-85 in Clinoptilolite Adsorbent.

\begin{tabular}{|c|c|c|c|c|c|c|c|}
\hline $\begin{array}{c}\text { Empty Bed } \\
\text { Residence } \\
\text { Time (min) }\end{array}$ & $\begin{array}{c}\text { Bed } \\
\text { Volume } \\
(\mathbf{m L})\end{array}$ & $\begin{array}{c}\text { Pore } \\
\text { Volume } \\
(\mathbf{m L})\end{array}$ & $\begin{array}{c}\text { Flow } \\
\text { rate } \\
(\mathrm{BV} / \mathrm{h})\end{array}$ & $\begin{array}{c}\text { Pore Space } \\
\text { Residence } \\
\text { Time (min) }\end{array}$ & $\begin{array}{c}\text { BV at 0.7\% } \\
\text { Breakthrough }\end{array}$ & $\begin{array}{c}\text { BV at 3.5\% } \\
\text { Breakthrough }\end{array}$ & $\begin{array}{c}\text { Breakthrough } \\
\text { at End of Run }\end{array}$ \\
\hline 13.4 & 6.89 & 3.68 & 4.35 & 7.2 & 540 & 860 & $\begin{array}{c}40 \% \text { at } \\
4,700 \mathrm{BV}\end{array}$ \\
\hline 27 & 10.12 & 5.38 & 2.17 & 14.5 & 970 & 1,400 & $\begin{array}{c}15 \% \text { at } \\
2,400 \mathrm{BV}\end{array}$ \\
\hline
\end{tabular}

NOTE: $0.7 \%$ breakthrough $=$ approximately $8 \mathrm{pCi} / \mathrm{L}$ and $3.5 \%$ breakthrough $=$ approximately $41 \mathrm{pCi} / \mathrm{L}$.

Sources:

Mattigod, S. V., R. J. Serne, T. L. Gervais, D. S. D. Burke, and N. Neerchal, 1995, Remediation of ${ }^{90} \mathrm{Sr}$ Contaminated Groundwater from $100 \mathrm{~N}$ Area Using Clinoptilolite Ion Exchange Columns: Data from Bench Scale Tests, In Preparation, Pacific Northwest National Laboratory, Richland, Washington.

$\mathrm{BV}=$ bed volume 
DOE/RL-95-59

Rev. 0 
Rev. 0

\subsection{GROUNDWATER MONITORING AND ASSESSMENT ACTIVITIES}

This chapter describes hydrologic and contaminant impacts associated with extracting and injecting groundwater at the B-5 Reverse Well and the BY-Cribs. Well suitability test data are presented in Section 4.1. Well suitability data are used in conjunction with baseline water quality data to determine well yield, injection capacity, and evaluate well locations as points of extraction/injection. Water-level monitoring efforts to assess hydrologic impacts are presented in Section 4.2. Section 4.3 describes baseline water quality and the contaminant response to pumping at the extraction well. Because of scheduling constraints, post-treatability groundwater samples were not collected. In situ groundwater flow velocity and other assessment activities (e.g., sonic cone penetrometer test) are discussed in Section 4.4.

\subsection{WELL SUITABILITY INVESTIGATION}

Groundwater monitoring wells near the planned pumping and injection centers and those wells proposed as extraction/injection wells were evaluated to assess fitness-for-use before treatability testing. Tasks performed to assess fitness consisted of borehole camera surveys, well scrubbing and cleaning, and withdrawal and injection tests. The withdrawal/injection tests were performed to determine well yield and injection capacity. Selected wells were redeveloped or deepened (e.g., cement plug drilled out/drilled deeper) to maximize water production during testing. Data collected during well suitability testing and baseline groundwater sampling (Sections 4.3.1 and 4.3.5) were used to select potential extraction and injection wells. Well suitability tests were performed in wells 299-E28-1, 299-E28-2, 299-E28-7, 299-E28-23, 299-E28-24, and 299-E28-25 at the B-5 Reverse Well site. Wells 299-E28-23 and 299-E28-25 were also sampled during suitability tests to assess changes in contaminant concentrations over time. Well suitability tests were performed in wells 699-49-55A, 699-49-57A, and 699-50-53A at the BY-Cribs site. Table 4-1 summarizes activities performed in each well and gives production data.

Wells 299-E28-23 and 299-E28-7 were selected as the extraction and injection well, respectively, at the B-5 Reverse Well site. Well 299-E28-23 was selected as the extraction well because it is located in the most contaminated section of the plume and the well yield was sufficient to support designed pumping rates. Well 299-E28-7 was selected as the site of injection because it is located within the plume and because minor changes in head were observed with respect to gallons injected. The injection well was later changed to well 299-E28-25 to enhance tracer testing (see discussion in Section 4.4.4). Wells 299-E28-1 and 299-E28-2 were not used as extraction or injection centers because they are outside of the plume. Well 299-E28-24 was not used as an extraction well because of high turbidity and low yield.

Samples collected over time during suitability testing in wells 299-E28-23 and 299-E28-25 showed contaminant concentrations declining $32 \%$ to $65 \%$ after approximately $2.5 \mathrm{~h}$ of pumping. The concentration of ${ }^{137} \mathrm{Cs}$ decreased by $32 \%$ in the these wells over the same period of time. The reduction in the concentrations of ${ }^{239240} \mathrm{Pu}$ and ${ }^{90} \mathrm{Sr}$ varied in these wells, but was greater than $45 \%$. The groundwater data are presented in Table 4-2.

Wells 699-50-53A and 699-49-55A were selected as extraction and injection wells, respectively, at BY-Cribs. Well 299-50-53A was chosen because it is located in the most contaminated section of the plume. Well $699-49-55 \mathrm{~A}$ was selected as the site of injection because it is upgradient of the 
extraction well, located within the plume, and the closest available well. Well 699-49-57A was not used for extraction or injection because it is too distant from other wells evaluated. None of the wells evaluated at the BY-Cribs produced appreciable amounts of groundwater during pumping.

\subsection{WATER-LEVEL MONITORING IN SUPPORT OF TREATABILITY TESTING}

This section describes groundwater conditions before and during treatability testing. Data are not yet available to determine groundwater conditions after completion of the test.

\subsubsection{Pre-Treatability Test Water-Level Monitoring at the 216-B-5 Reverse Well Site}

Groundwater monitoring wells in the vicinity of the B-5 Reverse Well are located in an area where the hydraulic gradient is very small, hydraulic conductivities are high, and flow direction is controlled by the regional gradient from the west and mounding from the B Pond to the east. Based on the available data, the apparent flow direction at the site was to the southeast about 2 weeks before the start of treatability testing (Figure 4-1). The level of confidence placed in data used to create the groundwater map is low as the potential error using standard measuring techniques (e.g., surveying, depth to water measurements, verticality of the borehole) may be large in contrast to the gradient. However, the groundwater flow direction as depicted is not unreasonable based on the regional flow in the vicinity of the 200 East Area. Pre-treatability test water-level measurements collected on August 16, 1994, were used to estimate groundwater flow direction.

Water-level data also indicate that the elevation of the water table is currently declining at a rate of about $1.8 \mathrm{~m} / \mathrm{yr}(0.6 \mathrm{ft} / \mathrm{yr})$. The decline in the elevation of the water table is the result of the reduction in effluent discharge to the sediment column over the last decade, primarily at B Pond.

\subsubsection{Water-Level Monitoring During Operation at the 216-B-5 Reverse Well Site}

Water levels were monitored at the extraction well (299-E28-23), two injection wells (299-E28-7 and 299-E28-25), and an observation well (299-E28-24) during treatability testing. Well 299-E28-7 was used as the return well until April 7, 1995. Well 299-E28-25 was used as the injection well after that date to support tracer testing.

Water levels in the extraction and observation wells showed no response to pump-and-treat operations. Observed water-level fluctuations correspond mainly to barometric pressure changes. The daily average pumping rate at the extraction well was approximately $102 \mathrm{~L} / \mathrm{min}(27 \mathrm{gal} / \mathrm{min}) \mathrm{during}$ operations. Maximum sustained yield during operation could not be determined because of the lack of drawdown.

Groundwater was injected into well $299-\mathrm{E} 28-7$ at an average rate of $132 \mathrm{~L} / \mathrm{min}$ (35 gal $/ \mathrm{min})$. This resulted in an average head increase of $0.15 \mathrm{~m}(0.5 \mathrm{ft})$ [a maximum of $0.6 \mathrm{~m}(2 \mathrm{ft}$ was observed]. The average injection capacity is $80.8 \mathrm{~L} / \mathrm{min} / \mathrm{m}(70 \mathrm{gal} / \mathrm{min} / \mathrm{ft})$, and the average rate of injection in well $299-\mathrm{E} 28-25$ was $178 \mathrm{~L} / \mathrm{min}$ (47 $\mathrm{gal} / \mathrm{min})$. The average head is $0.15 \mathrm{~m}(0.5 \mathrm{ft}$ ) [maximum of 


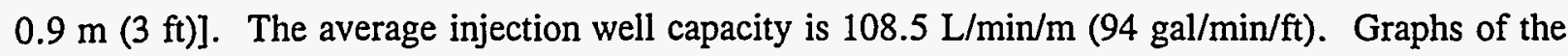
complete water-level data set are presented in Appendix D.

During the two tracer tests at the 216-B-5 site, pumping at approximately $106 \mathrm{~L} / \mathrm{min}$ ( $28 \mathrm{gal} / \mathrm{min}$ ) occurred continuously for more than $120 \mathrm{~h}$. Water level monitoring data collected during the tests indicated 0.6 to $1.3 \mathrm{~cm}(0.25$ to $0.5 \mathrm{in}$.) of drawdown in the extraction well. The uncertainty in hydraulic gradient and aquifer hydraulic properties is much greater in magnitude. Further, top-ofcasing surveys include an allowable error greater than $0.01 \mathrm{~m}$, which could corrupt any inference about the cone of depression made from the data. Describing the effects of the extraction well on the aquifer with such little drawdown requires much more precision in aquifer characterization and absolute water level measurement techniques than currently exist.

\subsubsection{Post-Treatability Test Water-Level Data at the 216-B-5 Reverse Well Site}

Water-level data were not collected to assess groundwater flow direction after treatability testing.

\subsubsection{Pre-Treatability Test Water-Level Monitoring at the 216-BY Cribs}

Groundwater monitoring wells in the vicinity of the BY-Cribs are located north of the B-5 Reverse Well and are controlled by the same regional flow regime described in Section 4.2.1. The water-table map suggests that groundwater flow direction beneath the site is predominantly to the northwest and is controlled more by mounding from B Pond than by regional gradient. The water table in the vicinity of the BY-Cribs site is shown in Figure 4-2. Pre-treatability test water-level data indicate that the elevation of the water table is declining at a rate of about $0.18 \mathrm{~m} / \mathrm{yr}(0.6 \mathrm{ft} / \mathrm{yr})$. Pre-treatability test water-level measurements collected during June 1994 were used to estimate groundwater flow direction at the BY-Cribs.

\subsubsection{Water-Level Monitoring During Operation at the 216-BY Cribs}

During treatability testing water levels were monitored at extraction well 699-50-53A, injection well 699-49-55A, and two nearby deeper confined aquifer wells (699-50-53B and 699-49-55B) that penetrated the Elephant Mountain basalt into the Rattlesnake Ridge interbed. The extraction and injection wells were monitored to assess optimum rate of extraction/injection as other unconfined wells in the network were not in the area influenced by the test. Wells monitoring the confined aquifer were evaluated to assess communication with the unconfined aquifer.

Water levels in confined aquifer wells showed no response to treatability test activities. For all wells monitored, water-level fluctuations corresponded mainly to barometric pressure changes. The extraction well sustained an average drawdown of $2.21 \mathrm{~m}(7.26 \mathrm{ft})$ at an average pumping rate of 13.2 $\mathrm{L} / \mathrm{min}(3.5 \mathrm{gal} / \mathrm{min})$. The average well capacity at the extraction well is $0.6 \mathrm{~L} / \mathrm{min} / \mathrm{m}$ $(0.5 \mathrm{gal} / \mathrm{min} / \mathrm{ft})$. The injection well sustained an average injection rate of $95 \mathrm{~L} / \mathrm{min}(25 \mathrm{gal} / \mathrm{min})$ with an average head increase of $2.9 \mathrm{~m}(9.5 \mathrm{ft})$ [maximum of $3 \mathrm{~m}(11 \mathrm{ft})$ ]. The average injection capacity in the injection well is $3.0 \mathrm{~L} / \mathrm{min} / \mathrm{m}(2.6 \mathrm{gal} / \mathrm{min} / \mathrm{ft})$.

At the BY-Cribs site, drawdown in the extraction well exceeded the thickness of the aquifer. The resulting water level was below the Ringold/Hanford contact. No observation wells were available to 
provide additional drawdown data. The cone of depression would have to be based on the drawdown data collected from the extraction well. Interpretation of the data becomes ambiguous because of the uncertainty of the source of the water in the well. The drawdown in the extraction well is not interpretable with regard to areal influence because the cone of depression at the extraction well exceeds the aquifer thickness.

\subsubsection{Post-Treatability Test Water-Level Monitoring at 216-BY Cribs}

Water-level data were not collected to assess groundwater flow direction after treatability testing.

\subsection{CONTAMINANT CONCENTRATION RESPONSE}

This section describes baseline water quality and the contaminant response to pumping at the extraction well. Data are not available to determine post-treatability test water quality at the B-5 Reverse Well and the BY-Cribs sites.

\subsubsection{Baseline Groundwater Quality in the 216-B-5 Reverse Well Plume}

4.3.1.1 Cesium-137. Cesium-137 was detected in three monitoring wells before treatability testing. A maximum activity of $2,550 \mathrm{pCi} / \mathrm{L}$ was detected in extraction well 299-E28-23 in June 1994. Cesium-137 was also detected in wells 299-E28-7 and 299-E28-25 ranging between 15.3 and $280 \mathrm{pCi} / \mathrm{L}$. Cesium-137 was not detected in well $299-\mathrm{E} 28-1$. The distribution of ${ }^{137} \mathrm{Cs}$ before treatability testing is shown in Figure 4-3. Baseline groundwater data are presented in Table 4-2.

4.3.1.2 Plutonium-239/240. Plutonium-239/240 was detected in two wells at the B-5 Reverse Well site before treatability testing in excess of the MCL $(1.2 \mathrm{pCi} / \mathrm{L})$. A maximum activity of $25.7 \mathrm{pCi} / \mathrm{L}$ was detected in well 299-E28-23 in March 1994. The level of contamination in well 299-E28-25 did not exceed $17.5 \mathrm{pCi} / \mathrm{L}$. Plutonium-239/240 was not detected in wells 299-E28-1 and 299-E28-7. The distribution of ${ }^{239240} \mathrm{Pu}$ before treatability testing is shown in Figure 4-3. Baseline groundwater data are presented in Table 4-2.

4.3.1.3 Strontium-90. Elevated levels of ${ }^{90} \mathrm{Sr}$ in excess of the MCL ( $\left.8 \mathrm{pCi} / \mathrm{L}\right)$ were detected in wells $299-\mathrm{E} 28-7,299-\mathrm{E} 28-23$, and $299-\mathrm{E} 28-25$. The maximum activity exceeded $11,400 \mathrm{pCi} / \mathrm{L}$ in well 299-E28-23 during the June 1994 sampling event. Concentrations in wells 299-E28-7 and 299-E28-25 range between 160 and $4,730 \mathrm{pCi} / \mathrm{L}$. Strontium-90 activity did not exceed $0.5 \mathrm{pCi} / \mathrm{L}$ in well 299-E28-1. The distribution of strontium-90 before treatability testing is shown in Figure 4-3. Baseline groundwater data are presented in Table 4-2.

\subsubsection{Contaminant Response to Pumping at Extraction Well 299-E28-23}

Groundwater samples were collected daily during Run 1 at the B-5 Reverse Well site to assess the contaminant response to pumping. Although sampling and testing started on August 29, 1994, effective operations of the system did not begin until January 17, 1995. Run 1 ended on March 17,1995, concluding a 2-month cycle of pumping groundwater an average of 8-h/day, 5 days/week (i.e., weekly operation). Starting on February 6,1995 , the extraction well was pumped 
continuously for 5 days and then shut off. The average pumping rate during all stages of testing in Run 1 was about $102 \mathrm{~L} / \mathrm{min}(27 \mathrm{gal} / \mathrm{min})$ and resulted in total volume of 2,283,967 L (603,362 $\mathrm{gal})$ of groundwater being extracted. During Run 1, groundwater was injected into well 299-E28-7, located about $17 \mathrm{~m}(57 \mathrm{ft})$ southeast of the extraction well.

Run 2 started on April 10, 1995 (about 3 weeks after Run 1 was completed). Groundwater samples were collected every other day. Well 299-E28-25 located about $7 \mathrm{~m}(24 \mathrm{ft})$ northwest of the extraction well was used as the injection well. Run 2 continued for 6 weeks at an average pumping rate of $100 \mathrm{~L} / \mathrm{min}(26.4 \mathrm{gal} / \mathrm{min})$. The average pumping cycle was $8 \mathrm{~h} /$ day, 5 days/week (i.e., weekly operation). The rate of extraction was increased to $105 \mathrm{~L} / \mathrm{min}(27.8 \mathrm{gal} / \mathrm{min})$ on May 21 , 1995 , and the well was continuously pumped for 5.5 days. Samples were collected every day during continuous pumping. During weekly operation, $700,299 \mathrm{~L}(185,000$ gal) was pumped compared to $660,583 \mathrm{~L}(174,508 \mathrm{gal})$ during continuous pumping in Run 2.

Accounting for processing during startup activities and other operating periods, a total of $37,325,255 \mathrm{~L}(986,032 \mathrm{gal})$ was processed through the B-5 Reverse Well treatment system (see Section 3.1.1.1). Using porosities of 0.22 and 0.30 estimated from the tracer tests (see Section 4.4.4), the calculated ratios of capture over the duration of the B-5 Reverse Well treatability test ranged from 15 to $20 \mathrm{~m}(50$ to $65 \mathrm{ft})$.

During Runs 1 and 2, the concentration of ${ }^{137} \mathrm{Cs},{ }^{239 / 240} \mathrm{Pu}$, and ${ }^{90} \mathrm{Sr}$ ultimately decline by the end of each run. Figures 4-4, 4-5, and 4-6 show the variability and overall reduction in the concentration of ${ }^{137} \mathrm{Cs}$, ${ }^{239 / 240} \mathrm{Pu}$, and ${ }^{90} \mathrm{Sr}$, respectively, in the groundwater. The average concentration during each stage of pumping (e.g., weekly versus continuous) in Runs 1 and 2 are summarized and ranked in Table 4-3 to show the contaminant response to groundwater extraction. Discussions of the contaminant response to pumping at the extraction well are presented in the following sections.

4.3.2.1 Cesium-137. The concentration of ${ }^{137} \mathrm{Cs}$ was $1,470 \mathrm{pCi} / \mathrm{L}$ in the initial groundwater sample collected during Run 1. This concentration can be compared to an average baseline concentration of ${ }^{137} \mathrm{Cs}(2,265 \mathrm{pCi} / \mathrm{L})$ in the groundwater to assess the initial contaminant response to pumping, which indicates that ${ }^{137} \mathrm{Cs}$ contamination was reduced approximately $35 \%$. A similar response (32\% reduction) was also observed during well suitability testing.

The concentration of ${ }^{137} \mathrm{Cs}$ ranged between 1,170 and $1,870 \mathrm{pCi} / \mathrm{L}$ during weekly operations in Run 1 [pumping $107 \mathrm{~L} / \mathrm{min}(26.7 \mathrm{gal} / \mathrm{min})$, generally $8 \mathrm{~h} /$ day, 5 days/week], and a gradual downward trend in the level of contamination was observed. An average concentration of $1,450 \mathrm{pCi} / \mathrm{L}$ was detected in the groundwater during the first half of Run 1 compared to an average of $1,252 \mathrm{pCi} / \mathrm{L}$ during the second half of Run 1 . This indicates that the contaminant response to pumping was greater at the beginning of Run 1. At the end of weekly operations, the concentration of ${ }^{137} \mathrm{Cs}$ was $1,210 \mathrm{pCi} / \mathrm{L}$. This concentration is $47 \%$ below baseline and $18 \%$ below the initial concentration of $1,470 \mathrm{pCi} / \mathrm{L}$ in Run 1. An average concentration of $1,360 \mathrm{pCi} / \mathrm{L}$ was detected in the groundwater during weekly operations. The data also suggest that the level of ${ }^{137} \mathrm{Cs}$ contamination occasionally increased $10 \%$ over weekends when no pumping occurred.

Slightly more than a $10 \%$ decline in the level of ${ }^{137} \mathrm{Cs}$ contamination was observed during continuous pumping ( $28.3 \mathrm{gal} / \mathrm{min}$ for 5 days) in Run 1 . Contamination ranged between 1,350 and $1,570 \mathrm{pCi} / \mathrm{L}$ during continuous pumping, and the average concentration of ${ }^{137} \mathrm{Cs}$ in the groundwater was $1,425 \mathrm{pCi} / \mathrm{L}$. 
Run 2 began after a 3-week period without extracting groundwater. Groundwater samples collected during Run 2 indicated that ${ }^{137} \mathrm{Cs}$ contamination increased by $12 \%$ to $1,380 \mathrm{pCi} / \mathrm{L}$ at the start of the test, and an upward trend in the concentration of ${ }^{137} \mathrm{Cs}$ was observed. A general pattern of concentrations decreasing and increasing during periods of extraction and no pumping, respectively, were also observed. The 3-week recovery period accounts for the initial rise in ${ }^{137} \mathrm{Cs}$ at the start of Run 2. Changing the site of groundwater injection to well 299-E28-25 is likely the major factor governing the upward trend observed during pumping. The pumping rate probably had a negligible effect on the trend as the pumping rate approximates the average extraction rate in Run 1 . The average concentration of ${ }^{137} \mathrm{Cs}$ in the groundwater during weekly operations was $1,590 \mathrm{pCi} / \mathrm{L}$ in Run 2.

During Run 2, groundwater was extracted continuously at a rate of $105 \mathrm{~L} / \mathrm{min}(27.8 \mathrm{gal} / \mathrm{min})$ for 5 days. A downward trend in the level of contamination was observed during this period. The initial and final concentration of ${ }^{137} \mathrm{Cs}$ was 1,820 and $1,310 \mathrm{pCi} / \mathrm{L}$, respectively, and represents a $28 \%$ decline in the concentration of ${ }^{137} \mathrm{Cs}$. An average concentration of $1,490 \mathrm{pCi} / \mathrm{L}$ was detected in the groundwater during continuous pumping in Run 2.

4.3.2.2 Plutonium-239/240. The concentration of ${ }^{239 / 240} \mathrm{Pu}$ was $12 \mathrm{pCi} / \mathrm{L}$ in the initial groundwater sample collected during Run 1 . This concentration is $48 \%$ below the baseline level of $23 \mathrm{pCi} / \mathrm{L}$ established before the test.

The concentration of ${ }^{239 / 240} \mathrm{Pu}$ ranged between 12 and $44 \mathrm{pCi} / \mathrm{L}$ during weekly operations in Run 1 . Contaminant levels near the beginning of the test increased to a maximum of $44 \mathrm{pCi} / \mathrm{L}$, indicating that higher concentrations of ${ }^{239 / 240} \mathrm{Pu}$ were made available by extracting groundwater. The higher concentrations observed near the beginning of the test resulted in the greater contaminant mass (average $24 \mathrm{pCi} / \mathrm{L}$ ) being removed in the first part of Run 1 compared to an average of $17 \mathrm{pCi} / \mathrm{L}$ during the later half of the test. The final concentration of ${ }^{239 / 240} \mathrm{Pu}$ in Run 1 was $13.7 \mathrm{pCi} / \mathrm{L}$ and within $1.7 \mathrm{pCi} / \mathrm{L}$ of the initial concentration $(12 \mathrm{pCi} / \mathrm{L})$ at the start of the test. If the initial concentration of $12 \mathrm{pCi} / \mathrm{L}$ is not considered at the start of Run 1 , a clownward decline in the level of contamination is observed over the length of the test. The average concentration in the groundwater during weekly pumping in Run 1 is approximately $19 \mathrm{pCi} / \mathrm{L}$.

The concentration of ${ }^{239 / 240} \mathrm{Pu}$ ranged between 15.6 and $17.5 \mathrm{pCi} / \mathrm{L}$ during continuous pumping [107 L/min (28.3 gal/min)] in Run 1. A downward trend in the level of ${ }^{239} / 240 \mathrm{Pu}$ concentration was observed, and the average concentration in the groundwater was about $16.5 \mathrm{pCi} / \mathrm{L}$. The average groundwater concentration during continuous pumping compares similarly to the average groundwater concentration $(17 \mathrm{pCi} / \mathrm{L})$ during the later half of weekly operations in Run 1 .

The concentration of ${ }^{239 / 240} \mathrm{Pu}$ in the groundwater during Run 2 increased by $31 \%$ to $20 \mathrm{pCi} / \mathrm{L} 3$ weeks after Run 1 was completed. As described regarding ${ }^{137} \mathrm{Cs}$ concentrations in Run 2, the 3-week recovery period and change in injection site form the basis for the higher contaminant levels. The concentration of ${ }^{239 / 240} \mathrm{Pu}$ ranged between 15.7 and $24.1 \mathrm{pCi} / \mathrm{L}$ during routine pumping [107 L/min ( $28.3 \mathrm{gal} / \mathrm{min})$ ] in Run 2 . The average concentration during weekly pumping in Run 2 was about $20 \mathrm{pCi} / \mathrm{L}$.

During the last stage of Run 2, groundwater was extracted continuously at a rate of $105 \mathrm{~L} / \mathrm{min}$ $(27.8 \mathrm{gal} / \mathrm{min})$ for 5 days. The concentration of ${ }^{239 / 240} \mathrm{Pu}$ ranged between 19.9 and $21.1 \mathrm{pCi} / \mathrm{L}$ during continuous pumping in Run 2 , and a slight downward trend in the level of contamination was 
observed. The decline in contaminant concentration was about $5 \%$. The average concentration during pumping was $20 \mathrm{pCi} / \mathrm{L}$.

4.3.2.3 Strontium-90. The concentration of ${ }^{90} \mathrm{Sr}$ was $4,560 \mathrm{pCi} / \mathrm{L}$ in the initial groundwater sample collected during Run 1 . This concentration is $52 \%$ below the baseline level of $9,850 \mathrm{pCi} / \mathrm{L}$ established before the test. A similar response (greater than a $45 \%$ reduction in the concentration of ${ }^{90} \mathrm{Sr}$ ) was also observed during well suitability testing.

The concentration of ${ }^{90} \mathrm{Sr}$ ranged between 3,230 and $4,570 \mathrm{pCi} / \mathrm{L}$, and a gradual, decline in the level of contamination was observed in Run 1 during weekly pumping. An average concentration of $3,856 \mathrm{pCi} / \mathrm{L}$ was detected in the groundwater during the first phase of Run 1 compared to an average of $3,490 \mathrm{pCi} / \mathrm{L}$ during the later half of Run 1 . This indicates that the contaminant response to pumping was greater in the beginning of Run 1 . The average concentration of ${ }^{90} \mathrm{Sr}$ in the groundwater during weekly pumping was approximately $3,663 \mathrm{pCi} / \mathrm{L}$ in $\mathrm{Run} 1$. In addition, at the end of weekly operations the concentration of ${ }^{90} \mathrm{Sr}$ was $3,520 \mathrm{pCi} / \mathrm{L}$, which is $65 \%$ below baseline and $23 \%$ below the initial concentration of $4,560 \mathrm{pCi} / \mathrm{L}$ in Run 1 .

The concentration of ${ }^{90} \mathrm{Sr}$ ranged between 3,400 and $4,500 \mathrm{pCi} / \mathrm{L}$ during continuous pumping, and a downward decline in the level of contamination was observed. The average concentration during continuous pumping was $3,894 \mathrm{pCi} / \mathrm{L}$. This average concentration approximates average contaminant levels observed in the groundwater during the first half of weekly pumping in Run 1.

The concentration of ${ }^{90} \mathrm{Sr}$ in the groundwater during Run 2 increased by $23 \%$ to $4,610 \mathrm{pCi} / \mathrm{L} 3$ weeks after Run 1 was completed. As described regarding ${ }^{137} \mathrm{Cs}$ and ${ }^{239 / 240} \mathrm{Pu}$ concentrations in Run 2 , the 3-week recovery period and change in injection site form the basis for the higher contaminant levels. A general increase in the concentration of ${ }^{90} \mathrm{Sr}$ was observed in Run 2. However, a general pattern of concentrations declining during extraction and increasing during periods of no pumping were also observed. The average rate of removal during Run 2 was $4,970 \mathrm{pCi} / \mathrm{L}$.

Continuous pumping at a rate of $95 \mathrm{~L} / \mathrm{min}(25 \mathrm{gal} / \mathrm{min})$ at the end of Run 2 resulted in a decline in the concentration of ${ }^{90} \mathrm{Sr}$ from 6,410 to $3,600 \mathrm{pCi} / \mathrm{L}$. The average concentration in the groundwater was $4,488 \mathrm{pCi} / \mathrm{L}$.

\subsubsection{Review of Data}

As indicated in Sections 1.3.2 and 4.2 of the Pilot-Scale Treatability Test Plan for the 200-BP-5 Operable Unit (DOE-RL 1995), radionuclide concentrations in the groundwater were expected to rapidly decrease following the start of extraction. The conceptual model assumed that the contaminants dissolved in the groundwater would be depleted after several days to weeks of pumping. This was suggested by the limited migration of the plumes in the last 50 years and the generally high

$\mathrm{K}_{\mathrm{d}}$ values of the contaminants. Specifically, once the contaminated groundwater in the aquifer porespaces had been extracted, contamination concentrations would decline to very low levels. The rate of re-equilibration between sediments contaminated with the radionuclides and "fresh" groundwater would proceed very slowly and would be further limited by continued groundwater pumping. Thus, at some stage of operations, contaminant concentrations would drop and the corresponding process plant extraction efficiency would decline to a very low level. At this point, overall test efficiency would benefit from a halt to allow the aquifer contaminant concentrations to reequilibrate. The concern over this possibility was such that the test plan was modified to require an 
agreement between DOE, EPA and Ecology to approve shutdown and restart of operations. Thus, the consistent concentration of contaminated groundwater was unexpected and prompted an examination of extraction data.

Baseline groundwater data and groundwater data collected in Run 1 were compared to assess the initial contaminant response to pumping. The data indicate that the contaminant response to pumping was substantial during the initial stage of pumping. The initial decline in contaminant concentrations for ${ }^{137} \mathrm{Cs},{ }^{239 / 240} \mathrm{Pu}$, and ${ }^{90} \mathrm{Sr}$ were $35 \%, 48 \%$, and $52 \%$ below baseline, respectively. Comparing these initial changes in the level of contamination to published $\mathrm{K}_{\mathrm{d}}$ values would suggest that ${ }^{239 / 240} \mathrm{Pu}\left(\mathrm{K}_{\mathrm{d}}=\right.$ $2,000 \mathrm{~mL} / \mathrm{g}$, very highly sorbed) and ${ }^{137} \mathrm{Cs}\left(\mathrm{K}_{\mathrm{d}}=500 \mathrm{~mL} / \mathrm{g}\right.$ to $\mathrm{mL} / \mathrm{g}$, highly sorbed) concentrations should respond at a slower rate than anticipated to the effects of further pumping. Only the concentration of ${ }^{90} \mathrm{Sr}\left(\mathrm{K}_{\mathrm{d}}=20 \mathrm{~mL} / \mathrm{g}\right.$, moderately sorbed) was expected to change significantly during pumping. However, data indicate that once the concentrations declined from baseline values, there was a fairly constant range of concentrations for any run.

At least two possible explanations for the differences in the contaminant response to pumping versus the assumed response, as based on reported $\mathrm{K}_{\mathrm{d}}$ values can be offered:

- The contaminants' chemical properties (i.e., sorption rate) may be different than the published $\mathrm{K}_{\mathrm{d}}$ values indicate. The waste stream was injected directly into the groundwater and may still be influenced by the waste stream chemistry. Therefore, the contaminants could be less strongly bonded to the sediment and would be more mobile.

- There may be greater quantities of the contaminants in the aquifer system than calculated from historical process knowledge. Process knowledge quantities were calculated from sample analyses taken from individual batches sent to Tank 241-B-361. Sampling or laboratory measurement inaccuracies may have under-reported the quantities of waste actually going to the ground. Therefore, a greater quantity of the contaminants may be present in the groundwater.

Additional direct evidence is not available to support either alternative. New $\mathrm{K}_{d}$ values cannot be calculated from available test data, and new values cannot be assumed. Circumstantial evidence for larger quantities of waste reaching the ground is presented in Section 5.3.1 and was taken from Smith (1980). Evidence for different $K_{d}$ values may be inferred in the discussion of the B-5 site's phosphate-based geochemistry in Section 5.3.1.

Trends outlined in Section 4.3 suggest that the best operational setting for optimum contaminant removal is the weekly pumping cycle in the configuration of the extraction and injection wells in Run 2. The data also indicate that a recovery period between pumping cycles allows equilibration between the groundwater and contaminants in the aquifer system. The recovery period results in greater contaminant concentrations being available for extraction, which, in turn, enhances removal of the radionuclides mass from the plume. Enhanced contaminant extraction through the use of reactants to remobilize the plume.

The addition into the aquifer of chemical agents to increase the solubility of the contaminants would result in increased contaminant extraction rates and increased process efficiency. 
DOE/RL-95-59

Rev. 0

\subsubsection{Post-Treatability Test Water Quality}

Post-treatability test groundwater data were not collected for this investigation.

\subsubsection{Baseline Groundwater Quality at the 216-BY Cribs Plume}

4.3.5.1 Cobalt-60. Cobalt- 60 was detected at a maximum activity of $74.3 \mathrm{pCi} / \mathrm{L}$ in well $699-52-54$. The contaminant was also detected in wells 299-E33-7, 699-49-55A, 699-50-53A, and 699-55-57, ranging between $6.0 \mathrm{pCi} / \mathrm{L}$ and 50.4 , as well as in three cone penetrometer samples from pushes 49-53, 49-54, and 50-54. Cobalt-60 ranged between $9.7 \mathrm{pCi} / \mathrm{L}$ and $20.1 \mathrm{pCi} / \mathrm{L}$ in cone penetrometer samples. All samples analyzed for ${ }^{60} \mathrm{Co}$ were below the $\mathrm{MCL}$ of $100 \mathrm{pCi} / \mathrm{L}$. The distribution of ${ }^{60} \mathrm{Co}$ before treatability testing is shown in Figure 4-7. Baseline groundwater data are presented in Table 4-4.

4.3.5.2 Technetium-99. Technetium-99 was detected in all groundwater samples. The concentration of ${ }^{99} \mathrm{Tc}$ ranges between 2.47 and $4,310 \mathrm{pCi} / \mathrm{L}$, with the maximum activity occurring in well 699-52-54 during the April 1994 sampling event. The MCL of $900 \mathrm{pCi} / \mathrm{L}$ was exceeded in wells 299-E33-13, 699-49-57A, 699-50-53A, 699-52-54, and 699-55-57, as well as sonic push 50-54.

Technetium-99 in all other groundwater samples collected ranges between 2.47 and $775 \mathrm{pCi} / \mathrm{L}$. The distribution of ${ }^{99} \mathrm{Tc}$ before treatability testing is shown in Figure 4-7. Baseline groundwater data are presented in Table 4-4.

4.3.5.3 Contaminant Response to Pumping at Extraction Well 699-50-53A. Groundwater samples were collected during operations at the BY-Cribs site to assess the contaminant response to pumping. Although sampling and testing started on August 29, 1995, effective operations of the system did not begin until January 18, 1995. The treatability test continued for 4 months (until May 22, 1995). Groundwater samples were collected from a sample port located before the treatment system prefilters. Samples were analyzed for ${ }^{60} \mathrm{Co}$ and ${ }^{99} \mathrm{Tc}$ at the $222-\mathrm{S}$ Laboratory. Confirmatory samples were also occasionally collected and shipped to an offsite laboratory for analyses.

Groundwater was extracted from the aquifer at an average rate of approximately $13.2 \mathrm{~L} / \mathrm{min}$ ( $3.5 \mathrm{gal} / \mathrm{min})$. The maximum average sustainable pumping rate was approximately $12.9 \mathrm{~L} / \mathrm{min}$ (3.4 $\mathrm{gal} / \mathrm{min})$ and was limited by the saturated thickness $[\sim 0.3 \mathrm{~m}(1 \mathrm{ft})]$ of the unconfined aquifer. A total volume of $1,426,187 \mathrm{~L}(376,760 \mathrm{gal})$ was extracted during testing. Using estimated porosity range of 0.2 to 0.3 , the calculated radios of capture over the duration of the treatability test ranged from 70 to $86 \mathrm{~m}$ ( $231 \mathrm{ft}$ to $283 \mathrm{ft}$ ).

4.3.5.3.1 Cobalt-60. The concentration of ${ }^{60} \mathrm{Co}$ was $63 \mathrm{pCi} / \mathrm{L}$ in the initial groundwater sample collected at the BY-Cribs site. This concentration can be compared to the baseline concentration of ${ }^{60} \mathrm{Co}(28 \mathrm{pCi} / \mathrm{L})$ to assess the initial contaminant response to pumping. The initial contaminant response to pumping indicates that ${ }^{60} \mathrm{Co}$ contamination increased by $125 \%$. A gradual increase in the level of contamination was observed in the rest of the treatability test. The final concentration at the end of the test was $177 \mathrm{pCi}$. This increase in the level of contamination is over $600 \%$ above baseline and $280 \%$ above the initial concentration at the start of the test. The data indicate that ${ }^{60} \mathrm{Co}$ is very loosely bonded within the aquifer system and is readily mobilized during pumping. The average concentration of ${ }^{60} \mathrm{Co}$ in the groundwater during pumping was $160 \mathrm{pCi} / \mathrm{L}$. Figure 4-8 shows the variability and overall increase in the concentration of ${ }^{60} \mathrm{Co}$ in the groundwater at the BY-Cribs site. 
The published $\mathrm{K}_{\mathrm{d}}$ of ${ }^{60} \mathrm{Co}(2,000 \mathrm{~mL} / \mathrm{g}$, highly immobile) suggests that the contaminant should not respond significantly to pumping. As discussed in Section 1.3.2, the increased mobility of ${ }^{60} \mathrm{Co}$ is attributed to complexing with ferrocyanide. A possible explanation for the upward trend in the level of contamination may be inherently related to the length of time groundwater was extracted from the aquifer, as the higher levels of contamination were not observed during routine/baseline sampling. The higher levels of contamination were likely due to the larger area influenced by pumping over the average extraction period (e.g., $8 \mathrm{~h} /$ day, 5 days/week).

4.3.5.3.2 Technetium-99. The concentration of ${ }^{99} \mathrm{Tc}$ was $3,270 \mathrm{pCi} / \mathrm{L}$ in the initial groundwater sample collected at the BY-Cribs site. This concentration is two times greater than the baseline level of $1,585 \mathrm{pCi} / \mathrm{L}$ established before the test. A gradual increase in the level of contamination was observed throughout the rest of the test. The final concentration at the end of the test was $6,960 \mathrm{pCi} / \mathrm{L}$. The increase in the level of contamination is over $400 \%$ above baseline and $200 \%$ above the initial concentration at the start of the test. The average concentration of ${ }^{99} \mathrm{Tc}$ in the. groundwater during pumping was $8,810 \mathrm{pCi} / \mathrm{L}$, and values above $10,000 \mathrm{pCi} / \mathrm{L}$ were frequently observed. Figure 4-9 shows the variability and overall increase in the concentration of ${ }^{99} \mathrm{Tc}$ in the groundwater at the BY-Cribs site.

The sample data suggest that ${ }^{99} \mathrm{Tc}$ is very loosely bonded or entrained within the aquifer system and, therefore, is readily available for extraction. The high mobility of ${ }^{99} \mathrm{Tc}$ observed is consistent with the published $\mathrm{K}_{\mathrm{d}}$ value of $0 \mathrm{~mL} / \mathrm{g}$. A possible explanation for the upward trend in the level of contamination is related to the length of time groundwater was extracted from the aquifer as described for ${ }^{60} \mathrm{Co}$.

\subsubsection{Post-Treatability Test Water Quality}

Post-treatability test groundwater data were not collected for this investigation:

\subsection{DESCRIPTION OF OTHER HYDROGEOLOGIC ASSESSMENT ACTIVITIES}

The activities described in this section were performed to respond to test objectives in (DOE-RL 1995c) specifying greater aquifer characterization. A more detailed list of activities was agreed to in the 200 NPL Agreement/Change Control Form (BHI-00203).

\subsubsection{Sonic Push Groundwater Sampling for 216-BY-Cribs Plume Definition}

On July 10, 1994, a 200 NPL Agreement/Change Control Form (BHI-00203) was submitted to approve additional aquifer characterization activities in the vicinity of the BY-Cribs plume in the 200-BP-5 Operable Unit. The work was intended to locate areas of greater aquifer thickness and high contaminant concentrations in the area south of planned extraction well 699-50-53A and the northern fenceline of the 200 East Area. To accomplish these objectives, a Water Development Company sonic drill rig was used to push standard 1-m-long, 4.45-cm- (1-3/4-in.) outer diameter, $2.5-\mathrm{cm}$ (1-in.) inner diameter cone penetrometer rods to collect groundwater samples and determine the bottom of the aquifer. Figure 4-10 presents the eight locations proposed for testing. 
Table 4-5 summarizes the field work that was performed. In 15 operating days, approximately $546 \mathrm{~m}$ $(1,790 \mathrm{ft})$ of hole was pushed in 16 attempts at six of the eight sites. More than $61 \mathrm{~m}(200 \mathrm{ft})$ of cone penetrometer rod was abandoned in the ground above the water table because of stress failures of the rod couplings. The sonic push program was terminated because of schedule constraints and the inability of the rods to handle the drilling stresses necessary to penetrate the lower Hanford gravel unit that overlies and comprises the aquifer.

Groundwater samples were successfully collected at three locations shown in Figure 4-11. The data are presented in Section 4.3.5. The figure also shows the three sites where the sonic push rig was unable to penetrate to groundwater. In all cases of refusal, penetration terminated in the lower Hanford gravel unit with all attempts ending within $9 \mathrm{~m}(30 \mathrm{ft})$ of the expected water-table elevation.

Holes that reached the water table terminated in a hard layer that refused further penetration. It is assumed that the depth of refusal below the water table corresponds to the bottom of the aquifer (top of the basalt). Table 4-6 presents the depths below ground surface of the water table and the refusal unit. The difference between the two numbers is listed as the assumed thickness of the unconfined aquifer.

\subsubsection{Production Testing During Treatability Testing}

Preliminary analysis of data collected from treatability test activities indicates that the aquifer and contaminant distribution of the BY-Cribs plume are not adequately defined to support the decisionmaking process. In lieu of a drilling program, a series of activities was performed as part of the 200 NPL Agreement/Change Control Form (BHI-00203) to support a hydrogeologic assessment of the 200-BP-5 plumes.

4.4.2.1 Production Testing at Well 699-55-57. As part of the 200 NPL Agreement/Change Control Form (BHI-00203), a well fitness-for-use assessment was called out for well 699-55-57. Groundwater samples collected from this well had, over the past several years indicated that the aquifer in this area contained ${ }^{99} \mathrm{Tc}$ concentrations at or above the MCL. This assessment activity was intended to determine if the well could be used as a supplementary or alternate extraction well for the BY-Cribs plume treatability test.

Well 699-55-57 was drilled in 1975 to a depth of $55 \mathrm{~m}$ (180 ft) bgs. Fifteen-centimeter (six-inch) casing was set at the top of basalt, $52 \mathrm{~m}(170 \mathrm{ft}) \mathrm{bgs}$, and supposedly perforated by a cutting torch. The bottom $3 \mathrm{~m}(10 \mathrm{ft})$ of the well was uncased in the underlying fractured basalt. Earlier borehole camera surveys failed to recognize any perforations in the casing, and an attempt to mechanically perforate the $1.3-\mathrm{cm}(0.5-\mathrm{in}$.) heavy-walled casing failed in 1982 . The well was producing approximately $8 \mathrm{~L} / \mathrm{min}$ ( $2 \mathrm{gal} / \mathrm{min}$ ) when it was cleaned and redeveloped as part of the 200-BP-1 Operable Unit site characterization activity in 1990.

In late 1994, the well was cleaned and a second borehole camera survey was conducted. This survey also could not identify any evidence of perforations in the casing. After a measurement of the discharge of the well during a sampling event confirmed that the well was still capable of producing approximately $8 \mathrm{~L} / \mathrm{min}$ ( $2 \mathrm{gal} / \mathrm{min}$ ), a decision was made to perforate the casing using explosive charges in an attempt to stimulate increased well production. The well was jet-shot perforated in the interval $3 \mathrm{~m}$ (10 ft) above the top of basalt. A 10-cm.- (4-in.) diameter \#20 slot screen was later set 
from the top of the perforations to the bottom of the well to control fine formation material that was running into the well through the perforations.

An 8-h pumping test was performed in the well on March 1, 1995, and groundwater samples were collected at 2-h intervals to identify any changes in contaminant concentrations during the test. The results of the sample analyses are found in Table 4-7. An upward trend in the level of contamination was observed as described in Sections 4.3.5.3.1 and 4.3.5.3.2 for ${ }^{60} \mathrm{Co}$ and ${ }^{99} \mathrm{Tc}$.

Because of generator/pump fluctuations during the test, a steady pumping rate could not be established. It was observed that a pump rate of about $9.5 \mathrm{~L} / \mathrm{min}(2.5 \mathrm{gal} / \mathrm{min})$ produced a rapid drawdown of the water level and exceeded the productivity of the well.

Because this production rate was not satisfactory for a candidate extraction well, further investigations were terminated.

4.4.2.2 Sampling at Well 699-55-60. The 200 NPL Agreement/Change Control Form (BHI-00203) also called for the expansion of the BY-Cribs monitoring network to aid in evaluating the extent of the plume. One of the activities outlined in that notice was the sampling of wells $699-55-60 \mathrm{~A}$ and 699-55-60B. Well 699-55-60A was drilled in 1945 as a water supply well to the 200 north facilities and was the nearest well west of the BY-Cribs monitoring network. Well 699-55-60B was also drilled in 1945 as a water supply well for the 200 north facilities. Upon inspection, well 699-55-60B was found to be unusable because of debris in well.

Well 699-55-60A was sampled on March 2, 1995 using a temporary submersible pump. Before sampling, the well was purged at a rate of $8.3 \mathrm{~L} / \mathrm{min}(2.2 \mathrm{gal} / \mathrm{min})$ for 73 minutes. The $\mathrm{pH}$, dissolved oxygen, and temperature were monitored to ensure collection of a representative sample. The results of the sampling found that all three major contaminants of concern were well below the MCL: $26.2 \mathrm{pCi} / \mathrm{L}$ of ${ }^{99} \mathrm{Tc}$ were detected $(\mathrm{MCL}=900 \mathrm{pCi} / \mathrm{L}) ; 0.975 \mathrm{pCi} / \mathrm{L}$ of ${ }^{137} \mathrm{Cs}$ were detected $(\mathrm{MCL}=120 \mathrm{pCi} / \mathrm{L})$; and ${ }^{60} \mathrm{Co}$ was below detection limit of $7.11 \mathrm{pCi} / \mathrm{L}$. Thus, the data do not suggest any current influence from the BY-Cribs plume in this part of the aquifer.

\subsubsection{Groundwater In Situ Flow Survey}

To further support the hydrogeologic assessment of the BY-Cribs plume, as directed by the 200 NPL Agreement/Change Control Form (BHI-00203), in-well flow velocity measurements were performed in wells monitoring the plume. The wells, listed in Table 4-8, were all located between the north end of the 200 East Area and the Gable Mountain Gap. Flow velocities were determined by the thermal perturbation method at various levels within each well (see Table 4-8). Figure 4-12 is a well location map.

The groundwater flow direction and magnitude for each well are shown in Figure 4-12. In general, across the study area, the following may be inferred from the flow velocity measurements:

- Groundwater flow direction in the northwest portion of the 200 East Area is to the south, with magnitudes ranging from $0.13 \mathrm{~m} /$ day to $0.49 \mathrm{~m} /$ day $(0.43 \mathrm{ft} /$ day to $1.6 \mathrm{ft} /$ day).

- Groundwater flow direction northeast of the BY-Cribs is to the northwest around a basalt high with a magnitude of $0.6 \mathrm{~m} /$ day $(1.9 \mathrm{ft} /$ day $)$. 
- Groundwater flow direction north of the 200 East Area and south of West Lake is northerly with a magnitude ranging from less than $0.012 \mathrm{~m} /$ day $(0.04 \mathrm{ft} /$ day) to $0.34 \mathrm{~m} /$ day (1.1 ft/day).

Groundwater velocity measurements less than $0.012 \mathrm{~m} /$ day $(0.04 \mathrm{ft} /$ day $)$ are considered less than the practical resolution of the flowmeter and necessarily invalidate the flow direction and rate.

The complete analysis and results of the flowmeter survey are discussed in Appendix E.

\subsubsection{6-B-5 Reverse Well Tracer Tests}

Tracer tests were performed in the B-5 Reverse Well plume to characterize contaminant transport properties of the aquifer and determine the extent of recirculation within the plume resulting from the proximity of the extraction well (299-E28-23) to injection wells. Wells 299-E28-23 and 299-E28-7 were used in the first test as the discharge and recharge well, respectively, and wells 299-E28-23 and 299-E28-25 were used in the second test as the discharge and recharge well, respectively. The state plane coordinates of the wells are east $683,472 \mathrm{~m}(2,242,361 \mathrm{ft})$ and north $136,746 \mathrm{~m}(448,643 \mathrm{ft})$ for well 299-E28-23, east $683,484 \mathrm{~m}(2,242,402 \mathrm{ft})$ and north $136,734 \mathrm{~m}(448,603 \mathrm{ft})$ for well 299-E28-7, and east $683,466 \mathrm{~m}(2,242,344 \mathrm{ft})$ and north $136,751 \mathrm{~m}(448,660 \mathrm{ft})$ for well 299-E28-25. Based on these coordinates, wells 299-E28-23 and 299-E28-7 are located $17.46 \mathrm{~m}$ $(57.28 \mathrm{ft})$ apart, and wells 299-E28-23 and 299-E28-25 are located $7.32 \mathrm{~m}$ (24.02 ft) apart. Both tracer tests involved 24-h/day extraction and injection at roughly equal flow rates. Tracer sampling of the extraction well started at the onset of slug injection and was performed on an hourly basis throughout the tests. Samples were collected from the injection wellhead at the start of tracer injection and periodically afterwards until the tracer supply was depleted. Three tracer slug samples were collected from test 1 , and four samples were collected from test 2 . The following sections outline tracer preparation techniques, test start/finish times, flow rates, and volume totals for each tracer test.

4.4.4.1 Tracer Test 1. Before starting tracer test 1 , approximately $5 \mathrm{~kg}$ of lithium bromide was mixed with water in a drum and pumped into the base of the effluent tank. Tracer mixing within the effluent tank was accomplished by the turbulence generated from the process flow and pumping. Tracer test 1 started on February 6, 1995, at 08:24 with the injection of approximately 21,198 L $(5,600 \mathrm{gal})$ of lithium bromide at an average flow rate of $199.3 \mathrm{~L} / \mathrm{min}(52.5 \mathrm{gal} / \mathrm{min})$. Tracer samples were collected at 08:39,09:35, and 10:05, and tracer injection finished around 10:25. After charging the effluent tank, effluent injection began at 14:15, and continued until 04:00 hours, February 11,1995 , at an average flow rate of $98 \mathrm{~L} / \mathrm{min}(26 \mathrm{gal} / \mathrm{min})$. Effluent extraction began on February 6, 1995, at 08:02, and continued until 04:00 hours, February 11, 1995, with one interruption: generator servicing occurred on February 7, 1995, from 07:20 to 07:40. The average extraction rate during the test was $107.1 \mathrm{~L} / \mathrm{min}(28.3 \mathrm{gal} / \mathrm{min})$, and the total volume extracted was $507,266 \mathrm{~L}(134,006 \mathrm{gal})$. Effluent sampling began on February 6, 1995 at 8:56, and continued hourly until the test ended. Table 4-9 provides a synopsis of the tracer test 1 events.

4.4.4.2 Tracer Test 2. Daily background bromide sampling at the extraction well began on May 1, 1995, and continued until the tracer was injected on May 21, 1995, excluding May 6 and 7, May 12 through 14, and May 18 through 20, 1995. On May 19, 1995, $10 \mathrm{~kg}$ of potassium bromide was mixed with water and pumped into the effluent tank in the same manner as in tracer test 1 . The tracer volume in the tank measured 23,352 L (6,169 gal). Tracer test 2 began on May 21, 1995 at 
08:36, with the bromide tracer injected at an average of $1,900.3 \mathrm{~L} / \mathrm{min}(50.2 \mathrm{gal} / \mathrm{min})$. Tracer samples were collected at 08:40, 09:10, 09:40, and 10:10, and tracer injection finished around 10:30. Effluent injection began subsequently and continued until 11:00 hours on May 26, , 1995, at an average flow rate of $83 \mathrm{~L} / \mathrm{min}$ ( $22 \mathrm{gal} / \mathrm{min})$. Effluent extraction began on May 21, 1995, at 08:40, and continued until 11:00 hours, May 26, 1995, with one interruption: generator servicing occurred on May 23, 1995, from 07:27 to 07:47. The average extraction rate during the test was $105.6 \mathrm{~L} / \mathrm{min}$ (27.9 $\mathrm{gal} / \mathrm{min})$, and the total volume extracted was $660,583 \mathrm{~L}(174,508 \mathrm{gal})$. Effluent sampling began on May 21,1995 , at 8:46, and continued hourly until the test ended. Table 4-10 provides a synopsis of the tracer test 2 events.

4.4.4.3 Tracer Test Analysis and Results. Data collected from the tracer test were analyzed according to the method described in Grove (1971) for a discharging-recharging well pair. The concentration of the discharged effluent is calculated by solving the transport equation:

$$
\frac{\delta c}{\delta t}=-\frac{q}{\phi} \frac{\delta c}{\delta x}+D \frac{\delta^{2} c}{\delta x^{2}}
$$

where:

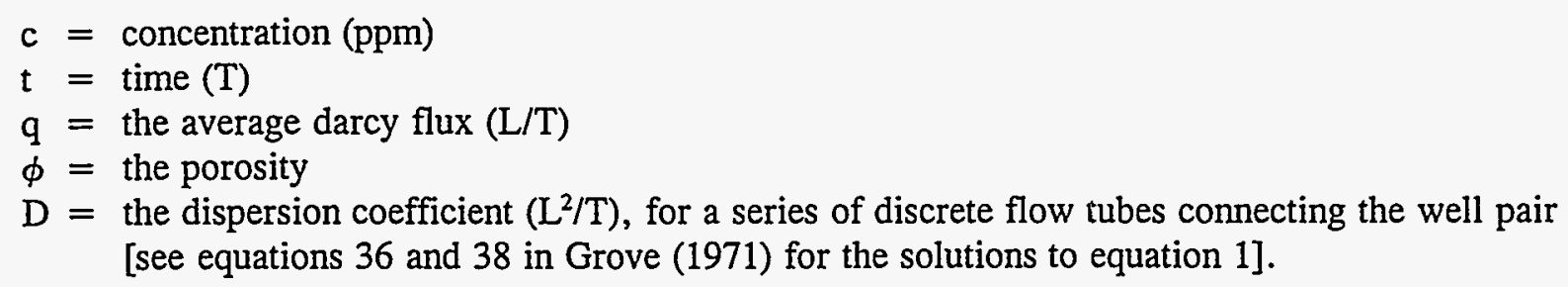

The individual concentration values are summed incrementally through time into a composite concentration. The porosity and dispersion coefficient are varied until a suitable match is obtained between the calculated concentration curve and the field data. The concentration curves were generated using the FORTRAN program presented in the appendix of Grove (1971), and the curve matching was performed visually.

Certain assumptions govern the analysis. The aquifer is assumed to be homogeneous, and all flow occurs horizontally and radially outward from the recharge well and horizontally and radially toward the discharge well. The groundwater velocity is assumed to be steady state and dependent only on the pumping rate, and if diffusional effects are neglected, the dispersion coefficient is then proportional to the dispersivity (L). Although a tracer test is transient by nature, assuming a steady-state flow field is reasonable here because most of the changes occurred early in the test, especially compared to the overall test duration. These assumptions allow equation 1 to be solved analytically and avoid the necessity of a numerical solution.

For both tests, the bromide solution was injected into the aquifer at approximately $189 \mathrm{~L} / \mathrm{min}$ (50 gal/min) for 112 minutes, and then the recharge rate was reduced to match the discharge rate. Considering the overall duration of the tests, pumping at $189 \mathrm{~L} / \mathrm{min}(50 \mathrm{gal} / \mathrm{min})$ for that time [instead of around 107 or $105 \mathrm{~L} / \mathrm{min}$ (28.3 or $27.8 \mathrm{gal} / \mathrm{min}$ )] probably did not result in significant changes in the velocity field. However, it did result in the injection of almost twice the quantity of bromide into the aquifer than is accounted for in the equations. This would be expected to cause the theoretical curves to deviate from the data in at least two ways: (1) the bromide would arrive at the discharge well sooner than calculated and (2) the actual shape of the concentration pulse would be 
broader than the calculated curve. The greater volume of bromide solution and elevated injection rate would initially push the bromide solution farther out from the recharge well. In addition to the greater solution volume displacing a correspondingly greater volume in the aquifer, the elevated injection rate would also increase the hydraulic gradient away from the recharging well. Although this effect would be short-lived, especially compared to the overall duration of the test, it would influence the results to some degree. The actual shape of the concentration pulse would be broader than the calculated curve simply because the greater quantity of bromide solution would require a greater amount of time to be pumped out of the aquifer. These elements introduce some uncertainty into the analysis, but the mathematics involved are robust enough to keep the interpretation meaningful.

4.4.4.4 Tracer Test 1 , February 6 through 11, 1995. Approximately $5 \mathrm{~kg}$ of lithium bromide was dissolved in a 5,600-gal tank, and the solution was injected into well 299-E28-23. Bromide concentrations measured at the recharge well averaged $195 \mathrm{ppm}$, which agreed with the calculated concentration of around $217 \mathrm{ppm}$. Baseline bromide concentration values measured at the discharging well ranged between 0.139 and $0.241 \mathrm{ppm}$. Because the background range represented greater than $20 \%$ of the maximum measured concentration at the discharge well $(0.673 \mathrm{ppm})$, a background concentration of $0.149 \mathrm{ppm}$ was subtracted from the concentration measured at the discharge well. The value of 0.149 was based on the trend of the background data and the rising limb of the concentration curve associated with the injected tracer pulse.

Figure 4-13 shows the measured data with the fitted analytical curve, with the dispersivity equal to $7 \mathrm{~m}(22 \mathrm{ft})$ and the porosity equal to 0.30 . The data exhibit some scattering, which may be the result of preferential transport pathways and heterogeneities in the soil properties, changes and variations in the recharging and discharging rates, and variations in the sample measurements of the bromide concentration. The measured concentration exhibits an apparent downward trend from the 80- to 110-h mark of the test, but later measurements (216 to $238 \mathrm{~h}$ ) of the bromide concentration ranged between 0.343 and $0.399 \mathrm{ppm}$ above background. The downward trend diverges from the analytical solution, but the later measurements are in much closer agreement. Considering the high transmissivity and inherent heterogeneities of the aquifer, as well as the magnitude of the concentration measurements, especially compared to background measurements, the scatter exhibited by the data should be expected, and a wider range should be accorded to the calculated parameters.

Figures 4-14 and 4-15 show the effects of varying the porosity and dispersivity values, respectively. In general, the two parameters are essentially independent of one another: changes in one parameter do not affect the other. Changes in the porosity mostly affect the amplitude of the maximum concentration pulse but also influence the time required for the maximum concentration to reach the discharge well. Changes in the dispersivity mostly affect the time that the concentration peaks at the discharge well but also influence the amplitude of the concentration pulse. The porosity term (as used in this analysis) describes the amount of water in each flow tube that dilutes the tracer concentration. As the porosity value is increased, the dilution increases, hence the concentration decreases. The dispersivity describes the extent to which the tracer will spread longitudinally about the advective front in each flow tube. This affects how quickly the tracer reaches the discharging well.

The amplitude of the maximum concentration pulse is strongly correlated to the porosity; the correlation is almost inversely linear. Figure 4-14 shows that doubling the porosity reduces the peak concentration by about one-half, whereas halving the porosity increases the peak concentration by about a factor of two. Figure 4-15 shows the effects of varying the dispersivity. As the dispersivity increases, the breakthrough time of the concentration peak shifts to the left. In general, the curves 
also become more peaked as the dispersivity increases, as seen by comparing the curves with dispersivities of 5,7 , and $9 \mathrm{~m}(16,22$, and $28 \mathrm{ft})$.

4.4.4.5 Tracer Test 2, May 21 through 25, 1995. Ten kilograms of potassium bromide were dissolved in the $3-\mathrm{m}-(10-\mathrm{ft})$ diameter tank holding $320 \mathrm{~cm}$ (126 in.) of water $\{23,352 \mathrm{~L}$

$\left[\mathrm{B} \times(5 \mathrm{ft})^{2} \times 126 / 12 \mathrm{ft} \times 7.48 \mathrm{gal} / \mathrm{ft}^{3}=6,169 \mathrm{gal}\right.$ of water $]$, and the solution was injected into well 299-E28-25. All bromide concentrations measured at the recharge well exceeded 3,500 ppm, which is an order of magnitude higher than what the concentration was calculated to be ( $-288 \mathrm{ppm})$. The reason for this discrepancy has not yet been determined. For these calculations, it was assumed that through the process of mixing in the tank, turbulence through the injection, and further mixing in the aquifer, the bromide should have dispersed fairly uniformly throughout the solution to the $288 \mathrm{ppm}$ concentration.

Figure 4-16 shows the data resulting from the fitted analytical curve, with the dispersivity equal to $3.7 \mathrm{~m}(12 \mathrm{ft})$ and the porosity equal to 0.22 . Bromide concentration measurements taken before the test indicated that the background bromide concentration at well 299-E28-23 was $0.162 \mathrm{ppm}$. As expected, the initial bromide breakthrough arrived at the discharge well before the curve predicted, and the peak of the measured concentrations was broader than the theoretical curve. Also, the later time-measured concentration data remained higher than the predicted analytical curve, indicating that either recirculation of the bromide from the extraction well to the injection well occurred, or the bromide injected over the $105 \mathrm{~L} / \mathrm{min}(27.8 \mathrm{gal} / \mathrm{min}$ ) (and thus not accounted for in the analysis equations) resulted in the elevated values. Considering that the brornide concentration attenuated by a factor of about 50 between the injection and extraction wells, even recirculation of the bromide would not be sufficient to maintain the elevated concentrations measured at the extraction well. Thus, the second explanation appears more plausible. Figures 4-17 and 4-18 show the sensitivity of the analysis to the effects of varying the porosity and dispersivity values, respectively.

The results of the two tests indicate that the effective porosity ranges between 0.22 and 0.30 , and the dispersivity ranges between 3.7 and $6.3 \mathrm{~m} \mathrm{(12} \mathrm{and} 22 \mathrm{ft})$. Based on the assumptions of the analysis, the values determined from the second test are probably more representative of the aquifer properties. The wells used in the second test were more than twice as close as the wells used in the first test, and thus much more likely to create the flow field described by the mathematics. With a transmissivity estimated to be $20,000 \mathrm{~m}^{2} /$ day $\left(216,000 \mathrm{ft}^{2} /\right.$ day $)$, pumping at $106 \mathrm{~L} / \mathrm{min}(28 \mathrm{gal} / \mathrm{min})$ would not result in more than $1.3 \mathrm{~cm}(0.5 \mathrm{in}$.) of drawdown outside the well casing (according to the Theis equation). Thus, the influence of the pumping on the aquifer would not extend out very far radially from the well. With such a small hydraulic change in the aquifer, differentiating between the transport caused by the pumping and the transport because of ambient conditions becomes difficult. As the distance between the wells increases, the injected bromide would be less likely to follow a direct path to the extraction well, and the extraction well would pump more ambient water than tracer-charged water from the injection well. Tracer arriving at the extraction well would be more diluted than the mathematics would dictate, thus skewing the analytical curve toward higher porosity and dispersivity values. The wells used in the second test were probably close enough to establish the flow field described by the analytical equation, and the values derived from that analysis provide good estimates of the aquifer properties. The results from the first tracer test provide bounds on the maximum values of the porosity and dispersivity. Although greater in magnitude than the results from the second test, the values from the first test are within reason for such a highly transmissive aquifer.

As a check of the values determined from the tracer analyses, the gradient calculated from the tracer analysis was compared to the drawdown predicted by the Theis equation. The tracer test gradient was 
based on the straight-line distance between the injection and recharge wells and the travel time along this streamline. The actual gradient would have to be greater than this value because all other streamlines are longer than the straight-line distance. Using Darcy's law,

$$
v=\frac{q}{\phi}=\frac{K}{\phi} \frac{\Delta H}{\Delta x}
$$

where:

$$
\begin{aligned}
& \mathrm{v}=\text { groundwater linear velocity (m/day) } \\
& \mathrm{q}=\text { darcy flux (m/day) } \\
& \phi \quad=\text { porosity } \\
& \mathrm{K}=\text { hydraulic conductivity }(\mathrm{m} / \text { day) } \\
& \Delta \mathrm{H}=\text { hydraulic head difference }(\mathrm{m}) \\
& \Delta \mathrm{x}=\text { distance }(\mathrm{m})
\end{aligned}
$$

Equation 2 can be rearranged to solve for the hydraulic head difference,

$$
\Delta H=\frac{\nu \phi}{K} \Delta x
$$

The velocity can be estimated from the travel time along the straight line connecting the two wells (provided in the output files: $206.6 \mathrm{~h}$ for test 1 and $28.3 \mathrm{~h}$ for test 2) and the distance between the two wells [17.46 m $(57.28 \mathrm{ft})$ for test 1 and $7.32 \mathrm{~m}(24.02 \mathrm{ft})$ for test 2]:

$$
v_{1}=\left(\frac{57.28 f t}{206.6 h r}\right)\left(\frac{24 h r}{1 d a y}\right)=6.66 \frac{f t}{d a y} \text { or } 2.03 \frac{m}{d a y s}
$$

and

$$
v_{2}=\left(\frac{24.02 f t}{26.8 h r}\right)\left(\frac{24 h r}{1 d a y}\right)=21.5 \frac{f t}{d a y} \text { or } 6.56 \frac{\mathrm{m}}{d a y}
$$

For $\mathrm{K}=1,500 \mathrm{~m} /$ day $(4,800 \mathrm{ft} /$ day) (e.g., see Connelly et al. 1992) and $\phi=0.25$ (based on the tracer test results),

$$
\Delta H_{1}=\left(6.66 \frac{f t}{d a y}\right) \frac{0.25}{\left(4800 \frac{f t}{d a y}\right)}(57.28 f t)=2.0 \times 10^{-2} f t \text { or } 5.9 \times 10^{-3} \mathrm{~m}
$$

and

$$
\Delta H_{2}=\left(21.5 \frac{f t}{d a y}\right) \frac{0.25}{\left(4800 \frac{f t}{d a y}\right)}(24.02 f t)=2.6 \times 10^{-2} f t \text { or } 8.0 \times 10^{-3} \mathrm{~m}
$$

Because the system is symmetrical, the drawdown at the extraction well is one-half of the hydraulic head difference, or $3.0 \times 10^{-3} \mathrm{~m}\left(1.0 \times 10^{-2} \mathrm{ft}\right)$ and $4.0 \times 10^{-3} \mathrm{~m}\left(1.3 \times 10^{-2} \mathrm{ft}\right)$, respectively. 
Rev. 0

The Theis equation can be used to calculate the drawdown as a result of pumping at a well,

$$
s=\frac{Q}{4 \pi T} W(u), \quad u=\frac{r^{2} S y}{4 T t}
$$

where:

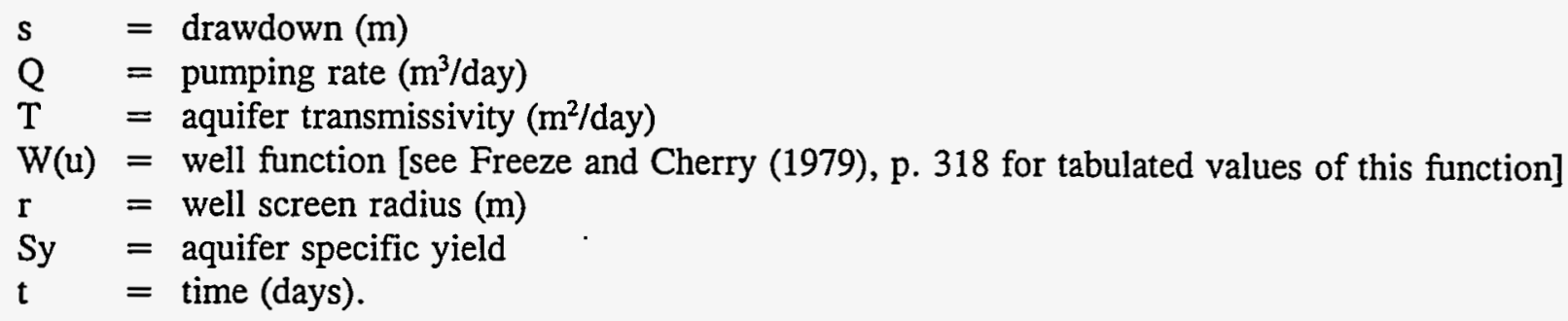

For this analysis, the porosity was substituted for the specific yield and $T=1,500 \mathrm{~m} /$ day $x 13.7 \mathrm{~m}$ $(4,800 \mathrm{ft} /$ day $\times 45 \mathrm{ft})=20,000 \mathrm{~m}^{3} /$ day $\left(216,000 \mathrm{ft}^{2} /\right.$ day $)$. For a well screen radius of $0.051 \mathrm{~m}$ $(0.167 \mathrm{ft}$ ) (4-in.-diameter well) and a time of 3 days (sufficient to reach reasonably steady-state conditions),

$$
u=\frac{(0.051 \mathrm{~m})^{2}(0.25)}{4\left(20,000 \frac{\mathrm{m}^{2}}{d a y}\right)(3 d a y s)}=2.7 \times 10^{-9}
$$

and $\mathrm{W}\left(2.7 \times 10^{-9}\right)=19.33$. For a pumping rate of $154.2 \mathrm{~m}^{3} /$ day $\left(5,448 \mathrm{ft}^{3} / \mathrm{day}\right)(28.3 \mathrm{gal} / \mathrm{min})$, the drawdown is

$$
s_{1}=\frac{\left(154.2 \frac{\mathrm{m}^{3}}{d a y}\right)}{(4)(\pi)\left(20,000 \frac{\mathrm{m}^{2}}{d a y}\right)}(19.33)=1.2 \times 10^{-2} \mathrm{~m}
$$

For a pumping rate of $151.5 \mathrm{~m}^{3} /$ day $\left(5,352 \mathrm{ft}^{3} /\right.$ day $)(27.8 \mathrm{gal} / \mathrm{min})$, the drawdown is

$$
s_{2}=\frac{\left(151.5 \frac{\mathrm{m}^{3}}{d a y}\right)}{(4)(\pi)\left(20,000 \frac{\mathrm{m}^{2}}{d a y}\right)}(19.33)=1.2 \times 10^{-2} \mathrm{~m}
$$

The drawdown values calculated by the two methods are the same order of magnitude $\left(3.0 \times 10^{-3}\right.$ and $4.0 \times 10^{-3} \mathrm{~m}$ compared to $1.2 \times 10^{-2}$ and $1.2 \times 10^{-2} \mathrm{~m}$, respectively), and provide additional confidence in the values calculated by the tracer test analysis. As noted before, the drawdown determined from the tracer test analysis represents a minimum value; the actual drawdown would be expected to be greater, bringing the values into even closer agreement. 


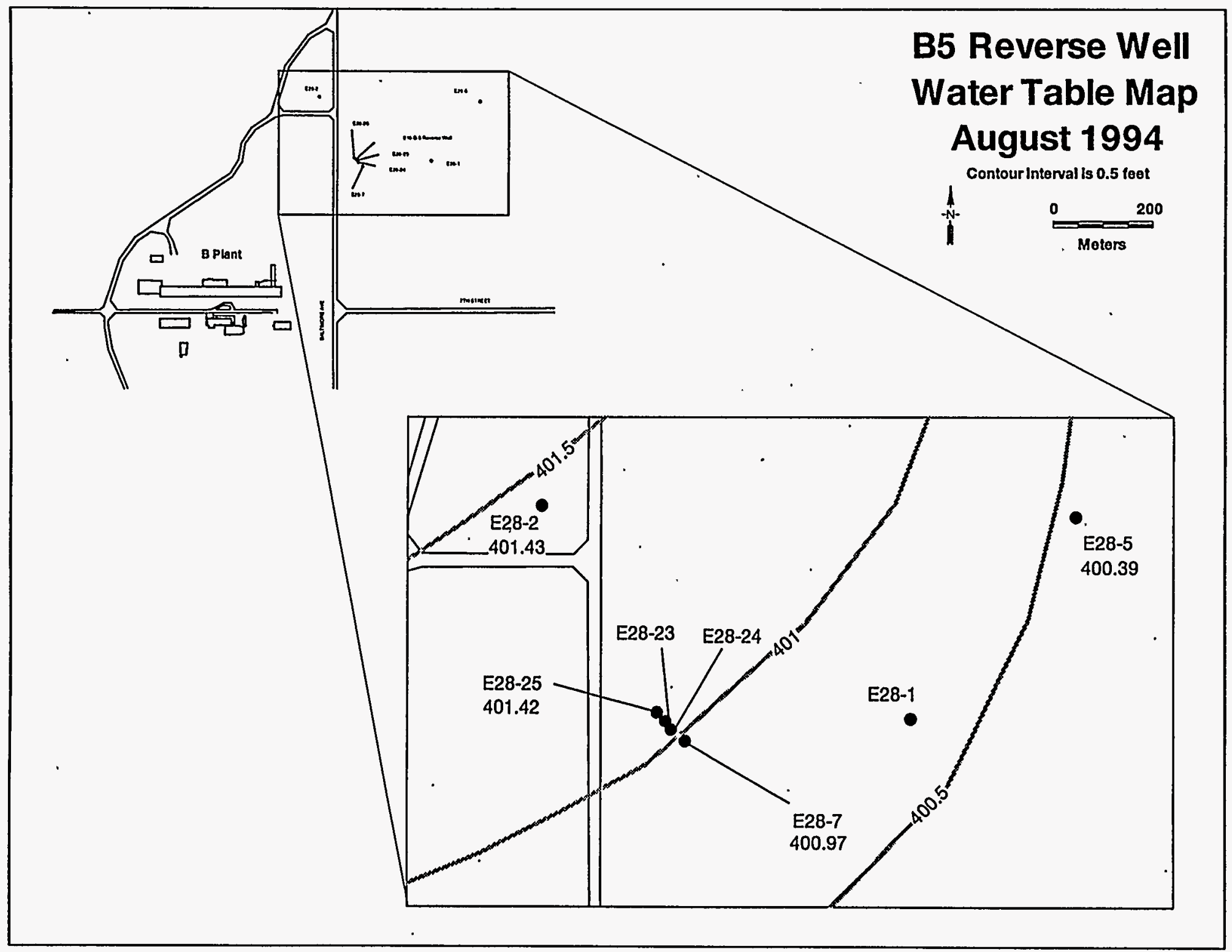

告 
DOE/RL-95-59

Rev. 0

Figure 4-2. Water-Table Map at 216-BY Cribs Plume.

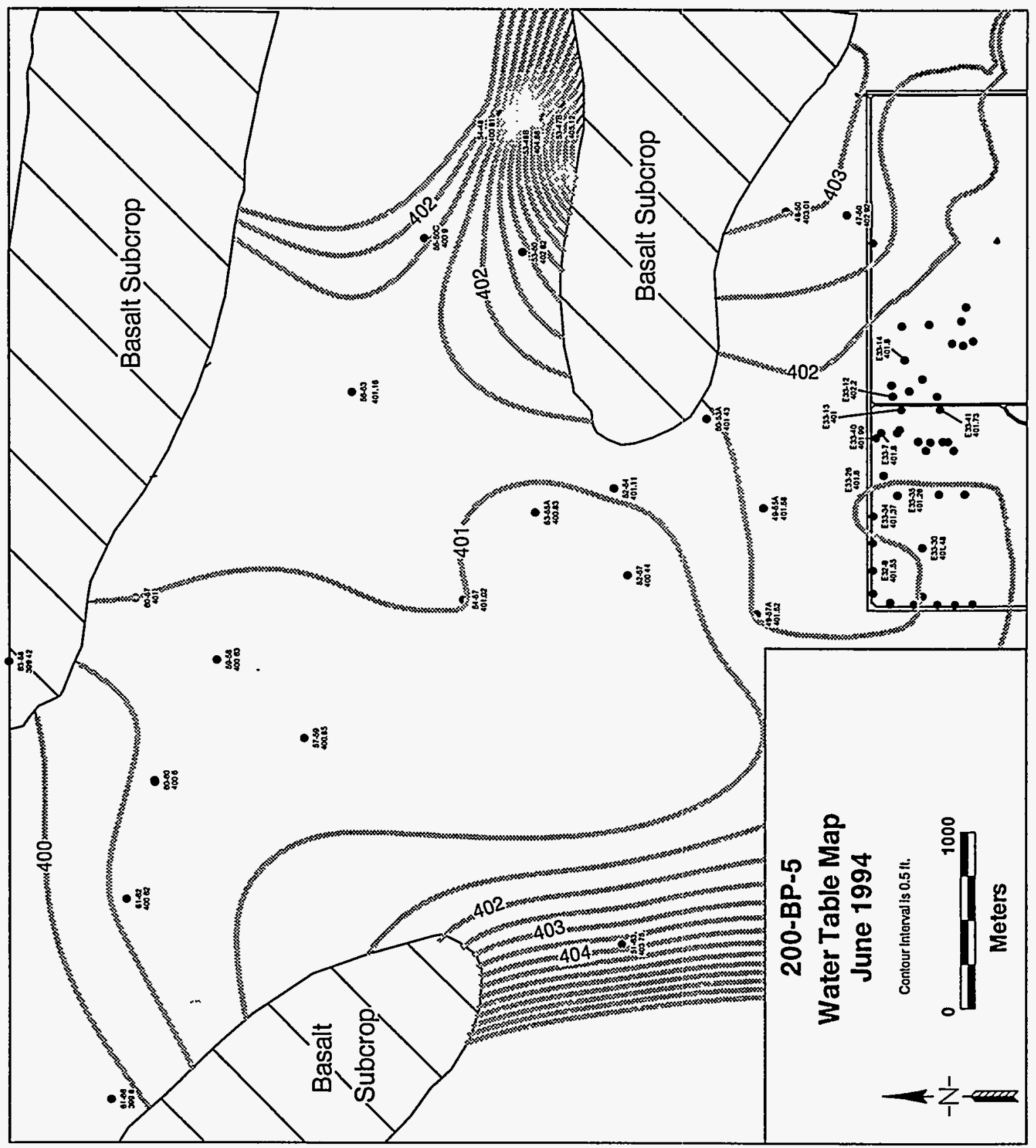




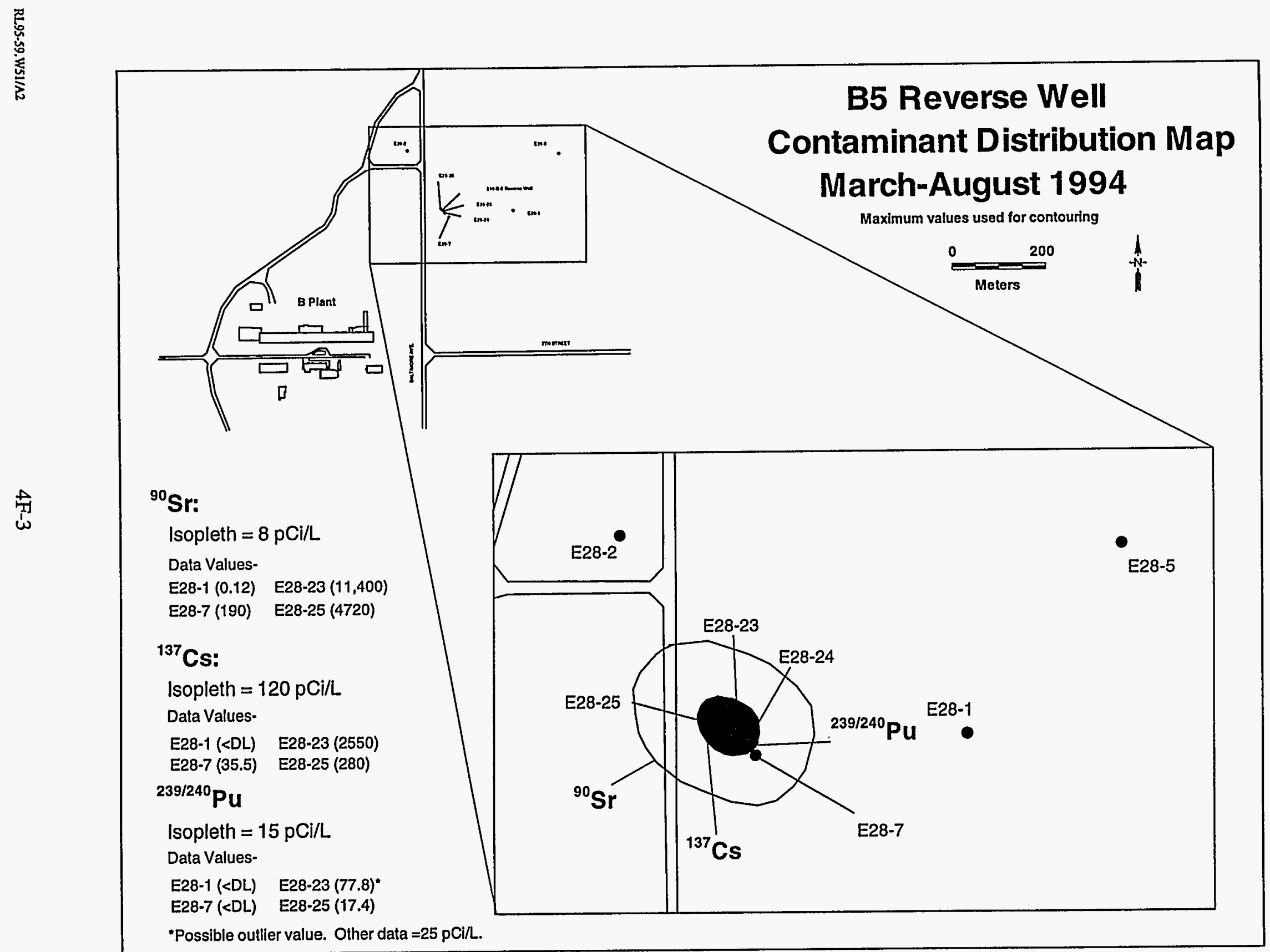


DOE/RL-95-59

Rev. 0

Figure 4-4. Plutonium-239/240 Extraction at 216-B-5 Reverse Well Site.

앙

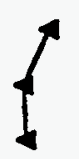

용ㅇㅇ

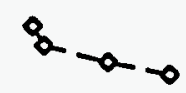

용
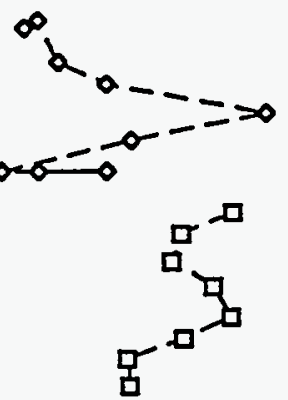

呂
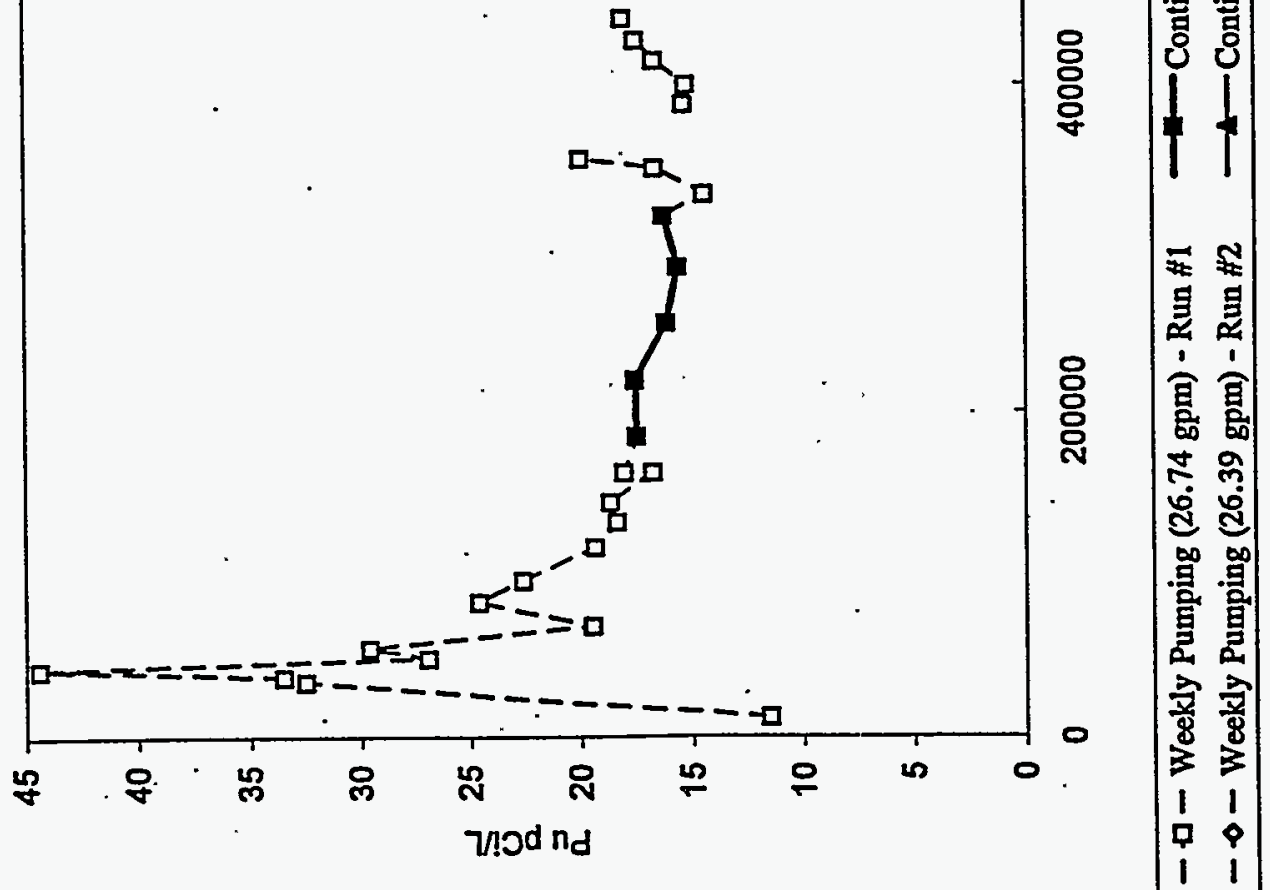
DOE/RL-95-59

Rev. 0

Figure 4-5. Cesium-137 Extraction at the 216-B-5 Reverse Well Site.

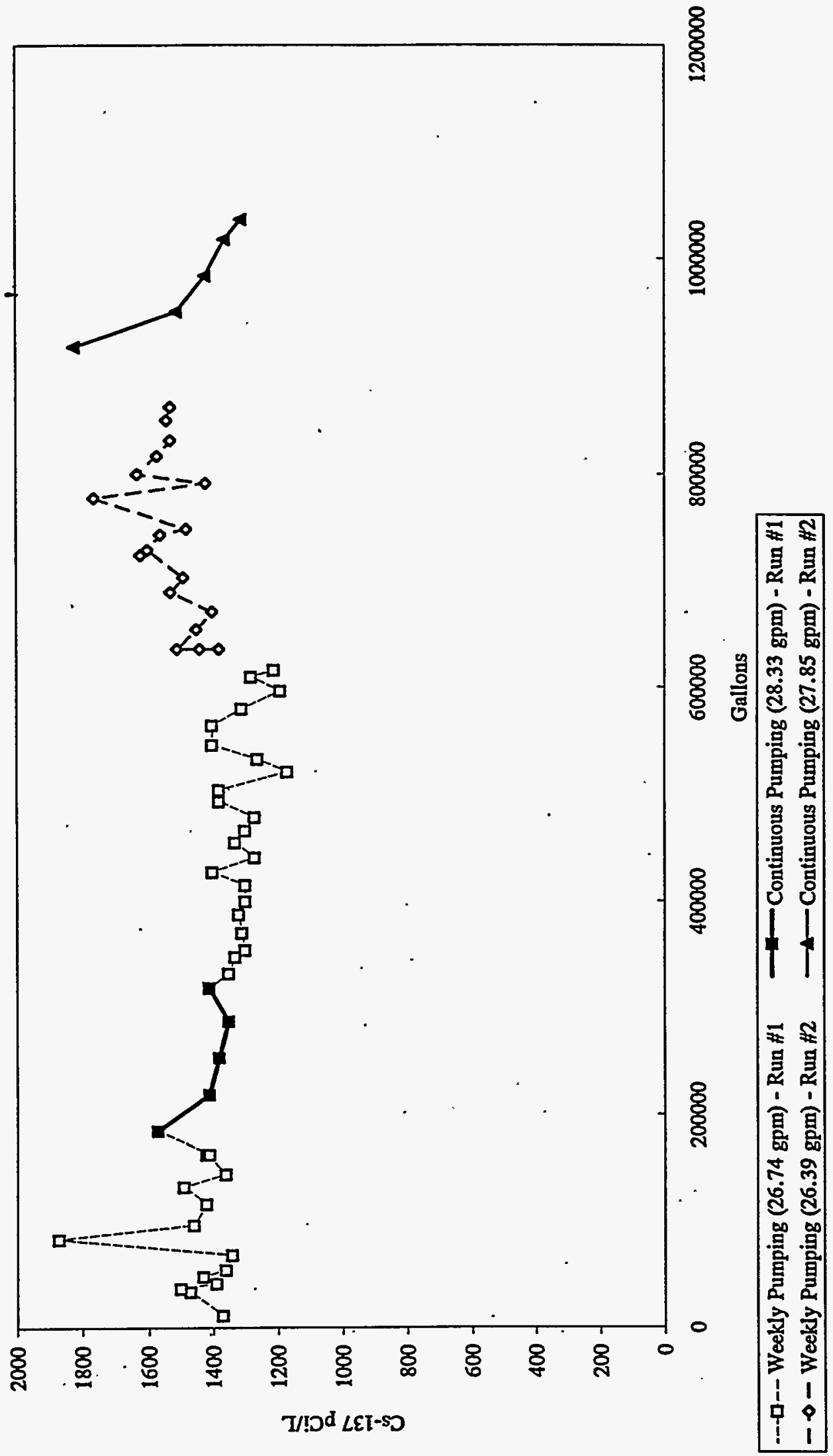


DOE/RL-95-59

Rev. 0

Figure 4-6. Strontium-90 Extraction at the 216-B-5 Reverse Well Site.

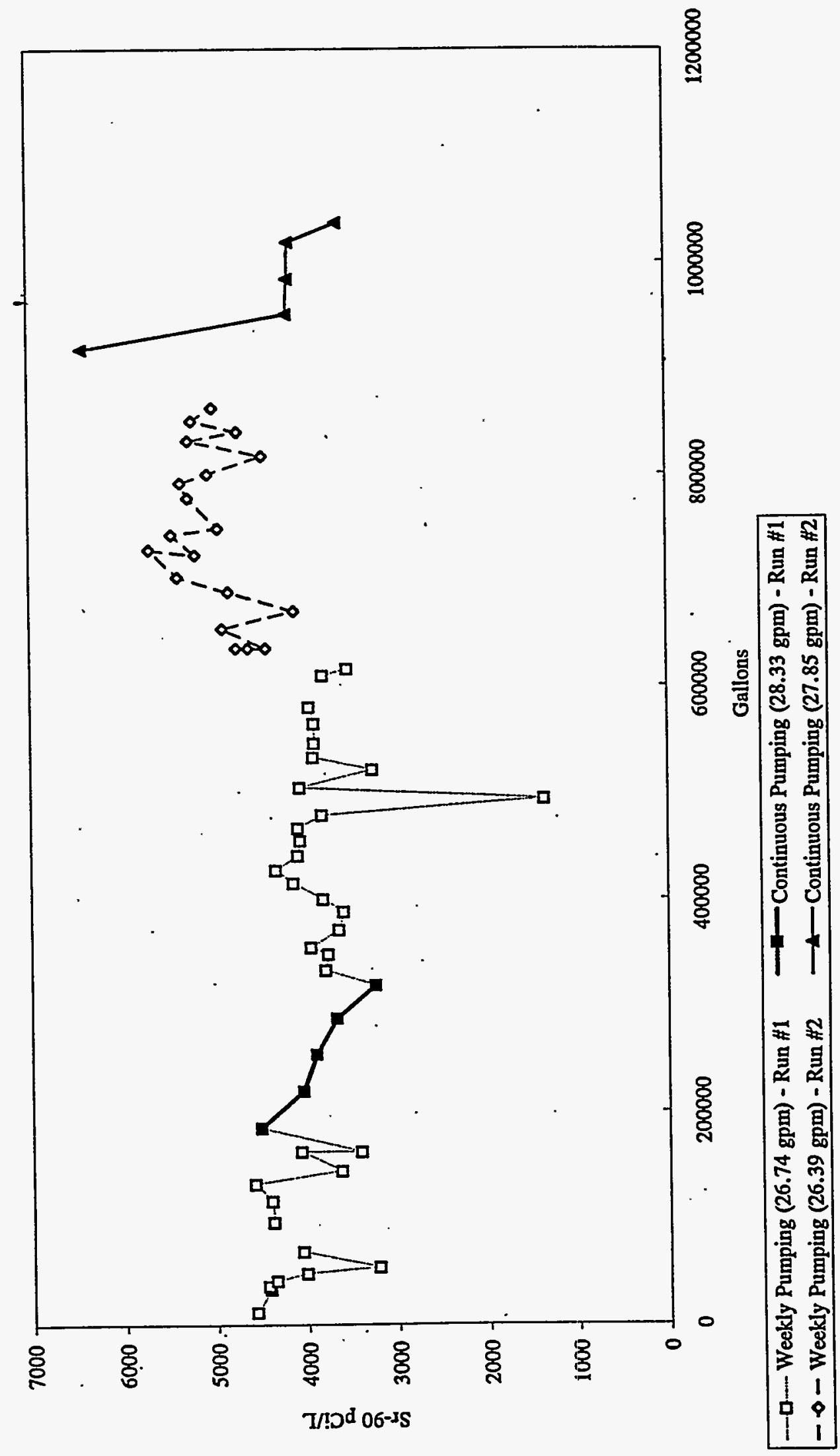




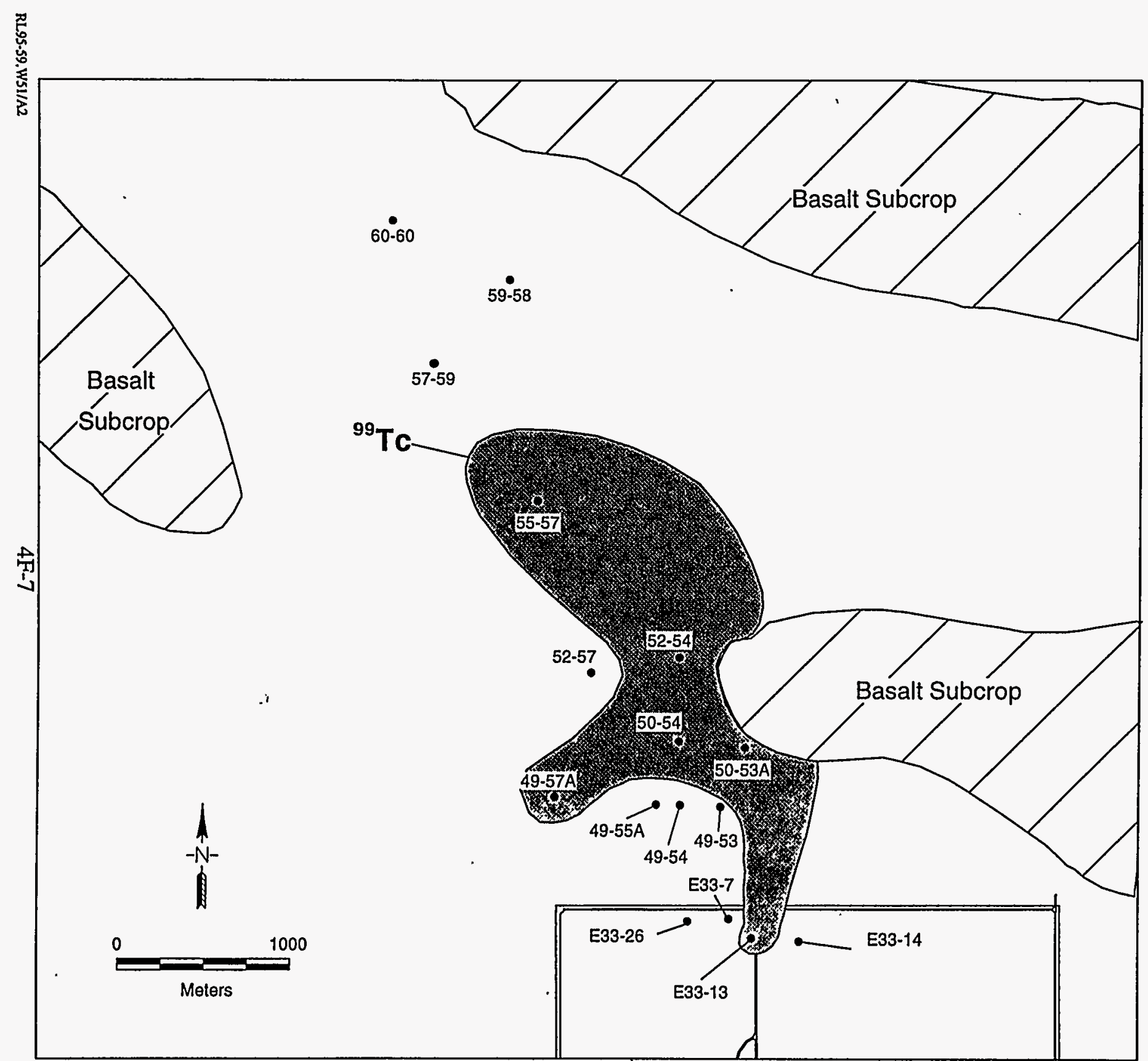

\section{BY Cribs}

Contaminant Distribution Map

\section{April 1994}

${ }^{99}$ Tc:

Isopleth $=900 \mathrm{pCi} / \mathrm{L}$

Data Values-

E33-7 (619) 50-53A (1690;

E33-13 (1380) 50-54 (1380)

E33-14(35) 52-54 (4310)

E33-26(775) 52-57 (2)

49-53(200) 55-57 (2100)

49-54 (480) 57-59(49.9)

49-55A (381) $\quad 59-58$ (221)

$49.57 A(1525) 60-60(144)$

${ }^{60} \mathrm{Co}$ :

Isopleth $=100 \mathrm{pCi} / \mathrm{L}^{*}$

Data Values-

E33-7 (22)

E33-13 (9)

E33-14(4)

E33-26(6)

49-53(10)

50-53A (27)

50-54 (19)

$52.54(74)$

55-57 (50)

49-54(20) $\quad 57-59(<\mathrm{DL})$

49-55A (8) $\quad 59-58(1)$

49-57A (17) $\quad 60-60(<\mathrm{DL})$

"No ${ }^{60} \mathrm{Co}$ value

exceeds $100 \mathrm{pCin}$. 
DOE/RL-95-59

Rev. 0

Figure 4-8. Cobalt-60 Extraction at the 216-BY Cribs Site.

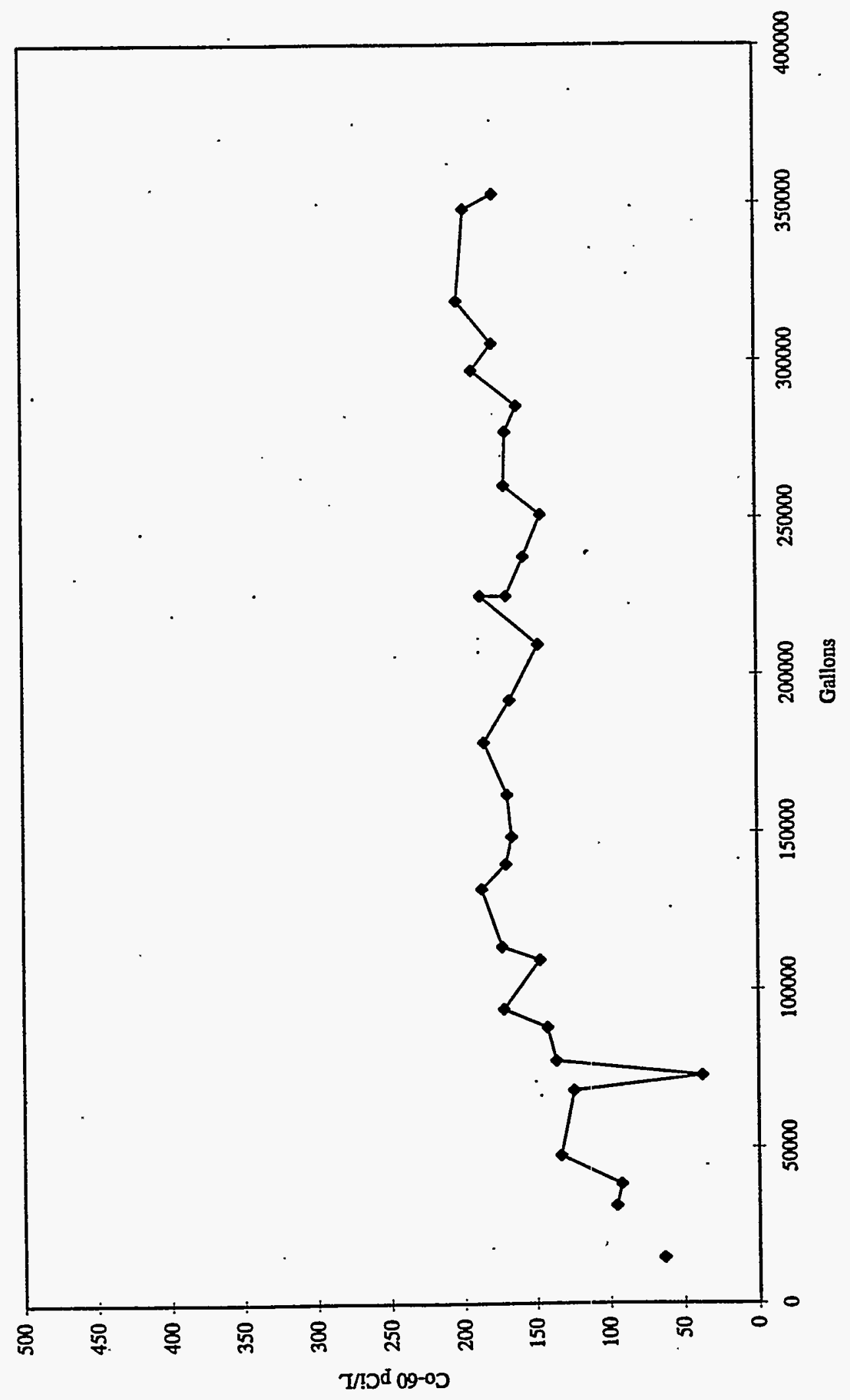


DOE/RL-95-59

Rev. 0

Figure 4-9. Technetium-99 Extraction at the 216-BY Cribs Plume Site.

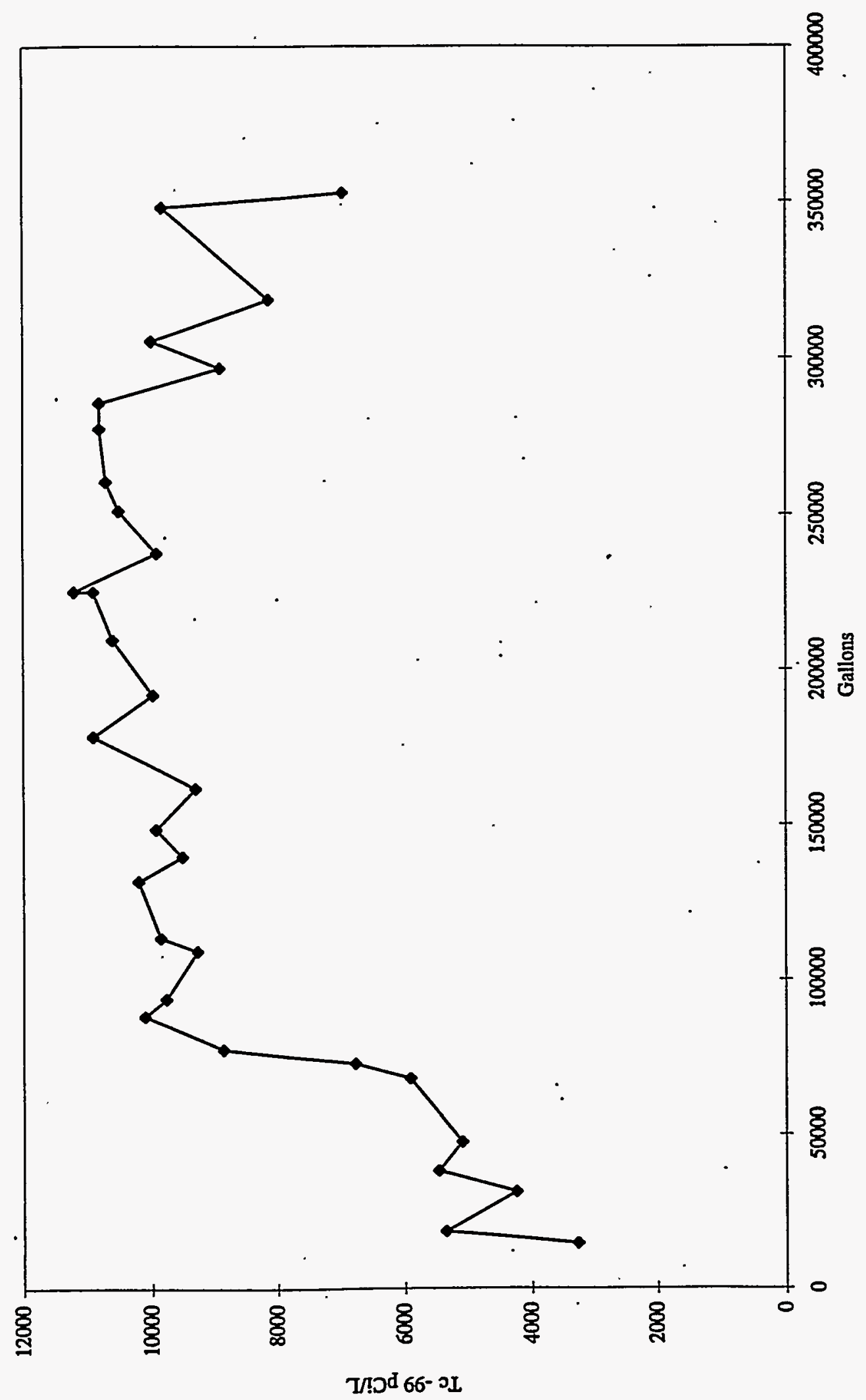




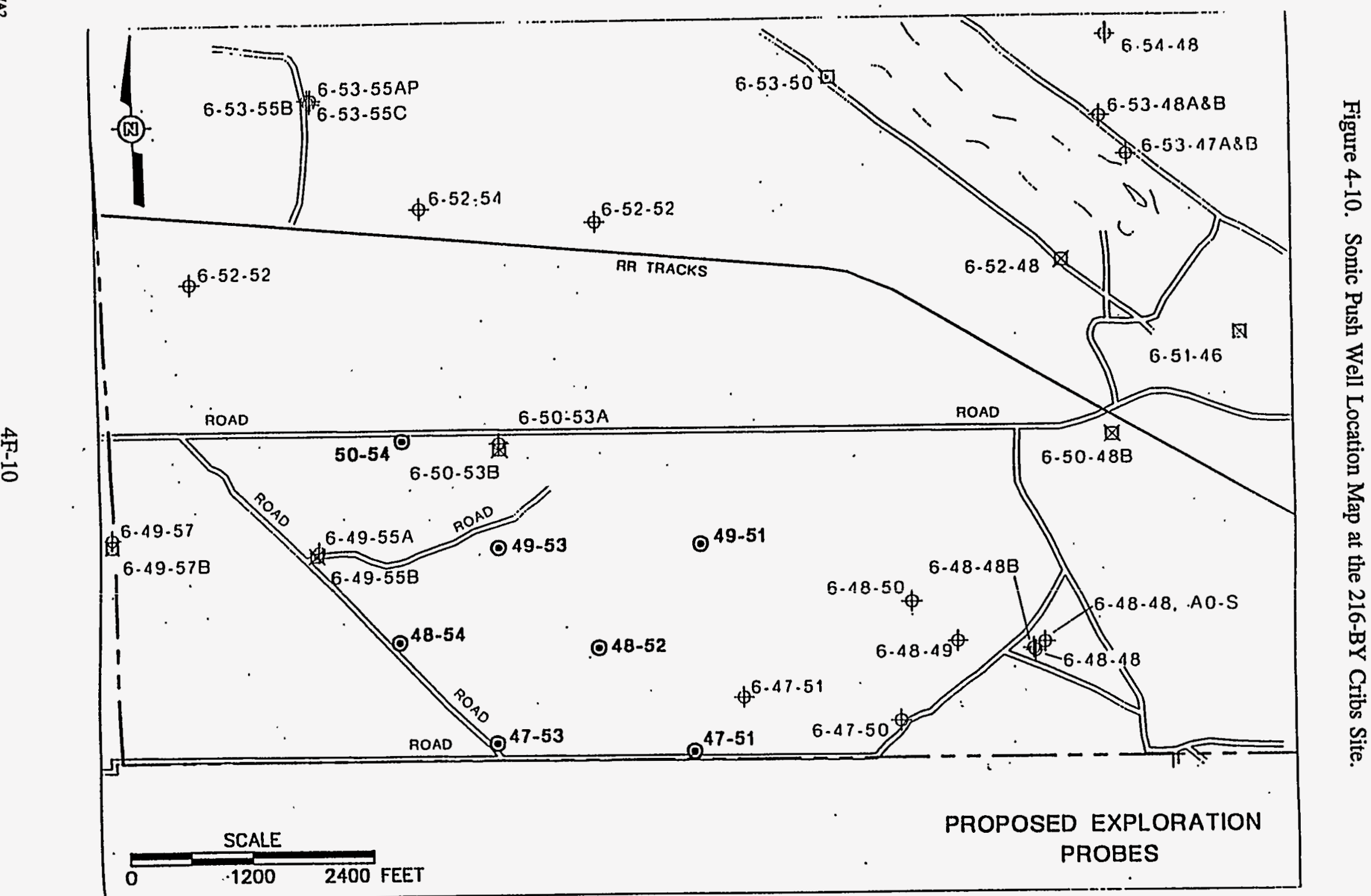


DOE/RL-95-59

Rev. 0

Figure 4-11. Groundwater Sampling Map for Sonic Push Testing at 216-BY Cribs.

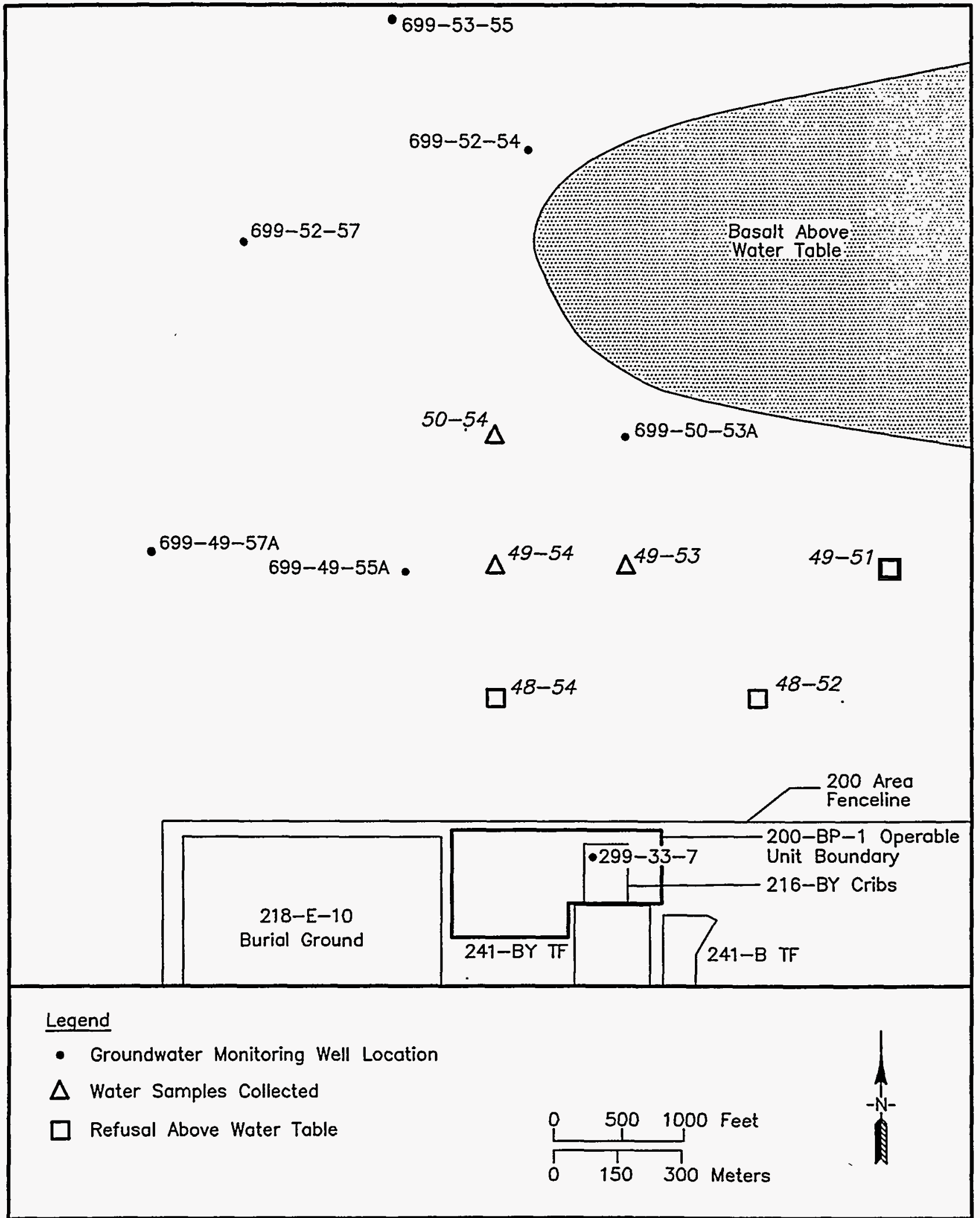


Rev. 0

Figure 4-12. In Situ Velocity Flowmeter Test Wells in the 216-BY Cribs Plume.

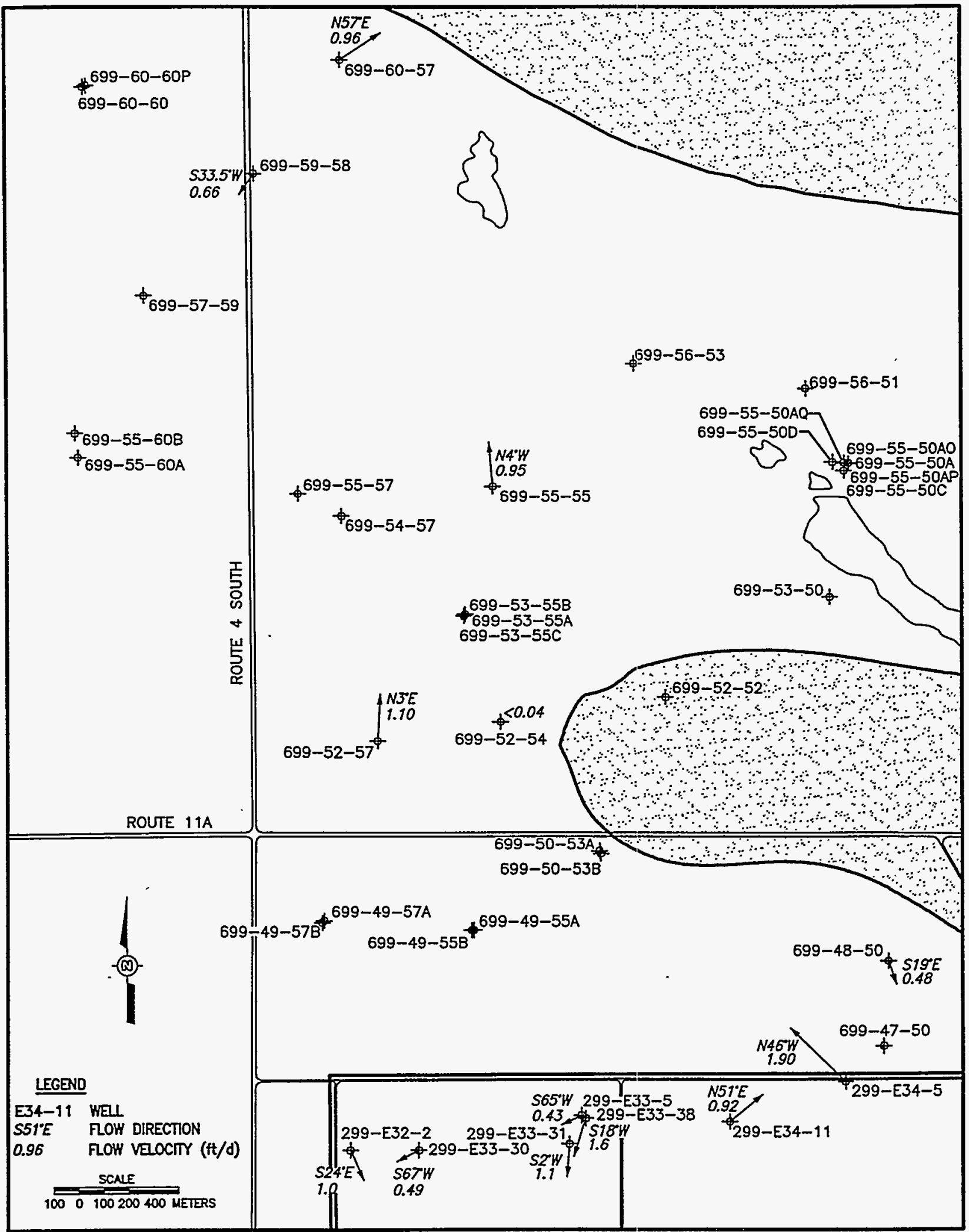


Rev. 0

Figure 4-13. Comparison of the Analytical Solution Output to the Measured Bromide Concentration at Well 299-E28-23.

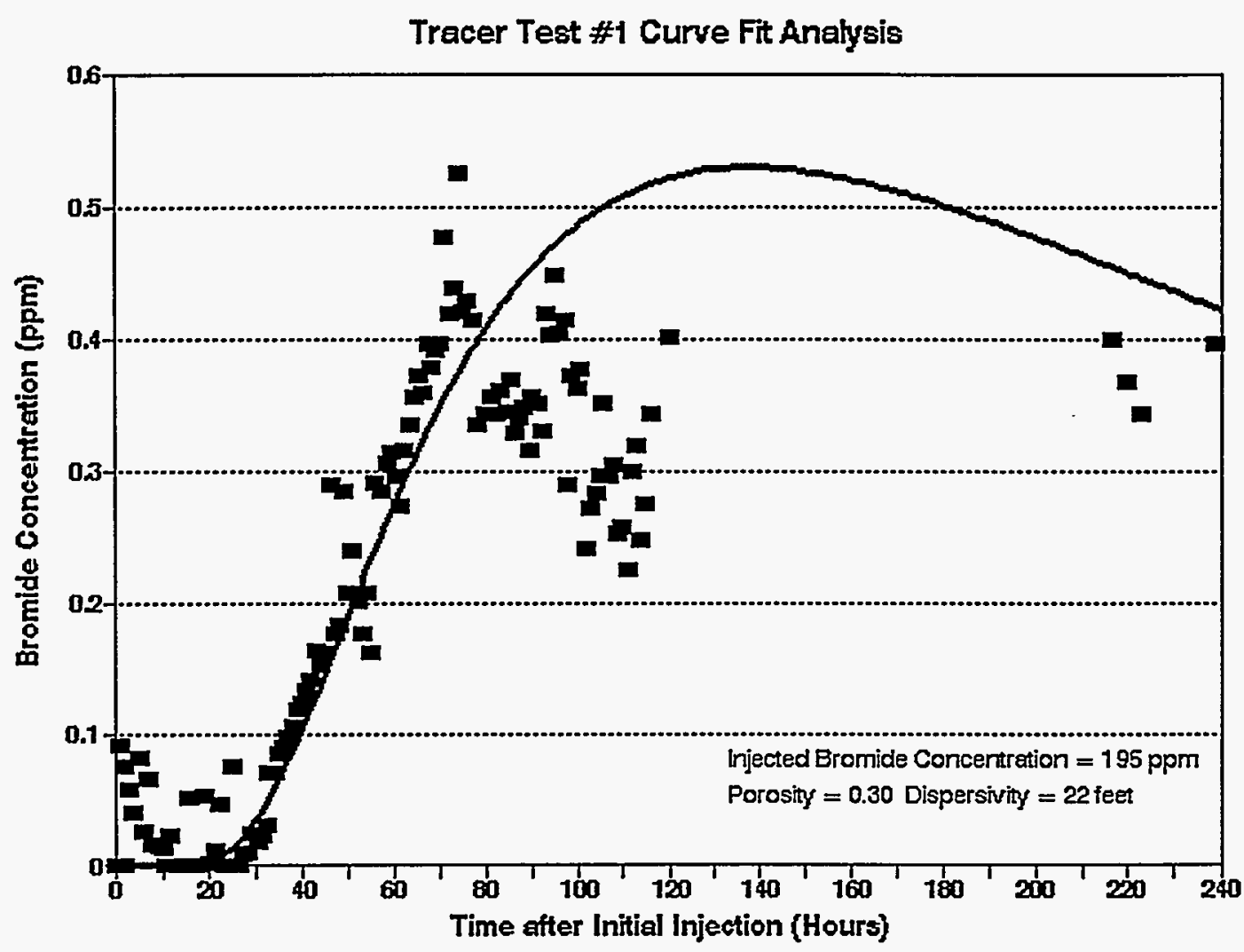


Rev. 0

Figure 4-14. Sensitivity Analysis of the Analytical Solution Output to the Porosity Term Varied by $17 \%$.

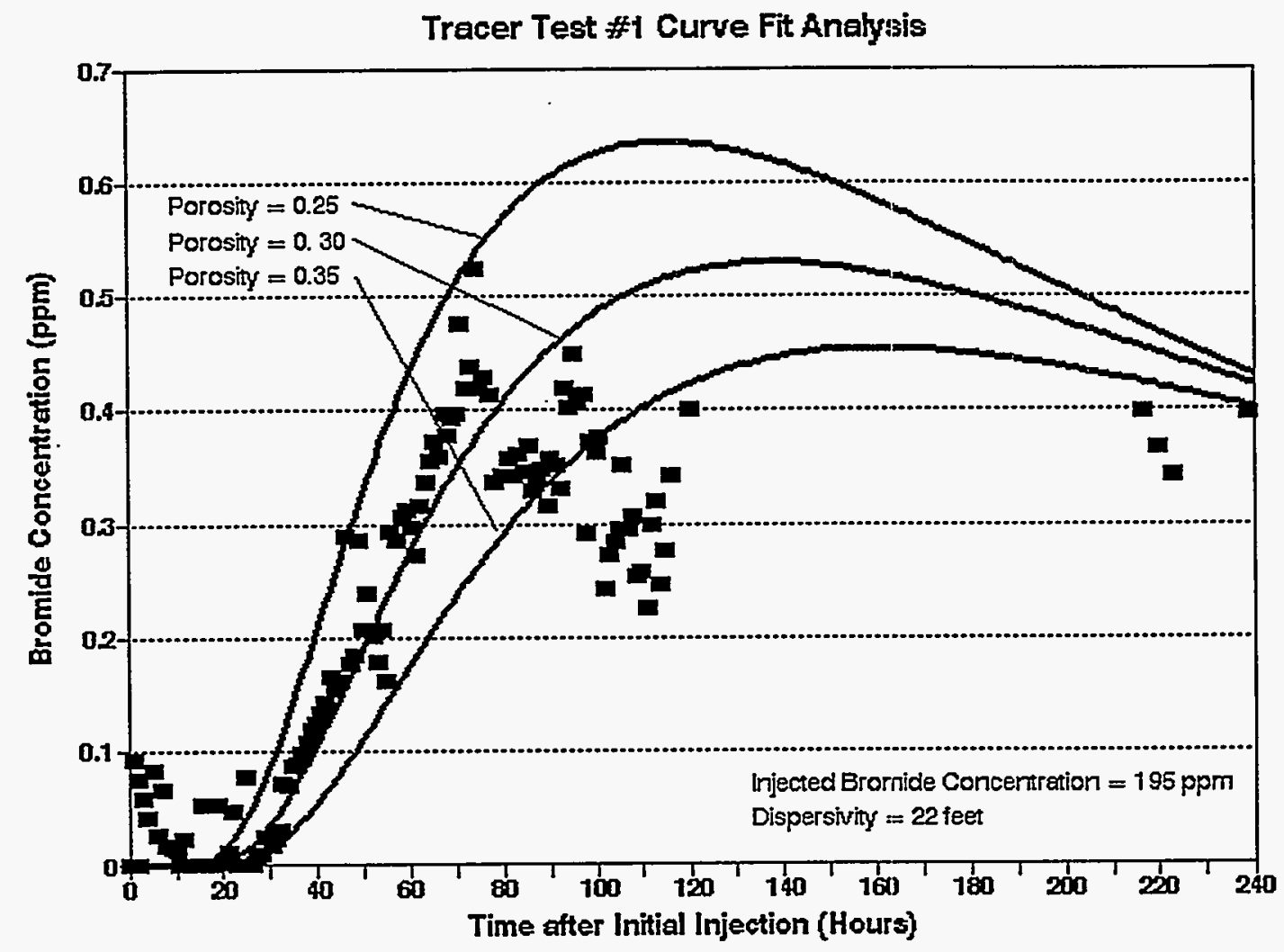


DOE/RL-95-59

Rev. 0

Figure 4-15. Sensitivity Analysis of the Analytical Solution Output to the Dispersivity Term Varied by $27 \%$.

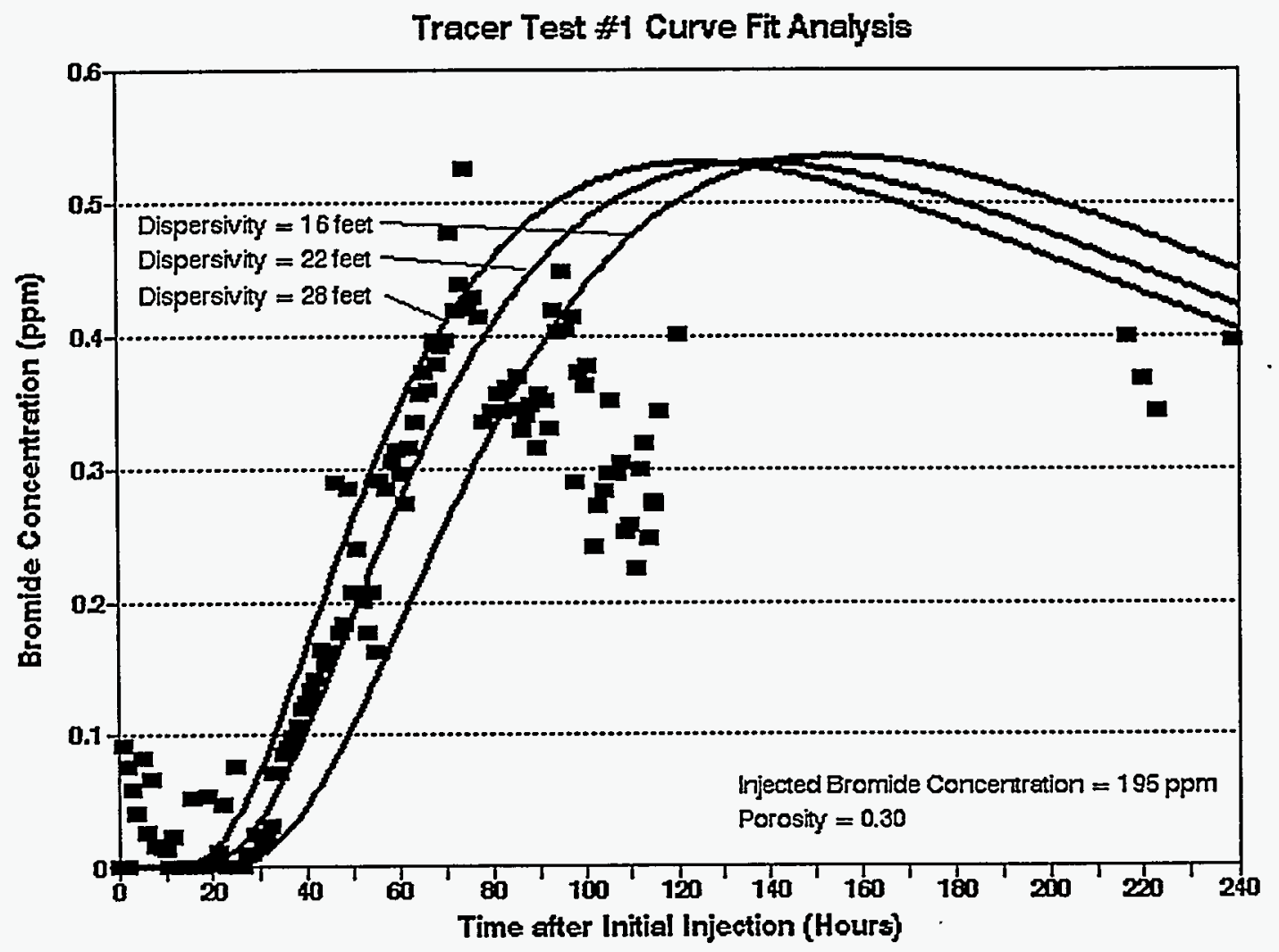


DOE/RL95-59

Rev. 0

Figure 4-16. Comparison of the Analytical Solution Output to the Measured Bromide Concentration at Well 299-E28-23.

Tracer Test \#2 Curve Fit Analysis

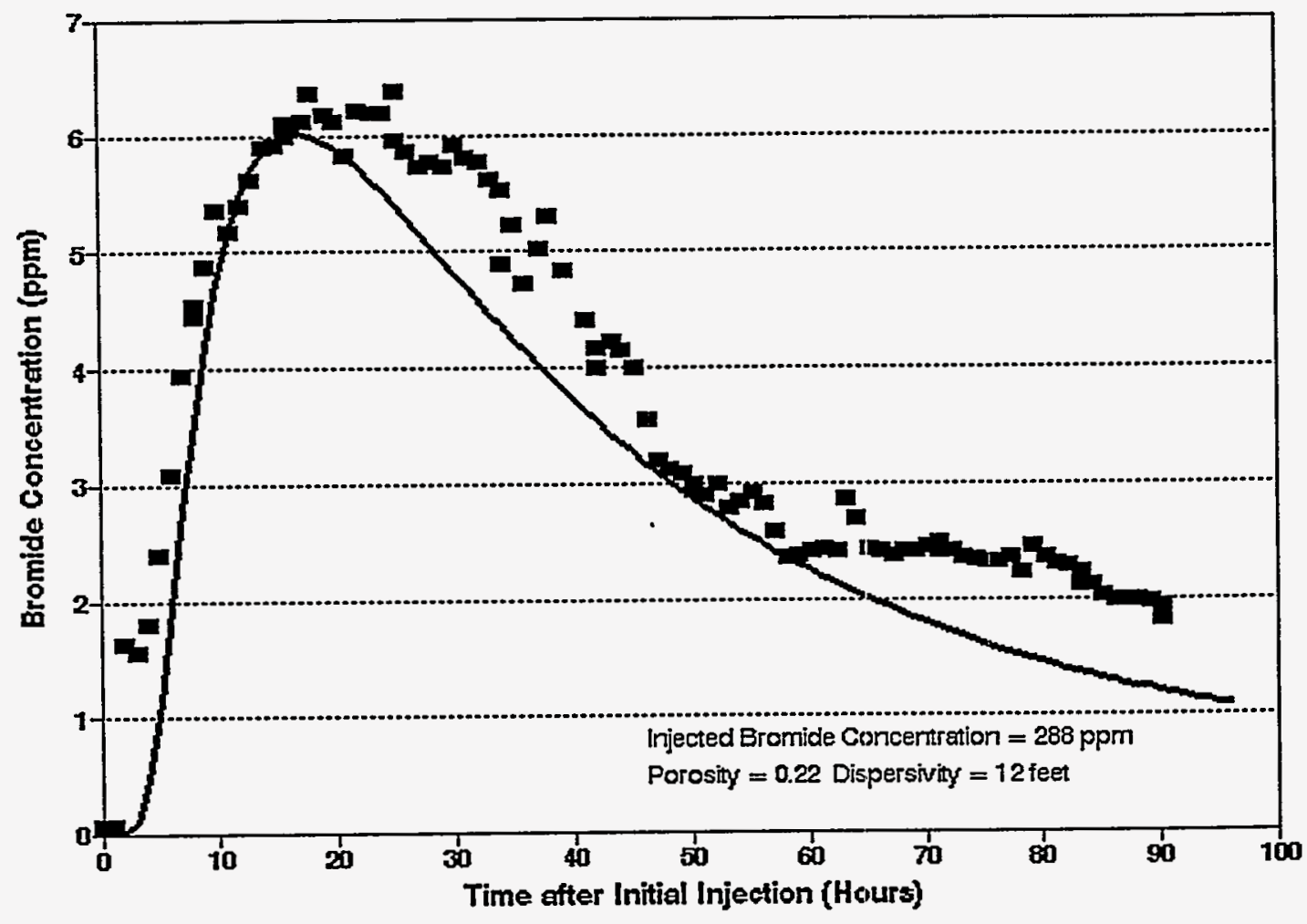


Rev. 0

Figure 4-17. Sensitivity Analysis of the Analytical Solution Output to the Porosity Term Varied by $27 \%$.

Tracer Test \#2 Curve Fit Analysis

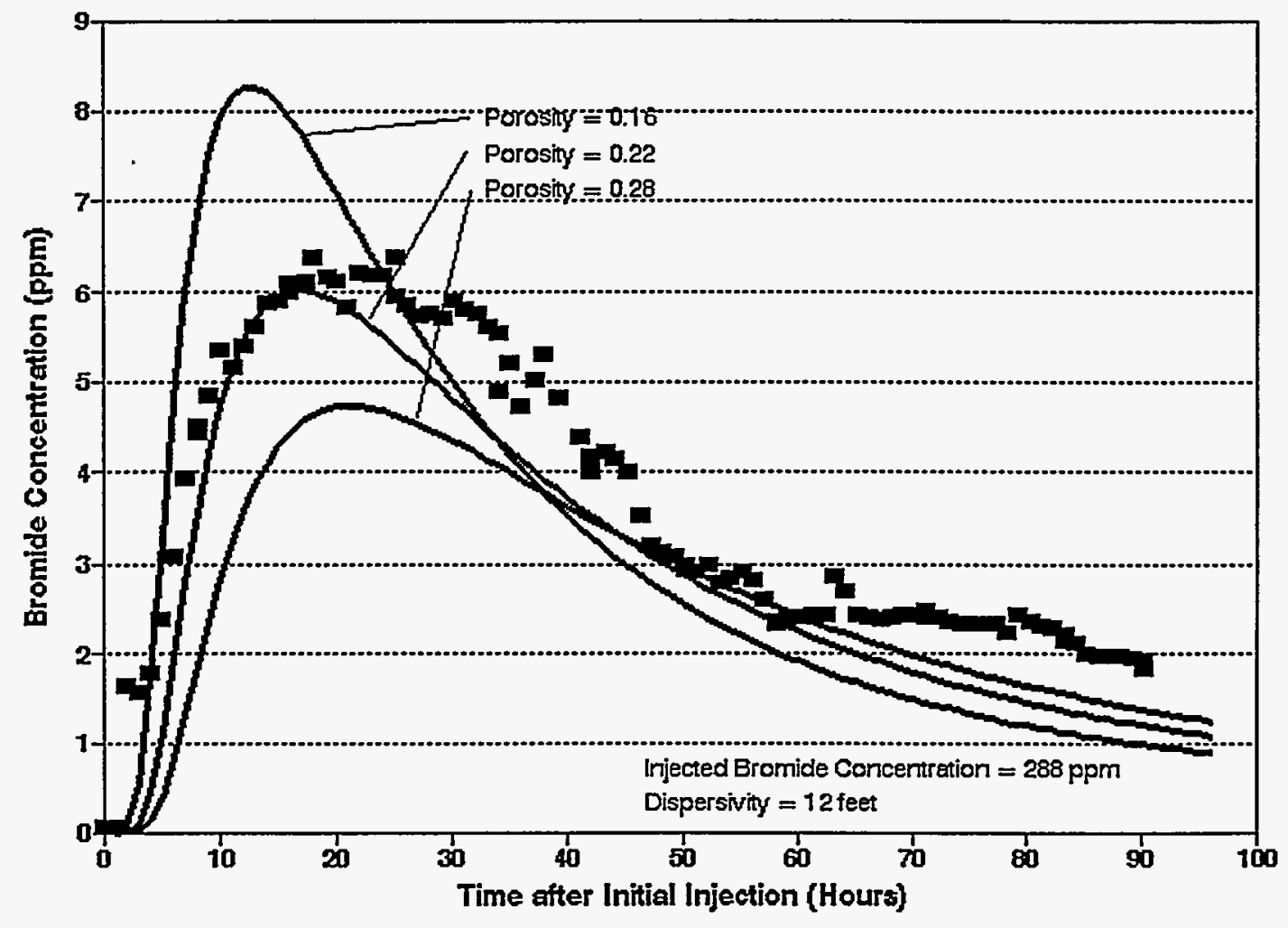


Rev. 0

Figure 4-18. Sensitivity Analysis of the Analytical Solution Output to the Dispersivity Term Varied by $25 \%$.

\section{Tracer Test \#2 Curve Fit Anahysis}

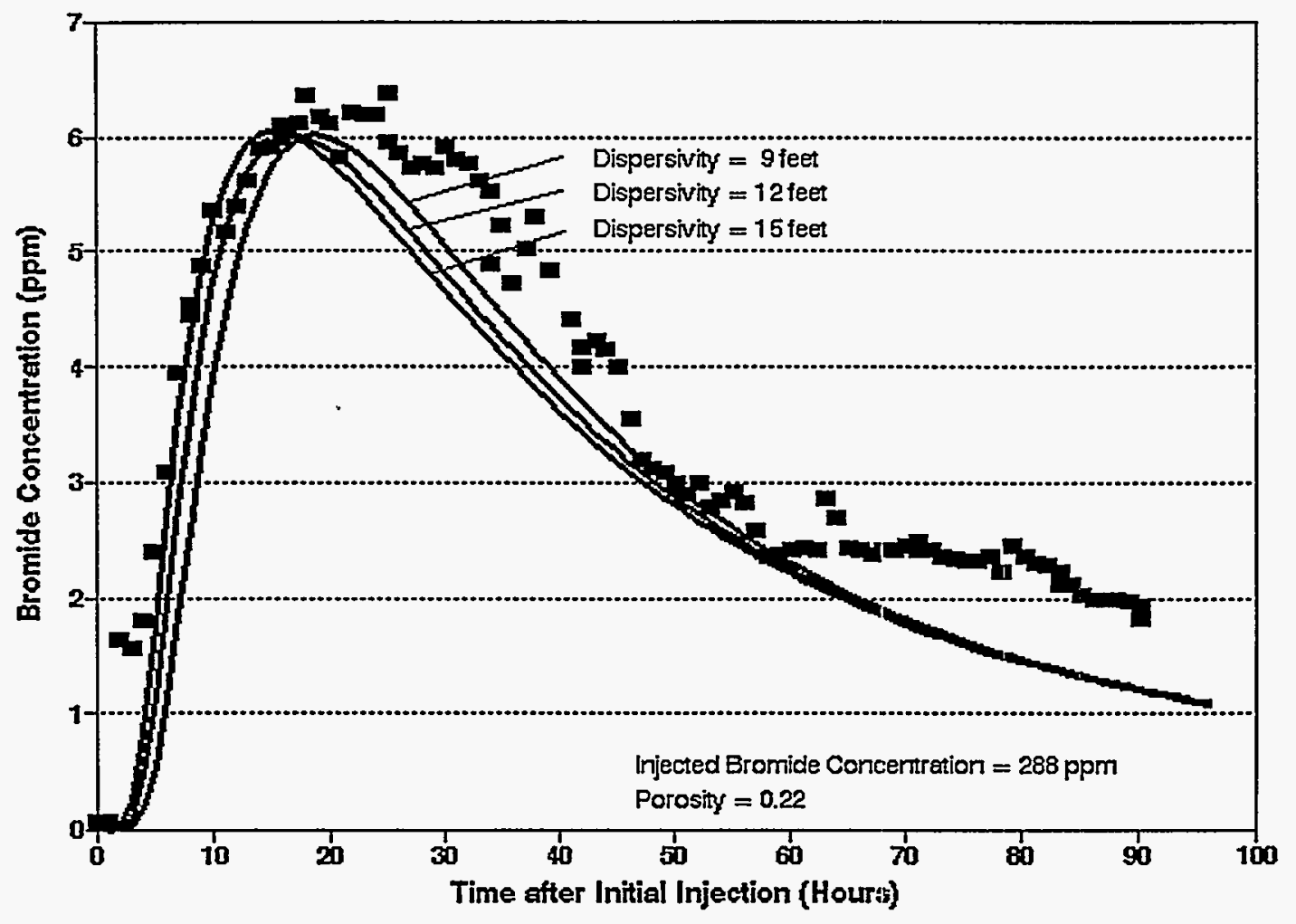


DOE/RL-95-59

Rev. 0

Table 4-1. Summary of Well Suitability Activities and Production Data.

\begin{tabular}{|c|c|c|c|c|c|c|}
\hline Well & $\begin{array}{c}\text { Camera } \\
\text { Survey }\end{array}$ & $\begin{array}{c}\text { Well } \\
\text { Scrubbed/ } \\
\text { Cleaned }\end{array}$ & $\begin{array}{c}\text { Well } \\
\text { Redeveloped }\end{array}$ & $\begin{array}{c}\text { Well } \\
\text { Deepened }\end{array}$ & $\begin{array}{c}\text { Pump/ } \\
\text { Head } \\
\text { Loss/Gain }\end{array}$ & $\begin{array}{c}\text { Injection } \\
\text { Rate } \\
\text { (L/min) }\end{array}$ \\
\hline $299-E 28-1$ & Yes & Yes & No & No & $0.2 / 5.5$ & $75 / 76$ \\
\hline $299-E 28-2$ & Yes & Yes & No & No & NMD/- & 76 \\
\hline $299-E 28-7$ & No & No & No & No & NMD/1.5 & $16.3 / 208$ \\
\hline $299-E 28-23$ & No & No & No & No & $.01 /-$ & 70 \\
\hline $299-E 28-24$ & No & No & Yes & No & $8.3 /-$ & 5.7 \\
\hline $299-E 28-25$ & No & No & No & No & $0.2 /-$ & 76.5 \\
\hline $699-49-55 A$ & Yes & No & No & No & $9 / 6.4$ & $8.7 / 76$ \\
\hline $699-49-57 A$ & Yes & No & No & No & NMD & 23 \\
\hline $699-50-53 \mathrm{~A}$ & No & No & Yes & Yes & 16.5 & 19 \\
\hline
\end{tabular}

${ }^{2}$ Well $699-50-53 \mathrm{~A}$ was drilled over $6 \mathrm{~m}(20 \mathrm{ft})$ into the upper basalt. The extraction pump was placed within the basalt to increase well yield due to the limited saturated thickness.

$\mathrm{NMD}=$ no measurable drawdown. 
Table 4-2. 216-B-5 Reverse Well Baseline Water Quality Data. (Section 4.3.1.2) (2 Sheets)

\begin{tabular}{|c|c|c|c|c|}
\hline Well & Date Sampled & Contaminant & Activity & Units \\
\hline \multirow{2}{*}{ 299-E28-1 } & $03-23-94$ & ${ }^{137} \mathrm{Cs}$ & -0.8 & $\mathrm{pCi} / \mathrm{L}$ \\
\hline & $03-23-94$ & ${ }^{137} \mathrm{Cs}$ & -5.63 & $\mathrm{pCi} / \mathrm{L}$ \\
\hline $299-E 28-2^{a}$ & - & -- & - & -- \\
\hline $299-E 28-5^{a}$ & -- & -- & - & -- \\
\hline \multirow[t]{2}{*}{ 299-E28-7 } & $04-18-94$ & ${ }^{137} \mathrm{Cs}$ & 15.3 & $\mathrm{pCi} / \mathrm{L}$ \\
\hline & $08-30-94$ & ${ }^{137} \mathrm{Cs}$ & 35.5 & $\mathrm{pCi} / \mathrm{L}$ \\
\hline \multirow{3}{*}{ 299-E28-23 } & $03-29-94$ & ${ }^{137} \mathrm{Cs}$ & 2,215 & $\mathrm{pCi} / \mathrm{L}$ \\
\hline & $06-30-94$ & ${ }^{137} \mathrm{Cs}$ & $2,550^{\mathrm{b}}$ & $\mathrm{pCi} / \mathrm{L}$ \\
\hline & $07-18-94$ & ${ }^{137} \mathrm{Cs}$ & 2,030 & $\mathrm{pCi} / \mathrm{L}$ \\
\hline 299-E28-24 & - & - & - & - \\
\hline \multirow{3}{*}{ 299-E28-25 } & $03-29-94$ & ${ }^{137} \mathrm{Cs}$ & 180 & $\mathrm{pCi} / \mathrm{L}$ \\
\hline & $07-20-94$ & ${ }^{137} \mathrm{Cs}$ & $234 / 159^{c}$ & $\mathrm{pCi} / \mathrm{L}$ \\
\hline & $08-29-94$ & ${ }^{137} \mathrm{Cs}$ & 280 & $\mathrm{pCi} / \mathrm{L}$ \\
\hline 299-E28-1 & $03-23-94$ & ${ }^{239} 9240 \mathrm{Pu}$ & -0 & $\mathrm{pCi} / \mathrm{L}$ \\
\hline $299-E 28-2^{a}$ & - & - & - & -- \\
\hline $299-E 28-5^{a}$ & - & -- & - & -- \\
\hline 299-E28-7 & $04-18-94$ & ${ }^{239 / 240} \mathrm{Pu}$ & -0 & $\mathrm{pCi} / \mathrm{L}$ \\
\hline \multirow{3}{*}{ 299-E28-23 } & $03-29-94$ & ${ }^{239 / 240} \mathrm{Pu}$ & 25.7 & $\mathrm{pCi} / \mathrm{L}$ \\
\hline & $06-30-94$ & ${ }^{239 / 240} \mathrm{Pu}$ & $20.1^{b}$ & $\mathrm{pCi} / \mathrm{L}$ \\
\hline & $07-18-94$ & ${ }^{239 / 240} \mathrm{Pu}$ & $77.8^{c} / 25^{d}$ & $\mathrm{pCi} / \mathrm{L}$ \\
\hline 299-E28-24a & - & - & - & - \\
\hline \multirow{2}{*}{ 299-E28-25 } & $03-29-94$ & ${ }^{239 / 240} \mathrm{Pu}$ & 17.35 & $\mathrm{pCi} / \mathrm{L}$ \\
\hline & $08-29-94$ & ${ }^{239 / 240} \mathrm{Pu}$ & 0 & $\mathrm{pCi} / \mathrm{L}$ \\
\hline 299-E28-1 & $03-23-94$ & ${ }^{90} \mathrm{Sr}$ & 0.12 & $\mathrm{pCi} / \mathrm{L}$ \\
\hline $299-E 28-2^{a}$ & -- & - & - & - \\
\hline $299-E 28-5^{a}$ & - & -- & -- & -- \\
\hline \multirow[t]{2}{*}{ 299-E28-7 } & $04-18-94$ & ${ }^{90} \mathrm{Sr}$ & 160 & $\mathrm{pCi} / \mathrm{L}$ \\
\hline & $08-30-94$ & ${ }^{90} \mathrm{Sr}$ & 190 & $\mathrm{pCi} / \mathrm{L}$ \\
\hline \multirow{3}{*}{ 299-E28-23 } & $03-29-94$ & ${ }^{90} \mathrm{Sr}$ & 9,460 & $\mathrm{pCi} / \mathrm{L}$ \\
\hline & $06-30-94$ & ${ }^{90} \mathrm{Sr}$ & $11,400^{b}$ & $\mathrm{pCi} / \mathrm{L}$ \\
\hline & $07-18-94$ & ${ }^{90} \mathrm{Sr}$ & $8,690 / 4,710^{c}$ & $\mathrm{pCi} / \mathrm{L}$ \\
\hline 299-E28-24a & -- & - &.-- & -- \\
\hline
\end{tabular}




\section{DOE/RL-95-59}

Rev. 0

Table 4-2. 216-B-5 Reverse Well Baseline Water Quality Data. (Section 4.3.1.2) (2 Sheets)

\begin{tabular}{|c|c|c|c|c|}
\hline Well & Date Sampled & Contaminant & Activity & Units \\
\hline \multirow{2}{*}{$299-E 28-25$} & $03-29-94$ & ${ }^{90} \mathrm{Sr}$ & 4,720 & $\mathrm{pCi} / \mathrm{L}$ \\
\cline { 2 - 5 } & $07-20-94$ & ${ }^{90} \mathrm{Sr}$ & 4,250 & $\mathrm{pCi} / \mathrm{L}$ \\
\hline
\end{tabular}

NOTES:

${ }^{a}$ Well not sampled.

${ }^{b}$ Value used for initial resin testing.

'Possible outlier.

dThe two values represent changes in concentration over time during well suitability testing. 
Rev. 0

Table 4-3. Summary of the Average Concentration of Contaminants in Groundwater During Pumping.

\begin{tabular}{|c|c|c|c|}
\hline Ranking & Run \# and Pumping Cycle & Contaminant & $\begin{array}{l}\text { Average Concentration } \\
\qquad(\mathrm{pCi} / \mathrm{L})\end{array}$ \\
\hline 1 & $\begin{array}{l}\text { Run 2. Pumping } 99.94 \mathrm{~L} / \mathrm{min} \text {, } \\
8 \mathrm{~h} / \text { day. }\end{array}$ & ${ }^{137} \mathrm{Cs}$ & 1,590 \\
\hline 2 & $\begin{array}{l}\text { Run 2. Continuous pumping at } \\
105.2 \mathrm{~L} / \mathrm{min} \text {. }\end{array}$ & ${ }^{137} \mathrm{Cs}$ & 1,490 \\
\hline 3 & $\begin{array}{l}\text { Run 1. Continuous pumping at } \\
107.1 \mathrm{~L} / \mathrm{min} .\end{array}$ & ${ }^{137} \mathrm{Cs}$ & 1,425 \\
\hline 4 & $\begin{array}{l}\text { Run 1. Pumping } 101.1 \mathrm{~L} / \mathrm{min} \text {, } \\
8 \mathrm{~h} / \text { day. }\end{array}$ & ${ }^{137} \mathrm{Cs}$ & 1,360 \\
\hline $1^{\mathrm{b}}$ & $\begin{array}{l}\text { Run 2. Pumping } 99.9 \mathrm{~L} / \mathrm{min} \text {, } \\
8 \mathrm{~h} \text { /day. }\end{array}$ & ${ }^{239 / 240} \mathrm{Pu}$ & 20 \\
\hline $1^{b}$ & $\begin{array}{l}\text { Run 2. Continuous pumping at } \\
105.2 \mathrm{~L} / \mathrm{min} \text {. }\end{array}$ & ${ }^{239 / 240} \mathrm{Pu}$ & 20 \\
\hline 2 & $\begin{array}{l}\text { Run 1. Pumping } 101.1 \mathrm{~L} / \mathrm{min} \text {, } \\
8 \mathrm{~h} / \text { day. }\end{array}$ & ${ }^{239 / 240} \mathrm{Pu}$ & 19 \\
\hline 3 & $\begin{array}{l}\text { Run 1. Continuous at pumping } \\
107.1 \mathrm{~L} / \mathrm{min} \text {. }\end{array}$ & ${ }^{239 / 240} \mathrm{Pu}$ & 17 \\
\hline 1 & $\begin{array}{l}\text { Run 2. Pumping } 99.9 \mathrm{~L} / \mathrm{min} \text {, } \\
8 \mathrm{~h} / \text { day. }\end{array}$ & ${ }^{90} \mathrm{Sr}$ & 4,970 \\
\hline 2 & $\begin{array}{l}\text { Run 2. Continuous pumping at } \\
105.2 \mathrm{~L} / \mathrm{min} \text {. }\end{array}$ & ${ }^{90} \mathrm{Sr}$ & 4,488 \\
\hline 3 & $\begin{array}{l}\text { Run 1. Continuous pumping at } \\
\text { 107.1 L/min. }\end{array}$ & ${ }^{90} \mathrm{Sr}$ & 3,894 \\
\hline 4 & $\begin{array}{l}\text { Run 1. Pumping } 101.1 \mathrm{~L} / \mathrm{min} \text {, } \\
8 \mathrm{~h} / \text { day. }\end{array}$ & ${ }^{90} \mathrm{Sr}$ & 3,663 \\
\hline
\end{tabular}

${ }^{2} \mathrm{~A}$ " 1 " denotes the highest average concentration of contaminant in the groundwater during treatability testing; a "4" denotes the lowest.

'The average concentration of ${ }^{239 / 240} \mathrm{Pu}$ in the groundwater is the same. 
Table 4-4. 216-BY Cribs Baseline Groundwater Data.

\begin{tabular}{|c|c|c|c|c|}
\hline Well & Date Sampled & Contaminant & Activity & Units \\
\hline \multirow{2}{*}{ 299-E33-7 } & $04-26-94$ & ${ }^{60} \mathrm{Co}$ & 22.1 & $\mathrm{pCi} / \mathrm{L}$ \\
\hline & $08-29-94$ & ${ }^{60} \mathrm{Co}$ & 9.02 & $\mathrm{pCi} / \mathrm{L}$ \\
\hline 299-E33-13 & $04-14-95$ & ${ }^{60} \mathrm{Co}$ & 9.21 & $\mathrm{pCi} / \mathrm{L}$ \\
\hline 299-E33-14 & $04-28-94$ & ${ }^{60} \mathrm{Co}$ & 3.61 & $\mathrm{pCi} / \mathrm{L}$ \\
\hline 299-E33-26 & $04-28-94$ & ${ }^{60} \mathrm{Co}$ & 5.95 & $\mathrm{pCi} / \mathrm{L}$ \\
\hline $699-49-55 A$ & $04-11-94$ & ${ }^{60} \mathrm{Co}$ & 7.83 & $\mathrm{pCi} / \mathrm{L}$ \\
\hline $699-49-57 A$ & $04-11-94$ & ${ }^{60} \mathrm{Co}$ & 17 & $\mathrm{pCi} / \mathrm{L}$ \\
\hline \multirow{2}{*}{$699-50-53 A$} & $04-11-94$ & ${ }^{60} \mathrm{Co}$ & 27.2 & $\mathrm{pCi} / \mathrm{L}$ \\
\hline & $06-30-94$ & ${ }^{60} \mathrm{Co}$ & $28.3^{a}$ & $\mathrm{pCi} / \mathrm{L}$ \\
\hline $699-52-54$ & $04-21-94$ & ${ }^{60} \mathrm{Co}$ & 74.3 & $\mathrm{pCi} / \mathrm{L}$ \\
\hline $699-52-57$ & $04-20-94$ & ${ }^{60} \mathrm{Co}$ & 5.47 & $\mathrm{pCi} / \mathrm{L}$ \\
\hline $699-55-57$ & $04-19-94$ & ${ }^{60} \mathrm{Co}$ & 50.4 & $\mathrm{pCi} / \mathrm{L}$ \\
\hline $699-57-59$ & $04-15-94$ & ${ }^{60} \mathrm{Co}$ & -4.53 & $\mathrm{pCi} / \mathrm{L}$ \\
\hline $699-59-58$ & $04-21-94$ & ${ }^{60} \mathrm{Co}$ & 1.2 & $\mathrm{pCi} / \mathrm{L}$ \\
\hline $699-60-60$ & $04-21-94$ & ${ }^{60} \mathrm{Co}$ & -0.46 & $\mathrm{pCi} / \mathrm{L}$ \\
\hline $49-53^{b}$ & $07-30-94$ & ${ }^{60} \mathrm{Co}$ & 9.7 & $\mathrm{pCi} / \mathrm{L}$ \\
\hline $49-54^{b}$ & $07-26-94$ & ${ }^{60} \mathrm{Co}$ & 20.1 & $\mathrm{pCi} / \mathrm{L}$ \\
\hline $50-54^{b}$ & $07-28-94$ & ${ }^{60} \mathrm{Co}$ & 19.2 & $\mathrm{pCi} / \mathrm{L}$ \\
\hline \multirow{2}{*}{ 299-E33-7 } & $04-26-94$ & ${ }^{99} \mathrm{Tc}$ & 619 & $\mathrm{pCi} / \mathrm{L}$ \\
\hline & $08-29-94$ & ${ }^{99} \mathrm{Tc}$ & 685 & $\mathrm{pCi} / \mathrm{L}$ \\
\hline 299-E33-13 & $01-14-94$ & ${ }^{99} \mathrm{Tc}$ & 1,380 & $\mathrm{pCi} / \mathrm{L}$ \\
\hline 299-E33-14 & $04-28-94$ & ${ }^{99} \mathrm{Tc}$ & 34.7 & $\mathrm{pCi} / \mathrm{L}$ \\
\hline 299-E33-26 & 04-28-94 & ${ }^{99} \mathrm{Tc}$ & 775 & $\mathrm{pCi} / \mathrm{L}$ \\
\hline $699-49-55 \mathrm{~A}$ & $04-11-95$ & ${ }^{99} \mathrm{Tc}$ & 381 & $\mathrm{pCi} / \mathrm{L}$ \\
\hline $699-49-57 \mathrm{~A}$ & $04-11-94$ & ${ }^{99} \mathrm{Tc}$ & 1,525 & $\mathrm{pCi} / \mathrm{L}$ \\
\hline \multirow{2}{*}{$699-50-53 \mathrm{~A}$} & $04-11-94$ & ${ }^{99} \mathrm{Tc}$ & 1,690 & $\mathrm{pCi} / \mathrm{L}$ \\
\hline & $06-30--94$ & ${ }^{99} \mathrm{Tc}$ & $1,480^{\mathrm{a}}$ & $\mathrm{pCi} / \mathrm{L}$ \\
\hline $699-52-54$ & $04-21-94$ & ${ }^{99} \mathrm{Tc}$ & 4,310 & $\mathrm{pCi} / \mathrm{L}$ \\
\hline $699-52-57$ & $04-20-94$ & ${ }^{99} \mathrm{Tc}$ & 2.47 & $\mathrm{pCi} / \mathrm{L}$ \\
\hline $699-55-57$ & $04-19-94$ & ${ }^{99} \mathrm{Tc}$ & 2,100 & $\mathrm{pCi} / \mathrm{L}$ \\
\hline $699-57-59$ & $04-15-94$ & ${ }^{99} \mathrm{Tc}$ & 49.9 & $\overline{\mathrm{pCi} / \mathrm{L}}$ \\
\hline 699-59-58 & $04-21-94$ & ${ }^{99} \mathrm{Tc}$ & 221 & $\mathrm{pCi} / \mathrm{L}$ \\
\hline $699-60-60$ & $04-21-94$ & ${ }^{99} \mathrm{Tc}$ & 144 & $\mathrm{pCi} / \mathrm{L}$ \\
\hline $49-53^{b}$ & $07-30-94$ & ${ }^{99} \mathrm{Tc}$ & 200 & $\mathrm{pCi} / \mathrm{L}$ \\
\hline $49-54^{b}$ & $07-26-94$ & ${ }^{99} \mathrm{Tc}$ & 480 & $\mathrm{pCi} / \mathrm{L}$ \\
\hline $50-54^{b}$ & $07-28-94$ & ${ }^{99} \mathrm{Tc}$ & 1,380 & $\mathrm{pCi} / \mathrm{L}$ \\
\hline
\end{tabular}

NOTES:

${ }^{2}$ Value used for initial resin testing.

bSonic push groundwater samples. 
Table 4-5. Sonic Push Activity Summary.

\begin{tabular}{|c|c|c|}
\hline Date & $\begin{array}{c}\text { Hole } \\
\text { Number }\end{array}$ & Activity \\
\hline $07 / 19$ & $49-53$ & $\begin{array}{l}\text { Mobilize to site, push rod to refusal at } 26 \mathrm{ft} \text {, push to } \\
\text { refusal at } 24 \mathrm{ft} \text {, run pilot casing. }\end{array}$ \\
\hline $07 / 20$ & $49-53$ & $\begin{array}{l}\text { Run pilot casing, push rod to refusal at } 124.6 \mathrm{ft} \text {, plug and abandon } \\
\text { hole. }\end{array}$ \\
\hline $07 / 21$ & $48-52$ & $\begin{array}{l}\text { Mobilize to site, push rod to refusal at } 36 \mathrm{ft} \text {, run pilot casing, push } \\
\text { rod to refusal at } 168.9 \mathrm{ft} \text {. }\end{array}$ \\
\hline $07 / 22$ & $48-52$ & Repairs to rig, plug and abandon hole. \\
\hline $07 / 23$ & & Rig Repairs, Weekend. \\
\hline $07 / 24$ & & Weekend. \\
\hline $07 / 25$ & $49-54$ & Mobilize to site, run pilot casing. \\
\hline $07 / 26$ & $49-54$ & $\begin{array}{l}\text { Push rod, fish rod, push to refusal below water table at } 133 \mathrm{ft} \text {, } \\
\text { establish Radiation Control Area (RCA), collect groundwater } \\
\text { sample, plug and abandon hole. }\end{array}$ \\
\hline $07 / 27$ & $50-54$ & $\begin{array}{l}\text { Mobilize to site, run pilot casing, fish pilot casing, run pilot casing, } \\
\text { push rods to refusal and breakage at } 112 \mathrm{ft} \text {, plug and abandon hole. }\end{array}$ \\
\hline $07 / 28$ & $50-54$ & $\begin{array}{l}\text { Push rods to refusal below water table at } 162 \mathrm{ft} \text {, establish } \mathrm{RCA} \text {, } \\
\text { collect groundwater samples, plug and abandon hole. }\end{array}$ \\
\hline $07 / 29$ & $49-53$ & $\begin{array}{l}\text { Water Development Company, Bechtel Hanford, Inc. contract } \\
\text { meeting, mobilize to site, run pilot casing. }\end{array}$ \\
\hline $07 / 30$ & $49-53$ & $\begin{array}{l}\text { Run Pilot casing, push rods to refusal below water table at } 135.6 \mathrm{ft} \text {, } \\
\text { establish RCA, collect samples, plug and abandon hole. }\end{array}$ \\
\hline $07 / 31$ & & Weekend. \\
\hline $08 / 01$ & $48-52$ & Mobilize to site, rig repairs, run pilot casing, push rod to $37 \mathrm{ft}$. \\
\hline $08 / 02$ & $48-52$ & $\begin{array}{l}\text { Continue to push rod to refusal and breakage at } 61 \mathrm{ft} \text {, Magnaflux all } \\
\text { rods available, push to refusal and breakage at } 161 \mathrm{ft} \text {. }\end{array}$ \\
\hline $08 / 03$ & $49-51$ & $\begin{array}{l}\text { Plug and abandon } 48-52, \text { mobilize to } 49-51 \text {, run pilot casing, } \\
\text { Magnaflux rods used yesterday, push rod to refusal and breakage at } \\
135 \mathrm{ft} \text {, decide new rod needed. }\end{array}$ \\
\hline $08 / 04$ & $49-51$ & Start long weekend. \\
\hline $08 / 05$ & & Weekend. \\
\hline $08 / 06$ & & Weekend. \\
\hline $08 / 07$ & & Weekend. \\
\hline $08 / 08$ & & Weekend. \\
\hline $08 / 09$ & & Waiting for new rod. \\
\hline $08 / 10$ & $49-51$ & $\begin{array}{l}\text { Ready new rod, push rod to refusal and breakage at } 131 \mathrm{ft} \text { (same } \\
\text { pilot hole), plug and abandon } 49-51 \text {, mobilize to } 48-54 \text {, run pilot } \\
\text { casing, push rods to breakage at } 53 \mathrm{ft} \text {, fish rod. }\end{array}$ \\
\hline $08 / 11$ & $48-54$ & $\begin{array}{l}\text { Push rod to refusal and breakage at } 193 \mathrm{ft} \text {, plug and abandon } 48-54 \text {, } \\
\text { return to } 49-51 \text {, run starter casing, Magnaflux rods used for last } \\
\text { push, push rod to suspected refusal at } 134.9 \mathrm{ft} \text {, stop for the day. }\end{array}$ \\
\hline $08 / 12$ & $49-51$ & $\begin{array}{l}\text { Continue to push, refusal and breakage at } 135 \mathrm{ft} \text {, major rig repairs } \\
\text { required, hole plugged and abandoned on } 08 / 13 \text {. }\end{array}$ \\
\hline
\end{tabular}


Rev. 0

Table 4-6. Measurement Results from Sonic Push.

\begin{tabular}{|c|c|c|c|c|c|}
\hline Hole Number & $\begin{array}{c}\text { Depth to } \\
\text { Water (m bgs) }\end{array}$ & $\begin{array}{c}\text { Depth to } \\
\text { Basalt (m bgs) }\end{array}$ & $\begin{array}{c}\text { Aquifer } \\
\text { Thickness } \\
(\mathbf{m})\end{array}$ & $\begin{array}{c}{ }^{60} \mathrm{Co} \\
(\mathbf{p C i} / \mathrm{L})\end{array}$ & $\begin{array}{c}{ }^{99} \mathrm{Tc} \\
\text { (pCi/L) }\end{array}$ \\
\hline $49-54$ & 38.1 & 40.5 & 2.19 & ND & 480 \\
\hline $50-54$ & 47.2 & 49.4 & 2.10 & ND & 1,380 \\
\hline $49-53$ & 39.3 & 41.1 & 1.95 & ND & 200 \\
\hline
\end{tabular}

bgs $=$ below ground surface

$\mathrm{ND}=$ not detected.

Table 4-7. Groundwater Data Collected Over Time at Well 699-55-57 During Production Testing.

\begin{tabular}{|c|c|c|c|c|}
\hline $\begin{array}{c}\text { Elapsed Time } \\
(\mathrm{min})\end{array}$ & Liters pumped & $\begin{array}{c}{ }^{60} \mathrm{Co} \\
(\mathrm{pCi} / \mathrm{L})\end{array}$ & $\begin{array}{c}{ }^{137} \mathrm{Cs} \\
(\mathrm{pCi} / \mathrm{L})\end{array}$ & $\begin{array}{c}{ }^{99} \mathrm{Tc} \\
(\mathrm{pCi} / \mathrm{L})\end{array}$ \\
\hline 32 & 356 & 27.1 & 3.3 & 1,790 \\
\hline 152 & 1,684 & 34.9 & 2.83 & 1,970 \\
\hline 272 & 3,016 & 34.9 & 2.26 & 1,950 \\
\hline 392 & 4,346 & 22.6 & 1.89 & 1,960 \\
\hline 512 & 5,678 & 35.6 & 0.55 & 2,160 \\
\hline
\end{tabular}


DOE/RL-95-59

Rev. 0

Table 4-8. In Situ Flow Meter Results. (2 Sheets)

\begin{tabular}{|c|c|c|c|c|}
\hline \multirow{2}{*}{ Well } & \multirow{2}{*}{ DBWL (ft) } & \multicolumn{2}{|c|}{ Velocity (ft/d) } & \multirow{2}{*}{ Direction } \\
\hline & & $\phi=0.20 \%$ & $\phi=0.25 \%$ & \\
\hline 299-E32-2 & $\begin{array}{l}3.7 \\
7.7\end{array}$ & $\begin{array}{l}0.89 \\
1.8\end{array}$ & $\begin{array}{l}0.7 \\
1.4 \\
\end{array}$ & $\begin{array}{c}\mathrm{S} 30^{\circ} \mathrm{E} \\
\mathrm{S} 34.3^{\circ} \mathrm{E}\end{array}$ \\
\hline Average & & & 1.0 & $\mathrm{~S} 24^{\circ} \mathrm{E}$ \\
\hline 299-E33-30 & $\begin{array}{r}4.3 \\
8.3 \\
12.3 \\
\end{array}$ & $\begin{array}{l}0.73 \\
0.66 \\
0.45\end{array}$ & $\begin{array}{l}0.58 \\
0.53 \\
0.36 \\
\end{array}$ & $\begin{array}{c}\mathrm{S} 69^{\circ} 9^{\circ} \mathrm{W} \\
\mathrm{S} 63^{\circ} \mathrm{W} \\
\mathrm{S} 68^{\circ} \mathrm{W}\end{array}$ \\
\hline Average & & & 0.49 & $\mathrm{~S} 67^{\circ} \mathrm{W}$ \\
\hline 299-E33-31 & $\begin{array}{l}2.9 \\
6.9 \\
8.9 \\
\end{array}$ & $\begin{array}{l}1.7 \\
2.1 \\
0.59\end{array}$ & $\begin{array}{l}1.3 \\
1.7 \\
0.47 \\
\end{array}$ & $\begin{array}{l}\mathrm{S} 22.6^{\circ} \mathrm{W} \\
\mathrm{S} 18.7^{\circ} \mathrm{E} \\
\mathrm{S} 20.0^{\circ} \mathrm{W}\end{array}$ \\
\hline Average & & & 1.1 & $\mathrm{~S} 2^{\circ} \mathrm{W}$ \\
\hline 299-E33-35 & $\begin{array}{l}2.8 \\
5.8 \\
8.8 \\
\end{array}$ & $\begin{array}{l}0.33 \\
1.2 \\
0.23\end{array}$ & $\begin{array}{l}0.27 \\
0.94 \\
0.18 \\
\end{array}$ & $\begin{array}{l}\mathrm{S} 42.2^{\circ} \mathrm{W} \\
\mathrm{S} 78.4^{\circ} \mathrm{W} \\
\mathrm{S} 21.3^{\circ} \mathrm{W}\end{array}$ \\
\hline Average & & & 0.43 & $564.5^{\circ} \mathrm{W}$ \\
\hline 299-E33-38 & $\begin{array}{l}4.2 \\
8.2 \\
\end{array}$ & $\begin{array}{l}1.4 \\
2.4 \\
\end{array}$ & $\begin{array}{l}1.1 \\
2.0\end{array}$ & $\begin{array}{l}\text { S23.6 } \\
\text { S15. W } \\
\text { S15 }\end{array}$ \\
\hline Average & & & 1.6 & $\mathrm{~S} 18.4^{\circ} \mathrm{W}$ \\
\hline 299-E34-5 & 1.4 & 2.37 & 1.9 & $\mathrm{~S} 46.6^{\circ} \mathrm{W}$ \\
\hline 299-E34-11 & $\begin{array}{l}2.0 \\
3.5\end{array}$ & $\begin{array}{l}1.2 \\
1.1\end{array}$ & $\begin{array}{l}0.96 \\
0.87\end{array}$ & $\begin{array}{l}\mathrm{N} 51.4^{\circ} \mathrm{E} \\
\mathrm{N} 51.4^{\circ} \mathrm{E}\end{array}$ \\
\hline Average & & & 0.92 & $\mathrm{~N} 51.4^{\circ} \mathrm{E}$ \\
\hline $699-48-50$ & $\begin{array}{l}1.2 \\
5.7 \\
9.7 \\
\end{array}$ & $\begin{array}{r}<0.04 \\
0.60 \\
0.04 \\
\end{array}$ & $\begin{array}{r}<0.04 \\
0.48 \\
<0.04 \\
\end{array}$ & $\begin{array}{c}a \\
S 18.6^{\circ} \mathrm{E} \\
\left(\mathrm{S} 52.7^{\circ} \mathrm{E}\right)^{\mathrm{a}}\end{array}$ \\
\hline Average & & & 0.48 & $\mathrm{~S} 18.6^{\circ} \mathrm{E}$ \\
\hline $699-52-54$ & $\begin{array}{l}0.9 \\
1.4\end{array}$ & $\begin{array}{r}0.04 \\
<0.04 \\
\end{array}$ & $\begin{array}{l}<0.04 \\
<0.04\end{array}$ & $\begin{array}{c}\left(\mathrm{S} 46.5^{\circ} \mathrm{E}\right)^{\mathrm{a}} \\
\mathrm{a}\end{array}$ \\
\hline Average & & & alid value & \\
\hline $699-52-57$ & 0.8 & 1.4 & 1.1 & $\mathrm{~N} 2.9^{\circ} \mathrm{E}$ \\
\hline $699-55-55$ & $\begin{array}{l}2.1 \\
5.1 \\
8.1\end{array}$ & $\begin{array}{l}1.5 \\
0.99 \\
1.1 \\
\end{array}$ & $\begin{array}{l}1.2 \\
0.79 \\
0.91 \\
\end{array}$ & $\begin{array}{c}\mathrm{N} 1.0^{\circ} \mathrm{E} \\
\mathrm{N} 21.7^{\circ} \mathrm{W} \\
\mathrm{N} 4.3^{\circ} \mathrm{E}\end{array}$ \\
\hline Average & & & 0.95 & $\mathrm{~N} 4.1^{\circ} \mathrm{W}$ \\
\hline
\end{tabular}


Table 4-8. In Situ Flow Meter Results. (2 Sheets)

\begin{tabular}{|c|c|c|c|c|}
\hline \multirow{2}{*}{ Well } & \multirow{2}{*}{ DBWL (ft) } & \multicolumn{2}{|c|}{ Velocity (ft/d) } & \multirow{2}{*}{ Direction } \\
\cline { 3 - 5 } & & $\phi=0.20 \%$ & $\phi=\mathbf{0 . 2 5 \%}$ & \\
\hline $699-59-58$ & 2.2 & 0.60 & 0.48 & $\mathrm{~S} 11.2^{\circ} \mathrm{W}$ \\
& 6.3 & 0.77 & 0.61 & $\mathrm{~S} 35.0^{\circ} \mathrm{W}$ \\
& 9.3 & 1.2 & 0.93 & $\mathrm{~S} 43.9^{\circ} \mathrm{W}$ \\
\hline Average & & & 0.66 & $\mathrm{~S} 33.5^{\circ} \mathrm{W}$ \\
\hline $699-60-57$ & 3.0 & 2.0 & 1.6 & $\mathrm{~S} 79.3^{\circ} \mathrm{W}$ \\
& 65.5 & 0.86 & 0.69 & $\mathrm{~N} 55.6^{\circ} \mathrm{E}$ \\
& 69.5 & 1.6 & 1.2 & $\mathrm{~N} 58.1^{\circ} \mathrm{E}$ \\
\hline & & & $0.96^{\mathrm{b}}$ & $\mathrm{N} 57.2^{\circ} \mathrm{E}$ \\
\hline
\end{tabular}

NOTES:

aFlow velocities below $0.04 \mathrm{ft} /$ day are below practical measurement capabilities of instrument. Values in parentheses are directions for velocities calculated using $0.20 \%$ porosity.

bonly the two lower flow velocities and directions were used in determining the average values.

Average $=$ average value calculated using vector addition methods. NOTE: not an arithmetic average.

DBWL = depth below water level

$\phi \quad=$ effective porosity 
Rev. 0

Table 4-9. Synopsis of Tracer Test 1 Events.

\begin{tabular}{|l|r|r|r|r|}
\hline & Day & Hour & $\begin{array}{c}\text { Flow Rate } \\
\text { (L/min) }\end{array}$ & $\begin{array}{c}\text { Volume } \\
\text { (L) }\end{array}$ \\
\hline Begin Bromide Injection & $02 / 06 / 95$ & $08: 24$ & & \\
\hline End Bromide Injection & $02 / 06 / 95$ & $-10: 25^{\mathrm{a}}$ & & \\
\hline Average Bromide Injection Rate & & & 198.7 & \\
\hline Bromide Injection Volume & & & & $\sim 21,198^{\mathrm{b}}$ \\
\hline Bromide Injection Sample 1 & $02 / 06 / 95$ & $08: 39$ & & \\
\hline Bromide Injection Sample 2 & $02 / 06 / 95$ & $09: 35$ & & \\
\hline Bromide Injection Sample 3 & $02 / 06 / 95$ & $10: 05$ & & \\
\hline Begin Effluent Injection & $02 / 06 / 95$ & $14: 15$ & & \\
\hline End Effluent Injection & $02 / 11 / 95$ & $04: 00$ & & \\
\hline Average Effluent Injection Rate & & & 98 & \\
\hline Begin Effluent Extraction & $02 / 06 / 95$ & $08: 02$ & & \\
\hline End Effluent Extraction & $02 / 11 / 95$ & $04: 00$ & & \\
\hline Average Extraction Rate & & & 107 & \\
\hline Effluent extraction off February 7, 1995, 07:20 to 07:55 for generator service. & \\
\hline Begin Effluent Sampling (Continue Hourly) & $02 / 06 / 96$ & $08: 56$ & & \\
\hline
\end{tabular}

NOTES:

${ }^{a}$ Time estimated from the effluent tank volume and the average injection rate.

bolume calculated from effluent tank dimensions and height of water in tank. 
DOE/RL-95-59

Rev. 0

Table 4-10. Synopsis of Tracer Test 2 Events.

\begin{tabular}{|c|c|c|c|c|}
\hline & Day & Hour & $\begin{array}{c}\text { Flow Rate } \\
\text { (L/min) }\end{array}$ & $\begin{array}{l}\text { Volume } \\
\text { (L) }\end{array}$ \\
\hline Begin Bromide Injection & $05 / 21 / 95$ & $08: 36$ & & \\
\hline End Bromide Injection & $05 / 21 / 95$ & $-10: 30^{a}$ & & \\
\hline Average Bromide Injection Rate & & & 190 & \\
\hline Bromide Injection Volume & & & & $23,352^{b}$ \\
\hline Bromide Injection Sample 1 & $05 / 21 / 95$ & $08: 40$ & & \\
\hline Bromide Injection Sample 2 & $05 / 21 / 95$ & $09: 10$ & & \\
\hline Bromide Injection Sample 3 & $05 / 21 / 95$ & $09: 40$ & & \\
\hline Bromide Injection Sample 4 & $05 / 21 / 95$ & $10: 10$ & & \\
\hline Begin Effluent Injection & $05 / 21 / 95$ & $10: 30$ & & \\
\hline End Effluent Injection & $05 / 26 / 95$ & $11: 00$ & & \\
\hline Average Effluent Injection Rate & & & 83 & \\
\hline Begin Effluent Extraction & $05 / 21 / 95$ & 08:02 & & \\
\hline End Effluent Extraction & $05 / 26 / 95$ & $11: 00$ & & \\
\hline Average Extraction Rate & & & 107 & \\
\hline \multicolumn{5}{|c|}{ Effluent extraction off May $23,1995,07: 27$ to $07: 47$ for generator service. } \\
\hline Begin Effluent Sampling (Continue Hourly) & $05 / 21 / 96$ & $08: 46$ & & \\
\hline
\end{tabular}

NOTES:

"Time estimated from the effluent tank volume and the average injection rate.

bolume calculated from effluent tank dimensions and height of water in tank. 
DOE/RL-95-59

Rev. 0 
DOE/RL-95-59

Rev. 0

\subsection{ASSESSMENT OF 200-BP-5 PLUMES}

In addition to reporting the results of the pilot-scale treatability tests, a major objective of the 200-BP-5 Treatability Test Report as discussed briefly in Section 2.6.8 is to present assessments of the three major plumes in the 200-BP-5 Operable Unit. To achieve this objective, Section 5.1 presents background data on the processes and plants that were the source of the groundwater contamination. Section 5.2 provides details of the history of changes in the water-table level and groundwater chemical concentrations because of the Hanford Site operations. The comprehensive plume-specific data are then used in Section 5.3 to develop interpretations relating to the contaminant plumes originating from the B-5 Reverse Well, the BY-Cribs, and the Gable Mountain Pond. For each contaminant plume, the interaction and interrelationship of Hanford Site process operations, the chemistry of the contaminant constituents, and the local geology and hydrology are evaluated to determine the most probable models of contaminant behavior and transport in the subsurface environment. This information is then incorporated in Section 5.4 into determinations of the risk to human health presented by each plume. Data uncertainties are evaluated and data needs are identified in Section 5.5.

\subsection{OPERATIONAL HISTORY}

The Hanford Site, established in 1943, was originally designed, built, and operated to produce plutonium for nuclear weapons using production reactors and chemical reprocessing plants. In March 1943, construction began on three reactor facilities (B, D, and F Reactors) in the 100 Areas and three chemical processing facilities (B, T, and U Plants) in the 200 Areas. After World War II, six more reactors were built (H, DR, KW, KE, and $N$ Reactors). Shutdown of the reactors began in 1964. By 1971, eight of the nine reactors were shut down. Shutdown of $N$ Reactor began in October 1991.

Operations in the 200 Areas (200 East and 200 West Areas) are related to separation of plutonium and uranium from irradiated nuclear fuel. Irradiated nuclear fuel from the reactors was stored in facilities in the 200 North Aggregate Area before transfer to separation facilities in the 200 East and 200 West Areas. Each separation facility consisted of a canyon building that contained most of the chemical processing systems, tank farms, and ancillary process control buildings, many with their own waste streams. The 200 Areas also contain nonradioactive support facilities, including transportation maintenance buildings, service stations, coal-fired powerhouses for process steam production, steam transmission lines, raw water treatment plants, water-storage tanks, electrical maintenance facilities, and subsurface sewage disposal systems.

Highly radioactive waste streams from the separations process were predominantly discharged to tank farms; moderate-activity wastes were discharged to the soil column using cribs, trenches, French drains, and reverse wells; and low-activity waste streams were predominantly discharged to the soil column using ponds and ditches. 


\subsubsection{Area Facility Operational Histories}

The 200 East Area has one active processing area, B Plant, and two inactive processing areas [the PUREX Plant and Semi-Works (C Plant)] (Figure 5-1). The 200 North Aggregate Area is north of and approximately midway between the 200 East and 200 West Areas. The 200 West Area has four inactive processing areas: S Plant, T Plant, U Plant, and Z Plant (Figure 5-2). The following sections summarize operations and waste disposal information for the 200 East and 200 West Area separation facilities and the 200 North Aggregate Area facilities.

5.1.1.1 B Plant Aggregate Area. The major processes at the 200 East B Plant Aggregate Area involved extraction of plutonium from irradiated uranium fuel; purification, precipitation, and encapsulation of cesium and strontium from PUREX-derived waste streams; various waste-handling processes such as evaporation; and transfer of single-shell tank waste.

The 221-B Building is one of the main B Plant facilities. It began operation in 1945, separating plutonium from irradiated nuclear fuel by the bismuth phosphate $\left(\mathrm{BiPO}_{4}\right)$ process. The $\mathrm{BiPO}_{4}$ process produced a dilute plutonium nitrate solution that was then purified and concentrated in the 224-B Building using a lanthanum fluoride process. The concentrated plutonium nitrate solution was then transferred to the Z Plant Aggregate Area for further refinement. Plutonium separation operations at B Plant ceased in 1952. Various waste treatment operations began at the 221-B Building in 1965, such as ${ }^{137} \mathrm{Cs}$ and ${ }^{90} \mathrm{Sr}$ recovery from 216 -BY Tank Farm liquids and from the U Plant Uranium Recovery Project waste stream. Several additions to the 221-B Building, such as the 225-B Waste Encapsulation and Storage Facility (WESF) and the 221 Cask Transfer Facility, were constructed to support waste treatment operations.

Some B Plant tank wastes were transferred to the U Plant area for uranium recovery between 1952 and 1956. The wastes were then returned to the $B$ Plant area and disposed to the ground using the BY-Cribs. Waste evaporators and ITS units have been used in the 241-B, 241-BX, and 241-BY Tank Farms to minimize the volume of waste in the tanks. Condensate from ITS B-5 Reverse Well and BY-Cribs was discharged to the 216-B-50 and 216-B-57 Cribs, respectively.

5.1.1.2 PUREX Plant Aggregate Area. Recovery of uranium and plutonium from irradiated nuclear fuel was the principal activity at the 200 East PUREX Plant Aggregate Area. In the PUREX process, irradiated uranium fuel was dissolved in a nitric acid solution, and then the uranium and plutonium were separated from the solution by a solvent extraction process using tributyl phosphate (TBP) in normal paraffin hydrocarbon solvent. The 202-A Canyon Building, the main facility in the PUREX Plant Aggregate Area, operated from 1955 until 1972 and was shut down from 1972 until 1983. Operations at the 202-A Canyon Building resumed in 1982 and were terminated in December 1992. Other facilities active in the PUREX Plant Aggregate Area include the 293-A Building, the 204-AR Waste Unloading Station, and the 242-A and 243-A Evaporators. The 242-A Evaporator started in 1977 and continues to treat wastes stored in tanks. The 242-A Evaporator steam condensate and cooling water continues to be discharged to the $216-\mathrm{B}-3 \mathrm{C}$ Pond in the near term.

The PUREX Plant Aggregate Area contains eight tank farms. The 241-A, 241-AX, and 241-C Tank Farms are inactive and have undergone initial stabilization. The 241-AN, 241-AP, 241-AW, 241-AY, and 241-AZ Tank Farms are active.

5.1.1.3 Semi-Works Aggregate Area. The 201-C Process Building and the Critical Mass Laboratory (209-E Building) are the principal facilities in the 200 East Semi-Works Aggregate Area. 
DOE/RL-95-59

Rev. 0

The 201-C Process Building was constructed in 1949 as a pilot plant for separation of uranium and plutonium from irradiated nuclear fuel using the reduction-oxidation (REDOX) process. The 201-C Process Building was converted in 1954 to a pilot plant for the PUREX process and functioned in this capacity until 1956, when operations were terminated. In 1961, the 201-C Process Building was converted to recover strontium from fission product waste and also to recover cesium, technetium, and promethium. This facility operated until 1967. Decommissioning work began in 1983 , and more than $49,210,200 \mathrm{~L}(30,000,000$ gal) was discharged to the ground during operations.

The Critical Mass Laboratory (209-E Building) in which criticality experiments and research were conducted operated from 1960 to 1983.

5.1.1.4 200 North Aggregate Area. Irradiated nuclear fuel from the plutonium production reactors in the 100 Areas was stored in the 200 North Aggregate Area to allow decay of short-lived radionuclides. The 212-N, 212-P, and 212-R Buildings were constructed in 1944 and used until 1952 for this purpose. Large quantities of water were pumped from wells $699-55-60 \mathrm{~A}$ and $699-55-60 \mathrm{~B}$ to $\mathrm{cool}$ the stored fuel. The cooling water was then discharged to the $216-\mathrm{N}-1,216-\mathrm{N}-4$, and $216-\mathrm{N}-6$ Ponds. The 212-N, 212-P, and 212-R Buildings have been used for other purposes since 1952.

5.1.1.5 S Plant Aggregate Area. S Plant was constructed in the 200 West Area between May 1950 and August 1951 to separate plutonium and uranium from irradiated nuclear fuel using the REDOX chemical separation process. In the REDOX process, irradiated uranium fuel was dissolved in a nitric acid solution, and then the uranium and plutonium were separated from the solution by methyl isobutyl ketone solvent extraction. The plant operated from 1951 until it was shut down in July 1967. The major waste streams from S Plant were dissolution waste, aqueous process waste, and organic process wastes that were discharged to tanks and cribs. Also, during the period 1951 through 1991, a total of $59,700,000,000 \mathrm{~L}(15,800,000,000)$ gal of cooling water was discharged to six ponds:

216-S-10P, 216-S-11, 216-S-15, 216-S-16P, 216-S-17, and 216-S-19; and two associated ditches: 216-S-10D and 216-S-16D (DOE-RL 1993b). The ponds and ditches are situated southwest and west of the plant.

5.1.1.6 T Plant Aggregate Area. T Plant was built in the 200 West Area in 1944. It was one of the first plutonium separation facilities at the Hanford Site and used the same $\mathrm{BiPO}_{4}$ process used by B Plant to separate plutonium from irradiated nuclear fuel in the 221-T Building. The dilute plutonium nitrate solution was purified and concentrated in the 224-T Bulk Reduction Building and then sent to the $\mathrm{Z}$ Plant Aggregate Area for further refinement. Operations at the 221- $\mathrm{T}$ and 224-T Buildings ceased in 1956. Primary waste streams from the 221-T and 224-T Buildings included process waste and aqueous process waste that was discharged to tanks, cribs, and trenches. Decontamination water was discharged to a crib. Also, a total of $60,945,000,000 \mathrm{~L}$ $(16,100,000,000 \mathrm{gal})$ of cooling water was discharged to $216-\mathrm{T}-4$ Ponds, $610 \mathrm{~m}(2,000 \mathrm{ft})$ west of T Plant, from 1944 through 1976 (DOE-RL 1993b).

The 221-T Building, presently known as the Containment Systems Testing Facility, was used for a series of testing programs from 1964 to 1990. Activities in the 221-T Building now include radioactive decontamination, reclamation, and decommissioning of process equipment.

5.1.1.7 U Plant Aggregate Area. U Plant was constructed in the 200 West Area in 1944 to separate plutonium from irradiated nuclear fuel using the $\mathrm{BiPO}_{4}$ process. However, the process was never used at $U$ Plant because $B$ Plant and $T$ Plant were sufficient to meet plutonium production requirements. The 221-U Building was converted for the Uranium Recovery Project when existing 
tank space became limited. Recovery of uranium from the $\mathrm{BiPO}_{4}$ waste took place in the 221-U Building between 1952 and 1958 using a TBP process. The 221-U Building went on standby in 1958 and has not been used for uranium separation since that time. Primary waste streams from the 221-U Building include process waste and water from uranium recovery that was discharged to cribs, French drains, ponds, and ditches, and spent solvents and carbonate scrub solution from solvent treatment that was discharged to cribs. From 1944 through 1985, a total of $165,000,000 \mathrm{~L}$ $(43,600,000,000 \mathrm{gal})$ of cooling water was discharged to the $216-\mathrm{U}-10$ Pond (DOE-RL 1993b).

The 224-U Building began operation in 1952 as a uranium reduction facility and was converted in 1955 to support PUREX Plant activities. A stabilization run was completed in 1994. Primary waste streams from the 224-U Building include process waste and water from the $\mathrm{UO}_{3}$ conversion that was discharged to the 216-U-10 Pond, cribs, and ditches.

5.1.1.8 Z Plant Aggregate Area. Operations at Z Plant in the 200 West Area began in 1945 at the 231-Z Plutonium Isolation Facility (PIF), which concentrated plutonium nitrate solution produced by the separation facilities and converted the concentrate to a plutonium nitrate paste for shipment to Los Alamos, New Mexico, for further refinement. This operation took place from 1945 to 1949. Primary waste streams from the PIF included process waste and water that was discharged to a trench, crib, and reverse well.

In 1949, Z Plant was converted to produce plutonium metal and/or plutonium oxide from plutonium nitrate solutions produced in the separations plants. This Z Plant complex, also known as the PFP, operated from 1949 to 1973 and intermittently from 1985 to 1988 . Primary waste streams from the PFP included process waste and waters that were discharged to cribs, tanks, ponds, ditches, and seepage basins. The RECUPLEX Facility (234-5Z Building) and the Plutonium Reclamation Facility (PRF) (236-Z Building) also operated in Z Plant to recover plutonium from the PFP liquid waste stream. The RECUPLEX Facility began operation in 1955 and shut down in 1962 following a criticality event. The PRF operated from 1964 to 1979 and from 1984 to 1987 . The primary waste streams from the RECUPLEX Facility included aqueous process waste, organic solvent waste, and spent silica gel that were discharged to a ditch, pond, trench, and French drain. The primary waste streams from PRF were aqueous process waste and organic process waste that was discharged to cribs and tile fields. A process line also operated in the 242-Z Building from 1949 to 1959 and from 1964 to 1976 to recover americium for the PFP waste stream. This line was shut down in 1976 after an explosion occurred in one of the americium recovery units. The primary waste stream was spent ionexchange resin that discharged to ditches and a pond. 
DOE/RL-95-59

Rev. 0

\subsubsection{0-BP-5 Contaminant and Effluent Sources}

Operational details and effluent disposal histories for the B-5 Reverse Well, BY-Cribs, the 216-B-3 Pond System, and the 216-A-25 Gable Mountain Pond are presented below. The B-5 Reverse Well and BY-Cribs are discussed because they were sources of the contaminants of interest to the treatability test. The 216-B-3 Pond system is discussed because discharges of large volumes of cooling water at the system modified the groundwater flow in and from the 200 East Area, and probably influenced migration of contaminants from the B-5 Reverse Well and BY-Cribs. The 216-A-25 Gable Mountain Pond is discussed because discharges of large volumes of cooling water at this pond modified the groundwater flow from the 200 East Area and because the pond is the source of a ${ }^{90} \mathrm{Sr}$ plume.

5.1.2.1 216-B-5 Reverse Well. The B-5 Reverse Well is an inactive, 92-m- (302-ft) deep, 20-cm(8-in.) diameter (Brown and Ruppert 1950) waste management unit located approximately $305 \mathrm{~m}$ $(1,000 \mathrm{ft})$ northeast of the 221-B, 221-T, and 221-U Buildings and east of Baltimore Road. It received overflow waste from the 241-B-361 Settling Tank, which received waste from the 224-B Concentration Facility and from Tank 5-6 in the 221-B Building from April 1945 until September 1946. Between September 1946 and October 1947, cell drainage and other liquid waste from Tank 5-6 was injected into the well (WHC 1991, Brown et al. 1990). Approximately $3.10 \times 10^{7} \mathrm{~L}$ of liquid was discharged to the 216-B-361 Settling Tank from the 224-B Concentration Facility and the 221-B Building, containing an estimated $4.28 \times 10^{3} \mathrm{~g}$ of plutonium and $3.80 \times 10^{3} \mathrm{Ci}$ of mostly short-lived beta-gamma activity (Brown and Ruppert 1950). The waste stream contained an estimated $76 \mathrm{Ci}$ of ${ }^{90} \mathrm{Sr}, 106 \mathrm{Ci}$ of ${ }^{106} \mathrm{Ru}$, and $81 \mathrm{Ci}$ of ${ }^{137} \mathrm{Cs}$ (Maxfield 1979). Dates of operation, volumes of waste received, and radiological and chemical inventories for the B-5 Reverse Well are included in Tables 5-1, 5-2, and 5-3.

In 1947, the water-table elevation in well 299-E33-18 at the 241-BY Tank Farms demonstrated that

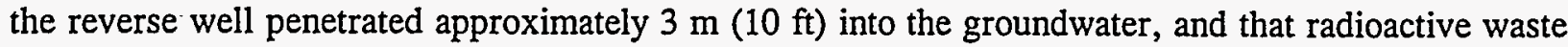
was being discharged directly into the groundwater. The B-5 Reverse Well was deactivated on September 27, 1947, and the Tank 5-6 wastes were rerouted to the 216-B-7A and 216-B-7B Cribs (Maxfield 1979). In November 1947, drilling began on the first of 11 wells to investigate groundwater contamination associated with B-5 Reverse Well. The last well was completed in May 1948. The drilling and regular groundwater sampling defined a broad plume of short-lived beta emitters $\left({ }^{106} \mathrm{Ru}\right)$ and a smaller plume of alpha emitters (Brown and Ruppert 1950).

5.1.2.2 216-BY Cribs. The BY-Cribs consist of nine inactive cribs, 216-B-43 through 216-B-50, and 216-B-57 in the 200-BP-1 Operable Unit (Figure 5-3). The 216-B-43 through 21-B-50 Cribs are located adjacent to the northern boundary of the 241-BY Tank Farm. The 216-B-57 Crib is located next to the northwest corner of the 241-BY Tank Farm and southwest of the BY-Cribs. The 216-B-43 through 216-B-50 Cribs are arranged in two north-trending lines of four cribs each; two lines run north from the 201-B Flush Tank, and individual feed pipes extend perpendicular from the central lines to individual cribs. Each crib consists of a $4-\mathrm{m}-(15-\mathrm{ft})$ deep by $9-\mathrm{m}(30-\mathrm{ft})$ by $9-\mathrm{m}$ (30-ft) excavation with a basal layer of gravel covered by layers of gravel, sand, and soil fill. Effluent was discharged by vertical pipes to the basal gravel layer and then infiltrated into the underlying vadose zone. The $216-\mathrm{B}-57 \mathrm{Crib}$ is a $61-\mathrm{m}-(200-\mathrm{ft})$ long, 3-m- $(10-\mathrm{ft})$ deep, and 4-m(15-ft) wide (at the bottom) excavation in which a $30-\mathrm{cm}$ (12-in.) in which a $30-\mathrm{cm}$ - (12-in.) diameter

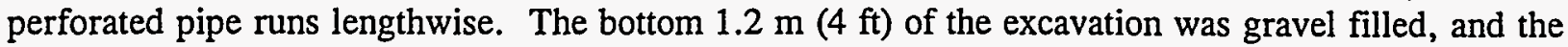
remaining $1.8 \mathrm{~m}(6 \mathrm{ft})$ was backfilled with soil to original ground level. The $B$ Plant Source 
Aggregate Area Management Study Report (DOE-RL 1993c) includes construction details and as-built drawings in plan- and cross-section views for the cribs.

The 216-B-43 through 216-B-49 Cribs received scavenged TBP supernatant waste from the 221-U Building and the 241-BY tanks. TBP acid waste from the 221-U Building was made alkaline for transport and sent to the 241-BY Tank Farm, where it was treated with potassium ferrocyanide as a cesium scavenger. The supernatant from the tanks was allowed to cascade from tank to tank to allow precipitation of cesium and was then discharged to the cribs (DOE-RL 1990, Jungfleisch 1984). This supernatant effluent contained large concentrations of radionuclides including ${ }^{137} \mathrm{Cs},{ }^{60} \mathrm{Co},{ }^{106} \mathrm{Ru}$, ${ }^{90} \mathrm{Sr}$, plutonium, and uranium (Maxfield 1979, Brown et al. 1990, WHC 1991, DOE-RL 1992). Inorganic compounds in the effluent included ferrocyanide, nitrate, phosphate, sodium, and sulfate-based compounds. It was intended that discharge at each crib would be stopped before the specific retention capacity of the vadose zone for radionuclides was exceeded. Discharges to these cribs began in November 1954 at the 216-B-43 Crib and ended in December 1955 at the 216-B-49 Crib. These seven cribs received a total of $34,000,000 \mathrm{~L}(9,034,000 \mathrm{gal})$ of TBP supernatant. Discharge of the TBP supernatant was halted in 1956 before use of the 216-B-50 Crib could begin, in 1956, when groundwater concentrations of ${ }^{60} \mathrm{Co}$ from a monitoring well adjacent to the cribs exceeded the discharge limit of $40,000 \mathrm{pCi} / \mathrm{L}$ by a factor of more than 100 (Thomas et al. 1956). Dates of operation, volumes of waste received, and radiological and chemical inventories for the cribs are included in Tables 5-1, 5-2, and 5-3.

The 216-B-50 and 216-B-57 Cribs received low-level radioactive condensate generated by the ITS B-5 Reverse Well and BY-Cribs, respectively. The ITS units operated in the 241-BY Tank Farm and reduced the volume of liquid in the single-shell waste storage tanks. Radionuclides in the ITS condensate included ${ }^{137} \mathrm{Cs},{ }^{106} \mathrm{Ru},{ }^{90} \mathrm{Sr}$, plutonium, and uranium (WHC 1991, Brown et al. 1990). Dates of operation, volumes of waste received, and radiological and chemical inventories for the cribs are presented in Tables 5-1, 5-2, and 5-3. The 216-B-50 and 216-B-57 Cribs received a total of $139,300,000 \mathrm{~L}(36,800,000 \mathrm{gal})$ from January 1965 through January 1974.

Stabilization of the BY-Crib area began in 1975 and was completed in November 1977 (Maxfield 1979). In 1991, interim stabilization actions under the Comprehensive Environmental Response, Compensation, and Liability Act were completed at the 216-B-43 to 216-B-50 Cribs and the 216-B-57 Crib. The interim stabilization was performed to eliminate surface contamination and migration deficiencies, to maintain environmental compliance in preparation for remedial investigation/feasibility study activities, and to maintain environmental compliance until the final remediation strategy is implemented.

The Phase I remedial investigation field activities at the 200-BP-1 Operable Unit began in 1990 and were completed in 1993, and included the BY-Cribs as part of the source and vadose zone investigations. Crib materials and the underlying unsaturated sediments were sampled and analyzed to determine contamination levels (DOE-RL 1993d). Column leach testing of materials collected during the source and vadose zone sampling was performed to assess potential contaminant fluxes that might be generated by infiltration of water through the vadose zone (DOE-RL 1993d). The Phase I remedial investigation of the 200-BP-1 Operable Unit included the following hydrologic and geologic investigation activities:

- A seismic refraction survey

- Groundwater monitoring well installation

- Groundwater sampling and analysis 
DOE/RL-95-59

Rev. 0

- Aquifer testing

- Sorption testing.

Results of these investigation activities and other 200-BP-1 Operable Unit Phase I remedial investigation activities are presented in the Phase I Remedial Investigation Report for the 200-BP-1 Operable Unit (DOE-RL 1993d).

5.1.2.3 216-B-3 Pond System. The 216-B-3 Pond System consists of the 216-B-3 Main Pond and the 216-B-3A, 216-B-3B, and 216-B-3C Expansion Ponds. This pond system is a RCRA facility located approximately $1,100 \mathrm{~m}(3,500 \mathrm{ft})$ east of the 200 East Area perimeter fence and approximately $1,500 \mathrm{~m}(5,000 \mathrm{ft})$ northeast of the 202-A Building, as shown in Figure 5-3. The 216-B-3 Pond System received an estimated total waste volume of $261,000,000,000 \mathrm{~L}$ (68,901,000,000 gal) between 1945 and 1995 (WHC 1991, DOE-RL 1994). The 216-B-3C Pond continues to receive effluent. Dates of operation, volumes of waste received, and radiological and chemical inventories for the 216-B-3 Ponds are included in Tables 5-1, 5-2, and 5-3. Figure 5-4 shows the estimated annual effluent discharges in liters from all sources inside the 200 East Area, and from the 216-B-3 Ponds and the 216-A-25 Gable Mountain Pond for the period 1945 through 1994. Discharges from the 216-B-3 Ponds and the 216-A-25 Gable Mountain Pond locally raised the water-table elevations in the unconfined aquifer under the 200 East Area, modified the groundwater flow directions, and may have influenced the movement of the BY-Cribs and B-5 Reverse Well plumes. Groundwater flow directions are illustrated by six water-table and groundwater flow maps presented in the 200 East Groundwater Aggregate Area Management Study Report (DOE-RL 1993a) for the period 1944 through 1991.

B Plant and PUREX Plant were the main sources of effluent discharged to the 216-B-3 Pond System. The 283-E Water Treatment Facility, 284-E Powerhouse, and Semi-Works also contribute, but to a lesser extent. Effluent was transported to the pond using a series of unlined ditches, which also increased the area available for infiltration of effluent, and through buried pipelines. The ditches and pipelines are shown in Figure 5-5.

The 216-B-2-1, 216-B-2-2, and 216-B-2-3 Ditches transported effluent from sources including B Plant, 284-E Powerhouse, and Semi-Works to the buried 216-B-2-3 corrugated metal pipeline (Maxfield 1979), which conveyed the effluent to the 216-B-3-1, 216-B-3-2, and 216-B-3-3 Ditches feeding the 216-B-3 Pond. The 216-B-2-1 Ditch was used from April 1945 until November 1963; the 216-B-2-2 Ditch, from November 1963 until May 1970; and the 216-3-3 Ditch, from April 1970 until 1987. The 216-B-3-1 Ditch was used from April 1945 until July 1964; the 216-B-3-2 Ditch, from July 1964 until September 1970; and the 216-3-3 Ditch, from September 1970 until October 1994. The 216-B-2-1, 216-B-2-2, 216-B-3-1, and 216-B-3-2 Ditches were removed from service after they were contaminated by unplanned releases of fission products at the PUREX Plant and B Plant Canyon Buildings. The $216-\mathrm{B}-2-3$ Ditch was replaced by a buried polyethylene pipeline in 1987 , and the 216-B-3-3 Ditch was removed from service when the 216-B-3 Pond was shut down.

Waste streams from B Plant consisted of 221-B Building steam condensate, process cooling water, and chemical sewer effluent; 241-BY ITS B-5 Reverse Well and BY-Cribs condenser cooling water; effluent from cleanup of the 207-B Retention Basin; and the WESF cooling water (Stenner et al. 1988). 284-E Powerhouse contributed water, and 241-CR Vault cooling water came from the Semi-Works (Stenner et al. 1988). 
Effluent from the PUREX Plant discharged into the western end of the 216-B-3-3 Ditch via the PUREX Cooling Water Line and the 216-A-29 Ditch. The PUREX Cooling Water Line effluent included 202-A Building cooling water, process waste, steam condensate, air sampling vacuum pump seal cooling water, chemical sewer effluent, and acid fractionator condensate; 241-A Ventilation System Complex cooling water; 242-A Evaporator steam condensate and cooling water; 244-AR Vault cooling water; 283-E Water Treatment Facility overflow water; and 284-E Powerhouse water (DOE-RL 1993e, Maxfield 1979, Stenner et al. 1988, WHC 1991). The effluent contained low levels of radionuclides including ${ }^{241} \mathrm{Am},{ }^{137} \mathrm{Cs},{ }^{3} \mathrm{H},{ }^{147} \mathrm{Pm},{ }^{106} \mathrm{Ru},{ }^{90} \mathrm{Sr}$, and plutonium (Brown et al. 1990, WHC 1991). The 216-A-29 Ditch operated from November 1955 until July 1991. It conveyed 202-A Building chemical sewer effluent, cooling water, and air-sampling vacuum pump effluent to the 216-B-3 Pond via the 216-B-3-3 Ditch (DOE-RL 1993e).

The PUREX Plant steam condensate and cooling water waste streams contributed large volumes of effluent to the pond. This effluent was primarily river water with little potential for chemical or radioactive contamination. Although releases into these waste streams occurred, they represent a small fraction of the waste volume discharged to the pond. Operational records from the 1980's for the B Pond system show effluent discharge rates of 49,210 to $56,781 \mathrm{~L} / \mathrm{min}(13,000$ to $15,000 \mathrm{gal} / \mathrm{min})$.

5.1.2.3.1 216-B-3 Main Pond. The 216-B-3 Main Pond began receiving effluent in 1945 following construction of an earthen dam that impounded a natural topographic depression. The pond received effluent until 1994 when it was closed. During the 1970's, an area west of the 216-B-3 Main Pond was diked to provide a 1.7-ha (4.1-acre) overflow area adjacent to the pond.

During its 49 years of operation, the area of the 216-B-3 Main Pond ranged from 3.6 to 18.6 ha (19 to 46 acres). In 1994, the pond covered approximately 13 ha (32 acres) and had a maximum depth of $13 \mathrm{ft}$ (Smith 1993). The 1.7-ha (4.1-acre) overflow area west of the 216-B-3 Main Pond was decommissioned and backfilled in 1985. Discharge of effluent to the 216-B-3 Main Pond ceased in early 1994 and was followed by interim stabilization actions that were completed in October 1994 (BHI 1995a). These actions also included the 216-B-3-3 Ditch and the 216-B-3A Expansion Pond.

5.1.2.3.2 216-B-3A Expansion Pond. The 216-B-3A and 216-B-3B Expansion Ponds were built in 1983 to handle the increased discharge flow rate resulting from the restart of the 202-A Building (PUREX Plant) operations. In January 1984, the dike separating the 216-B-3A and 216-B-3B Expansion Ponds breached at the channel connecting the two ponds. The dike was repaired, a slide gate was installed, and a north-south-trending ditch, $1.8 \mathrm{~m}(6 \mathrm{ft})$ deep, $6 \mathrm{~m} \mathrm{(20 \textrm {ft } )}$ wide, and approximately $244 \mathrm{~m}(800 \mathrm{ft}$ ) long, was excavated into the bottom of the 216-B-3A Expansion Pond to improve percolation. The ponds were reopened for use in 1984. The trench increased the maximum depth of the pond to approximately $1.8 \mathrm{~m}(6 \mathrm{ft})$. The 216-B-3A Expansion Pond remained in service until 1994 when interim stabilization was completed (BHI 1995a).

The 216-B-3A Expansion Pond covered approximately 4.5 ha (11 acres) and was originally approximately 0.6 to $0.9 \mathrm{~m} \mathrm{(2} \mathrm{to} 3 \mathrm{ft}$ ) deep. The surface elevation of this pond was approximately $5.5 \mathrm{~m}(18 \mathrm{ft})$ lower than the $216-\mathrm{B}-3$ Pond. The pond had a very low infiltration rate.

5.1.2.3.3 216-B-3B Expansion Pond. This pond was returned to service in June 1984, after the dike repair. It is a roughly rectangular, 4.5 -ha (11-acre) excavation that is currently dry and has not been used since 1985. It was dredged in 1986. 
5.1.2.3.4 216-B-3C Expansion Pond. This pond has been active since its construction in 1985. The 216-B-3C Expansion Pond was built to handle the increased discharge to the 216-B-3 Pond System that arose from the decommissioning of the 216-A-25 Gable Mountain Pond. The 216-B-3C Expansion Pond is an excavated structure that does not use embankments to impound effluent. The 216-B-3C Expansion Pond has the lowest elevation of the 216-B-3 Ponds. The 216-B-3C Expansion Pond was excavated in a coarse gravel layer to increase the infiltration rate. Within the roughly rectangular depression of the pond, a series of distribution channels run the length of the pond bottom.

5.1.2.4 216-A-25 Gable Mountain Pond. The 216-A-25 Gable Mountain Pond, the largest of the Hanford Site pond-type effluent disposal facilities, was a 29-ha (71-acre) natural depression located $1.6 \mathrm{~km}(1 \mathrm{mi})$ south of the west end of Gable Mountain. An estimated total 307,000,000,000 L $(81,100,000,000 \mathrm{gal})$ of effluent, principally from the 202-A Building, was discharged to the 216-A-25 Pond between 1957 and 1987 (Coony and Thomas 1989) as shown in Figure 5-4. Dates of operation and volumes of waste received by the 216-A-25 Gable Mountain Pond are shown in Table 5-1. Discharges to the 216-A-25 Pond locally raised the water-table elevation north of the 200 East Area, modified the groundwater flow directions, and may have influenced the movement of the BY-Cribs and B-5 Reverse Well plumes.

Waste reached Gable Mountain Pond through the PUREX Cooling Water Line. This corrugated metal pipeline was broken and capped when the Gable Mountain Pond was decommissioned in 1987. Effluent discharged to the 216-A-25 Gable Mountain Pond by the PUREX Cooling Water Line is discussed in Section 5.1.2.3. Although the 216-A-25 Gable Mountain Pond received low levels of chemically and radioactively contaminated wastes since its startup, a single unplanned release (UPR-200-E-34) on June 11, 1964 caused the discharge of about 10,000 Ci of short- and long-lived mixed fission products to this pond, as well as to the 216-B-3 Pond, and 216-B-3-1 Ditch.

Approximately 7,500 $\mathrm{Ci}$ of this release went to the Gable Mountain Pond. Actions were taken in 1964 at Gable Mountain Pond to prevent the spread of contamination, to reduce exposure by increasing water depth above the contaminated sediments, and to prevent contamination of migratory wild fowl. The original contaminated pond inlet was replaced with a new inlet (Maxfield 1979).

Cleanup stabilization actions started in July 1984 and were completed in December 1988. The unit

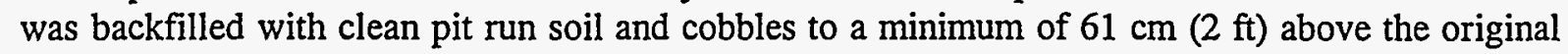
shoreline (Hayward 1989). The pond was revegetated after the entire backfilled area was covered with $30 \mathrm{~cm}$ ( $1 \mathrm{ft}$ ) of topsoil. Wells 699-53-47, 699-55-50C, and 699-52-52 monitor the groundwater beneath the site of the backfilled pond (WHC 1991). The estimated radionuclide inventory in 1995 for the 216-A-25 Gable Mountain Pond, decayed from the data presented in Table 5-2, is $1.66 \times 10^{2}$ $\mathrm{Ci}$ of ${ }^{137} \mathrm{Cs}, 1.28 \times 10^{2} \mathrm{Ci}$ of ${ }^{3} \mathrm{H}, 3.37 \times 10^{-7} \mathrm{Ci}$ of ${ }^{106} \mathrm{Ru}, 2.06 \times 10^{2} \mathrm{Ci}$ of ${ }^{90} \mathrm{Sr}, 428 \mathrm{~g}$ of plutonium, $4.24 \mathrm{Ci}$ of uranium, and $5.21 \times 10^{-4} \mathrm{Ci}$ of ${ }^{241} \mathrm{Am}$.

\subsubsection{West Area Groundwater Movement}

Three pond systems were used in the 200 West Area to dispose of large volumes of liquid effluent, consisting predominantly of cooling water, from 200 West Area separations and processing plants (i.e., S Plant, T Plant, and U Plant). These pond systems operated from 1944 until 1985 and disposed of $265,000,000,000 \mathrm{~L}(70,100,000,000)$ gal of effluent. Figure 5-5 shows the estimated annual effluent discharges in liters to the S Ponds, T Pond, and U Pond for 1944 through 1993 . The largest effluent discharges occurred between 1952 and 1958, and the maximum for the entire 49 years 
DOE/RL-95-59

Rev. 0

occurred in 1953 (Figure 5-6). In later years, the second and third largest volumes of effluent discharge occurred between 1960 and 1965 and between 1974 and 1980. From 1944 through 1951, the major effluent discharges occurred at T Pond. Between 1952 and 1959, and between 1966 and 1984 , the majority of effluent disposal occurred at U Pond. The S Ponds received most of the effluent from 1959 through 1965 and since 1984 have been active. Figure 5-7 shows the estimated annual effluent discharges in liters from all sources in S Plant, T Plant, U Plant, and Z Plant for 1944 through 1993.

This disposal of effluent raised the elevation of groundwater in the unconfined aquifer beneath the 200 West Area, creating a groundwater mound that changed groundwater flow in the unconfined aquifer (DOE-RL 1993b). The elevation of groundwater increased approximately $14 \mathrm{~m}(45 \mathrm{ft}$ ) by 1951, relative to the 1944 elevation, and by 1955 the groundwater elevation was $23 \mathrm{~m}(75 \mathrm{ft})$ higher than in 1944 (DOE-RL 1993b). Through 1987, the groundwater elevation was 17 to $18 \mathrm{~m}$ (55 to $60 \mathrm{ft}$ ) higher than in 1944 (DOE-RL 1993b). The apex of the mound was centered over the U Plant area until 1955; by 1965, it had shifted south approximately $3 \mathrm{~km}(1.9 \mathrm{mi})$ to an area near the S Ponds. By 1973, it had moved north to the U Pond area (DOE-RL 1993b). Because of the decommissioning of the 216-U-10 Pond in 1984, the mound has fallen significantly; groundwater elevations decreased by $3 \mathrm{~m}(10 \mathrm{ft})$ between 1985 and 1990 near the pond (DOE-RL 1993b).

Before the 200 West Area effluent discharges began at the Hanford Site in 1944, the general groundwater flow direction in the unconfined aquifer was from west to east, with some flow north through the gap between the Yakima Ridge and Gable Butte (DOE-RL 1993b). Groundwater flow directions are illustrated by seven water-table and groundwater flow maps presented in the 200 West Groundwater Aggregate Area Management Study Report (DOE-RL 1993b) for the period 1944 through 1987. These maps show a generally radial groundwater flow pattern resulting from the 200 West Area effluent discharges, with some groundwater flow northward through the gap between Gable Butte and Gable Mountain in addition to the flow through the gap between the Yakima Ridge and Gable Butte (DOE-RL 1993b). The groundwater flow directions have also been influenced by agricultural irrigation in the Cold Creek Valley, which is located west of the 200 West Area (DOE-RL 1993b).

\subsection{HISTORICAL GEOSCIENCES INFORMATION}

This section explains how the regional aquifer has been modified by local waste stream discharges and how the radionuclide and chemical plumes have migrated during the operational history of the site. Water-table distribution and plume migration have been monitored since the early days of the Hanford Site and are discussed in this section.

\subsubsection{Water Levels}

Artificial recharge of the unconfined aquifer from liquid effluent disposal to surface ponds, cribs, and ditches has had a profound impact on the water-table distribution beneath the 200 East Area. Approximately one-half of the liquid effluent waste disposed of to the ground in the 200 East Area was routed to two surface ponds, 216-B-3 (B Pond) and 216-A-25 (Gable Mountain Pond). The remainder was disposed of to numerous cribs and ditches (Figure 5-8). 
Rev. 0

The effect of groundwater mounding on the water table beneath the 200 East Area is illustrated in Figure 5-9. The January 1944 map is an estimated pre-Hanford Site water-table map. The flow illustrated in the figure is generally from west to east/southeast. As stated in Section 5.1, B Pond began receiving liquid effluent waste in 1945, and the development of a groundwater mound beneath the facility is clearly evident in the March 1951 map. Disposal to the facility has continued to the present, and the mound appears in each subsequent water-table map. Gable Mountain Pond began receiving effluent wastes in 1957 and continued operations until 1985. In the June 1960 contour map the Gable Mountain Pond and B Pond groundwater mounds are interpreted to coalesce. It was not until 1980 that the two mounds were contoured as separate mounds. The Gable Mountain Pond groundwater mound quickly disappeared following closure of the facility in 1987, and it is not discernable in the June 1990 map.

The effects of water disposal on the water table in the vicinity of the areas of concern for this report are illustrated in Figure 5-10. Hydrographs for wells in the vicinity of each disposal site are illustrated, as well as near B Pond. Increased production at the fuel separation operations in the late 1950 's resulted in dramatic increases in liquid effluent disposal to the two ponds and resultant elevated water tables.

Effluent disposed to ponds in the vicinity of the 200 East Area created groundwater mounds, which altered the predominantly west-to-east direction of flow that existed before Hanford Site operations. The primary effect of this mounding has been to establish a hydrologic dam on the eastern boundary of the 200 East Area, forcing flow to divert either to the north/northwest through Gable Gap or to the southeast. The increased effluent discharges in this area resulted in a groundwater divide that controls flow diversion. The divide axis is oriented approximately east-west, and its location has migrated along a northwest-to-southeast axis beneath the 200 East Area in response to varying amounts and locations of effluent discharge. Effluent and contaminants that migrated to, or flowed with, groundwater to the south of the divide were driven to the southeast. Those that entered groundwater to the north of the divide were transported to the north/northwest and eventually through Gable Gap.

Chemical contaminant information discussed in Section 5.2.2 provides the best evidence of when the hydrologic divide developed beneath the 200 East Area. Gross beta contamination from the B-5 Reverse Well and the BY-Cribs is represented as having been transported to the southeast in contaminant plumes from the mid- to late 1950's. The first good evidence of northward movement of gross beta contamination is represented in the October-December 1959 contaminant map. From that time to the present, hydrologic conditions have existed that have resulted in a continued north/northwesterly movement of groundwater beneath these disposal facilities. Contamination evidence that supports this evaluation is presented in more detail in Section 5.2.2. However, the evidence for contaminant movement for Gable Mountain Pond is not as well defined. Flow during operation was directed radially out from beneath the facility because of the development of a groundwater mound. The basalt subcrop feature at the water table restricted flow to the south, and it appears that $B$ Pond mounding limited flow to the east. The majority of flow beneath the facility is believed to have been directed to the northwest towards Gable Gap. Once discharges to the facility ceased in late 1987, the influence of B Pond strongly dominated flow.

The recent (1993) flow regime is represented in Figure 5-11. Streamlines from the BY-Cribs Area (A), B-5 Reverse Well (B), and Gable Mountain Pond (C) all indicate that flow from beneath all three facilities is currently moving to the north/northwest through Gable Gap. As the B Pond mound dissipates in the future and the hydrologic divide disappears, flow may return to a more southerly direction. 
DOE/RL-95-59

Rev. 0

\subsubsection{Groundwater Contamination Concentrations and Plume Migration}

Groundwater monitoring activities have been conducted since the earliest days of Hanford Site operations and were first reported in 1945 (Parker and Gamertsfelder 1945). A general summary of past monitoring activities, focusing on 200 Area operations, is reported in Ground-Water Contribution to Dose from Past Hanford Operations (Freshley and Thorne 1992). Over the years, sample analytical techniques, as well as analytes of interest, have been modified. Gross beta has been measured from the beginning of monitoring activities to provide indications of liquid effluent migration to groundwater from disposal facilities. The methodology for routine gross beta analysis was refined to improve the detection limit from $300 \mathrm{pCi} / \mathrm{L}$ in 1945 , to $150 \mathrm{pCi} / \mathrm{L}$ during the 1950 's, to $80 \mathrm{pCi} / \mathrm{L}$ in 1959 , to $16 \mathrm{pCi} / \mathrm{L}$ in the mid-1980's, and to $4 \mathrm{pCi} / \mathrm{L}$ in 1991 (Freshley and Thorne 1992). In 1959, Bierschenk (1959a), reported that any groundwater sample that exceeded $100,000 \mathrm{pCi} / \mathrm{L}$ for gross beta was analyzed for ${ }^{60} \mathrm{Co},{ }^{137} \mathrm{Cs}$, and ${ }^{90} \mathrm{Sr}$. By 1962 , many samples were analyzed for uranium, ${ }^{60} \mathrm{Co},{ }^{137} \mathrm{Cs},{ }^{106} \mathrm{Ru},{ }^{90} \mathrm{Sr}$, and tritium (Brown and Raymond 1962). A primary contaminant of concern for this treatability test report, ${ }^{99} \mathrm{Tc}$, was not listed for analysis.

Technetium-99 analyses were not routinely performed until the mid-1980's, when it was recognized that the gross beta results did not balance well with the summation of the individual gross beta emitters. This may have been made more obvious as the activity contribution from ${ }^{106} \mathrm{Ru}$ declined because of natural decay. The unknown contributor to the gross beta activities was suspected to be either ${ }^{129} \mathrm{I}$ or ${ }^{99} \mathrm{Tc}$, and both were included for routine monitoring from that time to the present.

Groundwater monitoring reports as early as 1945 noted detections of contamination in individual wells around the site. The first discussion of widespread contaminant movement in groundwater appeared in a 1956 report (Parker 1956). It was also in 1956 that the first detection of groundwater contamination outside of the 200 East and 200 West Areas was reported and the distribution of gross beta contamination was mapped (Earth Science Personnel 1956). A summary containing the 1956 map and subsequent gross beta distributions maps is presented in Figure 5-12. This figure serves as a time reference for individual discussions particular to the three areas of groundwater contamination of interest in this report. The concentration value of the contour used to define the extent of the gross beta contamination was not identified in maps until the October-December 1957 map was produced (Bierschenk 1959b). It is presumed to have been equal to $150 \mathrm{pCi} / \mathrm{L}$. The shape of the area of contamination has varied through time because of changing detection limits, interpretations of water-table distribution, increased well control, and decay of radioisotopes (primarily ${ }^{106} \mathrm{Ru}$ ). However, a locus of contamination has always been associated with the B-5 Reverse Well and subsequently the BY-Cribs contamination, which remains as an area of elevated concentrations.

5.2.2.1 216-B-5 Reverse Well Groundwater Contamination. As mentioned in Section 5.1, during a 2-year period from 1945 to 1947 , approximately $3.03 \times 10^{7} \mathrm{~L}\left(8 . \times 10^{6} \mathrm{gal}\right)$ of intermediate-level liquid wastes from $\mathrm{BiPO}_{4}$ process operations at $\mathrm{B}$ Plant was discharged to the 241-B-361 Settling Tank. The overflow was disposed of to the B-5 Reverse Well. The settling tank was designed to remove waste solids before water disposal to the reverse well. At the time of deactivation of the system, approximately $121,000 \mathrm{~L}(32,000 \mathrm{gal})$ of sludge remained in the $132,000-\mathrm{L}(35,000$-gal) tank. The well penetrated approximately $3.7 \mathrm{~m}(12 \mathrm{ft})$ below the water table, and waste was introduced into the aquifer at this level. Descriptions of waste disposal activities and subsequent characterization work are contained in Brown and Ruppert (1950), Smith (1980), and Hodges (1995).

Operational estimates of radioactive waste inventories indicate that approximately $4.27 \mathrm{~kg}$ of plutonium, $81 \mathrm{Ci}$ of ${ }^{137} \mathrm{Cs}, 163 \mathrm{Ci}$ of ${ }^{106} \mathrm{Ru}, 76 \mathrm{Ci}$ of ${ }^{90} \mathrm{Sr}$, and $3,800 \mathrm{Ci}$ of miscellaneous beta activity 
were sent to the settling tank. The quantity of uranium was not estimated. Characterization of the sludge remaining in the settling tank in 1979 (Smith 1980) indicates that the reported operational numbers underestimated the inventory discharged to the settling tank, in some cases by many orders of magnitude (e.g., 30 times the reported inventory of ${ }^{90} \mathrm{Sr}$ was estimated to exist in the settling tank alone).

The B-5 Reverse Well was removed from service on September 19, 1947, when a water sample from well 299-E33-18, located $655 \mathrm{~m}(2,149 \mathrm{ft})$ north of the reverse well, indicated the presence of alpha contamination in groundwater (Brown and Ruppert 1950). Subsequent water samples from the well indicated that the initial sample was in error and no groundwater contamination from B-5 Reverse Well disposal operations occurred that far to the north. The B-5 Reverse Well was never returned to service, and by the time subsequent sampling and analyses had been conducted on well 299-E33-18, the waste stream had been rerouted to the 216-7A and 216-7B Cribs, and a study of the extent of groundwater contamination had been initiated. Eleven wells were drilled from November 1947 to May 1948 to attempt to characterize groundwater contamination in the vicinity of the reverse well. The wells were drilled $9 \mathrm{~m}(29.5 \mathrm{ft})$ below the water table. No radioactive contaminants were detected in any of the sediment samples, but beta-gamma (fission product) and alpha activity were detected in the groundwater. Brown and Ruppert's (1950) radionuclide distribution estimates for the time period November 1947 to July 1949 are illustrated in Figure 5-13. The rapid decrease in the area of fission product contamination was attributed to decay of short-lived radionuclides and dispersion and dilution of the plume. The November 1947 and July 1948 depictions of the plume appear to indicate a southeasterly movement. The same apparent southeast orientation is present in the November 1947 depiction of alpha contamination.

Three groundwater wells (i.e., 299-E28-23, 299-E28-24, and 299-E28-25) were drilled in 1979 to 1980 to characterize radionuclide distributions around the reverse well. The locations of these wells relative to the reverse well are shown in Figure 5-14. Estimates of the present distribution of two fission products $\left({ }^{138} \mathrm{Cs}\right.$ and $\left.{ }^{90} \mathrm{Sr}\right)$ and one alpha emitter (plutonium), which remain as groundwater contaminants in the vicinity of the reverse well, are presented in Figures 5-15 through 5-17. Determination of the groundwater distribution of radionuclides around the reverse well is hampered both by the lack of wells away from the immediate vicinity of the reverse well and by the practice of analyzing only unfiltered samples for radionuclides. As shown in the time history plots in Figures 5-15 through 5-17, analytical results for radionuclides in wells adjacent to the reverse well are highly variable, and discerning dissolved from particulate fraction is not possible. Contaminants appear to be localized, yet ${ }^{90} \mathrm{Sr}$ appears to have been transported to the northwest to well 299-E28-2, indicating that the present-day direction of groundwater movement has shifted nearly 180 degrees from the transport direction proposed by Brown and Ruppert (1950). Discussion of a conceptual model of groundwater contamination from the B-5 Reverse Well is presented in Section 5.3.

5.2.2.2 216-BY Cribs Groundwater Contamination. Waste disposal to the eight BY-Cribs was conducted during two time periods. A summary of waste disposal activities at the cribs and subsequent groundwater monitoring beneath the cribs is contained in DOE-RL (1993a, 1993c, 1993e) and Kasza (1993). During 1954 and 1955, approximately $3.38 \times 10^{7} \mathrm{~L}\left(8.94 \times 10^{6}\right)$ gal of waste solutions from the TBP process was discharged to the soil column at seven of the eight cribs. A primary concern at the time was to mediate disposal to the cribs so as not to exceed the sorptive capacity of the soil beneath the cribs, thereby preventing the release of ${ }^{137} \mathrm{Cs}$ and ${ }^{90} \mathrm{Sr}$ to the groundwater (Rhodes et al. 1954, Stedwell 1954). Disposal to the cribs was terminated in December 1955 when beta activity, specifically ${ }^{137} \mathrm{Cs}$, was detected in the groundwater under the cribs. In early 1956, revised laboratory methodology allowed for the detection of ${ }^{60} \mathrm{Co}$ in the 
groundwater, a previously unknown contaminant in the TBP waste stream. Cobalt-60 was present in the groundwater in concentrations that were many hundreds of times higher than then-current standards allowed. Between 1965 and 1974, $6.06 \times 10^{7} \mathrm{~L}\left(1.6 \times 10^{7}\right.$ gal) of tank liquor condensate from the ITS B-5 Reverse Well was discharged to the remaining BY-Crib. An additional $8.33 \mathrm{x}$ $10^{7} \mathrm{~L}\left(2.2 \times 10^{7} \mathrm{gal}\right)$ of tank liquor condensate from ITS BY-Cribs was discharged to the nearby 216-B-57 Crib between 1968 and 1973. Estimated quantities of the primary contaminants in the liquid effluent streams disposed of to the cribs include $0.45 \mathrm{Ci}$ of ${ }^{60} \mathrm{Co}, 18,900 \mathrm{~kg}(41,667 \mathrm{lb})$ of ferrocyanide, $5.68 \times 10^{6} \mathrm{~kg}\left(1.25 \times 10^{7} \mathrm{lb}\right)$ of nitrate, and an unknown quantity of ${ }^{99} \mathrm{Tc}$.

Groundwater contamination emanating from beneath the crib sites is discussed in Parker (1956) as a primary source for the southeast-trending gross beta contaminant plume illustrated in the 1956 map in Figure 5-12. The contour level is not specified in the 1956 map, but is presumed to be $150 \mathrm{pCi} / \mathrm{L}$. A chart containing the gross beta time history at well 299-E33-4, which monitors the upper approximate $3.1 \mathrm{~m}$ (10 ft) of the aquifer, is presented in Figure 5-18. In April 1956, a gross beta result of $9.8 \times 10^{8} \mathrm{pCi} / \mathrm{L}$ is reported for the well. With decay of the shorter-lived fission products, the gross beta concentrations in the well dropped 1,000-fold by September 1959 (see Figure 5-12). The growing influence of groundwater mounds beneath the B Pond and Gable Mountain Pond on the hydrologic flow regime during the late 1950's can be discerned from the contaminant distributions illustrated in Figure 5-12. By late 1956 and early 1957, the gross beta contaminant plume beneath the 200 East Area had been displaced to the west because of the increased disposal to B Pond. The startup of disposal to Gable Mountain Pond to the northeast may have created a slight damming effect to the north, but its effect on contaminant movement from the BY-Cribs may have been moderated by an intervening basalt high, which extends above the water table. By 1959, elevated gross beta contamination was present in well 699-50-53A (Figure 5-19 and the October-December 1959 map in Figure 5-12) indicating northward movement of the plume. Well 699-50-53A has remained a center of contamination for BY-Crib-sourced contamination to the present.

The present-day distribution of cyanide and two beta emitters $\left({ }^{60} \mathrm{Co}\right.$ and $\left.{ }^{99} \mathrm{Tc}\right)$ is presented in Figures 5-20 through 5-22. A similar distribution for all three contaminants can be recognized from review of the three figures. The highest contaminant concentrations are centered on wells 699-50-53A and 699-52-54. Of the two wells, 699-52-54 is showing increasing concentration trends indicating that contaminant movement is continuing to the north-northwest. Concentrations in well 699-50-53A had been trending downward the last few years and have shown slight increases in the last year (before pump-and-treat operations). Another interesting trend can be seen in well 699-49-57A, where concentrations for all three contaminants are elevated and possibly increasing for cyanide and ${ }^{99} \mathrm{Tc}$. This would indicate a continued westward movement of the plume in addition to the north-northwest trend. A discussion of the conceptual model of contaminant distribution sources from the BY-Cribs is presented in Section 5.4.

5.2.2.3 Gable Mountain Pond Groundwater Contamination. Between the years 1957 and 1987, an estimated $3.07 \times 10^{11} \mathrm{~L}\left(8.1 \times 10^{10} \mathrm{gal}\right)$ of liquid mixed waste primarily from the $202-\mathrm{A}$ Building was disposed of to the 216-A-25 Pond (Gable Mountain Pond). The pond received low-level radioactive liquid wastes, primarily tritium $(213 \mathrm{Ci}),{ }^{241} \mathrm{Am}\left(5.3 \times 10^{-4} \mathrm{Ci}\right),{ }^{137} \mathrm{Cs}(204 \mathrm{Ci})$, ${ }^{106} \mathrm{Ru}\left(1.6 \times 10^{-4} \mathrm{Ci}\right),{ }^{90} \mathrm{Sr}(257 \mathrm{Ci})$, and plutonium $(428 \mathrm{~g})$. As mentioned in Section 5.1 , on June 1, 1964, a single unplanned release from a cooling coil in the PUREX Plant contributed about $100,000 \mathrm{Ci}$ of mixed fission products to Gable Mountain Pond, B Pond, and the 216-B-3-1 Ditch. Following the incident, bentonite clay was added to the pond in an effort to bind radionuclides in the upper sediment layers and reduce the percolation rates (Maxfield 1979). In addition, new inlet 
ditches were constructed, and the water level in the pond was maintained until the contamination level in pond water decreased (Strait and Moore 1982).

Elevated gross beta was quickly detected in groundwater wells following the June 1964 unplanned release (e.g., gross beta results in well 699-55-50A illustrated in Figure 5-23). The area of gross beta contamination beneath the pond was reported and mapped in 1964 (map for January-December 1964 in Figure 5-12). By the mid-1970's, a gross beta plume was no longer being mapped beneath the pond (see January-December 1974 map in Figure 5-12). Concentrations in well 699-55-50A are shown to have declined to less than $100 \mathrm{pCi} / \mathrm{L}$, which was the minimum contour interval on the contaminant distribution map. By 1985 , however, a beta plume reappeared in the vicinity of the pond. Strontium-90 concentrations began to increase in the mid-1980's as illustrated in the time-history plots in Figure 5-24 for wells that monitor contamination in the vicinity of the Gable Mountain Pond site. Contaminant trends in most of these wells have continued to increase to the present day.

\subsection{CONTAMINANT CONCEPTUAL MODELS}

This section presents conceptual models for the B-5 Reverse Well, BY-Cribs, and Gable Mountain Pond contaminant plumes. Relevant details concerning the source chemistry, solubility, and response to aquifer conditions as well as mobility are discussed. The contaminant response during the treatability test is compared to the conceptual model. Where multiple conceptual models have been proposed, tests are discussed to relate the conceptual model to actual aquifer conditions.

\subsubsection{6-B-5 Reverse Well}

Waste from the $\mathrm{B}$ Plant operation, which used the $\mathrm{BiPO}_{4}$ separation process, was disposed of in the B-5 Reverse Well between 1945 and 1947 (see Figure 5-13). Disposal of the waste, which contained significant quantities of plutonium, ${ }^{137} \mathrm{Cs},{ }^{106} \mathrm{Ru}$, and ${ }^{90} \mathrm{Sr}$, was halted in 1947 because of groundwater contamination. Subsequent work indicated that the B-5 Reverse Well penetrated approximately $3 \mathrm{~m}$ (10 ft) into the aquifer and that significant quantities of radionuclides are present beneath the water table. Descriptions of waste disposal activities and subsequent characterization work are contained in Brown and Ruppert (1950) and Smith (1980). Hodges (1995) provided the basis for the current conceptual model.

5.3.1.1 216-B-5 Plume Groundwater Contamination. As discussed previously in Sections 5.1 and 5.2, groundwater contamination occurred at the B-5 Reverse Well between 1945 and 1947, when approximately $3.07 \times 10^{7} \mathrm{~L}\left(8.1 \times 10^{6} \mathrm{gal}\right)$ of high-activity effluent from the B Plant complex was sent to the reverse well for disposal. The effluent was routed to tank 241-B-361 for precipitation of the entrained solids, and overflow from tank 241-B-361 was disposed of in the B-5 Reverse Well. The settling tank had a volume of approximately 132,000 L (35,000 gal); thus, the total effluent volume represents approximately 230 tank volumes. Most of the water and an unknown portion of waste solids went to the reverse well. Approximately $121,000 \mathrm{~L}(32,000 \mathrm{gal})$ of sludge remained in the settling tank after waste disposal operations were terminated.

Estimates from operational records indicate that approximately $4.27 \mathrm{~kg}$ of plutonium, $81 \mathrm{Ci}$ of ${ }^{137} \mathrm{Cs}$, $163 \mathrm{Ci}$ of ${ }^{106} \mathrm{Ru}, 76 \mathrm{Ci}$ of ${ }^{90} \mathrm{Sr}$, and 3,800 $\mathrm{Ci}$ of miscellaneous beta activity were sent to the 241-B-361 Settling Tank. Analysis of sludge in tank 241-B-361 in 1979 indicates that approximately one-half of 
Rev. 0

the $4.27 \mathrm{~kg}$ of plutonium discharged passed through the tank and entered B-5 Reverse Well. However, ${ }^{137} \mathrm{Cs}$ and ${ }^{90} \mathrm{Sr}$ concentrations reported for the sludge indicate that the settling tank contains considerably more ${ }^{137} \mathrm{Cs}$ ( 2 times) and ${ }^{90} \mathrm{Sr}$ (30 times) than was reportedly discharged to the system (decay corrected to 1979). This discrepancy indicates considerable uncertainty in the reported discharge numbers and may account for the difference between the expected contaminant response and the observed concentrations measured during the test operation (see Section 4.3.3).

Under the conditions reported for the effluent stream, plutonium would have far exceeded its solubility and would have been transported as a solid phase, either as oxide, hydroxide, or phosphate. The following evidence indicates that a large portion of the plutonium and ${ }^{90} \mathrm{Sr}$ disposed in the B-5 Reverse Well was in the form of $\mathrm{BiPO}_{4}$ solids.

- Phosphate phases have a well-known affinity for actinides. In the $\mathrm{BiPO}_{4}$ separation process, the precipitation of $\mathrm{BiPO}_{4}$ from solution was used to remove plutonium from solution. Phosphates also have a strong affinity for strontium and other alkaline earth elements.

- Analysis of the sludge remaining in the settling tank indicates a strong partitioning of plutonium and ${ }^{90} \mathrm{Sr}$ into the solid phase, which is principally $\mathrm{BiPO}_{4}$. Cesium-137 does not share in this strong partitioning into the solids.

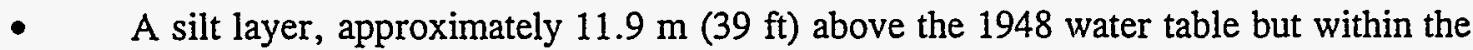
perforated interval, contains significant quantities of ${ }^{137} \mathrm{Cs}$; however, plutonium and ${ }^{90} \mathrm{Sr}$ were not detected. This can be explained if effluent carrying dissolved ${ }^{137} \mathrm{Cs}$ were wicked into the silt by capillary attraction and particles carrying plutonium and ${ }^{90} \mathrm{Sr}$ were excluded (filtered) because of their size.

- Characterization of sediments from wells drilled in 1979 indicates that plutonium and ${ }^{90} \mathrm{Sr}$ within the sediments are highly localized, contained within a zone less than $20 \mathrm{~m}$ across. Cesium-137 was found to have a very different distribution; significant concentrations within the sediments extend past the boundaries of the study area, approximately $22 \mathrm{~m}$ from the reverse well. Plutonium, because of its low solubility and very high sorption $\mathrm{K}_{\mathrm{d}}$, would be expected to be localized around the injection site. In the case of ${ }^{137} \mathrm{Cs}$ and ${ }^{90} \mathrm{Sr}$, if sorption on sediments is the major factor controlling distribution, ${ }^{137} \mathrm{Cs}$ and ${ }^{90} \mathrm{Sr}$ should behave in a similar manner. In addition, the sorption $\mathrm{K}_{d}$ for ${ }^{90} \mathrm{Sr}$ on Hanford Site sediments is approximately half that for ${ }^{137} \mathrm{Cs}$. Thus, the ${ }^{90} \mathrm{Sr}$ should have moved further than the ${ }^{137} \mathrm{Cs}$, the opposite of what was observed.

These differences and similarities support phosphate as the major control on the distribution of plutonium and ${ }^{90} \mathrm{Sr}$ within the aquifer. This mechanism would be reinforced by the fact that any dissolved phosphate in the waste stream, or any phosphate resulting from the dissolution of $\mathrm{BiPO}_{4}$, would quickly react with calcium ions in groundwater to form the very insoluble mineral phase apatite $\left[\mathrm{Ca}_{5}\left(\mathrm{PO}_{4}\right)_{3} \mathrm{OH}, \mathrm{K}_{\mathrm{SP}}=10^{-57.8}\right.$ (Krauskopf 1979)], which has a strong affinity for strontium and actinides.

Determination of the groundwater distribution of radionuclides around the B-5 Reverse Well is difficult because of the lack of wells away from the immediate vicinity of the reverse well and the practice of analyzing only unfiltered samples for radionuclides. Analytical results for radionuclides in wells adjacent to the reverse well are highly variable, and it is impossible to determine, on the basis of existing data, how much of the measured activity is in solution and how much is contained within 
or on solid particles. Analytical data for the present concentrations of plutonium, ${ }^{137} \mathrm{Cs}$, and ${ }^{90} \mathrm{Sr}$ in groundwater around the B-5 Reverse Well are indicated in Figures 5-15 through 5-17. The zone bounded by the $1-\mathrm{pCi} / \mathrm{L}$ plutonium contour is approximately $180 \mathrm{~m}(591 \mathrm{ft})$ across; the zone defined by the ${ }^{90} \mathrm{Sr} 8-\mathrm{pCi} / \mathrm{L}$ contour is approximately $300 \mathrm{~m}(984 \mathrm{ft})$ across; and the zone bounded by the ${ }^{137} \mathrm{Cs} 120-\mathrm{pCi} / \mathrm{L}$ contour is approximately $200 \mathrm{~m}(656 \mathrm{ft})$ across.

5.3.1.2 Source Characteristics. The waste discharged to the 241-B-361 Settling Tank, and thus to the B-5 Reverse Well, was a low-salt, alkaline waste containing approximately $1.4 \times 10^{-4} \mathrm{~g} / \mathrm{L}$ of plutonium, $2.6 \times 10^{-6} \mathrm{Ci} / \mathrm{L}$ of ${ }^{137} \mathrm{Cs}, 5.3 \times 10^{-6} \mathrm{Ci} / \mathrm{L}$ of ${ }^{106} \mathrm{Ru}, 2.5 \times 10^{-6} \mathrm{Ci} / \mathrm{L}$ of ${ }^{90} \mathrm{Sr}$, and $1.2 \times 10^{-5}$ $\mathrm{Ci} / \mathrm{L}$ of gross beta activity. Analyses of the sludge in tank 241-B-361 indicate that the major nonradioactive constituent was $\mathrm{BiPO}_{4}$ with lesser quantities of manganese, iron, lanthium, sodium, nitrate, and fluoride, consistent with waste from the $\mathrm{BiPO}_{4}$ separations process.

The indicated concentration of plutonium far exceeds the solubility of plutonium under these conditions, and it is likely that plutonium was transported in a solid form. The $\mathrm{BiPO}_{4}$ that forms a large portion of the sludge in the settling tank would have also had very low solubility under the alkaline conditions of the effluent and would have consisted principally of solid particles. $\mathrm{BiPO}_{4}$ was precipitated, during the $\mathrm{BiPO}_{4}$ process, to scavenge plutonium from solution. It is reasonable to assume that a portion of the plutonium, and probably of the strontium as well, was transported as part of the $\mathrm{BiPO}_{4}$ solids.

5.3.1.3 Solubility and Sorption Controls. The transport and behavior of plutonium and associated fission products $\left({ }^{137} \mathrm{Cs}\right.$ and $\left.{ }^{90} \mathrm{Sr}\right)$ are highly dependent on both solubility and sorption/desorption controls. Accordingly, data relevant to both control mechanisms are discussed as follows.

5.3.1.3.1 Cesium. Cesium, like other alkali metals, has high solubility in aqueous systems, and the principal controlling mechanism will be sorption and not solubility. A wide range of sorption $\mathrm{K}_{\mathrm{d}}$ have been reported in the literature; however, the most reasonable value for Hanford Site sediments seems to be approximately $50 \mathrm{~mL} / \mathrm{g}$ (Ames and Serne 1991). Using this value for $\mathrm{K}_{d}$, and assuming a bulk density of $2.1 \mathrm{~g} / \mathrm{cm}^{3}$ and a porosity of 0.22 , yields a retardation factor of 525 . Thus, if the groundwater flow rate during the time (48 years) since the waste was disposed in the B-5 Reverse Well had been $1 \mathrm{~m} /$ day $(3.3 \mathrm{ft} /$ day), groundwater would have moved $18 \mathrm{~km}(11 \mathrm{mi})$; however, during this time, the cesium would have moved approximately $34 \mathrm{~m} \mathrm{(110} \mathrm{ft).} \mathrm{The} \mathrm{initial}$ rate of movement may have been higher, however, because high concentrations of cesium adjacent to the reverse well may have saturated sorption sites.

5.3.1.3.2 Plutonium. Based on effluent discharge records, the average concentration of plutonium in alkaline aqueous waste discharged to the reverse well was approximately $6 \times 10^{-7} \mathrm{M}$, which is well above the solubility of plutonium in the (IV) or (VI) oxidation states in alkaline solutions. For example, Serne and Wood (1990) reported a laboratory solubility for plutonium oxides of $1.8 \times 10^{-8} \mathrm{M}$, which is equivalent to $3.26 \times 10^{-7} \mathrm{Ci} / \mathrm{L}$ of ${ }^{239} \mathrm{Pu}$. Barney (1988) indicates a solubility limit of $3.5 \times 10^{-9} \mathrm{M}(\mathrm{pH}$ of $8+$ ) for $\mathrm{Pu}(\mathrm{VI})$. Thus, much of the plutonium present in the waste stream would be present in a solid phase, possibly hydrous oxide or hydroxide phases, but probably in this case principally in the particulate $\mathrm{BiPO}_{4}$ phase. Barney (1988) also conducted laboratory sorption tests using Hanford Site (200 East) sediments at plutonium concentrations below $3.5 \times 10^{-9} \mathrm{M}$ and found that sorption $K_{d}$ values for plutonium initially added as $\mathrm{Pu}(\mathrm{VI})$ averaged 4,600 \pm $1,000 \mathrm{~mL} / \mathrm{g}$ after an 18-day contact time [the apparent $\mathrm{K}_{\mathrm{d}}$ increased with time during the first few days, which was attributed to reduction of Pu(VI) to Pu(IV) by the sediments in the batch sorption tests]. The sediments used for the laboratory sorption determination may not be representative of the 
DOE/RL-95-59

Rev. 0

aquifer sediments surrounding the B-5 Reverse Well. $\mathrm{K}_{\mathrm{d}} \mathrm{s}$ presented here are best estimates based on existing data.

Solubility considerations, as discussed previously, suggest that most of the plutonium initially injected into the aquifer was present as a particulate and/or colloidal phase. The solubility of plutonium included in $\mathrm{BiPO}_{4}$ or apatite phases is uncertain; however, if the solid phase is an oxide or hydroxide, pore fluid in the immediate vicinity of the solid phase would theoretically reach a solubility controlled maximum concentration of 326,000 to $63,400 \mathrm{pCi} / \mathrm{L}$, depending on the solubility limit used (see above). However, because of the affinity of sediments for the solute phase, the pore fluid concentrations would theoretically be reduced in proportion to the apparent $\mathrm{K}_{\mathrm{d}}$. Assuming the $\mathrm{K}_{\mathrm{d}}$ value noted above is applicable to B-5 Reverse Well chemical conditions, the predicted final pore fluid concentration would be reduced by a factor of 4,600 , or a pore fluid concentration of $326,000 / 4,600=71 \mathrm{pCi} / \mathrm{L}$ to $63,400 / 4,600=14 \mathrm{pCi} / \mathrm{L}$.

5.3.1.3.3 Strontium. Strontium is more likely to have solubility controls than cesium, because it has a lower solubility than calcium carbonate (calcite) and is very insoluble in the presence of phosphate. On Hanford Site soils, it has a $\mathrm{K}_{\mathrm{d}}$ of approximately $25 \mathrm{~mL} / \mathrm{g}$, approximately one-half the value for cesium (Ames and Serne 1991). If sorption on sediments is the primary control, the ${ }^{90} \mathrm{Sr}$ should have migrated approximately twice as far as ${ }^{137} \mathrm{Cs}$ during the same time period. During the 33 years between disposal and the 1979 characterization study, the ${ }^{90} \mathrm{Sr}$ would be expected to have migrated approximately $46 \mathrm{~m}$ (150 ft); however, drilling indicated that ${ }^{90} \mathrm{Sr}$ was restricted to

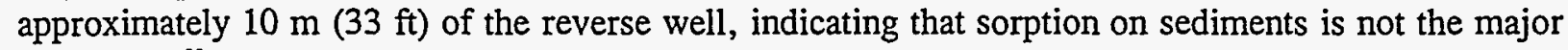
control on ${ }^{90} \mathrm{Sr}$ mobility. As indicated previously, the major control on strontium mobility is probably one or more phosphate phases. The nature of these phases and the solubility of ${ }^{90} \mathrm{Sr}$ contained in them is unknown.

5.3.1.4 Predicted Response to Pump-and-Treat Operations. If plutonium and strontium within the sediments are principally contained within phosphate phases, the ability to remove them by pump-and-treat technology is uncertain. If the main phosphate phase is $\mathrm{BiPO}_{4}$, any pumping that resulted in increased solubilization of the phosphate would also introduce groundwater calcium that would favor the precipitation of the mineral apatite. In the absence of data on possible phosphate phases in the aquifer, the following discussion assumes that the plutonium is sorbed on sediments and/or exists as solid oxide or hydroxide phases. It also assumes, given uncertainty in the discharge numbers, that the total reported inventory of plutonium was discharged into the reverse well.

Assuming that the volume within which most of the plutonium is contained is a cylinder with a radius of $10 \mathrm{~m}(33 \mathrm{ft})$, depth of $41 \mathrm{~m}(133 \mathrm{ft})$, and a porosity of 0.26 [tracer test porosities are 0.22 and 0.30 (Section 4.4.4)], the volume $(V)$ of plutonium-contaminated groundwater within the sediments is:

$$
\mathrm{V}=3.14 \times 10^{2} \times 10 \times 0.62=816 \mathrm{~m}^{3} \text { or } 8.16 \times 10^{5} \mathrm{~L}\left(2.16 \times 10^{5} \mathrm{gal}\right)
$$

At the highest pore fluid concentration noted, the quantity of plutonium removable in one pore volume from the assumed volume of contaminated aquifer solids would be:

$$
\text { quantity }=8.16 \times 10^{5} \mathrm{~L} \times 3.26 \times 10^{5} \mathrm{pCi} / \mathrm{L}=2.66 \times 10^{11} \mathrm{pCi} / \mathrm{L} \text { or } 0.26 \mathrm{Ci} .
$$

The total injected was:

$$
\mathrm{Ci}=4,270 \mathrm{~g} \mathrm{x} 0.0613 \mathrm{Ci} / \mathrm{g}=262 \mathrm{Ci}\left(\text { as }{ }^{239} \mathrm{Pu}\right) \text {. }
$$


Thus, under the most favorable conditions, the amount removed would be:

$$
0.26 / 262 \times 100=0.10 \% \text { per pore volume removed. }
$$

Assuming simple plug flow (no dilution of plume during withdrawal), 1,000 pore volumes $\left(8 \times 10^{8} \mathrm{~L}\right.$ ) would be required to hypothetically remove the injected quantity, assuming also that the aquifer would be allowed to reequilibrate after each pore volume. With continuous pumping, extraction of a much larger volume would be required. In addition, if the plutonium is contained within a solid phosphate phase, the above number may be a lower estimate for the quantity of water required for a simple pump-and-treat operation. This can be compared to the 2.3 pore volumes $\left(1.88 \times 10^{6} \mathrm{~L}\right)$ that would be required to remove $90 \%$ of the plutonium if it were not sorbed on or contained within solid phases.

Because of the similar behavior of ${ }^{90} \mathrm{Sr}$ and plutonium around the reverse well and the likelihood that both are contained within a solid phosphate phase, it is likely that similar techniques and similar volumes of groundwater would be required to remove a significant quantity of ${ }^{90} \mathrm{Sr}$ from the aquifer. Because the distribution of ${ }^{137} \mathrm{Cs}$ seems to be controlled by sorption on sediments, it is likely that any pump-and-treat process that remediated plutonium and ${ }^{90} \mathrm{Sr}$ around the reverse well would also remove most of the ${ }^{137} \mathrm{Cs}$ trapped on the sediments near the well.

\subsubsection{6-BY Cribs Plume}

Waste solutions from the TBP process were disposed of during 1954 and 1955 to a group of cribs in the northern portion of the 200 East Area commonly known as the BY-Cribs (216-B-43 through 216-B-49) (see Figure 5-3). Between 1965 and 1974, additional liquid waste in the form of condensate effluent from the ITS process was disposed of in the remaining unused BY-Crib (216-B-50) and the adjacent $216-\mathrm{B}-57 \mathrm{Crib}$. As early as 1956, beta-gamma and ${ }^{60} \mathrm{Co}$ contamination were recognized in the groundwater beneath these cribs and farther south in the 200 East Area. Currently, ${ }^{60} \mathrm{Co}$ and ${ }^{99} \mathrm{Tc}$ contamination is recognized in the groundwater underneath the cribs and north of the 200 East Area. Descriptions of the waste disposal operations and recent characterization activities are described in DOE-RL (1993a, 1993c, 1993d) and Kasza (1993).

5.3.2.1 216-BY Cribs Plume Groundwater Contamination. As reported in earlier sections, scavenged TBP supernatant waste was generated during the ferrocyanide scavenging of TBP process effluent and was routed to the 241-BY Tank Farm to allow settling of suspended solids before releasing the liquids to the cribs. About 33,841,000 L (8,940,000 gal) of this liquid effluent passed through a three-tank cascade system and was discharged to seven of the eight BY-Cribs. Disposal of TBP process wastes to the BY-Cribs was terminated after beta activity was detected in the groundwater beneath the cribs. Between 1965 and 1974, 61,000,000 L (16,000,000 gal) of tank liquor condensate from the ITS B-5 Reverse Well was discharged to the 216-B-50 Crib. The nearby 216-B-57 Crib received 83,000,000 L (22,000,000 gal) of tank condensate from the ITS BY-Cribs during the period between 1968 and 1973 . Estimated quantities of the primary contaminants in all liquid effluent streams disposed of to the BY-Cribs included $0.45 \mathrm{Ci}{ }^{60} \mathrm{Co}, 18,900 \mathrm{~kg}$ ferrocyanide, $5,691,500 \mathrm{~kg}$ nitrate, and an unknown amount of ${ }^{99} \mathrm{Tc}$ (DOE-RL 1993d).

Groundwater monitoring activities have identified a large groundwater contamination plume located at the northern fenceline and north of the 200 East Area toward Gable Gap (DOE-RL 1993a, 1993c, 1993d). Hanford Site records indicate that the BY-Cribs are the most probable source of groundwater 
contamination at or near this location. Discharges from the 200 North Area (Section 5.1.1.4) were examined as a potential contaminant source; however, the position of the plume and the presence of specific process effluents ( ${ }^{60} \mathrm{Co}$ and cyanide) suggest that the plume migrated to its current location and is the result of disposal practices at the BY-Cribs. A northerly local groundwater flow direction is reflected in the areal distribution of the plume.

5.3.2.2 Solubility and Sorption Controls. Data presented in the 200 East Groundwater Aggregate Area Management Study Report (DOE-RL 1993a) suggest there is little tendency for the primary contaminants ${ }^{60} \mathrm{Co}$ and ${ }^{99} \mathrm{Tc}$ to adsorb to the fine-grained soils beneath the Hanford Site. Cobalt-60 normally exists as a divalent cation in acidic to mildly alkaline solution and is prone to adsorbing onto soil via cation exchange. However, greater mobility is possible as ${ }^{60} \mathrm{Co}$ can form anion or neutral complexes. In particular, the complexing of ${ }^{60} \mathrm{Co}$ by cyanide has been proposed as a means of explaining the observed high mobility of ${ }^{60} \mathrm{Co}$ in the BY-Cribs plume (DOE-RL 1993d).

Technetium-99 typically forms negative ions in oxidizing environments and does not readily complex with other chemical species. Technetium-99 also has a very low soil-water $\left(\mathrm{K}_{d}=0\right)$. Consequently, there is limited tendency for ${ }^{99} \mathrm{Tc}$ to adsorb to the Hanford Site sedirnents, which makes the radionuclide mobile.

5.3.2.3 Local Geohydrology. The geohydrology of the area containing the BY-Cribs plume is controlled to a major extent by the underlying Elephant Mountain basalt. Basalt structural highs generally restrict groundwater flow to the more conductive sedimentary deposits located between the basalt highs. Erosional features incised into the basalt may provide localized preferential flow paths. The erosional window, as identified in wells 699-55-55 and 699-55-53, may be acting as pathway for vertical migration between the uppermost unconfined aquifer and the underlying interbed. Borehole television survey logs of the basalt portion of several wells within the plume reveal that the basalt contains numerous subvertical to horizontal fractures, which could act as conduits for groundwater flow. The conductivity of these fractures is unknown.

The BY-Cribs ${ }^{99} \mathrm{Tc}$ plume is defined by five groundwater monitoring wells. It is important to note that these five wells penetrate the full thickness of the aquifer and also enter into the underlying basalt. Wells 699-50-53A and 699-52-54 have thin [<0.6-m-thick ( $<2$-ft-thick)] saturated unconfined aquifer interval. Both wells are located near the westerly margin of a subsurface structural basalt high that extends above the current groundwater table. Wells 699-49-55A, 699-49-57A, and 699-55-57 are located west of the basalt high and are situated in a thicker portion of the unconfined aquifer. Based on the most recent groundwater level measurements, the saturated thickness is approximately $3.1 \mathrm{~m}(10 \mathrm{ft})$ at well $699-49-55 \mathrm{~A}$ and about $2.7 \mathrm{~m}(9 \mathrm{ft})$ at well 699-49-57A.

Aquifer data in the vicinity of the BY-Cribs plume are limited by the age of the wells and the distance between them. Based on data provided in the 200 East Groundwater Aggregate Area Management Study Report (DOE-RL 1993a), the hydraulic conductivity and transmissivity of the aquifer are relatively high. Section 4.4 provides additional aquifer property information assembled during the treatability test aquifer investigations.

5.3.2.4 Contaminant Source Models. Much of the success of a groundwater remediation program depends on the ability to define the contaminant source model. It is imperative to determine if all of the available contaminant has already entered the aquifer, or if a continuing source of contamination exists that contributes to the future growth of the contaminant plume. If a continuing source exists, its location should be determined so that remedial activities can be directed at the areas of highest 
concentration. Two models currently exist that try to define the source of the BY-Cribs contaminant plumes. For these models to be acceptable, the following observed conditions must be explained.

- $\quad$ Cyanide and ${ }^{99} \mathrm{Tc}$ are still present in detectable, elevated concentrations in wells associated with the BY-Cribs (e.g., wells 299-E33-7 and 299-E33-13). It does not seem likely that the BY-Cribs continue to be an active source 20 years after receiving the final waste effluent. Site characterization activities conducted for the 200-BP-1 remedial investigation determined no large, active source of groundwater contamination currently exists in the soils beneath the BY-Cribs (DOE-RL 1993d).

- High contaminant concentrations in the groundwater north of the BY-Cribs, and especially associated with wells 699-50-53A and 699-52-54, have been known for many years. Technetium-99 concentrations at well 699-50-53A increased ten-fold over background values during the operation of the pilot-scale treatment plant.

One proposed explanation for the observed trends in contamination north of the BY-Cribs is that the lowered water tables in the area during the mid-1970's to mid-1980's left contaminants in the lower vadose zone as sorbed material on mineral surfaces and in interstitial water (see Figure 5-9 for well hydrographs in the vicinity of the BY-Cribs). Subsequent increases in the elevation of the water table beginning in the mid-1980's resaturated this contaminated zone and led to the remobilizing of contaminants and increased observed concentrations. The proposed correlation can be seen by comparing the fluctuations in water level for well $699-50-53 \mathrm{~A}$ in Figure 5-9 with the ${ }^{60} \mathrm{Co}$ trend for the same well as illustrated in Figure 5-20.

An alternative model proposed by Kasza (1993) is based on the known high density of the process wastes disposed of to the BY-Cribs and on the results of depth-specific groundwater sampling conducted in the 1960's. Process records and laboratory simulation experiments indicate that the scavenged TBP supernatant disposed of to the BY-Cribs had a high specific gravity (1.21 to 1.32). Field studies conducted between 1956 and 1980 recognized that the scavenged TBP supernatant formed mobile contaminant mass, which had a density greater than water, that migrated southward along the bottom of the unconfined aquifer. Depth-specific groundwater sampling and borehole geophysical logging shows that the dense contaminant mass migrated several thousand feet to the south.

Kasza (1993) proposes that after saturation of the open pore space beneath the BY-Cribs, the dense waste was able to enter the aquifer with little attendant mixing with the groundwater. Beneath the BY-Cribs, the aquifer was approximately $3 \mathrm{~m}(10 \mathrm{ft})$ thick during the period of waste disposal, and the initial dilution of the dense scavenged TBP supernatant was likely minimal. Once at the bottom of the aquifer, the dense waste appears to have behaved as a separate dense phase and moved as a coherent mass primarily because of its density difference with the groundwater. The waste moved along the surface of the basalt, displacing groundwater from fractures and depressions, while it migrated down the topographic surface and away from the BY-Cribs. Movement was likely accompanied by mixing and diffusing into the surrounding groundwater. The principal contaminant migration direction away from the cribs was toward the south, down the southward-dipping top of the basalt unit underlying the aquifer. Smith (1980) and others record increased contaminant concentrations in the sediments immediately above the basalt at wells several hundred feet south of the BY-Cribs. Because detailed configuration of the basalt surface is not known, it is not possible to establish the migration path of the dense contaminant mass. 
During the intervening years, density-driven movement probably slowed or ceased because dilution reduced the density differences between the groundwater and the waste. This decrease would be most likely caused by the dense waste mixing with, and diffusing into, the surrounding groundwater. The rising regional water table for some period of time established northward groundwater flow. Dissolved contaminant movement eventually followed the regional groundwater flow to the north and became the dominant contaminant transport mechanism.

Because minimal vertical advection and diffusion is likely to occur in a fracture-controlled aquifer system, any portion of the contaminant mass that had entered the fracture system in the basalt through density-driven displacement of the groundwater would likely remain stratified in the basalt and relatively undiluted. In that position, it is undetected by the majority of the groundwater monitoring wells, which sample only the upper portion of the aquifer. As shown in Figure 5-22, the wells that comprise the ${ }^{99} \mathrm{Tc}$ contaminant plume penetrate and collect groundwater samples from both the saturated thickness of the aquifer sediments and the upper portion of the basalt. This access to the fluids contained in the fractures of the basalt may be responsible for the increased contaminant levels measured at those wells. The observed increase in ${ }^{60} \mathrm{Co}$ and ${ }^{99} \mathrm{Tc}$ concentrations at the extraction well (699-50-53A) during the operation of the pilot plant may have occurred because the large amount of drawdown at the well caused more concentrated waste from the fractures to be drawn into the well's capture zone.

Both of the models introduced here satisfy the previously stated conditions to various degrees. The rising water-table model would not itself address contaminants found in wells associated with the BY-Cribs if the local groundwater flow direction were still to the north. The dense contaminant source located deep in the aquifer would not supply contaminants to the plume if groundwater beneath the BY-Cribs flowed to the south. Either model may have been dominant at various times in the history of the plume. A hybrid model combining aspects from both of the proposed models may be an appropriate predictor of future plume behavior. More hydrogeologic and contaminant character information is needed before the model can be validated.

\subsubsection{6-A-25 Gable Mountain Pond Plume}

The 216-A-25 Gable Mountain Pond received an estimated total waste volume of $307,000,000,000 \mathrm{~L}$ $(81,100,000,000 \mathrm{gal}$ ) of effluent between 1957 and 1987 (Coony and Thomas 1989). Figure 5-4 shows the effluent discharge history. The effluent was principally 202-A Building process cooling water, 241-A-431 surface condenser cooling water, 242-A Evaporator cooling water, 244-AR Vault cooling water, and 284-E Powerhouse water (Maxfield 1979, WHC 1991). The effluent contained low levels of radionuclides, including ${ }^{241} \mathrm{Am},{ }^{137} \mathrm{Cs},{ }^{3} \mathrm{H},{ }^{147} \mathrm{Pm},{ }^{106} \mathrm{Ru},{ }^{90} \mathrm{Sr}$, and plutonium, and reached the 216-A-25 Gable Mountain Pond via the PUREX Cooling Water Line, which discharged into the southeastern end of the pond (Brown et al. 1990, WHC 1991). A single, unplanned release in 1964 resulted in the discharge of approximately 7,500 $\mathrm{Ci}$ of mixed fission products to the pond, of which about $99 \%$ were short-lived (Maxfield 1979). The estimated radionuclide inventory in 1995 for the 216-A-25 Gable Mountain Pond, decayed from the data presented in Table 5-2, are $5.21 \times 10^{-4}$ $\mathrm{Ci}$ of $\mathrm{Am}^{241}, 1.66 \times 10^{2} \mathrm{Ci}$ of ${ }^{137} \mathrm{Cs}, 1.28 \times 10^{2} \mathrm{Ci}$ of ${ }^{3} \mathrm{H}, 3.37 \times 10^{-7} \mathrm{Ci}$ of ${ }^{106} \mathrm{Ru}, 2.06 \times 10^{2} \mathrm{Ci}$ of ${ }^{90} \mathrm{Sr}, 428 \mathrm{~g}$ of plutonium, and $4.24 \mathrm{Ci}$ of uranium. The inventory at the pond is a consequence of the 30 years of routine effluent discharges combined with the unplanned release in 1964.

A plume of ${ }^{90} \mathrm{Sr}$-contaminated groundwater exists at the pond. The extent of the 216-A-25 Gable Mountain Pond ${ }^{90} \mathrm{Sr}$ plume is shown in Figure $5-25$ by 8 - and $100-\mathrm{pCi} / \mathrm{L}{ }^{90} \mathrm{Sr}$ contours generated from 
1994 data. The area enclosed by the $8-\mathrm{pCi} / \mathrm{L}$ contour is about $5.9 \times 10^{5} \mathrm{~m}^{2}\left(6.35 \times 10^{6} \mathrm{ft}^{2}\right)$. The area enclosed by the $100 \mathrm{pCi} / \mathrm{L}$ contour is about $4.5 \times 10^{4} \mathrm{~m}^{2}\left(4.83 \times 10^{5} \mathrm{ft}^{2}\right)$.

Before decommissioning, the pond elevation was $131.9 \mathrm{~m}(432.6 \mathrm{ft})$ and had a maximum depth of about $2.4 \mathrm{~m}$ ( $8 \mathrm{ft}$ ) (Hayward 1989). Decommissioning of the pond began in 1984 and was completed in 1988 with the interim stabilization of the site (see Section 5.1.2.4).

5.3.3.1 Gable Mountain Pond Source Characteristics. The unplanned release (UPR-200-E-34) on June 11,1964 , released approximately $7,500 \mathrm{Ci}$ of short- and long-lived fission products to the 216-A-25 Gable Mountain Pond. The following description of the release and responses is summarized in Maxfield (1979). The short-lived fission products (e.g., those with half-lives $<2.5$ years) constituted approximately $99 \%$, or $7,445 \mathrm{Ci}$, of the release. In 1964 , most of the activity was attributed to ${ }^{95} \mathrm{Nb},{ }^{103} \mathrm{Ru},{ }^{106} \mathrm{Ru}$, and ${ }^{95} \mathrm{Zr}$. Approximately $25 \mathrm{Ci}$ of ${ }^{137} \mathrm{Cs}$ and $30 \mathrm{Ci}$ of ${ }^{90} \mathrm{Sr}$, the half-lives of which are 29.1 and 30.2 years, respectively, were released. Bentonite clay was added to the 216-A-25 Gable Mountain Pond soon after the release to bind radionuclides in the upper sediment layers and raise the water level in the pond by reducing the percolation rate. However, the pond water level did not rise after application of bentonite. Concurrently, to reduce radiation exposure and prevent the spread of contamination, bulldozers were used to push fill into the pond to cover contaminated sediment at shoreline and in the shallows. As this earthmoving proceeded, it was noted that the pond water level began rising. When the earthmoving was completed, fill had been pushed into the pond along the entire perimeter to an average width of $6 \mathrm{~m}(20 \mathrm{ft})$. It was surmised that percolation had been occurring principally at the pond margins before the placement of the fill.

In 1971 and 1972, PNNL personnel conducted a study of Gable Mountain Pond (Cushing and Watson 1974). Cushing and Watson (1974) found that ${ }^{137} \mathrm{Cs}$ accounted for $90 \%$ of the radioactivity at the pond, and $90 \%$ of ${ }^{137} \mathrm{Cs}$ occurred in the top $5 \mathrm{~cm}\left(2 \mathrm{in}\right.$.) of pond sediment. In contrast to ${ }^{137} \mathrm{Cs}$, the ${ }^{90} \mathrm{Sr}$ concentration in the pond sediment was greater in deeper core sample intervals, although specific sample intervals and dimensions of the cores were not published (Cushing and Watson 1974).

5.3.3.2 Hydrologic and Hydrochemical Concept. Strontium-90 is the primary contaminant of concern at the 216-A-25 Gable Mountain Pond; groundwater monitoring since the 1980's has not disclosed other plumes. The ${ }^{90} \mathrm{Sr}$ is assumed to have been a dissolved constituent in the effluent and to have been adsorbed onto the aquifer materials.

Wells 699-53-47A, 699-53-47B, 699-53-48A, 699-53-48B, 699-54-48, 699-54-49, 699-55-50, and 699-55-50D provide geologic and hydrologic characterization data for the unconfined aquifer near the Gable Mountain Pond. These wells and others are shown in Figure 5-26. Five of the wells (i.e., 699-53-47B, 699-53-48A, 699-53-48B, 699-54-48, and 699-54-49) were drilled as part of an investigation of the pond in 1984 (Law et al. 1986).

The unconfined aquifer intercepted in the boreholes consists of silt; sands; sands and gravel; and gravel, cobbles, and boulders of the Hanford formation. The aquifer thickness (i.e., from static water

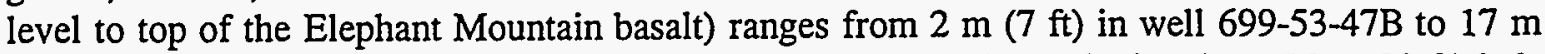
$(55 \mathrm{ft}$ ) in well 699-55-50C. The Elephant Mountain basalt subcrop is 6 to $9 \mathrm{~m}$ (20 to $30 \mathrm{ft}$ ) below grade at the southeast end of the Gable Mountain Pond (well 699-53-47A) and 27 to $30 \mathrm{~m}$ (90 to $100 \mathrm{ft}$ ) below grade at the northwest end of the pond (well 699-54-50C). North and south of the pond, the Elephant Mountain basalt forms extensive subcrops above the water table. Figure 5-26 shows the basalt subcrops that extend above the water table and the resulting northwest flow of groundwater (i.e., toward Gable Gap). 
Tests conducted in 1956 revealed the following characteristics of the unconfined aquifer: transmissivities ranged from $5.6 \times 10^{4}$ to $3.7 \times 10^{4} \mathrm{~m}^{2} /$ day $\left(6.0 \times 10^{5}\right.$ to $4.0 \times 10^{5} \mathrm{ft}^{2} /$ day), equivalent hydraulic conductivities ranged from $7.6 \times 10^{3}$ to $2.6 \times 10^{3} \mathrm{~m} /$ day $\left(2.5 \times 10^{4}\right.$ to $8.5 \times 10^{3} \mathrm{ft} /$ day), and storage coefficients were 0.21 and 0.21 at wells $699-55-50 \mathrm{C}$ and $699-55-50 \mathrm{D}$, respectively (DOE-RL 1993a). The aquifer properties in the area tested by 699-55-50 series wells were summarized by Deju (1974) as follows: transmissivity of $5.52 \times 10^{4} \mathrm{~m}^{2} /$ day $\left(5.94 \times 10^{5} \mathrm{ff}^{2} /\right.$ day $)$, hydraulic conductivity of $2.8 \times 10^{3} \mathrm{~m} /$ day $\left(9.1 \times 10^{3} \mathrm{ft} /\right.$ day $)$, and coefficient of storage 0.07 .

The ${ }^{90} \mathrm{Sr} \mathrm{K}_{\mathrm{d}}$ in seven sediment samples from wells $699-53-48 \mathrm{~A}$ and $699-54-48$ are reported by Law et al. (1986). The $\mathrm{K}_{\mathrm{d}} \mathrm{s}$ ranged from 21.9 to $95.1 \mathrm{~mL} / \mathrm{g}$. The $\mathrm{K}_{\mathrm{d}}$ of $95.1 \mathrm{~mL} / \mathrm{g}$ was from a sample of silt; the other $\mathrm{K}_{d}$ values were from coarser grained sediment. $A \mathrm{~K}_{\mathrm{d}}$ of $25 \mathrm{~mL} / \mathrm{g}$ was selected as a conservative, representative value for the Hanford formation. This $K_{d}$ correlates to a retardation factor of 120 (e.g., the rate of ${ }^{90} \mathrm{Sr}$ movement through the aquifer is 120 times less than the rate of groundwater movement) (Law et al. 1986).

The 1984 hydrologic investigation at Gable Mountain Pond was initiated after an increasing trend of ${ }^{90} \mathrm{Sr}$ in groundwater monitored by well 699-53-47A was noted in 1983 (Law and Allen 1984). The static water-level elevation in June 1984 ranged from $125.47 \mathrm{~m}(411.65 \mathrm{ft})$ above mean sea level in well $699-53-47 \mathrm{~B}$ to $123.23 \mathrm{~m}$ ( $404.31 \mathrm{ft}$ ) above mean sea level in well $699-55-50 \mathrm{C}$. The average groundwater concentrations of ${ }^{90} \mathrm{Sr}$ in 1984 exceeded the Rockwell Hanford Operations administrative guideline of $30 \mathrm{pCi} / \mathrm{L}$ in wells $699-53-47 \mathrm{~A}(65 \mathrm{pCi} / \mathrm{L}), 699-53-47 \mathrm{~B}(63 \mathrm{pCi} / \mathrm{L})$, and $699-53-48 \mathrm{~B}$ $(608 \mathrm{pCi} / \mathrm{L})$ (Law et al. 1986). Only low concentrations of ${ }^{90} \mathrm{Sr}$ were found in groundwater from other upgradient and downgradient monitoring, which indicated that significant ${ }^{90} \mathrm{Sr}$ contamination was localized near well 699-53-48B (Law et al. 1986).

5.3.3.3 Contaminant Source Model. Section 5.3.1.3 addresses the roles that solubility and sorption-desorption play in the mobility of ${ }^{137} \mathrm{Cs}$ and ${ }^{90} \mathrm{Sr}$. Sorption-desorption is probably the primary control for ${ }^{90} \mathrm{Sr}$ and ${ }^{137} \mathrm{Cs}$ migration at the $216-\mathrm{A}-25$ Gable Mountain Pond. Cushing and Watson (1974) noted that ${ }^{137} \mathrm{Cs}$ appears to be strongly held in the sediments immediately below the pond. The same is not expected for ${ }^{90} \mathrm{Sr}$; it is thought to occur at the top of the aquifer (Serkowski and Jordan 1989). Given the ${ }^{90} \mathrm{Sr}$ Rf of 120 , appreciable mobility of ${ }^{90} \mathrm{Sr}$ is not expected and has not occurred.

The ${ }^{90} \mathrm{Sr}$ concentrations in groundwater from 1980 through 1995 for wells 699-53-47A, 699-53-47B, 699-53-48A, 699-53-48B, 699-54-48, and 699-54-49 are shown in Figure 5-27. Note that samples with nondetected or negative concentration results were plotted as "0" in the graphs of Figure 5-28. Interpretation of these data is complicated by the change in sampling frequency from quarterly to semiannually in 1990 . The ${ }^{90} \mathrm{Sr}$ concentrations are greatest in well 699-53-48B and have increased roughly five-fold in wells $699-53-47 \mathrm{~B}$ and $699-53-48 \mathrm{~B}$ between 1990 and 1995 . The cause of this phenomenon is not known. The changes in concentrations do not appear to be correlated, between wells, with the changes in water-table elevations shown in Figure $5-27$. Concentrations of ${ }^{90} \mathrm{Sr}$ in well 699-53-47B increased as water-table elevations declined gradually while from January 1990 until October 1991 , concentrations of ${ }^{90} \mathrm{Sr}$ in well $699-53-48 \mathrm{~B}$ decreased as the water-table elevations declined. Since October 1991, both the water-table elevations and ${ }^{90} \mathrm{Sr}$ concentrations in well 699-53-48B have increased. The water-table elevations since 1986 in well 699-53-47B correspond to an interval of basalt boulders and fine sand.

The ${ }^{137} \mathrm{Cs}$ concentrations in groundwater from 1970 through 1995 for wells $699-53-47 \mathrm{~A}, 699-53-47 \mathrm{~B}$, 699-53-48A, 699-53-48B, 699-54-48, and 699-55-50C are shown in Figure 5-29. Samples with 
nondetected or negative concentration results were plotted as "0" in the graphs of Figure 5-29. The maximum concentration of ${ }^{137} \mathrm{Cs}$ is $32 \mathrm{pCi} / \mathrm{L}$ from well $699-53-47 \mathrm{~A}$.

\subsection{RISK ANALYSIS}

Risk analyses were performed for the following three groundwater contaminant plumes within the 200-BP-5 Operable Unit: BY-Cribs plume, B-5 Reverse Well plume, and Gable Mountain Pond plume.

This section provides a summary of the risk analyses performed for these sites. The details are documented separately in Risk-Based Decision Analysis for the 200-BP-5 Groundwater Operable Unit (BHI 1995c).

The contaminants of potential concern (COPC) in the three plumes are the radionuclides ${ }^{60} \mathrm{Co}$ and ${ }^{99} \mathrm{Tc}$ in the BY-Cribs plume; ${ }^{137} \mathrm{Cs}$, ${ }^{2391240} \mathrm{Pu}$, and ${ }^{90} \mathrm{Sr}$ in the B-5 Reverse Well plume; and ${ }^{90} \mathrm{Sr}$ in Gable Mountain Pond plume. The methodology used in the analysis is based on Risk-Based Decision Analysis for Groundwater Operable Units (BHI 1995b).

Risk assumptions and scenarios were based on Hanford Site Risk Assessment Methodology (HSRAM) (DOE-RL 1995b). Hypothetical exposure scenarios were assessed based on both current and future plume conditions. For current conditions, a hypothetical industrial groundwater ingestion scenario was evaluated; for future conditions, both industrial and residential ingestion scenarios were assumed. The industrial ingestion scenario, which is derived from HSRAM, was used in this risk analysis for illustrative purposes only. There is currently no use of the 200 Area groundwater for drinking water nor is any anticipated in the foreseeable future; therefore, it should not be implied by this risk analysis that DOE is advocating use of this groundwater for direct human ingestion.

For future conditions, the transport of ${ }^{239 / 240} \mathrm{Pu}$ in the B-5 Reverse Well, the ${ }^{99} \mathrm{Tc}$ in the BY-Cribs plume, and the ${ }^{90} \mathrm{Sr}$ in the Gable Mountain Pond plume was modeled using a two-dimensional analytical flow and transport model called CONMIG (Walton 1989). Modeling simulated dispersion, adsorption, and radioactive decay of constituents during transport.

\subsubsection{6-BY Cribs Plume}

The maximum concentration of ${ }^{99} \mathrm{Tc}$ measured during the period between January 1993 and March 1995 was used as the input concentration for each well in the "existing conditions" risk assessment model. The $95 \%$ UCL concentration of ${ }^{99} \mathrm{Tc}$ measured since 1988 was used as the input concentration for well $699-50-53 \mathrm{~A}$ in the "future conditions" risk assessment model.

5.4.1.1 Existing Conditions. The hypothetical industrial scenario risk based on contaminant concentrations and groundwater plume conditions was estimated, plotted, and contoured. The results show that most of the health risk is attributable to ${ }^{99} \mathrm{Tc}$ and not ${ }^{60} \mathrm{Co}$. The baseline incremental lifetime cancer risk (ILCR) $\left(6.9 \times 10^{-5}\right)$ is calculated for groundwater at monitoring well $699-50-53 \mathrm{~A}$, which during the baseline pre-treatability test period had a maximum ${ }^{99} \mathrm{Tc}$ concentration of $8,640 \mathrm{pCi} / \mathrm{L}$. During the operation of the treatability test, the ${ }^{99} \mathrm{Tc}$ concentration increased to $11,200 \mathrm{pCi} / \mathrm{L}$ in this well, producing a corresponding ILCR of $8.9 \times 10^{-5}$. 
The maximum ILCR for this plume, based on the historical highest concentration of ${ }^{99} \mathrm{Tc}$ measured at well 699-50-53A during the period 1988 to $1992(27,548 \mathrm{pCi} / \mathrm{L})$, would be $2.19 \times 10^{-4}$. The risk contours for the existing plume of ${ }^{99} \mathrm{Tc}$ are plotted in Figure $5-30$.

5.4.1.2 Future Conditions. The objective of transport modeling was to determine the flow path length at which the maximum ILCR for ${ }^{99} \mathrm{Tc}$ at any location in the plume was no greater than $1 \times 10^{-5}$ (this objective was requested by the EPA). However, modeling results show that, because of the large size of the ${ }^{99} \mathrm{Tc}$ plume, ILCRs will exceed $1 \times 10^{-5}$ at the end of the flow path (the Columbia River).

Because ${ }^{60} \mathrm{Co}$ has a short half-life of 5.3 years, it was eliminated from consideration for estimating future risk. The modeled transport of ${ }^{99} \mathrm{Tc}$ is essentially dependent on dispersivity because radioactive decay is negligible. There is, however, uncertainty in the specification of values for dispersivity. Based on the judgement of the modelers, a longitudinal dispersivity range of 61 to $305 \mathrm{~m}$ (200 $\mathrm{ft}$ to $1,000 \mathrm{ft}$ ) was selected for the analysis to show its sensitivity in the calculated risk results. Using these assumptions, modeling predicted the following:

\begin{tabular}{|c|c|c|}
\hline & 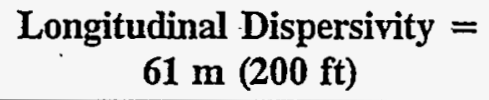 & $\begin{array}{l}\text { Longitudinal Dispersivity }= \\
\qquad 305 \mathrm{~m}(1,000 \mathrm{ft})\end{array}$ \\
\hline $\begin{array}{l}{ }^{99} \mathrm{Tc} \text { Concentration in Well } \\
699-50-53 \mathrm{~A}, \mathrm{pCi} / \mathrm{L} \text { (existing } \\
\text { plume) }\end{array}$ & $2,633 \mathrm{~m}(8,640 \mathrm{ft})$ & $2,633 \mathrm{~m}(640 \mathrm{ft})$ \\
\hline Travel Time, Years & 75 & 75 \\
\hline $\begin{array}{l}\text { Travel Distance (to maximum } \\
\text { risk point), } \mathrm{m} \text { (ft) }\end{array}$ & $8,778 \mathrm{~m}(28,800 \mathrm{ft})$ & $8,778 \mathrm{~m}(28,800 \mathrm{ft})$ \\
\hline $\begin{array}{l}\text { Maximum }{ }^{99} \mathrm{Tc} \text { Concentration, } \\
\mathrm{pCi} / \mathrm{L}\end{array}$ & 4,190 & 1,270 \\
\hline Industrial Risk, ILCR & $2.70 \mathrm{E}-5$ & $8.30 \mathrm{E}-6$ \\
\hline Residential Risk, ILCR & $1.20 \mathrm{E}-4$ & $3.60 \mathrm{E}-5$ \\
\hline
\end{tabular}

At the request of EPA, additional modeling runs were performed to estimate the location and magnitude of risks posed by the ${ }^{99} \mathrm{Tc}$ plume in the year 2018. Three modeling cases were addressed as follows:

- $\quad$ Case 1 - $\mathrm{A}{ }^{99} \mathrm{Tc}$ concentration observed in well $699-50-53 \mathrm{~A}$ of $11,200 \mathrm{pCi} / \mathrm{L}$ during pump-and-treat operations. One dispersivity scenario was modeled for this concentration: $30 \mathrm{~m}(1,000 \mathrm{ft})$ longitudinal/30 $\mathrm{m}(100 \mathrm{ft})$ transverse.

- $\quad$ Cases $2 \mathrm{a}$ and $2 \mathrm{~b}$ - Historical high concentrations of ${ }^{99} \mathrm{Tc}$ in well $699-50-53 \mathrm{~A}$ as represented by the $95 \%$ UCL of sample concentrations obtained during the period from June 26, 1987 to February 8, 1993. Two dispersivity scenarios were addressed: Case $2 \mathrm{a}-305 \mathrm{~m}(1,000 \mathrm{ft})$ longitudinal/30 m (100 ft) transverse and Case $2 \mathrm{~b}-30 \mathrm{~m}(100 \mathrm{ft})$ longitudinal/3 $\mathrm{m}(10 \mathrm{ft})$ transverse. The $95 \%$ UCL was calculated to be $27,548 \mathrm{pCi} / \mathrm{L}$. 
Results of these modeling cases are shown in the following table. Figure 5-30 shows the risk contours for Case $2 \mathrm{a}$ based on a residential scenario. The existing plume (industrial scenario) is plotted on the same base map in Figure 5-30 for comparison.

\begin{tabular}{|l|c|c|c|}
\hline \multicolumn{1}{|c|}{ Case } & $\mathbf{1}$ & 2a & 2b \\
\hline${ }^{99}$ Tc concentration in well 699-50-53A, pCi/L & 11,200 & 27,548 & 27,548 \\
\hline Dispersivity: longitudinal/transverse, m (ft) & $\begin{array}{c}305 / 30 \\
(1,000 / 100)\end{array}$ & $\begin{array}{c}305 / 30 \\
(1,000 / 100)\end{array}$ & $\begin{array}{c}30 / 3 \\
(100 / 10)\end{array}$ \\
\hline Travel time (to 2018), yr & 23 & 23 & 23 \\
\hline Travel distance to maximum risk point, m (ft) & $\begin{array}{c}2,682 \\
(8,800)\end{array}$ & $\begin{array}{c}2,682 \\
(8,800)\end{array}$ & $\mathrm{a}$ \\
\hline Maximum ${ }^{99}$ Tc in future plume, pCi/L & 3,800 & 7,843 & $\mathrm{a}$ \\
\hline Industrial Risk, ILCR & $2.5 \mathrm{E}-5$ & $5.1 \mathrm{E}-5$ & $\mathrm{a}$ \\
\hline Residential Risk, ILCR & $1.1 \mathrm{E}-4$ & $2.2 \mathrm{E}-4$ & $\mathrm{a}$ \\
\hline aUnable to model this dispersivity and travel-time condition. & & \\
\hline
\end{tabular}

The Case $2 \mathrm{~b}$ dispersivity and travel-time conditions could not be modeled. An attempted run indicated that future ${ }^{99} \mathrm{Tc}$ concentrations were greater than the maximum source concentration. This does not imply that the dispersivity and travel-time conditions are physically impossible, only that the analytical model will not provide a correct solution under the constraints imposed.

A comparison of Cases 1 and 2a shows that future maximum concentrations and the corresponding risks are approximately proportional to current historical maximums assuming the same dispersivity. For example, if the source concentration is assumed to be doubled, the maximum risk in the future plume is approximately doubled.

5.4.1.3 Conclusions. At the year 2018 and based on the historical $95 \%$ UCL ${ }^{99} \mathrm{Tc}$ concentration of $27,548 \mathrm{pCi} / \mathrm{L}$, the modeling shows that the concentration of ${ }^{99} \mathrm{Tc}$ is predicted to be $7,843 \mathrm{pCi} / \mathrm{L}$ (compared to the MCL of $900 \mathrm{pCi} / \mathrm{L}$ ) and will have moved about $2,682 \mathrm{~m}(8,800 \mathrm{ft}$ ) beyond its present location. This corresponds to a residential ILCR of $2.2 \times 10^{-4}$. When it reaches the river, the concentration of ${ }^{99} \mathrm{Tc}$ is predicted to be higher than the existing MCL and the maximum risk will still exceed the Model Toxics Control Act (MTCA) standard.

\subsubsection{6-B-5 Reverse Well Plume}

Calculation of risk from ${ }^{137} \mathrm{Cs}$ and ${ }^{90} \mathrm{Sr}$ in the B-5 Reverse Well plume is based on the highest concentration measured in each well during the period January 1993 through March 1995. For all wells except 299-E28-25, the most recent sample collection provided the highest value.

Risk for ${ }^{239 / 240} \mathrm{Pu}$ in the B-5 Reverse Well plume was calculated from the analysis of groundwater samples collected during the same January 1993 through March 1995 time period. Input to the risk model was provided by the most recent sampling event, with the exception of wells 299-E28-23 and 299-E28-25, where the higher concentrations were found during earlier sampling events. The highest concentration, and coincidentally the most recent ${ }^{239240} \mathrm{Pu}$ sampling from well $299-\mathrm{E} 28-24$, was rejected as suspect data because it was over 100 times greater than the average of earlier analyses 
from that well. The well was resampled in June 1995 (after calculation of the risk) and had an activity that was $2 \%$ of the previous analysis. The next-highest concentration was used as input data for the risk calculation.

5.4.2.1 Existing Conditions. The risk analysis shows that no one radionuclide is consistently the major contributor to the ILCR but, rather, the major contributor differs in each monitoring well. The maximum ILCR $\left(2.1 \times 10^{-3}\right)$ was calculated for groundwater at monitoring well 299-E28-23. In this well, ${ }^{90} \mathrm{Sr}$ is the major contributor ( $86 \%$ of the ILCR), with a concentration of $2,310 \mathrm{pCi} / \mathrm{L}$. The highest ILCR because of ${ }^{239 / 240} \mathrm{Pu}$ alone is $1.4 \times 10^{-4}$, because of $125 \mathrm{pCi} / \mathrm{L}$ of ${ }^{239 / 240} \mathrm{Pu}$ in groundwater at monitoring well 299-E28-25. The risk contours for the existing plume are plotted in Figure 5-31.

5.4.2.2 Future Conditions. Future conditions consider risk because of the B-5 Reverse Well plume COPCs at a point representing the boundary of the initial buffer zone surrounding the Central Plateau, as proposed by the Hanford Future Site Uses Working Group. Because of uncertainty in future flow conditions (due to the dissipation of a groundwater mound beneath the 216-B-3 Pond System), both northwest and southeast flow paths to the proposed buffer zone boundary were considered. The

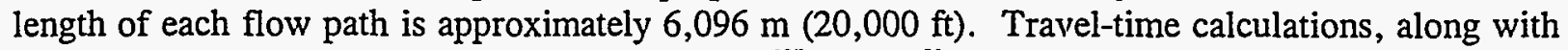
radioactive decay calculations, demonstrated that ${ }^{137} \mathrm{Cs}$ and ${ }^{90} \mathrm{Sr}$ concentrations will decay to negligible levels before reaching the boundary for both flow paths. This is because of the moderate-to-high adsorption of these radionuclides combined with their relatively short half-lives. Therefore, the transport of these two isotopes did not need to be modeled; however, ${ }^{239240} \mathrm{Pu}$ still exhibited significant concentrations at the boundary and, therefore, was modeled. The transport modeling results are tabulated as follows:

\begin{tabular}{|c|c|c|c|c|}
\hline Risk Scenario & $\begin{array}{c}\text { Flow Path } \\
\text { Direction }\end{array}$ & $\begin{array}{c}239 / 240 \text { Pu Maximum } \\
\text { Concentration } \\
(\mathrm{pCi} / \mathrm{L})\end{array}$ & $\begin{array}{c}\text { Travel time } \\
\text { (years) }\end{array}$ & $\begin{array}{c}\text { Incremental } \\
\text { Lifetime Cancer } \\
\text { Risk }\end{array}$ \\
\hline Industrial & Northwest & 0.11 & 28,500 & $1.3 \times 10^{-7}$ \\
\hline Industrial & Southeast & 0.20 & 7,500 & $2.3 \times 10^{-7}$ \\
\hline Residential & Northwest & 0.11 & 28,500 & $5.7 \times 10^{-7}$ \\
\hline Residential & Southeast & 0.20 & 7,500 & $1.0 \times 10^{-6}$ \\
\hline
\end{tabular}

The risk contours for the future plume conditions are shown in Figure 5-31.

As requested by the EPA, a travel-time analysis was also performed to calculate travel distances of ${ }^{137} \mathrm{Cs}$ and ${ }^{90} \mathrm{Sr}$ at 50,100 , and 200 years into the future. Both isotopes will decay approximately three half-lives in 100 years and approximately six half-lives in 200 years. The travel-time analysis results are tabulated as follows:

\begin{tabular}{|c|c|c|c|c|}
\hline $\begin{array}{c}\text { Number of Years } \\
\text { for Contaminant } \\
\text { Migration to } \\
\text { Occur }\end{array}$ & $\begin{array}{c}\text { Distance (m) } \\
\begin{array}{c}{ }^{90} \text { Sr Migrates } \\
\text { in Southeast } \\
\text { Direction }\end{array}\end{array}$ & $\begin{array}{c}\text { Distance (m) } \\
{ }^{\text {90 }} \text { Sr Migrates } \\
\text { in Northwest } \\
\text { Direction }\end{array}$ & $\begin{array}{c}\text { Distance (m) } \\
\text { Cs Migrates in } \\
\text { Southeast } \\
\text { Direction }\end{array}$ & $\begin{array}{c}\text { Distance (m) } \\
\text { Cs Migrates in } \\
\text { Northwest } \\
\text { Direction }\end{array}$ \\
\hline 50 & 198 & 45.7 & 7.6 & 1.5 \\
\hline 100 & 396.2 & 91.4 & 15 & 3 \\
\hline 200 & 792.5 & 182.9 & 30 & 6.1 \\
\hline
\end{tabular}


Rev. 0

5.4.2.3 Conclusions. The risk analysis results show that the future offsite risk associated with the B-5 Reverse Well plume is well below levels of concern because of the relative immobility of the principal contaminants.

\subsubsection{Gable Mountain Pond Plume}

The highest ${ }^{90} \mathrm{Sr}$ concentrations during the period January 1993 through March 1995 were recorded during the most recent sampling of the wells that comprise the Gable Mountain Pond plume. These concentrations were used as input to the risk calculations.

5.4.3.1 Existing Conditions. Strontium-90 is the only COPC for the Gable Mountain Pond plume. The maximum industrial ILCR $\left(1.8 \times 10^{-4}\right)$ is calculated for groundwater at monitoring well $699-53-48 \mathrm{~B}$, which had a ${ }^{90} \mathrm{Sr}$ concentration of $994 \mathrm{pCi} / \mathrm{L}$. The risk contours for the existing plume are shown in Figure 5-32.

5.4.3.2 Future Conditions. Based on EPA's request, the objective of transport modeling was to determine the flow path length at which the maximum ILCR for ${ }^{90} \mathrm{Sr}$ at any location in the plume attenuates to, below $1 \times 10^{-5}$, as the plume migrates to the northwest. Modeling results are tabulated as follows:

\begin{tabular}{|l|c|c|}
\hline & Industrial & Residential \\
\hline $\begin{array}{l}\text { Maximum }{ }^{90} \mathrm{Sr} \text { source concentration } \\
\text { (existing plume), pCi/L }\end{array}$ & 1,008 & 1,008 \\
\hline $\begin{array}{l}\text { Travel time to reach } 1.0 \times 10^{-5} \\
\text { ILCR, yr }\end{array}$ & 79 & 127 \\
\hline $\begin{array}{l}\text { Travel distance to reach } 1.0 \times 10^{-5} \\
\text { ILCR, m }\end{array}$ & 914.4 & 1,372 \\
\hline $\begin{array}{l}{ }^{90} \mathrm{Sr} \text { concentration at } 1.0 \times 10^{-5} \\
\text { ILCR, pCi/L }\end{array}$ & 57 & 13 \\
\hline
\end{tabular}

The risk contours for the plume based on future conditions are shown in Figure 5-32.

5.4.3.3 Conclusions. The risk analysis results show that the Gable Mountain Pond plume will migrate slowly toward the northwest, but the principal contaminant ${ }^{90} \mathrm{Sr}$ will decay to negligible levels before the plume travels a significant distance.

\subsection{UNCERTAINTIES AND DATA NEEDS}

This section identifies the uncertainties in the conceptual model for each plume in the 200-BP-5 Operable Unit and the data needs that were recognized during the treatability test operations and associated groundwater studies. 
DOE/RL-95-59

Rev. 0

\subsubsection{6-B-5 Reverse Well Plume}

The major uncertainty in the conceptual model of the B-5 Reverse Well Contaminant Plume is the physical-chemical form of the contaminants. The contaminants at the B-5 Reverse Well are expected to be highly insoluble, but this cannot be confirmed from physical samples. The anions present in the aquifer that combined with the plutonium, cesium, and strontium cations determine the solubility of the plume source. This, along with the character of the aquifer sediments and groundwater flow, may control the mobility and concentration of the contaminant plume. Physical samples from drill cuttings or core are needed to determine the $\mathrm{K}_{\mathrm{d}} \mathrm{s}$ of the contaminant source material.

Adequate monitoring well coverage and sampling are needed at the B-5 Reverse Well location to ensure detection of migration of the contaminant plume in any direction. The B-5 Reverse Well is located in an area with a very flat groundwater gradient, and no preferential flow direction has been defined. Groundwater flow to the southeast was recognized during the early years of plant operations. Currently, wells to the south and southeast of the B-5 Reverse Well (wells 299-E28-14 and 299-E28-4) are not in sample-ready condition and could not detect contamination spread in those directions. A series of monitoring wells constructed closer to the B-5 Reverse Well would provide an early warning if the contaminants were more mobile than expected.

\subsubsection{6-BY Cribs Contaminant Plume}

The first uncertainty about the BY-Cribs plume is the conceptual model for this plume and whether pockets of more highly concentrated contaminants are contributing to the growth of the plume. As discussed in Section 5.3.2, there are at least two models with which to explain the distribution of contaminants within the current plume. The existence of high-activity contaminants in sediments or basalt fractures near or currently above the water table or as dense solutions within basalt fractures at the bottom of the aquifer remains uncertain.

The remaining uncertainty is the location of any preferential groundwater flowpath within the plume. The BY-Cribs plume is relatively confined and thin, due in part to the configuration of the surface of the underlying basalt. Erosion of the upper surface of the basalt may have resulted in basalt highs that divert the flow of groundwater or, conversely, erosional channels that tend to provide preferential flow paths for the groundwater. These erosional channels might be the optimal target for extraction well locations because of the potential increased aquifer thickness.

The continued monitoring of the BY-Cribs plume will remain a data need as regular monitoring will be necessary to detect changes in the plume configuration or concentration.

\subsubsection{6-A-25 Gable Mountain Pond Plume}

There is uncertainty about groundwater flow at the Gable Mountain Pond plume and the potential for contaminant migration before radioactive decay reduces its level of risk. The monitoring well network at the Gable Mountain Pond appears to be adequate to recognize contaminant migration, but should be confirmed by flow modeling. In addition, a regular sampling program must be maintained. 
DOE/RL-95-5̄9

Rev. 0

Figure 5-1. 200 East Processing Areas.

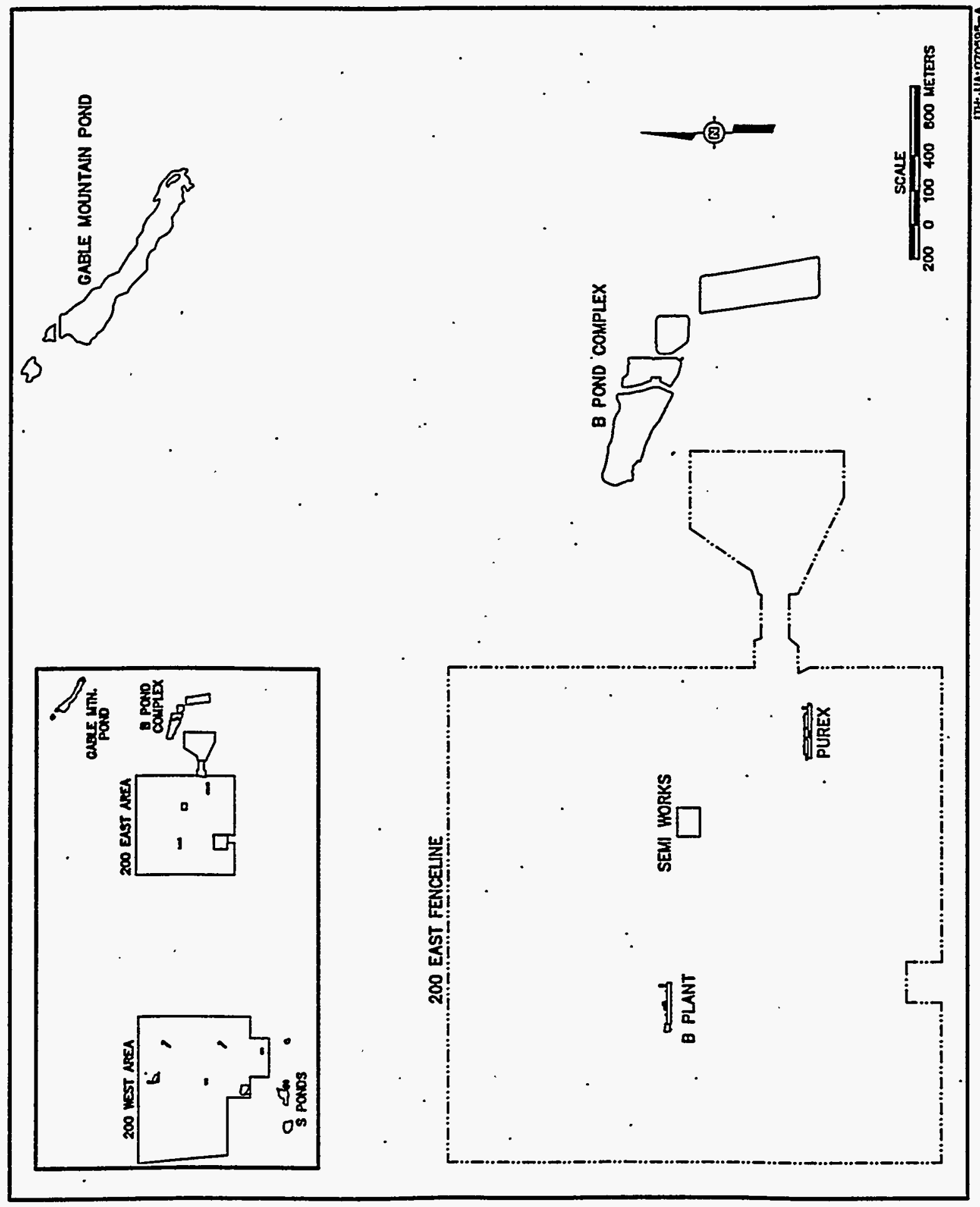


DOE/RL-95-59

Rev. 0

Figure 5-2. 200 West Processing Areas.

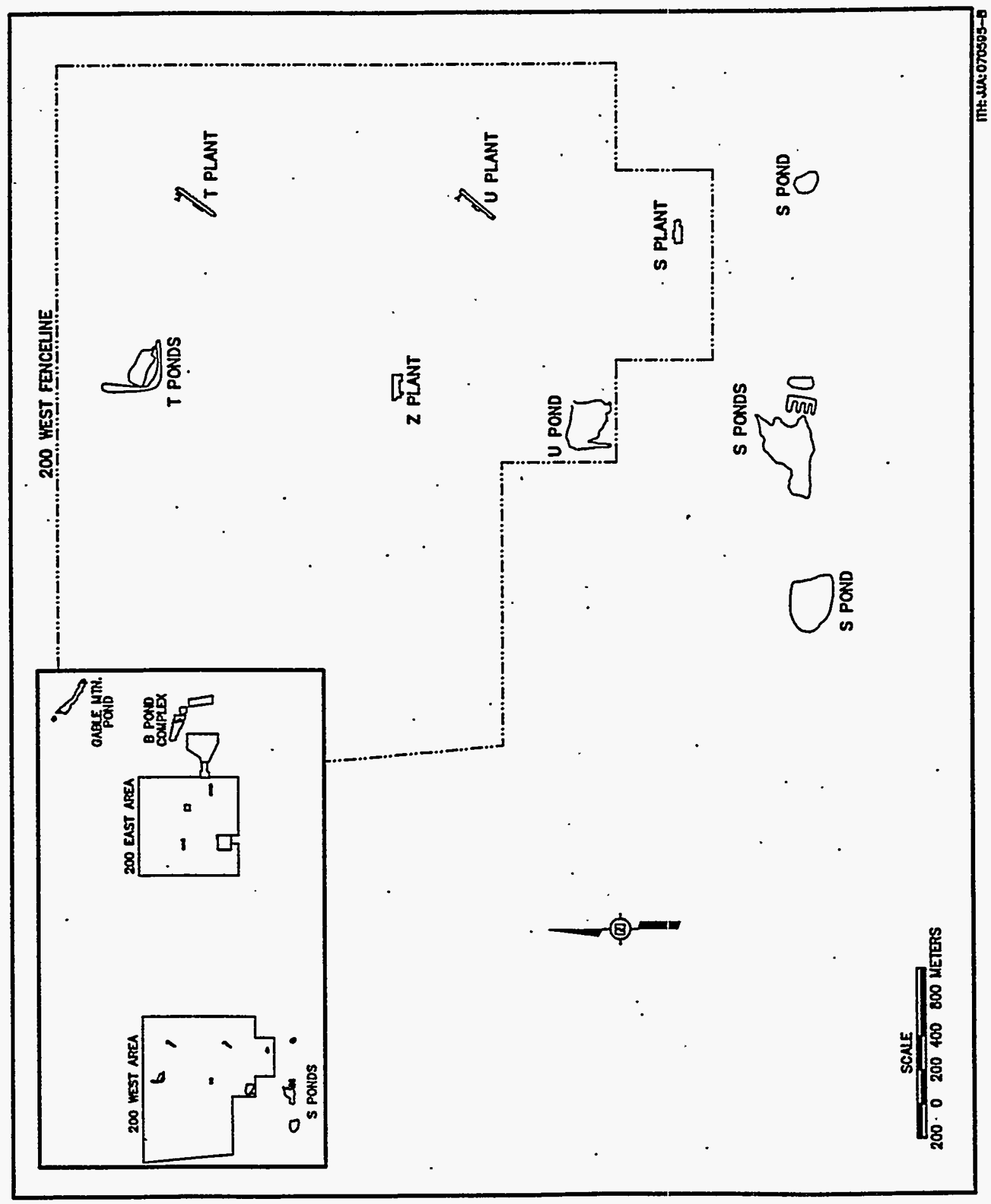




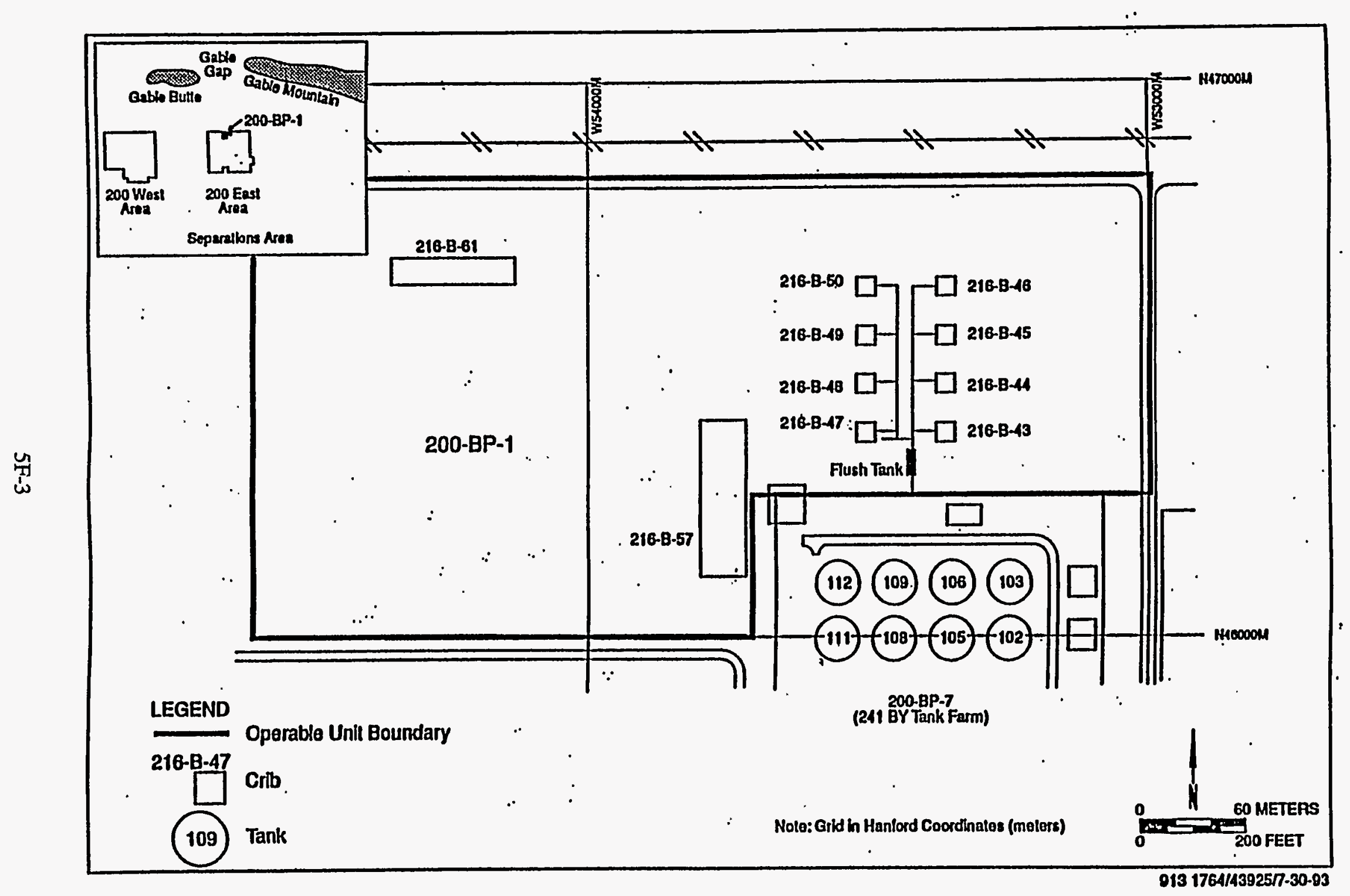


Figure 5-4. Estimated Annual Discharge (in liters) to Gable Mountain Pond (216-A-25), and B Pond System (216-B-3 Ponds), 200 East Area, 1945 to 1994.

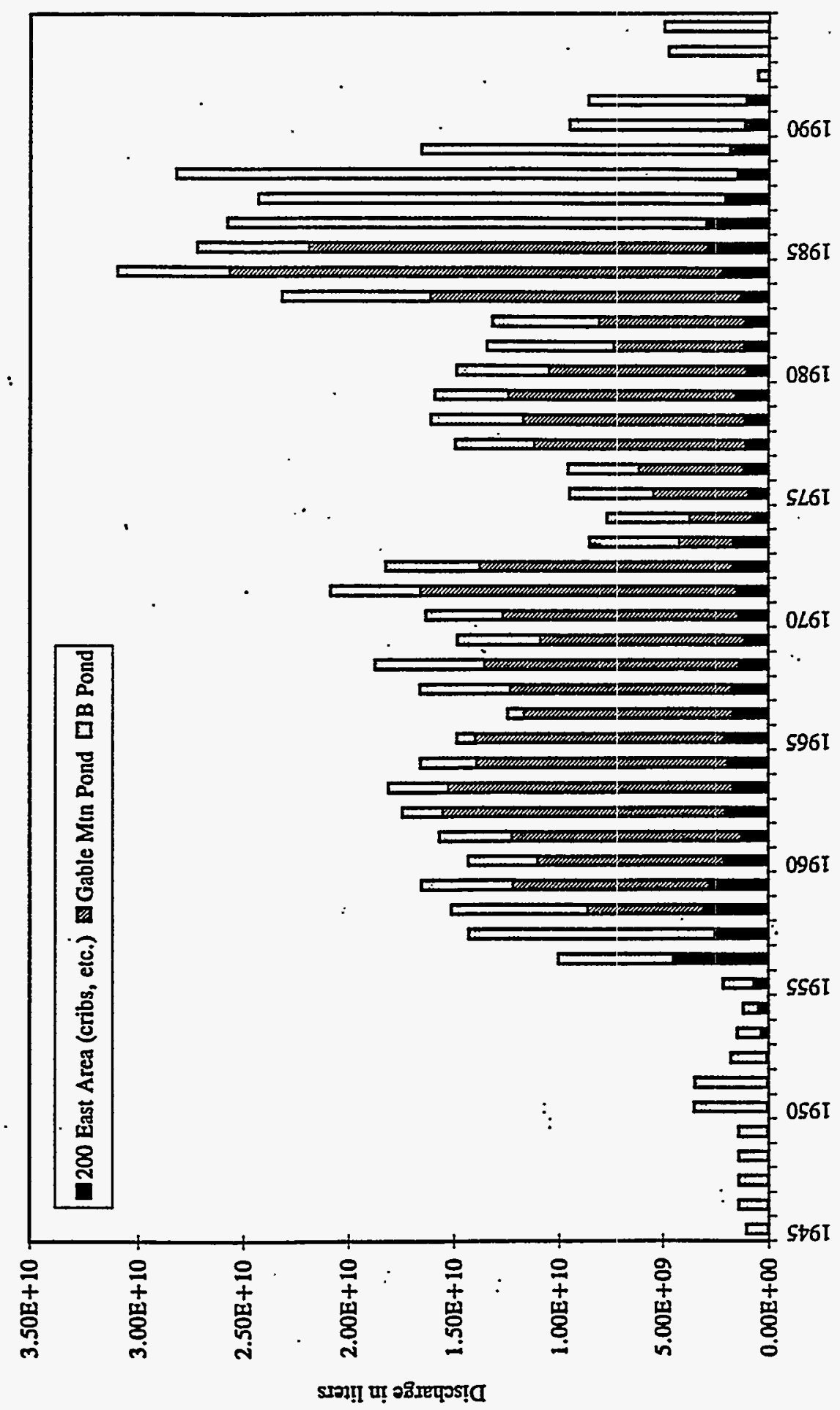




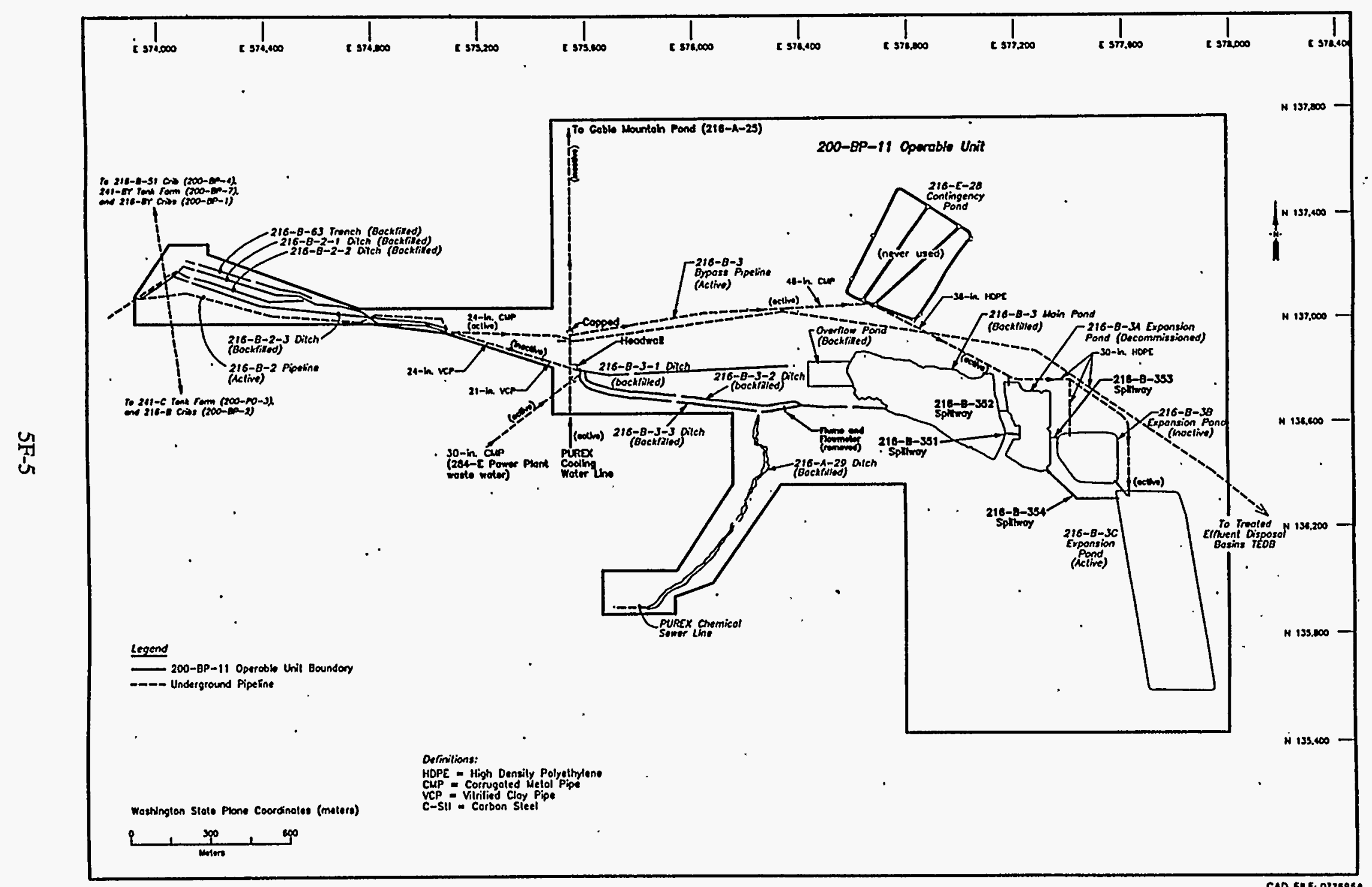

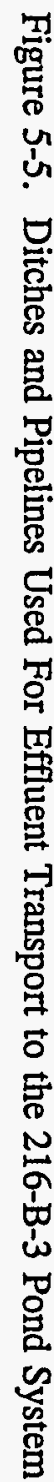

总 


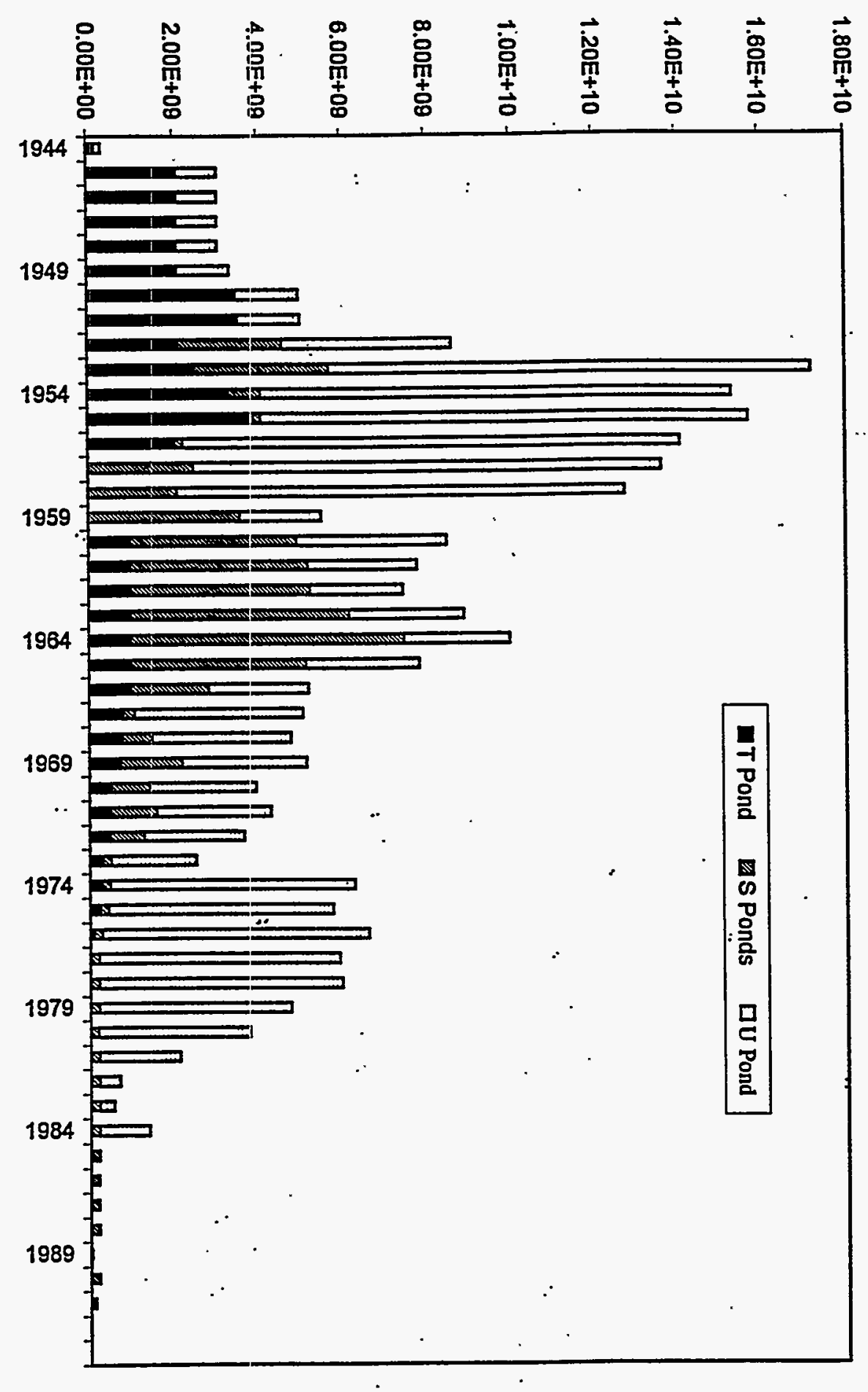

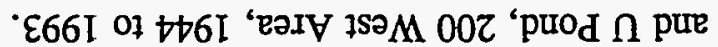

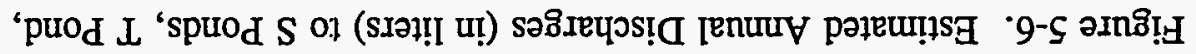


Figure 5-7. Estimated Annual Discharge (in liters) to S Plant, T Plant, U Plant, and Z Plant, 1944 to 1993.

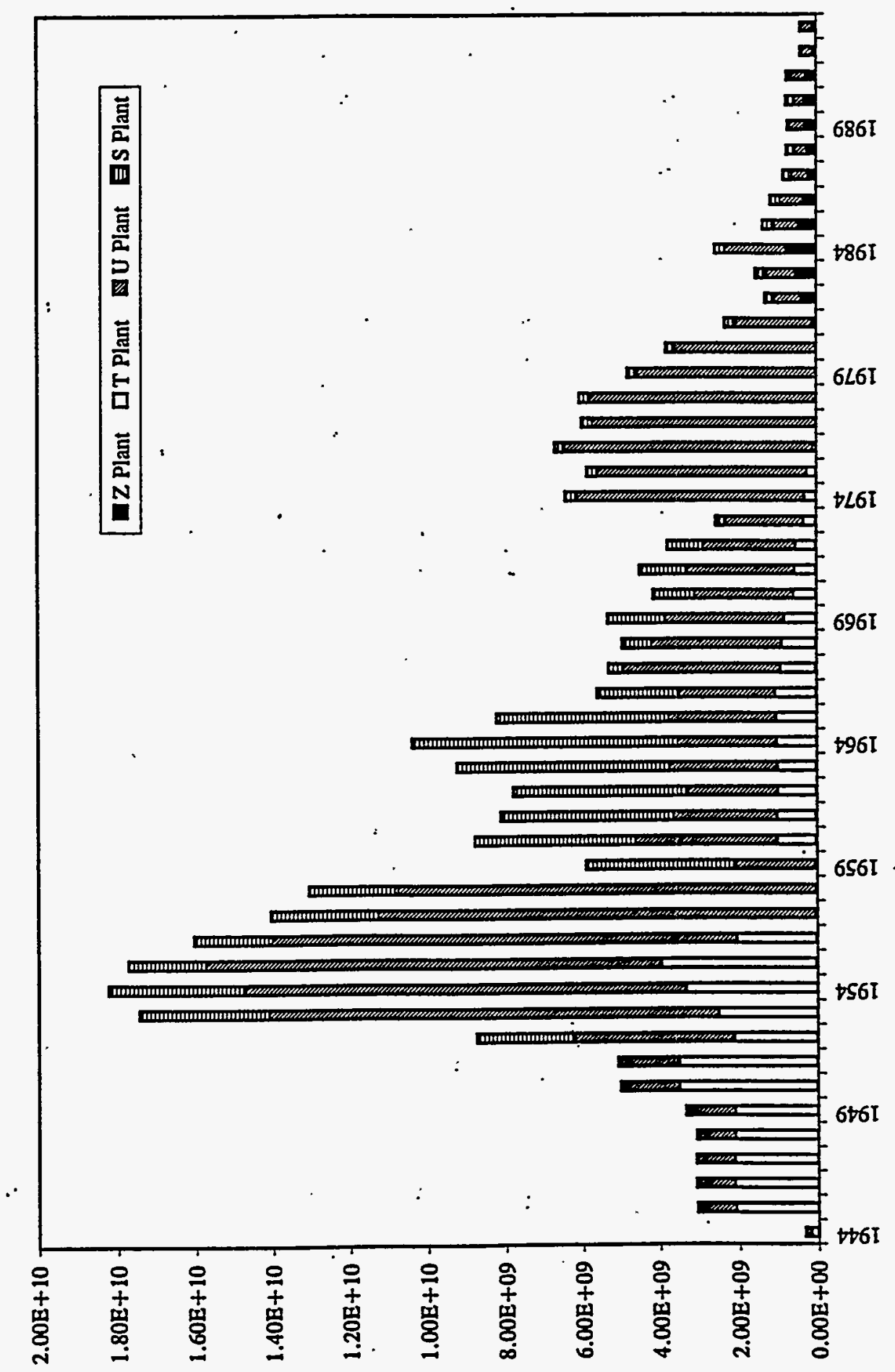


Rev. 0

Figure 5-8. Estimated Effluent Discharge Volumes to 216-B-3 Pond, 216-A-25 Gable Mountain Pond, and 200 East Area Total.

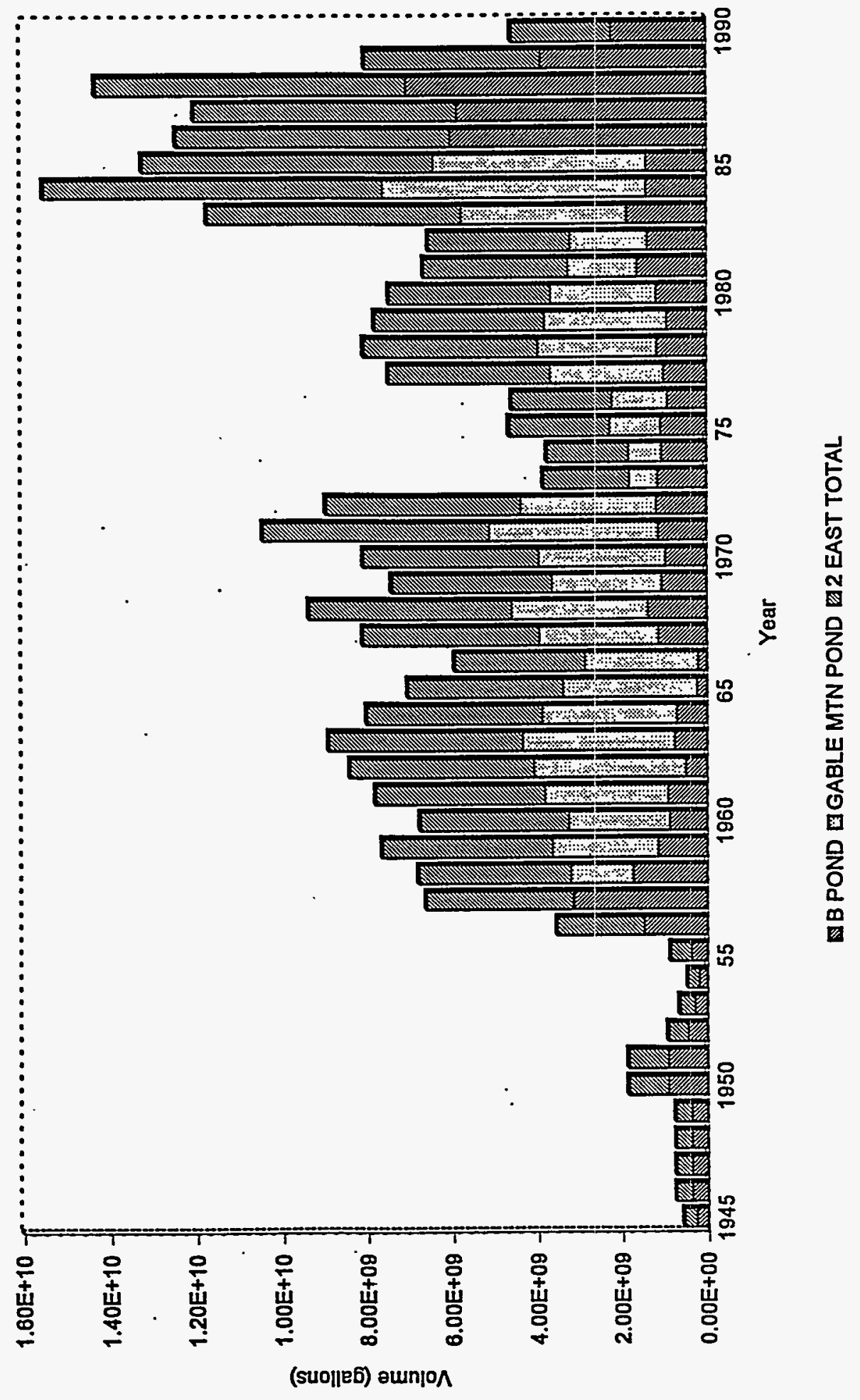




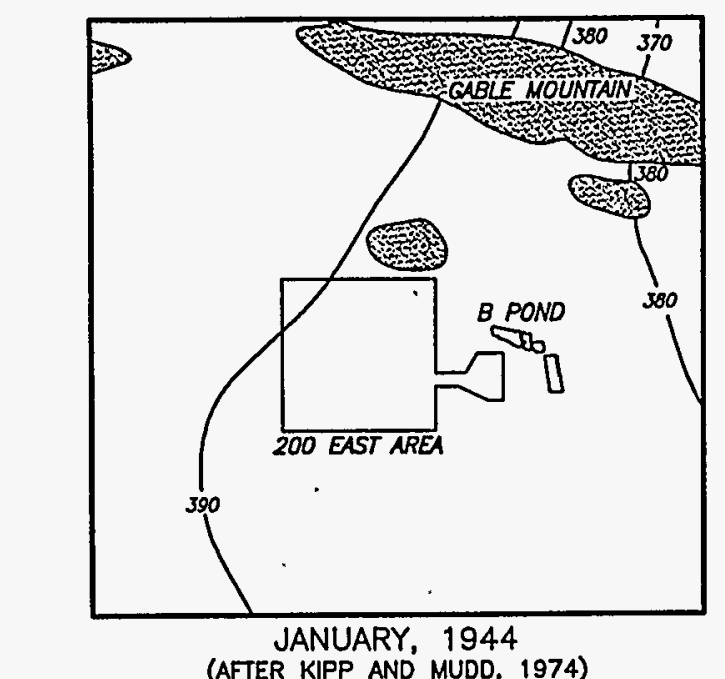

ไึ

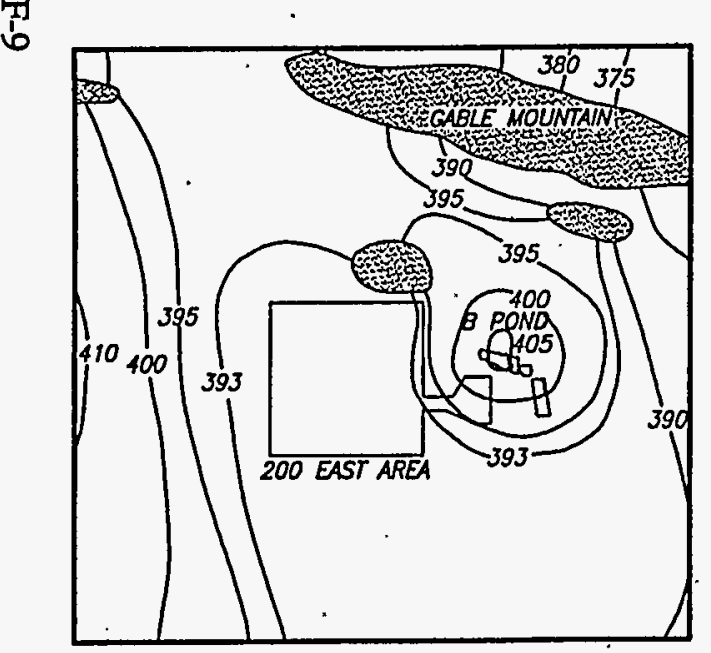

MARCH, 1951

. (AFTER KIPP AND MUDD, 1974)

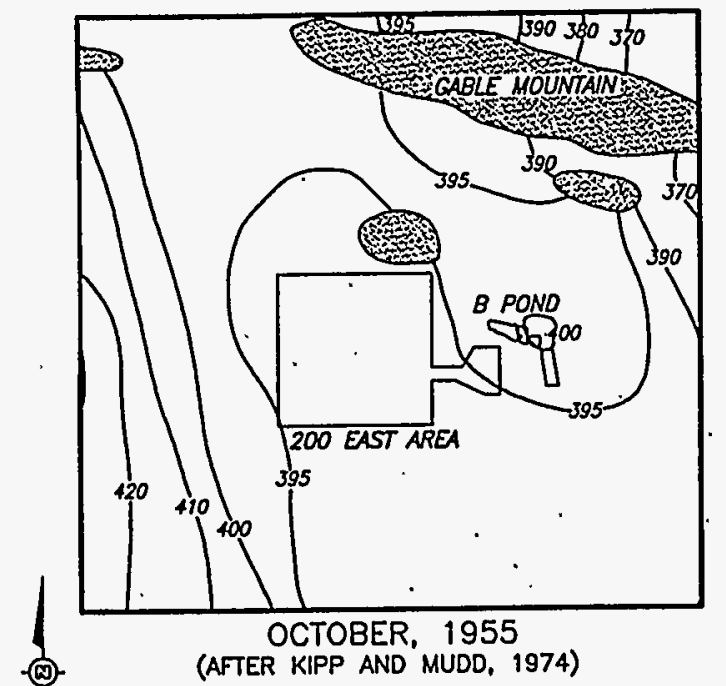

(․)

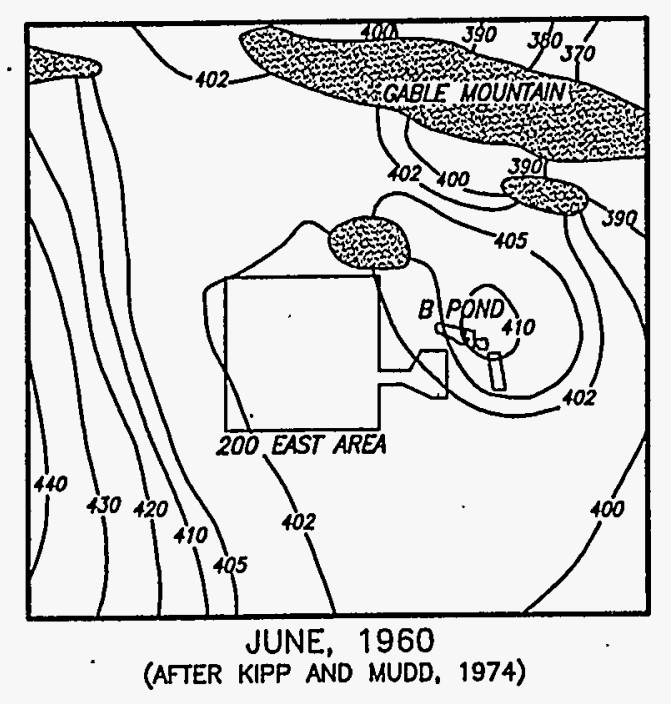

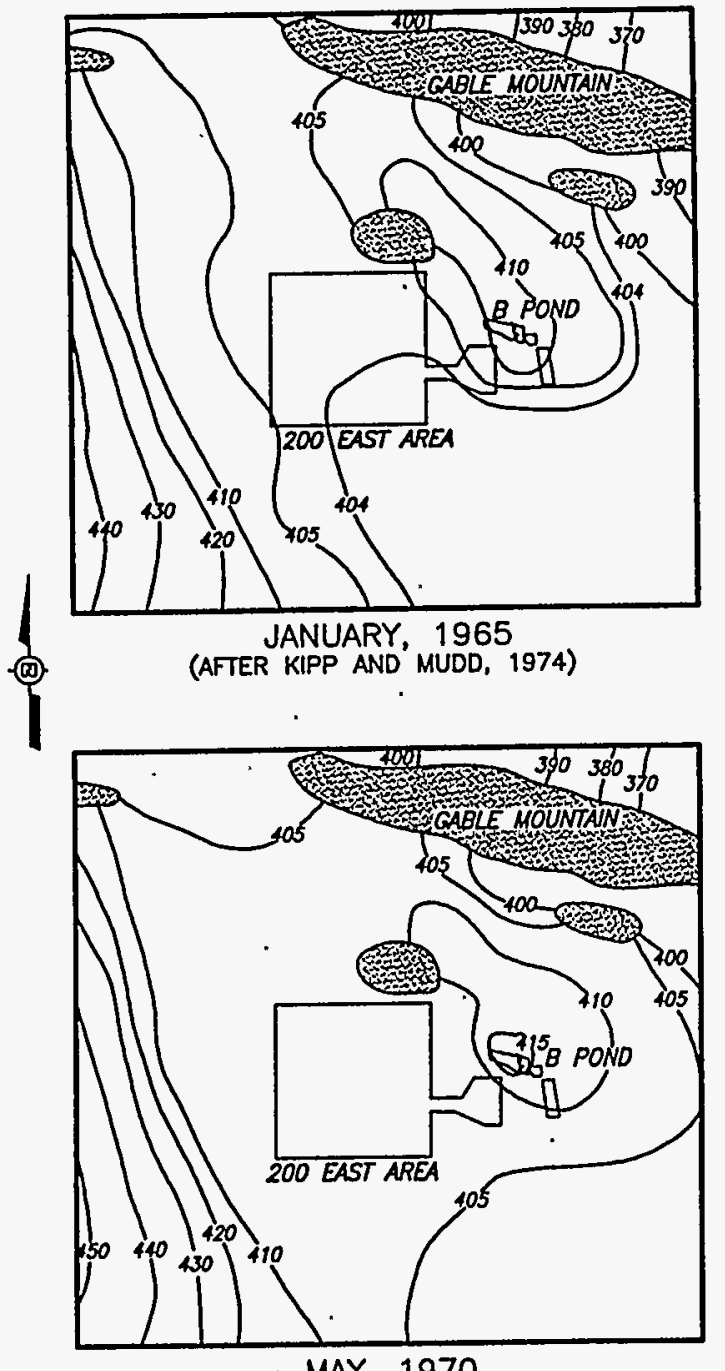

. (AFTER KIPP AND MUDD, 1974) 


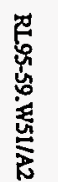
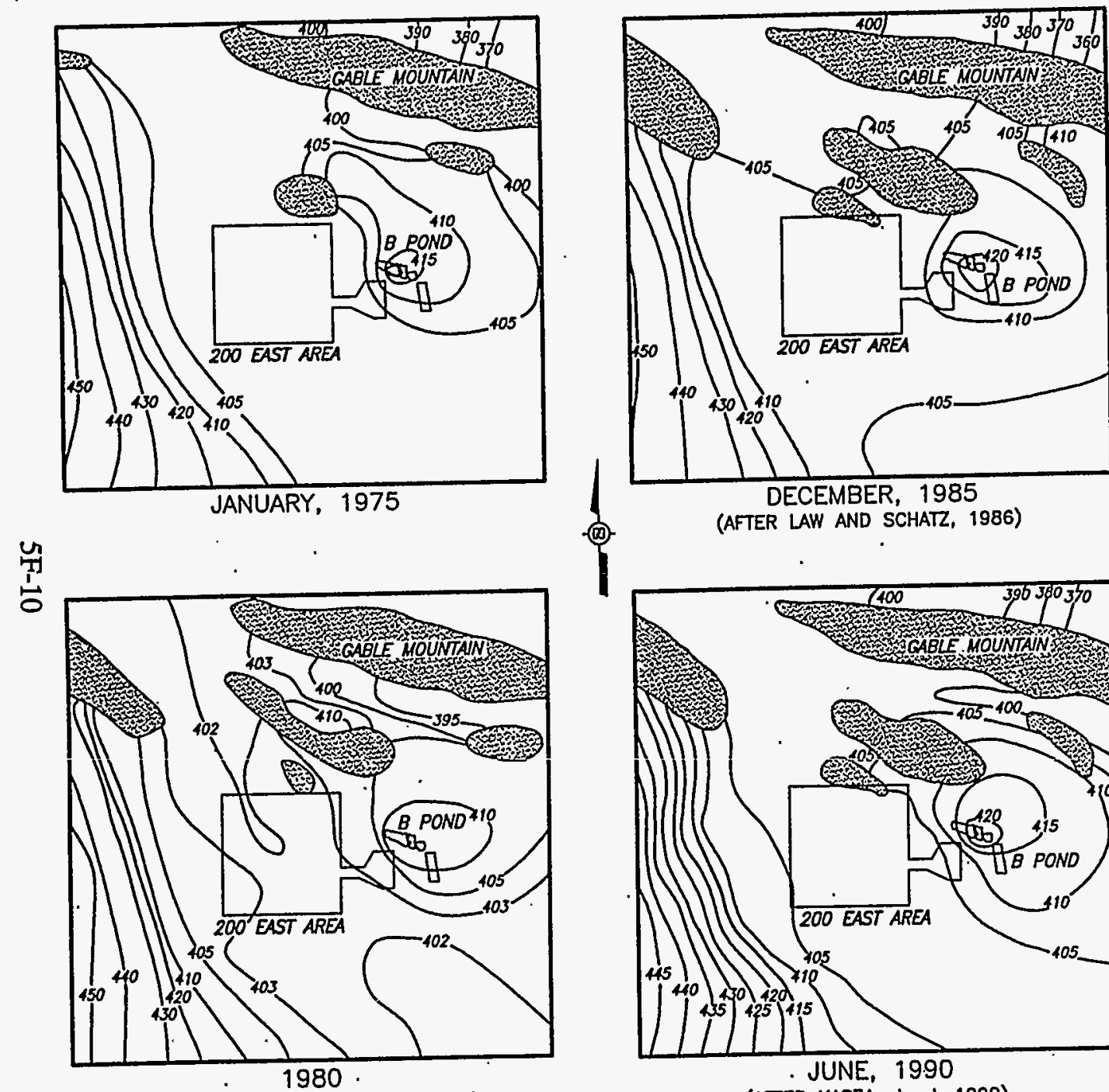

(ATTER GRAHAM AND BROWN, 1981) (⿴囗十)
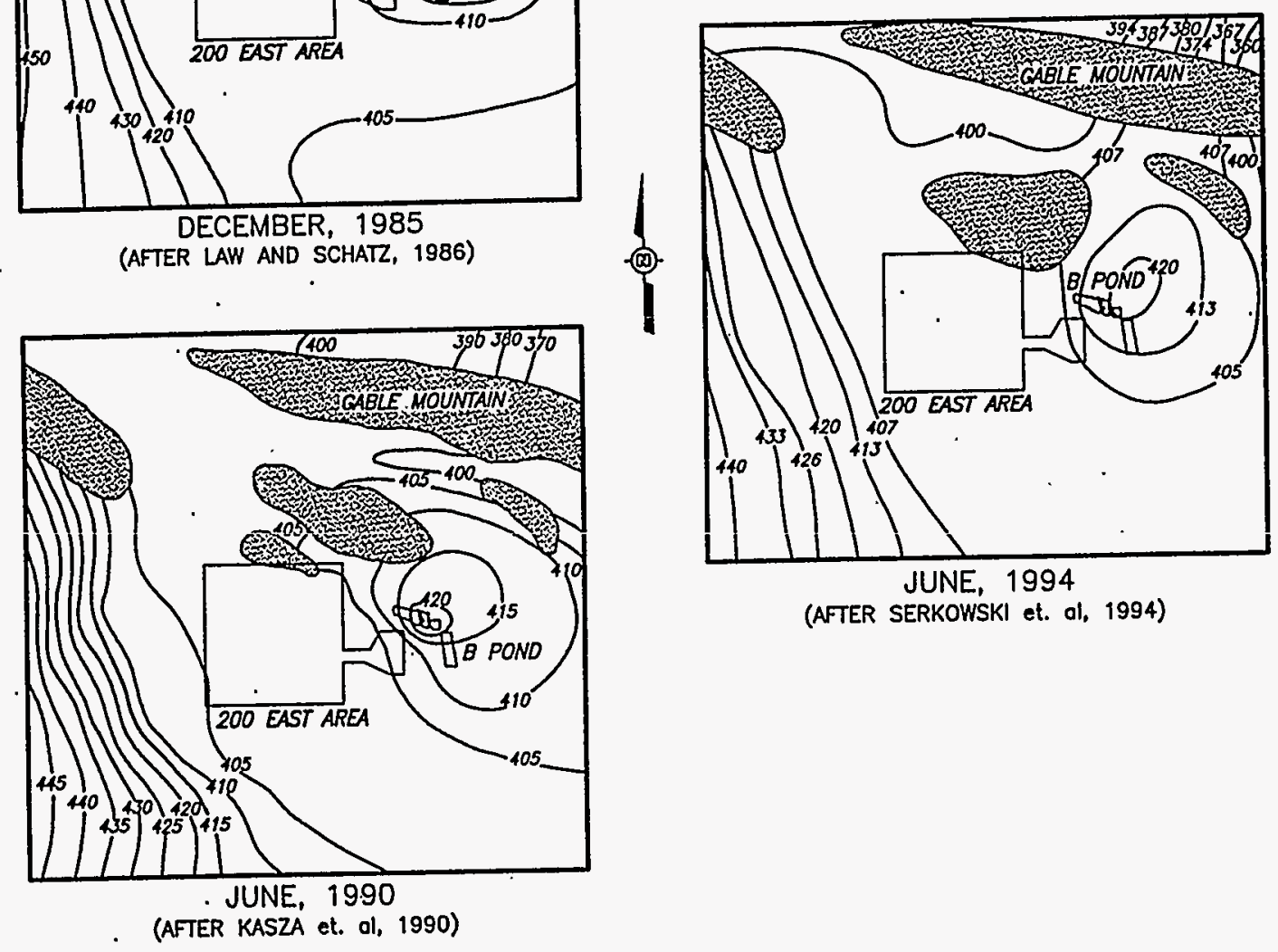

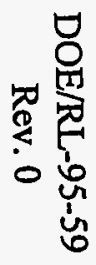

(ATTER SERKOWSKI et. al, 1994) 

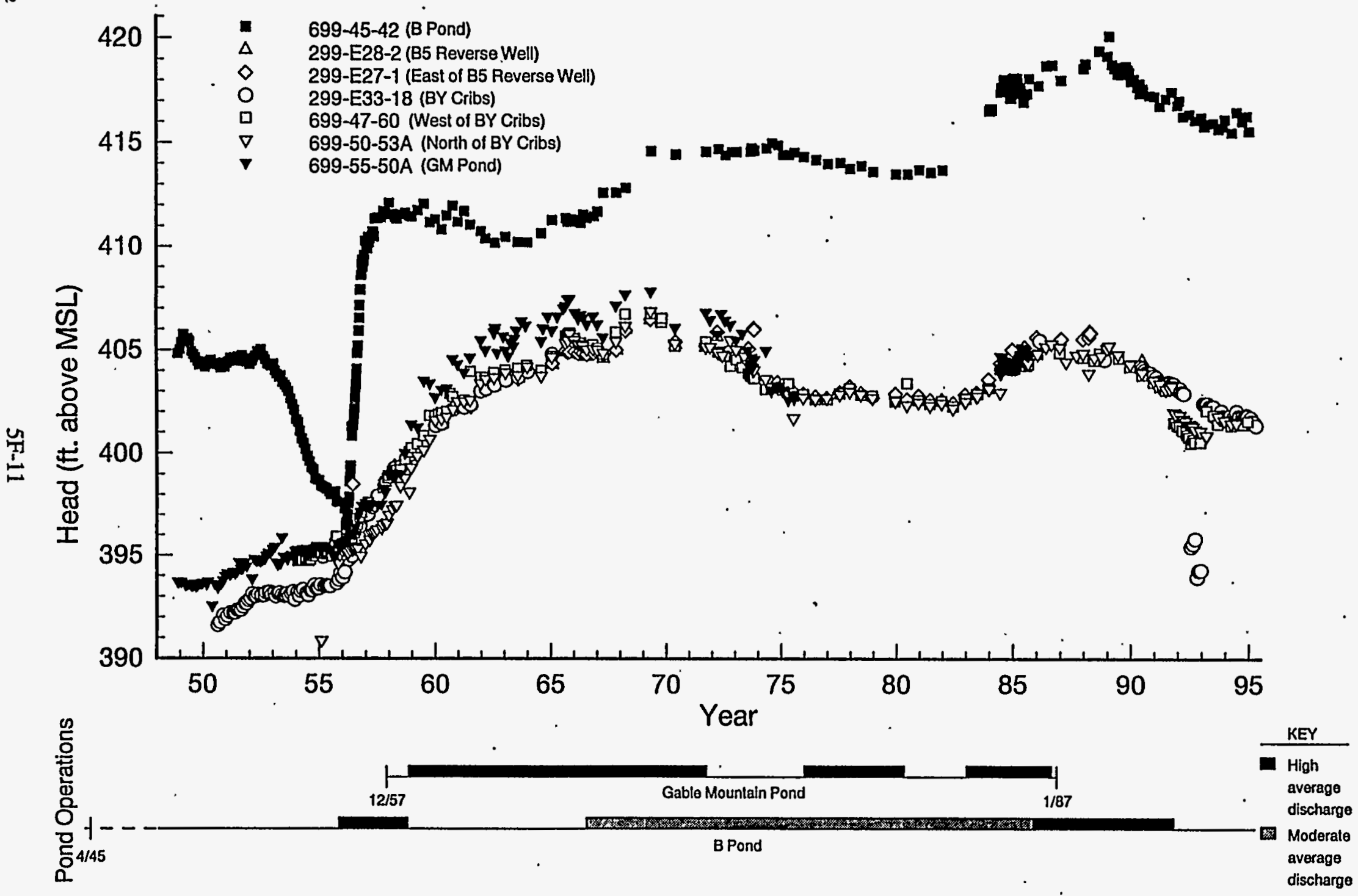

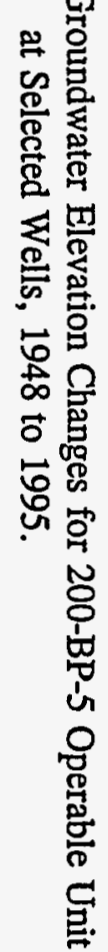




\section{DOE/RL- $9 \overline{5}-\overline{5}$}

Rev. 0

Figure 5-11. Streamline Analysis for 200 East Area, 1993.

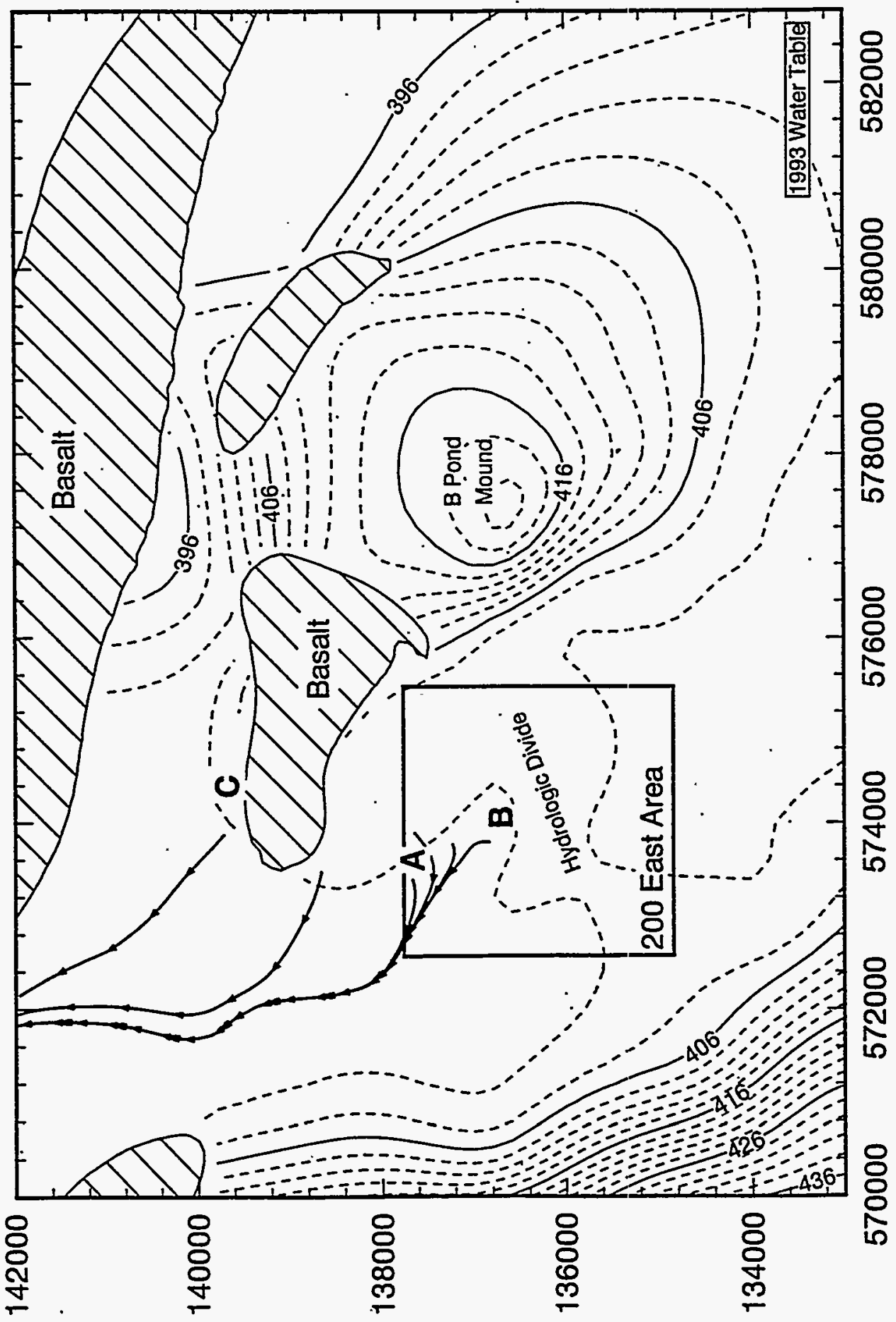


DOE/RL-95-59

Rev. 0

Figure 5-12. Historic Gross Beta Distribution Maps in 200 Areas, 1956 to 1992. (4 Sheets)

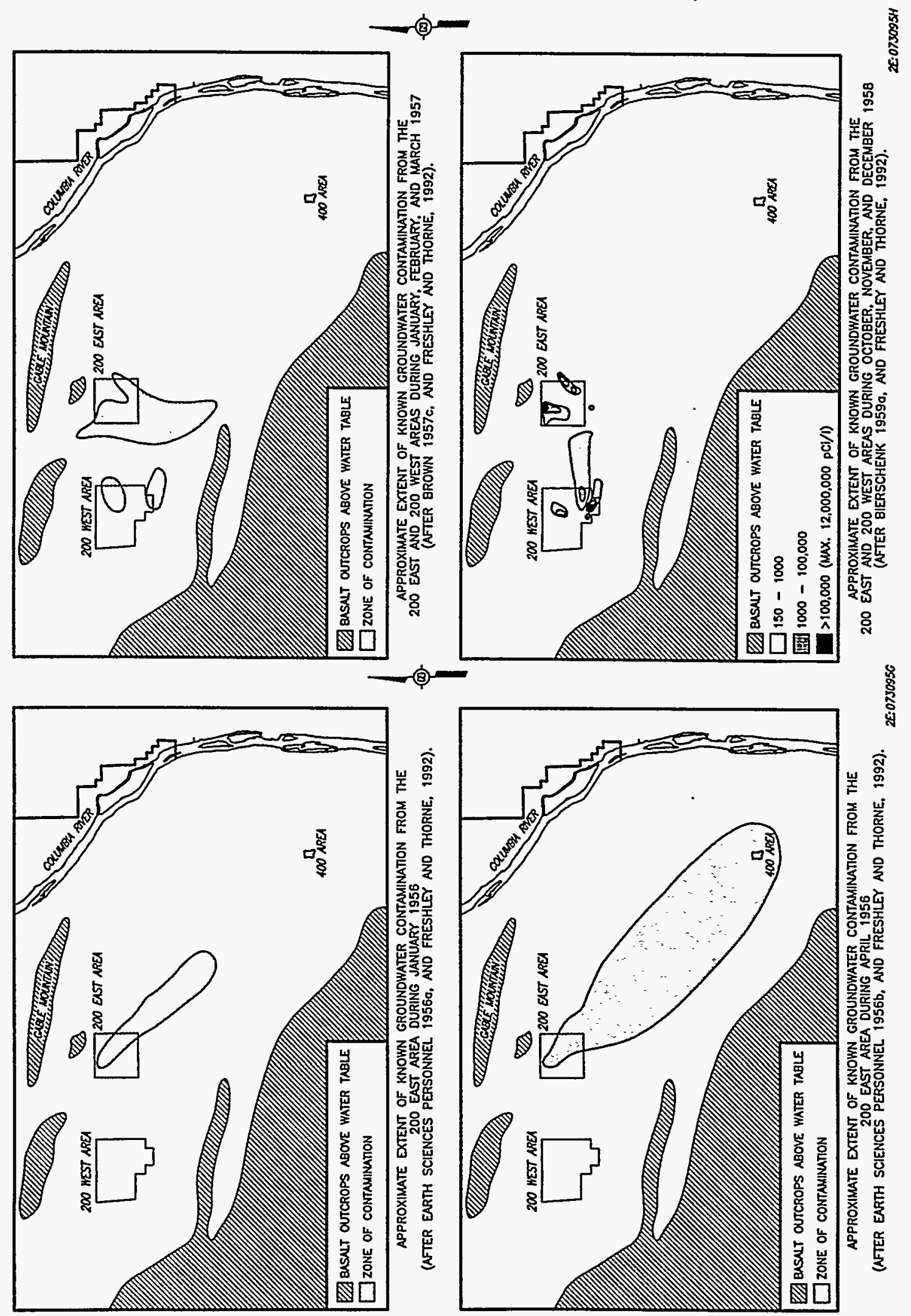




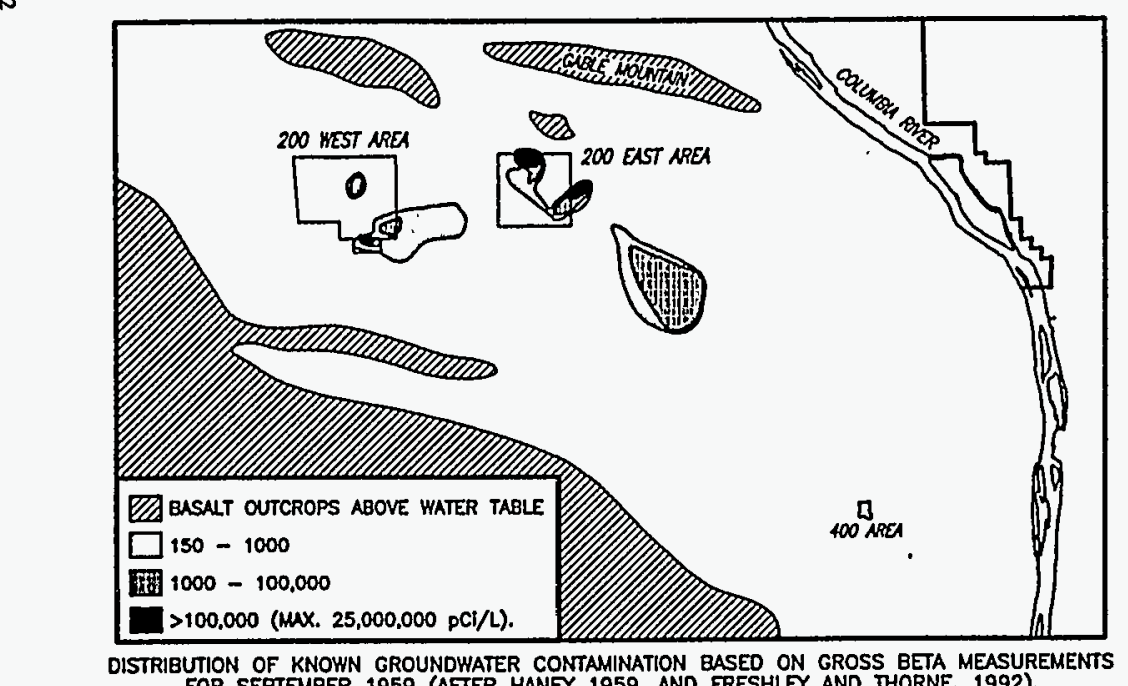

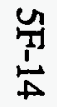

DISTRIBUTION OF KNOWN GROUNDWATER CONTAMINATION BASED ON GROSS BEA MEASUREM
FOR SEPTEMEER 1959 (ATER HANEY 1959, AND FRESHLLY AND THORNE, 1992).

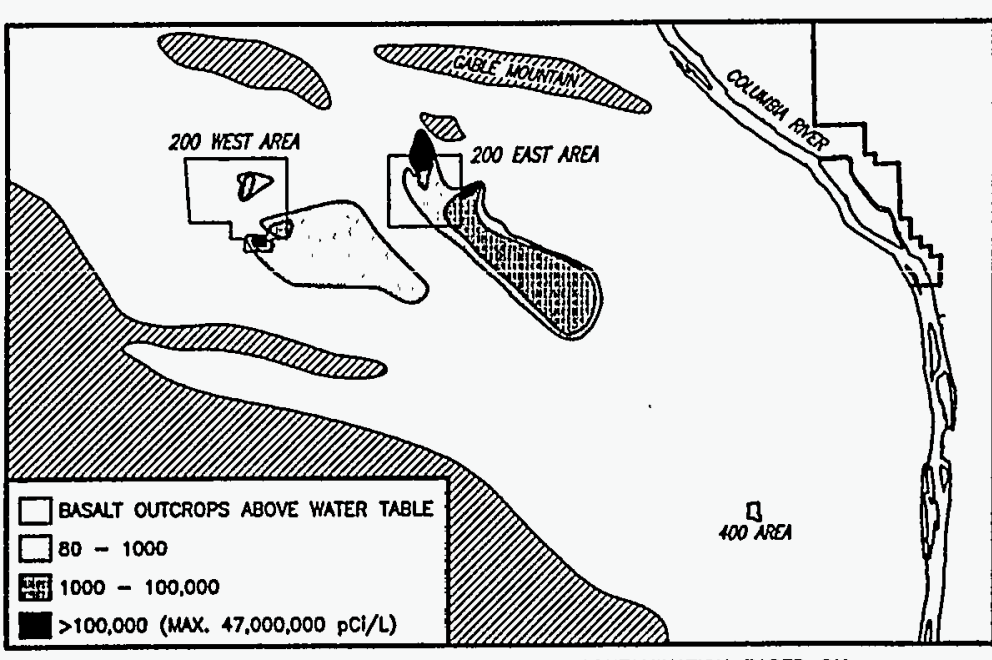

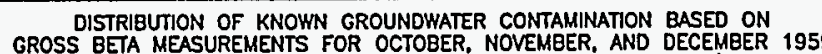
(ATTER HANEY 1960a, AND FRESHLEY AND THORNE, 1992).

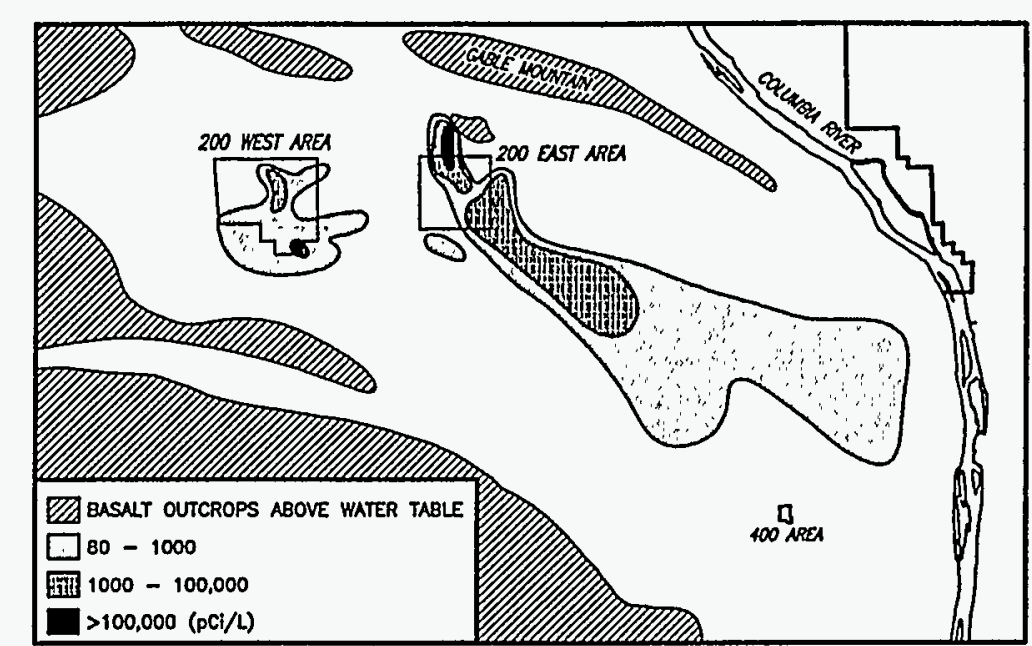

DISTRIBUTION OF AVERAGE GROSS EETA CONCENTRATIONS IN THE UNCONFINED AQUIFER DURING

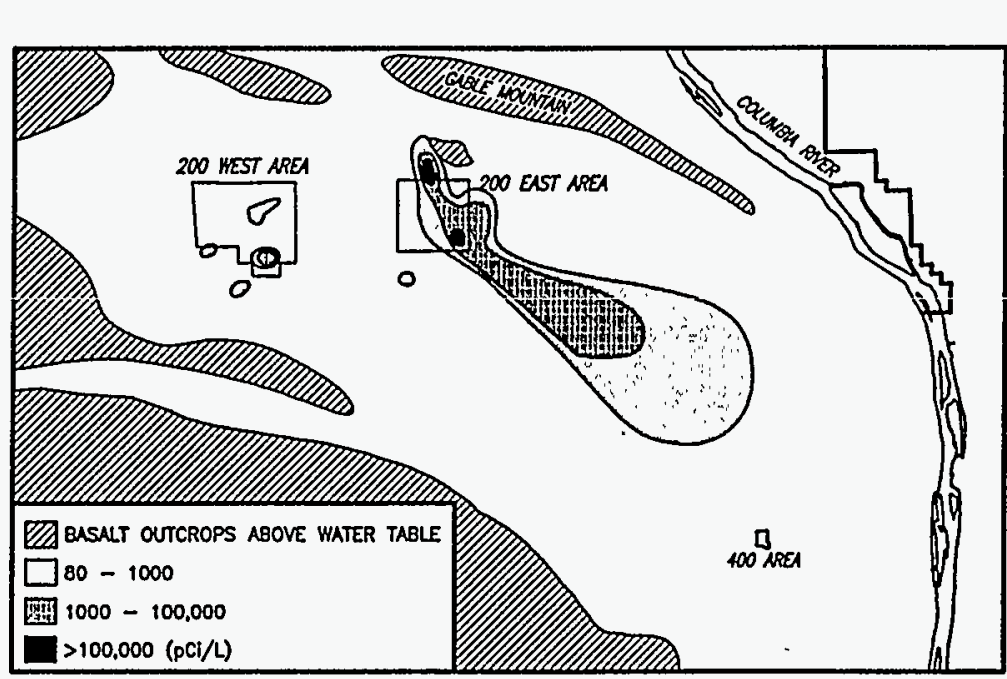

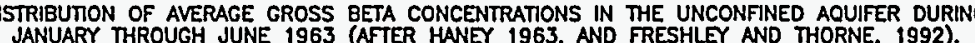
25:075095/ 
DOE/RL-95-59

Rev. 0

Figure 5-12. Historic Gross Beta Distribution Maps in 200 Areas, 1956 to 1992. (4 Sheets)

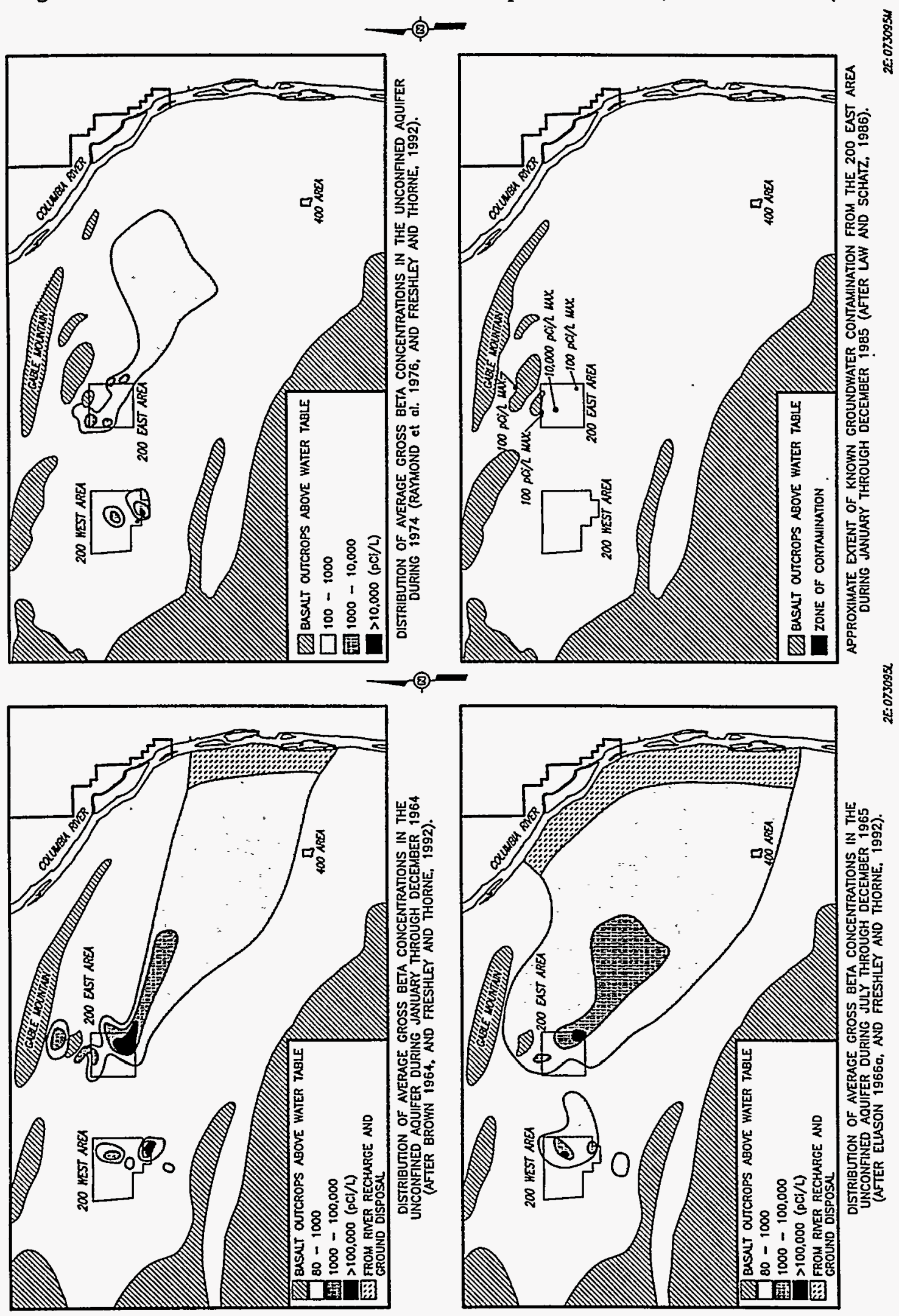


DOE/RL-95-59

Rev. 0

Figure 5-12. Historic Gross Beta Distribution Maps in 200 Areas, 1956 to 1992. (4 Sheets)

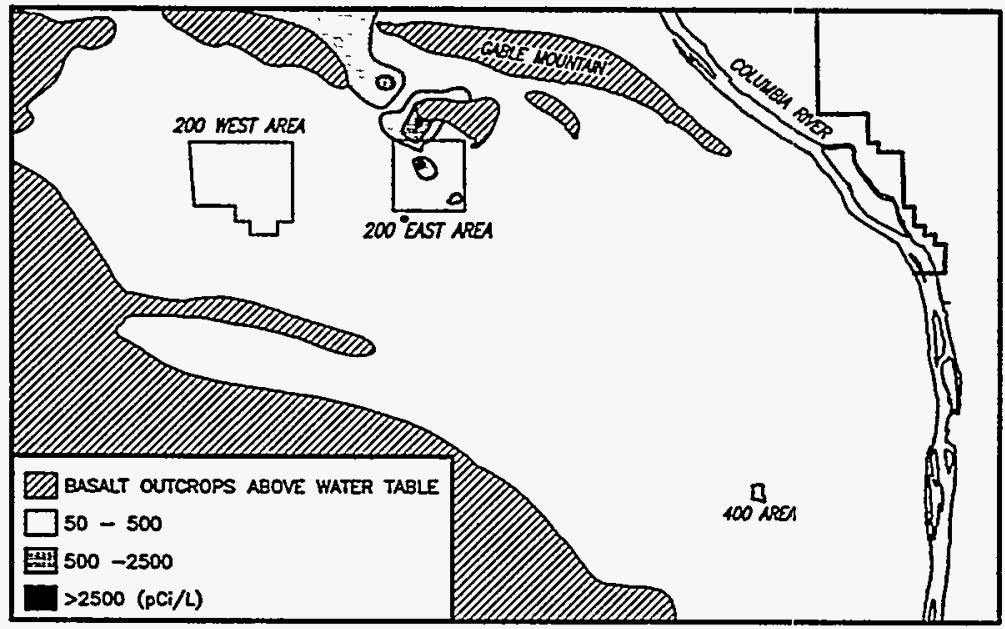

APPROXIMATE EXTENT OF KNOWN GROUNDWATER CONTAMINATON FROM THE 200 EAST AREA DURING 1990 THROUGH 1992 (ATTER FORD, 1993) 
DOE/RL-95-59

Rev. 0

Figure 5-13. Well and Facility Locations, 216-B-5 Reverse Well.

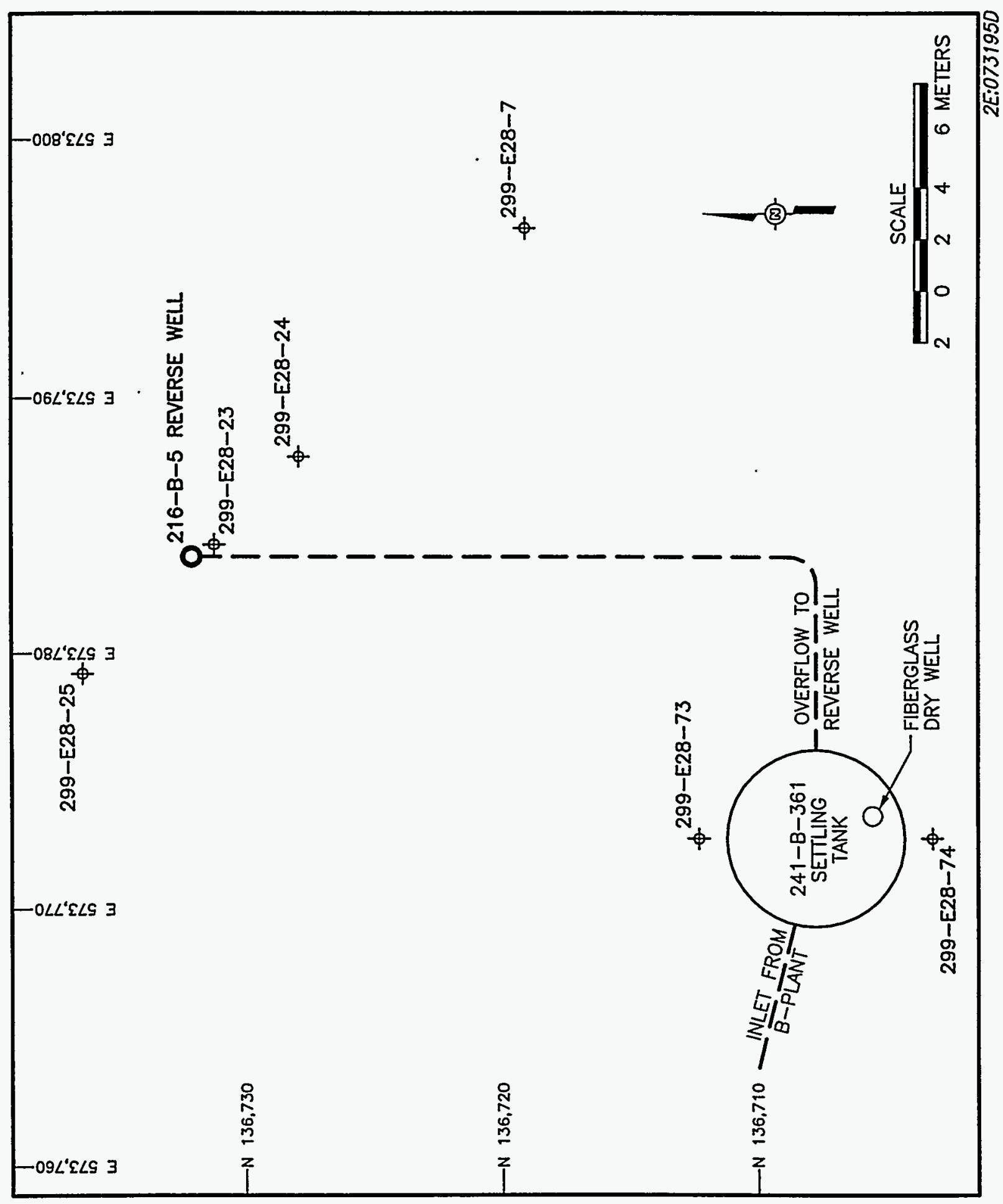




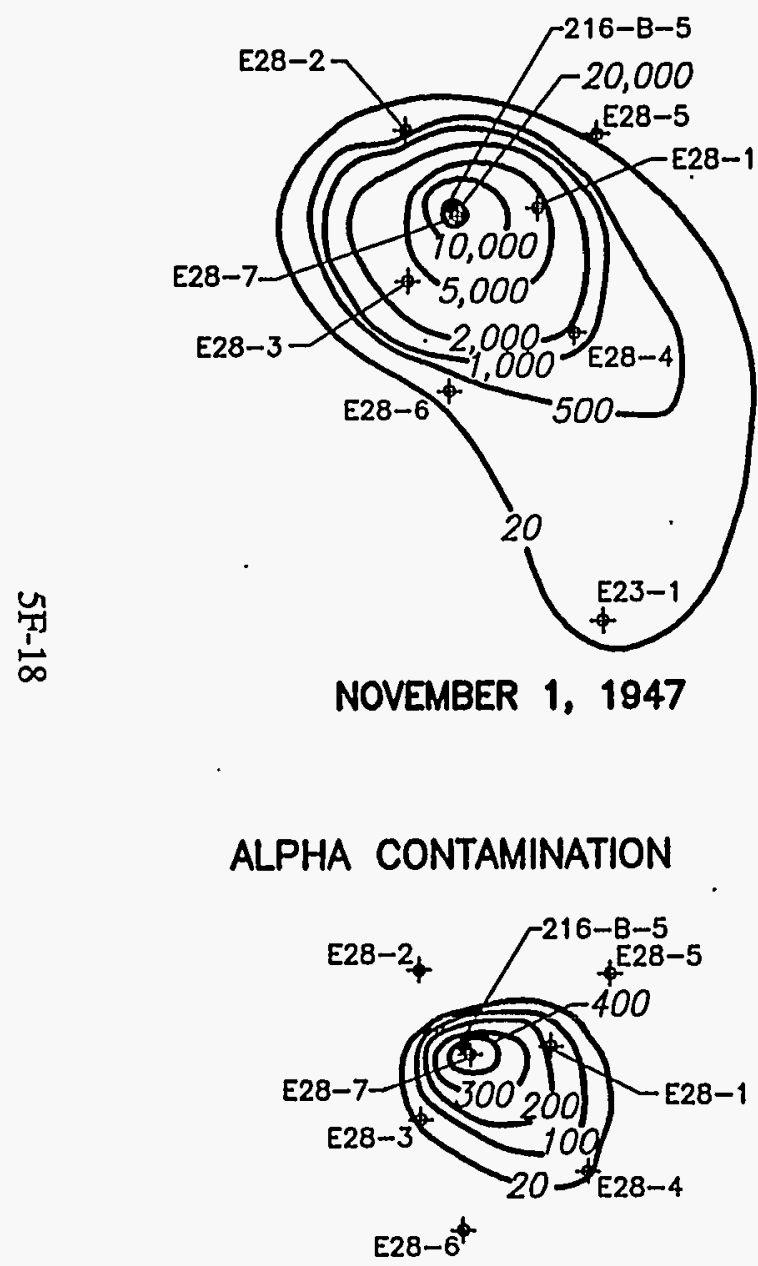

NOVEMBER 1, 1947

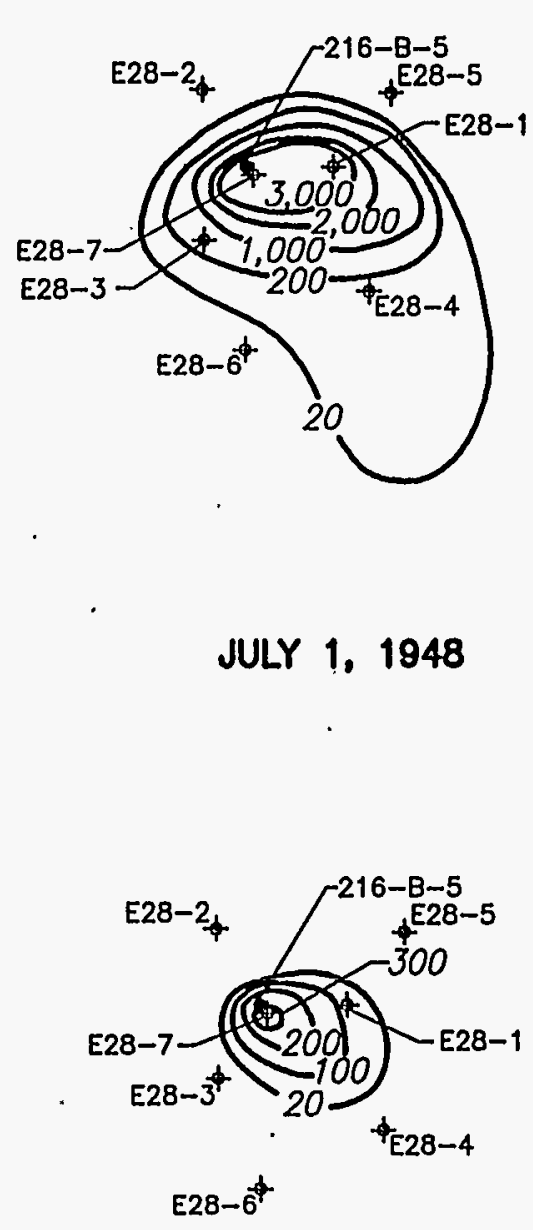

JANUARY 1, 1949

JULY 1, 1949

CONTOUR INTERVAL AS INDICATED ACTIVITY MEASURED IN PCi FISSION PRODUCTS PER LITER OF WATER. AND OF ACTIMTY CHOSEN AT 20 PCI/LITER AND 10 DIS/ MIN LTTER FOR FISSION PRODUCTS AND URANIUM RESPECTNELY.

+ WELLS TO WATER

JULY 1, 1949 

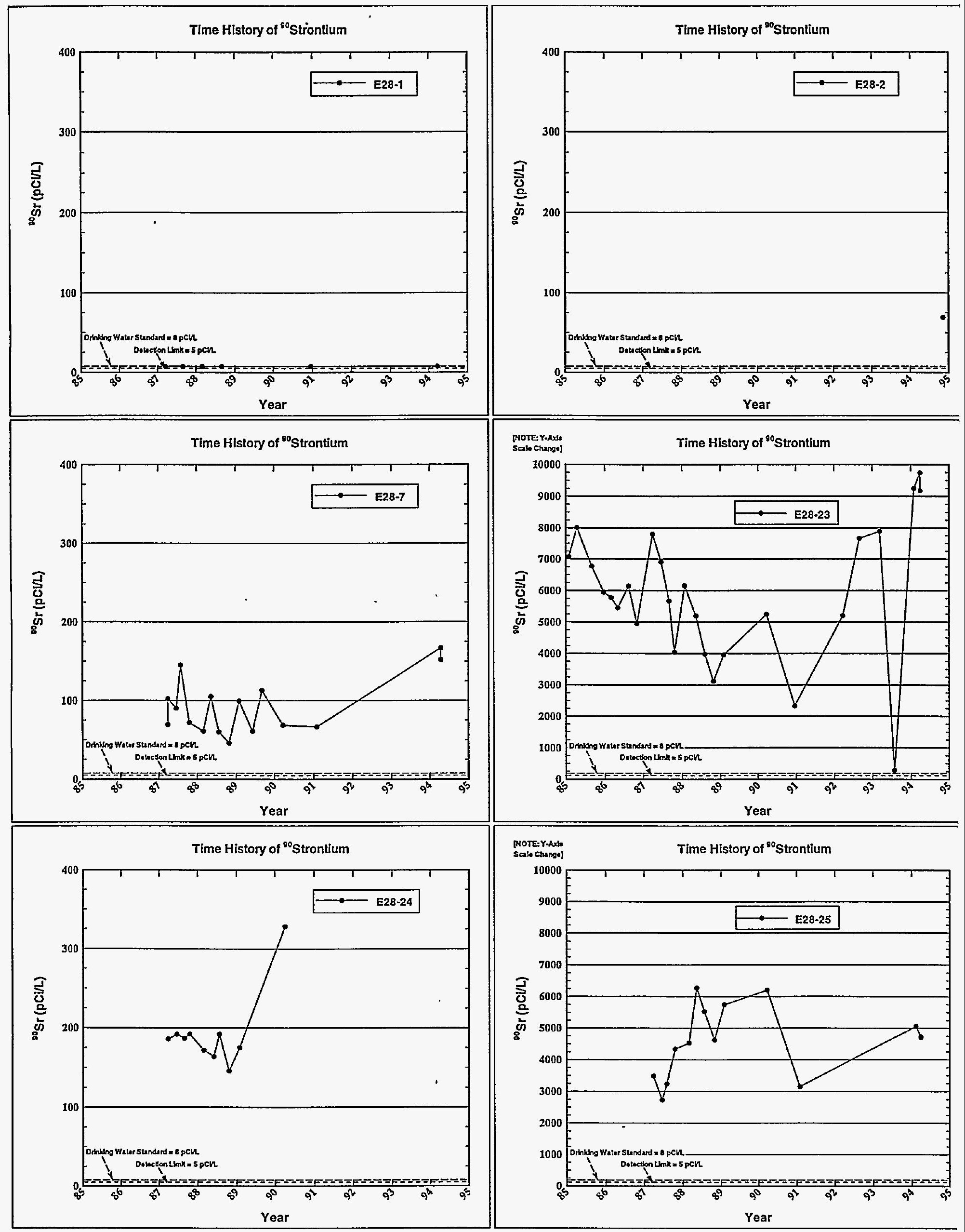


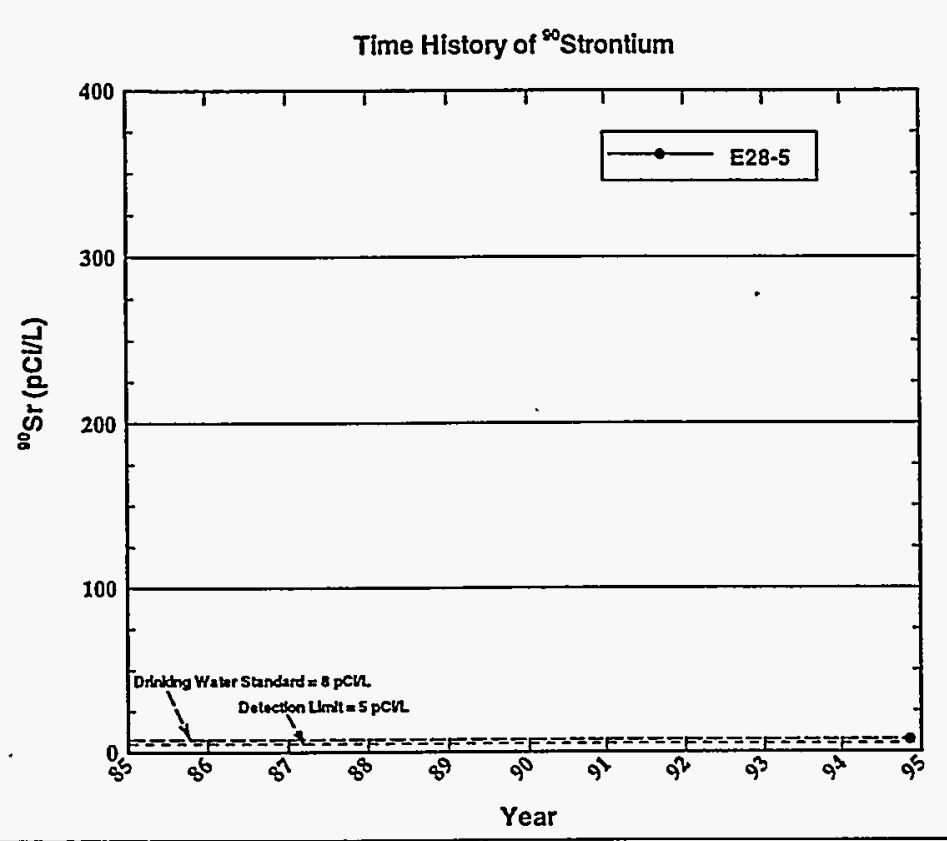

DOE/RL-95-59

Rev. 0

Figure 5-15. Strontium-90 Concentrations in Wells at the 216-B-5 Reverse Well, 1985 to 1994.

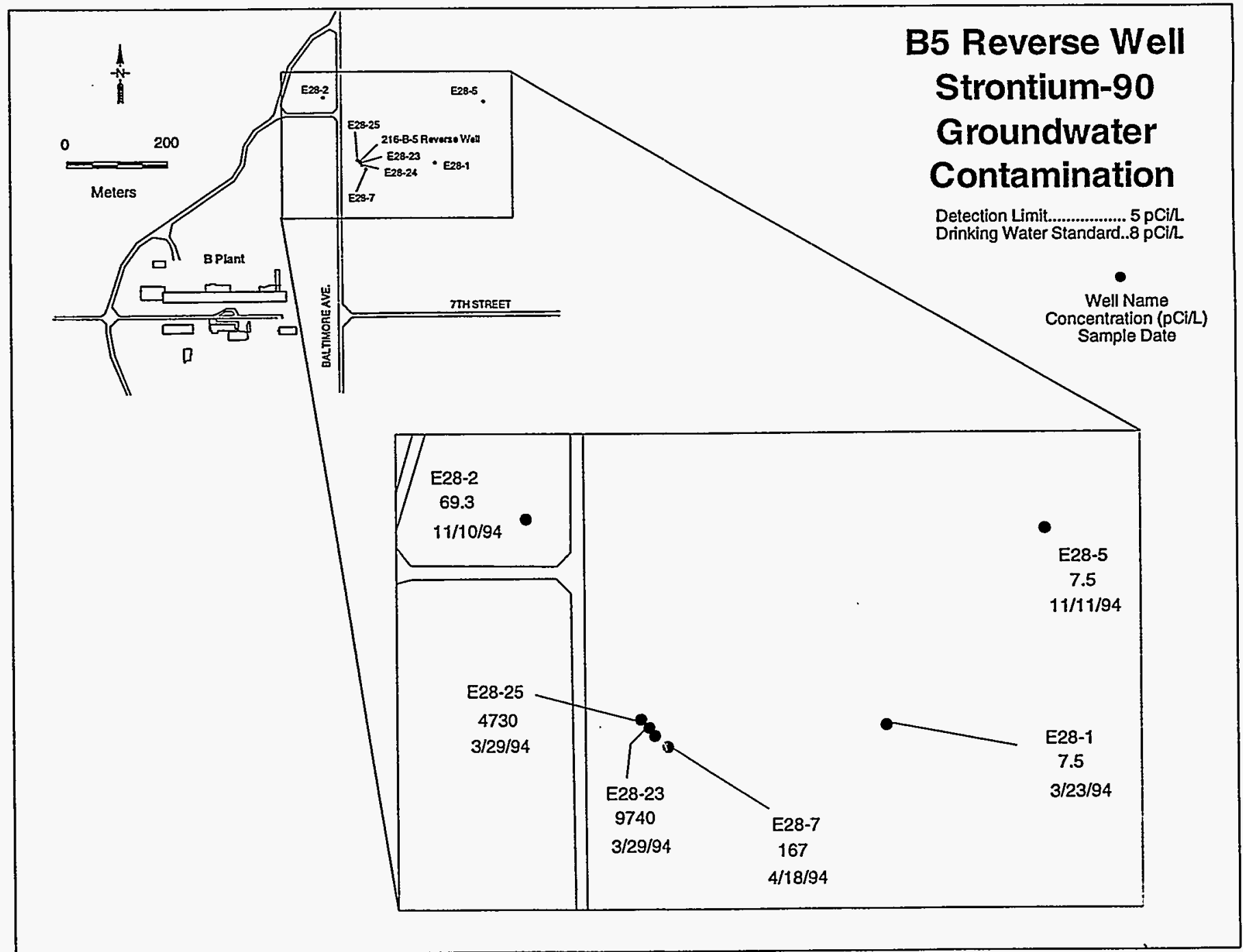



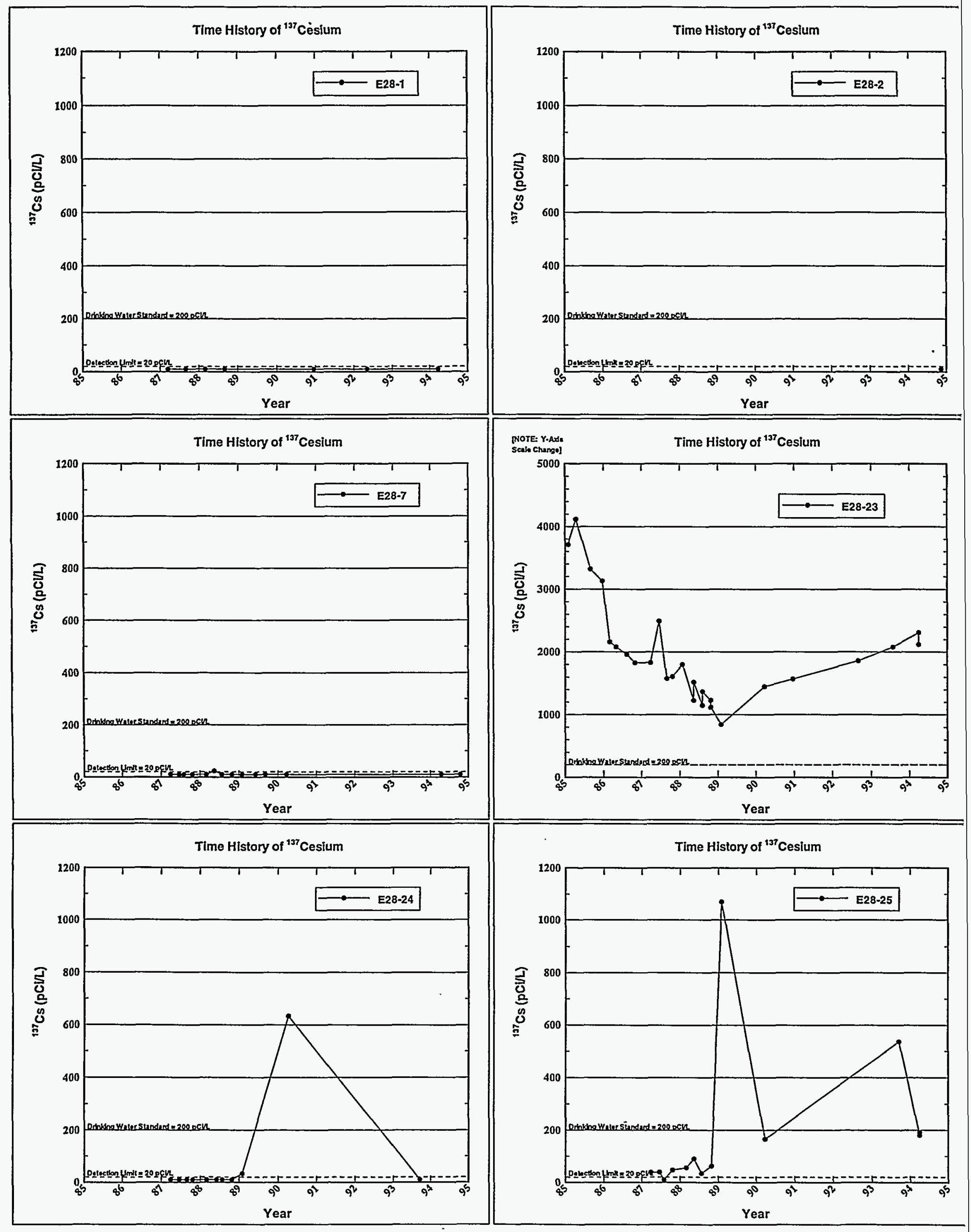

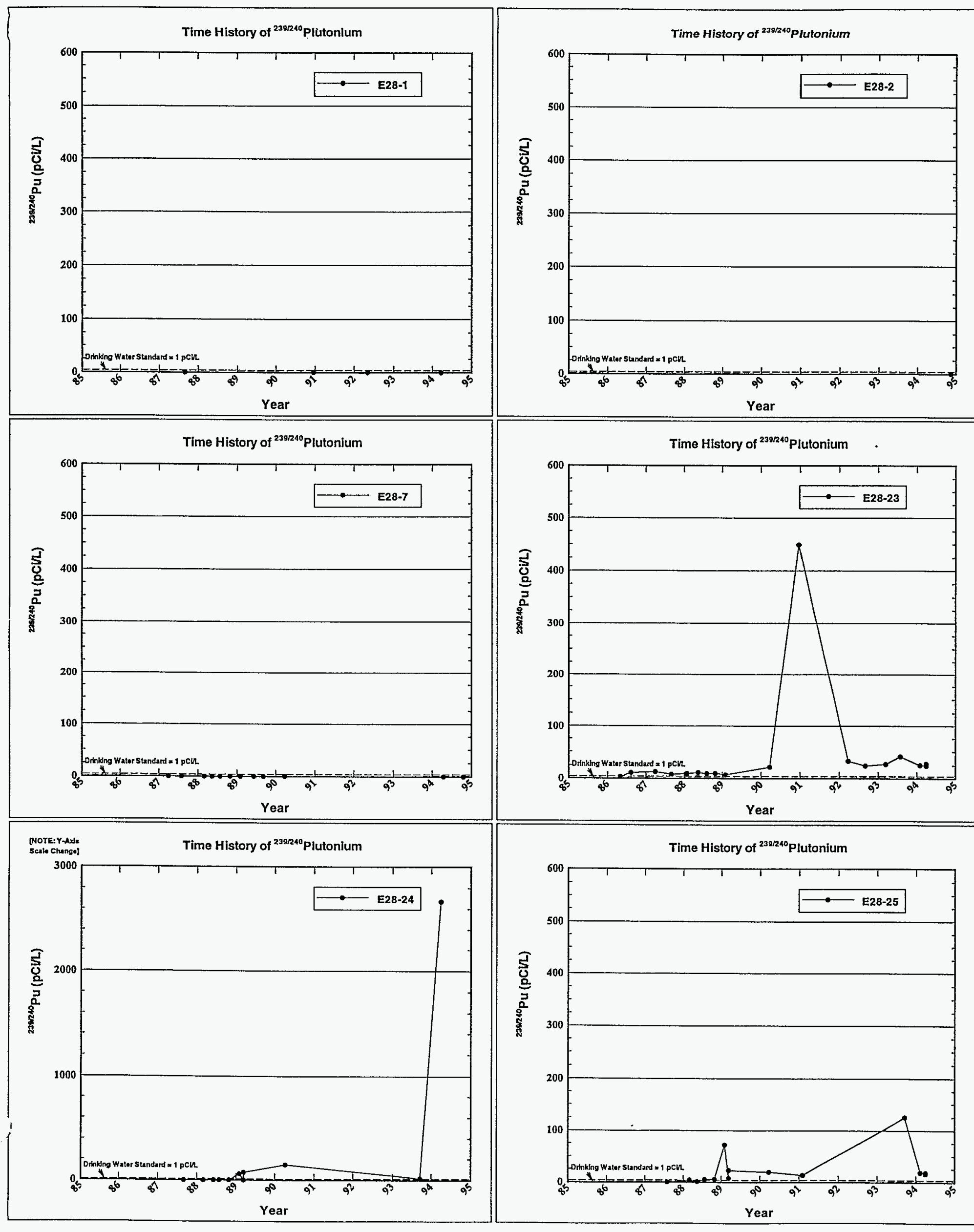


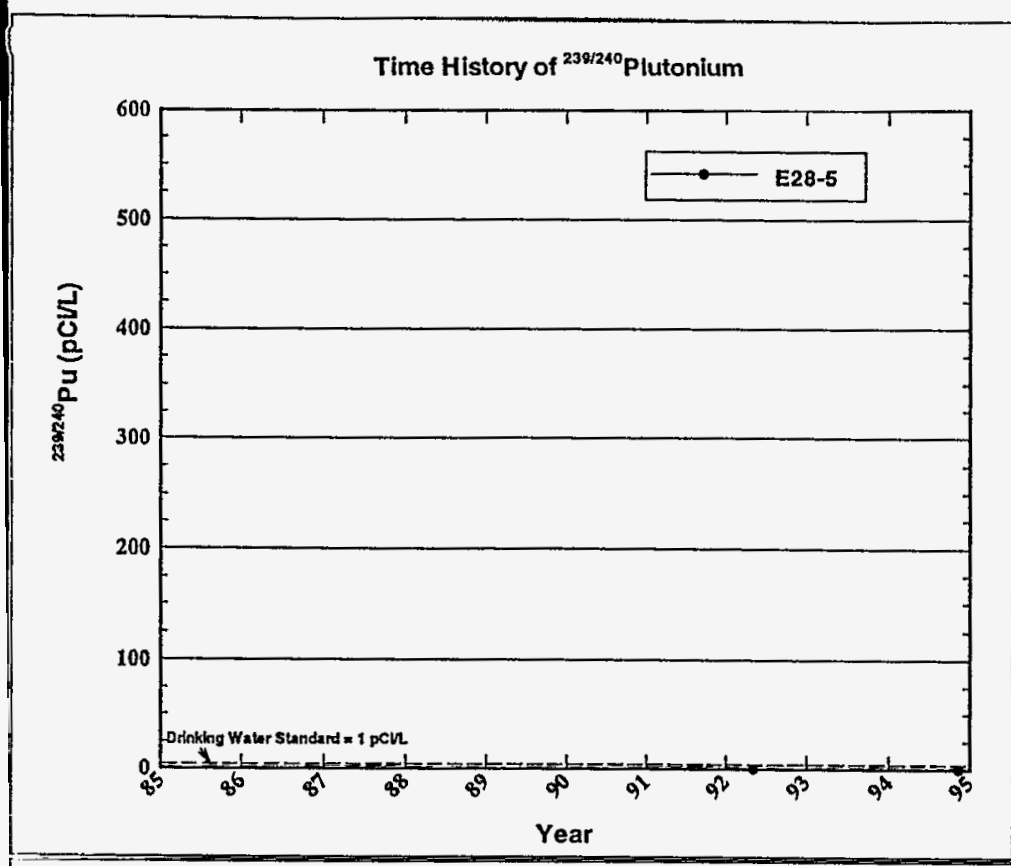

DOE/RL-95-59

Rev. 0

Figure 5-17. Plutonium-239/240 Concentrations in Wells at the 216-B-5 Reverse Well, 1985 to 1994.

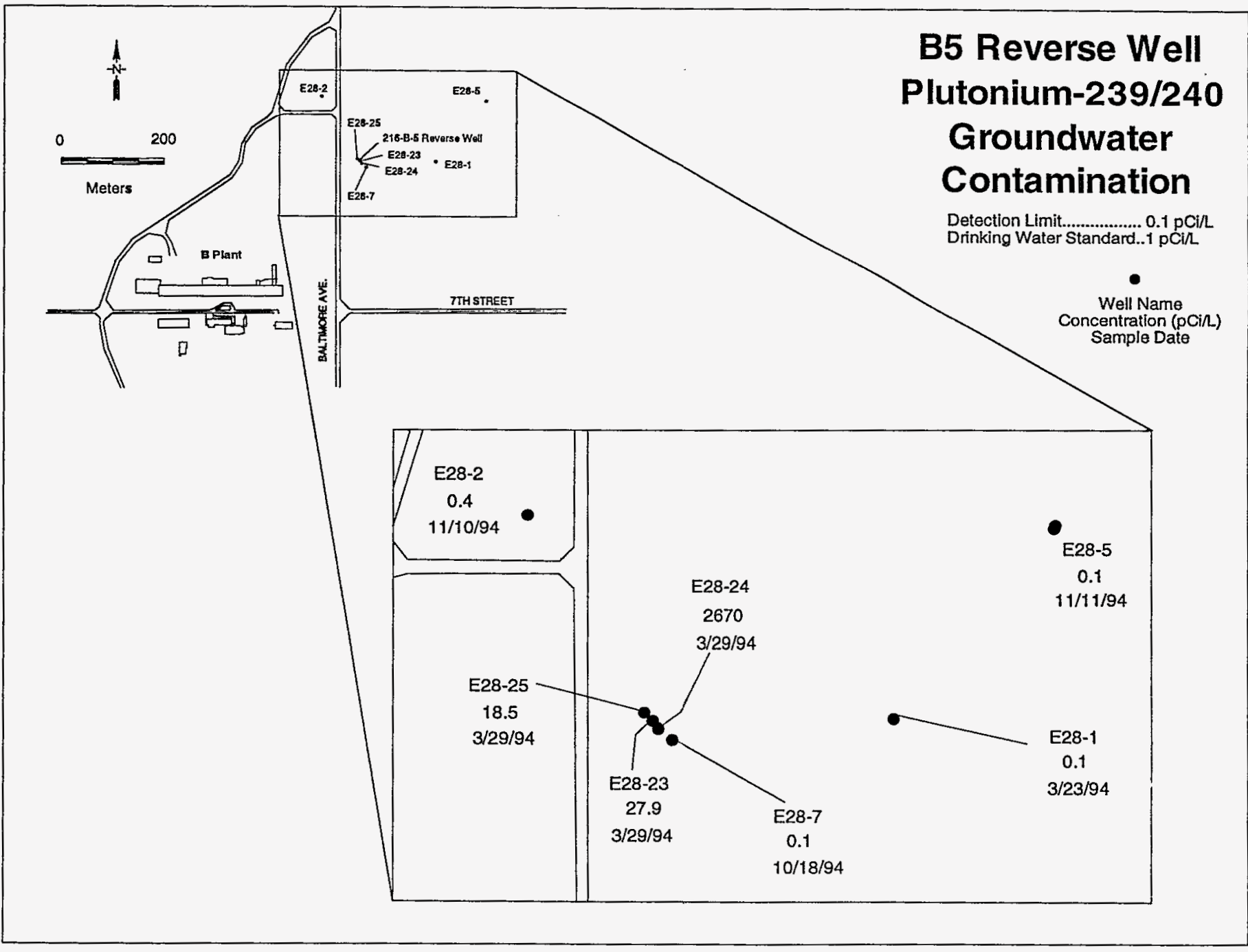


Rev. 0

Figure 5-18. Gross Beta Time History at 299-E33-4 216-BY Cribs, 1952 to 1993.

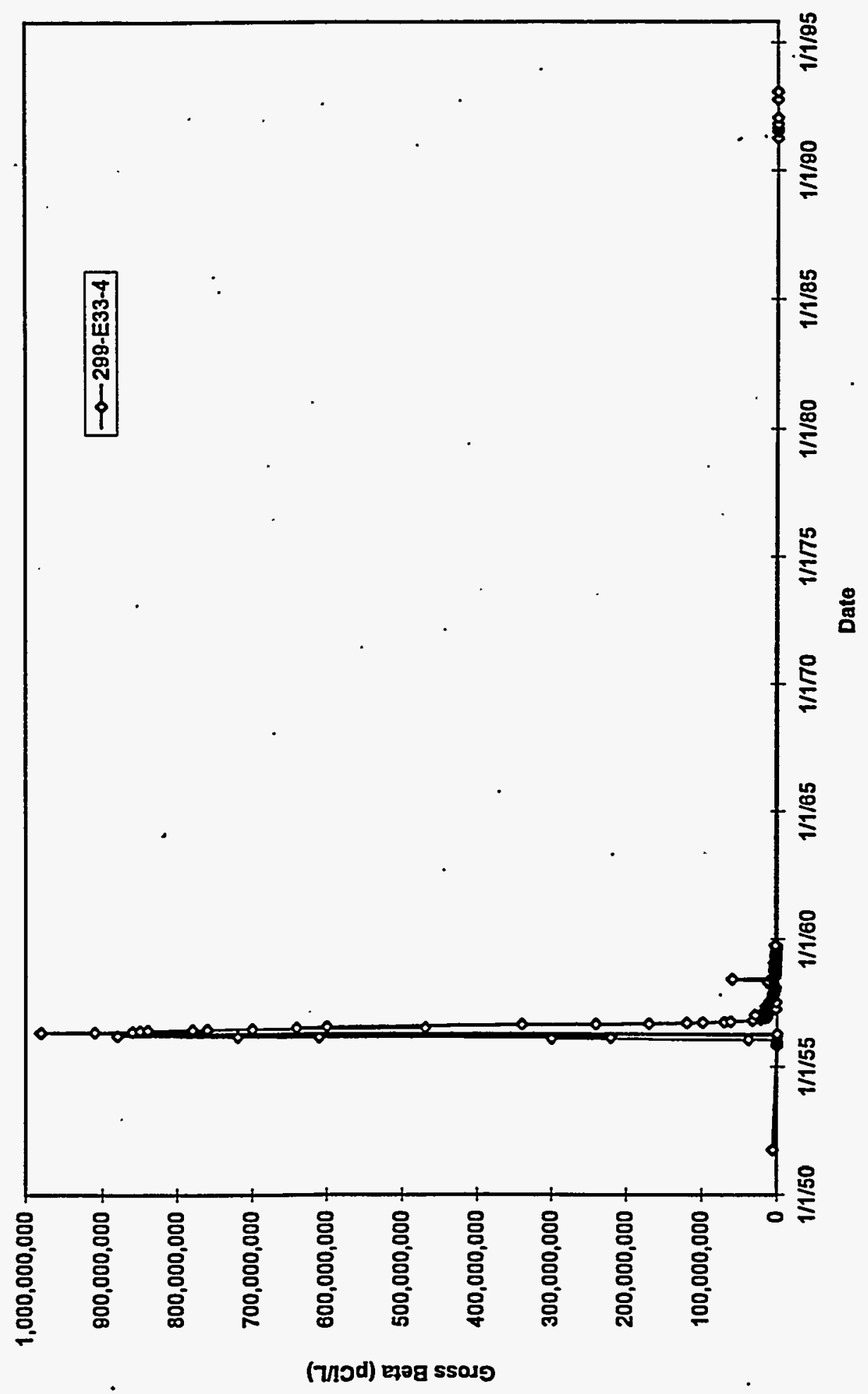



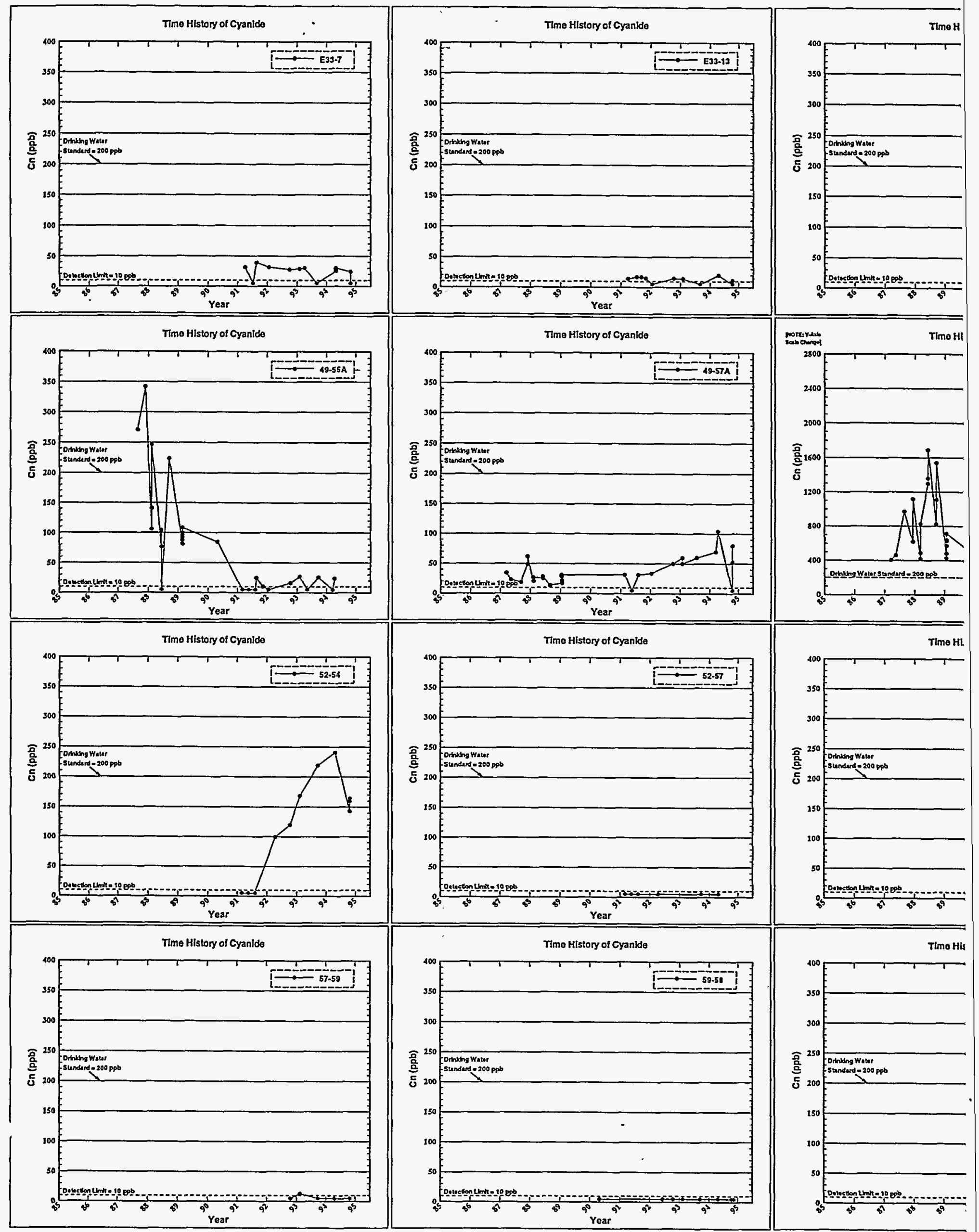


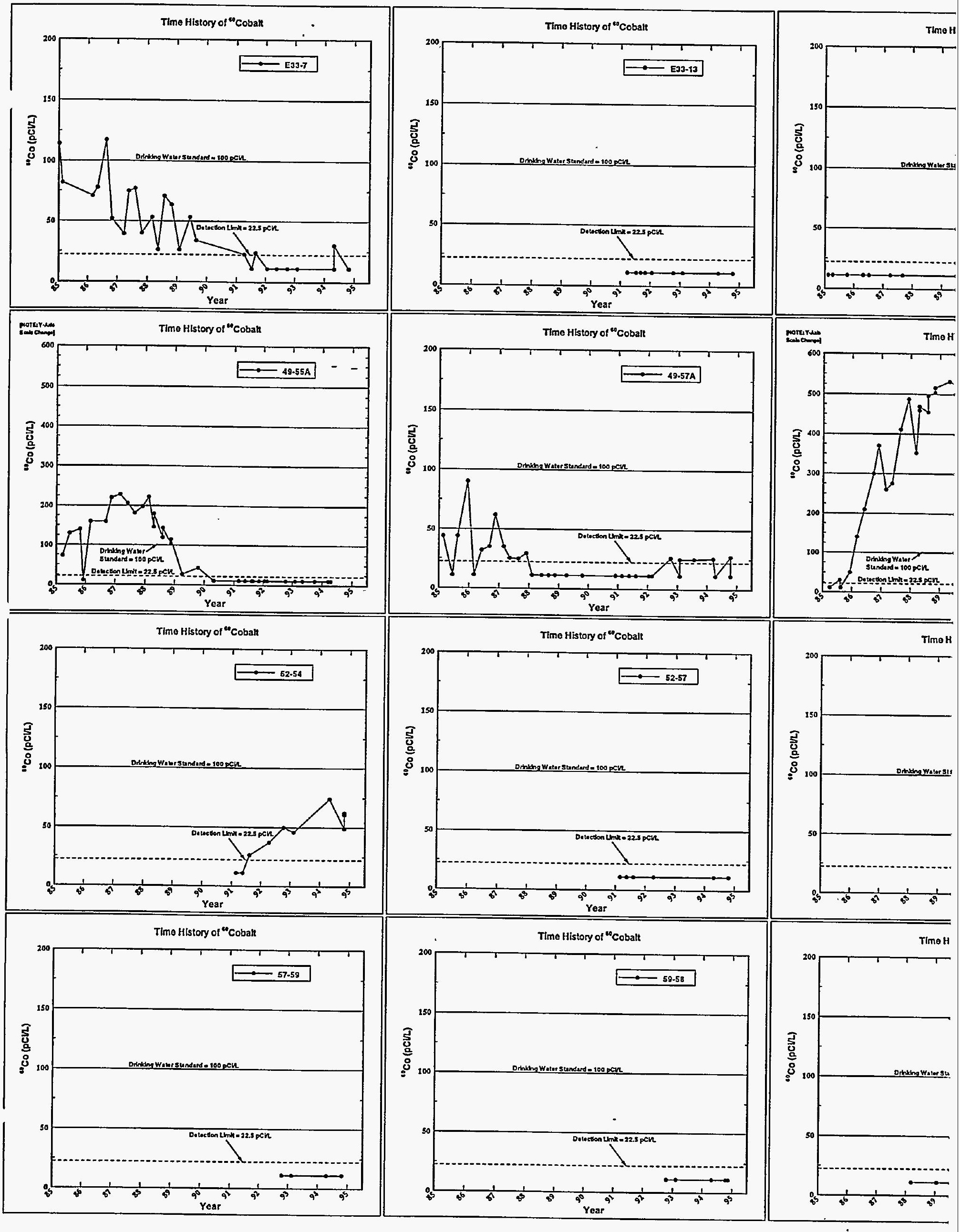



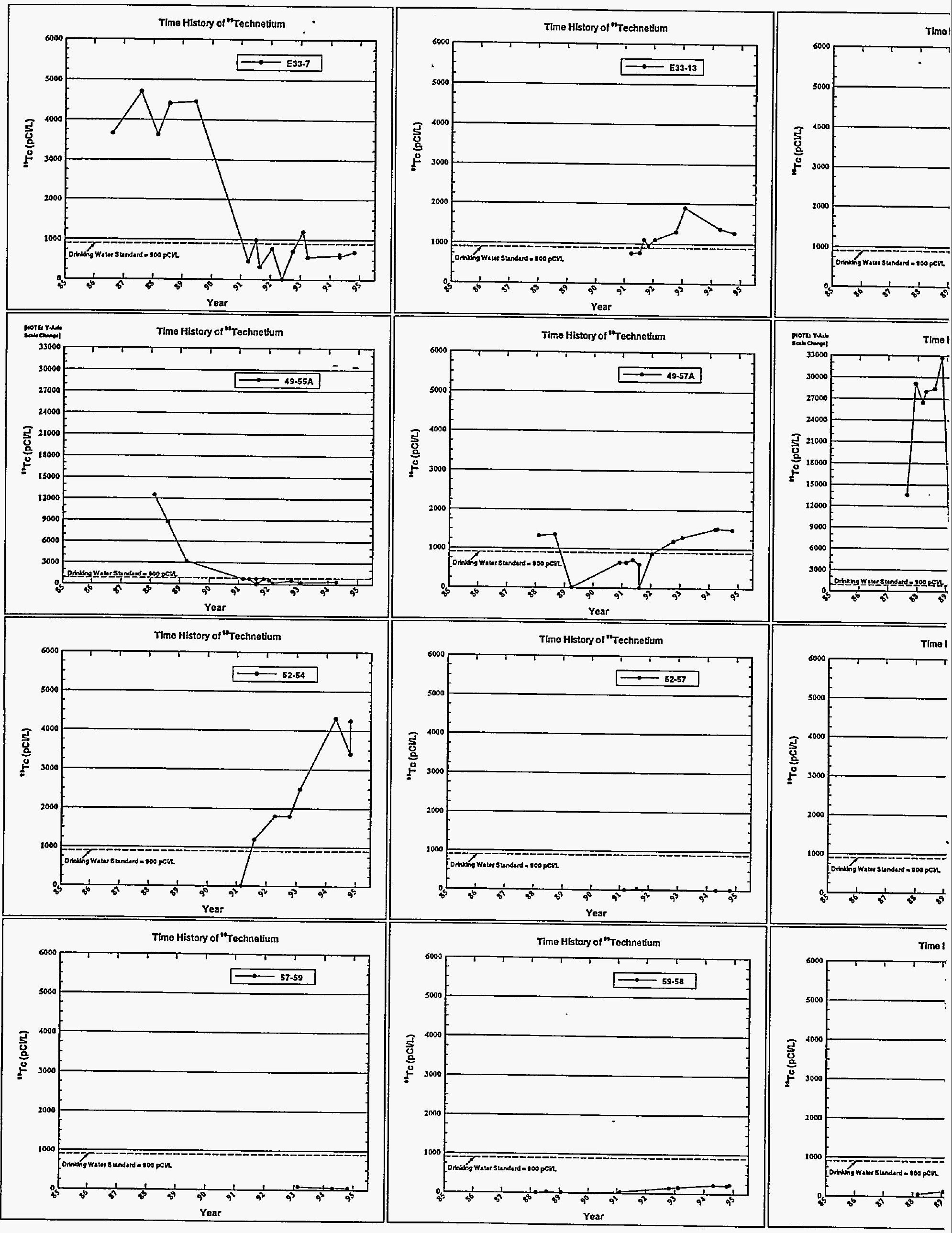
DOE/RL-95-59

Rev. 0

Figure 5-23. Gross Beta Time History at Well 699-55-50A, 215-A-25 Gable Mountain Pond, 1952 to 1990.

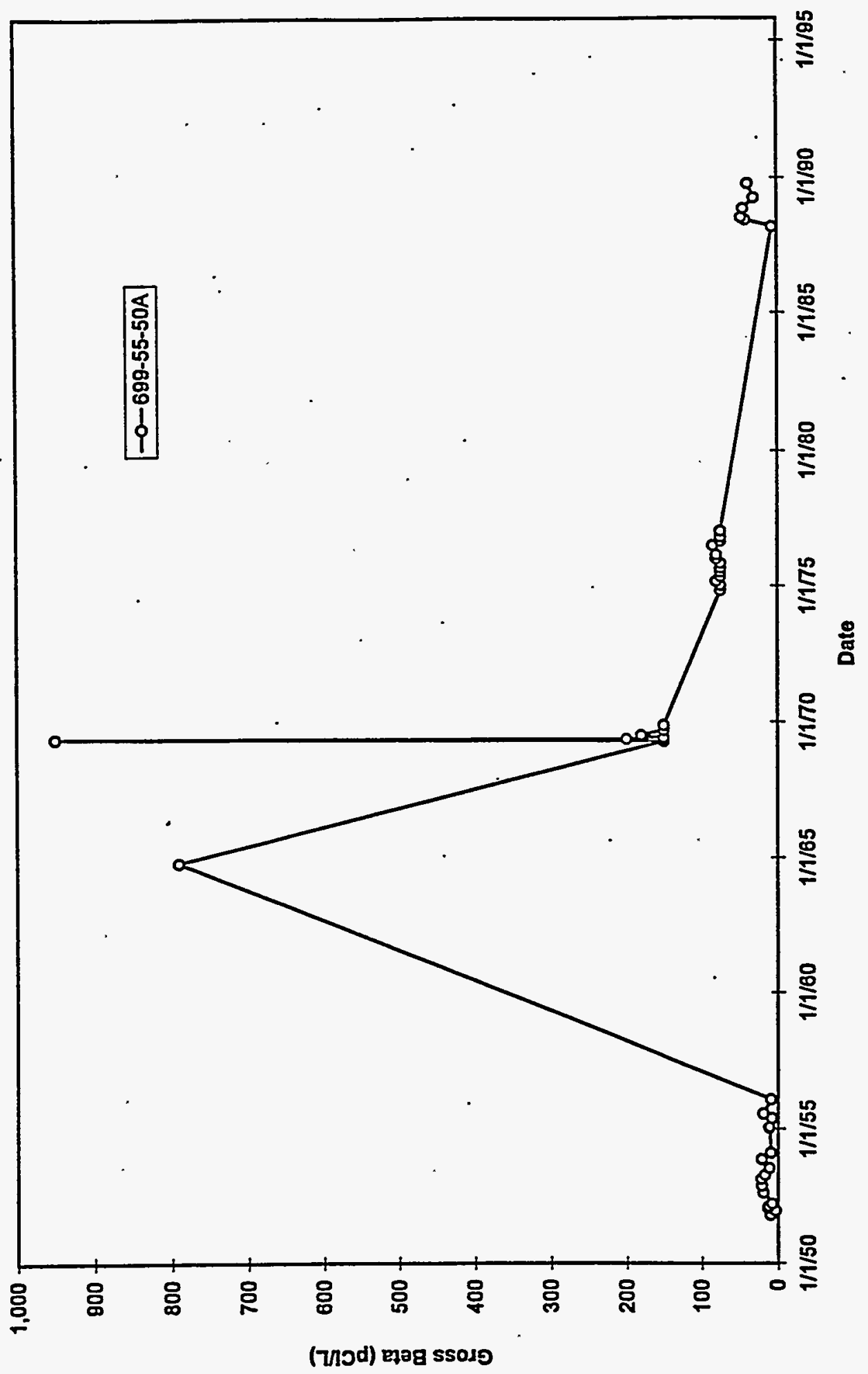


DOE/RL-95-59

Rev. 0

Figure 5-24. Strontium-90 Time History at Wells in the 216-A-25 Gable Mountain Pond Plume, 1980 to 1995. (2 sheets)
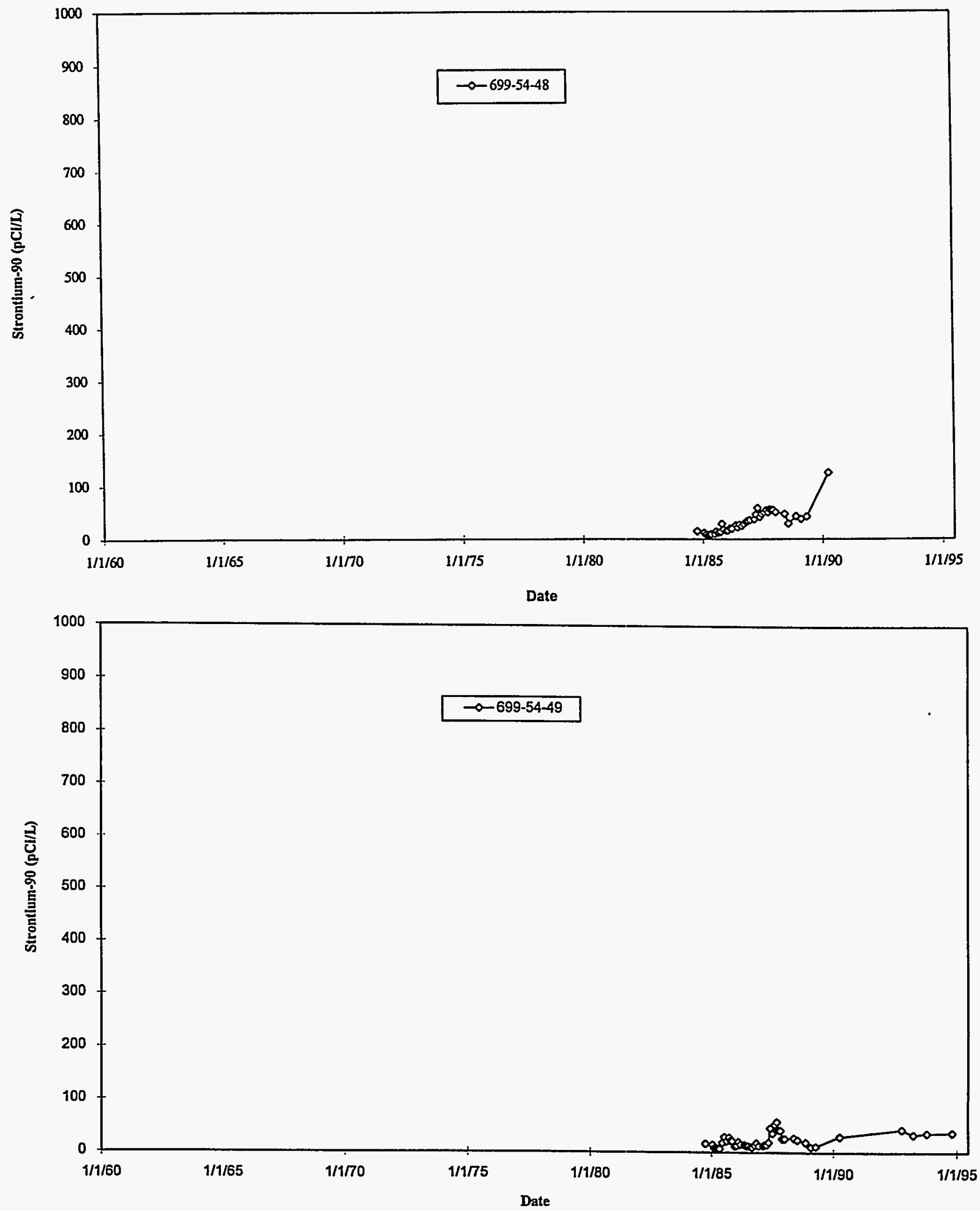

5F-34 


\section{DOE/RL-95-59}

Rev. 0

Figure 5-24. Strontium-90 Time History at Wells in the 216-A-25 Gable Mountain Pond Plume, 1980 to 1995 . (2 sheets)
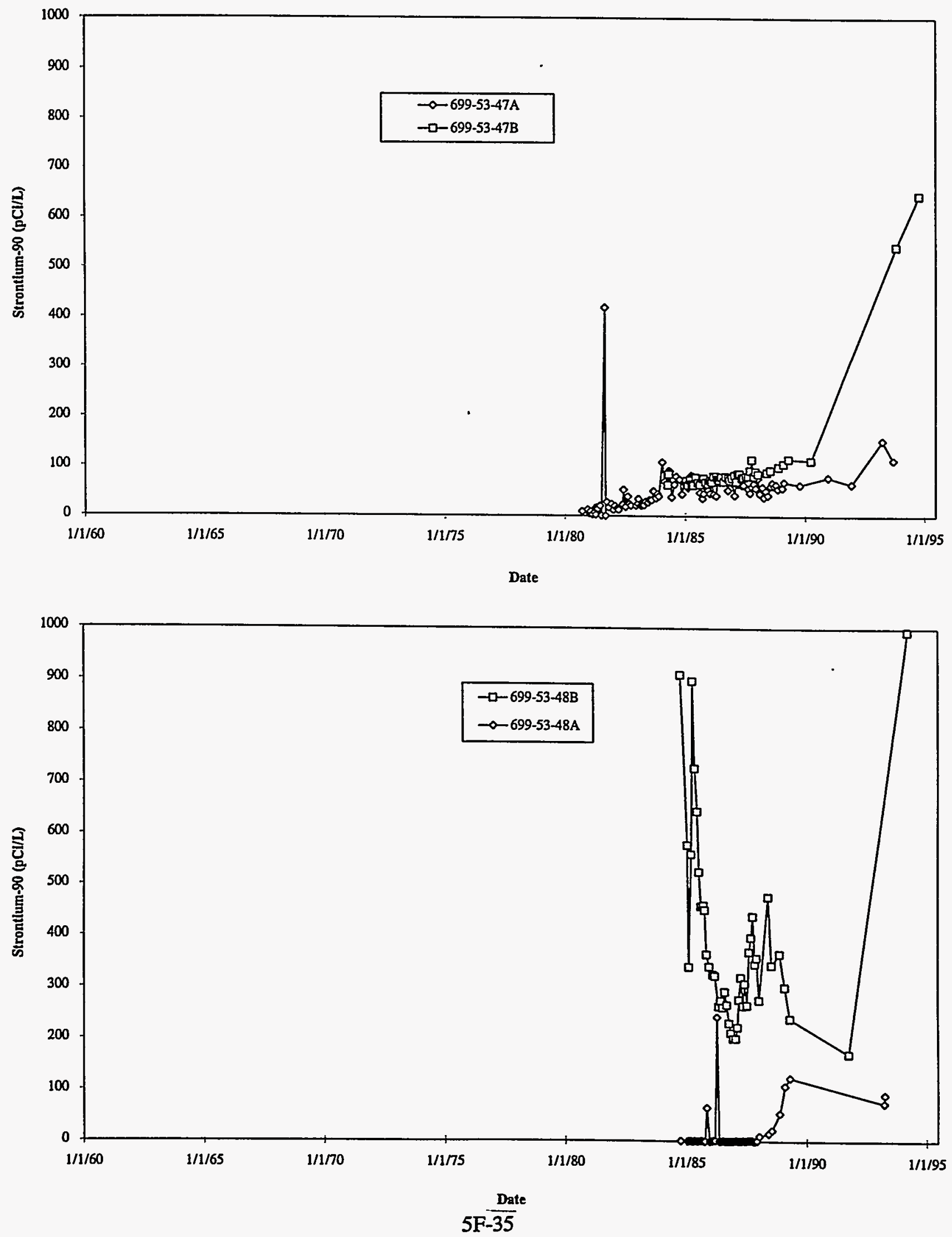
Figure 5-25. Gable Mountain Pond Strontium-90 Plume: Data are from 1994.

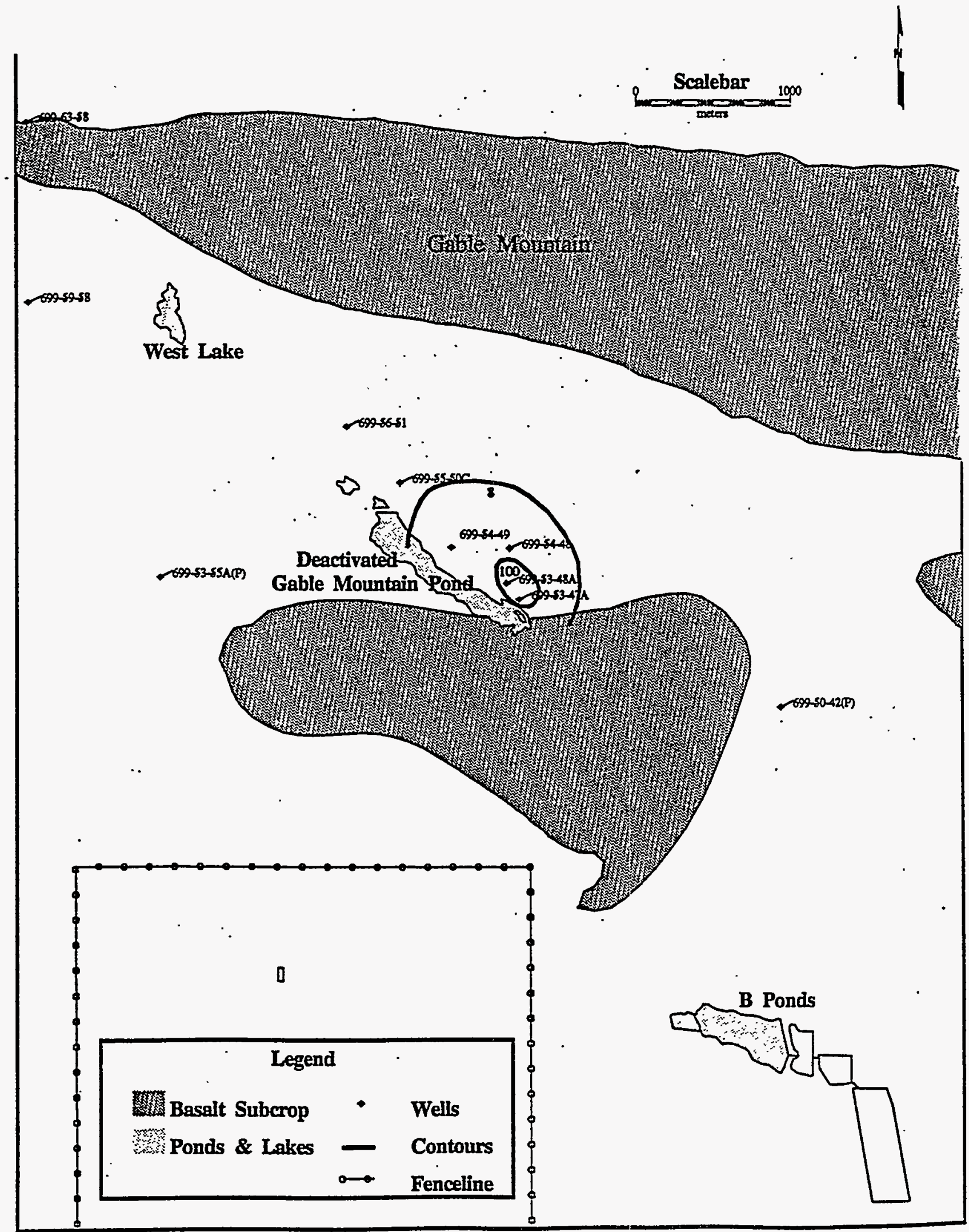


Figure 5-26. Site Map of the Deactivated 216-A-25 Gable Mountain Pond Showing Well Locations.

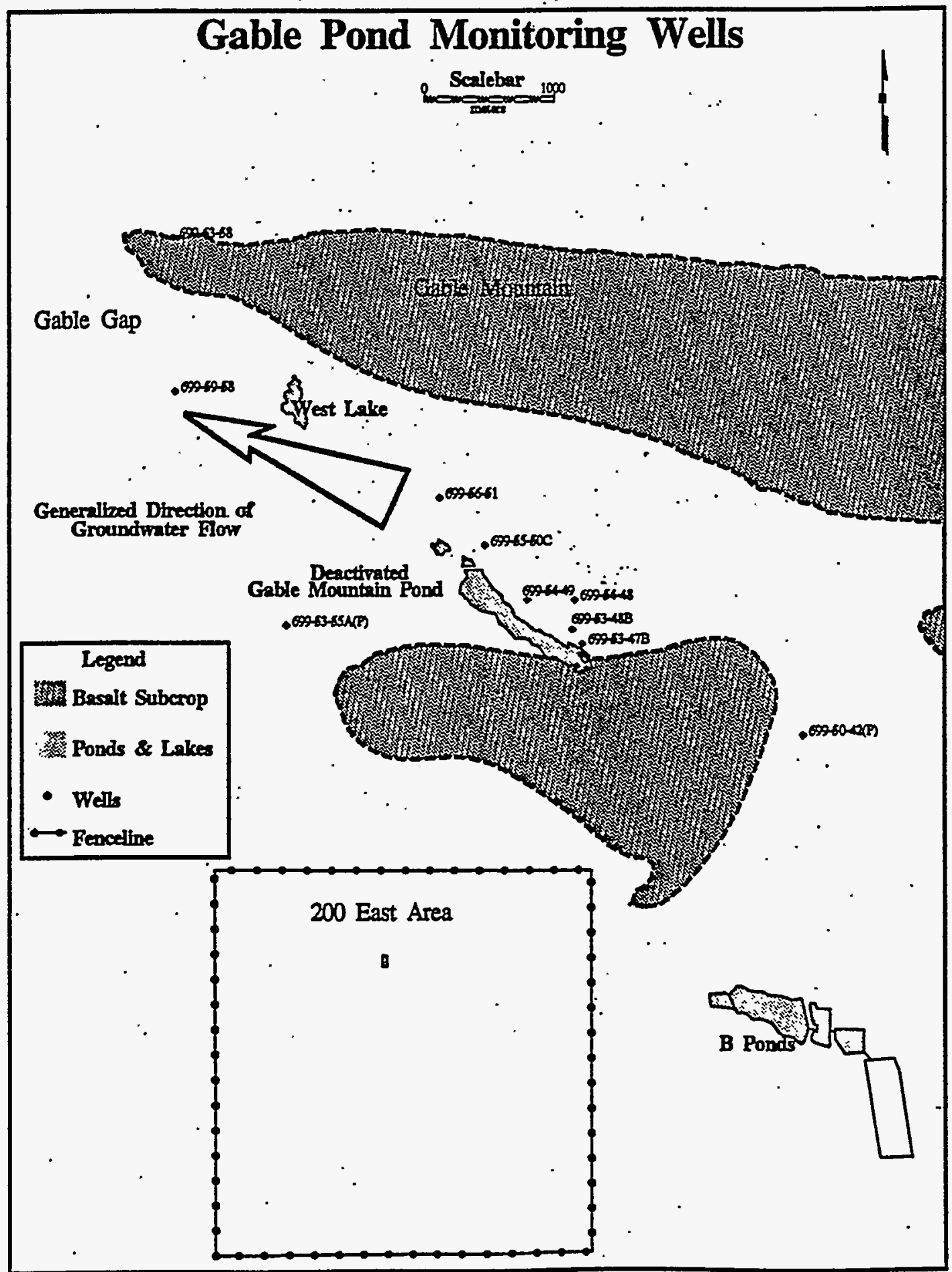


DOE/RL-95-59

Rev. 0

Figure 5-27. History of Strontium-90 Concentrations in Groundwater and Water-Table Elevations in Wells 699-53-47B and 699-53-48B, Gable Mountain Pond.

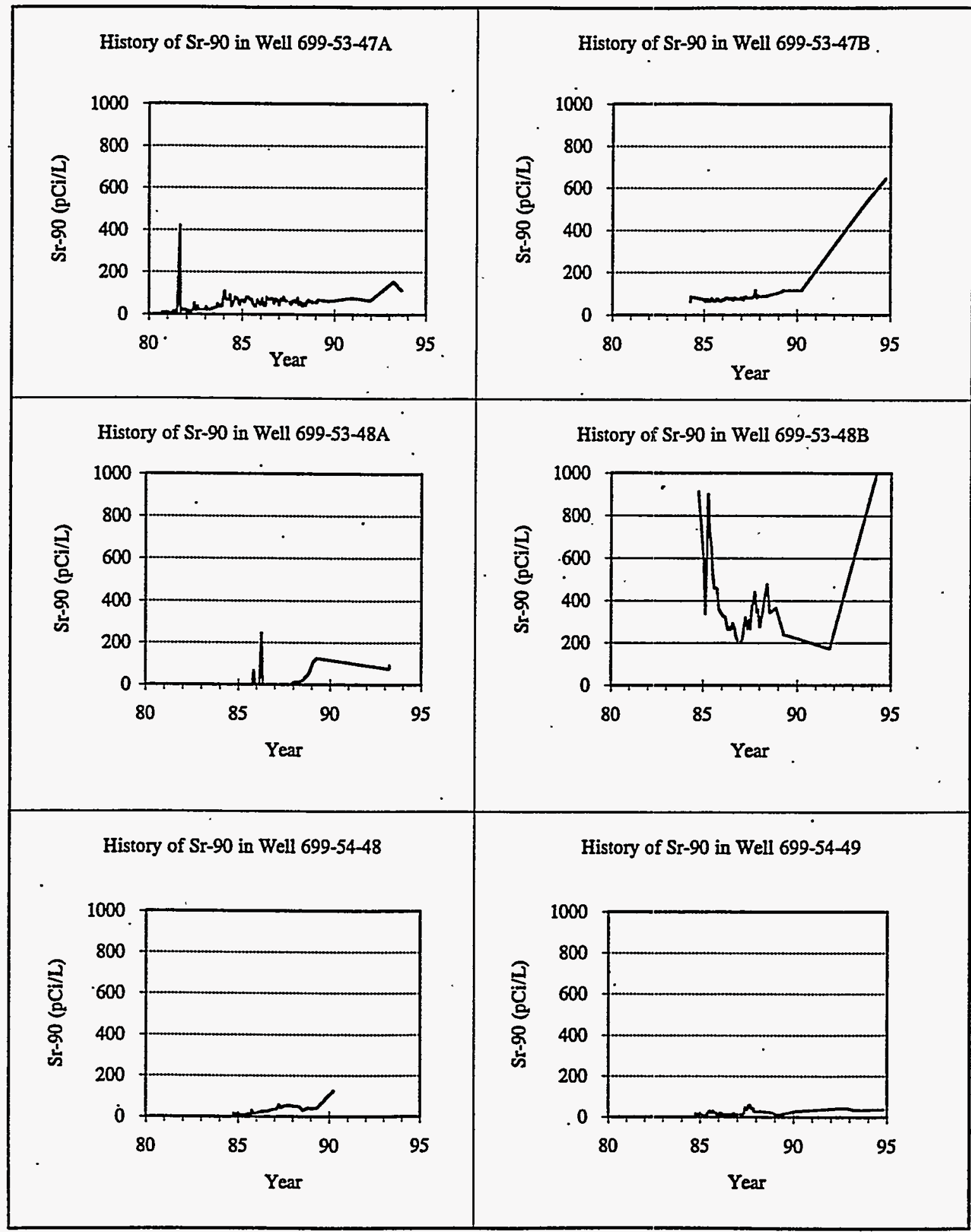


DOE/RL-95-59

Rev. 0

Figure 5-28. History of Strontium-90 Concentrations in Groundwater at Gable Mountain Pond.

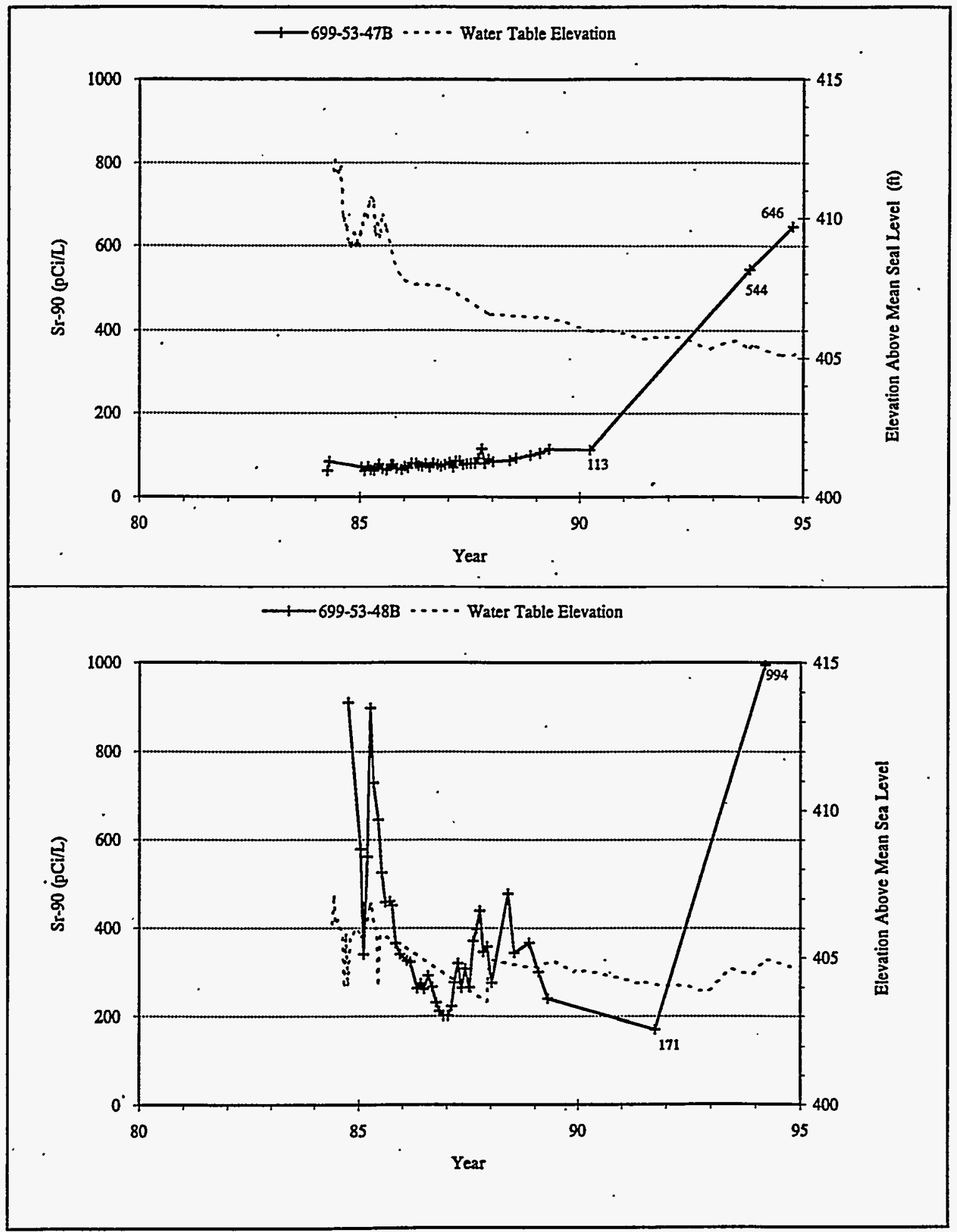


DOE/RL-95-59

Rev. 0

Figure 5-29. History of Cesium-137 Concentrations in Groundwater at Gable Mountain Pond.

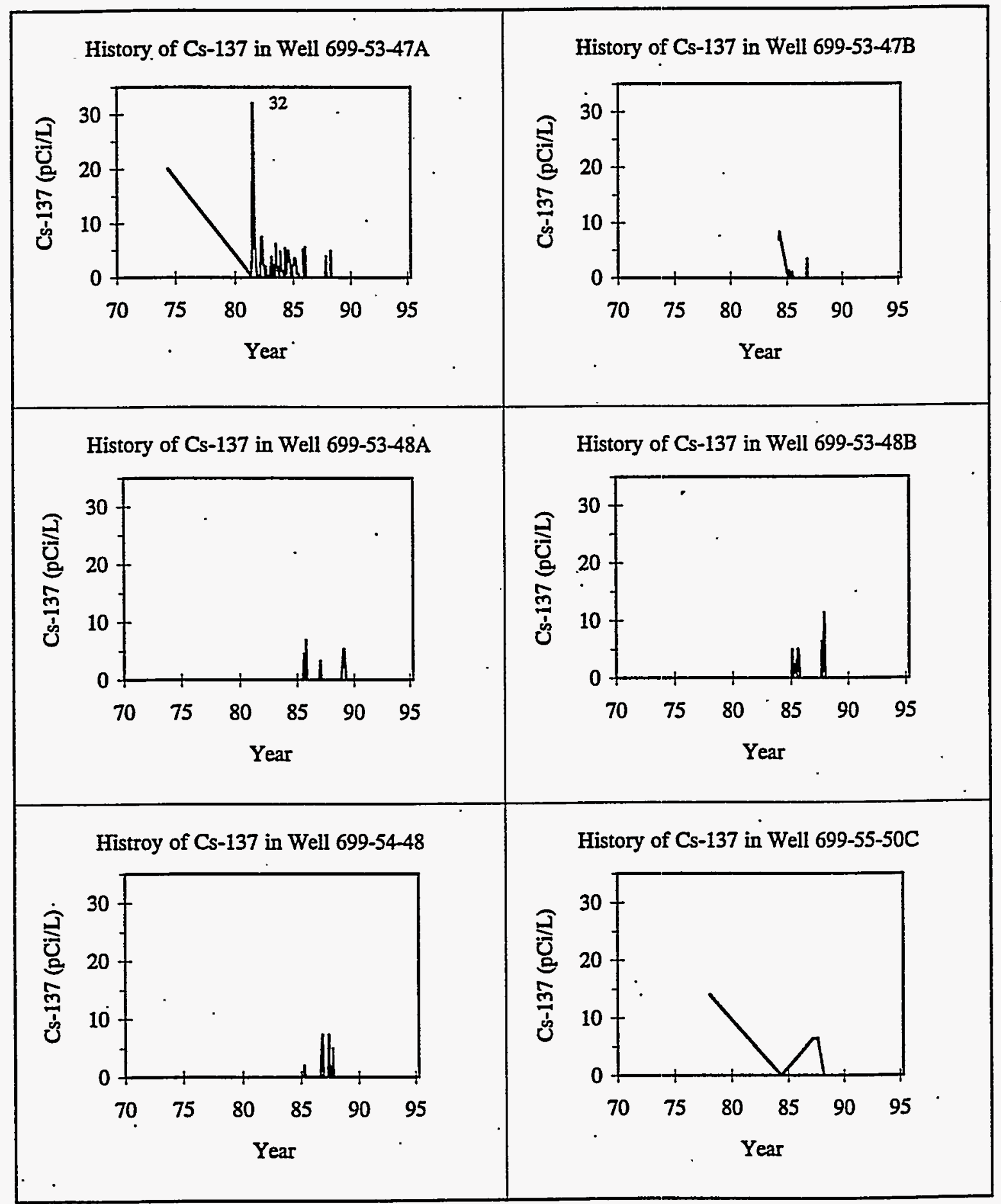


Rev. 0

Figure 5-30. 216-BY Cribs Plume Incremental Lifetime Cancer Risk for Reasonable Maximum Exposure to Technetium-99 in Groundwater, Existing and Future Conditions.

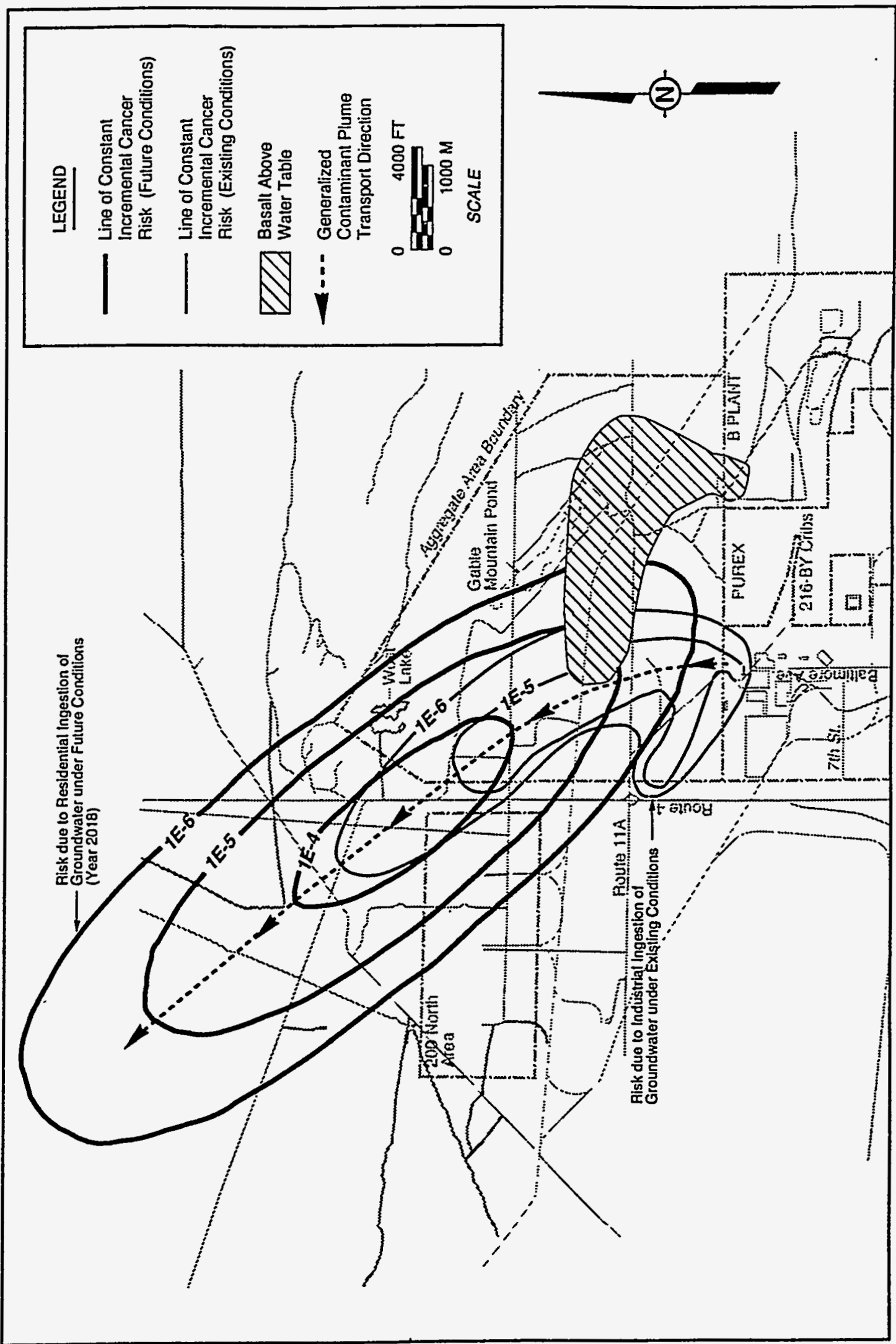




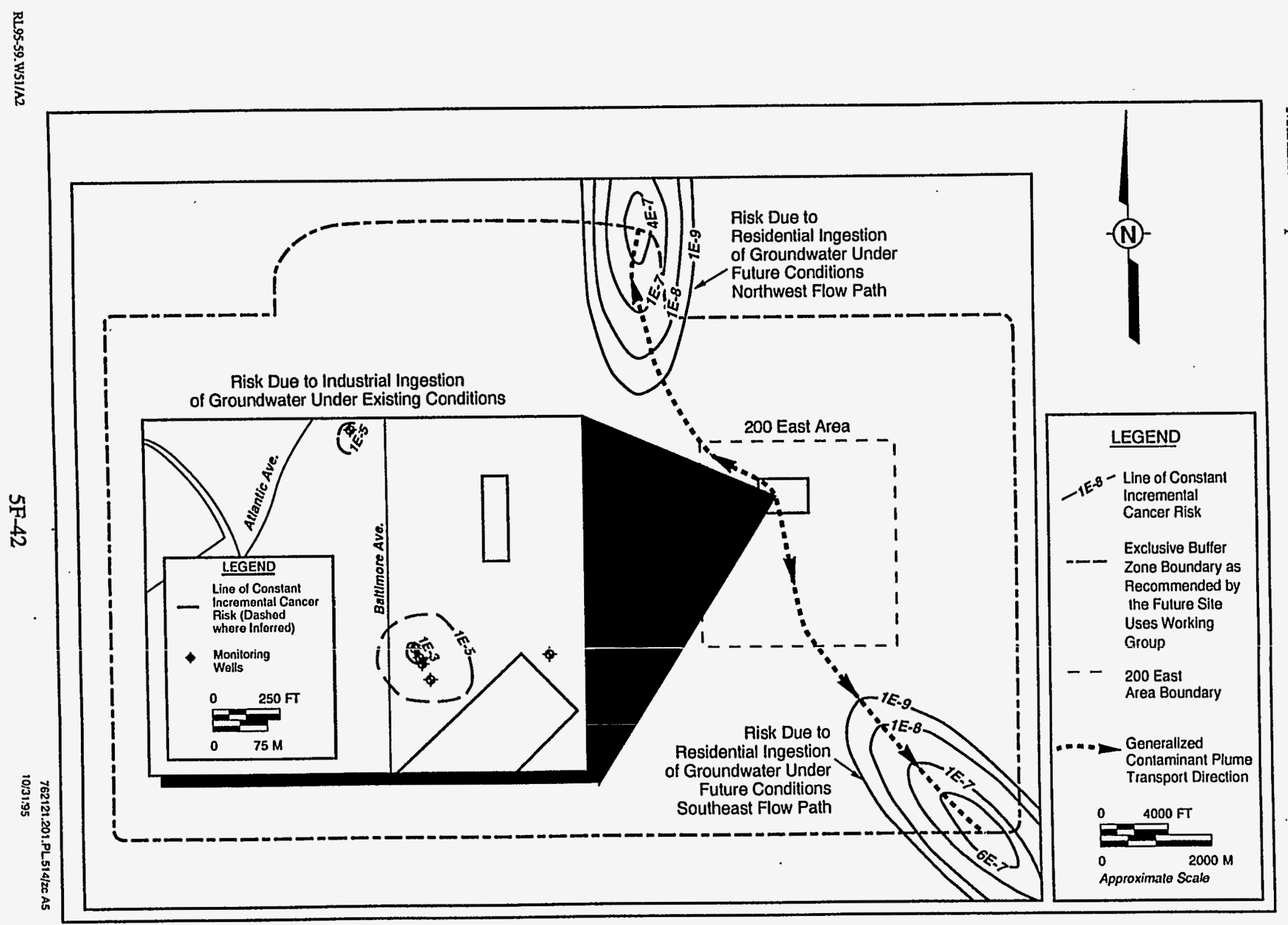

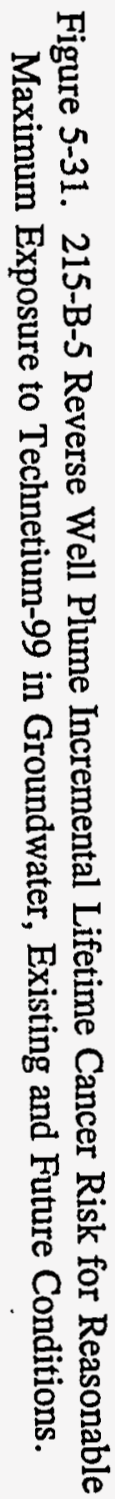


Figure 5-32. Gable Mountain Pond Plume Incremental Lifetime Cancer Risk for Reasonable Maximum Exposure to Strontium-90 in Groundwater, Existing and Future Conditions.

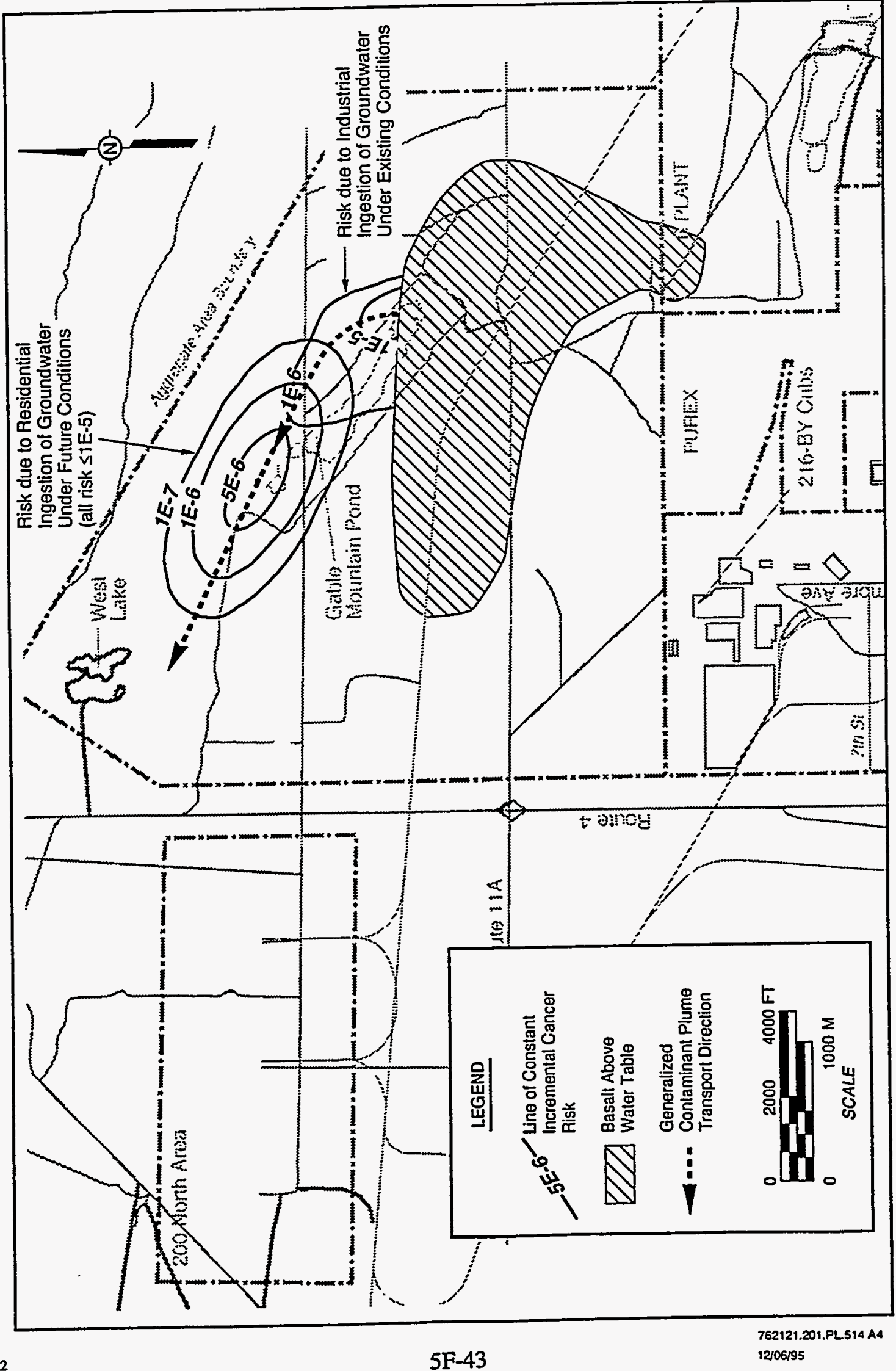


DOE/RL-95-59

Rev. 0 
Table 5-1. Summary of Waste Management Units Pertinent to 200-BP-5 Treatability Test.

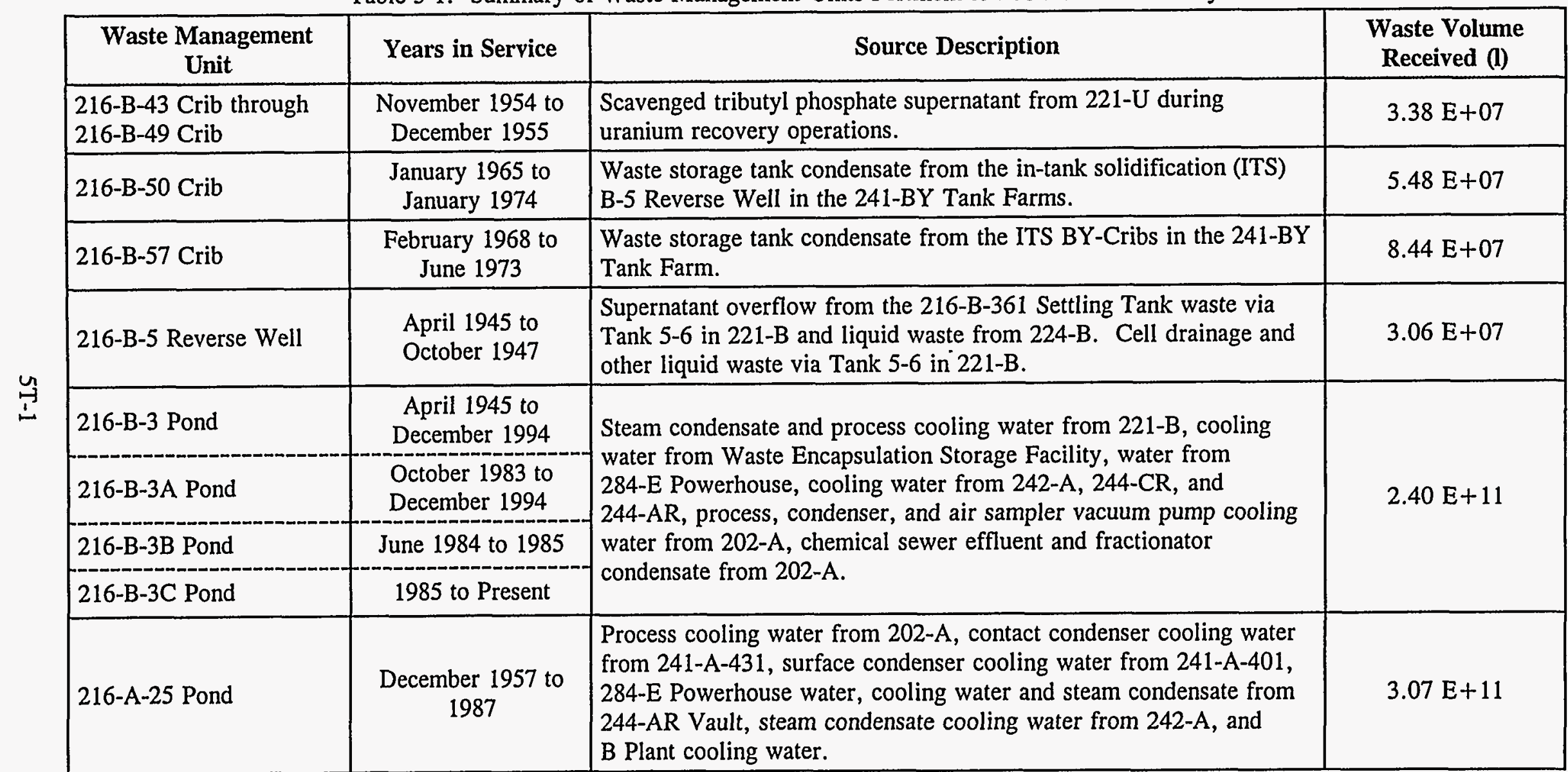

Source: WHC (1991).

Source: Maxfield (1979). 
Table 5-2. Radionuclide Waste Inventory Summary.

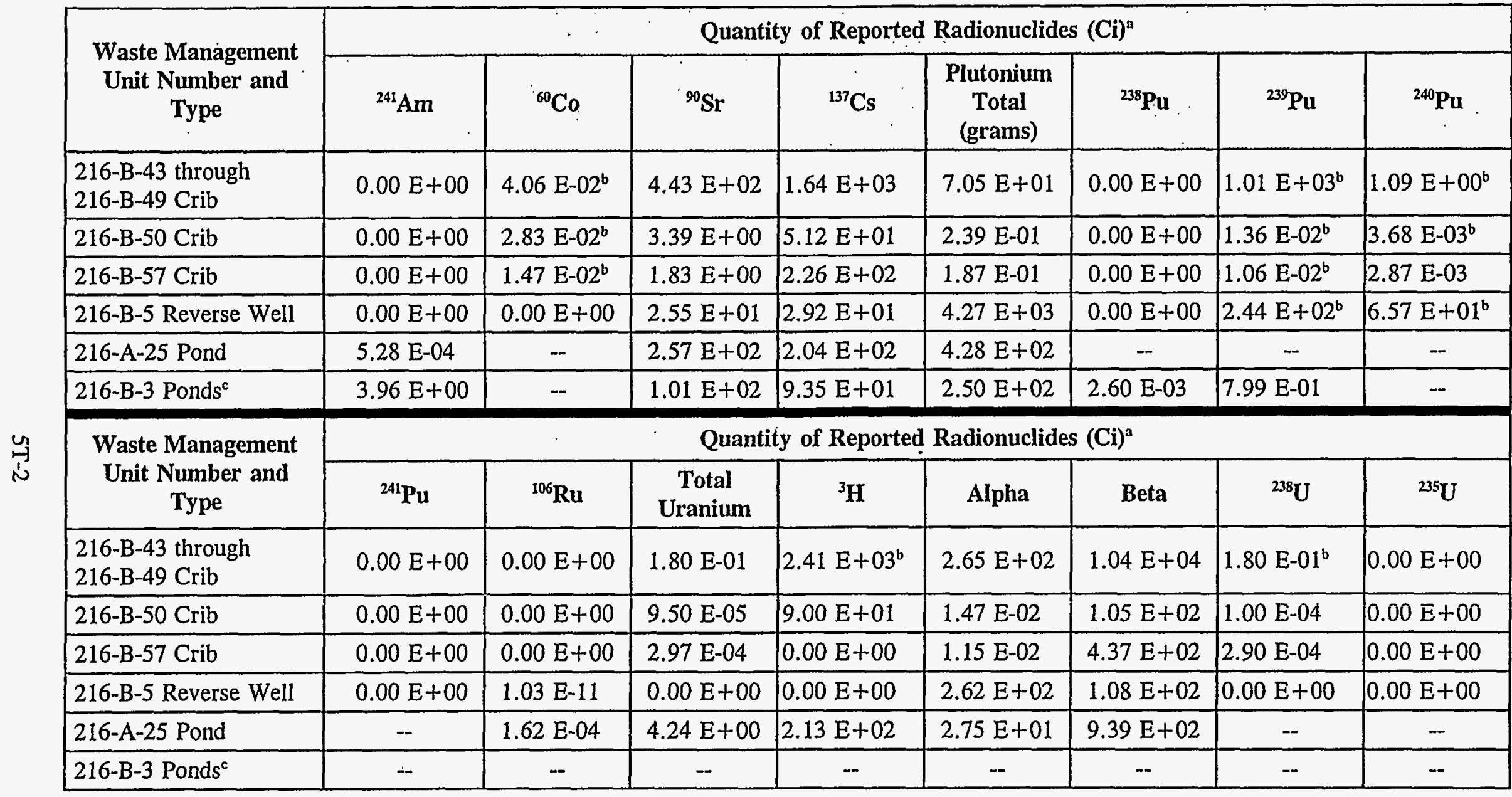

NOTES:

${ }^{2}$ Values decayed through December 31, 1989 unless otherwise noted.

bValues are decayed through April 1, 1986.

'Unplanned releases UN-200-E-32, UN-200-E-34, and UN-200-E-138 contained approximately $21,000 \mathrm{Ci}$ of activity.

-- indicates no inventory data available. 
Table 5-3. Chemical Waste Inventory Estimates.

\begin{tabular}{|c|c|c|c|c|c|c|c|c|}
\hline \multirow{2}{*}{$\begin{array}{c}\text { Waste Management } \\
\text { Unit Number and } \\
\text { Type }\end{array}$} & \multicolumn{8}{|c|}{ Quantity of Reported Chemicals (kg) } \\
\hline & $\mathrm{AlNO}_{3}$ & $\mathbf{F}$ & $\mathrm{FeCN}$ & $\mathrm{H}_{2} \mathrm{SO}_{4}$ & $\mathrm{HNO}_{3}$ & $\mathbf{K}$ & $\mathrm{Na}$ & $\mathrm{NaAl}$ \\
\hline $\begin{array}{l}\text { 216-B-43 Crib through } \\
216-\mathrm{B}-49 \text { Crib }\end{array}$ & -- & - & $2.27 \mathrm{E}+04$ & -- & - & -- & $2.65 \mathrm{E}+06$ & - \\
\hline $216-\mathrm{B}-50 \mathrm{Crib}$ & - & - & -- & - & - & - & $5.00 \mathrm{E}+02$ & - \\
\hline 216-B-57 Crib & - & -- & - & - & - & -- & -- & -- \\
\hline 216-B-5 Reverse Well & $5.00 \mathrm{E}+03$ & $5.00 \mathrm{E}+04$ & - & - & - & $8.00 \mathrm{E}+04$ & -- & - \\
\hline 216-A-25 Pond & -- & -- & - & - & - & - & - & -- \\
\hline 216-B-3 Ponds & - & - & -- & -- & - & - & -- & - \\
\hline \multirow{2}{*}{$\begin{array}{c}\text { Waste Management } \\
\text { Unit Number and } \\
\text { Type }\end{array}$} & \multicolumn{8}{|c|}{ Quantity of Reported Chemicals (kg) ${ }^{\mathrm{a}}$} \\
\hline & $\mathrm{NaCr}_{2} \mathrm{O}_{7}$ & $\mathrm{NH}_{4} \mathrm{CO}_{3}$ & $\mathrm{NH}_{4} \mathrm{NO}_{3}$ & $\mathrm{NO}_{2}$ & $\mathrm{NO}_{3}$ & Oxalate & $\mathrm{PO}_{4}$ & $\mathrm{SO}_{4}$ \\
\hline $\begin{array}{l}\text { 216-B-43 Crib through } \\
216-\mathrm{B}-49 \text { Crib }\end{array}$ & -- & - & -- & -- & $5.69 \mathrm{E}+06$ & -- & $3.32 \mathrm{E}+05$ & $4.69 \mathrm{E}+05$ \\
\hline $216-\mathrm{B}-50 \mathrm{Crib}$ & - & $9.10 \mathrm{E}+04$ & $1.00 \mathrm{E}+04$ & - & $1.50 \mathrm{E}+03$ & - & -- & -- \\
\hline 216-B-57 Crib & - & $1.20 \mathrm{E}+04$ & - & - & -- & - & -- & -- \\
\hline 216-B-5 Reverse Well & - & - & - & - & $4.00 \mathrm{E}+05$ & $1.20 \mathrm{E}+04$ & $2.90 \mathrm{E}+04$ & $3.30 \mathrm{E}+03$ \\
\hline 216-A-25 Pond & - & -- & - & -- & - & - & - & - \\
\hline 216-B-3 Ponds & -. & -- & - & -- & - & -- & - & -- \\
\hline
\end{tabular}

NOTES:

aThe reported inventories are derived from the Waste Information Data System (WHC 1991) and Stenner et al. (1988). Not all sites have reported inventories, and the inventories do not necessarily list all of the contaminants disposed of at a site.

-- indicates no inventory data available. 
DOE/RL-95-59

Rev. 0 
DOE/RL-95-59

Rev. 0

\subsection{6-BY CRIBS TREATMENT SYSTEM}

This chapter describes a proposed system scale-up for the plume at the BY-Cribs site and includes cost estimates for system design, fabrication, operation, and well drilling. Because of similar treatment rate capabilities and system design, the N-Springs pump-and-treat system can be used as a model for system design and construction costs. A significant fraction of the cost is in locating significant quantities of highly contaminated groundwater. Operational costs are presented on a per-year basis and totaled for 5 years. Cost escalation is not included.

\subsection{CONTAMINANT EXTRACTION SYSTEM CONCEPTUAL DESIGN}

The interim remedial approach described here for the BY-Cribs Plume is intended to prevent further northward migration of the contaminant plume and eliminate the highest concentration core of the contaminant plume within a reasonable period of time (Figure 4-7). Based on the level of uncertainty in the contaminant conceptual model and the parameters established in Section 6.2 for system operations, a better understanding of the local aquifer properties and contaminant plume geometry is required to optimize the contaminant extraction system design and operation. A focused subsurface investigation program is necessary to refine the aquifer hydrology, geology, and contaminant trend data necessary to design an efficient and inexpensive extraction network.

The groundwater flow pattern for the BY-Cribs plume is restricted on the east due to the basalt subcrop located east of wells 699-50-53A and 699-52-54. Geologic logs of the local wells and regional geologic mapping indicate that the aquifer thickens to the west and north of the subcrop. Aquifer thickness in the area of the ${ }^{99} \mathrm{Tc}$ contaminant plume ranges from $0 \mathrm{~m}$ to less than $3 \mathrm{~m}(0 \mathrm{ft}$ to $<10 \mathrm{ft}$ ) thick. Section 5.3.2.3 proposes the possibility of a late-Pleistocene flood-related erosional channel incised into the basalt underlying the aquifer. The erosional window defined by well 699-53-55 cluster and well 699-55-55 (Section 1.4.3) substantiates the possibility of such erosional features. If present, any erosional channel would result in a local thickening of the aquifer.

For greatest efficiency, the contaminant extraction well network should be located in the area where the greatest aquifer thickness coincides with the highest contaminant concentration. If an erosional channel is present, its location may be the optimum site for the extraction well network. The focused subsurface investigation would be composed of a seismic reflection survey to determine the profile of the bottom of the aquifer and locate any preferential flowpaths in the area of the contaminant plume (Section 5.3.2.3) and a limited groundwater sampling program using the sonic-push technique to access the aquifer (Section 4.4.1) and determine both aquifer thickness and contaminant concentrations. The limited geophysical investigation and sonic-push probe activities would produce a refined plume thickness and contaminant concentration model.

The subsurface investigation would be followed by the construction of at least five new groundwater extraction wells. In addition to providing sites to extract contaminated groundwater, the new wells would provide confirmation of the geohydrologic properties of the aquifer and also provide aquifer sediments for laboratory analyses related to contaminant geochemistry and bench-scale treatment tests. Aquifer pump tests would be conducted at each extraction well before the construction of the succeeding well to confirm that sufficient groundwater production is available from the well, to ensure that unanticipated changes in the aquifer are mitigated by the appropriate location of the next well, and to update the capture-zone model. 
Rev. 0

A preliminary capture-zone analysis for the By-Cribs plume was conducted utilizing known aquifer properties. Due to the recognized thin aquifer and flat gradient, it is expected that well spacing on the order of 250 to $300 \mathrm{~m}$ ( 820 to $984 \mathrm{ft}$ ) between wells would be sufficient to capture the highest concentration portion of the plume and prevent northward migration. The analysis indicates that five extraction wells located in the thicker aquifer section along the north-south axis of the plume and producing $38 \mathrm{~L} / \mathrm{min}$ (10 gal/min) each would be necessary to effect plume containment and support contaminant mass reduction (Figure 6-1). According to a preliminary capture-zone analysis, groundwater pumping from each of the extraction wells shown in Figure 6-1 for a period of 5 years at a rate of $38 \mathrm{~L} / \mathrm{min}(10 \mathrm{gal} / \mathrm{min})$ would be sufficient to remediate the highest concentration core of the BY-Cribs plume.

The groundwater extraction wells would be constructed as 10-cm- (4-in.) diameter wells to reduce the

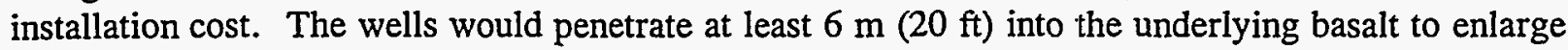
their cones of depression and to capture any contaminants migrating within the fractured portions of the basalt.

The ion-exchange plant would be located near the center of the extraction well network north of well 699-52-54. One 15-cm- (6-in.) diameter injection well located to the east of the extraction well network and north of the basalt subcrop would be used for the injection of processed water. The appropriate location of the injection well would establish a groundwater gradient to assist in moving the plume towards the extraction wells. The approximate locations of the extraction well network, the injection well, and the configuration of the contamination capture zone are shown in Figure 6-1.

The estimated costs of the focused subsurface investigation, the groundwater extraction well network, and the injection well are presented in Table 6-1.

\subsection{TREATMENT SYSTEM DESIGN PARAMETERS FOR THE 216-BY CRIB PLUME}

This section discusses the design basis for an ion-exchange treatment system. Assumptions are as follows:

- $\quad{ }^{99} \mathrm{Tc}$ is the primary target contaminant of concern and is assumed to be entering the system at an average of $10,100 \mathrm{pCi} / \mathrm{L}$. It is expected that ${ }^{60} \mathrm{Co}$ and cyanide will also be removed by the resin but nitrate will not.

- Round-the-clock operations will extract and treat groundwater at rates of $189 \mathrm{~L} / \mathrm{min}$ (50 $\mathrm{gal} / \mathrm{min}$ ) using the ion-exchange resin Dowex $21 \mathrm{~K}$. An operational life of 5 years is assumed of the system. An $80 \%$ service availability will be maintained with time out for scheduled maintenance, resin changeouts, etc.

- Fully automatic, failsafe, largely unmanned operation will be the norm. Daily/shift-wise examination of the system by operators and sampling for system performance by roving sampling crew.

- The system shall conform to all applicable environmental regulations. System will remove ${ }^{99} \mathrm{Tc}$ to below DWSs of $900 \mathrm{pCi} / \mathrm{L}$. 
- One large holding tank will be installed on either side of the treatment system to contain influent and effluent waters. Each tank will have a capacity of $49,210 \mathrm{~L}$ (13,000 gal).

- $\quad$ Operating design will be three resin vessels in series, plus a backup vessel, each column sized to provide 5-minute residence time. This will ensure no breakthrough of radionuclides while saturating the lead-column resin. No GAC treatment for organics is required.

- Equipment redundancies for mechanical operating components (pumps, filter systems, etc.) are required.

- No pre-treatment for removal of groundwater constituents is assumed.

- Laboratory analyses will be required for assessing system performance. No real-time, online techniques are available to quantify target radionuclide at historical concentrations. Regular sampling will be required until saturation of the lead column approaches. Continuous monitoring will not be required.

- $\quad$ Resin backwashing to remove fines will be performed using the offline vessel. Resin removal and addition will be accommodated through an adequately sized port.

- $\quad$ System winterization will be required. This is assumed to be implemented using gravity draining of the lines. The treatment system will need to be protected from the environment.

- Permanent power and utilities will be provided to process plant and extraction wells.

- Road construction will be required for access to the plant and to any wells used in plume treatment.

\subsection{SYSTEM DESIGN}

The N-Springs pump-and-treat system, used to remove ${ }^{90} \mathrm{Sr}$ at the $\mathrm{N}$-Springs site, is used as a basis for conceptual design and cost estimate for the scaled-up BY-Cribs ${ }^{99} \mathrm{Tc}$ plume treatment system. The $\mathrm{N}$-Springs treatment system functional and operational requirements have been presented in Frain and Jackson (1995), and a design description has been presented in DeSemple et al. (1995). The system design is included in this document by reference to the $100-\mathrm{N}$ Area, N-Springs Pump and Treat Piping and Instrumentation Diagrams, 0100N-DD-J001, 0100N-DD-J002, and 0100N-DD-J003. Conceptually, the system design is similar to that shown in Appendix A. Water pumped from the well(s) is sent to a large holding tank near the treatment system. That water is pumped through a pump/filtration system to the treatment system. A treatment train of three resin columns in series is specified to contain $.093 \mathrm{~m}^{3}\left(33 \mathrm{ft}^{3}\right)$ each of DOWEX $21 \mathrm{~K}$ resin. A fourth column is held in reserve for resin changeout/loading. The system is plumbed such that any sequence of resin columns can be connected/valved to provide three-tank series operation. Treated water is sent to a second large holding tank for post-treatment storage. Treated water will be sent to the injection well(s) by a booster pump/filtration system. Sampling ports are provided. All equipment except the extraction and injection wells and large storage tanks are placed inside a weatherproof enclosure. 
DOE/RL-95-59

Rev. 0

\subsection{SYSTEM COSTS}

Cost data provided from the N-Springs pump-and-treat project are actual constructed costs. The ability to build a system from the existing plans eliminates some of the costs associated with designing the system from scratch. Labor requirements for operation assume roving operator support on a daily or shift-wise basis. Engineering support is assumed for day shift only. Costs for a BY-Cribs system are directly factored from $\mathrm{N}$-Springs costs. Cost data are provided in Table 6-1. 
DOE/RL-95-59

Rev. 0

Figure 6-1. Preliminary Capture-Zone Analysis.

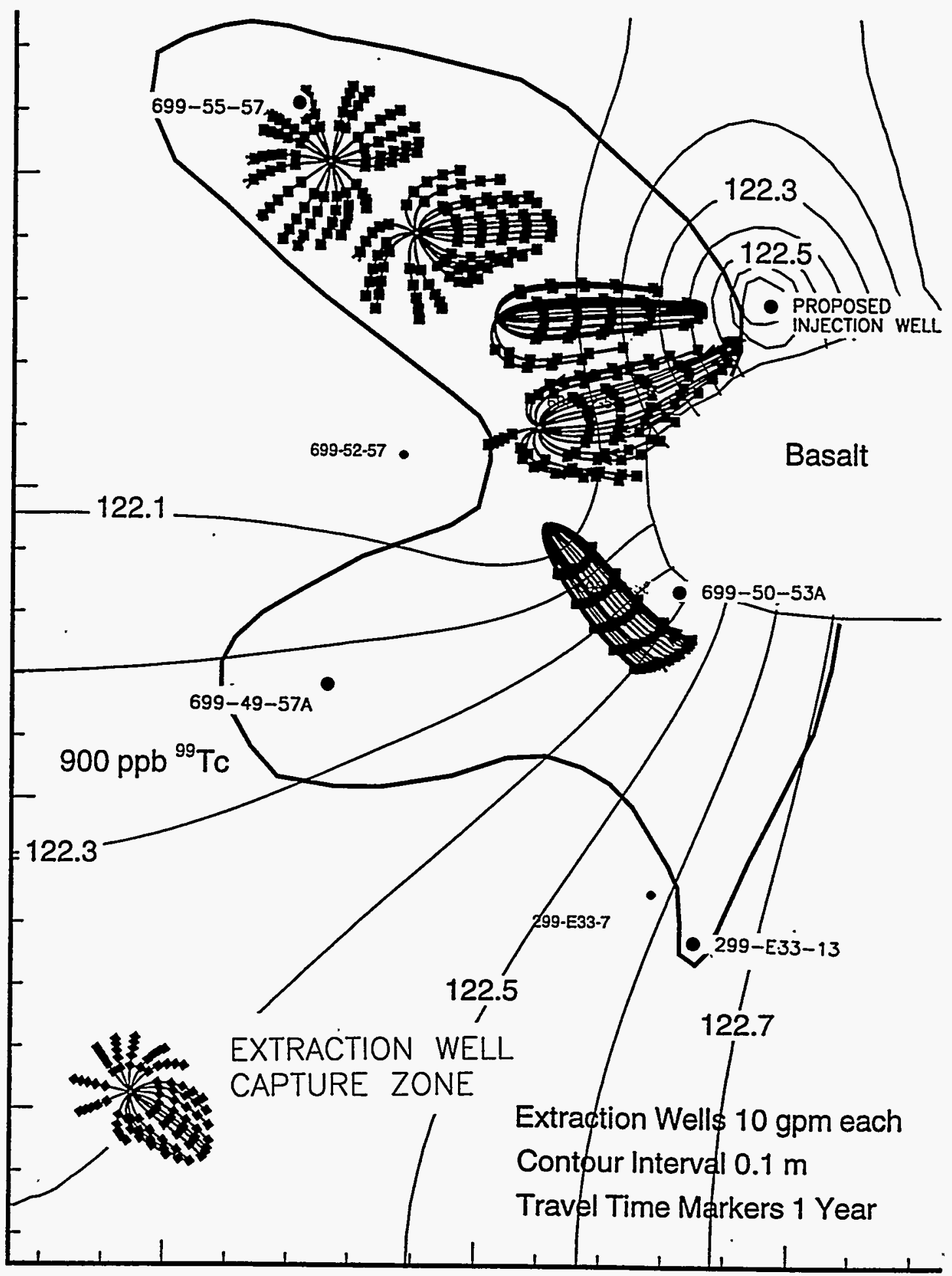




\section{DOE/RL-95-59}

Rev. 0 
Rev. 0

Table 6-1. 216-BY Cribs Treatment System Estimated Cost. (3 Sheets) (all costs are approximate)

\begin{tabular}{|c|c|c|}
\hline & $\begin{array}{l}\text { N-Spring } \\
\text { Actual }\end{array}$ & $\begin{array}{l}\text { BY-Cribs Site } \\
\text { Estimate }\end{array}$ \\
\hline \multicolumn{3}{|l|}{ System Design and Construction } \\
\hline \multicolumn{3}{|l|}{ Project Support } \\
\hline Direct Support & 157,378 & 157,378 \\
\hline Indirect Support & 297,940 & 297,940 \\
\hline Subtotal & 455,318 & 455,318 \\
\hline Well Design ${ }^{a}$ & 270,781 & 250,000 \\
\hline $\begin{array}{l}\text { Subsurface Investigations } \\
\text { High-Resolution Seismic Reflection Survey (To include } \\
\text { subcontractor labor/equipment/analysis/interpretation for surface } \\
\text { study and necessary cross-hole seismic velocity } \\
\text { testing/analysis/interpretation.) }\end{array}$ & & 500,000 \\
\hline \multirow{2}{*}{$\begin{array}{l}\text { Sonic Drilling Probe Holes } \\
\text { Subtotal }\end{array}$} & & 150,000 \\
\hline & & 650,000 \\
\hline \multirow{2}{*}{$\begin{array}{l}\text { Well Installation } \\
\text { Indirect } \\
\text { Installation } \\
\text { Evaluation/Characterization } \\
\text { Subtotal (To include costs of drilling, materials, aquifer testing and } \\
\text { evaluation, geological logging/sampling/reporting, geophysical } \\
\text { logging, etc.) }\end{array}$} & $\begin{array}{l}201,295 \\
841,112 \\
167,866\end{array}$ & 850,000 \\
\hline & $1,210,273$ & 850,000 \\
\hline \multicolumn{3}{|l|}{ Design } \\
\hline Skid Design & 88,241 & $N / A^{b}$ \\
\hline \multirow{2}{*}{$\begin{array}{l}\text { Basic Operating Plant Design } \\
\text { Subtotal }\end{array}$} & 458,133 & $150,000^{\mathrm{b}}$ \\
\hline & 546,374 & 150,000 \\
\hline Skid Procurement & 281,739 & 281,739 \\
\hline \multirow[t]{2}{*}{ Construction } & $\begin{array}{l}992,736 \\
180,571\end{array}$ & $\begin{array}{l}992,736 \\
180,571\end{array}$ \\
\hline & $1,173,307$ & $1,173,307$ \\
\hline \multirow[t]{3}{*}{ Construction Management } & 37,533 & 37,533 \\
\hline & 87,705 & 87,705 \\
\hline & 125,238 & 125,238 \\
\hline Waste Management & 7,537 & 7,537 \\
\hline Health and Safety & 41,547 & 41,547 \\
\hline
\end{tabular}


Table 6-1. 216-BY Cribs Treatment System Estimated Cost. (3 Sheets) (all costs are approximate)

\begin{tabular}{|c|c|c|}
\hline & $\begin{array}{l}\text { N-Spring } \\
\text { Actual }\end{array}$ & $\begin{array}{l}\text { BY-Cribs Site } \\
\text { Estimate }\end{array}$ \\
\hline \multirow[t]{3}{*}{ Acceptance Setup/Testing } & 114,881 & 114,881 \\
\hline & 211,029 & 211,029 \\
\hline & 325,910 & 325,910 \\
\hline \multicolumn{3}{|l|}{ Performance Monitoring } \\
\hline Data Quality Objective/Performance Monthly Plan & 42,408 & 42,408 \\
\hline Water Level and Groundwater Sampling & 299,432 & 299,432 \\
\hline Groundwater Modeling & 18,584 & 18,584 \\
\hline Performance Evaluation & 5,367 & 5,367 \\
\hline \multirow{2}{*}{$\begin{array}{l}\text { Treatability Technical Evaluation } \\
\text { Subtotal }\end{array}$} & 16,173 & 16,173 \\
\hline & 381,964 & 381,964 \\
\hline Site Maintenance & 39,712 & 39,712 \\
\hline Total & $4,859,700$ & $4,732,272$ \\
\hline \multicolumn{3}{|l|}{ System Operations } \\
\hline \multicolumn{3}{|l|}{ Labor } \\
\hline $\begin{array}{l}\text { Craft ( } 72 \mathrm{~h} / \mathrm{wk} \text {, includes operators, maintenance, health physics } \\
\text { technicians) }\end{array}$ & & 206,000 \\
\hline $\begin{array}{l}\text { Technical/Administrative }(72 \mathrm{~h} / \mathrm{wk} \text {, includes engineering, } \\
\text { geosciences, project management, samplers, clerical, etc.) }\end{array}$ & & 262,000 \\
\hline Field Supervisory $(24 \mathrm{~h} / \mathrm{wk})$ & & 87,500 \\
\hline \multirow{2}{*}{$\begin{array}{l}\text { Subtotal (per year) } \\
\text { Subtotal (for } 5 \text { years) }\end{array}$} & & 555,500 \\
\hline & & $2,777,500$ \\
\hline \multicolumn{3}{|l|}{ Sampling } \\
\hline $\begin{array}{l}\text { Performance Monitoring ( } 5 \text { well samples and } 1 \text { post-treatment } \\
\text { sample, } 7 \text { times } / 2 \text { wk for }{ }^{99} \mathrm{Tc} ; 35 \text { samples } / 2 \mathrm{wk}, \$ 200 / \text { sample) }\end{array}$ & & 182,000 \\
\hline $\begin{array}{l}\text { System Monitoring ( } 6 \text { post-treatment stage samples, } \\
7 \text { times } / 2 \text { wk for }{ }^{99} \mathrm{Tc} \text { ) }\end{array}$ & & 218,400 \\
\hline $\begin{array}{l}\text { Offsite Laboratory Sampling ( } 6 \text { samples } / \mathrm{mo} \text {, }{ }^{99} \mathrm{Tc} \text {, same sample } \\
\text { points as system monitoring, } \$ 200 / \text { sample) }\end{array}$ & & 14,400 \\
\hline $\begin{array}{l}\text { Resin Characterization/Disposal (21 samples/yr analyze for }{ }^{99} \mathrm{Tc} \text {, } \\
{ }^{60} \mathrm{Co} \text {, nitrate, metals) }\end{array}$ & & 105,000 \\
\hline $\begin{array}{l}\text { Miscellaneous ( }{ }^{60} \mathrm{Co} \text {, cyanide, nitrate, interfering groundwater } \\
\text { anions and cations, } 12 \text { times/yr, }{ }^{90} \mathrm{Sr} \text { quarterly) }\end{array}$ & & 100,000 \\
\hline \multirow{2}{*}{$\begin{array}{l}\text { Subtotal (per year) } \\
\text { Subtotal (for } 5 \text { years) }\end{array}$} & & 619,800 \\
\hline & & $3,099,000$ \\
\hline
\end{tabular}


Rev. 0

Table 6-1. 216-BY Cribs Treatment System Estimated Cost. (3 Sheets) (all costs are approximate)

\begin{tabular}{|c|c|c|}
\hline & $\begin{array}{l}\text { N-Spring } \\
\text { Actual }\end{array}$ & $\begin{array}{l}\text { BY-Cribs Site } \\
\text { Estimate }\end{array}$ \\
\hline \multicolumn{3}{|l|}{ Materials } \\
\hline Resin replacement (21 times/yr x $34 \mathrm{ft}^{3}, \$ 200 / \mathrm{ft}^{3}$ ) & & 143,000 \\
\hline Miscellaneous (maintenance replacement parts, materials, etc.) & & 45,000 \\
\hline \multirow{2}{*}{$\begin{array}{l}\text { Subtotal (per year) } \\
\text { Subtotal (for } 5 \text { years) }\end{array}$} & & 188,000 \\
\hline & & 940,000 \\
\hline \multicolumn{3}{|l|}{ Waste Disposal } \\
\hline \multicolumn{3}{|l|}{ Resin Removal and Replacement } \\
\hline $\begin{array}{l}\text { Craft Labor (decontaminating and decommissioning, health } \\
\text { physics technical, etc., } 4 \text { craft at } 16 \mathrm{~h}, 21^{\cdot} \text { times/yr) }\end{array}$ & & 74,000 \\
\hline Field Supervision (16 h, 21 times/yr) & & 23,500 \\
\hline $\begin{array}{l}\text { Materials (drums, burial boxes, miscellaneous materials, } \\
\$ 3,000 \text { /event, } 21 \text { events) }\end{array}$ & & 635,000 \\
\hline \multirow{3}{*}{$\begin{array}{l}\text { Disposal to the Environmental Restoration Disposal Facility } \\
\text { Subtotal (per year) } \\
\text { Subtotal (for } 5 \text { years) }\end{array}$} & & NO CHARGE \\
\hline & & 732,500 \\
\hline & & $3,662,500$ \\
\hline Total Operations per year & & $2,095,800$ \\
\hline Total Operations for 5 years & & $10,479,000$ \\
\hline Total System Design/Installation & & $4,732,272$ \\
\hline Total System Cost for 5 years & & $15,211,272$ \\
\hline \multicolumn{3}{|c|}{$\begin{array}{l}\text { 'Selection of well locations based on subsurface investigation and groundwater modeling, sizing } \\
\text { injection and extraction wells and extraction pumps; planning support facilities for wells including } \\
\text { transfer line design, booster pump system design, well instrumentation, and power system lines and } \\
\text { general site layout. } \\
\text { 'Costs not calculated or are reduced to reflect use of existing design. } \\
\text { N/A = not applicable. }\end{array}$} \\
\hline
\end{tabular}


DOE/RL-95-59

Rev. 0 
DOE/RL-95-59

Rev. 0

\subsection{CONCLUSIONS AND RECOMMENDATIONS}

The Risk-Based Decision Analysis for the 200-BP-5 Groundwater Operable Unit (BHI 1995c), summarized in Section 5.4, indicates that there is no significant future risk to human health associated with the ${ }^{137} \mathrm{Cs},{ }^{239240} \mathrm{Pu}$, and ${ }^{90} \mathrm{Sr}$ contamination at the B-5 Reverse Well plume. The treatment system for the B-5 Reverse Well performed satisfactorily for removal of all three contaminants. Aquifer pumping easily provided substantial quantities of groundwater containing significant concentrations of ${ }^{137} \mathrm{Cs}$ and ${ }^{90} \mathrm{Sr}$. However, the concentrations of ${ }^{239 / 240} \mathrm{Pu}$ in the extracted groundwater were small relative to the quantities of ${ }^{239240} \mathrm{Pu}$ discharged to the ground, confirming that the soil adsorbs plutonium to the extent that the groundwater is not excessively impacted. The future risks are low at this plume because both the ${ }^{137} \mathrm{Cs}$ and ${ }^{90} \mathrm{Sr}$ decay to negligible levels long before the plumes migrate off the Central Plateau and the ${ }^{239240} \mathrm{Pu}$ is essentially immobile. For this reason, it is recommended that the treatability test/pilot-scale pump-and-treat study be discontinued at the B-5 Reverse Well plume.

The plume beneath the 216-A-25 Gable Mountain Pond has already migrated off the Central Plateau, and the maximum risk associated with the ${ }^{90} \mathrm{Sr}$ in this plume exceeds an ILCR of $1 \times 10^{-5}$. Transport calculations show that this maximum risk will be reduced to the $10^{-5}$ residential ILCR level after the plume has traveled approximately $1,372 \mathrm{~m}(4,500 \mathrm{ft})$, which will take approximately 127 years.

The RBDA document also indicates that, at the BY-Cribs plume, the future risks associated with the ${ }^{99} \mathrm{Tc}$ in this plume are predicted to be above MTCA standards. The ion-exchange treatment system has been shown to work satisfactorily in removing elevated concentrations of ${ }^{60} \mathrm{Co}$ and ${ }^{99} \mathrm{Tc}$ at the BY-Cribs site. However, the demonstrated poor groundwater extraction rates at this site emphasize the large degree of uncertainty about plume geometry and aquifer characteristics. For this reason, it is recommended that the treatability test/pilot-scale pump-and-treat study be discontinued at the BY-Cribs plume.

A limited program of groundwater monitoring is necessary to assess the continued migration of plume contaminants at the 216-B-5 Reverse Well, the 699-505-3A site, and the 216-A-25 Gable Mountain Pond site. The monitoring program should be designed to determine the geometry and migration of the ${ }^{60} \mathrm{Co},{ }^{90} \mathrm{Sr},{ }^{99} \mathrm{Tc},{ }^{137} \mathrm{Cs}$, ${ }^{239240} \mathrm{Pu}$, nitrate, and cyanide plumes. In addition, wells not associated with a plume but that have shown increased concentrations in target contaminants should be sampled regularly to determine if the plume is moving in an unexpected direction. An annual monitoring program at wells within and adjacent to the plume should be sampled for only the target contaminants. Other plumes that may be in the 200-BP-5 Operable Unit boundaries (e.g., ${ }^{129} \mathrm{I},{ }^{3} \mathrm{H}$ ) are either at low concentrations, are not treatable with current technology, or are sampled by other programs. Regardless of which Hanford organization performs the sampling, the analytical results must be evaluated to determine plume changes and to evaluate and approve future sampling.

\subsection{TREATABILITY TESTING}

The 200-BP-5 Operable Unit treatability test began with the initial definition of success as meeting or exceeding $90 \%$ removal of radionuclides in the influent groundwater. At a later date, the requirement that each radionuclide be treated to concentrations less than its MCL was applied to ensure no out-of-plume contamination of the aquifer. In most cases, this requirement was easily met; but for 
${ }^{90} \mathrm{Sr}$, the new definition for success required a $99.8 \%$ plus system removal efficiency to achieve the $\mathrm{MCL}$, which was found to be more difficult to meet.

The treatability test results show that ${ }^{60} \mathrm{Co}$ and ${ }^{99} \mathrm{Tc}$ at the BY-Cribs plume and ${ }^{137} \mathrm{Cs}$ and ${ }^{239240} \mathrm{Pu}$ at the B-5 Reverse Well could be removed to below MCL levels by ion exchange. For ${ }^{60} \mathrm{Co}$ and ${ }^{239 / 240} \mathrm{Pu}$, the data show that the treatment systems either closely approached the $1.2 \mathrm{pCi} / \mathrm{L}$ MCL for ${ }^{239 / 240} \mathrm{Pu}$ or exceeded the $90 \%$ removal efficiency for ${ }^{60} \mathrm{Co}$.

The initial pilot test run at the B-5 Reverse Well showed that the ${ }^{90} \mathrm{Sr}$ MCL could not be effectively met, although greater than $90 \%$ removal occurred over about $500 \mathrm{BV}$ throughput. Increasing contact time in the second run significantly improved ${ }^{90} \mathrm{Sr}$ removal efficiency such that removal efficiency could be maintained above $90 \%$ for about $1,850 \mathrm{BV}$; the second pilot run did not achieve the ${ }^{90} \mathrm{Sr}$ $\mathrm{MCL}$ in the effluent.

The mini-column testing showed higher ${ }^{90} \mathrm{Sr}$ removal efficiencies relative to the pilot plant. Two mini-column tests run at approximately 5.5 minutes per column residence times indicated that ${ }^{90} \mathrm{Sr}$ system removal efficiencies of greater than $90 \%$ were achieved for 3,500 BV. For mini-column tests operated at 12 minutes per column empty-bed contact times, removal efficiencies greater than $90 \%$ were achieved for almost $2,900 \mathrm{BV}$. Additionally, ${ }^{90} \mathrm{Sr}$ was removed to below the 8 -pCi/L MCL for the first 1,000 to $1,250 \mathrm{BV}$ in the two 12 -minute per column tests. Based on analysis of the kinetic rate constants calculated for these data, an extrapolation indicates that a three-column clinoptilolite system with about 18-minute contact time in each column should be sufficient to meet the 8-pCi/L MCL for several thousand bed volumes. However, high removal efficiencies require higher capital investment for larger adsorbent beds than do lower removal efficiencies.

Resin/adsorbent saturations of $90 \%$ to $100 \%$ for the radionuclides were not achieved for any of the materials in the pilot-scale systems. Full saturation test results were only achieved at the BY-Cribs mini-column tests for ${ }^{99} \mathrm{Tc}$, where $90 \%$ saturation was achieved at 5,200 BV.

Bench-scale mini-column tests were useful in shortening the time needed to get results and in the ability to test alternate resins. However, because the mini-column tests outperform the pilot-scale system in removal of radionuclides, some conservatism is needed to project the smaller system's results to that of a larger system. Tests capable of meeting the demonstrated need for long runs to reach saturation are practical only in a field-based bench-scale test. This type of test would be required to determine the ultimate adsorbent consumption rate. The treatability test data are adequate for developing a conservative design of a treatment system.

The test objectives included development of recommendations for a scale-up of the pilot test systems to full-scale IRMs. A design has been proposed for a treatment system at the BY-Cribs plume for the target contaminant ${ }^{99} \mathrm{Tc}$. The design is based on the pilot-scale treatment resin, DOWEX $21 \mathrm{~K}$, in a system modeled after the $189-\mathrm{L} / \mathrm{min}(50-\mathrm{gal} / \mathrm{min}) \mathrm{N}$-Springs pump-and-treat system. However, it would first be necessary to characterize the ${ }^{99} \mathrm{Tc}$ contaminant plume prior to installing a treatment system. 


\subsection{GROUNDWATER REMEDIATION}

While there are no drivers for remediation of any of the 200-BP-5 plumes on the accelerated IRM pathway, it is recommended that monitoring of the groundwater plumes at the BY-Cribs be continued and monitoring of both the B-5 Reverse Well and 216-A-25 Gable Mountain Pond plumes be added to the project scope. These monitoring activities should be conducted on at least an annual basis and should be increased in frequency if significant concentration changes or plume movement are observed. Existing well coverage may not be adequate for all sites or for potential changes in plume migration direction. In the future, additional wells should be considered if such changes are noted or groundwater modeling indicates gaps in the groundwater monitoring network.

The RBDA for the BY-Cribs plume shows that the future risks associated with the ${ }^{99} \mathrm{Tc}$ in this plume exceed the risk level allowable by MTCA. The risk analysis predicts that at the year 2018 , the point of maximum concentration (based on a historical $95 \%$ UCL concentration of $27,548 \mathrm{pCi} / \mathrm{L}$ of ${ }^{99} \mathrm{Tc}$ ) will have moved about $2,682 \mathrm{~m}(8,800 \mathrm{ft})$ downgradient and the maximum concentration of ${ }^{99} \mathrm{Tc}$ will be about $7,843 \mathrm{pCi} / \mathrm{L}\left(2.2 \times 10^{-4}\right.$ residential cancer risk). The risk analysis further predicts that the plume will reach the river in about 75 years and the residential risk will still exceed the allowable MTCA risk standard. Because there is no effective means of remediating this plume, it is recommended that this plume be removed from the accelerated IRM pathway and all further work be deferred for the time being. If an IRM or other remediation activities were to be initiated at some point in the future, a substantial aquifer characterization effort would be required to resolve the many technical uncertainties regarding the contaminant conceptual model and hydrogeology of this site. Such characterization work would include drilling new wells across the extent of the plume to determine its areal extent and aquifer properties. New wells should be located using results from a seismic refraction survey, which would be used to map the top of basalt, and from direct drilling to those locations where topographic lows in the basalt may indicate thicker aquifer conditions. Aquifer production properties need to be tested as well. Undisturbed sediment and basalt samples and depthspecific groundwater samples need to be obtained to permit geochemical and hydrological analyses.

The RBDA indicates that the B-5 Reverse Well plumes will not produce an unacceptable risk to offsite groundwater users. Therefore, it is recommended that the plumes be removed from the accelerated IRM pathway and that the future course of action include only groundwater monitoring to track plume movement and verify modeling results. Existing groundwater monitoring wells located south and southeast of the B-5 Reverse Well should be remediated and added to the monitoring network should any future site groundwater modeling activities indicate the potential for southerly groundwater flow.

The 216-A-25 Gable Mountain Pond does not require additional characterization at this time. The site has received large quantities of contaminants, but most appear to be well-bound to the vadose zone and will decay to negligible levels. Because of the expected low migration potential for the site contaminants, predicted at $1,372 \mathrm{~m}(4,500 \mathrm{ft})$ in 127 years for ${ }^{90} \mathrm{Sr}$, by the risk analysis, only annual groundwater monitoring is required. Increases in groundwater ${ }^{90} \mathrm{Sr}$ concentrations observed over the last 5 years may require additional study if the trend continues. 
Rev. 0

\subsection{LESSONS LEARNED}

A number of problems were encountered during the course of developing the two pump-and-treat systems at the 200-BP-5 Operable Unit. Resolutions, consisting of either fixes to the problems or adjustments to the project, were ultimately found for the problems. A discussion of what was learned from these problems and responses is the subject of this section.

\subsubsection{Groundwater}

The most significant difficulty encountered in the 200-BP-5 Operable Unit was the lack of groundwater at the BY-Cribs site. Although the data were available during the course of treatability test plan preparation in 1993, in the form of semiannual and annual groundwater elevation reports (i.e., Kasza et al. 1990), the decline in groundwater levels was not recognized until early 1994 and was confirmed with the well suitability testing discussed in Section 4.1 .

In an effort to better assess aquifer thickness and plume distribution at the BY-Cribs site, a drilling program for new wells was proposed and implemented several months before start of the treatability testing. Plans to drill holes blindly in the presumed vicinity of the plume were rejected as being too much risk for the cost. The use of a push technique (Section 4.4.1) using a Water Development Company sonic drill rig and standard cone penetrometer rods was implemented. Although only three boreholes out of eight were completed successfully into the aquifer and another three were stopped short of the aquifer, the data were collected rapidly and efficiently. Problems with the cone penetrometer rods were not overcome during the course of testing but helped to direct modifications after completion of the BY-Cribs drilling. The technique offers considerable benefits for relatively limited costs.

The use of high-resolution seismic reflection surveys to map the top of basalt was discussed during the course of field work and needs to be investigated further. The technique offers the ability to get away from blind drilling by characterizing broad areas of the subsurface with surface-based geophysical techniques. The cost of subsurface characterization on a per-square-foot-basis for several miles of survey lines would be equal to that of several boreholes but would significantly increase the potential for locating thicker parts of the aquifer and could proportionately decrease the chances of dry holes. Formation seismic velocity data have been gathered that would significantly improve the technique's accuracy.

\subsubsection{Laboratory Testing}

Laboratory testing was recognized as an important phase of the treatability test development program during preparation of the treatability test plan. The value of mini-column tests was recognized by their ease and efficiency of testing treatment alternatives. The systems were able to deliver saturation data for some of the contaminants. For others, alternate adsorbents, longer residence times, and pretreatment alternatives were examined. Some of this data could have been obtained during laboratory testing, but the volume of water required would have limited laboratory test effectiveness. Field mini-column testing provided an effective alternate to making constant changes in pilot-scale system operation. 
DOE/RL-95-59

Rev. 0

\subsection{REFERENCES}

Ames, L.L., Jr., 1959, Zeolite Extraction of Cesium from Aqueous Solutions, HW-62607, Hanford Atomic Products Operation, General Electric Corporation, Richland, Washington.

Ames, L.L. and R.J. Serne, 1991, Compilation of Data to Estimate Groundwater Migration Potential for Constituents in Active Liquid Discharges at the Hanford Site, PNL-7660, Pacific Northwest Laboratory, Richland, Washington.

Anderson, J.D., 1990, A History of the 200 Area Tank Farms, WHC-MR-0132, Westinghouse Hanford Company, Richland, Washington.

Baker, S.M., J.L. Devary, R.P. Elmore, E.F. Lorang, A.J. Rossi, and M.D. Freshly, 1988, U1/U2 Uranium Plume Characterization, Remedial Action Review and Recommendation for Future Action, WHC-EP-0133, Westinghouse Hanford Company, Richland, Washington.

Barney, G.S., 1988, Adsorption of Plutonium on Hanford Sediments from Shallow Groundwaters Measurements of Distribution Coefficients, (internal memo 12714-PSL88-168 to J.L. Gieger, December 27, 1988), Westinghouse Hanford Company, Richland, Washington.

Barney, G.S., K.J. Lueck, and J.W. Green, 1992, Removal of Plutonium from Low-Level Process Wastewaters by Adsorption, "Environmental Remediation, Removing Organics and Metal Ion Pollutants," ACS Symposium Series 509, American Chemical Society, Washington D.C., pp. 34-46.

BHI, 1994, Environmental Investigation Procedures, BHI-EE-01, Bechtel Hanford, Inc., Richland, Washington.

BHI, 1995a, 216-B-3 Pond Interim Stabilization, Final Report, BHI-00219, Rev. 00, Bechtel Hanford, Inc., Richland, Washington.

BHI, 1995b, Risk-Based Decision Analysis for Groundwater Operable Units, BHI-00161, Rev. 01, Bechtel Hanford, Inc., Richland, Washington.

BHI, 1995c, Risk-Based Decision Analysis for the 200-BP-5 Groundwater Operable Unit, BHI-00416, Rev. 00, Bechtel Hanford, Inc., Richland, Washington.

BHI, 1995d, Workplan and Procedures for Bench-Scale Testing for the 200-BP-5, Unit \#2 Groundwater Operable Unit, BHI-OP-00042, Rev. 00, Bechtel Hanford, Inc., Richland, Washington.

BHI, 1995e, Workplan and Procedures for Bench-Scale Testing of Potential Absorbents for the 200-BP-5 Groundwater Operable Unit, BHI-OP-00015, Rev. 00, Bechtel Hanford, Inc., Richland, Washington.

Bierschenk, W.H., 1957, The Effect of Ground-Water Mounds on the PUREX Operation, HW-49728, General Electric Company, Hanford Atomic Products Operations, Richland, Washington. 
DOE/RL-95-59

Rev. 0

Bierschenk, W.H., ed. 1959a, Chemical Effluents Technology Waste Disposal Investigations, July, August, September, 1958, HW-58023-RD, General Electric Company, Hanford Atomic Products Operation, Richland, Washington.

Bierschenk, W.H., ed. 1959b, Chemical Effluents Technology Waste Disposal Investigations, October, November, December, 1957, HW-54848, General Electric Company, Hanford Atomic Products Operation, Richland, Washington.

Brown, D.J., 1957, Chemical Effluents Technology Waste Disposal Investigations, October, November, December 1956, HW-53225, General Electric Company, Hanford Atomic Products Operation, Richland, Washington.

Brown, D.J., 1963, Chemical Effluents Technology Waste Disposal Investigations, July - December 1962, HW-76120-RD, General Electric Company, Hanford Atomic Products Operation, Richland, Washington.

Brown, D.J., 1964, Chemical Effluents Technology Waste Disposal Investigations, January December 1964, HW-84549, General Electric Company, Hanford Atomic Products Operation, Richland, Washington.

Brown, D.J. and J.R. Raymond, 1962, Hanford Experience in the Radiological Monitoring of Ground Water, HW-SA-2566, General Electric Company, Hanford Atomic Products Operation, Richland, Washington.

Brown, R.E. and H.G. Ruppert, 1950, The Underground Disposal of Liquid Wastes at the Hanford Works, Washington, HW-17088, General Electric Company, Hanford Atomic Products Operation, Richland, Washington.

Brown, M.J., R.L. P'Pool, and S.P. Thomas, 1990, Westinghouse Hanford Company Effluent Discharges and Solid Waste Management Report for Calendar Year 1989: 200/600 Area, WHC-EP-0141-2, Westinghouse Hanford Company, Richland, Washington.

Connelly, M.P., J.V. Borghese, C.D. Delaney, B.H. Ford, J.W. Lindberg, and S.J. Trent, 1992, Hydrogeologic Model for the 200 East Groundwater Aggregate Area, WHC-SD-EN-TI-019, Westinghouse Hanford Company, Richland, Washington.

Coony, R.M. and S.P. Thomas, 1989, Westinghouse Hanford Company Effluent Discharges and Solid Waste Management Report for Calendar Year 1988: 200/600 Area, WHC-EP-0141-2, Westinghouse Hanford Company, Richland, Washington.

Cushing C.E. and D.G. Watson, 1974, Aquatic Studies of Gable Mountain Pond, BNWL-1884, Pacific Northwest Laboratory, Richland, Washington.

Deju, R.A., 1974, The Hanford Field Testing Program, ARH-00004, Atlantic Richfield Hanford Company, Richland, Washington.

Del Cul, G.D., W.D. Bostick, D.R. Trotter, and P.E. Osborne, 1992, "Technetium-99 Removal from Process Solutions and Contaminated Groundwater," In: Separation Science and Technology, 28(1-3), pp. 551-564. 
DOE/RL-95-59

Rev. 0

Delaney, C.D., K.A. Lindsey, and S.P. Reidel, 1991, Geology and Hydrology of the Hanford Site: A Standardized Text for Use in Westinghouse Hanford Company Documents and Reports, WHC-SD-ER-TI-003, Rev. 0, Westinghouse Hanford Corporation, Richland, Washington.

Delegard, C.H., R.L. Weiss, R.T. Kimura, A.G. Law, and R.C. Routson, 1986, Characterization and Anion Exchange Removal of Uranium from Hanford Groundwater, RHO-RE-SA-116P, Rockwell Hanford Operations, Richland, Washington.

DeSemple, D.L., J.R. Hoyle, and E.A. Nelson, 1995, $N$ Springs Pump-and-Treat System Design Description, BHI-00335, Bechtel Hanford, Inc., Richland, Washington.

DOE, 1988, Consultation Draft Site Characterization Plan, DOE/RW-0164, Vols. 1-9, Office of Civilian Waste management, U.S. Department of Energy, Washington, D.C.

DOE-RL, 1990, Remedial Investigation/Feasibility Study Work Plan for the 200-BP-1 Operable Unit, Hanford Site, Richland, Washington, DOE/RL-88-32, U.S. Department of Energy, Richland Operations Office, Richland, Washington.

DOE-RL, 1991, Hanford Past-Practice Strategy, DOE/RL-91-40, Rev. 0, U.S. Department of Energy, Richland Operations Office, Richland, Washington.

DOE-RL, 1992, Hanford Site Waste Management Units Reports, DOE/RL-88-30, U.S. Department of Energy, Richland Operations Office, Richland, Washington.

DOE-RL, 1993a, 200 East Groundwater Aggregate Area Management Study Report, DOE/RL-92-19, Rev. 0, U.S. Department of Energy, Richland Operations Office, Richland, Washington.

DOE-RL, 1993b, 200 West Groundwater Aggregate Area Management Study Report, DOE/RL-92-16, Rev. 0, U.S. Department of Energy, Richland Operations Office, Richland, Washington.

DOE-RL, 1993c, B Plant Source Aggregate Area Management Study Report, DOE/RL-92-05, Rev. 0, U.S. Department of Energy, Richland Operations Office, Richland, Washington.

DOE-RL, 1993d, Phase I Remedial Investigation Report for the 200-BP-I Operable Unit, DOE/RL-92-70, Rev. 0, U.S. Department of Energy, Richland Operations Office, Richland, Washington.

DOE-RL, 1993e, PUREX Source Aggregate Area Management Study Report, DOE/RL-92-04, Rev. 0, U.S. Department of Energy, Richland Operations Office, Richland, Washington.

DOE-RL, 1994, State Waste Discharge Permit Application for Industrial Discharge to Land, 200 East Area, W-252 Streams, DOE/RL-93-61, U.S. Department of Energy, Richland Operations Office, Richland, Washington.

DOE-RL, 1995a, Treatability Test Report for the 200-UP-1 Operable Unit - Hanford Site, DOE/RL-95-02, Rev. 0 , U.S. Department of Energy, Richland Operations Office, Richland, Washington. 
DOE-RL, 1995b, Hanford Site Risk Assessment Methodology, DOE/RL-91-45, Rev. 3, U.S. Department of Energy, Richland Operations Office, Richland, Washington.

DOE-RL, 1995c, Pilot-Scale Treatability Test Plan for the 200-BP-5 Operable Unit, DOE/RL-93-98, Rev. 1, U.S. Department of Energy, Richland Operations Office, Richland, Washington.

Earth Sciences Personnel, 1956, Earth Sciences' Waste Disposal Monitoring Activities Summary, April, 1956, HW-44354, General Electric Company, Hanford Atomic Products Operation, Richland, Washington.

Ecology, EPA, and DOE, 1994, Hanford Federal Facility Agreement and Consent Order, 2 vols., as amended, Washington State Department of Ecology, U.S. Environmental Protection Agency, and U.S. Department of Energy, Olympia, Washington.

Eliason, J.R., 1966, Earth Sciences Waste Disposal Investigations, July - December, 1965, BNWL-CC-574, Pacific Northwest Laboratory, Richland, Washington.

EPA, 1976, National Interim Primary Drinking Water Regulations, EPA-570/9-76-003, U.S. Environmental Protection Agency, Office of Water Supply, Washington, D.C.

EPA, 1990, Assessment of Technologies for the Remediation of Radioactively Contaminated Superfund Sites, EPA/540/2-90/001, U.S. Environmental Protection Agency, Washington, D.C.

EPA, 1992, Guide for Conducting Treatability Studies Under CERCLA, Final, EPA/540/R-92/071a, U.S. Environmental Protection Agency, Washington, D.C.

Ford, B.H., 1993, Groundwater Field Characterization Report for the 200 Aggregate Area Management Study, WHC-SD-EN-TI-020, Westinghouse Hanford Company, Richland, Washington.

Frain, J.M. and G.J. Jackson, 1995, N Springs Groundwater Pump-and-Treat System Functional and Operational Requirements, BHI-00030, Bechtel Hanford, Inc., Richland, Washington.

Freeze, R.A. and J.A. Cherry, 1979, Groundwater, Prentice-Hall, Inc., Englewood Cliffs, New Jersey, p. 318.

Freshley, M.D. and P.D. Thorne, 1992, Ground-Water Contribution to Dose from Past Hanford Operations, PNWD-1974 HEDR, Pacific Northwest Laboratory, Richland, Washington.

Freundlich, 1926, Colloid and Capillary Chemistry, Methuen and Company, London.

Graham, M.J. and D.A. Brown, 1981, Results for Separations Area Groundwater Monitoring Network for 1980, RHO-LD-0165, Rockwell Hanford Operations, Richland, Washington.

Grove, D.B., 1971, Part II: An Analysis of the Flow Field of a Discharging-Recharging Pair of Wells, USGS-474-99, United States Geological Survey, Denver, Colorado. 
Haney, W.A., ed., 1959, Chemical Effluents Technology Waste Disposal Investigations, July, August, September, 1959, HW-62692-RD, General Electric Company, Hanford Atomic Products Operation, Richland, Washington.

Haney, W.A., 1960, Chemical Effluents Technology Waste Disposal Investigations, October, November, December 1959, HW-64094-RD, General Electric Company, Hanford Atomic Products Operation, Richland, Washington.

Haney, W.A., ed., 1963, Chemical Effluents Technology Waste Disposal Investigations, January-June, 1963, HW-78951, General Electric Company, Hanford Atomic Products Operation, Richland, Washington.

Hayward, W.M., 1989, Gable Mountain Pond Interim Stabilization Report, WHC-SD-DD-TI-036, Westinghouse Hanford Company, Richland, Washington.

Hodges, F.N., 1995, In Preparation, Hanford B-5 Reverse Well: Controls on Radionuclide Distribution, WHC-EP-0863, Westinghouse Hanford Company, Richland, Washington.

Jelinek, R.T. and T.J. Sorg, 1988, "Operating a Small Full-Scale Ion Exchange System for Uranium Removal," In: Journal American Water Works Association, Volume 80, No. 7, pp. 79-83.

Jungfleisch, F.M., 1984, Preliminary Estimation of the Waste Inventories in Hanford Tanks through 1980, SD-WM-TI-057, Rockwell Hanford Operations, Richland, Washington.

Kasza, G.L., 1993, Potential for Groundwater Contamination from High Density Wastes Disposed at the BY Cribs, 200-BP-1 CERCLA Operable Unit, WHC-SD-EN-TA-003, Westinghouse Hanford Company, Richland, Washington.

Kasza, G.L., S.F. Harris, and M.J. Hartman, 1990, Ground Water Maps of the Hanford Site, WHC-EP-0394-1, Westinghouse Hanford Company, Richland, Washington.

Kipp, K.L. and R.D. Mudd, 1974, Selected Water Table Contour Maps and Well Hydrographs for the Hanford Reservation, 1944-1973, BNWL-B-360, Pacific Northwest Laboratory Water and Land Resources Department, Richland, Washington.

Krauskopf, K.B., 1979, Introduction to Geochemistry, 2nd Ed., McGraw-Hill Book Company.

Langmuir, 1918, "The Adsorption of Gases on Plane Surfaces of Glass, Mica, and Platinum," J. American Chemical Society, Vol. 40, No. 9, p. 1,361.

Last, G.V., B.N. Bjornstad, D.W. Wallace, D.R. Newcomer, J.A. Schranke, M.A. Chamness, C.S. Cline, S.P. Airhart, and J.W. Wilbur, 1989, Hydrogeology of the 200 Areas Low-Level Burial Grounds-An Interim Report, PNL-6820, Pacific Northwest Laboratory, Richland, Washington.

Law, A.G. and R.M. Allen, 1984, Results of Separations Area Ground-Water Monitoring Network for 1983, RHO-RE-SR-84-24P, Rockwell Hanford Operations, Richland, Washington. 
Law, A.G. and A.L. Schatz, 1986, Results of Separations Area Ground-Water Monitoring Network for 1985, RHO-RE-SR-86-24P, Rockwell Hanford Operations, Richland, Washington.

Law, A.G., A.L. Schatz, M.R. Fuchs, and K.L. Dillon, 1986, Results of Separations Area Ground-Water Monitoring for 1984, RHO-RE-SR-85-24P, Rockwell Hanford Operations, Richland, Washington.

Ledgerwood, R.K., 1993, Summaries of Well construction Data and Field Observations for Existing 200-East Resource Protection Wells, WHC-SD-ER-TI-007, Rev. 0, Westinghouse Hanford Company, Richland, Washington.

Lindsey, K.A., B.N. Bjornstad, J.W. Lindberg, and K. M. Hoffmann, 1992, Geologic Setting of the 200 East Area: An Update, WHC-SD-EN-TI-012, Westinghouse Hanford Company, Richland, Washington.

Maxfield, H.L., 1979, Handbook - 200 AREA Waste Sites, RHO-CD-673, Rockwell Hanford Operations, Richland, Washington.

Mercer, B.W., Jr., 1960, The Removal of Cesium and Strontium from Condensate Wastes with Clinoptilolite, HW-66276, Hanford Atomic Products Operations, General Electric Corporation, Richland, Washington.

Myers, C.W., S.M. Price, J.A. Caggiano, M.P. Cochran, J.W. Czimer, N.J. Davidson, R.C. Edwards, K.R. Fecht, G.E. Holmes, M.G. Jones, J.R. Kunk, R.D. Landon, R.K. Ledgerwood, J.T. Lillie, P.E. Long, T.H. Mitchell, E.H. Price, S.P. Reidel, and A.M. Tallman, 1979, Geologic Studies of the Columbia Plateau: A Status Report, RHO-BWI-ST-4, Rockwell Hanford Operations, Richland, Washington.

Newcomer, D.R., M.A. Chamness, D.L. McAlister, R.J. Brockman, A.W. Pearson, and S.T. Teel, 1992, Unconfined Aquifer Hydrologic Test Data Package for the 200 East Area, WHC-SD-EN-DP-030, Rev. 0, Westinghouse Hanford Company, Richland, Washington.

Parker, H.M., 1956, Radiological Sciences Department Quarterly Progress Report, Research and Development Activities, January-March, 1956, HW-42403, General Electric Company, Hanford Atomic Products Operation, Richland, Washington.

Parker, H.M., and C.C. Gamertsfelder, 1945, Weekly H. I. Reports on 200 Area and Environs for 1-5-45 Through 2-13-46 (\#I Through 58), HW-7-1115, E. I. duPont de Nemours and Company, Hanford Engineer Works, Richland, Washington.

Price, K.R., 1986, Environmental Monitoring at Hanford for 1985, PNL-5817, Pacific Northwest Laboratory, Richland, Washington.

Raymond, J.R., D.A. Myers, J.J. Fix, V.L. McGhan, and P.M. Schrotke, 1976, Environmental Monitoring Report on Radiological Status of the Ground Water Beneath the Hanford Site, January - December, 1974, BNWL-1970, Pacific Northwest Laboratory, Richland, Washington.

Reactor Handbook, 1961, Vol. II, Fuel Reprocessing, Interscience Publishers, New York, New York. 
Reidel, S.P., K.A. Lindsey, and K.R. Fecht, 1992, Field Trip Guide to the Hanford Site, WHC-MR-0391, Westinghouse Hanford Company, Richland, Washington.

Rhodes, D.W., K.R. Holtzinger, and J.R. McHenry, 1954, Adsorption of Radioactive Isotopes by Soil from a Bismuth Phosphate Waste, HW-32978, General Electric Company, Hanford Atomic Products Operation, Richland, Washington.

Robinson, S.M., 1990, Strategy for Management of Oak Ridge National Laboratory (ORNL) Process Wastewater, Draft, Martin Marietta Energy Systems.

Serkowski, J.A. and W.A. Jordan, 1989, Operational Groundwater Monitoring at the Hanford Site -1988, WHC-EP-0260, Westinghouse Hanford Company, Richland, Washington.

Serkowski, J.A., W.A. Jordan, and M.J. Hartman, Groundwater Maps of the Hanford Site, June 1994, WHC-EP-0394-9, Westinghouse Hanford Company, Richland, Washington.

Serne, R.J. and M.I. Wood, 1990, Hanford Waste-Form Release and Sediment Interaction Status Report with Rationale and Recommendations for Additional Studies, PNL-7297, Pacific Northwest Laboratory, Richland, Washington.

Smith, R.M., 1980, 216-B-5 Reverse Well Characterization Study, RHO-ST-37, Rockwell Hanford Operations, Richland, Washington.

Smith, D.L., 1993, Safety Evaluation for the Interim Stabilization of the 216-B-3 Pond, the 216-B-3-3 Ditch, and the 216-B-3A Lobe, WHC-SD-EN-TI-082, Westinghouse Hanford Company, Richland, Washington.

Sorg, T.J., 1989, Removal of Uranium from Drinking Water by Conventional Treatment Methods, EPA/600/D-89/020, Drinking Water Research Division, Risk Reduction Engineering Laboratory, U.S. Environmental Protection Agency, Cincinnati, Ohio.

Sorg, T.J., 1991, Radionuclide Removal, EPA/600/D-91/262, Drinking Water Research Division, Risk Reduction Engineering Laboratory, U.S. Environmental Protection Agency, Cincinnati, Ohio.

Stedwell, M.J., 1954, Evaluation of Nickel Ferrocyanide Scavenging of Uranium Recovery Plant Solvent Extraction Waste, HW-31428, General Electric Company, Richland, Washington.

Stenner, R. D., K. H. Cramer, K. A. Higley, S. J. Jette, D. A. Lamar, T. J. McLaughlin, D. R. Sherwood, and N. C. VanHouten, 1988, Inactive Waste Sites at Hanford, PNL-6456, Pacific Northwest Laboratory, Richland, Washington.

Strait, S.R. and B.A. Moore, 1982, Geohydrology of the Rattlesnake Ridge Interbed in the Gable Mountain Pond Area, RHO-ST-38, Rockwell Hanford Operations, Energy Systems Group, Richland, Washington.

Thomas, C.W., D.L. Reid, and E.A. Treibs, 1956, Cobalt-60 in Ground Water and Separations Plant Waste Streams, HW-42612, General Electric Company, Hanford Atomic Products Operation, Richland, Washington. 
DOE/RL-95-59

Rev. 0

Walton, W.C., 1989, Analytical Groundwater Modeling, Flow and Contaminant Migration, Lewis Publishers, Inc., Chelsea, Michigan.

WHC, 1988, Environmental Investigations and Site Characterization Manual, WHC-CM-7-7, Westinghouse Hanford Company, Richland, Washington.

WHC, 1991, Waste Information Data System, (WIDS), Westinghouse Hanford Company, Richland, Washington.

WHC, 1994, Treatment Tests for Ex Situ Removal of Chromate, Nitrate, and Uranium (VI) from Hanford (100-HR-3) Groundwater Final Report, WHC-SD-ER-DTR-001, Rev. 0, Westinghouse Hanford Company, Richland, Washington. 
DOE/RL-95-59

Rev. 0

APPENDIX A

PROCESS FLOW DIAGRAMS 
DOE/RL-95-59

Rev. 0 


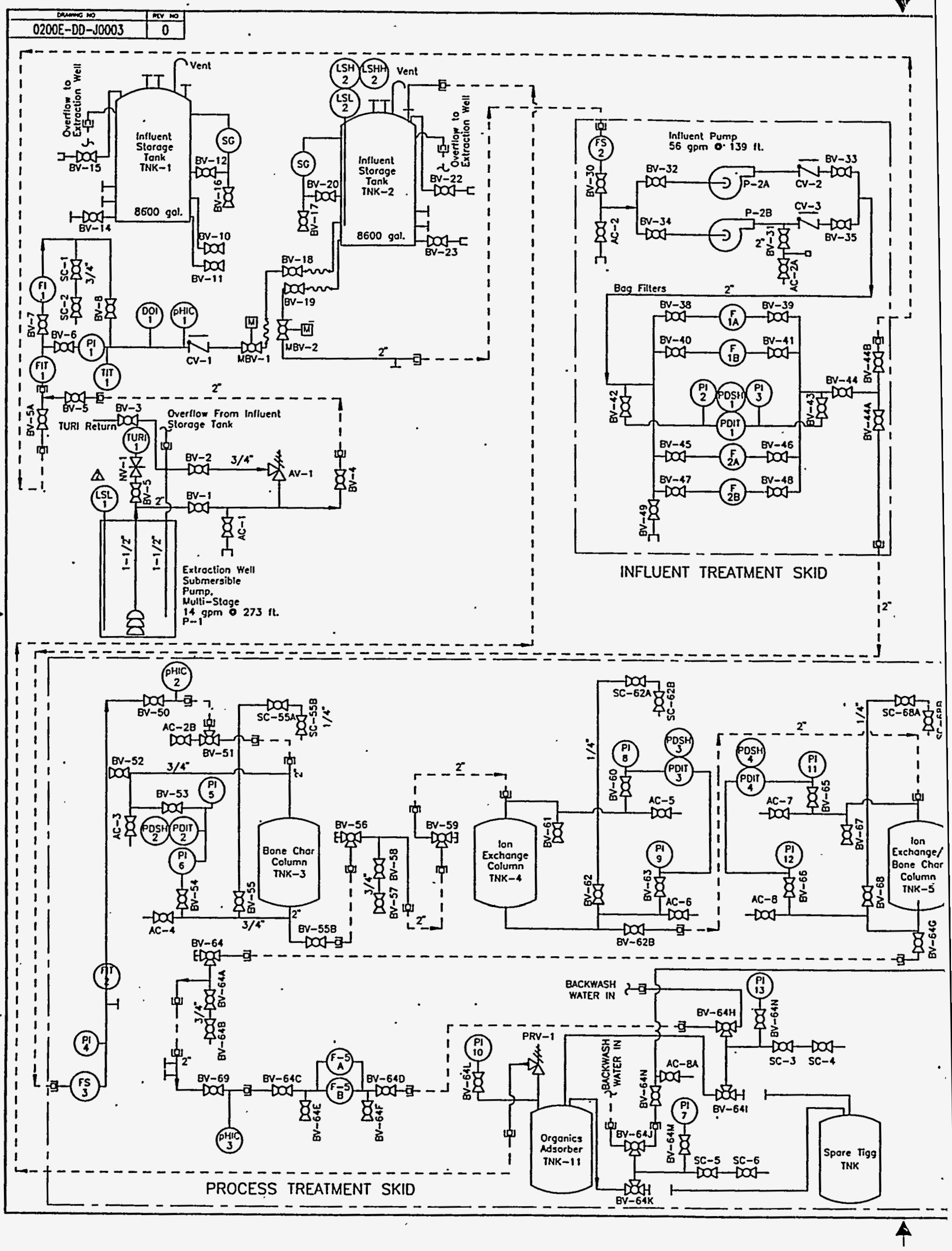


DOE/RL-95-59

Rev. 0

NOTES

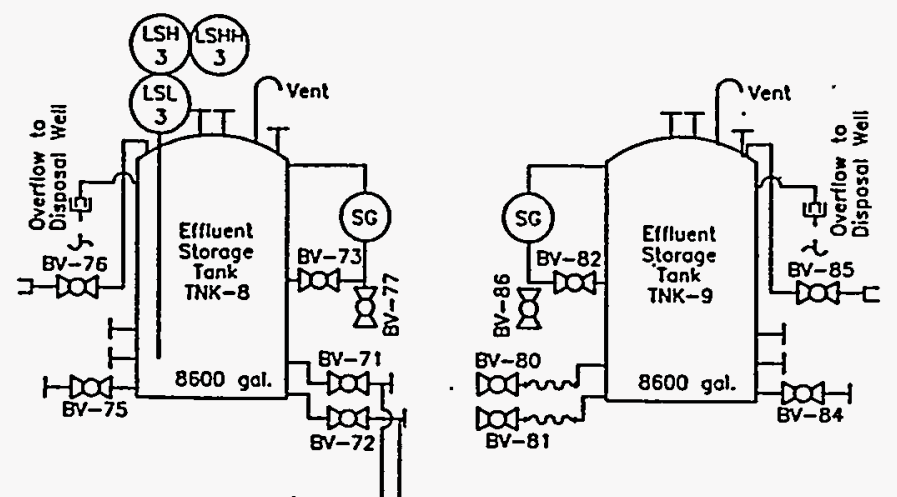

INSTRUMENTATION

(F) FLOW INDICATOR (SHA) LLEEL SHITCH HIGH

(FS FLOW SWITCH DISSOLVED OXYGEN

- (DI) MDICATOR

FiT Flow HNDICATING TIT TEMPERTIURE

TRANSAITTER . U TRANSMITER

(PI) PRESSURE INDICATOR: (PHIC) PH INDICATOR

PII PRESSURE INDICATING CONIROLLER

POT PRESSURE DIFFERENTIAL

(POI) PRESSURE OI

TURI) TURBOIT INOLCATOR

PDII PRESSURE DIFFERENTLLL

(POI) INDICATING TRANSMITER

(LSL) LEVEL SWITCH LOW

POSH)

(LSH) LEVEL SHITCH HIGH

(4)

PRESSURE DIFFERENTIAL

SWITCH HIGH

DOS BaLL VILVE PIPING

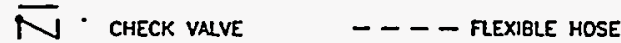

at ar vacuUm valve a FeXIBLe hose

PRESSURE REUEF J J FITING

M MOTOR OPERATOR SC-I SMMPLING CONNECTION

$\&$ SUEmersible PUMP AC-I NR CONNECTION

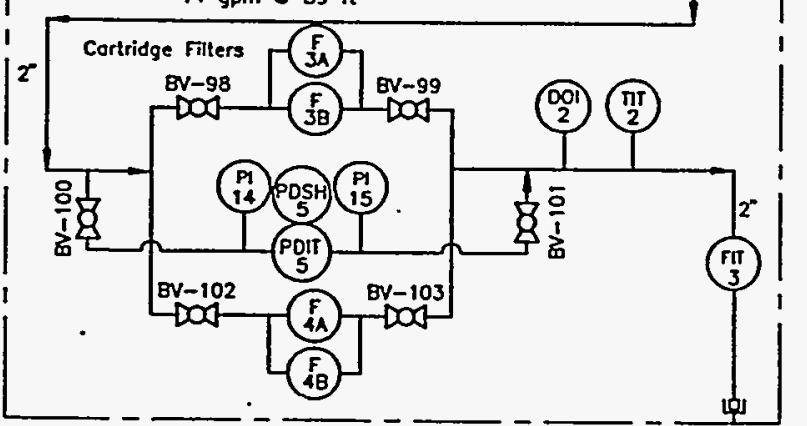

EFFLUENT PUMPING SKID

nUN FLEXIBLE CONNECTOR (SG) SIGHT CUSS

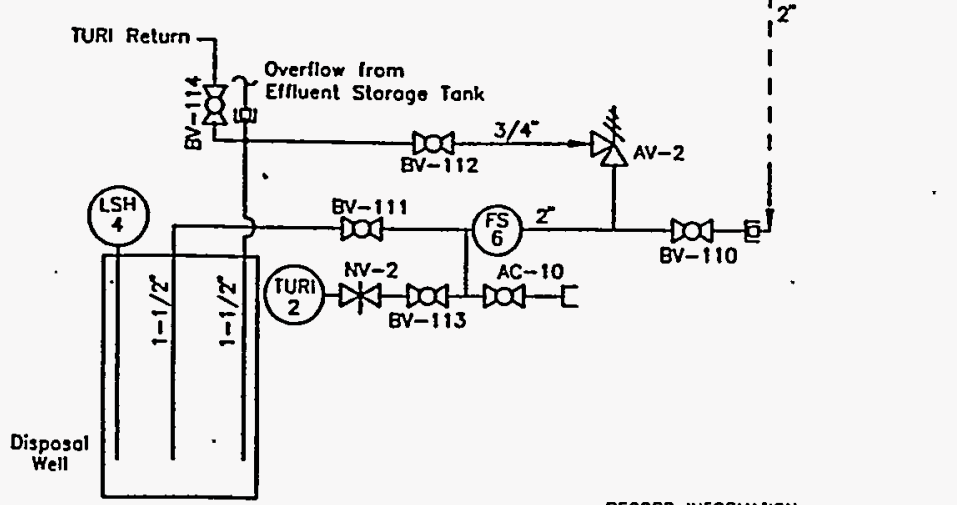

RECORD INFORMATION

BiII-DIS Lom ahlas

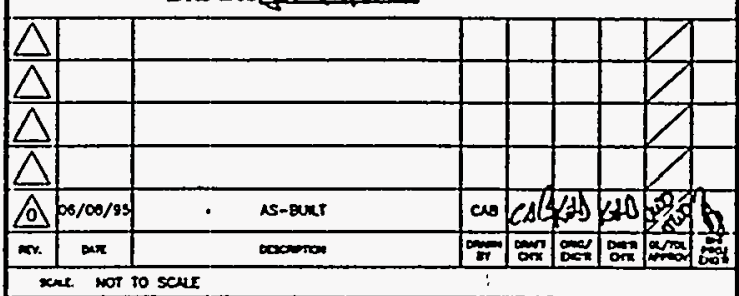

U.S. DEPARTMENT OF ENERGY HANFORD ENIVIRONMENTAL RESTORATION PROGRAM BECHTEL HANFORD INC. IT HANFORD INC. 200 EAST AREA

200-BP5-1 PILOT GROUNDWATER TREATMENT SYSTEM PROCESS FLOW DIAGRAM

\begin{tabular}{|c|c|c|}
\hline BECHIEL JOB RO. & DOE CONIRACT RO. & CADO FILEIAUE \\
\hline 22192 & DE-ACO5-93RL12367 & 2EOJ0003.DHG \\
\hline
\end{tabular}




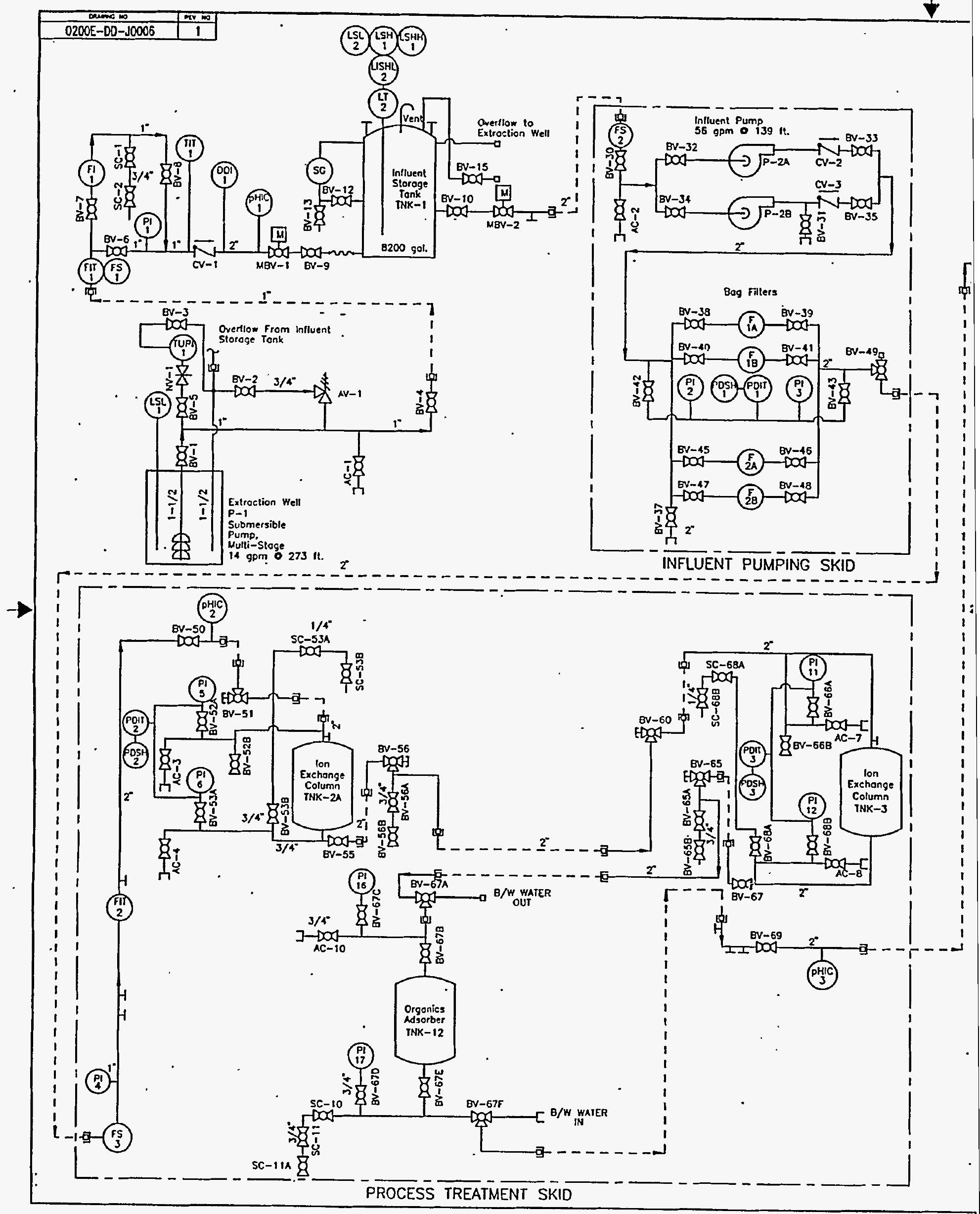


DOE/RL-95-59

Rev. 0

APPENDIX B

DATA SHEETS 
DOE/RL-95-59

Rev. 0 


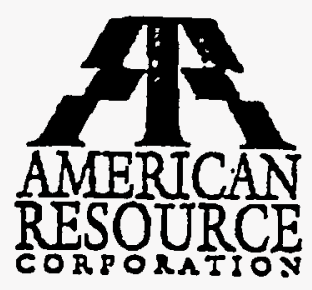

\section{$\because$ TECHNICAL DATA SHEET}

CATION EXCHANGE CAPACITY

This number moy vary as C.E.C. velues are reletive to procodure)

$1.85 \mathrm{meq} / \mathrm{gm}$.

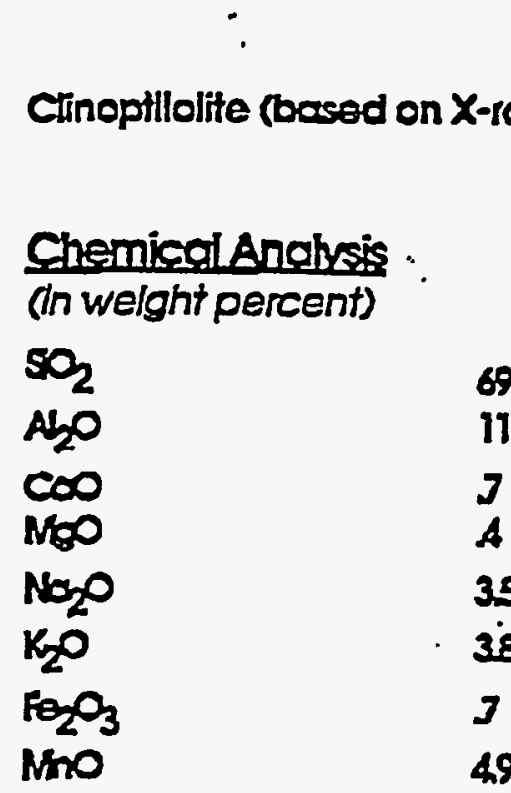

Maior Exchangeable Cstlions

$\mathrm{Fo}^{+} \mathrm{Li}^{+} \mathrm{K}^{+} \mathrm{Cs}^{+} \cdot \mathrm{NH}_{4}^{+} \mathrm{Na}^{+0}$

$69.1 \quad \therefore \quad \mathrm{Ag}^{+} \mathrm{Co}^{+2} \mathrm{Fo}^{+2} \mathrm{Zn}^{+2} \mathrm{Ba}^{+2}$

$11.9 \mathrm{\textrm {S } ^ { + 2 }} \mathrm{CH}^{+2} \mathrm{Hg}^{+2} \mathrm{Mg}^{+2} \mathrm{Fe}^{+3}$

$3 \quad \mathrm{CO}^{+3} \mathrm{~N}^{+3} \mathrm{CO}^{+3} \because$

Selectivity for the above cotlons is a function of

hydrated molecular sze and relstive concentration.

Priman Adsorbing Gassess

$\mathrm{CO} \mathrm{CO} 2 \mathrm{SO}_{2} \mathrm{H}_{2} \mathrm{NH}_{3} \mathrm{HCliO}$ Ar O

$\mathrm{N}_{2} \mathrm{H}_{2} \mathrm{O} \mathrm{He} \mathrm{H}_{2} \mathrm{Kr}$ Xe $\mathrm{CH}_{2}$. $\mathrm{OH}$

Freon Formaldehyde Mere:aptans
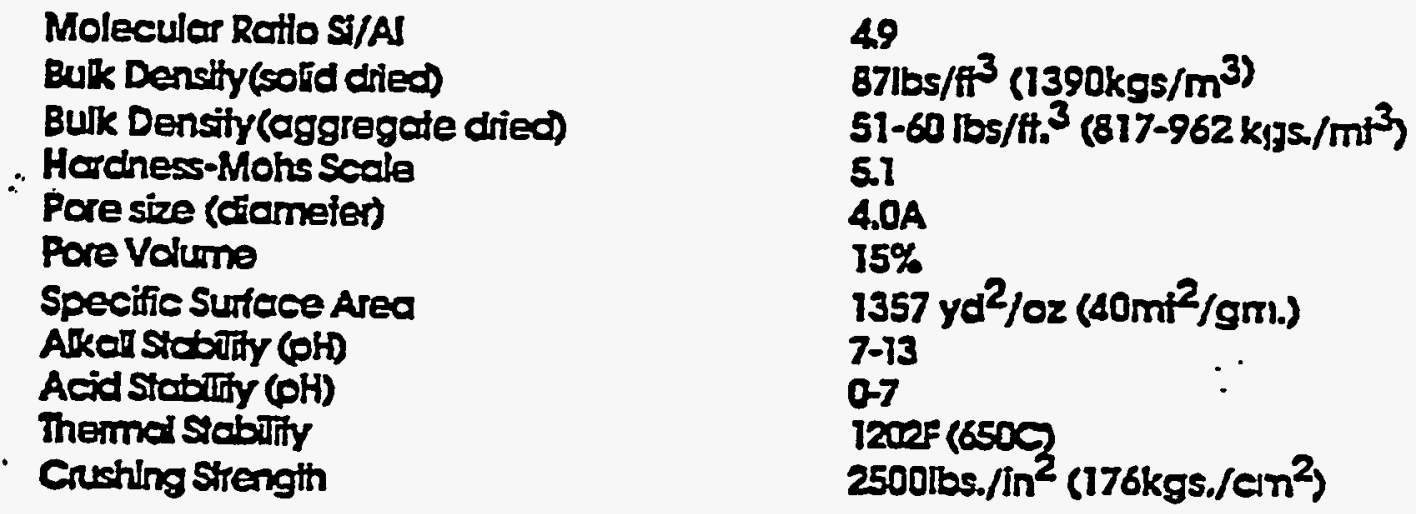

information hereh is cecurate to the best of our knowledge. Srggestions are made w thout waranty or guarantee of results, Before using, user should determine the surtablity of the product ior his infended use and user astumes the risk and liabllty in comectlon therewith. 
RESINTECH SIR-600 has a high ion exchange capacity that it is highly specific for Cesium, Ammonia and Strontium. when in the presence of large amounts of divalent ions such as Calclum and Magnesium. It has a unique crystalline structure that physically restricts its reactivity towards certain lons thus increasing its selectivity lowards others.

\section{FEATURES \& BENEFITS}

- HIGHLY SELECTIVE - Order of Selectuity:

$\mathrm{Cs}>>\mathrm{K}>\mathrm{NH}_{4}>\mathrm{Na}>\mathrm{Sr}>\mathrm{Ca}>\mathrm{Mg}$

ResinTech SIR-600 is a naturally occurring zeolite that is speclally purified and backwashed free of humus, fines and other foreign matter.

ResinToch SIR-600 is supplied as moist granular panicles with a size range essentlally the same as for standard lon exchange materlals used in water and radwaste treatment.

- MAXIMUM OXIDATION \& RADIATION STABILITY

ResinTech SIR-600 will give greatly increased life where resin degradation clue to oxidative effects such as from ionizing radlatlon or secondary thermal effects from radioactive decay are anticipated such as in high temperature or highly radioactive environments and waste treatment recovery operations.

* SUPERIOR PHYSICAL STABILITY

ths low shrink and swell characteristics, as it changes ionic form, Insures superb resistance to osmotic shock.

\section{HYDRAULIC PROPERTIES}

PRESSURE DROP.-The pressure drop of ResinTech SIR-600 treating a water at various temperatures and flow rates is shown below.

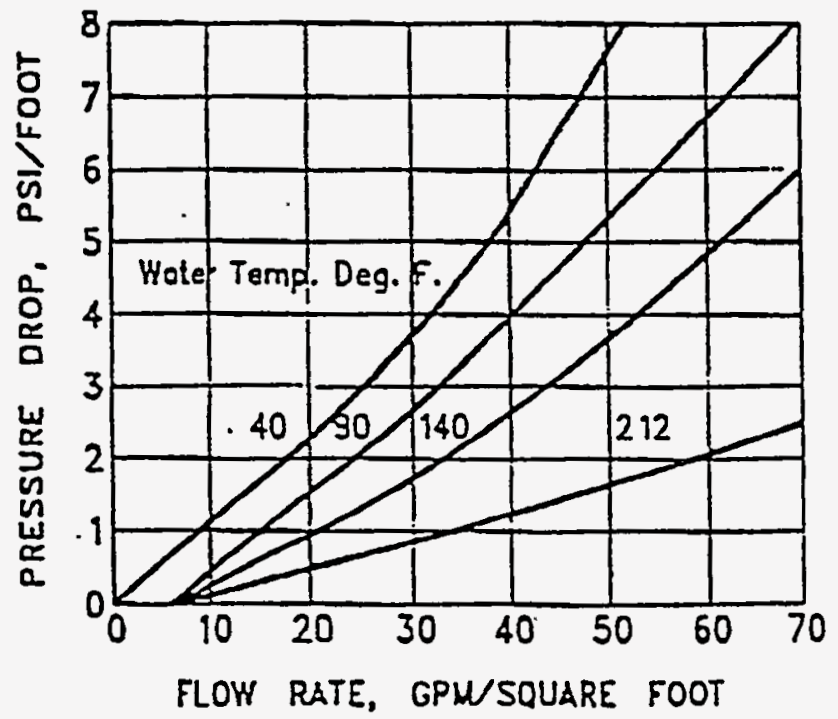

Cesium Exchsng: Caphcity... 1.4 to $1.6 \mathrm{meq} / \mathrm{g}$. Paricle size........ lix 50 raoh (IS\%)
BACKWASH-The resin bed should bo backwashed at a rate that expands the bed 25 to 75 parcent to classity the bed and remove fines generated during the loading process. The expansion characteriatics at 60 Deg. F are shown below.

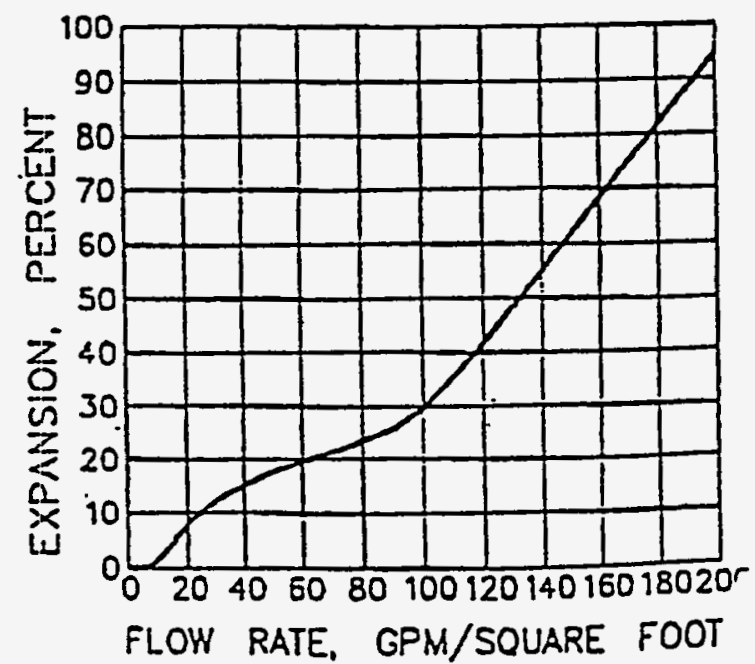

$\cdot B-4$

$\mathrm{PH}$ range............. 3. 30

Dulk deasity-............ Gi Llos/cu. ri. 


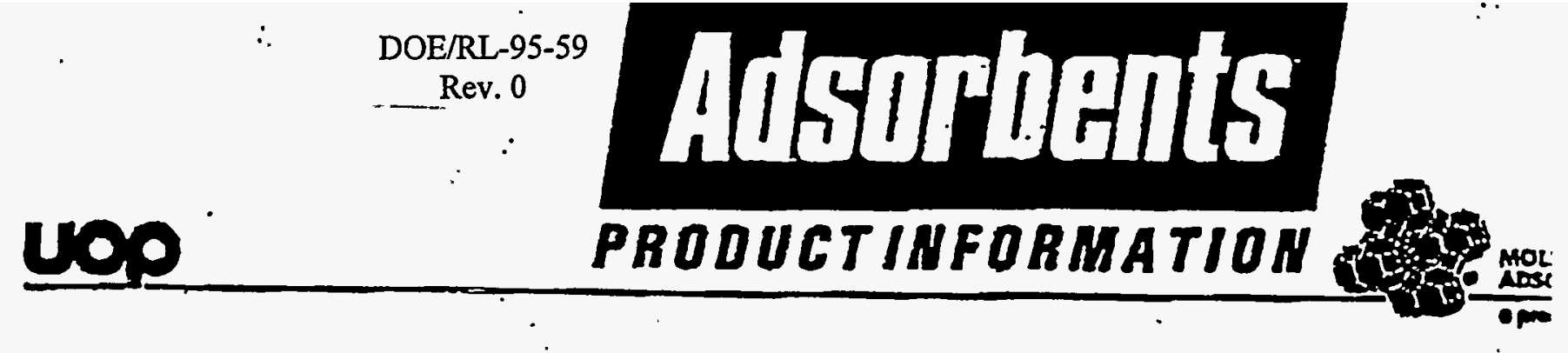

\section{A-50 ION EXCHANGER SERIES}

\section{Description}

UOP A-50 lon Exchanger Scries are an alkali metal alumino-silicate of the Type A crystal structure supplied in the $\mathrm{Na}+$ (sodium) form.

\section{Chemical Formula}

$\mathrm{Na}_{2} \mathrm{O}, \cdot \mathrm{Al}_{2} \mathrm{O}_{3} \cdot 2 \mathrm{SiO}_{2} \cdot 4.5 \mathrm{H}_{2} \mathrm{O}$

\section{Shipping Information}

A-50 lon Exchanger Scrics are available in powder and $20 \times 50$ mesh fonn. Samples may be oblaincd on request.

\section{Typical Application Arras}

A-50 Ion Exchanger Series products are generally highly effective cation exchangers for the removal of small ions from dilute solutions.
Typical Propertios

\begin{tabular}{|c|c|c|}
\hline & A. 50 & A.51 \\
\hline $\begin{array}{l}\text { Particle Size } \\
\text { Pore Openings }\end{array}$ & $\begin{array}{l}\text { Poxder (1 to } 10 \mu \mathrm{m}) \\
4.2 \AA \text { into } \alpha \text {-cage } \\
2.2 \AA \text { inlo } \beta \text {-cage }\end{array}$ & $\begin{array}{l}\text { Mesh }(20 \times 50) \\
4.2 \AA \text { into a-cage } \\
2.2 \AA \text { into } \beta \text { cage }\end{array}$ \\
\hline Bulk Irensity & & \\
\hline $\begin{array}{l}\text { As shipped } \\
\text { Hydrated, pucked } \\
\text { BS\&D Iensity }\end{array}$ & $\begin{array}{l}26 \mathrm{lbs} / \mathrm{cu} . \mathrm{ft} .- \\
420 \mathrm{~kg} / \mathrm{cu} . \mathrm{m} .\end{array}$ & $\begin{array}{l}42 \mathrm{lbs} / \mathrm{cu} . \mathrm{ft} . \\
670 \mathrm{~kg} / \mathrm{cu} . \mathrm{m} . \\
50 \mathrm{lbs} / \mathrm{cu} . \mathrm{ft} . \\
800 \mathrm{~kg} / \mathrm{cu} . \mathrm{m} .\end{array}$ \\
\hline (Hydrated) & & $\begin{array}{l}42 \mathrm{lbs} / \mathrm{cu} . \mathrm{ft} . \\
670 \mathrm{~kg} / \mathrm{cu} . \mathrm{m} .\end{array}$ \\
\hline $\begin{array}{l}\mathrm{H}_{2} \mathrm{O} \text { content } \\
\text { As shipped } \\
\text { Hydraled }\end{array}$ & $18-22 w \pi . \%$ & $\begin{array}{l}1-10 w 1 . \% \\
16-20 \mathrm{w} . \%\end{array}$ \\
\hline Cypacily & $\begin{array}{l}6.5-7.0 \mathrm{meg} / \mathrm{gm} \\
\text { (antrydrous) }\end{array}$ & $\begin{array}{l}5.0-5.5 \text { meg/gm } \\
\text { (antiydrous) }\end{array}$ \\
\hline
\end{tabular}

\section{Regeneration}

Typically, regeneration may bc accomplished by the use of $\mathrm{NaCl}$ solution as the regenerant fluid.

\section{Additional Information}

Bulletins discussing additional applications of UOP Molecular Sieves are available. Call or write your ncarest UOP Molecular Sieve Sales Orfice.

\section{Sales Offices}

UOP

Molecular Sileve Adsosbents

25 F. Al gonquin Ilond

Des H'lainc. IL 60017-5017

(708) $391-2000$

EASTLIIN RECION

Molecular Sleve Adsorbents

307 Fellowship Driva:

Suite 207

Mt, J.aumi, NJ O\$OSA

MIDWESTERN RECION

Molecular Sino Adsorbents

10 South Hiverside PluzH, Sujit 2200

Chicago, II, E0fint.3882

(312) $151-2230$

Moleculur Sieve Adentrents

25111 Curuitry C.lub Blud.

Suile 265

N. Olmsted, OII 44070

(210) 734-0088
SOUTHWFSTFRN REGION

Molceular Sieve Aisorlents

13105 Northwest Fromway

Suitc 600

Ilouston, TX770so

(71.3) 711.2810

PACIFIC:RECION

Mulecular Steve Adsorbents

J2399 I Auyls Stroct, Suite: 201

Gianden Girove, CA 92640

(711) 750-1551

CANADA

UOP Canndx, Inc.

Suite 18ER, 111-5th Ava. S.W.

Calgary. Albertu T2P 2TR, Canada (403) 284.1757
UOP Cianude, Inc:

120 Eglinturn Ave. F.25l

Suite 304

Toronlo, Onlario, Mâ' 1E2. Canudo (ब1i) $1888-1752$

FUROPE

UOPM.S. S.p.A.

VIa Durinl 27

20122 Millano. Italy

39-2-76004773

UOP

Molecular Sieve Adenrbents

R.O. Bix 9248, Fl. 25

Dubal Internatlonal Irade Centre

Dubai, Uniled Arab Emirates:

(A71-1) 313-841
FAR EAST

UOP K.K.

Singapore Represcontive Offio Mnlocular Sleve Adsorbents

101 Thomson Roxd

11-05 United Square

Singupure 1130

(65) 253-1652

UNION SHOWA K.K.

Molecular Sleve Adsorbonts Sanwa Buslding

27-17 Hamamatsu-cha 1 Chome

Minatn.kin, Tokyo 105. Japan

(81) $3.3132-7553$ 
DOE/RL-95-59

Rev. 0

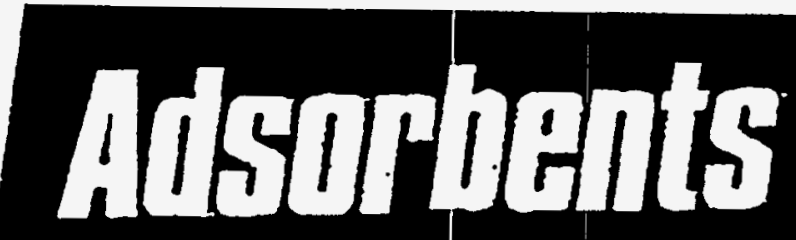

PRODUCTINFORMATION

\section{IE-95 ION EXCHANGER}

\section{Description}

UOP IE-95 Ion Exchanger is an alkali meal alumino silicate primarily of the chabarite structure type supplied in the mixed ionic

$(\mathrm{Na}+, \mathrm{Mg}++, \mathrm{Ca}++)$ form.

Chamical Formuls

$\left.\mathrm{QNa}_{2} \mathrm{O}, \mathrm{MgO}, \mathrm{CaO}\right)=\mathrm{Al}_{2} \mathrm{O}_{3}=4-6 \mathrm{SiO}_{2} \cdot \mathrm{H}_{2} \mathrm{O}$

\section{Shipping Infomstion}

IE-95 Ion Exchanger is available in $20 \times 50$ mesh form. Santies thay be obtained on reguest.

\section{Regeneration}

Typically, regeneration may be accomplished by the use of $\mathrm{NaCl}$ solution of the regenerant fluid.

\section{Typical Proparties}

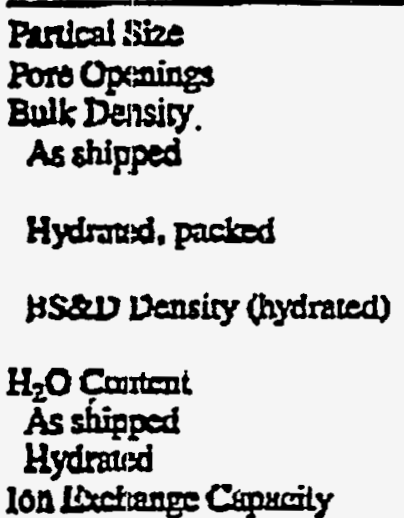

\section{Typical Applieation Areas}

UOP I3-95 Ion Exchanger products have been found to be effective for recovery and storage 0 radio-auclides and for cation exehange from ac solutions.
Mesh $(20 \times 50)$

$3.7 \times 4.2 \mathrm{~A}$ and:

$40 \mathrm{lbs} / \mathrm{du} . \mathrm{fl}$.

$640 \mathrm{~kg} / \mathrm{cur} . \mathrm{ss}$.

$46 \mathrm{lbs} / \mathrm{cus} . \pi$

$740 \mathrm{~kg} / \mathrm{cus} . \mathrm{m}$.

$38 \mathrm{lbu} / \mathrm{cu} . \mathrm{m}$.

$60 \mathrm{~kg} / \mathrm{er} . \mathrm{m}$.

$1-10$ wt. $\%$

$12-17$ at $\%$

20-2.5 megis (aninydrous)

\section{Additional laformation}

Bulletins discussing additional applications of UOP Molecular Sieves are available. Call or write your near UOP MOlecular Sieve Sales Office.

\section{Sales Offices}

ர्र

Moleculersilma how

25 E. Agorntuln Boad

Bes Plaloer, it $00017-5017$

(T0S) $384-2000$

EAstrantikctoN

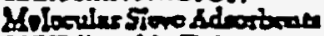

For Rellow fipip Drive

Sulte 207

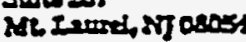

MTOWESTERN REGION

Nescocins Sim dolothents

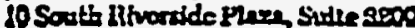

Caivery II. cosolshes

(J1ㄴ) 4510000

Muheules stest Aleadrents

zSIUS Counsy Civb Blud.

Sulle eas

N. Otoned on 41070

(216) 7340088
SOUIFWT:LIRN RECIOK

Molnculer STive Advorbent"

33105 Northwest Prowwiry

Sulte 100

Houton, TX77010

(213) 711-2810

PACricterioros

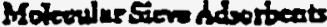

j2300 I evilestr.w, Sulte201

Gardon Grow Ch 92610

(114) 750.551

carinus

yor cinade, Ince

Eulte J600, 14t5eh Ave. S.W.

Gigary, Alburte TaP $2 T 2$ Canada

(403) $281-475$

B-6
VOF Conade, Ine.

100 Eolinion Are Ense

Srite 004

Turuta Ontaria MAT IEs Cunede (416) 488-4752

Luteurs:

yorms.sph

Vin Draritugt

Dores Miluna, Iteily

302-7600475s

vor

Molcenier Stere Adrasberts

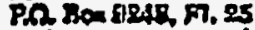

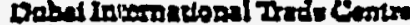

Dubel Unlled Arab Entrese

(672-1) 312841 


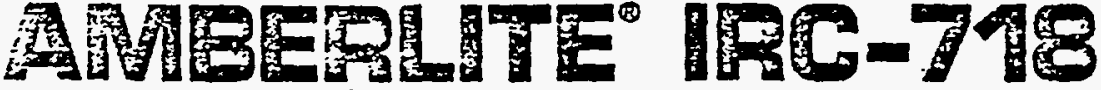

Amberlite IRC-718 is a crosslinked macroreticular cation exchange resin with a particular selectivity for the heavy metal cations over the more common alkali or alkaline earth cations such as sodium, potassium, calcium and magnesium. This selectivity is achieved by means of a unique chelating functionality chemically bound to the resin matrix. This chelating functionality has several cation active sites which coordinate with the heavy metal ion and render it much more tightly bound than the more common ions.

FIMPRAM

MIGHLY SELECTIVE FOR HEAVY METAL IONS-Amberlite IRC718 resin, by means of its unique chelating functionality, is selective for heavy metal cations in the presence of alkali or alkaline earth cations.

STABLe OVER THE ENTIRE pH RANGe-Amberlite IRC-718 has proven itself in both the field and the laboratory to be stable over the entire pH range, and functionally active over a wide $\mathrm{pH}$ range.

EXCELLEAT KINETICS-Because of its unique structure, Amberlite IRC-718 exhibits excellent kinetic behavior, resulting in low leakage of metal ions in the loading cycle. The elution of Amberlite IRC-718 resin is accomplished typically with a strong acid at pH 1 or less. Elution is very efficient and a high concentration of ions is obtained in the eluate. (After acid elution the resin must be returned to the appropriate form; e.g., to the sodium form using sodium hydroxide).

HIGHY RESISTANT TO PHYSICAL BREAKDOWN-The crosSlinked macroreticular structure of Amberlite IRC-718 prevents the excessive swelling and contracting that fragments gelular chelating resins:

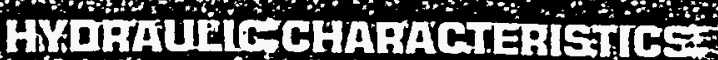

PRESSURE DROP-The approximate pressure drop for each foot of bed depth in normal downflow operation at various water temperatures and rates of flow are shown in the graphs below.
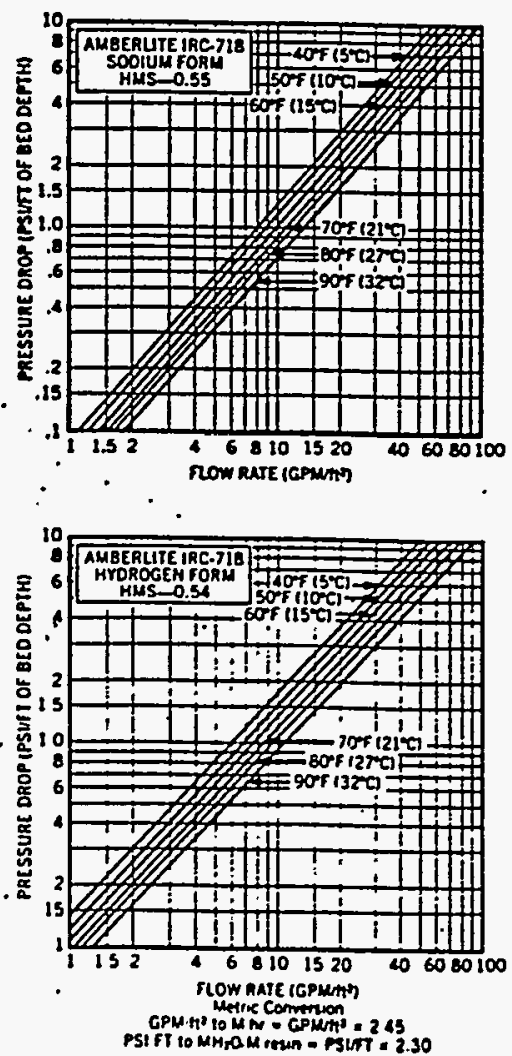

BACKWASH CHARACTERISTICS-After each operational cycle, Amberlite IRC-718 should be backwashed for approximately ten minutes to purge the bed of any. insoluble material that may have collected on top of the resin. The bed should be expanded a minimum of $50 \%$ during hackwash.
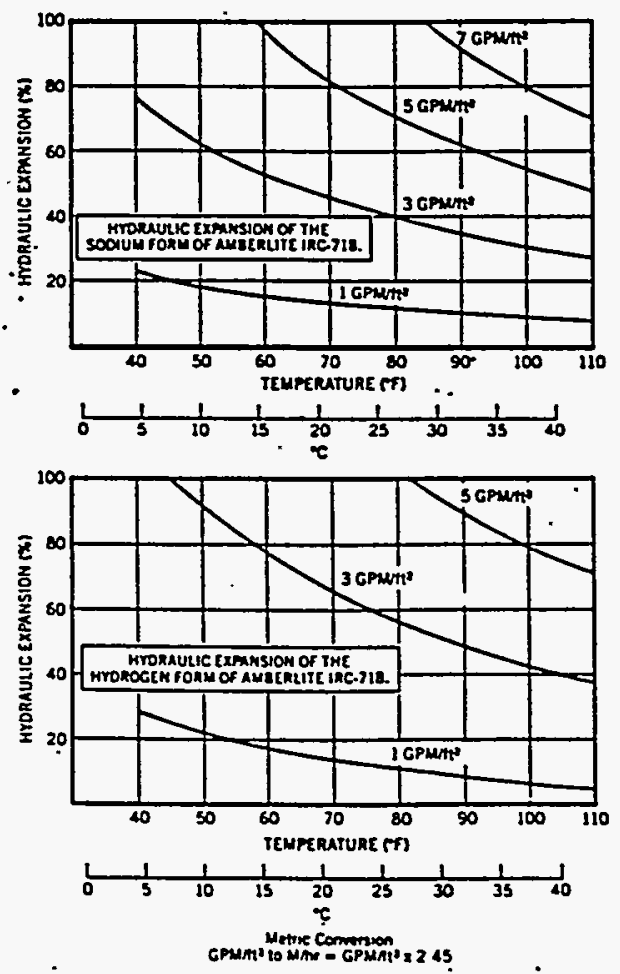
pH Range

Minimum Bed Depth

2.0 to 14.0

Maximum Temperature

\section{4 inches $(0.61 \mathrm{~m})$}

$160^{\circ} \mathrm{F}\left(71^{\circ} \mathrm{C}\right)$ in all forms (In some forms the resin is stable at higher temperatures. Contact the manufacturer for specific information)

Regenerant

Concentration*

Regeneration Flow Rate

Neutralization

Service Flow Rate

Cation Exchange Capacity

4 to $15 \% \mathrm{HCl}$ or $\mathrm{H}_{2} \mathrm{SO}_{4}$

0.25 to $0.50 \mathrm{gpm} / \mathrm{ft}^{3}$ (2.0 to $4.0 \mathrm{l} / \mathrm{hr} / \mathrm{l})$

1 to $15 \%$ sodium hydroxide 1.0 to $5.0 \mathrm{gpm} / \mathrm{ft}^{3}$ (8.0 to
$40.1 \mathrm{l} / \mathrm{hr} / \mathrm{l})$

$1.0 \mathrm{meq} / \mathrm{ml}$. wet resin

- See Safe Handling Information Section

PHYSICAL FORM-Attrition resistant, tan spherical particles supplied in the fully hydrated sodium form.

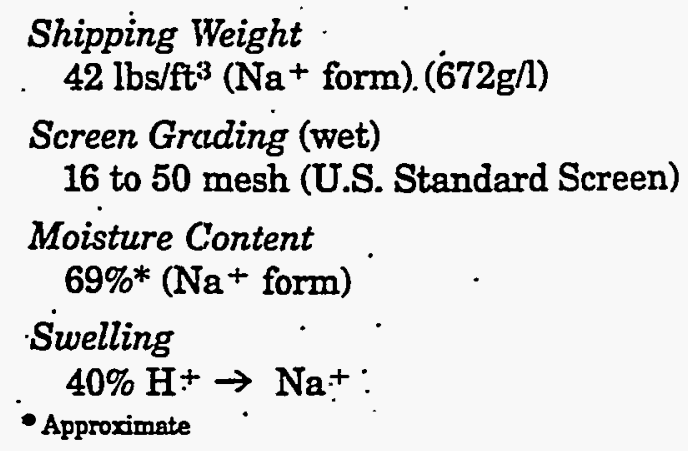

APPEICATIONS

RECOVERY OF HEAYY METALS FROM HYOROMETALLURGICAL LEACH STREANS-Because of the ability of Amberlite IRC-718 to function over a wide $\mathrm{pH}$ range, this resin can effectively recover heavy metal cations that have been leached from ores by either acids or bases. Elution of this resin is extremely efficient, yielding a concentrated solution of the desired metal ion.

PURIFICATIOH IF PROCESS STREAMS CONTAIHIKG TRACE TRANS. Imon METALS-A Amberlite IRC-718 can often effectively remove trace heavy metal cations that are present in process streams as catalysts or process aides, without altering the composition of the stream. This resin can also remove the products of corrosion encountered in process streams. The high selectivity of Amberlite IRC-718 for transition metal cations, as well as its activity over wide $\mathrm{pH}$ rarige make it a good choice for a variety ? specialized processing applications.

ELECTROPLATING InDUstay - The high selectivity of Amberlite IFiC-718 for heavy metals will also prove useful in the removal and recovery of metal ions from plating baths, iragout, and rinse waters in the plating industry. The macroreticular structure of this resin insures its stability in the aggressive solutions of a plating bath.

CHLOR-ALxau IMDUSim - Amberlite IRC-718 effectively removes hardness, to less than $0.1 \mathrm{ppm}$, from brine fed to chlor-alkali alectrolysis cells.

SAFE haNDLING INFORmation-A Material Safety Data Sheet is available for Amberlite IRC-718. To obtain a copy contact your Rohm and Haas representative.

CAUTION: Acidic and basic regenerant solutions are corrosive and should be handled in a manner that will prevent eye and skin contact.

Nitric acid and other strong oxidizing agents can cause explosive-type reactions when mixed with ion exchange resins. Proper design of process equipment to prevent rapid buildup of pressure is necessary if use of an oxidizing agent such as nitric acid is contemplated. Before using strong oxidizing agents in contact with ion exchange resins, consult sources knowledgeable in the handling of these materials.

AMBERLre is a trademark of Rohm and Haas Company. or of its subsidiants or affliates. - Company's policy is to register its trademarks where products designated thereby are mat by the Company, its subsidiaries or affiliates.

These suggestions and data are based on information we believe to be reliable. They are. fered in good faith, but without guarantee, as conditions and methods of use of our products are beyond our control. We recommend that the prospective user dutermine the suitability of our materials and suggestions before adopting them on a commercial scale.

Suggestions for uses of our products or the inclusion of descriptive material from patents and B-8 the citation of specific patents in this publication should not be understood as recommending of the Rohm and Haas Company.

1E-217-7576779

Juns, 1982

Prinied in USA 


\section{TECHNICAL BULLETIN}

\section{DURASIL $^{\circledR} \quad 230$ \\ Ion Exchange Media}

Description

Application
DURASIL ${ }^{\otimes} 230$ media is an inorganic oxide based cation exchanger with a high specificity for radioactive cesium (Cs) and a low specificity for such nonradioactive species as sodium $(\mathrm{Na})$ and lithium $(\mathrm{Li})$.

DURASIL ${ }^{\otimes} 230$ media was designed to selectively remove Cs radioisotopes from radwaste streams, and has been used at commercial nuclear power plants and DOE sites. It is sluiceable, bridges retention screens, and can be used in systems designed for organic resins.

DURASIL $^{\otimes} 230$ media has the following characteristics:

- High capacity for $\mathrm{Cs}$

- Excellent mechanical stability

- Invulnerable to attack by oxidants such as chromates and nitrates

- Non-flammable

- Does not shrink or swell

- Resists oil fouling

- Virtually immune to radiation damage and biological decay

- No effect on pH of waste stream

- Low pressure drop 


\section{Properties}

\section{Operafing Performance}

Average Cs Influent Activity

$0 \quad 1.9 \mathrm{E}-03 \mu \mathrm{Ci} / \mathrm{ml}$

Average Cs Effluent Activity $\triangle \quad$ 7.7E-06 $\mu \mathrm{Ci} / \mathrm{ml}$

Average

Decontamination Factor $=247$
Base Material

Bulk Density (dry)

Maximum Swelling (\%)

Particle Size

Ion Exchange Mechanism

Functional Group

Ionic Form Shipped

Exchange Capacity

$\mathrm{pH}$ Range

Operating Temperature

Storage Temperature

Shipped
Inorganic Oxide

$40 \mathrm{lbs} / \mathrm{cu} . \mathrm{ft}$. (0.65 g/ml)

20-50 mesh $(840 \mu-290 \mu)$

Sodium Exchange

Acidic

Sodium

$2.0 \mathrm{meq} / \mathrm{ml}$ (3.1 meq/g)

$3-10$

32-140 $140^{\circ}\left(0-60^{\circ} \mathrm{C}\right)$

$32-140^{\circ} \mathrm{F}\left(0-60^{\circ} \mathrm{C}\right)$

Wet

The selectivity of DURASIL 230 media results in high media capacity and large DFs for Cs. The graph below shows actual operating performance of DURASIL ${ }^{\otimes} 230$ media in the treatment of a radioactive wastewater stream. The total volume radwaste processed was $2,120,100$ gallons with an average conductivity of $163 \mu \mathrm{mho} / \mathrm{cm}$. Other chemistry data is presented below.

Actual Plant Date

Total Cesium Removal by Durasil 230

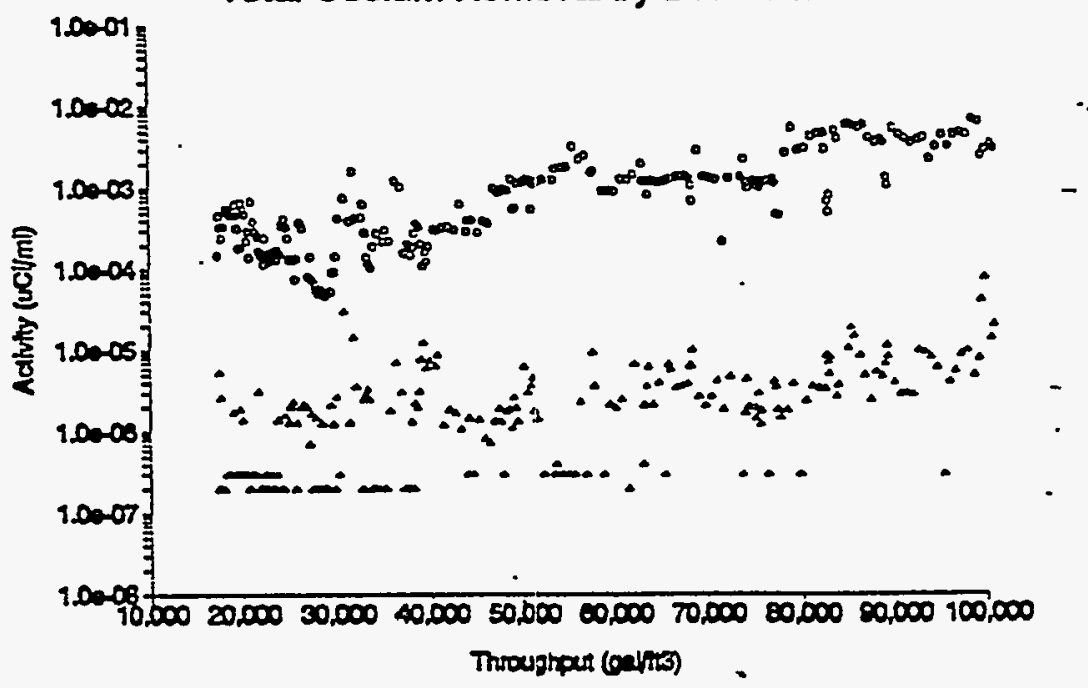

GTS DURATEK, INC. 8955 Guilford Road Suite 200

Columbia, MD 21046

(410) 312-5100

(301) 621-8211 (FAX)
GTS Duratek, Inc. reserves the right to alter characteristics of the Durasil ${ }^{\Phi}$ and Dura $\mathrm{C}^{\text {sx }}$ media. This technical bulletin is subject to revision without notice.

DURASIL is a registered trademark of GTS Duratek, Inc.

DURA $C^{\text {ra }}$ is a trademark of GTS Duratek, Inc. 


\section{Uranium Recovery with}

\section{DOW/2x Ion Mxchange Resins}

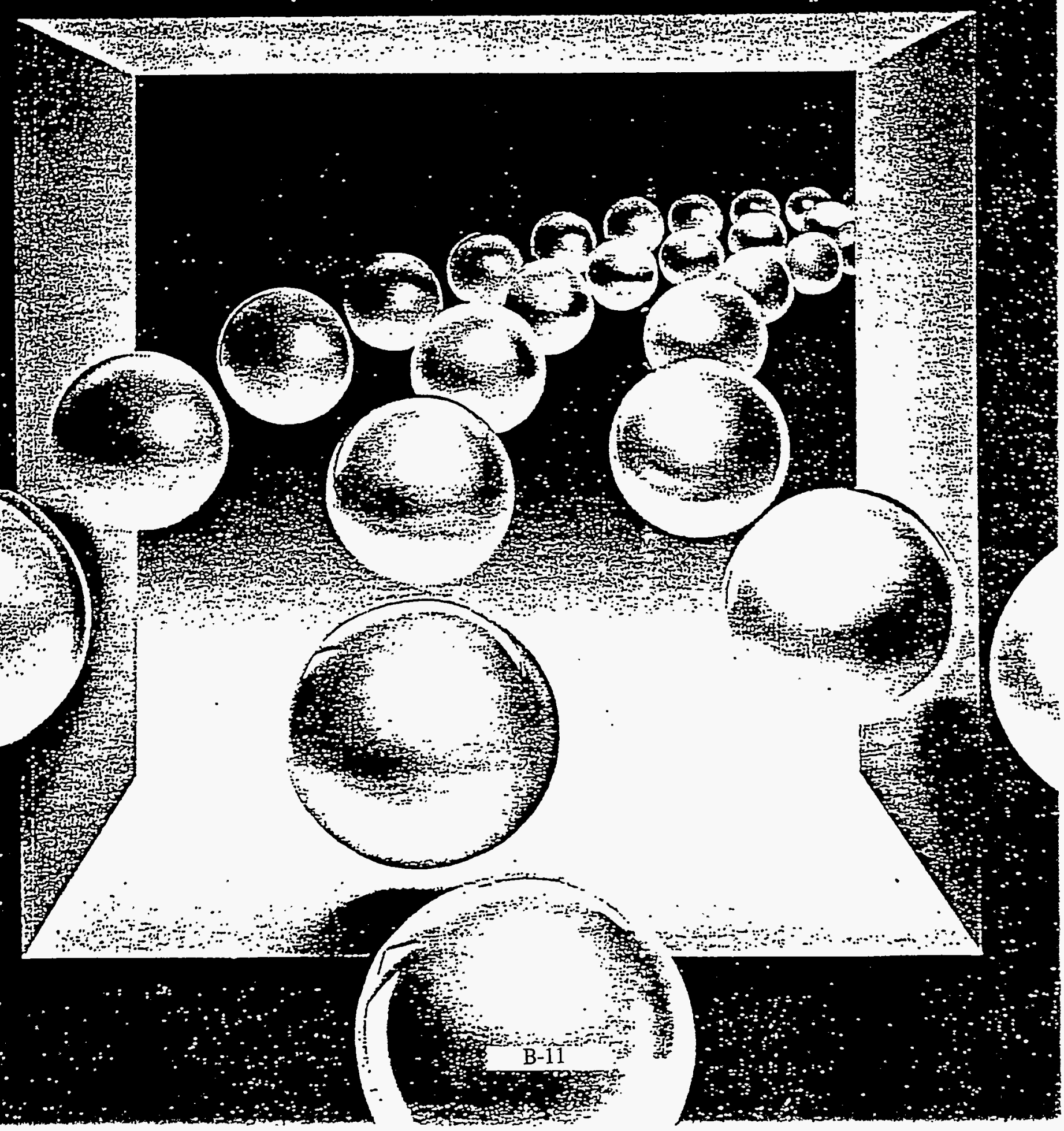




\section{Properties of DOWEX Anion Exchange Resins Tailored for Uranium Recovery.}

Strongly basic anion exchange resins, particulariy gel Type 1. are extremely versatile products. For this reason, they are widely used in various fixed bed and moving bed equipment configurations for uranium recovery. The DOWEX $21 \mathrm{~K}$ anion exchange resins have optimum levels of crosslinkage in the polymer matrix. This results in high porosity to afford efficient adsorption and elution of uranyl complexes.

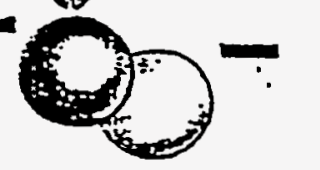

\section{TABLE 1}

DOWEX 21K Reșin Properties (Typical)

Physical Form

Sphericity

Total Exchange Capacity

(wet) Chloride Form

Water Retention Capacity

Chloride Form

Color Throw. APHA no.

Classified Density
Hard Golden Brown Colored Spheres 90\%6 Whole Bead (minimum) $1.2 \mathrm{meq} / \mathrm{ml}$ (minimum)

$50-58 \%$

20 (maximum)

$43 \mathrm{lb} / \mathrm{cu} \mathrm{ft}$
Performance is positively affected by other chernical properties of the family of DOWEX $21 \mathrm{~K}$ resirs. as well. These include:

- High available total exchange capacity that provides useful operating capacity.

- Appropriate moisture content. a property which impacts the kinetics of uranyl complex exchange in fixed bed and fluidized bed dissigns.

- Resistance to osmotic shock due to moderate changes in ionic form from regenerated to exhausted state.

- Resistance to organic fouling which affords more cycles before necessary resin replacement

DOWEX $21 \mathrm{~K}$ resins have superior physica! strength with low attrition rates. In processes where movement of ion exchange resins is necessary. this high bead strength minimizes increases in pressure drop due to bead fragmentation, and also lessens attrition losses. Typical properties are shown in Table 1.

\section{Screen Size - Important To Productivity}

In addition to the necessary chemical properties above. particle size (screen size distribution) is important to maximize productivity. Particle size optimization is required because of the differences in uranium mine streams. leach liquors. and the varying designs of the contacting equipment used.

DOWEX 21K, 16-20 mesh. resin is manufactured for use in resin-in-process (RIP) circuits, high flow rate fluidized bed processes, and high flow rate fixed bed columns. The large beads have higher terminal settling velocity, higher surface area per bead. and good skeletal density. Thus, they offer more resistance to fluidization in upflow systems. Concerns about pressure drop per square foot of bed depth are minimized in high flow systems using DOWEX 21K. 16-20. mesh resin.

DOWEX 21K. 20-40 mesh. resin facilitates a faster mass transfer of uranium complexes in conventional fixed bed downflow systems. The smaller beads are durable. with the good porosity and enhanced suriace area necessary for "exchange to take place.

A few systems now in operation require a compromise berween the 16-20 mesh and the 20-40 mesh products. DOWEX 21K. 16-30 mesh. resin is an intermediate product that allows for acceptable loading and elution in these designs. 
Figure. 1 shows a comparison of pressure drop versus flow rate for the three DOWEX $21 \mathrm{~K}$ resin products. Some operations require upflow in a fluidized bed and. in most cases, a backwash is employed to classify the resin bed or to remove particulates from the resin. The bed expansion characteristics of the resins are important for each of these cases. Figure 2 compares the various sized DOWEX $21 \mathrm{~K}$ resin products with respect to fluidization versus flow rate. Screen size specifications for DOWEX $21 \mathrm{~K}$ resins are listed in Table 2.
TABLE2

Screen Size Specifications of DOWEX 21K Resins 16-20 Mesh Resin

Through 20 Mesh (840 microns)

Through 25 Mesh (710 microns)

$10 \%$ maximum

2\% maximum

16-30 Mesh Resin

Through 16 Mesh on 30 Mesh (1.190 microns to 590 microns)

Through 30 Mesh (590 microns)

20-40 Mesh Resin

On 16 Mesh ( 1.190 microns)

On 20 Mesh (840 microns)

Through 40 Mesh (420 microns)
95\% minimum

$3 \%$ maximum

$2 \%$ maximum

20\% maximum

$5 \%$ maximum

$\%$

Photomicrographs of DOWEX 21K Resins

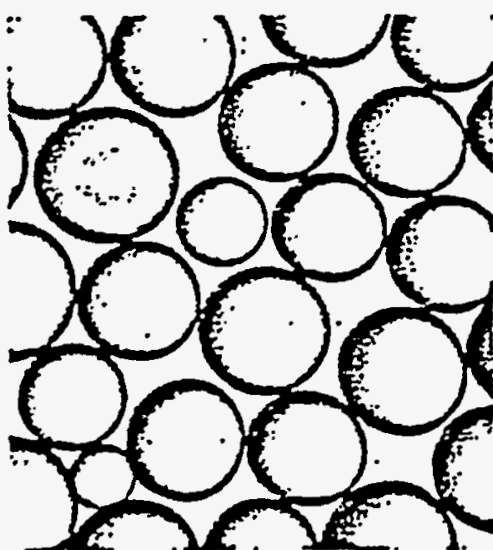

16-20 Mesh

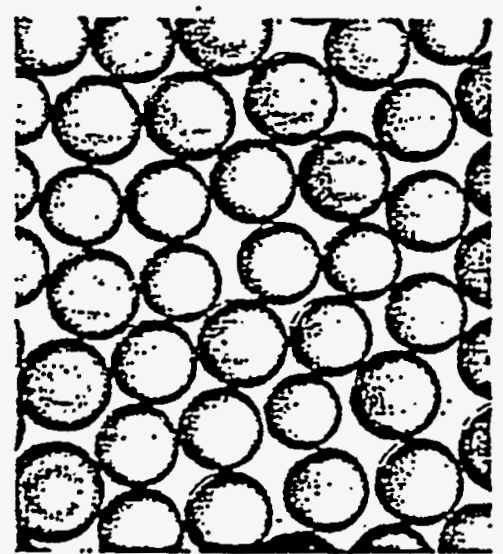

16-30 Mesh

FCURE 1

Pressure Drop vs. Flow Rate for DOWEX 21K Resin. Cl Form

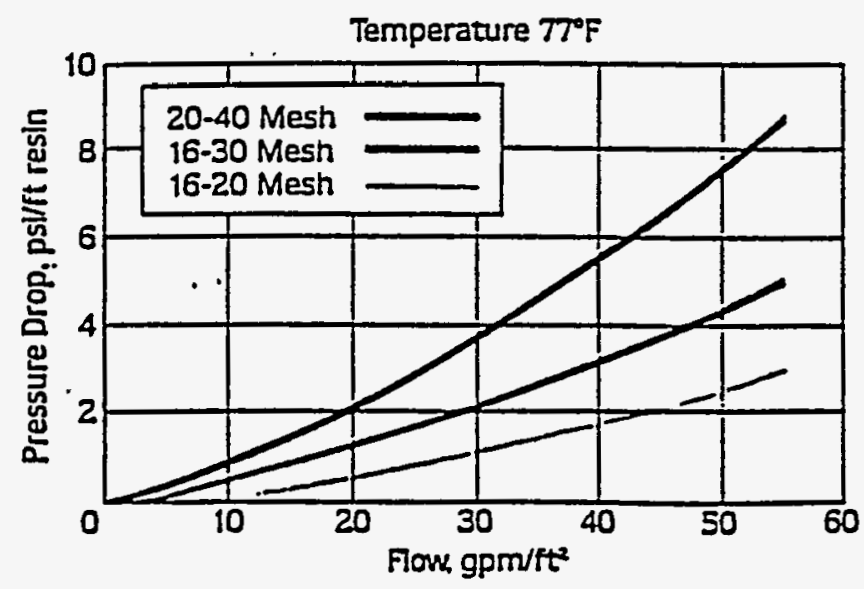

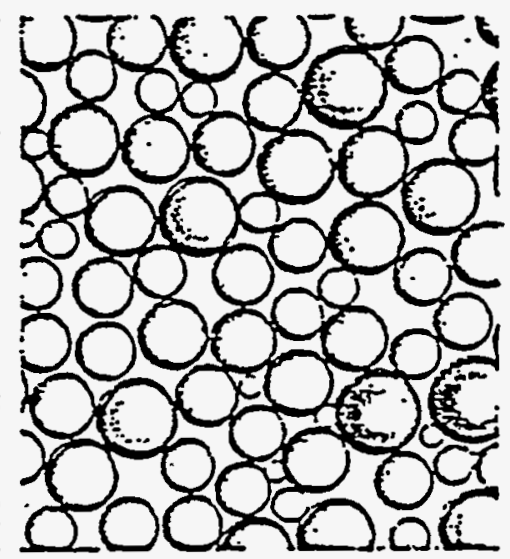

20-40 Mesh

FGURE2

Backwash Expansion vs. Flow Rate with DOWEX 21K Resin, Cl form

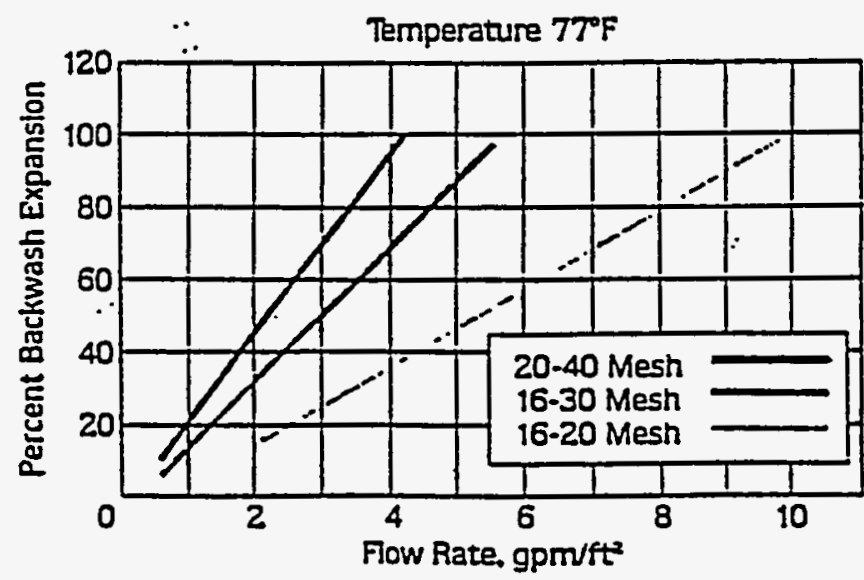


DOE/RL-95-59

Rev. 0

TABLE 3

\section{Suggested Operating Conditions for DOWEX 21K Resin}

pH Range
Maximum Temperatur
Hydroxyl Form
Chloride Form
Minimum Bed Depth
Service Flow Rate
Regenerants

Regenerant Leve! Regenerant Fow Rate

Regenerant Temperature Rinse Water Requirement Displacement Rinse Rate Backwash Flow Rate
$0-14$

$140^{\circ} \mathrm{F}$ or $60^{\circ} \mathrm{C}$ $220^{\circ} \mathrm{F}$ or $100^{\circ} \mathrm{C}$

30 inches

$2-4 \mathrm{gpm} / \mathrm{cu}$ ft (16 to 32 Bed Volumes/hr)

Dependent on the Particular Application Dependent on Capacity Desired 0.25-1.0 gpm/cu it ( 2.0 to 8.0 Bed Volumes/hr)

Ambient

Approximately 50 galva $f t$ Equivalent to Regeneration Rate Sufficient to Produce at Least 50\% Expansion in Bed Volume

\section{Operating Conditions}

DOWEX $21 \mathrm{~K}$ resin is shipped in the chloride form. When put in service. the chloride ion is replaced - or exchanged - with other anions. lon exchange resins change in size due to ionic interaction. Consequently, they shrink or swell. depending on the particular species and liquid composition. The shrink or swell between the regenerated and exhausted forms will cause a shift in size distribution of the beads. This. in turn. causes a change in pressure drop characteristics. Table 3 summarizes suggested operating conditions.

NOTE: Each facility should evaluate and optimize its procedures to assure the most efficient uranium recovery.

\section{Loading and Elution Behavior}

The economics of a uranium recovery operation will be influenced to varying degrees by the loading and elution characteristics of the ion exchange resins. Generally. large volumes of low concentration feed liquor are passed through a bed of resin for uranium uptake. Upon elution. a smaller volume of more highly concentrated effluent is obtained for further treatment and recovery.

Minimization of capital and reduction of operating costs are related to the choice of resin for the system. The resin should have a preference and a selectivity for uranyl complexes. and a loaded resin must be elutable. These are in addition to the properties discussed above. Performance will also be affected by the proper density. size, and other factors related to fiuid- ization and pressure drop. Other considerations. such as uranium concentration, temperature. competing ions. impurity levels. and flow rates will also have an influence on the system's performance. In sulfate leaching systems. most of which operate in the $\mathrm{pH} 1.5$ to 2.0 range. it has been found that uranium loading decreases as bisulfate levels increase.

As manuractured, an ion exchange resin contains a fixed number of functional groups or sites that are available for use. When uranium is being recovered from either acid or alkaline streams. four exchange sites on the resin must be used to recover one uranyltricarbonate. or one uranyltrisulfate complex. This is shown in equarions 1 and 2 . where $R$ represents one functional group attached to the polymer backbone.

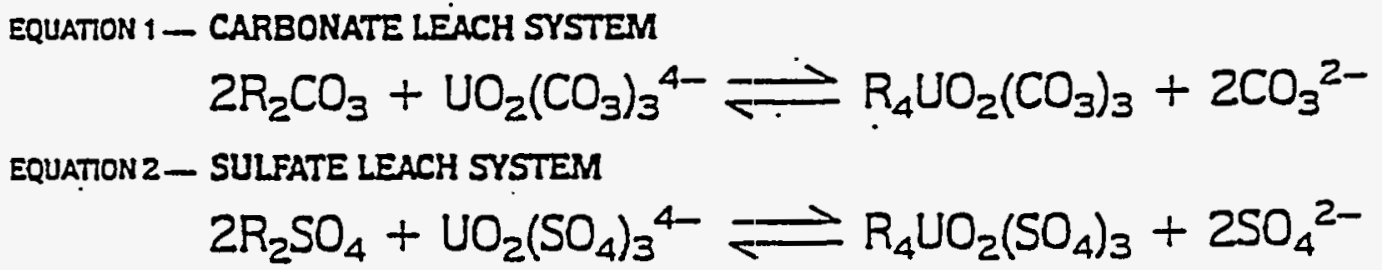


For a resin with a total exchange capacity of 12 milliequivalents/milliiter. the theoretical capacity for uranyltrisulfate would be less than $1.2 \mathrm{meq} / \mathrm{ml}$, depending upon equipment configuration and barren requirements.

Dow recognized that a high theoretical capacity resin may not give the highest operating capacity in an actual system. Therefore, a resin with a higher porosity was developed. The higher porosity increased the rate of uranyl complex exchange and thereby increased the operating loading. This change not only improved the loading enficiency, but also improved the sharpness of elution.

In acid systems. the ultimate loading capacity of a DOWEX $21 \mathrm{~K}$ resin is dependent upon the pregnant liquor temperature, ionic species present in solution. operating conditions. and resin properties. Cenerally, heating the pregnant liquor to $35-40^{\circ} \mathrm{C}$ will increase the loading significantly. However. as the temperature of the liquor is raised above $40^{\circ} \mathrm{C}$. the improvement in resin loading begins to diminish.

While foulants are a major cause of lower resin loadings, the particular foulants vary from mill to mill. However, one ionic species common to all acid leach operations is the bisulfate anion ( $\mathrm{HSO}_{4}^{-}$). Bisulfate ions readily form at $\mathrm{pH}$ values less than 3, and they compete with uranyltrisulfate species for resin sites.

In a similar way, uranium can also be removed with DOWEX $21 \mathrm{~K}$ resin in alkaline carbonate leach systems. Competition of chloride or carbonate with uranyl complexes for resin sites can result in lower operating capacities. As carbonate increases, the $\mathrm{U}_{3} \mathrm{O}_{8}$ loading declines. as shown in figure 3. The total loading for the 40 $g / \mathrm{Na}_{2} \mathrm{CO}_{3}$ liquor was $34.5 \mathrm{~g} \mathrm{U}_{3} \mathrm{O}_{8} \mathrm{n}$, and for the $60 \mathrm{~g} / \mathrm{l} \mathrm{Na} \mathrm{CO}_{3}$ liquor the loading was $20.7 \mathrm{~g} \mathrm{U}_{3} \mathrm{O}_{8} \mathrm{H}$.

A typical loading curve for an acid leach is shown in Figure 4. The rapid rise in uranium concentration from initial uranium breakthrough to the final effluent concentration reflects the efficient utilization of DOWEX $21 \mathrm{~K}$ ion exchange resin.

To minimize the cost of the chemicals used in the extraction and precipitation of uranium products, it is desirable to have a highly concentrated uranium feed solution. This objective is reached when the uranium elutes from the resin in a sharp. narrow band. Figure 5 shows several elution curves for different conditions in a carbonate leach system. The increase in $\mathrm{NaCl}$ concentration results in a sharper. concentrated eluent.
Commonly used eluents include sodium chloride. sodium carbonate. ammonium carbonate, or some mixture of these chemicals.

- Additional data on acid or carbonate leach systems for loading and elution is available from The Dow Chemical Company upon request.

\section{Column Loading from Low Uranium $\left(0.1 \mathrm{~g} \mathrm{U}_{3} \mathrm{O}_{8} /\right)$ High Carbonate Leach Liquors}

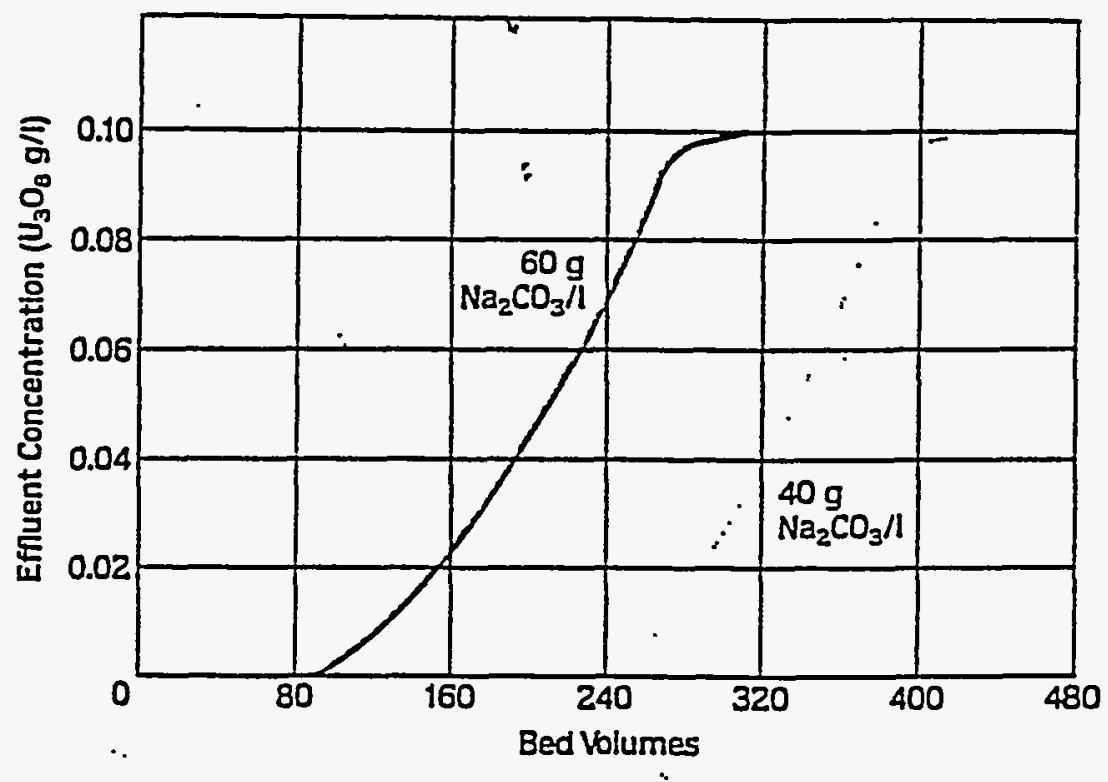

FGURE 4
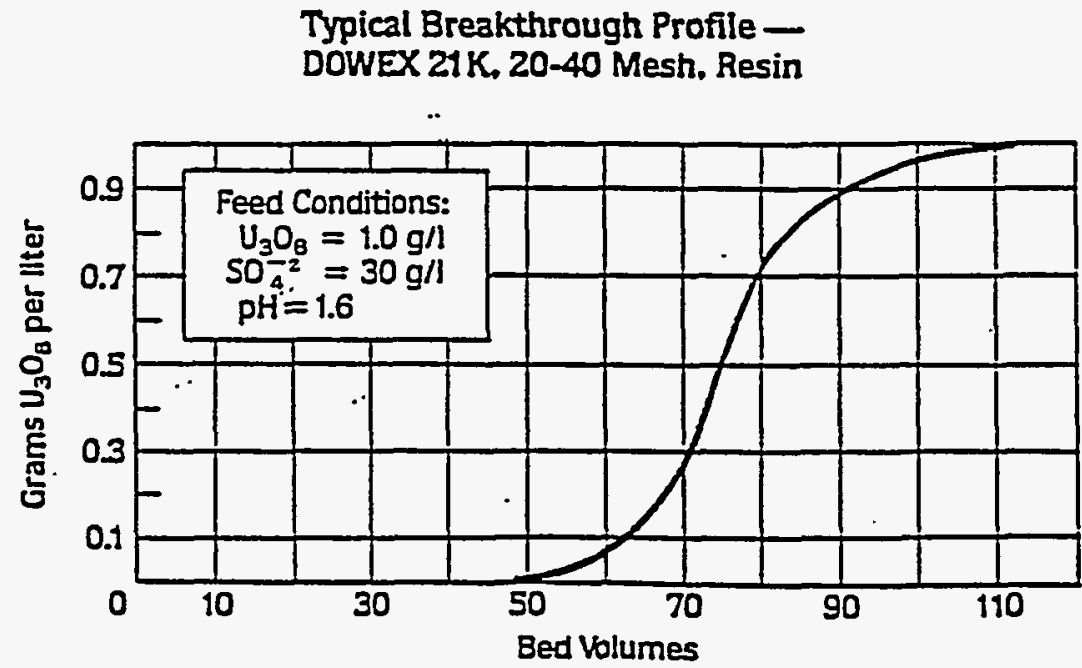

B-15 
Rev. 0

\section{TYPICAL PROPERTIES REILLEX $^{\mathrm{TM}}$ crosslinked poly-4-vinylpyridines}

\begin{tabular}{|c|c|c|}
\hline Reillex $^{\mathrm{TM}} 402$ & Reillex $^{\mathrm{TM}} 425$ & Reillex $^{\text {TM }}$ HP \\
\hline
\end{tabular}

Appearance granular powder spherical beads spherical beads spherical beads

$\begin{array}{cllll}\text { Weak Base } & 8.8 \mathrm{eq} / \mathrm{kg} \mathrm{dry} & 5.5 \mathrm{eq} / \mathrm{kg} \mathrm{dry} & 5.5 \mathrm{eq} / \mathrm{kg} \mathrm{dry} & 1.3 \mathrm{eq} / \mathrm{kg} \mathrm{dry} \\ \text { Capacity } & & 1.6 \mathrm{eq} / 1 \text { wet } & 1.6 \mathrm{eq} / 1 \text { wet :- } & 0.3 \mathrm{eq} / 1 \mathrm{wet}\end{array}$

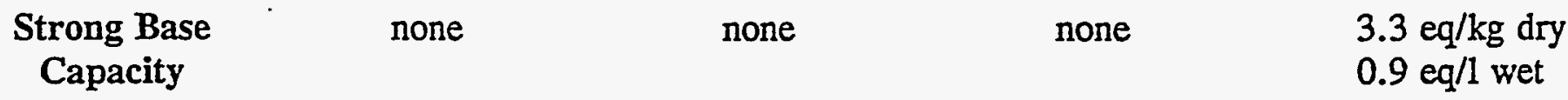

$\begin{array}{lllll}\text { Water (\%) } & 5-7 & 50-60 & 50-60 & 55-65\end{array}$

$\begin{array}{llllll}\text { DVB }(\%) & 2 & 25 & \cdot & 25 & 25\end{array}$

$\begin{array}{cccc}\text { Particle Size } & -60 /+200 & -18 /+50 & -30 /+60\end{array}$

\begin{tabular}{|c|c|c|c|c|}
\hline Bulk Density & - & 39.5 & 38.5 & 41.7 \\
\hline $\begin{array}{l}\text { Average Pore } \\
\text { Size (A) }\end{array}$ & none & $450^{\circ}$ & 1000 & 1000 \\
\hline
\end{tabular}

This information is for gudance in the use of this product only and. while the facts are believed to be reliable. suttability of this product for a particular application should be determined by theif user. Comments conceming the possible use of this product in commercial applications are not intended as a recommendation to infringe on any existing patents. Every possible effort has been made to insure the accuracy of the information based on research done at Reilly Industries. Inc., but no guarantee is implied or should be inferred.

B-16.

Reilly Industries. In(.. 1500 S. Tilbs Arenue. P.O. Box +2912. Indianapolis. IX +6242-0912

Phone: (317) $247-8141$ Fax: $(317) 248-6402)$ 


\begin{tabular}{ll}
\hline Typical Physical Propertles: & $\cdot$ \\
Mesh Size, Tyler Sleve, $90 \%$ Min. & $8 \times 24$ \\
Total Surface Area, $\mathrm{m}^{2} / \mathrm{g}$ & 100 \\
Pore Volume Within Particle), cc/g & 0.225 \\
Acid Soluble Ash, Wt.\% Max. & 3 \\
Moisture, Wt.\% Max. & 5 \\
Bulk Density, lbs./ $\mathrm{tt}^{3}$ & 40
\end{tabular}

TIGG Type MRM is a granular adsorbent used for applications involving removal of inorganle and organic materlals from potable and process water. Specific applications include removel of chlorine, fitorlde, and heavy metals (Including lead, cadmlum, mercury, zinc, iron, copper, manganese, aluminium, arsenic, sllver, strontlum, cobalt, vanadlum, and chromium). Furthermore, TIGQ Type MRM has applicatlons for removing radionuclldes (including radlolsotopes of elements above and ruthenlum, plutonium, and americlum). Frequently, economical applications of TIGG Type MRM are capable of achleveing non-detectable effluent quality.

Most applicatlons are initlally piloted to determine long-term economics and to optimize operating conditions. Pilot design data is then used to select the most appropriate TIGQ CANSORB vessel size to apply the edsorbent. TIGG Type MRM is backwashable, If the application requires this step.

Another grade, TIGQ Type MRM - AG is a specially prepared aquarium grade material useful for similar applications in fisheries and fish hatcheries. This material is usually supplled In a $5 \times 8$ Tyler Sieve slze.

While TIGG Type MRM is ususelly supplied in our standard preengineered CANSORB llquid phase modular adsorbers, if can be supplied separately as makeup when spent beds in preexisting adsorbers are replaced. Please contact us to order pllot or commercial adsorbers containing TIGG Type MRM, or for ordering replecement adsorbent. 
DOE/RL-95-59

Rev. 0 
DOE/RL-95-59

Rev. 0

\section{APPENDIX C}

DATA TABLES, DATABASE, AND SECONDARY CONTAMINANTS 
DOE/RL-95-59

Rev. 0 


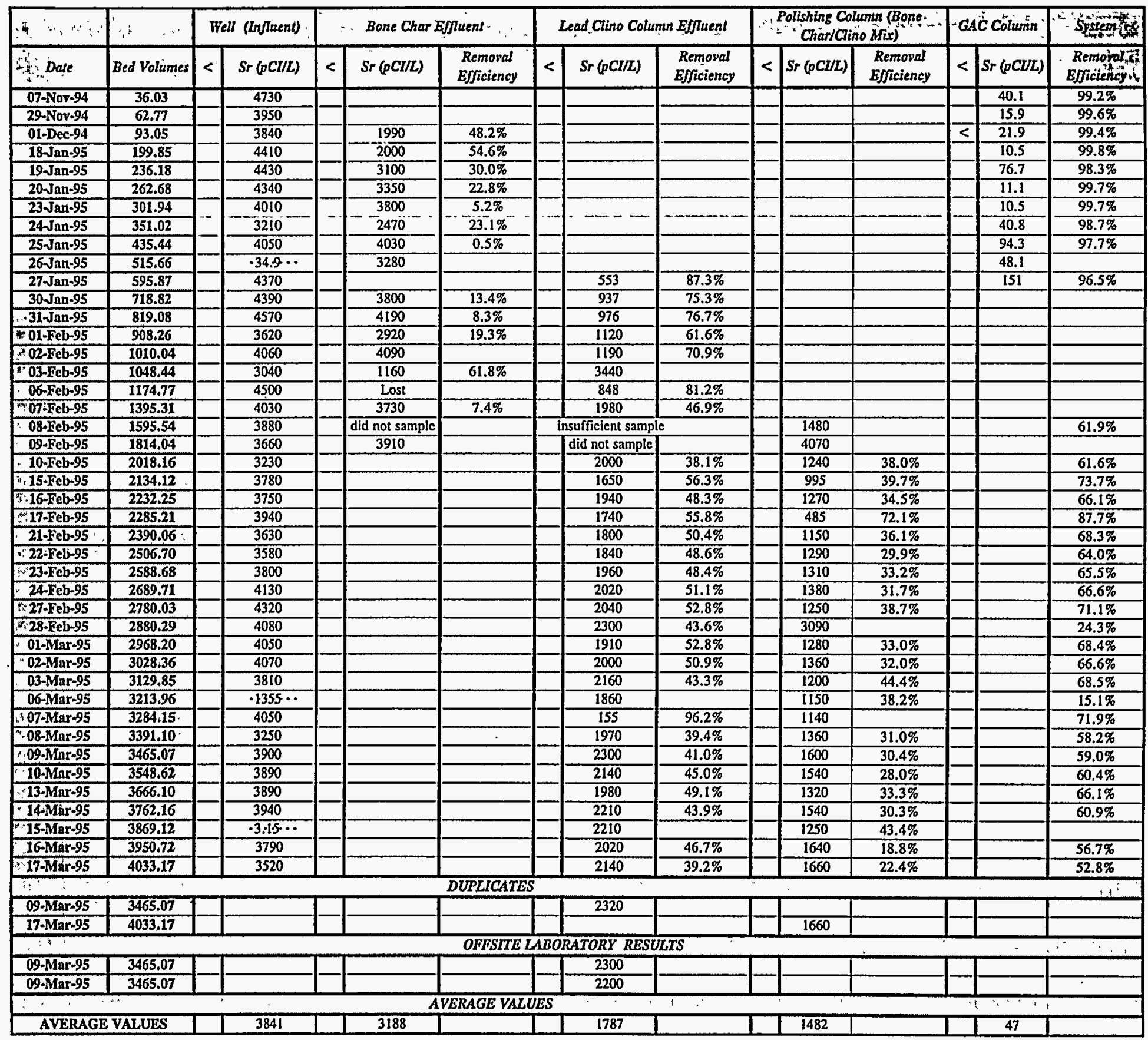




\begin{tabular}{|c|c|c|c|c|c|c|c|c|c|c|c|c|c|c|c|}
\hline \multirow{2}{*}{ 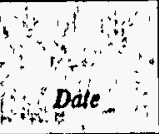 } & \multirow{2}{*}[\begin{array}{ll}{}&{}\\
{\text{BedVolumes}}&{}\\
{\hdashline}\end{array}]{} & \multicolumn{2}{|c|}{ Welli (Influent) } & \multicolumn{3}{|c|}{ Bone Char EJfuent } & \multicolumn{3}{|c|}{ Lead Clino Collumin Effluent } & \multicolumn{3}{|c|}{$\begin{array}{l}\text { Polishing Column (Bonge } \\
\text { Char/Clino Mix) }\end{array}$} & \multicolumn{2}{|c|}{ GAC Columin } & \multirow{2}{*}{ 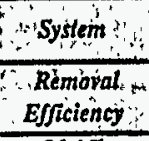 } \\
\hline & & $<1$ & $C s-137(p C L / L)$ & $<$ & $C s-13,7_{1}(p C l / L)$ & $\begin{array}{l}\text { Removal } \\
\text { Efficiency: }\end{array}$ & $<$ & $C s-137(p c t / L)$ & $\begin{array}{l}\text { 'Rembval' } \\
\text { 'Efficiency. } \\
\end{array}$ & $<1$ & $C S-137(p C, \mid L)$ & $\begin{array}{l}\text { Removal } \\
\text { Efficiency. }\end{array}$ & & $s r(p C l i L)$ & \\
\hline .07-Nov-94 & 36.03 & & 1040 & & & & & & & & & & & 40.1 & \\
\hline$\frac{29-\text { Nor-94 }}{\text { 01-Dec-94 }}$ & 62.77 & & 1180 & & & & & & & - & & & & 15.9 & $98.7 \%$ \\
\hline $\begin{array}{l}01-D e c-94 \\
18 \sqrt{a n}-95\end{array}$ & 93.05 & & 1220 & & 570 & $53.3 \%$ & & & & - & & & $\leq$ & 21.9 & $98.2 \%$ \\
\hline$\frac{18 \sqrt{3 a n}-95}{19.5 n-95}$ & 199.85 & 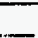 & 1470 & & 1140 & $22.4 \%$ & - & & -1 & 二 & & & & 10.5 & $99.3 \%$ \\
\hline 19-Jan-95 & 236.18 & - & $1500^{-}$ & & $1210^{-1}$ & $19.3 \%$ & $\bar{z}$ & & & & & & & 76.7 & $94.9 \%$ \\
\hline 20-Jan-95 & 262.68 & & 1390 & & 1240 & $10.8 \%$ & - & & & & & & - & -11.1 & $99.2 \%$ \\
\hline 23-Jan-95 & 301.94 & 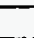 & 1430 & & 1300 & $9.1 \%$ & $\ldots$ & & & - & & - n. & & 10.5 & $99.3 \%$ \\
\hline 24 - & 351.02 & - & 1360 & - & $1350^{-}$ & $0.7 \%$ & $=$ & & & & & & & 40.8 & $97.0 \%$ \\
\hline 25-Jan- 95 & 435.44 & & 1340 & 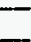 & 1440 & & 一 & & & ב & & & $\ldots$ & 94.3 & $93.0 \%$ \\
\hline 26-Jatt-95 & 515.66 & & 1870 & & 1480 & & - & & & E & & & & 48.1 & $97.4 \%$ \\
\hline $27 \sqrt{a n 1}-95$ & 595.87 & & 1460 & & & & $\leq$ & 60.7 & $95.8 \%$ & - & & & & 151 & $89.7 \%$ \\
\hline $30-\sqrt{\text { wai }-95}$ & 718.82 & & 1420 & & 1400 & $1.4 \%$ & & 262 & $81.3 \%$ & & & & & & \\
\hline 31 Jann-95 & 819.08 & 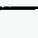 & 1490 & 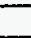 & 1650 & & $<$ & 58.2 & $96.5 \%$ & & & & & & \\
\hline $01-\mathrm{Feb}-95$ & 908.26 & 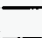 & 1360 & 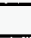 & 1480 & & $<$ & 61.4 & $95.9 \%$ & & & & & & \\
\hline $02-\mathrm{Feb}-95$ & 1010.04 & & 1420 & & 1420 & & $<$ & 58 & $95.9 \%$ & 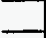 & & & & & \\
\hline $03-$ Feb-95 & 1048.44 & & 1410 & 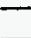 & 1260 & $10.6 \%$ & $<$ & 78.6 & $94.4 \%$ & E & & & & & \\
\hline $06-\mathrm{Feb}-95$ & 1174.77 & 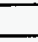 & 1570 & & & & $<$ & 59 & $96.2 \%$ & - & & & & & \\
\hline $07-$ Feb-95 & $\mathbf{1 3 9 5 . 3 1}$ & 二 & 1410 & 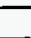 & 1430 & & $<$ & 55 & $96.2 \%$ & - & & & & & \\
\hline 08-Feb-95 & 1595.54 & & 1380 & E & 1420 & & & & & $<$ & 58.3 & & & & $95.8 \%$ \\
\hline $09=\mathrm{Feb}-95$ & 1814.04 & & 1350 & - & 1310 & $3.0 \%$ & & & & $\leq$ & 58.5 & & & & $95.7 \%$ \\
\hline $10-\mathrm{Feb}-95$ & 2018.16 & & 1410 & 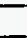 & & & $\leq$ & 59.5 & $95.8 \%$ & $<$ & 57.4 & $3.5 \%$ & & & $95.9 \%$ \\
\hline $15-\mathrm{Feb}-95$ & 2134,12 & & 1350 & 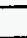 & & & $<$ & 57.3 & $95.8 \%$ & $<$ & 59.1 & & 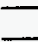 & & $95.6 \%$ \\
\hline $16 \div \mathrm{Feb}-95$ & 2232.25 & & 1330 & 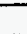 & & & & 57.2 & $95.7 \%$ & $<$ & 0 & $100.0 \%$ & & & $100.0 \%$ \\
\hline $17-\mathrm{Feb}-95$ & 2285.21 & 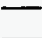 & 1300 & 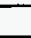 & & & $<$ & 57.1 & $95.6 \%$ & $\leq$ & 59.6 & & & & $95.4 \%$ \\
\hline $21-$ Feb-95 & 2390.06 & & 1310 & 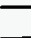 & & & $<$ & 59 & $95.5 \%$ & $<$ & 57.4 & $2.7 \%$ & & & $95.6 \%$ \\
\hline $22-\mathrm{Fel}-95$ & 2506.70 & - & 1320 & E & & & $<$ & 58.6 & $95.6 \%$ & $<$ & 58.6 & $0.0 \%$ & & & $95.6 \%$ \\
\hline 23-Feb-95 & 2588.68 & & 1300 & 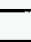 & & & $<$ & 57.7 & $95.6 \%$ & $<$ & 58.5 & & & & $95.5 \%$ \\
\hline 24-Feb-95 & 2689.71 & - & 1300 & - & & & $<1$ & 58.9 & $95.5 \%$ & $<$ & 46.1 & $21.7 \%$ & & & $96.5 \%$ \\
\hline $27-\mathrm{Feb}-95$ & 2780.03 & Z & 1400 & E & & & $<1$ & 55.9 & $96.0 \%$ & $<$ & 58.2 & & & & $95.8 \%$ \\
\hline 28 - Feb-95 & 2880.29 & - & 1270 & - & & & $<$ & 61.2 & $95.2 \%$ & $<$ & 59.6 & $2.6 \%$ & & & $95.3 \%$ \\
\hline $01 \cdot$ Mar -95 & 2968.20 & & 1330 & - & & & $<$ & 59.9 & $95.5 \%$ & $<$ & 57.9 & $3.3 \%$ & & & $95.6 \%$ \\
\hline $02-$ Mar-95 & 3028.36 & & 1300 & 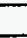 & & & $<$ & 57.1 & $95.6 \%$ & $<$ & 60.3 & & & & $95.4 \%$ \\
\hline $03-$ Mar-95 & 3129.85 & & 1270 & - & & & $<$ & 61 & $95.2 \%$ & $\leq$ & 58.8 & $3.6 \%$ & & & $95.4 \%$ \\
\hline $06-\mathbf{M a r}-95$ & 3213.96 & & 1380 & - & & & $<$ & 58.7 & $95.7 \%$ & $<$ & 60 & & & & $95.7 \%$ \\
\hline $07-\mathrm{Mar}-95$ & 3284.15 & E & 1380 & - & & & $\leq$ & 53.6 & $96.1 \%$ & $<$ & 57.7 & & & & $95.8 \%$ \\
\hline $08-$ Mar-95 & 3391.10 & & 1170 & 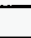 & & & & 59.9 & $94.9 \%$ & $<$ & 55.8 & $6.8 \%$ & & & $95.2 \%$ \\
\hline $09-\operatorname{Mar}-95$ & 3465.07 & & 1260 & - & & & $<1$ & 57.8 & $95.4 \%$ & $\leq$ & 58.6 & & & & $95.3 \%$ \\
\hline 10-Mar-95 & 3548.62 & & 1400 & & & & $<$ & 60.8 & $95.7 \%$ & $<$ & 58.1 & $4.4 \%$ & & & $95.9 \%$ \\
\hline 13-Mar-95 & 3666.10 & & 1400 & 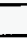 & & & $<$ & 59.4 & $95.8 \%$ & $<$ & 60 & & & & $95.7 \%$ \\
\hline 14-Mar-95 & 3762.16 & & 1310 & & & & $<$ & 59.2 & $95.5 \%$ & $\leq$ & 56.2 & $5.1 \%$ & & & $95.7 \%$ \\
\hline 15-Mar-95 & 3869.12 & & 1190 & & & & $<$ & 58.3 & $95.1 \%$ & $<$ & 57.1 & $2.1 \%$ & & & $95.2 \%$ \\
\hline $16-$ Mar- -95 & 3950.72 & & 1280 & & & & $<1$ & 58.8 & $95.4 \%$ & $<$ & 60.4 & & & & $95.3 \%$ \\
\hline 17-Már-95 & 4033.17 & & 1210 & & & & $<1$ & 57.4 & $95.3 \%$ & $<$ & 58.6 & & & & $95.2 \%$ \\
\hline & & & & & & DUPLICA & & & & & & & & & \\
\hline $09-$ Mar-95 & 3465.07 & & & & & & $<$ & 57.6 & & {[} & & & & & \\
\hline 17-Mar-95 & 4033.17 & & & & & & & & & $<$ & 56.4 & & & & \\
\hline & & & & & & OFFSITE & $\angle A B$ & BORATORY RES & ULTS & & & & & & \\
\hline $09 \cdot$ Mar-95 & 3465.07 & & & & & & $<$ & 11 & & & & & & & \\
\hline 09--NSar-95 & 3465.07 & & & & & & $<$ & 4.8 & & & & & & & \\
\hline & & & & & & AVERAC & $\overline{L U E S}$ & & & & & & & & \\
\hline AVERAG & VALUES & & 1354 & & 1319 & $14.5 \%$ & $\square$ & 65.7 & $95.1 \%$ & & 55.6 & $13.0 \%$ & & 47.4 & $96.0 \%$ \\
\hline
\end{tabular}


DOE/RL-95-59

Rev. 0

Table C-3. Plutonium Data, 216-B-5 Reverse Well Pilot-Scale, Run 1.

\begin{tabular}{|c|c|c|c|c|c|c|c|c|c|c|c|c|}
\hline \multirow{2}{*}{ 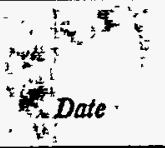 } & \multirow[b]{2}{*}{ Bed Volumes } & \multicolumn{2}{|c|}{ Well (Influent) } & \multicolumn{3}{|c|}{ Bone Char Effuient } & \multicolumn{3}{|c|}{ Lead Clino Column Effuent } & \multicolumn{2}{|c|}{ GAC Cotumin } & \multirow{2}{*}{ 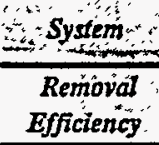 } \\
\hline & & $<$ & $P u(p C I / L)$ & $<$ & $P u(p C I / L)$ & $\begin{array}{l}\text { Removal } \\
\text { Efficiency }\end{array}$ & $<$ & $P A(p C I / L)$ & $\begin{array}{l}\text { Removal } \\
\text { Efficiency }\end{array}$ & $<$ & Pit $(p C I / \hat{L})$ & \\
\hline 07-Nor-94 & 36.03 & $<$ & 10 & & & & & & & $<$ & 10 & \\
\hline 29-Nov-94 & 62.77 & & 18.4 & & & & & & & $<$ & 10 & $45.7 \%$ \\
\hline 01-Dec-94 & 93.05 & & 30.1 & $<$ & 20 & $33.6 \%$ & & & & $<$ & 20 & $33.6 \%$ \\
\hline 18-Jan-95 & 199.85 & & 32.5 & $<$ & 10 & $69.2 \%$ & & & & $<$ & 10 & $69.2 \%$ \\
\hline 19-Jan-95 & 236.18 & & 33.5 & $<$ & 10 & $70.1 \%$ & & & & $<$ & 10 & $70.1 \%$ \\
\hline $20-J a n-95$ & 262.68 & & 44.6 & $<$ & 2.26 & $94.9 \%$ & & & & $<$ & 3.16 & $92.9 \%$ \\
\hline 23-Jan-95 & 301.94 & & 26.9 & $<$ & 2.18 & $91.9 \%$ & & & & $<$ & 2.81 & $89.6 \%$ \\
\hline $24-\operatorname{Jan}-95$ & 351.02 & & 29.6 & & 3.47 & $88.3 \%$ & & & & $<$ & 2.68 & $90.9 \%$ \\
\hline 25-Jan-95 & 435.44 & & 19.4 & & 2.48 & $87.2 \%$ & & & & $<$ & 2.42 & $87.5 \%$ \\
\hline $26-\mathrm{Jan}-95$ & 515.66 & & 24.6 & $<$ & 16.5 & $32.9 \%$ & & & & $<$ & 3.24 & $86.8 \%$ \\
\hline $27-\sqrt{a n}-95$ & 595.87 & & 22.6 & & & & $<$ & 2.2 & $90.3 \%$ & $<$ & 2.63 & $88.4 \%$ \\
\hline $30-J a n-95$ & 718.82 & & 19.3 & $<$ & 2.61 & $86.5 \%$ & $<$ & 2.48 & & & & $87.2 \%$ \\
\hline $31-J a n-95$ & 819.08 & & 18.3 & $<$ & 2.89 & $84.2 \%$ & $<$ & 2.23 & & & & $87.8 \%$ \\
\hline 01-Feb-95 & 908.26 & & 18.6 & $<$ & 2.64 & $85.8 \%$ & $<$ & 12.2 & & & & $34.4 \%$ \\
\hline 02-Eeb-95 & 1010.04 & & 16.7 & $<$ & 2.13 & $87.2 \%$ & $<$ & 2.26 & & & & $86.5 \%$ \\
\hline 03-Feb-95 & 1048.44 & & & & & & & & & & & \\
\hline 06-Feb-95 & 1174.77 & & 17.4 & $<$ & 2.47 & $85.8 \%$ & $<$ & 2.39 & & & & $86.3 \%$ \\
\hline 07-Feb-95 & 1395.31 & & 17.5 & $<$ & 2.18 & $87.5 \%$ & $<$ & 5.76 & & & & $67.1 \%$ \\
\hline 08-Feb-95 & 1595.54 & & 16.1 & $<$ & 3.73 & $76.8 \%$ & & & & & & \\
\hline 09-Feb-95 & 1814.04 & & 15.5 & $<$ & 4.77 & $69.2 \%$ & & & & & & \\
\hline 10-Feb-95 & 2018.16 & & 16.2 & & & & $<$ & 3.98 & $75.4 \%$ & & x & $75.4 \%$ \\
\hline $15-F e b-95$ & 2134.12 & & 14.4 & & & & $<$ & 18.4 & & & & \\
\hline 16-Feb-95 & 2232.25 & & & & & & & & & & & \\
\hline 17-Feb-95 & 2285.21 & & 19.9 & & & & $<$ & 2.91 & $85.4 \%$ & & & $85.4 \%$ \\
\hline 21-Feb-95 & 2390.06 & $<$ & 28 & & & & $<$ & 2.69 & $90.4 \%$ & & & $90.4 \%$ \\
\hline 22-Feh-95 & 2506.70 & & 15.3 & & & & $<$ & 2.11 & $86.2 \%$ & & & $86.2 \%$ \\
\hline 23-Feb-95 & 2588.68 & & 15.2 & & & & $<$ & 2.31 & $84.8 \%$ & & & $84.8 \%$ \\
\hline 24-Feb-95 & 2689.71 & & 16.6 & & & & $<$ & 3.78 & $77.2 \%$ & & & $77.2 \%$ \\
\hline 27-Feb-95 & 2780.03 & & 17.4 & & & & $<$ & 2.55 & $85.3 \%$ & & & $85.3 \%$ \\
\hline $28-F e b-95$ & 2880.29 & & 18 & & & & $<$ & 2.78 & $84.6 \%$ & & & $84.6 \%$ \\
\hline 01-Mar-95 & 2968.20 & $<$ & 5.93 & & & & $<$ & 6.17 & & & & \\
\hline 02-Mar-95 & 3028.36 & & 17.4 & & & & $<$ & 5.71 & $67.2 \%$ & & & $67.2 \%$ \\
\hline 03-Mar-95 & 3129.85 & & 17.6 & & & & $<$ & 5.61 & $68.1 \%$ & & & $68.1 \%$ \\
\hline 06-Mar-95 & 3213.96 & $<$ & 5.17 & & & & $<$ & 4.14 & & & & $19.9 \%$ \\
\hline 07-Mar-95 & 3284.15 & & 18.3 & & & & $<$ & 5.68 & $69.0 \%$ & & & $69.0 \%$ \\
\hline 08-Mar-95 & 3391.10 & & 18.4 & & & & $<$ & 4.46 & $75.8 \%$ & & & $75.8 \%$ \\
\hline 09-Mar-95 & 3465.07 & & 15.9 & & & & $<$ & 6.6 & $58.5 \%$ & & & $58.5 \%$ \\
\hline 10-Mar-95 & 3548.62 & & 13.8 & & & & $<$ & 2.67 & $80.7 \%$ & & & $80.7 \%$ \\
\hline 13-Mar-95 & 3666.10 & & 14.6 & & & & $<$ & 3.17 & $78.3 \%$ & & & $78.3 \%$ \\
\hline 14-Mar-95 & 3762.16 & & 16.4 & & & & $<$ & 3.32 & $79.8 \%$ & & & $79.8 \%$ \\
\hline 15-Mar-95 & 3869.12 & & 16 & & & & $<$ & 2.62 & $83.6 \%$ & & & $83.6 \%$ \\
\hline 16-Mar-95 & 3950.72 & & 13.7 & & & & $<$ & 2.53 & $81.5 \%$ & & & $81.5 \%$ \\
\hline 17-Mar-95 & 4033.17 & $<$ & 31.5 & & & & $<$ & 4.11 & $87.0 \%$ & & & $87.0 \%$ \\
\hline \multicolumn{13}{|c|}{ DUPLICATES } \\
\hline 09-Mar-95 & 3465.07 & 1 & & & & & $<$ & 5.52 & & & & \\
\hline 17-Mar-95 & 4033.17 & 1 & & & & & & & & & & \\
\hline \multicolumn{13}{|c|}{ OFFSITE LABORATORY RESULTS } \\
\hline 09-Mar-95 & 3465.07 & 1 & & & 1.6 & & & & & & & \\
\hline 09-Mar-95 & 3465.07 & i & & & 1.5 & & & $\cdot$ & & & & \\
\hline \multicolumn{4}{|c|}{ 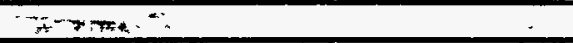 } & $\therefore$ & $\because \because \quad \overline{A V I}$ & $A G E$ VALUE & & $\because \because+$, & $\because \cdots, \quad \because, \cdots$ & & - & $\because \quad \therefore$ \\
\hline AVERAGE & VALUES & 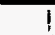 & 19.4 & $\overline{<}$ & 5.6 & $77.0 \%$ & $<$ & 4.4 & $79.4 \%$ & & 7.0 & $75.6 \%$ \\
\hline
\end{tabular}




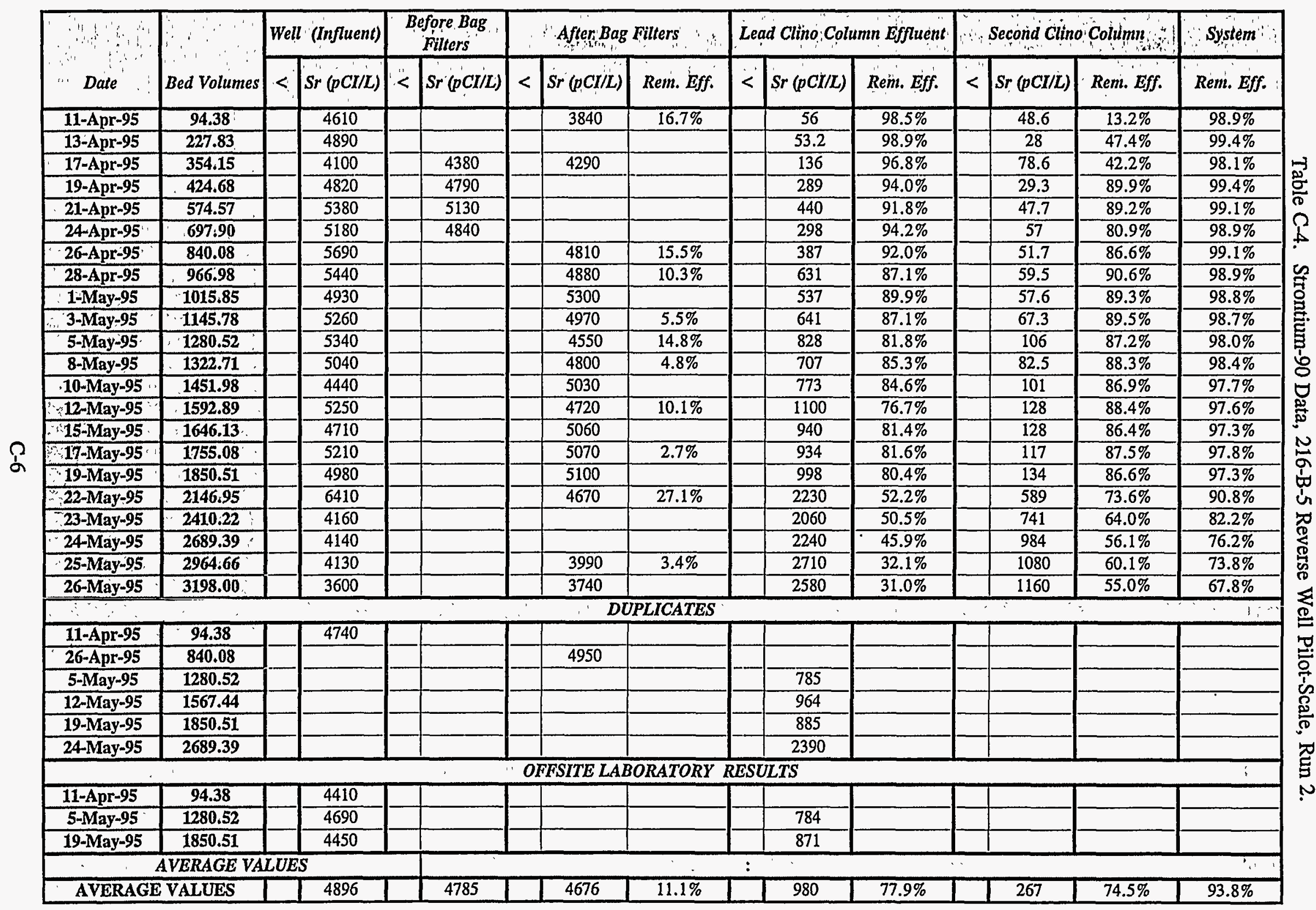


DOE/RL-95-59

Rev. 0

Table C-5. Cesium-137 Data, 216-B-5 Reverse Well Pilot-Scale, Run 2.

\begin{tabular}{|c|c|c|c|c|c|c|c|c|c|c|c|}
\hline \multirow{2}{*}{ Date } & \multirow[b]{2}{*}{ Bed Volumes } & \multicolumn{2}{|c|}{ Well (Influent) } & \multicolumn{2}{|c|}{ Before Bag Filters } & \multicolumn{2}{|c|}{ After Bag Filters } & \multicolumn{2}{|c|}{$\begin{array}{c}\text { Lead Clino Column } \\
\text { Effluent }\end{array}$} & \multicolumn{2}{|c|}{$\begin{array}{l}\text { Second Clino } \\
\text { Column Effluent }\end{array}$} \\
\hline & & $<$ & $\begin{array}{l}C s-137 \\
(p C I / L)\end{array}$ & $<$ & $\begin{array}{l}C s-137 \\
(p C I / L)\end{array}$ & $<$ & $\begin{array}{l}C_{s-137} \\
(p C I / L)\end{array}$ & $<$ & $\begin{array}{l}C s-137 \\
(p C I L)\end{array}$ & $<$ & $\begin{array}{l}C s-137 \\
(p C I / L)\end{array}$ \\
\hline -11-Apr-95 & 94.38 & & 1380 & & & & 1000 & $<$ & 59.1 & $<$ & 56 \\
\hline 13-Apr-95 & 227.83 & & 1450 & & & & & $<$ & 59.9 & $<$ & 61 \\
\hline 17-Apr-95 & 354.15 & 3 & 1400 & & 626 & & 280 & $<$ & 59 & $<$ & 58.9 \\
\hline 19-Apr-95 & 424.68 & 7 & 1530 & & 1360 & & & & & & \\
\hline 21-Apr-95 & 574.57 & & 1490 & & 1430 & & & & 60.9 & $<$ & 57.6 \\
\hline 24-Apr-95 & 697.90 & & 1620 & & 1440 & & & $<$ & 58 & & \\
\hline 26-Apr-95 & 840.08 & & 1600 & & & & 1390 & $<$ & 60.2 & $<$ & 59.3 \\
\hline 28-Apr-95 & 966.98 & & 1560 & & & & 1360 & $<$ & 58.2 & & \\
\hline 01-May-95 & 1015.85 & 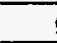 & 1480 & & & & 1470 & $<$ & 57.1 & & \\
\hline 03-May-95 & 1145.78 & 7 & 1760 & & & & 1430 & & & & \\
\hline 05-May-95 & 1280.52 & 7 & 1420 & & & & 1500 & $<$ & 58.7 & & \\
\hline 08-May-95 & 1322.71 & & 1630 & & & & & & & & \\
\hline 10-May-95 & 1451.98 & & 1570 & & & & & & & & \\
\hline 12-May-95 & 1592.89 & & 1530 & & & & 1590 & & & $<$ & 60.8 \\
\hline 15-May-95 & 1646.13 & & 147 & & & & & & & & \\
\hline 17-May-95 & 1755.08 & & 1540 & & & & & & & & \\
\hline 19-May-95 & 1850.51 & & 1530 & & & & 1500 & $<$ & 57.6 & & \\
\hline 22-May-95 & 2146.95 & & 1820 & & & & 1720 & $<$ & 58.2 & $<$ & 56 \\
\hline 23-May-95 & 2410.22 & & 1510 & & & & & & & & \\
\hline 24-May-95 & 2689.39 & & 1420 & & & & & $<$ & 60.2 & & \\
\hline 25-May-95 & 2964.66 & & 1360 & & & & & & & & \\
\hline 26-May-95 & 3198.00 & & 1310 & & & & 1300 & $<$ & 60.6 & & \\
\hline \multicolumn{12}{|c|}{ DUPLICATES } \\
\hline 11-Apr-95 & 94.38 & & 1440 & & & & & & & & \\
\hline 26-Apr-95 & 840.08 & 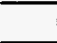 & & & & & 1460 & & & & \\
\hline 5-May-95 & 1280.52 & & & & & & & $<$ & 59.4 & & \\
\hline 12-May-95 & 1567.44 & L & & & & & & & & & \\
\hline 19-May-95 & 1850.51 & & & & & & & $<$ & 58 & & \\
\hline 24-May-95 & 2689.39 & & & & & & & $<$ & 69.9 & & \\
\hline \multicolumn{12}{|c|}{ OFFSITE LABORATORY RESULTS } \\
\hline 11-Apr-95 & 94.38 & & 1510 & & & & & & & & \\
\hline 5-May-95 & 1280.52 & & 1550 & & & & & & 6.76 & & \\
\hline 19-May-95 & 1850.51 & & 1370 & & & & & $<$ & 4.75 & & \\
\hline \multicolumn{5}{|c|}{$\because \quad$ AVERAGE VALUES } & \multicolumn{7}{|c|}{ 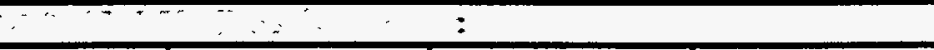 } \\
\hline AVERAG & VALUES & & 1457 & & 1214 & & 1322 & $<$ & 59.1 & $<$ & 58.5 \\
\hline
\end{tabular}


Table C-6. Technetium-99 Data, 216-BY Cribs Pilot-Scale System.

\begin{tabular}{|c|c|c|c|c|c|c|c|c|c|c|c|c|}
\hline . $\quad . \cdots$ & $a_{1}^{\prime} \therefore a^{\prime} \quad 11$ & & Before Filler & 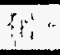 & After Filter & 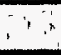 & Lead Colum & fluent: & & Polishing Colun & Effluent & \\
\hline Date. & Bed Volumes & $<$ & $T c-99(p C i / L)$ & $<$ & $T c-99(p C i / L)$ & $<$ & $T c-99(p C i / L)$ & $\begin{array}{l}\text { Removal } \\
\text { Efficiency }\end{array}$ & $<$ & $T c-9 g(p C i / L)$ & $\begin{array}{l}\text { Rénoval } \\
\text { Efficiency }\end{array}$ & $\begin{array}{l}\text { Removal } \\
\text { Efficiency }\end{array}$ \\
\hline 26-Jan-95 & 251 & & 4250 & & 6600 & & 118.0 & $98.2 \%$ & & & & \\
\hline 1-Feb-95 & 306 & & 5470 & & 5090 & $<$ & 60.9 & $98.8 \%$ & & & & \\
\hline 3-Feb-95 & 380 & & 5110 & & 4720 & $<$ & 67.9 & $98.6 \%$ & & & & \\
\hline 7-Feb-95 & 5,44 & & 6180 & & 5910 & $<$ & 79.4 & $98.7 \%$ & & & & \\
\hline 8-Feb-95 & 582 & & & & 6770 & $<$ & 82.6 & $98.8 \%$ & $<$ & 82.3 & $0.4 \%$ & $98.8 \%$ \\
\hline 9-Feb-95 & 619 & & 8860 & & 7030 & $<$ & 134.0 & $98.1 \%$ & & & & \\
\hline 15-Feb-95 & 703 & & 10100 & & 9230 & & 317.0 & $96.6 \%$ & & & & \\
\hline 17-Feb-95 & 750 & & & & 9770 & & 211.0 & $97.8 \%$ & & 352.0 & & $96.4 \%$ \\
\hline 22-Feb-95 & 874 & & 9280 & & 8310 & $<$ & 92.4 & $98.9 \%$ & & & & \\
\hline 23-Feb-95 & 907 & & & & 9860 & $<$ & 102.0 & $99.0 \%$ & & 113.0 & & $98.9 \%$ \\
\hline 27-Feb-95 & $\therefore \quad 1054$ & & 10200 & & 9980 & & 196.0 & $98.0 \%$ & & & & \\
\hline 1-Mar-95 & $\therefore \quad 1118$ & & & & 9520 & $<$ & 89.1 & $99.1 \%$ & & 160.0 & & $98.3 \%$ \\
\hline 3-Mar-95 & 1187 & & 9930 & & 9640 & & 177.0 & $98.2 \%$ & & & & \\
\hline 6Mar-95 & 1293 & & & & 9310 & $<$ & 82.6 & $99.1 \%$ & $<$ & 87.2 & & $99.1 \%$ \\
\hline $10-\mathrm{Mar}-95$ & 1426 & & 10900 & & 10700 & $<$ & 81.0 & $99.2 \%$ & & & & \\
\hline 13-Mar-95 & 1533 & & & & 9980 & & 269.0 & $97.3 \%$ & & 442.0 & & $95.6 \%$ \\
\hline 17-Mar-95 & 1674 & & 10600 & & 10700 & & 112.0 & $99.0 \%$ & & & $39.6 \%$ & $99.4 \%$ \\
\hline 24-Mar-95 & 1797 & & & & 10900 & $<$ & 67.2 & $99.4 \%$ & $<$ & 67.7 & & \\
\hline 30-Mar-95 & 1797 & & 11200 & & 10100 & & 144.0 & $98.6 \%$ & & & & \\
\hline$\therefore$ 5-Apr-95 & 1898 & & & & 9920 & & 206.0 & $97.9 \%$ & & 200.0 & $2.9 \%$ & $98.0 \%$ \\
\hline$\cdots 10-A p r-95$ & 2006 & & 10500 & & 9320 & $<$ & 146.0 & $98.4 \%$ & & & & \\
\hline $12-A p r-95$ & 2080 & & & & 10700 & $<$ & 160.0 & $98.5 \%$ & $<$ & 158.0 & $1.3 \%$ & $98.5 \%$ \\
\hline 19-Apr-95 & 2217 & & 10800 & & 9630 & & 271.0 & $97.2 \%$ & & & & \\
\hline 21-Apr-95 & 2283 & & 10800 & & & & 162.0 & & $<$ & 83.8 & $48.3 \%$ & \\
\hline 26-Apr-95 & 2372 & & 8910 & & 9030 & & 188.0 & $97.9 \%$ & & & & \\
\hline $28-\mathrm{Apr}-95$ & 2440 & & & & 10000 & $<$ & 166.0 & $98.3 \%$ & $<$ & 138.0 & $16.9 \%$ & $98.6 \%$ \\
\hline 4-May-95 & 2549 & & 8130 & & 11300 & & 271.0 & $97.6 \%$ & & & & \\
\hline 16-May-95 & 2782 & & 9830 & & 9760 & & 700.0 & $92.8 \%$ & & & & \\
\hline 18-May-95 & 2821 & & 6960 & & 8430 & & 342.0 & $95.9 \%$ & $<$ & 84.8 & $75.2 \%$ & $99.0 \%$ \\
\hline$\because$ & . & & & . & Offs & ite Lo & boratory Results & & & 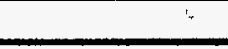 & & \\
\hline 4-May-95 & 2549 & & 10500 & & & & 251.0 & & & & & \\
\hline 18-May-95 & 2821 & & & & 8590 & & & & & & & \\
\hline
\end{tabular}


Table C-7. Cobalt-60 Data, 216-BY Cribs Pilot-Scale System.

\begin{tabular}{|c|c|c|c|c|c|c|c|c|c|c|c|c|}
\hline & & \multicolumn{2}{|r|}{ Before Filter } & \multicolumn{2}{|r|}{ After Filter } & \multicolumn{3}{|c|}{ Lead Column Effluent } & \multicolumn{3}{|c|}{ Polishing Column Effluent } & \multirow{2}{*}{$\begin{array}{c}\text { System } \\
\text { Removal } \\
\text { Efficiency }\end{array}$} \\
\hline Date & Bed Volumes & $<$ & $\mathrm{Co}-60(\mathrm{pCi} / L)$ & $<$ & $C 0-60(p C i / L)$ & $<$ & $\mathrm{Co-60}(\mathrm{pCi} / \mathrm{L})$ & $\begin{array}{l}\text { Eemoval } \\
\text { - Efficiency }\end{array}$ & $<$ & $C 0-60(p C i / L)$ & $\therefore$ Removal & \\
\hline 26-Jan-95 & 251 & & 95.5 & & 92.1 & $<$ & 40.7 & $55.8 \%$ & & & & \\
\hline 1-Feb-95 & 306 & & 92.2 & & 100.0 & $<$ & 40.7 & $59.3 \%$ & & & & \\
\hline 3-Feb-95 & 380 & & 133.0 & & 56.3 & $<$ & 36.6 & $35.0 \%$ & & & & \\
\hline 7-Feb-95 & 544 & & 158.0 & & 124.0 & $<$ & 42.1 & $66.0 \%$ & & & & \\
\hline 8-Feb-95 & 582 & & & & 111.0 & $<$ & 37.8 & $65.9 \%$ & $<$ & 38.9 & & $65.0 \%$ \\
\hline 9-Feb-95 & 619 & & 136.0 & & 157.0 & $<$ & 37.8 & $75.9 \%$ & & & & \\
\hline 15-Feb-95 & 703 & & 142.0 & & 146.0 & & ND & & & & & \\
\hline 17-Feb-95 & 750 & & & & 172.0 & $<$ & 40.7 & $76.3 \%$ & $<$ & 41.7 & & $75.8 \%$ \\
\hline 22-Feb-95 & 874 & & 147.0 & & 183.0 & & 37.7 & $79.4 \%$ & & & & \\
\hline 23-Feb-95 & 907 & & & & 173.0 & $<$ & 42.7 & $75.3 \%$ & $<$ & 39.6 & $7.3 \%$ & $77.1 \%$ \\
\hline 27-Feb-95 & 1054 & & 187.0 & & 126.0 & $<$ & 37.4 & $70.3 \%$ & & & & \\
\hline 1-Mar-95 & 1118 & & & & 170.0 & $<$ & 41.8 & $75.4 \%$ & $<$ & 41.0 & $1.9 \%$ & $75.9 \%$ \\
\hline 3-Mar-95 & 1187 & & 166.0 & & 186.0 & $<$ & 43.1 & $76.8 \%$ & & & & \\
\hline 6:Mar-95 & 1293 & & & & 169.0 & $<$ & 33.4 & $80.2 \%$ & $<$ & 35.8 & & $78.8 \%$ \\
\hline $10-M a r-95$ & 1426 & & 185.0 & & 176.0 & $<$ & 41.4 & $76.5 \%$ & & & & \\
\hline $13-M a r-95$ & 1533 & & & & 167.0 & $<$ & 42.4 & $74.6 \%$ & $<$ & 35.0 & $17.5 \%$ & $79.0 \%$ \\
\hline 17-Mar-95 & 1674 & & 147.0 & & 150.0 & & 36.6 & $75.6 \%$ & & & $100.0 \%$ & $100.0 \%$ \\
\hline 24-Mar-95 & 1797 & & & & 187.0 & $<$ & 40.0 & $78.6 \%$ & $<$ & 40.6 & & \\
\hline 30-Mar-95 & 1797 & & 169.0 & & 163.0 & $<$ & 36.6 & $77.5 \%$ & & & & \\
\hline $5-A p r-95$ & 1898 & & & & 157.0 & $<$ & 36.6 & $76.7 \%$ & $<$ & 37.8 & & $75.9 \%$ \\
\hline 10-Apr-95 & 2006 & & 145.0 & & 165.0 & $<$ & 39.2 & $76.2 \%$ & & & & \\
\hline 12-Apr-95 & $\cdot 2080$ & & & & 170.0 & $<$ & 41.4 & $75.6 \%$ & $<$ & 42.7 & & $74.9 \%$ \\
\hline 19-Apr-95 & 2217 & & 169.0 & & 172.0 & $<$ & 41.1 & $76.1 \%$ & & & & \\
\hline 21-Apr-95 & $\therefore 2283$ & & 161.0 & & & $<$ & 43.7 & & $<$ & 39.6 & $9.4 \%$ & \\
\hline 26-Apr-95 & 2372 & & 157.0 & & 166.0 & $<$ & 36.6 & $78.0 \%$ & & & & \\
\hline 28-Apr-95 & 2440 & & & & 178.0 & $<$ & 38.5 & $78.4 \%$ & $<$ & 37.8 & $1.8 \%$ & $78.8 \%$ \\
\hline 4-May-95 & 2549 & & 202.0 & & 181.0 & $<$ & 42.8 & $76.4 \%$ & & & & \\
\hline 16-May-95 : : & 2782 & & 197.0 & & 150.0 & $<$ & 32.0 & $78.7 \%$ & & & & \\
\hline 18-May-95 & 2821 & & 177.0 & & 161.0 & $<$ & 43.7 & $72.9 \%$ & $<$ & 35.0 & $19.9 \%$ & $78.3 \%$ \\
\hline \multicolumn{13}{|c|}{ Offsite Laboratory Results } \\
\hline 4-May-95 & 2549 & & 168.0 & & & $<$ & 10.5 & & & & & \\
\hline 18-May-95 & 2821 & & & & 147.0 & & & & & & & \\
\hline
\end{tabular}




\begin{tabular}{|c|c|c|c|c|c|c|c|c|}
\hline \multirow[t]{2}{*}{ HEIS\# } & \multirow{2}{*}{ DATE } & \multirow{2}{*}{ LOCATION } & \multirow{2}{*}{ PORT } & \multirow{2}{*}{ Alkalinity } & \multicolumn{3}{|c|}{ Anions, mg/l (ppm) } & \multirow[b]{2}{*}{ SO4: } \\
\hline & & & & & $\mathrm{Cl}=$ & $F$ & NO3 & \\
\hline BOFBN6 & 11-Apr-95 & Extraction Well & $A C-1$ & 101 & 18.4 & 0.26 & 2 & 30.4 \\
\hline BOFBN7 & 11-Apr-95 & Bone Char Effluent & SC-55B & 103 & 19.2 & 0.18 & 2.1 & 30.3 \\
\hline BOEBN8 & 11-Apr-95 & Lead Clino Effluent & SC-62B & $\overline{103}$ & 19.3 & 0.2 & 2.1 & 29.6 \\
\hline BOFBN9 & 11-Apr-95 & Second Clino Effluent & SC-68B & 108 & 19 & 0.22 & 2.08 & 29.8 \\
\hline & & $\ldots \quad \ldots$ & & & & & & \\
\hline BOFJF8 & 5-May-95 & Extraction Well & AC-1 & 103 & 18.9 & 0.38 & 2.18 & 29.5 \\
\hline BOFJG2 & 5-May-95 & Befóre Bag Filter & $\mathrm{AC}-2 \mathrm{~A}$ & 102 & 18.4 & 0.37 & 2.01 & 29.2 \\
\hline BOFJGO & $5-\mathrm{May}=95$ & After Bag Filter & $\mathrm{AC}-3$ & 102 & 5.54 & 0.43 & 4.6 & 62.1 \\
\hline BOFJF9 & 5-May-95 & Lead Clino: Effluent & SC-62B & 102 & 18.2 & 0.35 & 2.15 & 29.1 \\
\hline BOFJG1 & 5-May -95 & Second Clino Effluent & $\mathrm{SC}_{-68 \mathrm{~B}}$ & 103 & 18.3 & 0.36 & 2.08 & 29.1 \\
\hline \multicolumn{9}{|l|}{69} \\
\hline BOFL52 & 19-May-95 & Extraction Well. & $\mathrm{AC}-1$ & 104 & 16.5 & 0.39 & 2.23 & 27 \\
\hline BOFL54 & 19-May-95 & After Bag Filter & $\mathrm{AC}-3$ & 103 & 16 & 0.4 & 2.08 & 27 \\
\hline BOFL55 & 19-May-95 & Bone Char Effluent & SC-55B & 104 & 15.9 & 0.38 & 2.09 & 26.6 \\
\hline BOFL53 & 19-May-95 & Lead Clino Effluent & SC-62B & 104 & 16.4 & 0.37 & 2.1 & 26.9 \\
\hline BOFL56 & 19-May-95 & Second Clino Effluent & SC-68B & 104 & 16.2 & 0.38 & 2.12 & 27 \\
\hline \multicolumn{9}{|l|}{ Dunlicates } \\
\hline Duplicates & & Duplicates & & & & & & \\
\hline BOFBN6 & 11-Apr-95 & Extraction Well & $A C-1$ & 102 & 17.8 & 0.28 & 1.98 & 30.4 \\
\hline BOFJG2 & 5-May-95 & Before Bag Filter & $\mathrm{AC}-2 \mathrm{~A}$ & 103 & 18.4 & 0.37 & 2.02 & 29.3 \\
\hline BOFL52 & 19-May-95 & Extráction Well & AC-1 & 104 & 15.9 & 0.4 & 2.13 & 26 \\
\hline
\end{tabular}




\begin{tabular}{|c|c|c|c|c|c|c|c|c|c|c|c|c|c|c|}
\hline \multirow{3}{*}{ 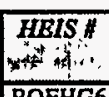 } & \multirow[t]{2}{*}{ DATE } & \multirow[t]{2}{*}{ LOCATION } & \multirow[t]{2}{*}{ PORT } & \multicolumn{11}{|c|}{ Cattons, ug $/(\mathrm{ppb})$} \\
\hline & & & & $\mathrm{Ca}$ & $\mathrm{Fe}$ & $\mathrm{Mg}$ & $\bar{K}$ & $\mathrm{Na}$ & $\mathrm{Zn}$ & $A l$ & $\mathrm{Cu}$ & $B a$ & $B e$ & $M\left(n:-n_{n}\right.$ \\
\hline & 27-Apr-95 & Raw Clino & $\operatorname{Resin}$ & 8658000 & 2667600 & 1825200 & 18720000 & 16224000 & 13416 & 14508000 & 1248 & 140400 & 858 & 213720 \\
\hline BOFHG7 & $27-\mathrm{Apr}-95$ & Raw Clino Duplicate & Resin & 9750000 & 3174600 & 2004600 & 17550000 & 16068000 & 17004 & 15132000 & 3744 & 139620 & 1014 & 265200 \\
\hline & & & & & & & & & & & & & & \\
\hline BOFBN6 & 11-Apr-95 & Extraction Well & $\mathrm{AC}-1$ & 28300 & 85.2 & 9140 & 5560 & 22600 & 70.6 & & & & & \\
\hline BOFBN7 & $11-$ Apr-95 & Bone Char Effluent & $S C-55 \mathrm{~B}$ & 28100 & 117 & 9470 & 4960 & 24500 & 45.4 & & & & & \\
\hline BOFBN8 & 11-Apr-95 & Lead Clino Effluent & SC-62B & 3210 & 130 & 9940 & 1180 & 54000 & 32.1 & & & & & \\
\hline BOFBN9 & 11-Apr-95 & Second Clino Erfluent & $S C-68 \mathrm{~B}$ & 2790 & 372 & 2350 & 1180 & 70700 & 36.3 & & & & & \\
\hline & & & & & & & & & & & & & & \\
\hline BOFJF8 & 5-May-95 & Extraction Well & $\mathrm{AC}-1$ & 30400 & 93.5 & 9700 & 7610 & 24000 & 83.8 & & & & & \\
\hline BOFJG2 & 5-May-95 & Before Bag Filter & $\frac{A C-2 A}{A C}$ & 29800 & $\frac{1990}{205}$ & 9540 & 7040 & 23300 & $\frac{1120}{663}$ & $\frac{365}{236}$ & 36 & & & \\
\hline BOFJG0 & $\frac{5-\text { May }-95}{5-95}$ & Affer Bag Filter & $\frac{A C-3}{S C-600}$ & 29600 & $\frac{225}{201}$ & $\frac{9460}{9550}$ & 6330 & $\frac{23200}{24100}$ & $\frac{63.2}{975}$ & & & & & \\
\hline BOFJF9 & $\frac{5-\text { May- } 95}{5-\text { May- } 95}$ & $\begin{array}{l}\text { Lead Clino Effluent } \\
\text { Second Clino Effluent }\end{array}$ & $\frac{\mid \mathrm{C} \cdot 6.62 \mathrm{~B}}{\mathrm{SC} \cdot 68 \mathrm{~B}}$ & $\frac{29300}{29500}$ & $\frac{201}{119}$ & $\frac{9530}{9430}$ & $\frac{7380}{6130}$ & $\frac{24100}{24300}$ & $\frac{27.5}{22.9}$ & & & & & \\
\hline BOHAOL & Jiklay-92 & Secona Cinno Erfuluent & & & & & & & & & & & & \\
\hline BOFLS2 & 19-May-95 & Extraction Well & AC-1 & 30300 & 88 & 9460 & 6930 & 23100 & 109 & & & & & \\
\hline BOFLSA & 19-May-95 & After Bag Fillet & $\mathrm{AC}-3$ & 30800 & 78.7 & 9780 & 7770 & 24000 & 68.4 & & & & & \\
\hline BOFLS5: & 19-May-95 & Bone Char Effluent & $\overline{S C-55 B}$ & 31400 & 1200 & 9960 & 7000 & 24400 & 168 & & & & & \\
\hline 80F.53 & 19-May-95 & Lead Clino Erfluent & $\overline{\text { SC-62B }}$ & 30800 & 226 & $\overline{9810}$ & 8500 & 24100 & 69.6 & & & & & \\
\hline BOFG56 & 19-May $=95$ & Second Clino Emuent & SC-68B & 30400 & 338 & 9760 & 8730 & 24800 & 37.8 & & & & & \\
\hline thisint & thet & & & & & & & & & & & & & \\
\hline
\end{tabular}


Rev. 0

Table C-8. 216-B-5 Reverse Well Secondary Contaminant Data. (6 Sheets)
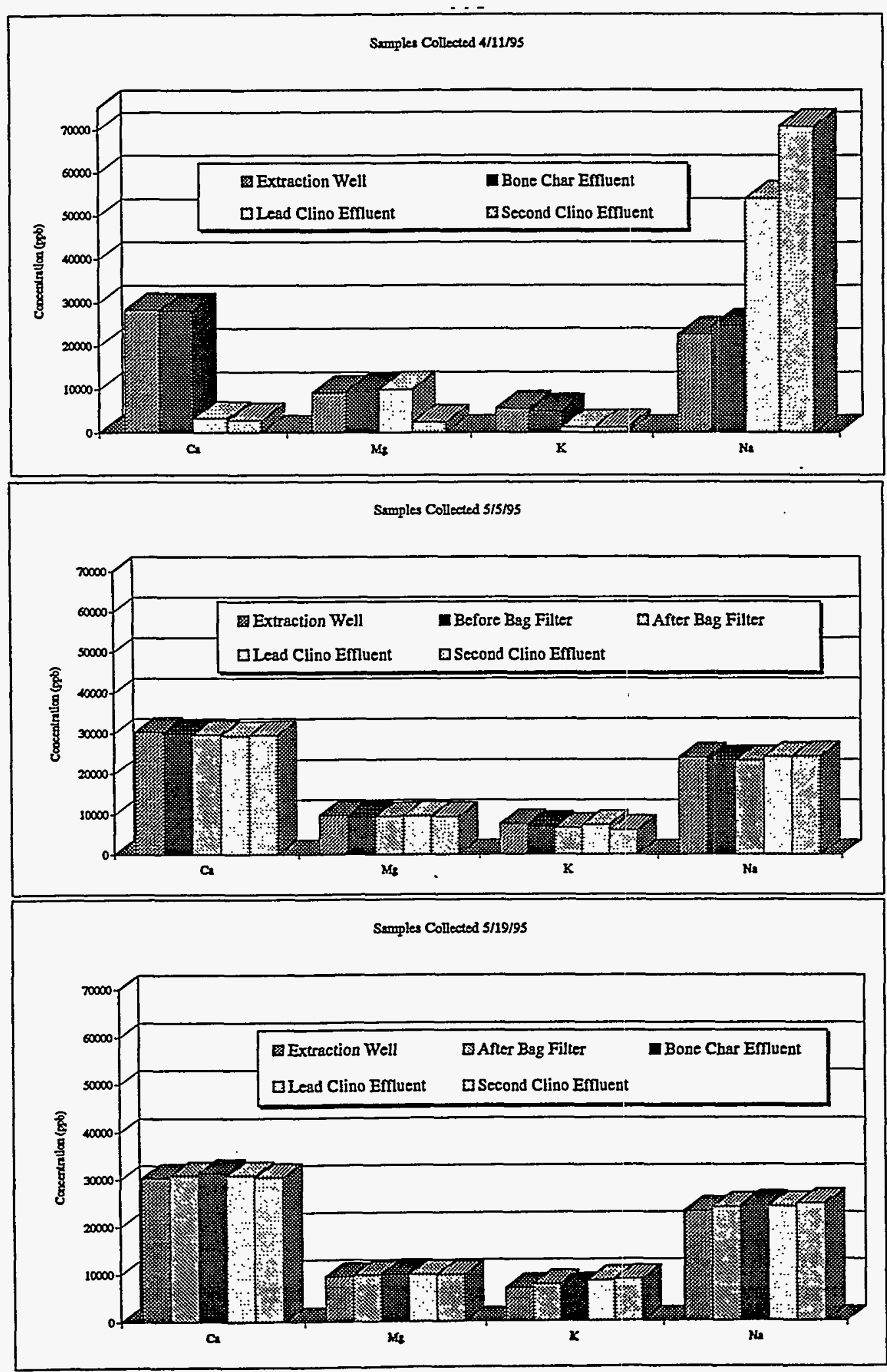
DOE/RL-95-59

Rev. 0

Table C-8. 216-B-5 Reverse Well Secondary Contaminant Data. (6 Sheets)
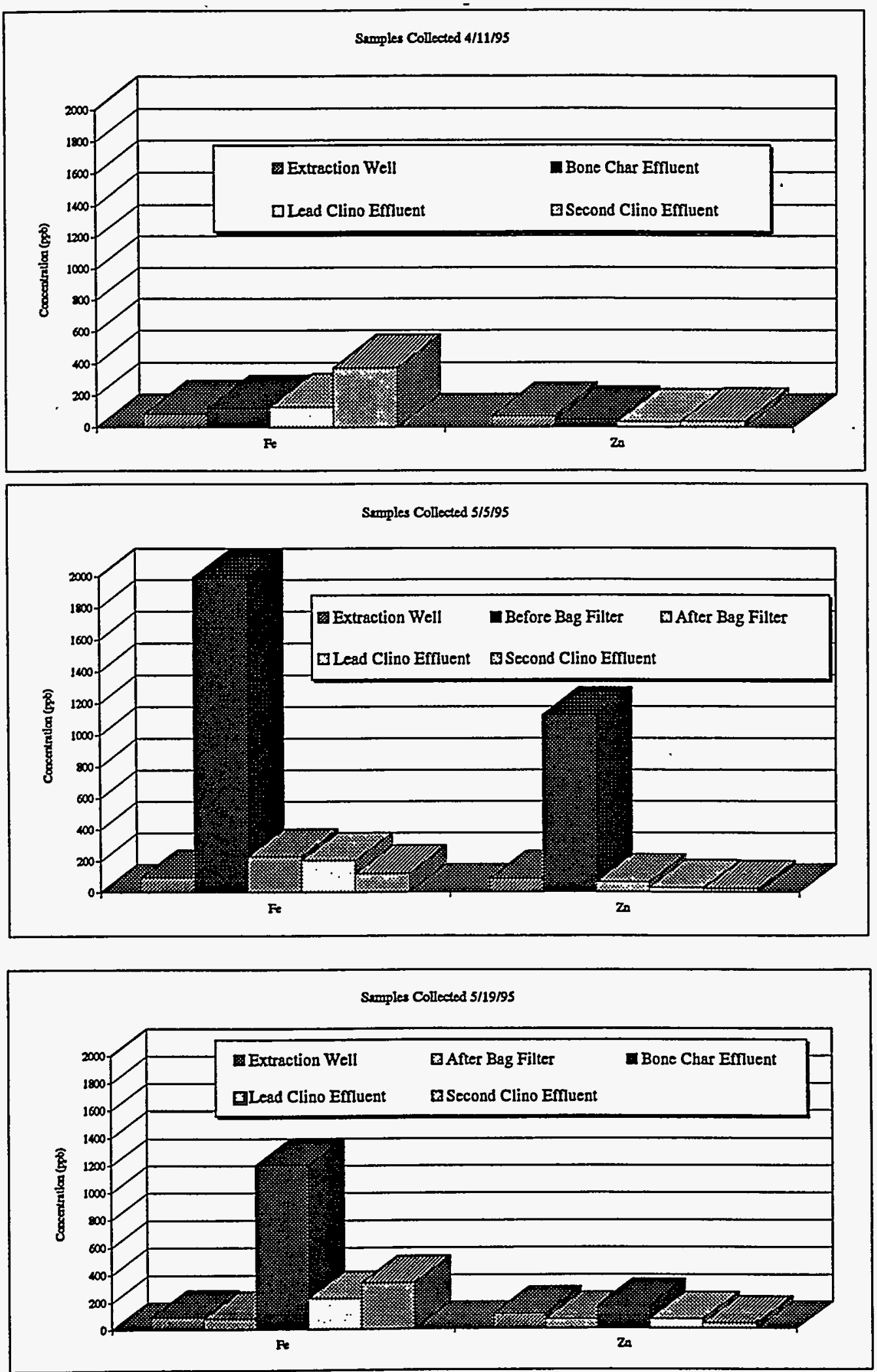
DOE/RL-95-59

Rev. 0

Table C-8. 216-B-5 Reverse Well Secondary Contaminant Data. (6 Sheets)
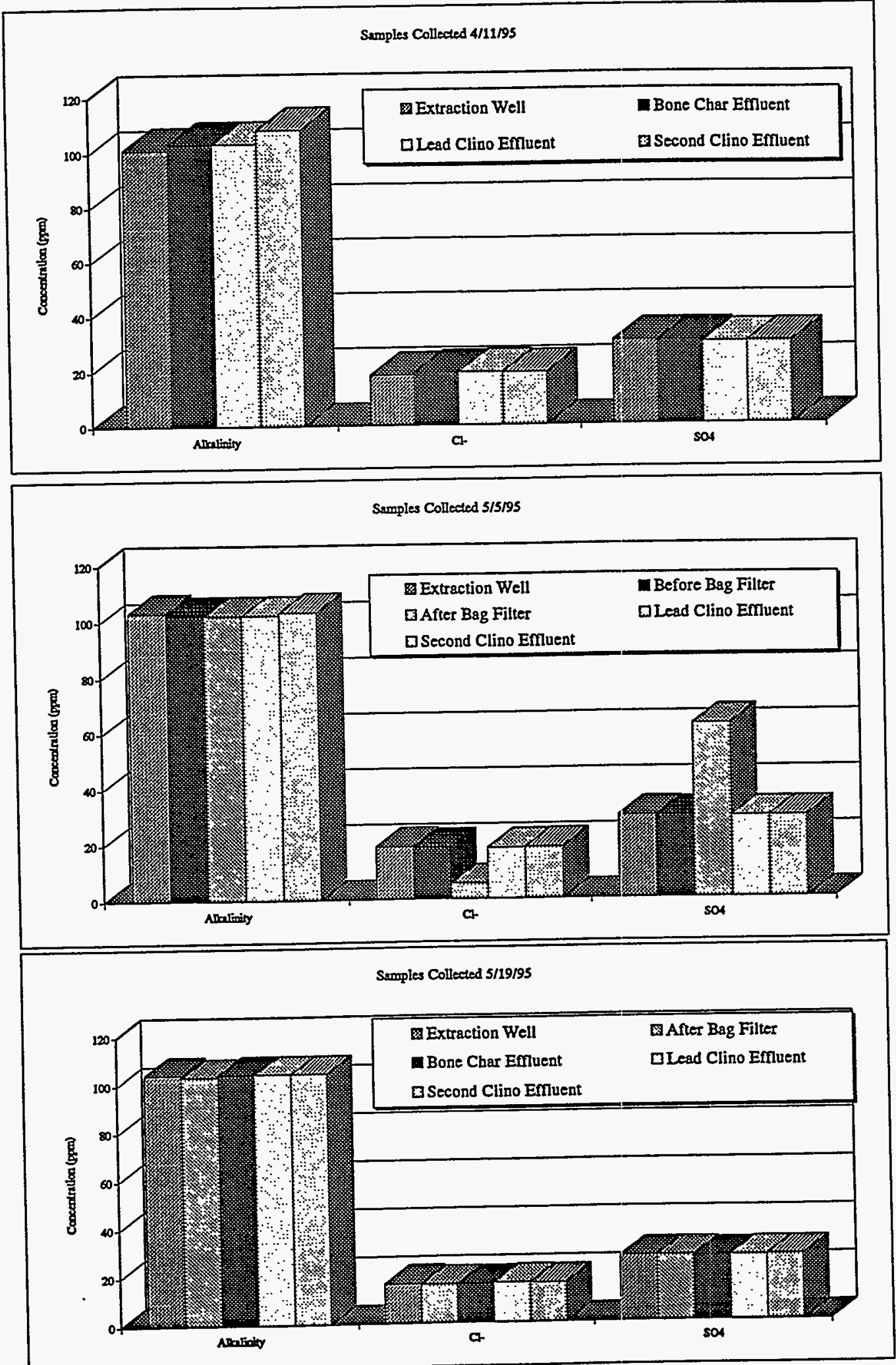
DOE/RL-95-5̄

Rev. 0

Table C-8. 216-B-5 Reverse Well Secondary Contaminant Data. (6 Sheets)

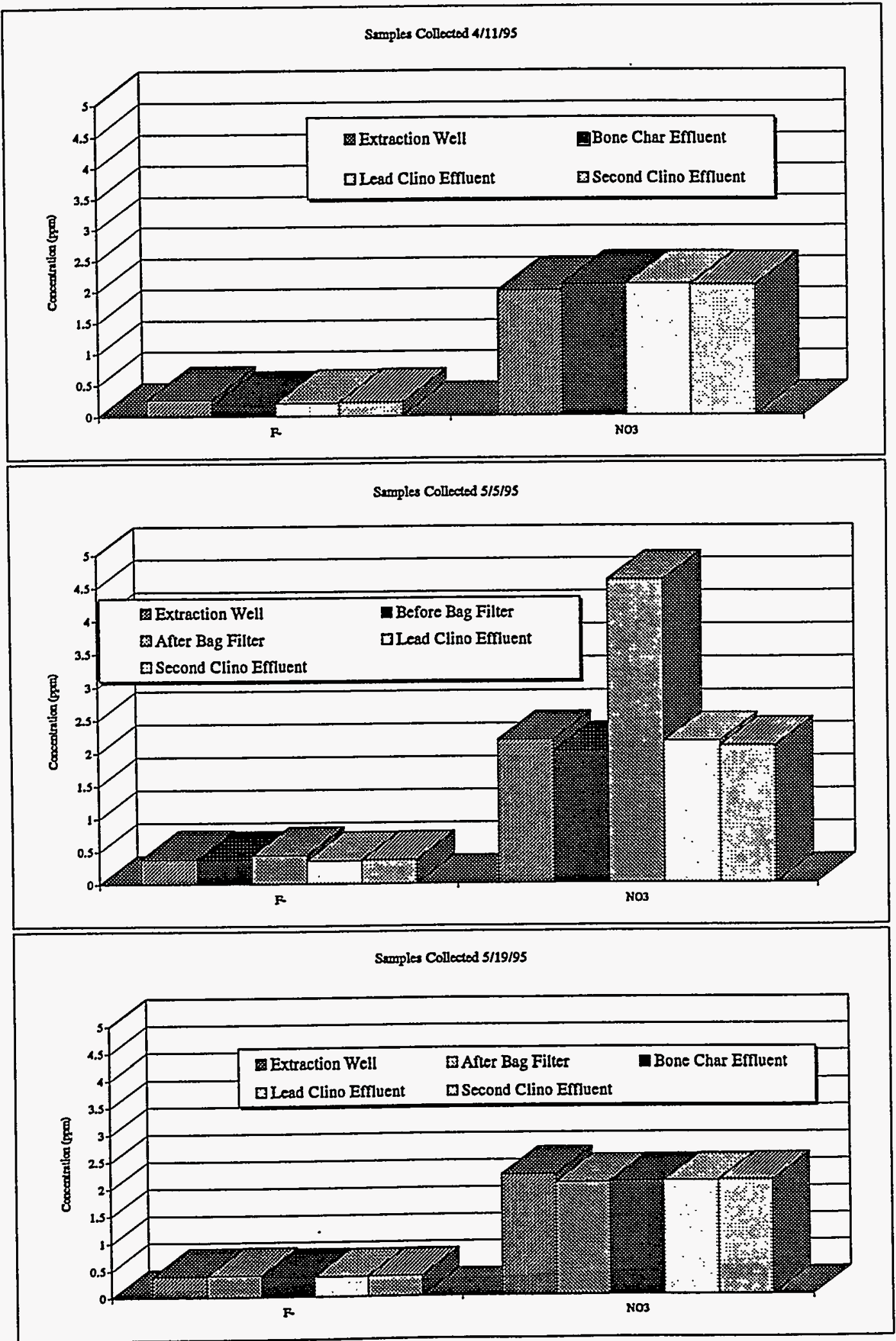




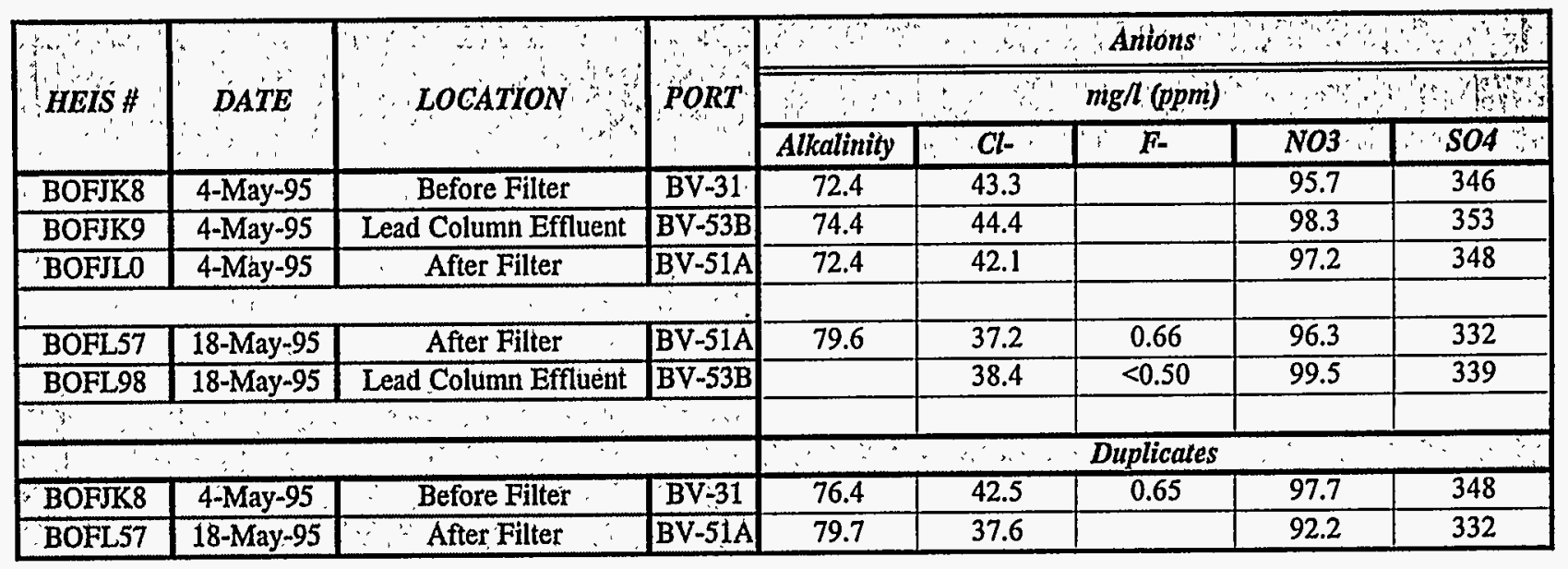

$\frac{1}{\sigma}$

\begin{tabular}{|c|c|c|c|c|c|c|c|c|c|c|}
\hline \multirow{3}{*}{ HEIS \# } & \multirow{3}{*}{ DATE } & \multirow{3}{*}{ LOCATION } & \multirow{3}{*}{ PORT } & \multicolumn{7}{|c|}{ Cations } \\
\hline & & & & \multicolumn{7}{|c|}{$u g / l(p p b)$} \\
\hline & & & & $\mathrm{Ca}$ & $F e$ & $M g$ & $\bar{K}$ & $\mathrm{Na}$ & $Z n$ & $\mathrm{Cu}$ \\
\hline BOFJK8 & 4-May-95 & Before Filter & $\mathrm{BV}: 31$ & 200000 & 299 & 58300 & 12500 & 48600 & 199 & 25.9 \\
\hline BOFJK9 & 4-May-95 & Lead Column Effluent & $\mathrm{BV}-53 \mathrm{~B}$ & 202000 & 74.5 & 59100 & 13200 & 49500 & 93.6 & 14.7 \\
\hline BOFJLO & 4-May-95 & After Filter & $\overline{B V}-51 \mathrm{~A}$ & 205000 & 333 & 59600 & 12600 & 50000 & 162 & 27.9 \\
\hline BOFL57 & 18-May-95 & After Filter & BV-51A & 201000 & 489 & 58700 & 13500 & 49600 & 128 & 14.2 \\
\hline BOFL98 & 18-May-95 & Lead Column Effluent & $\overline{B V}-53 \mathrm{~B}$ & & & & & & & \\
\hline & & & & & & & & & & \\
\hline
\end{tabular}


DOE/RL-95-59

Rev. 0

Table C-9. 216-BY Cribs Secondary Contaminant Data. (4 Sheets)
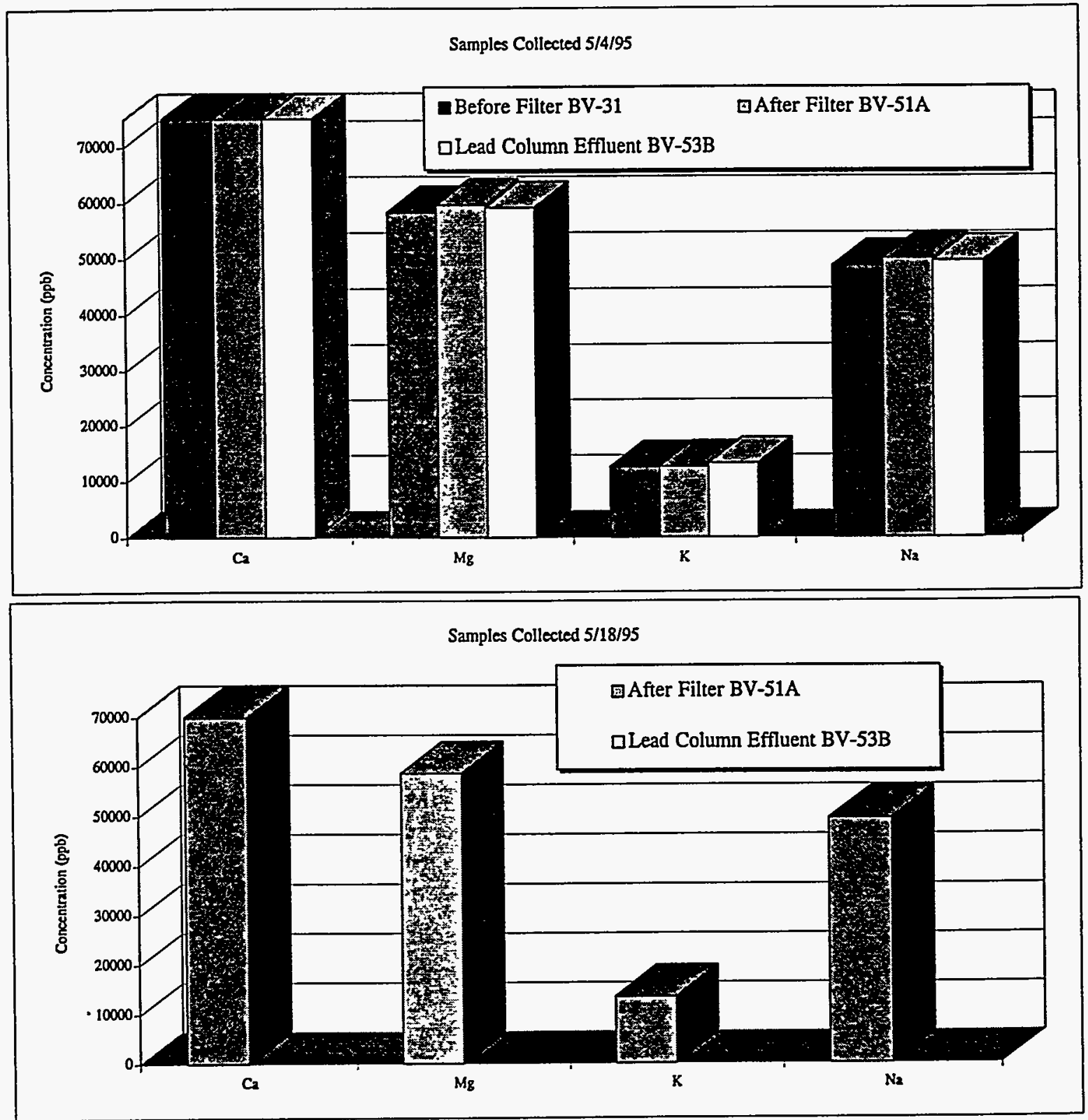
DOE/RL-95-59

Rev. 0

Table C-9. 216-BY Cribs Secondary Contaminant Data. (4 Sheets)
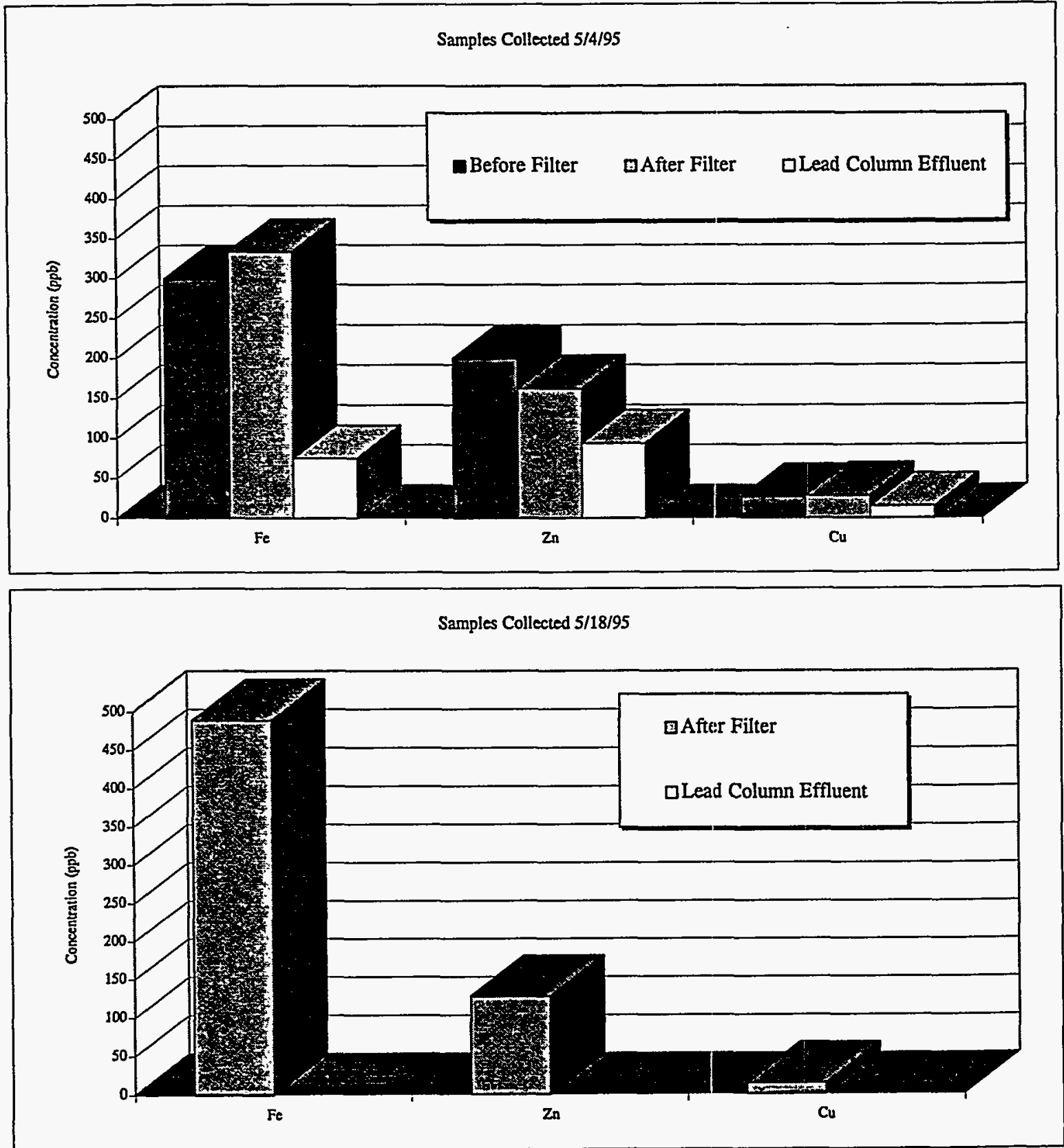
DOE/RL-95-59

Rev. 0

Table C-9. 216-BY Cribs Secondary Contaminant Data. (4 Sheets)
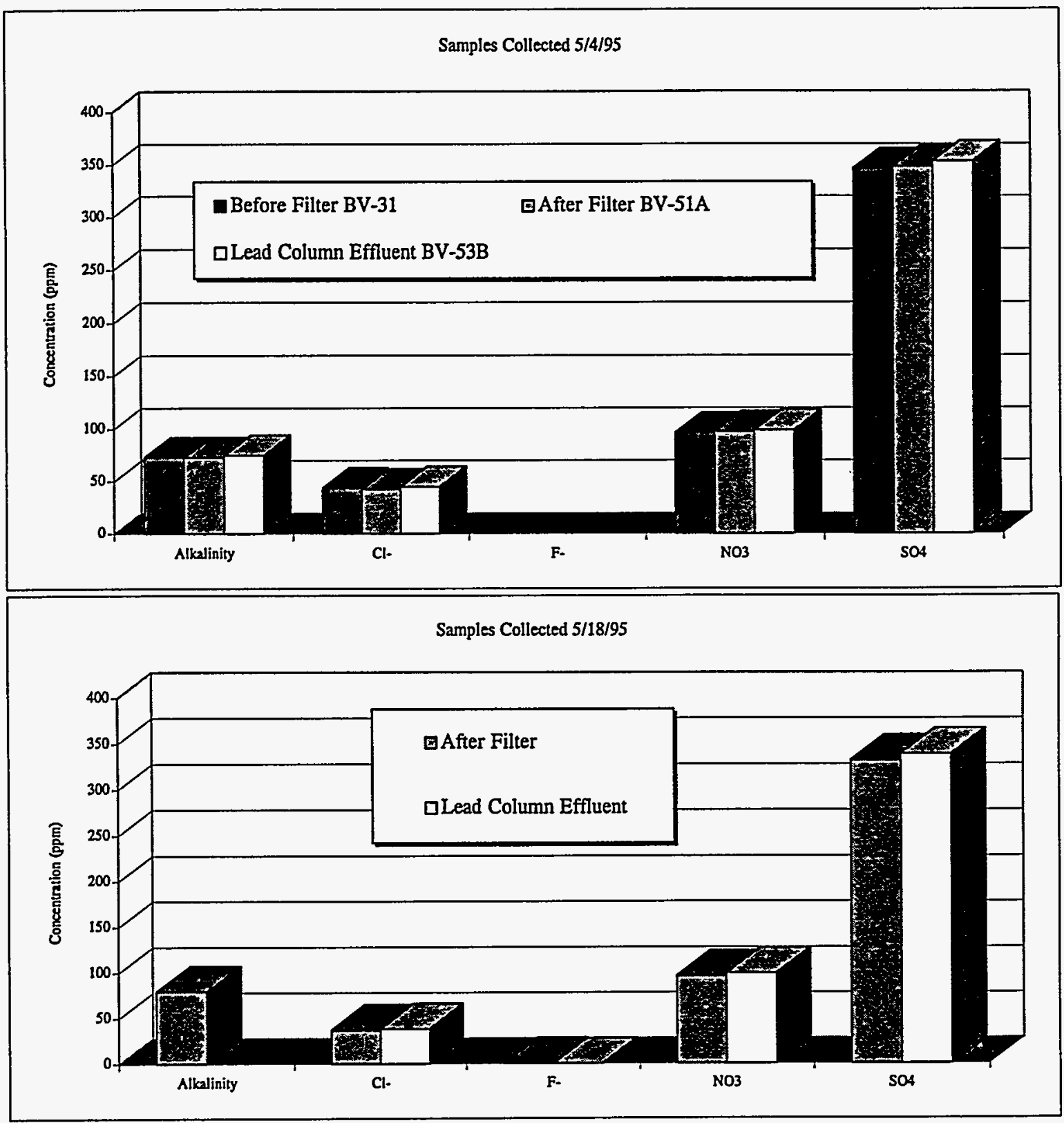


\begin{tabular}{|c|c|c|c|c|c|c|}
\hline WAsorbent \& Dose (g/L) & (pesidual Pu & $\begin{array}{c}\text { PuLoading } \\
\text { (pCi/g) }\end{array}$ & Residual Cs 137 & $\begin{array}{l}\text { Cs-137 Loading } \\
\text { (pCi/g) }\end{array}$ & Residual Sr-90 & Sricoading \\
\hline Initial Conc. & 20 & & 3424 & & 11400 & \\
\hline Clino (AmRec) 0.2 & 22 & 0 & 232 & 11590 & 6282 & 25590 \\
\hline Clino (AmRec) 0.5 & 18 & 4 & 115 & 4870 & 4265 & 14270 \\
\hline Clino (AmRec) 2.0 & 23 & 0 & 17 & 1267 & 1861 & 4770 \\
\hline Clinb (AmRec) 20 & 15 & 0 & 12 & 127 & 620 & 539 \\
\hline \multicolumn{7}{|c|}{. } \\
\hline Clinó (Resin Tech) 0.2 & & & 1480 & 5350 & 8690 & 13550 \\
\hline Clinó (Resin Tech) 0.5 & & & 662 & 3776 & 6960 & 8880 \\
\hline Clínó (Resin Tech) 2.0 & & & 219 & 1166 & 2770 & 4315 \\
\hline Clinó (Résin Tech) 20 & & & 20 & 127 & 332 & 553 \\
\hline \multicolumn{7}{|c|}{ 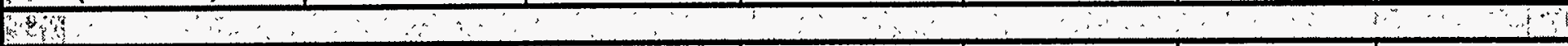 } \\
\hline BónęChar (RT) 0.2 & 16 & 22 & & $\cdot$ & 9900 & 7500 \\
\hline Boné Char (RT) 0.5 & 7 & 27 & & & 9520 & 3760 \\
\hline Bone Char (RT) 2.0 & 1 & 10 & & & 7690 & 1855 \\
\hline Boné Char (RT) 20 & 0 & 1 & & & 1040 & 518 \\
\hline \multicolumn{7}{|c|}{ 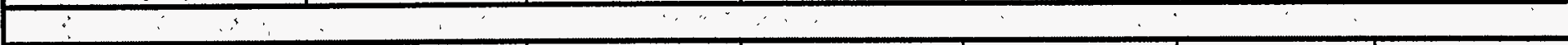 } \\
\hline Bone Char (TIGG) 0.2 & 13 & 35 & & & & \\
\hline Bone Char (TIGG) 0.5 & 7 & 26 & & & & \\
\hline Bone Char (TIGG) 2.0 & 2 & 9 & & & & \\
\hline Bone Char (TIGG) 20 & 0 & 1 & & & & \\
\hline \multicolumn{7}{|c|}{ 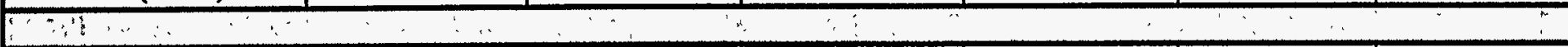 } \\
\hline IRC-718 0.2 & 12 & 39 & 2500 & 250 & 10400 & 5000 \\
\hline IRC-718 0.5 & 10 & 21 & 2520 & 60 & 9480 & 3840 \\
\hline IRC-7,18 2.0 & 13 & 3 & 2290 & 130 & 4430 & 3485 \\
\hline IRC-7,18. 20 & 8 & 1 & 92 & 123 & 5 & 570 \\
\hline
\end{tabular}


DOE/RL-95-59

Rev. 0

Table C-11. Batch Equilibrium Test Data, Dowex 21K (216-BY Cribs).

\begin{tabular}{|c|c|c|c|c|}
\hline Adsorbent \& Dose $(g / \mathcal{L})$ & $\begin{array}{l}\text { Residual Co-60 } \\
+(p C U / L)\end{array}$ & $\begin{array}{l}\therefore \text { Pu Loading } \\
\quad \cdots(p C L / g)\end{array}$ & 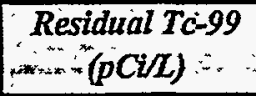 & $\begin{array}{l}\text { Tc-99 Loading } \\
\because(\hat{p} \text { Cîg) } \quad: t\end{array}$ \\
\hline Initial Conc. & 29 & & 1480 & \\
\hline Dowex 21K 0.2 & 19 & 51 & 487 & 4965 \\
\hline Dowex 21K 0.5 & 0 & 58 & 195 & 2570 \\
\hline Dowex 21K 2.0 & 8 & 10 & 55 & 712 \\
\hline Dowex 21K 20 & 46 & 0 & 4 & 74 \\
\hline
\end{tabular}

Table C-12. Clinoptilolite Flow Through Column Test Data.

\begin{tabular}{|c|c|c|c|}
\hline $\begin{array}{c}\text { Bed } \\
\text { Volumes }\end{array}$ & $\begin{array}{c}\text { Cum Bed } \\
\text { Volumes }\end{array}$ & $\begin{array}{c}\text { Sr-90 } \\
(p C i / L)\end{array}$ & $\begin{array}{c}\text { Remioval } \\
\text { Efficiency }\end{array}$ \\
\hline $\mathbf{0}$ & $\mathbf{0}$ & 11400 & \\
\hline $\mathbf{1 0 4}$ & $\mathbf{1 0 4}$ & 73.6 & $99.4 \%$ \\
\hline $\mathbf{6 4}$ & $\mathbf{1 6 8}$ & 88.3 & $99.2 \%$ \\
\hline $\mathbf{1 1 2}$ & $\mathbf{2 8 0}$ & 154.6 & $98.6 \%$ \\
\hline $\mathbf{1 7}$ & $\mathbf{2 9 7}$ & 242.9 & $97.9 \%$ \\
\hline $\mathbf{6 6}$ & $\mathbf{3 6 3}$ & 279.7 & $97.5 \%$ \\
\hline $\mathbf{1 3 6}$ & $\mathbf{4 9 9}$ & 647.7 & $94.3 \%$ \\
\hline $\mathbf{2 5}$ & $\mathbf{5 2 4}$ & 1067.2 & $90.6 \%$ \\
\hline $\mathbf{4 7}$ & $\mathbf{5 7 1}$ & 1435.2 & $87.4 \%$ \\
\hline $\mathbf{1 1 1}$ & $\mathbf{6 8 2}$ & 1023 & $91.0 \%$ \\
\hline $\mathbf{8 6}$ & $\mathbf{7 6 8}$ & 1369 & $88.0 \%$ \\
\hline $\mathbf{6 4}$ & $\mathbf{8 3 2}$ & 1346.9 & $88.2 \%$ \\
\hline $\mathbf{4 4}$ & $\mathbf{8 7 6}$ & 1361.6 & $88.1 \%$ \\
\hline $\mathbf{4 7}$ & $\mathbf{9 2 3}$ & 1361.6 & $88.1 \%$ \\
\hline $\mathbf{5 0}$ & $\mathbf{9 7 3}$ & 1567.7 & $86.2 \%$ \\
\hline
\end{tabular}




\begin{tabular}{|c|c|c|c|c|c|c|c|c|c|c|}
\hline $\begin{array}{l}\text { Adsorbent \& Dose } \\
\text { Mat }\end{array}$ & 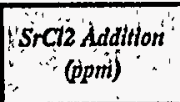 & $\begin{array}{l}\text { Residuat Sn } \\
-90(p C t / L)\end{array}$ & $\begin{array}{l}\text { AVG Résidual Sm } \\
\cdots, 90 \ldots\end{array}$ & $\begin{array}{l}\text { Srgo Loading } \\
\quad(\mathrm{pCl} / \mathrm{g})\end{array}$ & $\begin{array}{l}\text { Residual } \mathrm{Cs}-137 \\
\quad(p C \mathrm{~L} / \mathrm{L})\end{array}$ & Avg Resldual Cs: & $\begin{array}{c}\text { Cs.137 Lodding } \\
(p C \mathrm{i} / g)\end{array}$ & $\begin{array}{l}\text { Residual Pue } \\
(p C u / L)\end{array}$ & Avg Residual Ru & $\begin{array}{l}\text { putóding } \\
\therefore \text { (pCig) }\end{array}$ \\
\hline Initlal conc. & 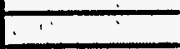 & 3790 & $=$ average $(\mathrm{B3}, \mathrm{B} 4)$ & $=($ SBS2-C3)/0.4 & 1390 & $=$ avcragc(E3,EA) & $=($ SES $2-\mathrm{F} 3) / 0.4$ & 18.8 & $=$ average $(\mathrm{E} 3, \mathrm{EA})$ & $=(\$ H \$ 2-13) / 0.4$ \\
\hline Bonechar" $0.4 \mathrm{~g} / 1$ & $2 \mathrm{ppm}$ & 4300 & 4300 & 0 & 1480 & 1490 & 0 & 4.6 & 4.525 & 35.7 \\
\hline Bonechar $0.4 \mathrm{~g} /$ & $2 \mathrm{ppm}$ & lost & & & 1500 & & & 4.45 & & \\
\hline Bonechar $4.0 \mathrm{~g} /$ & $2 \mathrm{ppm}$ & lost & 1990 & 450.0 & 1330 & 1395 & 0 & 4.39 & 4.455 & 3.6 \\
\hline Bonechar $4.0 \mathrm{~g} /$ & $2 \mathrm{ppm}$ & 1990 & & & 1460 & & & 4.52 & & \\
\hline Bonechar $20 \mathrm{~g} / \mathrm{I}$ & $2 \mathrm{ppm}$ & 178 & 166 & 181.2 & 1370 & 1340 & 2.5 & 8.9 & 6.865 & 0.6 \\
\hline Bonechar $20 \mathrm{~g} / \mathrm{l}$ & $2 \mathrm{ppm}$ & 154 & & & 1310 & & & 4.83 & & \\
\hline Boncchar $0.4 \mathrm{gl}$ & $5 \mathrm{ppm}$ & 4140 & 3890 & 0 & 1500 & 1430 & 0 & 15 & 9.91 & 22.2 \\
\hline Bonechar $0.4 \mathrm{~g} / \mathrm{l}$ & $5 \mathrm{ppm}$ & 3640 & & & 1360 & & & 4.82 & & \\
\hline Bonechar $4.0 \mathrm{~g} / \mathrm{I}$ & $5 \mathrm{ppm}$ & 2120 & 2880 & 227.5 & 1390 & 1385 & 1.3 & 4.75 & 4.705 & 3.5 \\
\hline Bonechar $4.0 \mathrm{~g} n$. & $5 \mathrm{ppm}$ & 2150 & & & 1380 & & & 4.66 & & \\
\hline Bónéchar $20 \mathrm{~g} / \mathrm{I}$ & $5 \mathrm{ppm}$ & 159 & 172 & 180.9 & 1280 & 1305 & 4.3 & 4.79 & 4.61 & 0.7 \\
\hline Bónechar $20 \mathrm{~g} / \mathrm{I}$ & $5 \mathrm{ppm}$ & 185 & & & 1330 & & & 4.43 & & \\
\hline Bonkechar $0.4 \mathrm{gl}$ & $0.2 \mathrm{ppm}$ & 4190 & 3970 & 0 & 1350 & 1420 & 0 & 6.76 & 6.825 & 29.9 \\
\hline Bofitechar $0.4 \mathrm{~g} / \mathrm{I}$ & $0.2 \mathrm{ppm}^{x^{2}}$ & 3750 & & & 1490 & & & 6.89 & & \\
\hline Bopecthar $4.0 \mathrm{~g} /$ & $0.2 \mathrm{ppm}$ & 1510 & 1555 & 558.8 & 1290 & 1345 & 11.3 & 13.1 & 9.035 & 2.4 \\
\hline Bopechar $4.0 \mathrm{~g} / \mathrm{l}$ & $0.2 \mathrm{ppm}$ & 1600 & & & 1400 & & & 4.97 & & \\
\hline Boinechar $20 \mathrm{~g} / \mathrm{I}$ & $=0.2 \mathrm{ppm}$ & 104 & 270 & 176.0 & 1370 & 1340 & 2.5 & 4.54 & 6.585 & 0.6 \\
\hline Bonechar $20 \mathrm{~g} n$ & $0.2 \mathrm{ppm}$ & 436 & & & 1310 & & & 8.63 & & \\
\hline 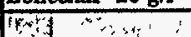 & & & & & 5 & & $\vdots$ & & $\therefore \quad 2$ & $\therefore \quad 11$ \\
\hline Clino 0.4 g/ & None & 2900 & 3050 & 1850.0 & 279 & 256 & 2835 & 14.2 & 14.05 & 11.9 \\
\hline Clino $0.4 \mathrm{~g} / \mathrm{h}^{2}$ & None & 3200 & & & 233 & & - & 13.9 & & \\
\hline Clinio $4.0 \mathrm{~g} / \mathrm{l}$ & None & 257 & 257 & 883.3 & 70.7 & 63.3 & 331.7 & 26.7 & 20.05 & 0 \\
\hline Clino $4.0 \mathrm{~g} / 1$ & None & & & & 55.8 & & & 13.4 & & \\
\hline Cilno $20 \mathrm{~g} /$ & None & 52.4 & 59.25 & 186.5 & 76 & 59.2 & 66.5 & 9.8 & 9.8 & 0.5 \\
\hline Clinb $20 \mathrm{~g} / \mathrm{h}$ & None & 66.1 & & & 42.3 & & & & & \\
\hline$\therefore \div$ & & & & & & & & & & \\
\hline Durisil $0.4 \mathrm{~g} /$ & $2 \mathrm{ppm}$ & 2710 & 2760 & 2575.0 & 141 & 144 & 3115 & 12.9 & 13.05 & 11.9 \\
\hline Dirssil $0.4 \mathrm{~g} /$ & $2 \mathrm{ppm}$ & 2810 & & & 147 & & & 13.2 & & \\
\hline Durasil $4.0 \mathrm{~g} /$ & $2 \mathrm{ppm}$ & 391 & 370 & 855.1 & 63 & 62.4 & 331.9 & 12.7 & 12.4 & 1.6 \\
\hline Durasil $4.0 \mathrm{~g} / 1$ & $2 \mathrm{ppm}$ & 348 & & & 61.8 & & & 12.1 & & \\
\hline Durásil 20 g 1 & $2 \mathrm{ppm}$ & 71.4 & 57.00 & 186.7 & 63.9 & 61.7 & 66.4 & 12.3 & 12.2 & 0.3 \\
\hline Durasil 20 g $\Omega$ & $2 \mathrm{ppm}$ & 42.6 & & & 59.4 & & & 12 & & \\
\hline Durasil $0.4 \mathrm{~g} /$ & $5 \mathrm{ppm}$ & 2950 & 2900 & 2225.0 & 160 & 130.5 & 3148.75 & 13.7 & 14.5 & 11.9 \\
\hline Durasil $0.4 \mathrm{~g} /$ & $5 \mathrm{ppm}$ & 2850 & & & 101 & & & 15.3 & & \\
\hline Durasil $4.0 \mathrm{~g} /$ & $5 \mathrm{ppm}$ & 412 & 227 & 890.7 & 47.4 & 54.6 & 333.9 & 19.3 & 24.6 & 0 \\
\hline Durasill $4.0 \mathrm{~g} / \mathrm{I}$ & $5 \mathrm{ppm}$ & 42.7 & & & 61.8 & & & 29.9 & & \\
\hline Ditrasil $20 \mathrm{~g} /$ & $5 \mathrm{ppm}$ & 54.6 & 53.90 & 186.8 & 44.2 & 52.6 & 66.9 & 13.1 & 12.7 & 0.3 \\
\hline Durisil $20 \mathrm{~g} /$ & $5 \mathrm{ppm}$ & 53.2 & & & 61 & & & 12.2 & & \\
\hline Dirasil $0.4 \mathrm{~g} /$ & $0.2 \mathrm{ppm}$ & 1440 & 2020 & 4425.0 & 104 & 109.5 & 3201.25 & 15.7 & 16.15 & 11.9 \\
\hline Drurasil $0.4 \mathrm{~g} /$ & $0.2 \mathrm{ppm}$ & 2600 & & & 115 & & & 16.6 & & \\
\hline Durastil $4.0 \mathrm{~g} /$ & $0.2 \mathrm{ppm}$ & 350 & 357 & 858.3 & 59.7 & 60.5 & 332.4 & 15.4 & 15.9 & 0.7 \\
\hline Durasil $4.0 \mathrm{~g} n$ & $0.2 \mathrm{ppm}$ & 364 & & $\cdot$ & 61.2 & & & 16.4 & & \\
\hline Durasil '20 gl I & $0.2 \mathrm{ppq}^{\mathrm{x}}$ & 54.8 & 51.15 & 186.9 & 58.5 & 56.6 & 66.7 & 14.4 & 14.4 & 0.2 \\
\hline Dúnasil 20 \& & $0.2 \mathrm{ppm}$ & 47.5 & & & 54.6 & & & lost & & \\
\hline
\end{tabular}




\begin{tabular}{|c|c|c|c|c|c|c|c|c|c|c|}
\hline 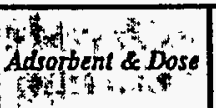 & $\begin{array}{c}\text { SrCl2 Addition } \\
:(p p m)\end{array}$ & $\begin{array}{l}\text { Residual Sm } \\
90(p C i / L)\end{array}$ & $\begin{array}{c}\text { AVG Residual Sr- } \\
90\end{array}$ & $\begin{array}{c}\text { Sr-90 Loading } \\
\quad(p C i / g)\end{array}$ & $\begin{array}{l}\text { Residual Cs. } \\
137(p C W / L)\end{array}$ & Avg Residual Cs- & $\begin{array}{c}\text { Cs-137 Loading } \\
\text { (pCi/g) }\end{array}$ & $\begin{array}{l}\text { Rešidual Prs: } \\
\quad(p \subset U / L)\end{array}$ & $\begin{array}{c}1 \\
\text { Avg Residual Pu } \\
\text { : }\end{array}$ & 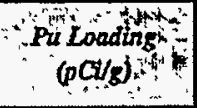 \\
\hline Initial conc. & & 3790 & $=$ average(B3,B4) & $=(\$ B \$ 2-C 3) / 0.4$ & 1390 & $=$ average(E3,EA) & $=(\$ E S 2-F 3) / 0.4$ & 18.8 & $=$ average(E3,E4) & $=($ SHS2-I3)/0.4 \\
\hline UOP A-51 $0.4 \mathrm{~g} / 1$ & $2 \mathrm{ppm}$ & 1130 & 1105 & 6712.5 & 402 & 372 & 2545 & 15.2 & 14.4 & 11 \\
\hline UOP A-51 $0.4 \mathrm{~g} / 1$ & $2 \mathrm{ppm}$ & 1080 & & & 342 & & & 13.6 & & \\
\hline UOP A-51 $4.0 \mathrm{~g} / 1$ & $2 \mathrm{ppm}$ & 9.5 & 8.14 & 945.5 & 60.5 & 58.8 & 332.8 & 9 & 9.2 & 2.4 \\
\hline UOP $A-51 \quad 4.0 \mathrm{~g} / 1$ & $2 \mathrm{ppm}$ & 6.78 & & & 57.1 & & & 9.4 & & \\
\hline UOP A-51 $20 \mathrm{~g} / \mathrm{l}$ & $2 \mathrm{ppm}$ & 16.4 & 11.5 & 188.9 & 63.3 & 62.5 & 66.4 & 4.6 & 5.4 & 0.7 \\
\hline UOP $\mathrm{A}-51 \quad 20 \mathrm{~g} / \mathrm{l}$ & $2 \mathrm{ppm}$ & 6.59 & & & 61.6 & & & 6.15 & & \\
\hline UOP A-51 $0.4 \mathrm{~g} / 1$ & $5 \mathrm{ppm}$ & 1220 & 1145 & 6612.5 & 375 & 357 & 2582.5 & 15.2 & 14 & 12 \\
\hline UOP $A-51 \quad 0.4 \mathrm{~g} n$ & $5 \mathrm{ppm}$ & 1070 & & & 339 & & & 12.8 & & \\
\hline UOP A $-51 \quad 4.0 \mathrm{~g} / 1$ & $5 \mathrm{ppm}$ & 4.09 & 7.8 & 945.5 & 61 & 52.1 & 334.5 & 9.49 & 9 & 2.5 \\
\hline UOP $A-51 \quad 4.0 \mathrm{~g} / 1$ & $5 \mathrm{ppm}$ & 11.6 & & & 43.2 & & & 8.5 & & \\
\hline UOPA-51 $20 \mathrm{~g} / \mathrm{l}$ & $5 \mathrm{ppm}$ & 8.03 & 7 & 189.2 & 58 & 59.5 & 66.5 & 4.98 & 5.4 & 0.7 \\
\hline UOR $A-51 \quad 20 \mathrm{~g} / \mathrm{I}$ & $5 \mathrm{ppm}$ & 5.97 & & & 60.9 & & & 5.9 & & \\
\hline $\mathrm{UOP}, \mathrm{A}-51 \quad 0.4 \mathrm{~g} / \mathrm{L}$ & $0.2 \mathrm{ppm}$ & 664 & 774.5 & 7538.8 & 310 & 341.5 & 2621.3 & 14.8 & 14.1 & 11.875 \\
\hline UOR. $\mathrm{A}^{1} 51 \quad 0.4 \mathrm{~g} /$ & $0.2 \mathrm{ppm}$ & 885 & & & 373 & & & 13.3 & & \\
\hline UOP $1514.0 \mathrm{~g} / 1$ & $0.2 \mathrm{ppm}$ & 12.3 & 11.1 & 944.7 & 55.1 & 59 & 332.8 & 9.7 & 10.5 & 2.1 \\
\hline UOPA:51 $4.0 \mathrm{~g} / \mathrm{I}$ & $0.2 \mathrm{ppm}$ & 9.93 & & & 62.8 & & & 11.2 & & \\
\hline UOR $A-5120 \mathrm{~g} / \mathrm{l}$ & $0.2 \mathrm{ppm}$ & 5.69 & 9.05 & 189.05 & 58.9 & 61.2 & 66.4 & 7.28 & 9.8 & 0.5 \\
\hline UOP $A-5120 \mathrm{~g} / 1$ & $0.2 \mathrm{ppm}$ & 12.4 & & & 63.5 & & & 12.3 & & \\
\hline \multicolumn{11}{|l|}{8} \\
\hline Clino $0.4 \mathrm{~g} / \mathrm{l}$ & $2 \mathrm{ppm}$ & 2730 & 2820 & 2425 & 237 & 207.5 & 2956.3 & 14.7 & 13.95 & 12.125 \\
\hline Clino $0.4 \mathrm{~g} /$ & $2 \mathrm{ppm}$ & 2910 & & & 178 & & & 13.2 & & \\
\hline Clino 410 g/ & $2 \mathrm{ppm}$ & 302 & 275.0 & 878.8 & 40.2 & 50.5 & 334.9 & 13.6 & 14 & 1.2 \\
\hline Clino $4.0 \mathrm{~g} / \mathrm{h}$ & $2 \mathrm{ppm}$ & 248 & & & 60.8 & & & 14.4 & & \\
\hline Clin $\hat{\sigma}^{\circ} 20 \mathrm{~g} / \mathrm{I}$ & $2 \mathrm{ppm}$ & 53.8 & 45.35 & 187.23 & 64.7 & 62.9 & 66.4 & 11.7 & 11.2 & 0.4 \\
\hline Clitio $20 \mathrm{~g} / \mathrm{l}$ & $2 \mathrm{ppm}$ & 36.9 & & & 61 & & & 10.6 & & \\
\hline Clino: $0.4 \mathrm{~g} / \mathrm{l}$ & $5 \mathrm{ppm}$ & 3060 & 3215 & 1437.5 & 148 & 191.5 & 2996.3 & 10.6 & 12.25 & 16.375 \\
\hline Clliro $0.4 \mathrm{~g} / 1$ & $5 \mathrm{ppm}$ & 3370 & & & 235 & & & 13.9 & & \\
\hline Clitio $4.0 \mathrm{~g} / 1$ & $5 \mathrm{ppm}$ & 335 & 348.5 & 860.4 & 40.7 & 51.15 & 334.7 & 15.5 & 14 & 1.2 \\
\hline Clino $4.0 \mathrm{~g} / \mathrm{l}$ & $5 \mathrm{ppm}$ & 362 & & & 61.6 & & & 12.6 & & \\
\hline Clino $20 \mathrm{~g} / \mathrm{I}$ & $5 \mathrm{ppm}$ & 43.6 & 44.85 & 187.26 & 60 & 58.3 & 66.6 & 8.61 & 11.0 & 0.4 \\
\hline Clino $20 \mathrm{~g} / 1$ & $5 \mathrm{ppm}$ & 46.1 & & & 56.6 & & & 13.3 & & \\
\hline Clino $0.4 \mathrm{~g} / \mathrm{l}$ & $0.2 \mathrm{ppm}$ & 2620 & 2610 & 2950 & 232 & 248 & 2855 & 13.5 & 14.4 & 11.125 \\
\hline Cliho $0.4 \mathrm{~g} / 1$ & $0.2 \mathrm{ppm}$ & 2600 & & & 264 & & & 15.2 & & \\
\hline Clino $4.0 \mathrm{~g} / \mathrm{l}$ & $0.2 \mathrm{ppm}$ & 34.7 & 122.4 & 916.9 & 39.4 & 49 & 335.3 & 12.7 & 13.4 & 1.4 \\
\hline Clino $4.0 \mathrm{~g} / 1$ & $0.2 \mathrm{ppm}$ & 210 & & & 58.2 & & & 14.1 & & \\
\hline Clino $20 \mathrm{~g} /]^{1}$ & $0.2 \mathrm{ppm}$ & 28 & 36.65 & 187.7 & 61.3 & 61.35 & 66.4 & 9.65 & 10.8 & 0.4 \\
\hline Clino $20 \mathrm{~g} / 1$ & $0.2 \mathrm{ppm}$ & 45.3 & & & 61.4 & & & 12 & & \\
\hline
\end{tabular}


DOE/RL-95-59

Rev. 0

Table C-13. Isotherms. (3 Sheets)

\begin{tabular}{|c|c|c|c|c|c|c|c|c|c|c|c|c|c|c|c|c|c|c|c|c|c|}
\hline 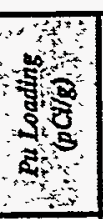 & 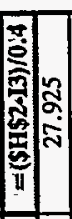 & & | & 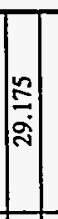 & $\mid$ & 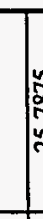 & & $\mid$ & הి & $\mid$ & $\mid \begin{array}{l}\overrightarrow{0} \\
0 \\
0\end{array}$ & & 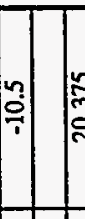 & 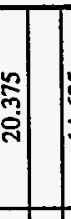 & $\mid$ & a & 䇾 & 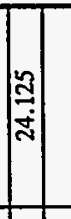 & $\left|\begin{array}{l}n \\
\vdots \\
\vdots \\
\vdots\end{array}\right|$ & $a$ & 弪 \\
\hline 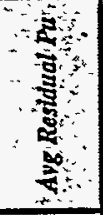 & 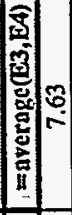 & & 赵 & $\stackrel{m}{=}$ & $\left|\begin{array}{l}0 \\
0 \\
\infty\end{array}\right|$ & & | & $\mid$ & $\frac{9}{7}$ & $\mid$ & 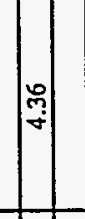 & & 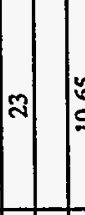 & | & 恣 & ले & $\mid$ & $\mid$ & 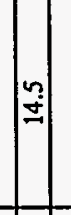 & 番 & $\mid$ \\
\hline 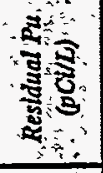 & 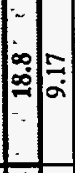 & & 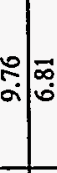 & : & $\stackrel{\circ}{\circ}$ & & & $\stackrel{n}{\sigma}$ & $\therefore=$ & $\mid$\begin{tabular}{c} 
: \\
\hdashline \\
\hdashline
\end{tabular} & 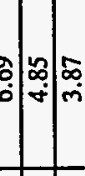 & 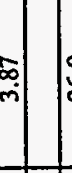 & $=$ & $\stackrel{3}{=} 0$ & \begin{tabular}{lll} 
& \\
$\infty$ & 0 & 0 \\
\hdashline & 0 & 0
\end{tabular} & $=$ & $\overrightarrow{ \pm}=$ & 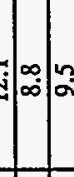 & $\overbrace{\substack{n \\
m}}^{n}$ & 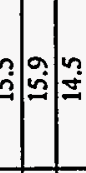 & $=$ \\
\hline 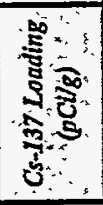 & \begin{tabular}{|l|l} 
\\
0 \\
0
\end{tabular} & & $\begin{array}{l}\infty \\
\\
\end{array}$ & $\mid \begin{array}{l}m \\
\sigma\end{array}$ & $\underline{\sim}$ & & 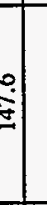 & 务 & 0 & 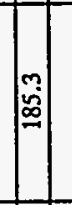 & 8 & & $\frac{8}{m}$ & స్లి & $\mid \begin{array}{l}0 \\
0 \\
0 \\
0\end{array}$ & 勇 & | & 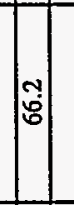 & 票 & $\mid$ & 8 \\
\hline 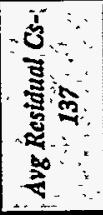 & 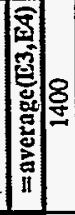 & & $\stackrel{2}{2}$ & 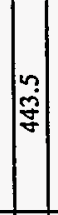 & 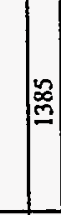 & & 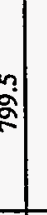 & $\mid$ & \& & 앙 & $\mid \begin{array}{l}m \\
0 \\
\hat{\sigma}\end{array}$ & & 离 & $\mid \begin{array}{c}9 \\
\overrightarrow{0}\end{array}$ & $\mid \begin{array}{l}a \\
\overrightarrow{0} \\
0\end{array}$ & 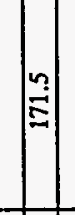 & 品 & $\mid$ & $\Xi$ & 6 & ? \\
\hline 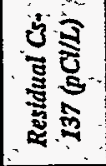 & 잉 & 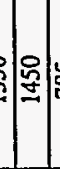 & $\infty$ & 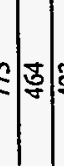 & Fิ & 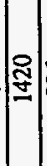 & ષ & $\sqrt[3]{\circ}$ & 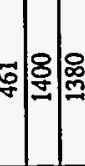 & : & $\overrightarrow{8}=\frac{a}{\Rightarrow}$ & 。. & $\Xi$ & \begin{tabular}{lll} 
& 0 \\
\hdashline & 0 & 0 \\
0 & 0 & 0 \\
\end{tabular} & $\frac{9}{0}$ & (6) & $\approx$ जิ & 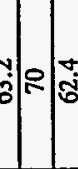 & $0=$ & $=\mid \begin{array}{l}\infty \\
0 \\
8\end{array}$ & $\mid \begin{array}{l}0 \\
\dot{0}\end{array}$ \\
\hline 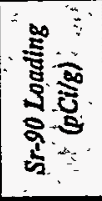 & | & & $\mid$\begin{tabular}{|}
$\mid \overrightarrow{0}$ \\
$\frac{0}{2}$ \\
\end{tabular} & $\left|\begin{array}{l}0 \\
0 \\
0 \\
- \\
-1\end{array}\right|$ & $\tilde{\sigma}$ & & 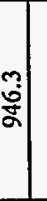 & 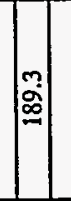 & : & 景 & 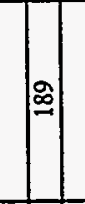 & & $\mid$ & 可 & $\left.\mid \begin{array}{l}0 \\
\vdots \\
\vdots \\
0\end{array}\right]$ & \&్త & $\mid$\begin{tabular}{|}
0 \\
$\vec{\pi}$ \\
$\infty$
\end{tabular} & $\mid \begin{array}{l}0 \\
0 \\
0 \\
0 \\
-1\end{array}$ & 管 & 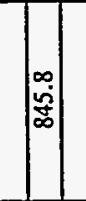 & $\mid \begin{array}{l}\stackrel{0}{\dot{0}} \\
=0\end{array}$ \\
\hline 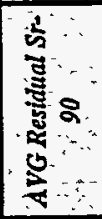 & 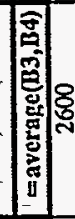 & & $\mid \begin{array}{l}y \\
5 \\
0\end{array}$ & בְ. & 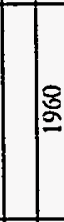 & & $\underset{\sim}{\mathbb{R}}$ & $\begin{array}{l}\approx \\
\dot{0} \\
\end{array}$ & ఫ్స్తి & 崩 & 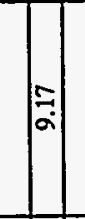 & & ڤి & $\mid$ & $\mid$ & 일 & 每 & $\left|\begin{array}{c}n \\
\infty \\
\infty \\
\infty\end{array}\right|$ & 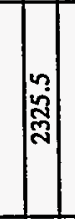 & 하 & $\mid \frac{9}{\forall}$ \\
\hline 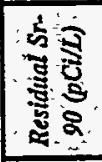 & 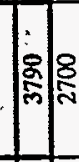 & 8 & ?ִ & तु) & 悉 & & $\frac{\square}{6}$ & $?$ & 궁유 & : & : & $\vec{m}$ & 串递 & F & 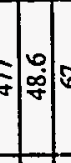 & ธ & 윌 & 它 & $\overrightarrow{8}$ & 형ㅇㅎㅎ & 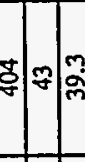 \\
\hline 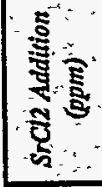 & & 름 & 틀 & 흐를 & 與 & & & 晋 & 表融 & 총 & 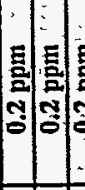 & 흠 & 黄 & ה & 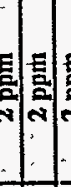 & 豆言 & 黄豆言 & 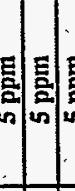 & 틀 & 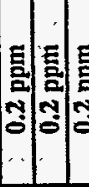 & 틀 \\
\hline 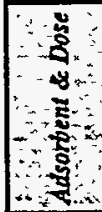 & : & 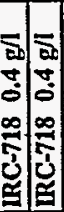 & 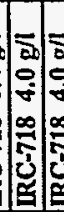 & \begin{tabular}{ll|} 
& \\
$\vdots$ \\
$\vdots$
\end{tabular} & 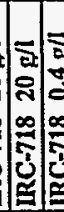 & 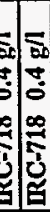 & & 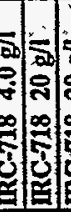 & 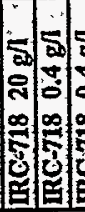 & 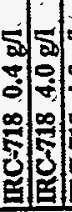 & $\begin{array}{l}5 \\
0 \\
0 \\
0 \\
0 \\
0 \\
0\end{array}$ & . & 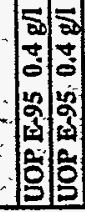 & 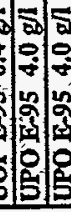 & $\begin{array}{ll}0 \\
\vdots \\
\vdots\end{array}$ & 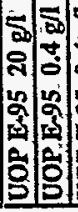 & 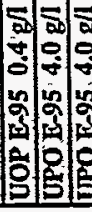 & 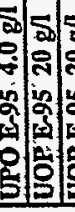 & 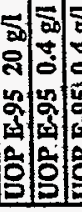 & 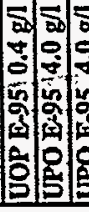 & 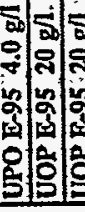 \\
\hline
\end{tabular}


DOE/RL-95-59

Rev. 0

Table C-14. Strontium-90 Isotherms.

\begin{tabular}{|c|c|c|c|c|c|c|}
\hline 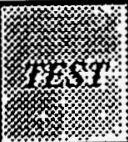 & 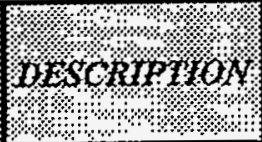 & $1 \%$ & $\frac{1}{5.60 \%}$ & 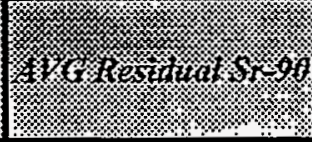 & 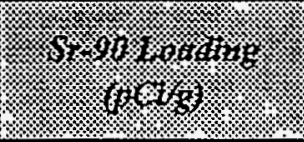 & (1) \\
\hline 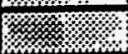 & 6 & $2 \%$ & 1 & 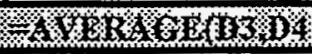 & 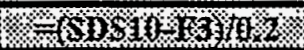 & 13.1. \\
\hline 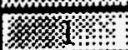 & $\therefore \quad 2 \% \mathrm{~g} 1 \mathrm{G}$ & 8.33 & 3920 & 3985 & 3025 & \\
\hline 16 & $1 \% 2,211 \%$ & 8.34 & 4050 & & & \\
\hline 1 & (280g1 & 8.36 & 441 & 470.5 & 2059.75 & \\
\hline $1 \%$ & $201 \mathrm{gl}$ & 8.37 & 500 & & & \\
\hline 䒽 & (2) $26 \mathrm{~g} t$ & & 23.8 & 24.4 & 228.28 & \\
\hline \%४ & $1 \% 200 \% 11 \ldots$ & 8.65 & 25 & & & \\
\hline 13 & AB B & 8.33 & 4590 & & & \\
\hline 1 & \%Bfonterjeed & 8.1 & & & & 0.164 \\
\hline W. & : $\quad 2 \mathrm{~g} \mathrm{~W}$ & 6.3 & 4410 & 4370 & 3000 & \\
\hline (16: & $1 \% 8 \%, 2 \mathrm{gdl} / \%$ & 6.3 & 4330 & & & \\
\hline 162 & 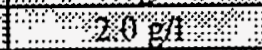 & 6.3 & 889 & 845 & 2062.5 & \\
\hline 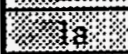 & 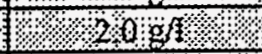 & 5.8 & 801 & & & \\
\hline 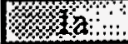 & 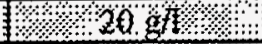 & 6.3 & 56 & 46.9 & 246.155 & \\
\hline \% & $20 . \mathrm{gl}$ & 6.4 & 37.8 & & & \\
\hline 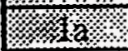 & B Banforeet & 6.3 & 4970 & & & \\
\hline V. & 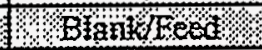 & 8.5 & & & & 0.167 \\
\hline 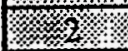 & $1 \% 2,0 \% \mathrm{~g} Z$ \% & 8.1 & 528 & 551 & 2514.5 & \\
\hline V. & 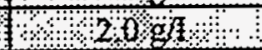 & 8 & 574 & & & \\
\hline $2 \%$ & A : $\quad 2 € \times g z$ & 8.3 & 62.1 & 62.65 & 275.8675 & \\
\hline 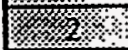 & $\% 29 \% 19$ & 8.3 & 63.2 & & & \\
\hline 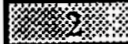 & TBfanditeced & 8 & 5580 & & & \\
\hline 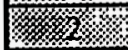 & 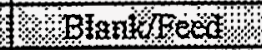 & & & & & 0.159 \\
\hline 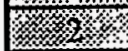 & 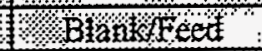 & & & & & 0.159 \\
\hline ( & 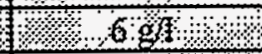 & & 119 & 137.5 & 845.4166667 & \\
\hline (1) & 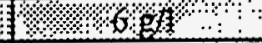 & & 156 & & & \\
\hline 8 s. & 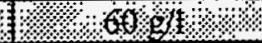 & & 26 & 28.85 & 863.525 & \\
\hline 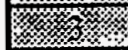 & 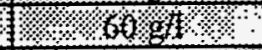 & & 31.7 & & & \\
\hline 6 济 & 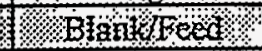 & & 5210 & & & \\
\hline 6 & B Bfandifeed & & & & & 0.426 \\
\hline 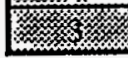 & 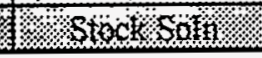 & & & & & 175 \\
\hline
\end{tabular}


DOE/RL-95-59

Rev. 0

Table C-15. MCT-1 Analytical Data.

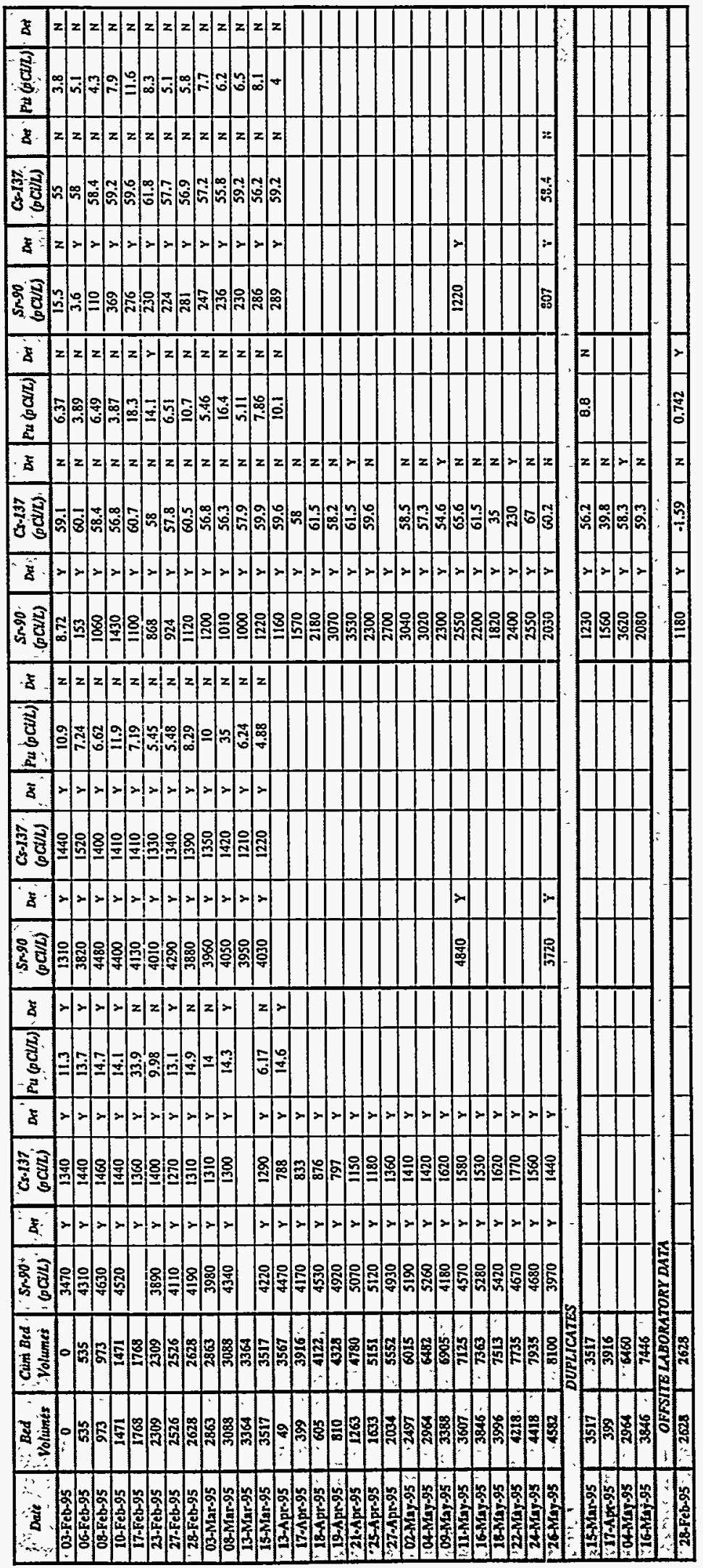




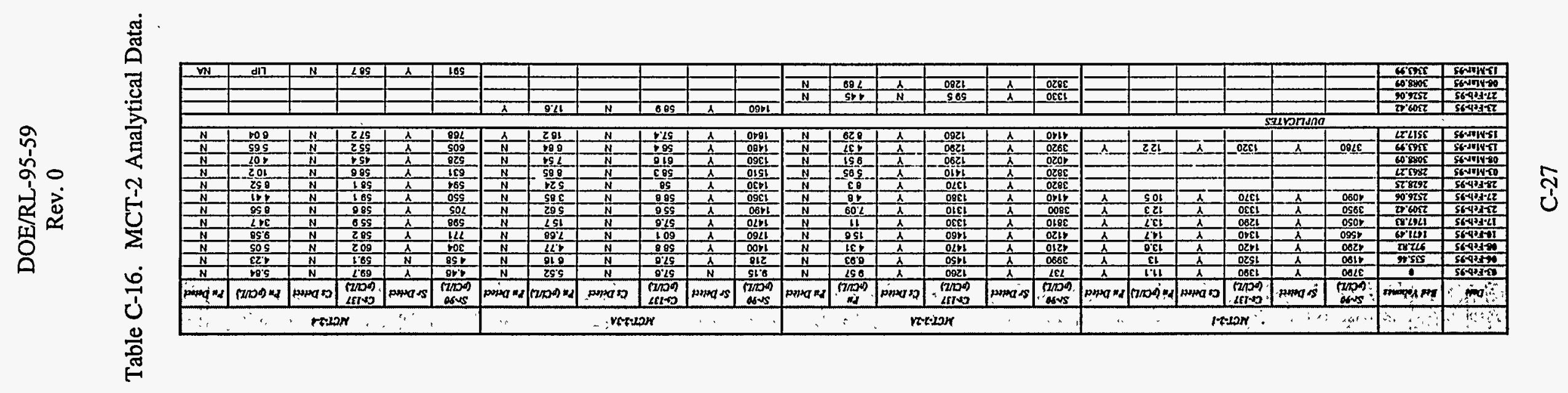




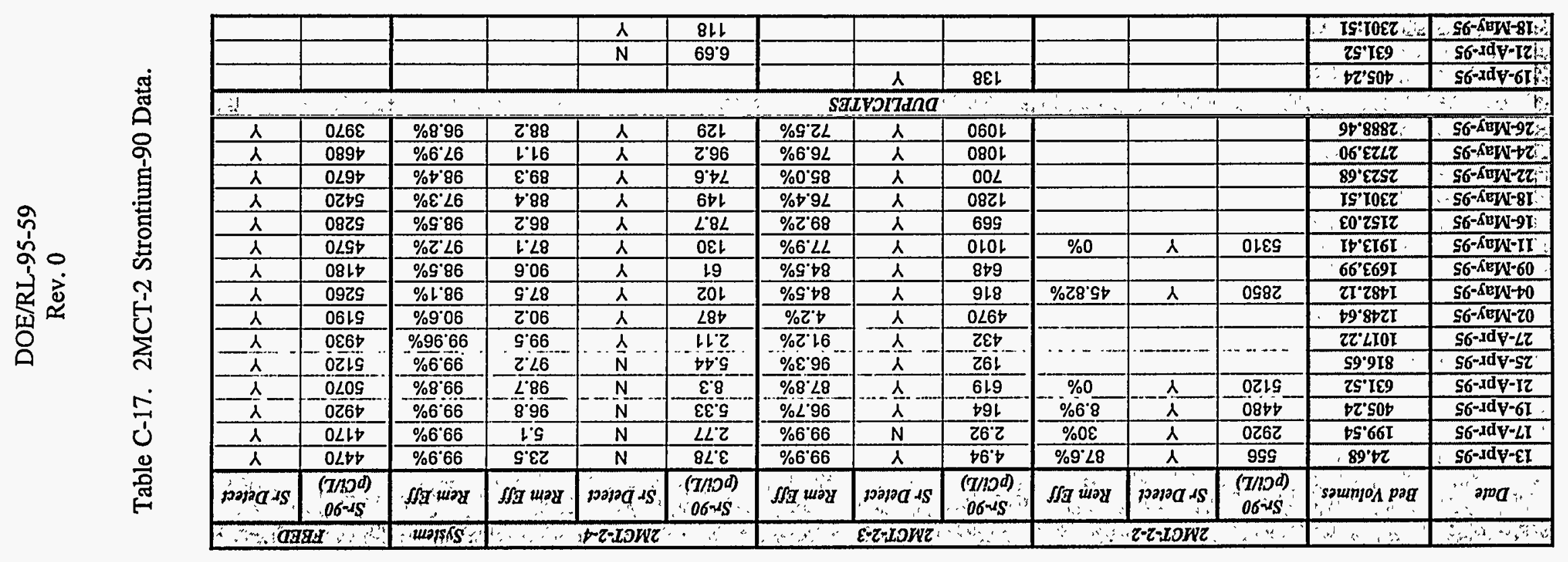




\begin{tabular}{|c|c|c|c|c|c|c|c|c|c|c|c|c|c|}
\hline & & \multicolumn{3}{|c|}{$2 M C T-3-2$} & \multicolumn{3}{|c|}{$2 M C T-3-3$} & \multicolumn{3}{|c|}{$2 M C T-3-4$} & \multirow{2}{*}{$\frac{\text { System }}{\text { Rern. Eff. }}$} & \multicolumn{2}{|c|}{ FEED } \\
\hline Date & Bed Volumes & $<$ & $\begin{array}{c}S m-90 \\
(p C i / L)\end{array}$ & Rem. Eff. & $<$ & $\begin{array}{c}5 n-90 \\
(p C i / L)\end{array}$ & Rem. Eff. & $<$ & $\begin{array}{c}S m-90 \\
(p C i / L)\end{array}$ & Rem. Eff. & & $<$ & $\begin{array}{c}S r-90 \\
(p C i / L)\end{array}$ \\
\hline 13-Apr-95 & 24.7 & & 322 & $92.8 \%$ & $<$ & 2.5 & $99.2 \%$ & $<$ & 5.08 & & $99.9 \%$ & & 4470 \\
\hline 17-Apr-95 & 199.5 & & 2630 & $36.9 \%$ & & 4.01 & $99.8 \%$ & $<$ & 14.3 & & $99.7 \%$ & & 4170 \\
\hline 19-Apr-95 & 405.2 & & 4500 & $8.5 \%$ & & 140 & $96.9 \%$ & & 5.82 & $95.8 \%$ & $99.9 \%$ & & 4920 \\
\hline 21-Apr-95 & 631.5 & & 4710 & $7.1 \%$ & & 397 & $91.6 \%$ & $<$ & 6.08 & $98.5 \%$ & $99.9 \%$ & & 5070 \\
\hline 25-Apr-95 & 816.7 & & & & & 238 & $95.4 \%$ & $<$ & 10.2 & $95.7 \%$ & $99.8 \%$ & & 5120 \\
\hline 27-Apr-95 & 1017.2 & & & & & 371 & $92.5 \%$ & & 5.64 & $98.5 \%$ & $99.9 \%$ & & 4930 \\
\hline 2.May-95 & 1248.6 & & 41.3 & $99.2 \%$ & & 471 & $90.9 \%$ & & 8.69 & $98.2 \%$ & $99.8 \%$ & & 5190 \\
\hline 4-May-95 & 1482.1 & & 5120 & $2.7 \%$ & & 976 & $80.9 \%$ & & 60.8 & $93.8 \%$ & $98.8 \%$ & & 5260 \\
\hline 9.May-95 & 1694.0 & & & & & 631 & $84.9 \%$ & - & 37.8 & $94.0 \%$ & $99.1 \%$ & & 4180 \\
\hline 11-May-95 & 1913.4 & & & & & 1150 & $74.8 \%$ & & 69.7 & $93.9 \%$ & $98.5 \%$ & & 4570 \\
\hline 16-May-95 & 2152.0 & & 5270 & $0.2 \%$ & & 640 & $87.9 \%$ & & 38.5 & $94.0 \%$ & $99.3 \%$ & & 5280 \\
\hline 18-May-95 & 2301.5 & & & & & 966 & $82.2 \%$ & & 82.7 & $91.4 \%$ & $98.5 \%$ & & 5420 \\
\hline 22-May-95 & 2623.7 & & & & & 940 & $79.9 \%$ & & 83.5 & $91.1 \%$ & $98.2 \%$ & & 4670 \\
\hline 24-May-95 & 2723.9 & & & & & 978 & $79.1 \%$ & & 95.4 & $90.2 \%$ & $98.0 \%$ & & 4680 \\
\hline 26-May-95 & 2888.5 & & & & & 777 & $80.4 \%$ & & 79.1 & $89.8 \%$ & $98.0 \%$ & & 3970 \\
\hline \multicolumn{14}{|c|}{ DUPLICATES } \\
\hline 13-Apr-95 & 24.7 & & & & & & & $<$ & 4.31 & & & & \\
\hline 2-May-95 & 1248.6 & & & & & & & & 10.00 & & & & \\
\hline 11-May-95 & 1913.4 & & & & & & & & 67.50 & & & & \\
\hline 22-May-95 & 2523.7 & & & & & 979.00 & & & & & & & \\
\hline 26-May-95 & 2888.5 & & & & & & & & 79.70 & & & & \\
\hline
\end{tabular}


DOE/RL-95-59

Rev. 0

Table C-19. Mini-Column Test 1 Analytical Results.

\begin{tabular}{|c|c|c|c|c|c|c|}
\hline $\begin{array}{c}\text { Bed Volumes } \\
\text { Treated }\end{array}$ & $\begin{array}{c}\text { Tc-99 } \\
\text { Feed } \\
(\mathrm{pCi} / \mathrm{L})\end{array}$ & $\begin{array}{c}\text { Tc-99 } \\
\text { Effluent } \\
(\mathrm{pCi} / \mathrm{L})\end{array}$ & $\begin{array}{l}\text { Removal } \\
\text { Efficiency } \\
\text { Tc-99 (\%) }\end{array}$ & $\begin{array}{c}\text { Co-60 } \\
\text { Feed } \\
(\mathrm{pCi} / \mathrm{L})\end{array}$ & $\begin{array}{c}\text { Co-60 } \\
\text { Effluent } \\
(\mathrm{pCi} / \mathrm{L})\end{array}$ & $\begin{array}{l}\text { Removal } \\
\text { Efficiency } \\
\text { Co-60 (\%) }\end{array}$ \\
\hline 205 & 9,010 & 125 & 99 & 146 & 43.1 & 70 \\
\hline 820 & 10,900 & 656 & 94 & 146 & 37.4 & 74 \\
\hline 1,435 & 8,880 & 90 & 99 & 160 & 38.5 & 76 \\
\hline 2,050 & . & & & 142 & 41.4 & 71 \\
\hline 2,460 & 9,960 & 725 & 93 & 162 & 37 & 77 \\
\hline 2,870 & 11,300 & 1,100 & 90 & 160 & 42.7 & 73 \\
\hline 2,993 & 10,700 & 1,350 & 87 & 156 & 40.7 & 74 \\
\hline 3,050 & 10,800 & 1,560 & 86 & 142 & 41 & 71 \\
\hline 3,100 & 10,600 & 1,660 & 84 & 174 & 32 & 82 \\
\hline 3,550 & 11,400 & 3320 & 71 & 164 & 39.6 & 76 \\
\hline 3,755 & 10,600 & 4170 & 61 & 151 & 35.4 & 77 \\
\hline 3,895 & 11,300 & 4900 & 57 & 167 & 39.2 & 77 \\
\hline 4,042 & 10,900 & 8880 & 19 & 171 & 39.3 & 77 \\
\hline 4,141 & 11,100 & 8140 & 27 & 155 & 39.6 & 74 \\
\hline 4,264 & 10,500 & 7400 & 30 & 166 & 41 & 75 \\
\hline 4,387 & 9,890 & 7840 & 21 & 160 & 41 & 74 \\
\hline 4,526 & & & & 155 & 38.9 & 75 \\
\hline 4,674 & 10,900 & 7980 & 27 & 135 & 40.3 & 70 \\
\hline 4,858 & 9,620 & 11200 & -16 & 182 & 33.8 & 81 \\
\hline 5,043 & 10,500 & 6710 & 36 & 162 & 42.1 & 74 \\
\hline 5,207 & 10,900 & 10400 & 5 & 166 & 38.1 & 77 \\
\hline 5,395 & 10,700 & 12800 & -20 & 154 & 37.4 & 76 \\
\hline 5,576 & 10,800 & 11000 & -2 & 166 & 35.8 & 78 \\
\hline 5,740 & 6,440 & 12500 & -94 & 166 & 34.6 & 79 \\
\hline 5,900 & 8,760 & 6540 & 25 & 149 & 36.6 & 75 \\
\hline
\end{tabular}


DOE/RL-95-59

Rev. 0

Table C-20. Mini-Column Test 2 Analytical Results.

\begin{tabular}{|c|c|c|c|c|c|c|}
\hline $\begin{array}{l}\text { Bed Volumes } \\
\text { Treated }\end{array}$ & $\begin{array}{c}\text { Tc-99 } \\
\text { Feed } \\
(\mathrm{pCi} / \mathrm{L})\end{array}$ & $\begin{array}{c}\text { Tc-99 } \\
\text { Effluent } \\
\text { (pCi/L) }\end{array}$ & $\begin{array}{l}\text { Removal } \\
\text { Efficiency } \\
\text { Tc-99 (\%) }\end{array}$ & $\begin{array}{c}\text { Co-60 } \\
\text { Feed } \\
(\mathrm{pCi} / \mathrm{L})\end{array}$ & $\begin{array}{c}\text { Co-60 } \\
\text { Effluent } \\
(\mathrm{pCi} / \mathrm{L})\end{array}$ & $\begin{array}{l}\text { Removal } \\
\text { Efficiency } \\
\text { Co-60 (\%) }\end{array}$ \\
\hline 205 & 9,010 & 84 & 99 & 146 & 38.5 & 74 \\
\hline 820 & 10,900 & 696 & 94 & 146 & 39.6 & 73 \\
\hline 1,435 & 8,880 & 97 & 99 & 160 & 43.9 & 73 \\
\hline 2,050 & -. & & & 142 & 38.5 & 73 \\
\hline 2,460 & 9,960 & 840 & 92 & 162 & 38.5 & 76 \\
\hline 2,870 & 11,300 & 677 & 94 & 160 & 38.5 & 76 \\
\hline 2,993 & 10,700 & 2,040 & 81 & 156 & 37 & 76 \\
\hline 3,050 & 10,800 & 2,200 & 80 & 142 & 42.1 & 70 \\
\hline 3,100 & 10,600 & 2,230 & 79 & 174 & 43.1 & 75 \\
\hline 3,550 & 11,400 & 4,040 & 65 & 164 & 39.6 & 76 \\
\hline 3,755 & 10,600 & 4,520 & 57 & 151 & 38.5 & 75 \\
\hline 3,895 & 11,300 & 5,310 & 53 & 167 & 38.5 & 77 \\
\hline 4,042 & 10,900 & 6,970 & 36 & 171 & 37 & 78 \\
\hline 4,141 & 11,100 & 7,380 & 34 & 155 & 35.9 & 77 \\
\hline 4,264 & 10,500 & 8,140 & 22 & 166 & 39.3 & 76 \\
\hline 4,387 & 9,890 & 7,000 & 29 & 160 & 41 & 74 \\
\hline 4,526 & & & & 155 & 36.2 & 77 \\
\hline 4,674 & 10,900 & 9,510 & 13 & 135 & 39.6 & 71 \\
\hline 4,858 & 9,620 & 433 & 95 & 182 & 37.4 & 79 \\
\hline 5,043 & 10,500 & 7,930 & 24 & 162 & 46 & 72 \\
\hline 5,207 & 10,900 & 10,000 & 8 & 166 & 37 & 78 \\
\hline 5,395 & 10,700 & 12,100 & -13 & 154 & 38.9 & 75 \\
\hline 5,576 & 10,800 & 11,600 & -7 & 166 & 33.4 & 80 \\
\hline 5,740 & 6,440 & 11,000 & -71 & 166 & 38.5 & 77 \\
\hline 5,900 & 8,760 & 8,150 & 7 & 149 & 37.4 & 75 \\
\hline
\end{tabular}




\begin{tabular}{|c|c|c|c|c|c|c|c|c|c|}
\hline iritiv & mon & . & (1) & k & $1 \%$ & 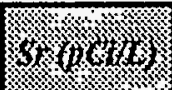 & (5) & ( $p(1)$ & s. \\
\hline 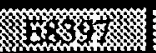 & $00 \%$ sen & W & 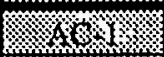 & 11.5 & $\mathrm{Y}$ & 4560 & $\mathrm{Y}$ & 1370 & $\mathrm{Y}$ \\
\hline 30 & 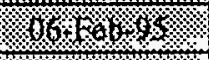 & 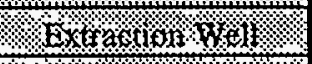 & tro.t. & 17.4 & $Y$ & 4500 & $\mathrm{Y}$ & 1570 & $\mathrm{Y}$ \\
\hline (1) & 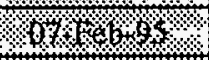 & 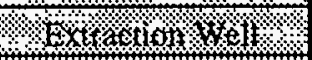 & $8, \alpha<$. & 17.5 & $\mathrm{Y}$ & 4030 & $\mathrm{Y}$ & 1410 & $\mathrm{Y}$ \\
\hline 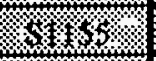 & $1084 \mathrm{teb}, 5$ & 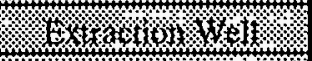 & \% & 16.1 & $\mathrm{Y}$ & 3880 & $\mathrm{Y}$ & 1380 & $Y$ \\
\hline 34 & 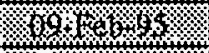 & 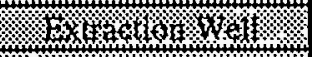 & x. & 15.5 & $Y$ & 3660 & $\mathrm{Y}$ & 1350 & $\mathrm{Y}$ \\
\hline 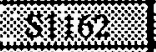 & 10+4 & 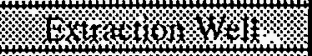 & 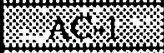 & 16.2 & $\bar{Y}$ & 3230 & $\bar{Y}$ & 1410 & $\mathrm{Y}$ \\
\hline $3 x$ & K.tuds & F & 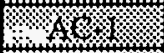 & 14.4 & $\mathrm{Y}$ & 3780 & $\mathrm{Y}$ & 1350 & $\mathrm{Y}$ \\
\hline 16 & 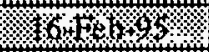 & 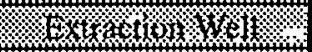 & 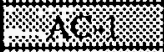 & 16.6 & $\mathrm{Y}$ & 3750 & $\mathrm{Y}$ & 1330 & $\mathrm{Y}$ \\
\hline$y_{1}$ & 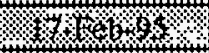 & F & 4 & 19.9 & $\mathrm{Y}$ & 3940 & $\mathrm{Y}$ & 1300 & $Y$ \\
\hline K & $x_{3} \ldots$ & 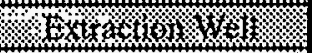 & 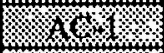 & 28 & $\mathrm{~N}$ & 3630 & $\mathrm{Y}$ & 1310 & $Y$ \\
\hline $4 \times 6.6$ & 6.2164 .95 & Ext, & 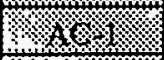 & 15.3 & $\mathrm{Y}$ & 3580 & $\mathrm{Y}$ & 1320 & $\mathrm{Y}$ \\
\hline 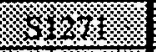 & $4.18-1.93$ & 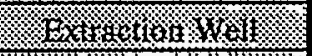 & . & 15.2 & $\mathrm{Y}$ & 3800 & $\mathrm{Y}$ & 1300 & $\mathrm{Y}$ \\
\hline $4 z$ & 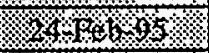 & Kty, & (1) 21 & 16.6 & $\bar{Y}$ & 4130 & $\overline{\mathrm{X}}$ & 1300 & $\mathrm{Y}$ \\
\hline x. & W. & 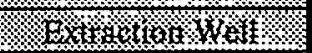 & k. & 17.4 & $\bar{Y}$ & 4320 & $\mathrm{Y}$ & 1400 & $\mathrm{Y}$ \\
\hline (6) & (6) ret & V & k. & 18 & $\bar{Y}$ & 4080 & $\mathrm{Y}$ & 1270 & $\mathrm{Y}$ \\
\hline (1) & 1) & 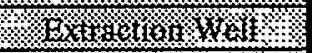 & 4.16 & 5.93 & $\mathrm{~N}$ & 4050 & $\mathrm{Y}$ & 1330 & $\mathrm{Y}$ \\
\hline X) & 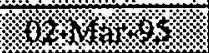 & 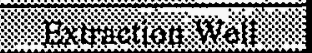 & 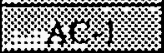 & 17.4 & $\mathrm{Y}$ & 4070 & $\bar{Y}$ & 1300 & $\mathrm{Y}$ \\
\hline (16. & OUS & V.t. & \%(\%) & 17.6 & $\bar{Y}$ & 3810 & $\bar{Y}$ & 1270 & $\mathrm{Y}$ \\
\hline 33449 & 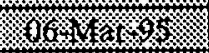 & 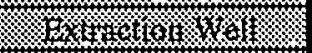 & 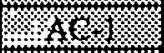 & 5.17 & $\mathrm{~N}$ & 1355 & $\bar{Y}$ & 1380 & $\mathrm{Y}$ \\
\hline (x) & (0) & Cxick & 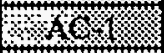 & 18.3 & $\mathrm{Y}$ & 4050 & $\mathrm{Y}$ & 1380 & $\bar{Y}$ \\
\hline 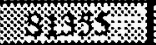 & (6\%) & 1 & \% & 18.4 & $\mathrm{Y}$ & 3250 & $\mathbf{Y}$ & 1170 & $\mathrm{Y}$ \\
\hline SSYso & 30j & $E_{x}=0,101, x_{01} !$ & $\because \approx \mathrm{C}$ & 15.9 & $\mathrm{Y}$ & 3900 & $Y$ & 1260 & $\mathrm{Y}$ \\
\hline $8 \times 63$ & 枆次化 & E & $1 \%$ & 13.8 & $\overline{\mathrm{Y}}$ & 3890 & $\mathrm{Y}$ & 1400 & $\mathrm{Y}$ \\
\hline Wut & 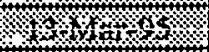 & (5) & 4 (1) 11 & 14.6 & $\mathbf{Y}$ & 3890 & $\mathbf{Y}$ & 1400 & $\mathbf{Y}$ \\
\hline 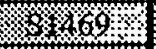 & (1) & Y & $\ldots$ & 16.4 & $\mathrm{Y}$ & 3940 & $\bar{Y}$ & 1310 & $\mathrm{Y}$ \\
\hline Surtiol & . & 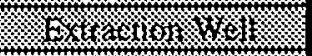 & \& & 16 & $\mathrm{Y}$ & 3.15 & $\mathrm{Y}$ & 1190 & $\mathrm{Y}$ \\
\hline Xines & (6) & 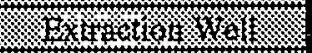 & (2. & 13.7 & $\bar{Y}$ & 3790 & $\bar{Y}$ & 1280 & $\bar{Y}$ \\
\hline 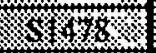 & xym & 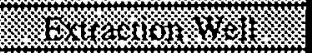 & 1.40 & 31.5 & $\mathrm{~N}$ & 3520 & $\mathrm{Y}$ & 1210 & $\bar{Y}$ \\
\hline (1) & 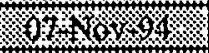 & 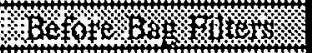 & $(x)$ & 10 & $\mathrm{~N}$ & 4730 & $\bar{Y}$ & 1040 & $\mathrm{Y}$ \\
\hline 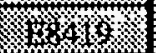 & $6 \%(x<y$ & 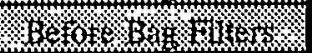 & 10. & 18.4 & $\bar{Y}$ & 3950 & $Y$ & 1180 & $\mathrm{Y}$ \\
\hline 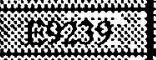 & $(13 \times<\%$ & 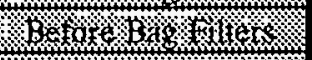 & 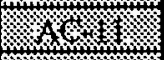 & 30.1 & $\mathrm{Y}$ & 3840 & $\mathrm{Y}$ & 1220 & $Y$ \\
\hline (4) & $\left(y_{1}\right.$ & (6) & (1) & 32.5 & $\mathrm{Y}$ & 4410 & $\bar{Y}$ & 1470 & $\bar{Y}$ \\
\hline 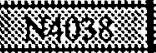 & 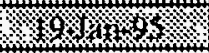 & B & $1 / 2 x$ & 33.5 & $\mathrm{Y}$ & 4430 & $\bar{Y}$ & 1500 & $\bar{Y}$ \\
\hline 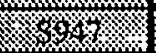 & 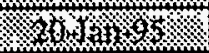 & 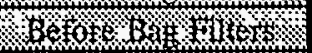 & $3 \times 1<2,4$ & 44.6 & $\bar{Y}$ & 4340 & $\bar{Y}$ & 1390 & $\bar{Y}$ \\
\hline 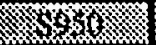 & (3) 2 I & 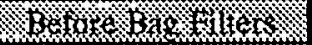 & 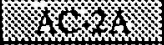 & 26.9 & $\mathrm{Y}$ & 4010 & $\mathrm{Y}$ & 1430 & $Y$ \\
\hline $8384=$ & 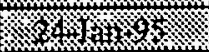 & 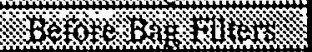 & A & 29.6 & $\bar{Y}$ & 3210 & $\mathrm{Y}$ & 1360 & $\mathrm{Y}$ \\
\hline $2056 \ldots$ & $\gamma / y_{1}$ & B & 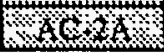 & 19.4 & $Y$ & 4050 & $\bar{Y}$ & 1340 & $\mathrm{Y}$ \\
\hline
\end{tabular}




\begin{tabular}{|c|c|c|c|c|c|c|c|c|c|}
\hline$\ldots$ & $1 \ldots$ & 1121 & II & (1) & $\ldots$ & 212 & L & $\ldots$ & $\ldots$ \\
\hline mon & 筒 & \& & \% & 24.6 & $\mathrm{Y}$ & 34.9 & $\mathrm{Y}$ & 1870 & $\mathbf{Y}$ \\
\hline (x) & W & W & 12 & 22.6 & $\bar{Y}$ & 4370 & $\mathbf{Y}$ & 1460 & $\overline{\mathbf{Y}}$ \\
\hline 42 & W & (j) & 瀑 & 19.3 & $Y$ & 4390 & $\mathrm{Y}$ & 1420 & $\bar{Y}$ \\
\hline$\ldots$ & $(x, \ldots \ldots$ & W & 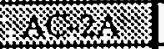 & 18.3 & $\mathrm{Y}$ & 4570 & $\mathrm{Y}$ & 1490 & $\mathrm{Y}$ \\
\hline$u_{1}$ & $10 \mathrm{EE} \times 6 \times 5$ & Botor -3 3 & 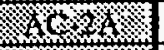 & 18.6 & $\mathrm{Y}$ & 3620 & $\bar{Y}$ & 1360 & $\bar{Y}$ \\
\hline - & $8 \%$ & 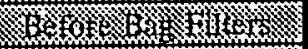 & 样 & 16.7 & $\mathrm{Y}$ & 4060 & $\bar{Y}$ & 1420 & $\mathrm{Y}$ \\
\hline ro & $(1)$ & 38\%s, & 1. & 18 & $\mathrm{Y}$ & 3040 & $\mathrm{Y}$ & 1410 & $\bar{Y}$ \\
\hline$\ldots$ & $\quad$ - & (1) & $\quad$ I & 8.15 & $\mathrm{Y}$ & 5390 & $\mathrm{Y}$ & 977 & $\mathrm{Y}$ \\
\hline W & 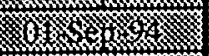 & (1) & $1 \quad$ & 5.14 & $\mathrm{~N}$ & 39.6 & $\mathrm{Y}$ & 58.4 & $\mathrm{~N}$ \\
\hline (6) & \% & (1) & ( & 20 & $\bar{N}$ & 1990 & $\mathrm{Y}$ & 570 & $\bar{Y}$ \\
\hline - & \% & (j) & $5<3$ & 10 & $\mathrm{~N}$ & 2000 & $\mathrm{Y}$ & 1140 & $\mathrm{Y}$ \\
\hline (1) & $\ldots \ldots$ & (1) & 48 & 10 & $\mathrm{~N}$ & 3100 & $\bar{Y}$ & 1210 & $\mathrm{Y}$ \\
\hline$\quad$. & . & \}) & 34 & 2.26 & $\mathrm{~N}$ & 3350 & $\mathrm{Y}$ & 1240 & $Y$ \\
\hline 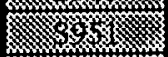 & $\ldots$ & toof & 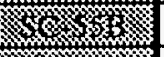 & 2.18 & $\mathrm{~N}$ & 3800 & $Y$ & 1300 & $\mathrm{Y}$ \\
\hline 4 & $4 \times 1 \%$ & 3.jo & 64 6313 & 3.47 & $Y$ & 2470 & $Y$ & 1350 & $\mathrm{Y}$ \\
\hline $3 \%$ & $\ldots$ & (6) & 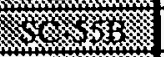 & 2.48 & $\bar{Y}$ & 4030 & $\mathrm{Y}$ & 1440 & $\bar{Y}$ \\
\hline 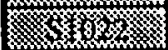 & 26. & 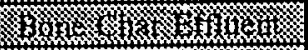 & 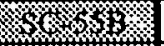 & 16.5 & $\mathrm{~N}$ & 3280 & $\bar{Y}$ & 1480 & $\bar{Y}$ \\
\hline (N) & 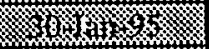 & Ko & 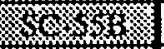 & 2.61 & $\mathrm{~N}$ & 3800 & $\mathrm{Y}$ & 1400 & $\mathrm{Y}$ \\
\hline 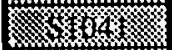 & F & (3) & 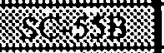 & 2.89 & $\mathrm{~N}$ & 4190 & $\mathrm{Y}$ & 1650 & $\mathbf{Y}$ \\
\hline 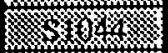 & (1) & (x) & (6) & 2.64 & $\mathrm{~N}$ & 2920 & $\bar{Y}$ & 1480 & $\mathrm{Y}$ \\
\hline 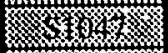 & 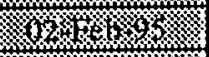 & K3 & 3. & 2.13 & $\mathrm{~N}$ & 4090 & $\mathrm{Y}$ & 1420 & $\mathrm{Y}$ \\
\hline . & . & (3) & $8\left(x_{3}\right.$ & 2.28 & $\mathrm{~N}$ & 1160 & $\bar{Y}$ & 1260 & $\mathbf{Y}$ \\
\hline 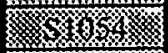 & 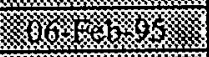 & Yoone & (6- & 2.47 & $\mathrm{~N}$ & 4190 & $\bar{Y}$ & 1380 & $\bar{Y}$ \\
\hline x & (10.6. & Fon & . & 2.18 & $\mathrm{~N}$ & 3730 & $\mathrm{Y}$ & 1430 & $\mathrm{Y}$ \\
\hline 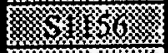 & 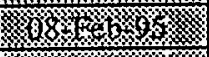 & Ko, & S. & 3.73 & $\mathrm{~N}$ & NDA & NA & 1420 & $\bar{Y}$ \\
\hline s. & 10. & 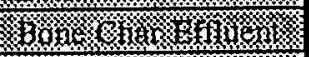 & (3. & 4.77 & $\mathrm{~N}$ & 3910 & $\mathrm{Y}$ & 1310 & $\mathrm{Y}$ \\
\hline - & (D. & X & ) & 3.29 & $\mathrm{~N}$ & 98.7 & $\mathrm{Y}$ & 59.4 & $\mathrm{~N}$ \\
\hline xys & . & Wr. & 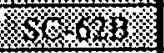 & 2.2 & $\mathrm{~N}$ & 553 & $\mathrm{Y}$ & 60.7 & $N$ \\
\hline 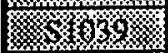 & K & 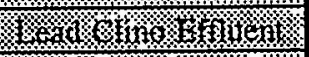 & 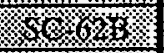 & 2.48 & $\mathrm{~N}$ & 937 & $\mathrm{Y}$ & 262 & $\mathrm{Y}$ \\
\hline 3. & 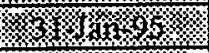 & K & S6\% & 2.23 & $\mathrm{~N}$ & 976 & $\mathrm{Y}$ & 58.2 & $\mathrm{~N}$ \\
\hline 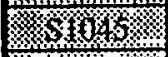 & W. Levos & 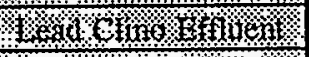 & 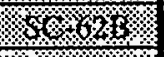 & 12.2 & $\mathrm{~N}$ & 1120 & $\mathrm{Y}$ & 61.4 & $\mathrm{~N}$ \\
\hline (3) & $102 \times 160 \%$ & ( & 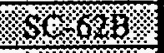 & 2.26 & $\mathrm{~N}$ & 1190 & $\mathrm{Y}$ & 58 & $\mathbf{N}$ \\
\hline (x) 10$)$ & 63으. & 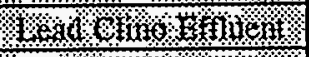 & \% $6.5 \%$ & 4.47 & $\mathbf{N}$ & 3440 & $\mathrm{Y}$ & 78.6 & $\mathrm{~N}$ \\
\hline W. & $106 \% 6 \%$ & 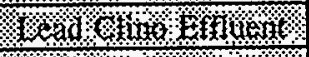 & 16. 6203 & 2.39 & $\mathbf{N}$ & 848 & $\mathrm{Y}$ & 59 & $\mathrm{~N}$ \\
\hline \% & $07+60.6 \%$ & X & K. & 5.76 & $\mathrm{~N}$ & 1980 & $\mathrm{Y}$ & 55 & $N$ \\
\hline 6) & 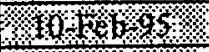 & How & 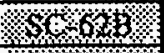 & 3.98 & $\mathrm{~N}$ & 2000 & $\mathrm{Y}$ & 59.5 & $\mathbf{N}$ \\
\hline K. & (.t. & K & \% 6 . & 18.4 & $\mathbf{N}$ & 1650 & $\mathrm{Y}$ & 57.3 & $\mathrm{~N}$ \\
\hline 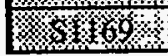 & 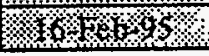 & 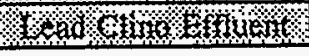 & $6 \% 60 \mathrm{~b}$ & 3.59 & $\mathrm{~N}$ & 1940 & $\mathbf{Y}$ & 57.2 & $\mathrm{Y}$ \\
\hline
\end{tabular}




\begin{tabular}{|c|c|c|c|c|c|c|c|c|c|}
\hline 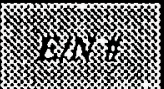 & 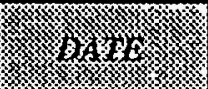 & 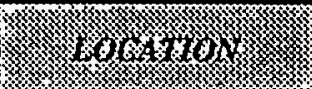 & (2) & $2 \%$ \% & work & \%) & $4 \%$ & kick & 3.6 \\
\hline 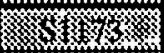 & 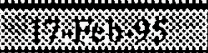 & 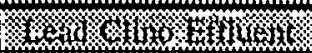 & $5<6$ & 2.91 & $\mathrm{~N}$ & 1740 & $\mathbf{Y}$ & 57.1 & $\mathrm{~N}$ \\
\hline 样 & 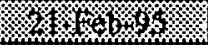 & 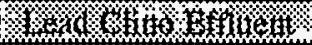 & $3 \% \delta \%$ & 2.69 & $\mathrm{~N}$ & 1800 & $\mathrm{Y}$ & 59 & $\bar{N}$ \\
\hline 36 & . & ( & 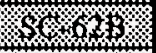 & 2.11 & $\bar{N}$ & 1840 & $\mathrm{Y}$ & 58.6 & $\mathrm{~N}$ \\
\hline $8 \times 2 \%$ & 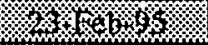 & 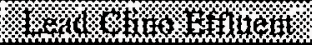 & 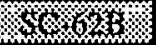 & 2.31 & $\mathrm{~N}$ & 1960 & $\mathrm{Y}$ & 57.7 & $\mathrm{~N}$ \\
\hline $512 \times 3$ & (2) $24.46 \%$ & r. & 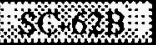 & 3.78 & $N$ & 2020 & $\mathrm{Y}$ & 58.9 & $\mathrm{~N}$ \\
\hline 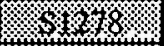 & 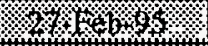 & 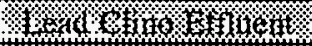 & 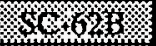 & 2.55 & $\mathrm{~N}$ & 2040 & $\mathrm{Y}$ & 55.9 & $\bar{N}$ \\
\hline 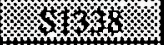 & $28464 \%$ & 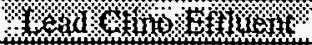 & 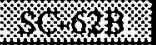 & 2.78 & $\mathrm{~N}$ & 2300 & $\mathrm{Y}$ & 61.2 & $\mathrm{~N}$ \\
\hline 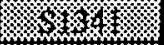 & \% & (K) & 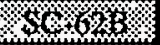 & 6.17 & $\mathrm{~N}$ & 1910 & $\mathrm{Y}$ & 59.9 & $\mathrm{~N}$ \\
\hline 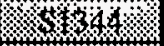 & 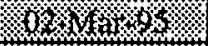 & 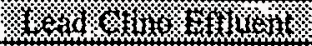 & s. & 5.71 & $\mathrm{~N}$ & 2000 & $\mathrm{Y}$ & 57.1 & $\mathrm{~N}$ \\
\hline $4 x+4$ & 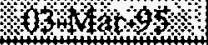 & 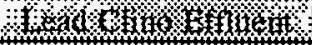 & $46 \%$ & 5.61 & $\mathrm{~N}$ & 2160 & $\mathrm{Y}$ & 61 & $\mathbf{N}$ \\
\hline 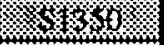 & 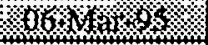 & (x) & - & 4.14 & $\mathbf{N}$ & 1860 & $\mathrm{Y}$ & 58.7 & $\mathrm{~N}$ \\
\hline 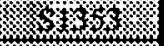 & 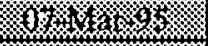 & (1) & (4) & 5.68 & $\mathbf{N}$ & 155 & $\mathrm{Y}$ & 53.6 & $\mathrm{~N}$ \\
\hline 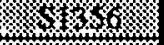 & (6) & Y. & (5). & 4.46 & $\mathrm{~N}$ & 1970 & $\mathbf{Y}$ & 59.9 & $\mathrm{Y}$ \\
\hline 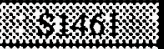 & 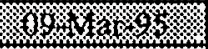 & 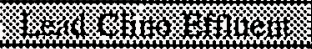 & 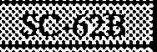 & 6.6 & $\mathrm{~N}$ & 2300 & $\mathrm{Y}$ & 57.8 & $\mathrm{~N}$ \\
\hline$x$ & $\left.x_{1}\right)$ & 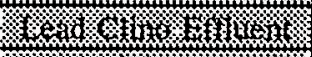 & (c) & 5.52 & $\mathrm{~N}$ & 2320 & $\mathrm{Y}$ & 57.6 & $\mathbf{N}$ \\
\hline 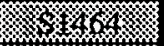 & 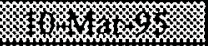 & Fir. & Sur & 2.67 & $\bar{N}$ & 2140 & $\bar{Y}$ & 60.8 & $\bar{N}$ \\
\hline 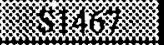 & 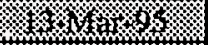 & 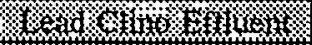 & (6) & 3.17 & $\mathbf{N}$ & 1980 & $\mathbf{Y}$ & 59.4 & $\bar{N}$ \\
\hline - & $\left.x_{1} x_{1}\right)$ & 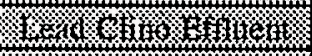 & . & 3.32 & $\mathrm{~N}$ & 2210 & $\bar{Y}$ & 59.2 & $\mathrm{~N}$ \\
\hline 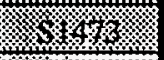 & 40.98 & (1) & 56.621 .1 & 2.62 & $\mathrm{~N}$ & 2210 & $\mathrm{Y}$ & 58.3 & $\mathrm{~N}$ \\
\hline (1) & 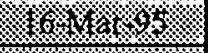 & H. & .96 .62 & 2.53 & $\mathrm{~N}$ & 2020 & $\mathrm{Y}$ & 58.8 & $\mathrm{~N}$ \\
\hline 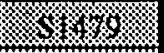 & m & (3) & (36.6. & 4.11 & $N$ & 2140 & $\mathrm{Y}$ & 57.4 & $\mathrm{~N}$ \\
\hline W & 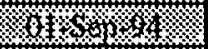 & ( & 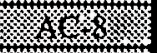 & 3.45 & $\bar{N}$ & 36.6 & $\bar{Y}$ & 65.3 & $\mathrm{~N}$ \\
\hline $4(x-2$ & 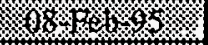 & 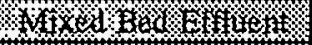 & 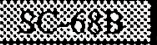 & 3.42 & $\mathrm{~N}$ & 1480 & $\mathrm{Y}$ & 58.3 & $\bar{N}$ \\
\hline$m 6$ & \% $14<1$ & (1) & 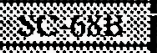 & 3.71 & $\mathrm{~N}$ & 4070 & $\bar{Y}$ & 58.5 & $\mathrm{~N}$ \\
\hline 4 & 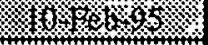 & 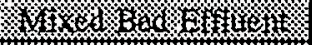 & 350.6083 & 2.54 & $\mathrm{~N}$ & 1240 & $\mathrm{Y}$ & 57.4 & $\mathrm{~N}$ \\
\hline (x) & . & 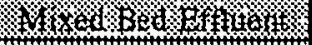 & 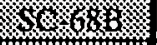 & 6.65 & $\mathrm{~N}$ & 995 & $\mathrm{Y}$ & 59.1 & $\mathbf{N}$ \\
\hline 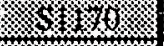 & (6.6. & axtago, & 86.663 & 4.39 & $\mathbf{N}$ & 1270 & $\mathrm{Y}$ & 0 & $\mathbf{N}$ \\
\hline 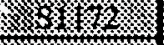 & - & 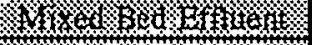 & $56.6,30$ & 3.43 & $\mathbf{N}$ & 485 & $\mathrm{Y}$ & 59.6 & $\mathbf{N}$ \\
\hline (x) & 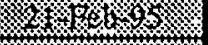 & 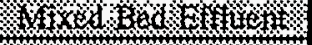 & 36.68 & 2.3 & $\mathrm{~N}$ & 1150 & $\mathrm{Y}$ & 57.4 & $\mathrm{~N}$ \\
\hline ( & $\%$ & - & 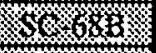 & 3.9 & $\mathrm{~N}$ & 1290 & $\mathrm{Y}$ & 58.6 & $\mathrm{~N}$ \\
\hline$(x)$ & $2,16 \%$ & 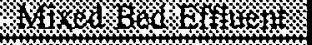 & 36.638 & 3.51 & $\mathbf{N}$ & 1310 & $\mathbf{Y}$ & 58.5 & $\mathrm{~N}$ \\
\hline 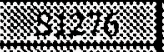 & $2 \times 1<1$ & 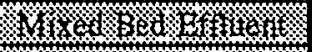 & (c) & 5.7 & $\mathrm{~N}$ & 1380 & $\bar{Y}$ & 46.1 & $\bar{N}$ \\
\hline $1<6$ & (6. & (y & 1. 68 & 2.19 & $\mathrm{~N}$ & 1250 & $\mathrm{Y}$ & 58.2 & $\bar{N}$ \\
\hline 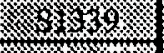 & 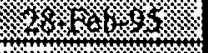 & 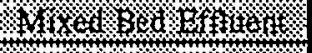 & 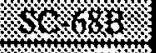 & 2.67 & $\mathrm{~N}$ & 3090 & $\mathrm{Y}$ & 59.6 & $\mathrm{~N}$ \\
\hline$\ldots$ & $631, y+2$ & 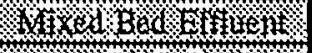 & $8<683$ & 7.07 & $\mathrm{~N}$ & 1280 & $\mathrm{Y}$ & 57.9 & $\mathrm{~N}$ \\
\hline - & $2(1)=3$ & 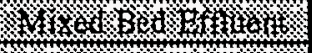 & scision & 2.36 & $\mathbf{N}$ & 1360 & $\mathrm{Y}$ & 60.3 & $\mathrm{~N}$ \\
\hline - & 1 & X & rocos & 6.26 & $\mathbf{N}$ & 1200 & $\mathrm{Y}$ & 58.8 & $\mathrm{~N}$ \\
\hline
\end{tabular}




\begin{tabular}{|c|c|c|c|c|c|c|c|c|c|}
\hline $1 \%$ & 1.26 & - & 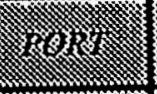 & . & $\ldots$ & $\ldots$ & 3 & $\ldots$ & 2 \\
\hline (1) & $\quad \quad \quad \quad \quad$ & 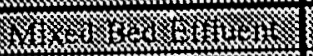 & 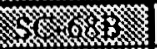 & 3.5 & $\mathrm{~N}$ & 1150 & $\mathrm{Y}$ & 60 & $\mathrm{~N}$ \\
\hline & $\quad$ & ( & W & 3.03 & $\mathbf{N}$ & 1140 & $\mathrm{Y}$ & 57.7 & $\mathrm{~N}$ \\
\hline - & 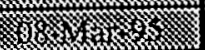 & 元 & 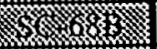 & 3.6 & $\mathrm{~N}$ & 1360 & $Y$ & 55.8 & $\mathrm{~N}$ \\
\hline . & - & (1) & ris & 3.8 & $\mathrm{~N}$ & 1600 & $\mathrm{Y}$ & 58.6 & $\mathbf{N}$ \\
\hline (1) & \% & (I) & 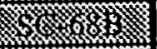 & 4.05 & $\mathrm{~N}$ & 1540 & $\bar{Y}$ & 58.1 & $\mathrm{~N}$ \\
\hline . & $\ldots$ & $(1)<<<3$ & r & 2.84 & $\mathrm{~N}$ & 1320 & $\bar{Y}$ & 60 & $\mathrm{~N}$ \\
\hline & $\ldots$ & 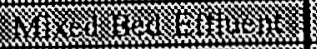 & 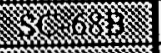 & 3.83 & $\mathrm{~N}$ & 1540 & $\mathrm{Y}$ & 56.2 & $N$ \\
\hline (1) & $\quad \ldots \quad \ldots$ & (z) & 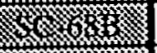 & 2.25 & $\mathrm{~N}$ & 1250 & $\mathrm{Y}$ & 57.1 & $\mathrm{~N}$ \\
\hline r & ( & 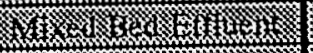 & \% & 2.35 & $\mathrm{~N}$ & 1640 & $\bar{Y}$ & 60.4 & $\mathrm{~N}$ \\
\hline ( & W & 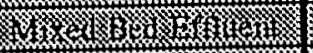 & ro & 33.7 & $\bar{N}$ & 1660 & $\mathrm{Y}$ & 56.4 & $\mathrm{~N}$ \\
\hline (3x) & m & X) & 5461 & 4.09 & $\mathrm{~N}$ & 1660 & $Y$ & 58.6 & $\mathrm{~N}$ \\
\hline \% & (1) & 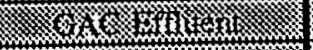 & $\ldots$ & 10 & $\mathrm{~N}$ & 40.1 & $\mathbf{Y}$ & 608 & $\mathrm{~N}$ \\
\hline . & 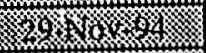 & - & & 10 & $\mathrm{~N}$ & 15.9 & $\bar{Y}$ & 59.1 & $\mathrm{~N}$ \\
\hline 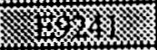 & W & $\ldots \ldots$ & & 20 & $\mathrm{~N}$ & 21.9 & $\mathrm{~N}$ & 59 & $\mathrm{~N}$ \\
\hline 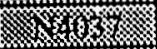 & 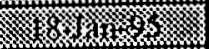 & (1) & 1 & 10 & $\mathbf{N}$ & 10.5 & $\bar{Y}$ & 55.9 & $\mathrm{~N}$ \\
\hline 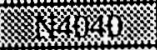 & 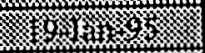 & $18 \alpha_{2}$ & $1 \%$ & 10 & $\mathrm{~N}$ & 76.7 & $\mathrm{Y}$ & 59.8 & $\bar{N}$ \\
\hline w & . & 1 7 - & 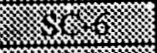 & 3.16 & $\mathbf{N}$ & 11.1 & $\mathrm{Y}$ & 61 & $\mathrm{~N}$ \\
\hline 3.54 & 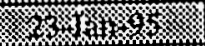 & \% / & 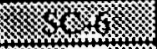 & 2.81 & $\mathbf{N}$ & 10.5 & $\bar{Y}$ & 60.2 & $\mathrm{~N}$ \\
\hline 43 & 2. & 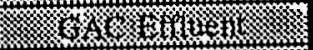 & (136 & 2.68 & $\mathbf{N}$ & 40.8 & $\bar{Y}$ & 60.7 & $Y$ \\
\hline (X) & \% & ( & 㙂 & 2.42 & $\mathbf{N}$ & 94.3 & $\bar{Y}$ & 61.1 & $\mathrm{~N}$ \\
\hline (r) & (1) & 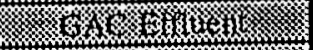 & \% & 3.24 & $\mathrm{~N}$ & 48.1 & $\mathrm{Y}$ & 0 & $\mathrm{~N}$ \\
\hline 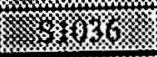 & \% & 洪 & 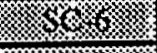 & 2.63 & $\mathrm{~N}$ & 151 & $\mathrm{Y}$ & 63 & $\mathbf{N}$ \\
\hline (3) & (2) & 1.8. & r. & $1010 \%$ & 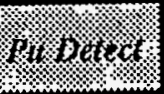 & Swore.1\% & s. olere. & (x) & 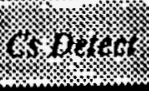 \\
\hline 8 & $0 \%(x+1 \%$ & A Frater of & 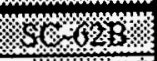 & 1.6 & $\mathrm{Y}$ & 2300 & $\mathrm{Y}$ & 11 & \\
\hline OUBP & $009 \mathrm{kiat}) \mathrm{s}$ & 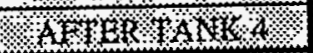 & $50 \times 10$ & 1.5 & $Y$ & 2200 & $Y$ & 4.8 & \\
\hline 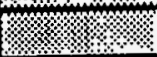 & $1 \% \%$ & 1.1. & $\%$ & $(p \mathrm{cos})$ & $1 \%$ & $(p(t) g)$ & . & $f(f)(g)$ & $\sqrt{132}$ \\
\hline N5063 & 21-Mar-95 & Lead Clino Column & Resin & 1.69 & $\mathrm{Y}$ & 6820 & $\mathrm{Y}$ & 7810 & $\mathrm{Y}$ \\
\hline DUP & 21-Mar-95 & Lead Clino Column & Resin & 1.97 & $\mathrm{Y}$ & 8150 & $\mathrm{Y}$ & 8460 & $\mathrm{Y}$ \\
\hline N5704 & 23-Mar-95 & Mixed Bed Column & Resin & 10.5 & $\mathrm{Y}$ & 3390 & $Y$ & 5.53 & $\underline{Y}$ \\
\hline DUP & 23-Mar-95 & Mixed Bed Column & Resin & 13.3 & $\bar{Y}$ & 3200 & $\mathbf{Y}$ & 6.44 & $\mathrm{Y}$ \\
\hline
\end{tabular}




\begin{tabular}{|c|c|c|c|c|c|c|c|c|c|c|}
\hline mas & (n) & ofph & 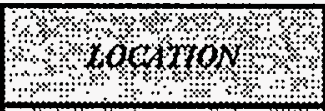 & optos & phorh) & pwoptes & $s+o, \alpha x)$ & 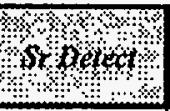 & $c_{\phi}(f)$ & ond wes \\
\hline 3010678 & s61607 & WA 95 & 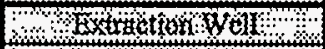 & $A C$ & 22.4 & $\mathrm{Y}$ & 4610 & Y & 1380 & $\mathrm{Y}$ \\
\hline BOMX & S4608: & 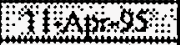 & 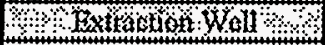 & Adot & 19.3 & $\bar{Y}$ & 4740 & $Y$ & 1440 & $\bar{Y}$ \\
\hline 301013 & 39613 & $33-\mathrm{Ar}+05$ & 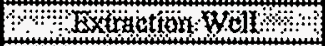 & At Ifit? & 18.2 & $\bar{Y}$ & 4890 & $\bar{Y}$ & 1450 & $\bar{Y}$ \\
\hline SODXKG & 51616 & 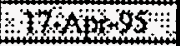 & 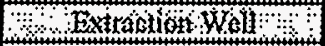 & AC: & 12.2 & $\mathrm{Y}$ & 4100 & $\bar{Y}$ & 1400 & $\bar{Y}$ \\
\hline HCOXXIf & S1621 & 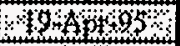 & 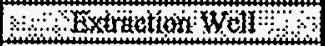 & $B A C+:$ & 19.3 & $Y$ & 4820 & $\bar{Y}$ & 1530 & $\bar{Y}$ \\
\hline SOFWW & stget & $24+4 y+95$ & 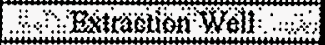 & Acis & 21.5 & $\bar{Y}$ & 5380 & $\bar{Y}$ & 1490 & $\bar{Y}$ \\
\hline BOEAN7 & N5 160 & 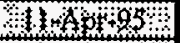 & 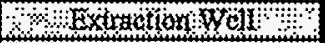 & $\triangle 8 Y-558$ & & & & & & \\
\hline EPFEN & (xtsigin & He & 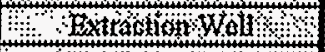 & 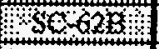 & & & & & & \\
\hline 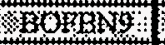 & $2 \times 5163$ & 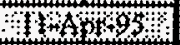 & 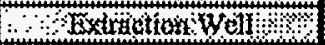 & $8 \mathrm{~S}-68 \mathrm{E}$ & & & & & & \\
\hline Wow & 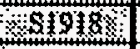 & $24 \times 2 \times 5$ & 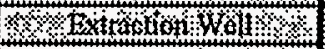 & 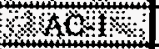 & & & 5180 & $Y$ & 1620 & $\bar{Y}$ \\
\hline KYORYWG & 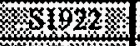 & 然6 & B & 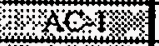 & 22.4 & $\mathrm{Y}$ & 5690 & $\mathrm{Y}$ & 1600 & $\bar{Y}$ \\
\hline 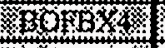 & 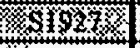 & \&8\% 8 \% & 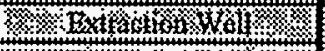 & (x) & 21.1 & $\bar{Y}$ & 5440 & $Y$ & 1560 & $\bar{Y}$ \\
\hline 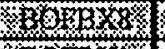 & soly & mold & 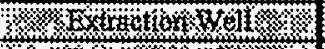 & $<\mathrm{AC}$ & 20.2 & $Y$ & 4930 & $\bar{Y}$ & 1480 & $\bar{Y}$ \\
\hline 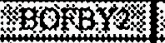 & 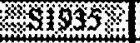 & 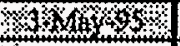 & 6) & ( & 22.7 & $Y$ & 5260 & $\bar{Y}$ & 1760 & $\bar{Y}$ \\
\hline 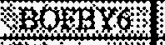 & \$1 $1 \mathrm{~s} \times$ & 33 Ways & 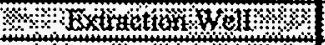 & (x) & 18.8 & $Y$ & 5340 & $\bar{Y}$ & 1420 & $\bar{Y}$ \\
\hline 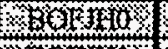 & $\$ 82 d \times$ & $80 x$ ano & Q & $0 \times 0 \times$ & 18.6 & $Y$ & 5040 & $\bar{Y}$ & 1630 & $Y$ \\
\hline 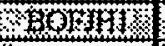 & 28 2 42 & 10 Mayss & 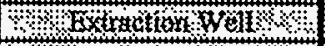 & $4 \times 10 ; 1$ & 21.7 & $Y$ & 4440 & $\mathrm{Y}$ & 1570 & $\bar{Y}$ \\
\hline (B@rasts & s. & 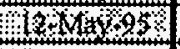 & 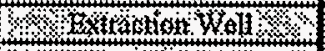 & 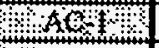 & 15.7 & $\bar{Y}$ & 5250 & $\mathrm{Y}$ & 1530 & $\bar{Y}$ \\
\hline 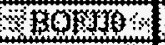 & 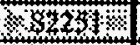 & 1PMAx+s & 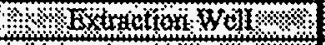 & AOSO & 18.4 & $Y$ & 4710 & $\mathrm{Y}$ & 147 & $Y$ \\
\hline $8102 y_{4}$ & \% 3254 & $17 \mathrm{M}+\mathrm{N}_{\mathrm{s}} \mathrm{s}$ & 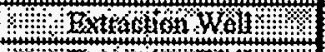 & $20 \times 19$ & 21.3 & $\bar{Y}$ & 5210 & $\mathrm{Y}$ & 1540 & $Y$ \\
\hline 洋 & 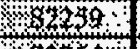 & 19May+95 & 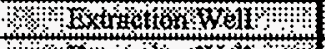 & ACH & 21.8 & $Y$ & 4980 & $\bar{Y}$ & 1530 & $\bar{Y}$ \\
\hline satidus & (c) 1254 & $22 \times 16 \times 9$ & 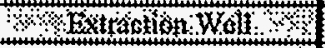 & $40 \times 10$ & & NA & 6410 & $\bar{Y}$ & 1820 & $\bar{Y}$ \\
\hline 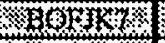 & (3) 2580 & 334 Way 95 & 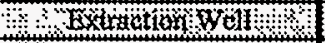 & Acit & 21 & $\mathrm{Y}$ & 4160 & $\bar{Y}$ & 1510 & $Y$ \\
\hline KOF M Y & 34533 & $24 \mathrm{M} \times 95$ & 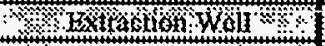 & on & 21.1 & $Y$ & 4140 & $\mathrm{Y}$ & 1420 & $Y$ \\
\hline 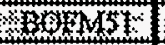 & 4537 & $230 \mathrm{May}+95$ & 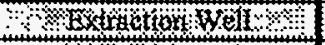 & Atts & 19.9 & $\mathrm{Y}$ & 4130 & $\mathrm{Y}$ & 1360 & $\mathrm{Y}$ \\
\hline Honds & 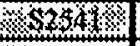 & $24 \times 14 \times 89$ & 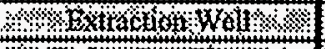 & 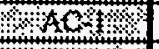 & & & 3600 & $\mathrm{Y}$ & 1310 & $\bar{Y}$ \\
\hline $301 \times 677$ & 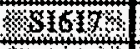 & $40 \times x+45$ & 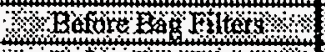 & $4<-2$, & 11.2 & $\mathrm{Y}$ & 4380 & $\bar{Y}$ & 626 & $Y$ \\
\hline angxy & \%sengen & 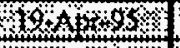 & 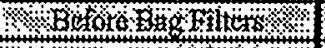 & $1 \mathrm{AE}, 2 \times$ & & & 4790 & $\bar{Y}$ & 1360 & $Y$ \\
\hline FonOM & Sfy & $210 \times+40$ & 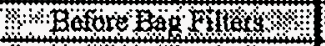 & $\mathrm{XC} \times \mathrm{N}$ & 21.8 & $Y$ & 5130 & $\bar{Y}$ & 1430 & $\mathrm{Y}$ \\
\hline OERWX & 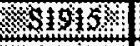 & $2 \mathrm{LAOy} 0 \mathrm{~S}$ & 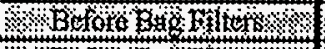 & 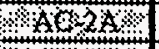 & 23.8 & $\bar{Y}$ & 5380 & $\bar{Y}$ & 1380 & $\mathrm{~N}$ \\
\hline Xom3 & \% & 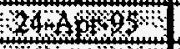 & 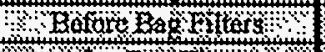 & $8 \mathrm{AQ2} X$ & & & 4840 & $\bar{Y}$ & 1440 & $\mathrm{Y}$ \\
\hline 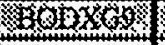 & 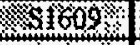 & (I) & 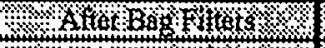 & (nok & 13.1 & $Y$ & 3840 & $Y$ & 1000 & $\bar{Y}$ \\
\hline $30 \% \times 4$ & Sum & 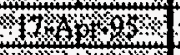 & 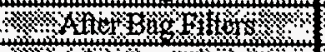 & (n) & 14.7 & $\mathrm{Y}$ & 4290 & $\bar{Y}$ & 280 & $\mathrm{Y}$ \\
\hline $200 \times 0$ & 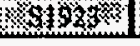 & 26 & ( & $3 \times 0 \times 4$ & & & 4810 & $\bar{Y}$ & 1390 & $\bar{Y}$ \\
\hline
\end{tabular}




\begin{tabular}{|c|c|c|c|c|c|c|c|c|c|c|}
\hline 4 & 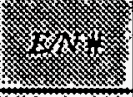 & 1) & $\log (10 \%$ & \% & (p) $(p<t)$ & 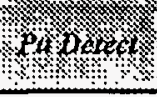 & $(x+6)$ & solow & $\alpha(p)$ & col \\
\hline OER & 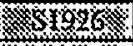 & $1 \times 6 \times 4 \times 2$ & 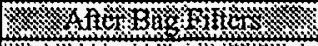 & $6 x+33$ & & & 4950 & $\mathrm{Y}$ & 1460 & $\mathrm{Y}$ \\
\hline $20 \%$ & 5828 & $28 \quad \& \quad>35$ & 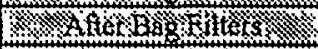 & 103 & & & 4880 & $\bar{Y}$ & 1360 & $\mathrm{Y}$ \\
\hline (3) $2 p \times 9$ & 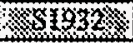 & $8 y_{1}$ & 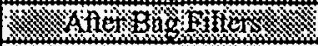 & $8 \times 3$ & & & 5300 & $Y$ & 1470 & $\bar{Y}$ \\
\hline 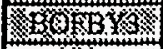 & $4 \quad 51936$ & $y_{1} \times 1+135$ & F & $4 \times 6$ & & & 4970 & $Y$ & 1430 & $Y$ \\
\hline KOKICS & \& 23 & 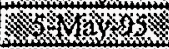 & 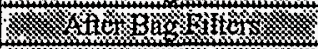 & 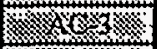 & & & 4550 & $\bar{Y}$ & 1500 & $\mathrm{Y}$ \\
\hline Sorign & ( 19 & 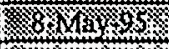 & 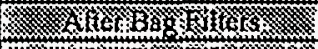 & 16 & & & 4800 & $Y$ & & \\
\hline (KIUIL & 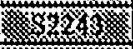 & 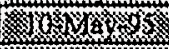 & - Kift & $1 \quad 1$ & & & 5030 & $\bar{Y}$ & & \\
\hline $3 \times 1 / 2$ & 浽 & 1 & 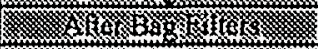 & ( & & & 4720 & $\bar{Y}$ & 1590 & $\mathrm{Y}$ \\
\hline S(K) & 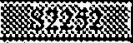 & 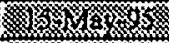 & Xich & . & & & 5060 & $\mathrm{Y}$ & & \\
\hline _ & $\quad y_{1}$ & (1) & 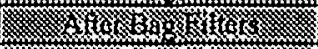 & $\ldots$ & & & 5070 & $\mathrm{Y}$ & & \\
\hline (2) & 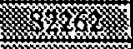 & (y) & ( & $\gamma / y_{y}$ & & & 5100 & $Y$ & 1500 & $Y$ \\
\hline (I) & $\ldots$ & (x) & ( & $\ldots$ & & & 4670 & $\underline{Y}$ & 1720 & $\bar{Y}$ \\
\hline ( & 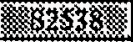 & 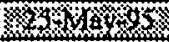 & C & rock & & & 3990 & $Y$ & & \\
\hline \% & cos & $6 c^{2}$ & 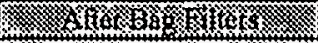 & (m) & & & 3740 & $\mathrm{Y}$ & 1300 & $Y$ \\
\hline $090 \times 19$ & 16 & $(4)$ & 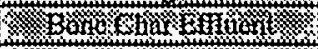 & 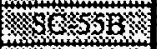 & & & 3790 & $\mathrm{Y}$ & & \\
\hline mo & 45 & 12 26 & 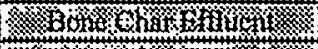 & 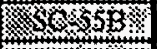 & & & 3660 & $Y$ & 1290 & $\mathrm{Y}$ \\
\hline 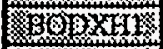 & S X & Un & 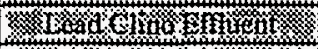 & soros & 2.56 & $\mathrm{~N}$ & 56 & $\bar{Y}$ & 59.1 & $\mathrm{~N}$ \\
\hline 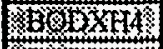 & 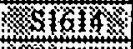 & X1 4 \& & 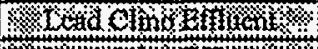 & 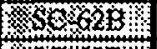 & 6.47 & $\mathrm{~N}$ & 53.2 & $Y$ & 59.9 & $\mathrm{~N}$ \\
\hline $30 \times \times x y$ & 8 818 & 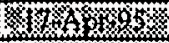 & 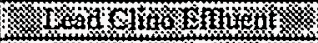 & 664213 & 4.07 & $N$ & 136 & $\mathrm{Y}$ & 59 & $\mathrm{~N}$ \\
\hline 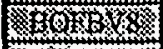 & (1) & 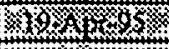 & H & 3662 & & & 289 & $\bar{Y}$ & & \\
\hline KOIBX & 1916 & $3 x$ & 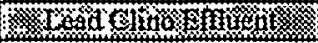 & x 621 & 6.38 & $\mathbf{N}$ & 440 & $Y$ & 60.9 & $\mathbf{N}$ \\
\hline (s) & \%o, & 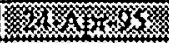 & 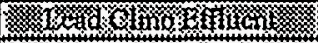 & (1) & & & 298 & $Y$ & 58 & $N$ \\
\hline 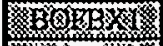 & 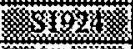 & 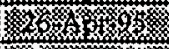 & N 1 C & 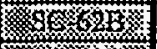 & & & 387 & $\bar{Y}$ & 60.2 & $\mathrm{~N}$ \\
\hline 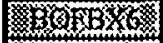 & $\$ 1525$ & 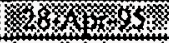 & 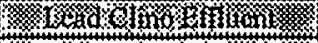 & S s & & & 631 & $\mathrm{Y}$ & 58.2 & $\mathbf{N}$ \\
\hline 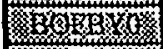 & sing & 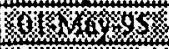 & 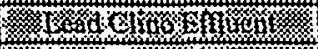 & 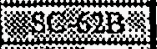 & & & 537 & $\mathrm{Y}$ & 57.1 & $\mathrm{~N}$ \\
\hline Grosing & 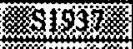 & 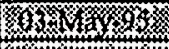 & 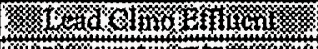 & 筑 & & & 641 & $\mathrm{Y}$ & & \\
\hline 嬨他 & $x+3$ & 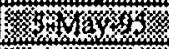 & 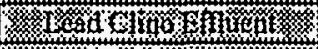 & 40 . & 4.12 & $\mathrm{~N}$ & 828 & $\mathrm{Y}$ & 58.7 & $\mathrm{~N}$ \\
\hline 6) & \% & 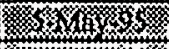 & 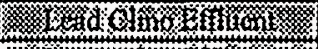 & 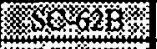 & 5.54 & $\mathrm{~N}$ & 785 & $Y$ & 59.4 & $\mathbf{N}$ \\
\hline mas & 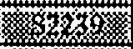 & (x) & S C & 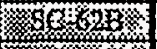 & & & 707 & $\bar{Y}$ & & \\
\hline 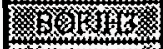 & 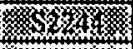 & 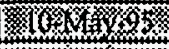 & 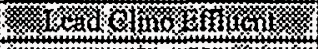 & 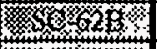 & & & 773 & $Y$ & & \\
\hline 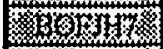 & 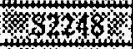 & W. 40 a 45 & 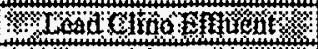 & ron & & & 1100 & $\bar{Y}$ & & \\
\hline 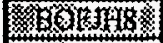 & S2 & $81+10 \times 4+95$ & 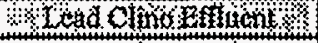 & 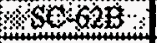 & & & 964 & $Y$ & & \\
\hline 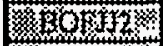 & 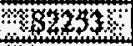 & 15M M $\quad$ os: & 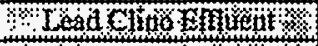 & $256=629$ & & & 940 & $\mathrm{Y}$ & & \\
\hline 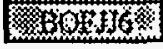 & Sorts? & $807 \mathrm{M}+80 \mathrm{~s}$ & 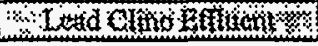 & $62 \times, 62 \mathrm{ES}$ & & & 934 & $Y$ & & \\
\hline
\end{tabular}


DOE/RL-95-59

Rev. 0

Table C-22. Pilot-Scale System Run 2. (4 Sheets)

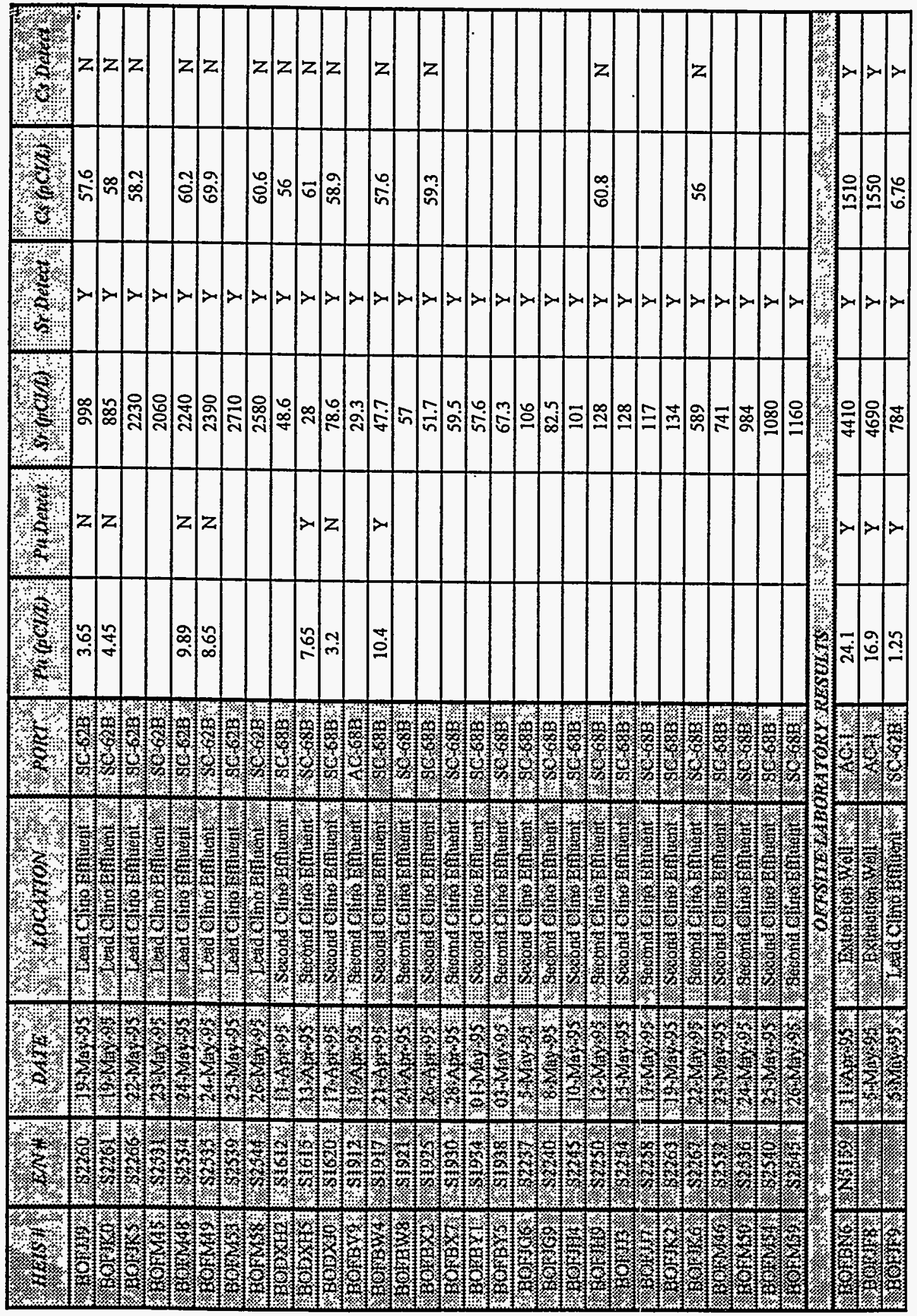


DOE/RL-95-59

Rev. 0

Table C-22. Pilot-Scale System Run 2. (4 Sheets)

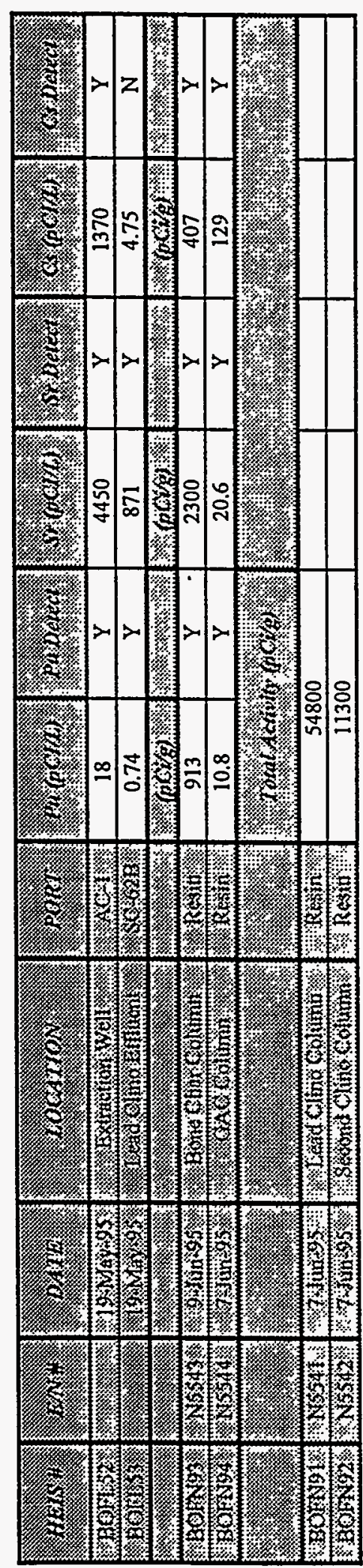


DOE/RL95-59

Rev. 0

Table C-23. BY-Database (Picocuries). (4 Sheets)

\begin{tabular}{|c|c|c|c|c|c|c|c|}
\hline tat & 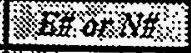 & Solare & 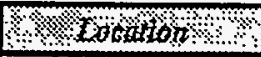 & $\xi$ & $\cos (\theta,(1))$ & 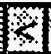 & 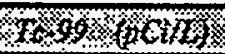 \\
\hline a & 851930 & 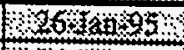 & 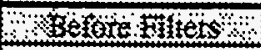 & & 95.5 & & 4250 \\
\hline Wag & F & 26 i d & 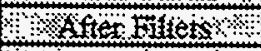 & & 9.2 .1 & & 6600 \\
\hline SaEARESOS & 慗 & 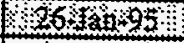 & 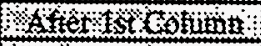 & $<$ & 40.7 & & 118 \\
\hline $1-12-14$ & $\mathrm{r}_{3}$ & 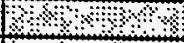 & 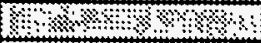 & & & & \\
\hline pogRTOU & 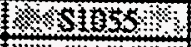 & 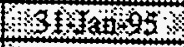 & 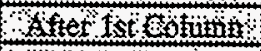 & $<$ & 43.4 & $\leq$ & 77.2 \\
\hline 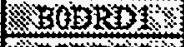 & 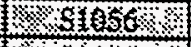 & 831 fot 95 & 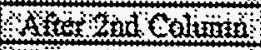 & $<$ & 33.2 & & 1220 \\
\hline $300 \mathrm{RP} 2$ & S & 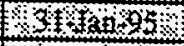 & $(\$, \mathrm{ffes}: G \mathrm{AC}$ & $<$ & 38.2 & $<$ & 84.5 \\
\hline $3 \times$ & +3 & 18 & $80848 \%$ & & & & \\
\hline 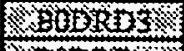 & O & of & WB Befated utfets & & 92.2 & & 5470 \\
\hline Q BOBRD $4=$ & 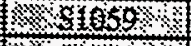 & G1, & WAfiat Fiftets & & 100 & & 5090 \\
\hline sopRes & 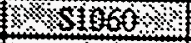 & Nal- Festos & 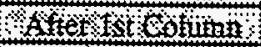 & $<$ & 40.7 & $<$ & 60.9 \\
\hline 3 & $18+8$ & 154 & 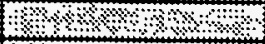 & & & & \\
\hline 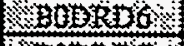 & 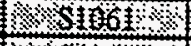 & 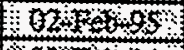 & Q A Aftet & $\leq$ & 57.6 & & 4710 \\
\hline PBOERPT & 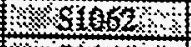 & 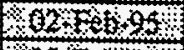 & 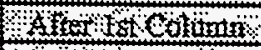 & $<$ & 40.3 & $<$ & 72.5 \\
\hline QEOEROR & 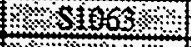 & $402+26$ & 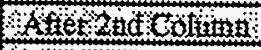 & $<$ & 38.9 & $<$ & 65.7 \\
\hline s_o & $1+2 \times 1$ & $1-43$ & $\mathrm{~S} / \mathrm{P}$ & & & & \\
\hline 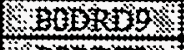 & S & 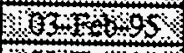 & 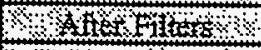 & $\leq$ & 56.3 & & 4720 \\
\hline 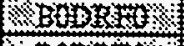 & 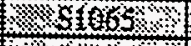 & 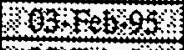 & 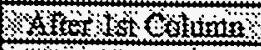 & $\leq$ & 36.6 & $<$ & 67.9 \\
\hline 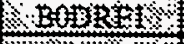 & $1+251066$ & 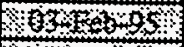 & 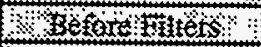 & & 133 & & 5110 \\
\hline 14 & +4 & 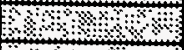 & 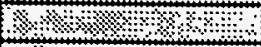 & & & & \\
\hline SEODRETE & S SMeth & 064 & 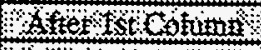 & $<$ & 39.2 & $\leq$ & 78.4 \\
\hline SBOpons & 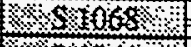 & 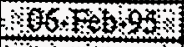 & 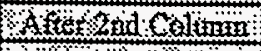 & $<$ & 40.3 & $<$ & 77.8 \\
\hline fegenta 4 & 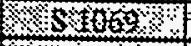 & 106test95 & Q $/$ Afre $\mathrm{COKC}$ & $<1$ & 40.7 & $<$ & 80.4 \\
\hline 34: & 8 & 361 & $808 \times 4$ & & & & \\
\hline fophes & 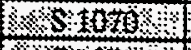 & otte & skeffared Kintens & & 158 & & 6180 \\
\hline Boptot 6 & (5:07) & $097606 \times 95$ & of affer Fiftefs & & 1.24 & & 5910 \\
\hline SBODRTO I & 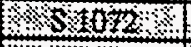 & 197, & 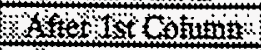 & $<$ & 42.1 & $<$ & 79.4 \\
\hline 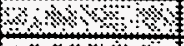 & $18 \times 18$ & $4 \times 3$ & $\mathrm{~B} \times \mathrm{Y} / \mathrm{Q}(\mathrm{Y}$ & & & & \\
\hline 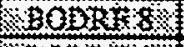 & 58 & 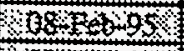 & 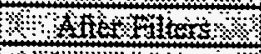 & & 111 & & 6770 \\
\hline SBODREY & 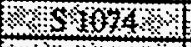 & $198, F E 6 ; 95$ & 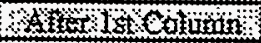 & $<$ & 37.8 & $<$ & 82.6 \\
\hline 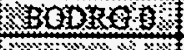 & 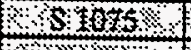 & 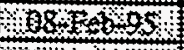 & 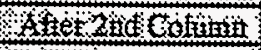 & $\leq$ & 38.9 & $<$ & 82.3 \\
\hline $30 \times<\times$ & 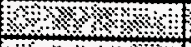 & 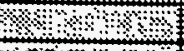 & $\mathrm{C}^{2} \times 4$ & & & & \\
\hline Boprea: & S. & $697 \mathrm{mos}$ & 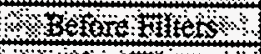 & & 136 & & 8860 \\
\hline KODRG 2 & S-5s & $09606+95$ & 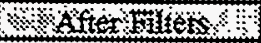 & & 157 & & 7030 \\
\hline 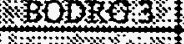 & 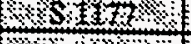 & 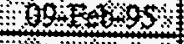 & 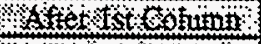 & $\leq$ & 37.8 & $<$ & 134 \\
\hline 30 & 8 & $8 \times$ & 408,14 & & & & \\
\hline soonastis & $6.5 \times 1+12$ & 10 rew & 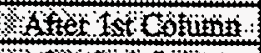 & $\leq$ & 39.2 & $<$ & 86.8 \\
\hline BEOPRG 3 & 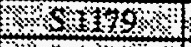 & 10456695 & 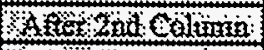 & $<$ & 34.6 & $<$ & 91.2 \\
\hline 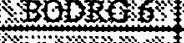 & 200 - & stanefos & 1,3 fffer:GAO & $<$ & 39.3 & $<$ & 86.4 \\
\hline $8+18 \%$ & 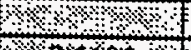 & $4, \quad 48$ & 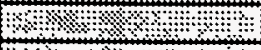 & & & & \\
\hline Bom & 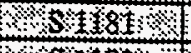 & 15 featos & 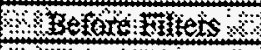 & & 142 & & 10100 \\
\hline BOAROA & 4 STIZ & STFet 93 & Q Afteriffifets & & 146 & & 9230 \\
\hline Boptes: & S4S: & $15+209$ & Xftets tsto Cofumen & & & & 317 \\
\hline 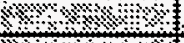 & $8 \times 4 \times$ & $3 \times 18 \%$ & 4 & & & & \\
\hline 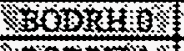 & $45 \% 184$ & 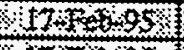 & 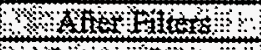 & & 172 & & 9770 \\
\hline 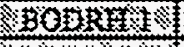 & 4 S & 17 Fenges & \& fter lshColusini & $\leq$ & 40.7 & & 211 \\
\hline 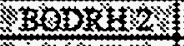 & W & $17+29$ & 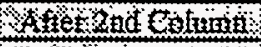 & $<$ & 41.7 & & 352 \\
\hline 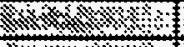 & $4 \times<+\%$ & 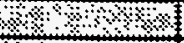 & 3 & & & & \\
\hline 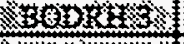 & W 321887 & SLEESTS & 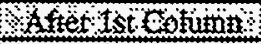 & $\leq$ & 39.6 & $<$ & 93.6 \\
\hline Sondz) & 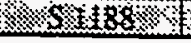 & 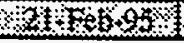 & 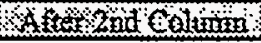 & $<$ & 36.6 & $<1$ & 91.2 \\
\hline
\end{tabular}


DOE/RL-95-59

Rev. 0

Table C-23. BY-Database (Picocuries). (4 Sheets)

\begin{tabular}{|c|c|c|c|c|c|c|c|}
\hline XEIS & 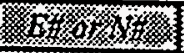 & ( & 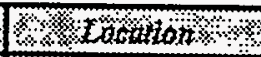 & 1 & 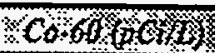 & 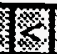 & 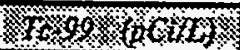 \\
\hline 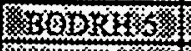 & 83 & 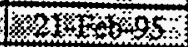 & H 4 After: $G A C$ & $<$ & 38.8 & $<$ & 89.4 \\
\hline 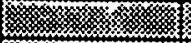 & 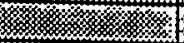 & 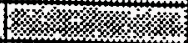 & $4 \times 4 \times 4 \%$ & & & & \\
\hline 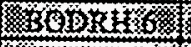 & 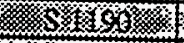 & 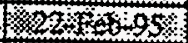 & 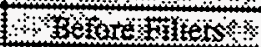 & & 147 & & 9280 \\
\hline 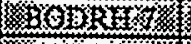 & S & $272 \times 66965$ & 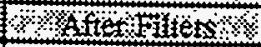 & & 183 & & 8310 \\
\hline 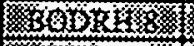 & - 3.192 & 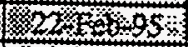 & of ffetetsitesoffition & & 37.7 & $<$ & 92.4 \\
\hline 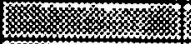 & rs & \% & l & & & & \\
\hline 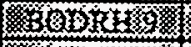 & 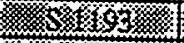 & 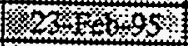 & 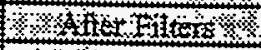 & & 173 & & 9860 \\
\hline$\$ 80 \mathrm{DRJ}$ & 济 & $23 \% 56=96$ & 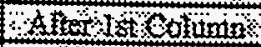 & $<$ & 42.7 & $<$ & 102 \\
\hline 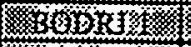 & 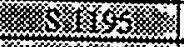 & 23 & 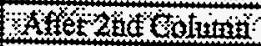 & $<$ & 39.6 & & 113 \\
\hline 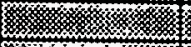 & 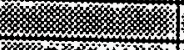 & 18, & (4> & & & & \\
\hline sBand & 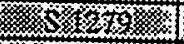 & 24 EUEg 95 & 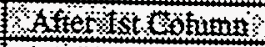 & $<1<1$ & 35.4 & & 252 \\
\hline 30 Daf & 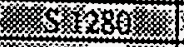 & 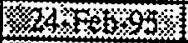 & 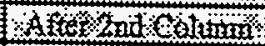 & $<$ & 39.7 & & 228 \\
\hline 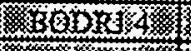 & S S S & 24 RES 695 & $\mathrm{O} / \mathrm{ffES}$ GAC & $<$ & 38.9 & & 105 \\
\hline 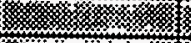 & 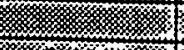 & 18 & 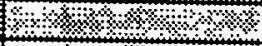 & & & & \\
\hline 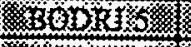 & s & 27 mets $95 \times$ & Sobeforeminftetis & & 187 & & 10200 \\
\hline 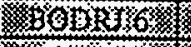 & S6 & $27565995 \%$ & W ziffer fiffes & & 126 & & 9980 \\
\hline 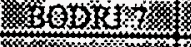 & 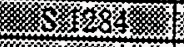 & 272 \& $35 \%$ & 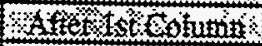 & $<1$ & 37.4 & & 196 \\
\hline (2, & 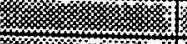 & 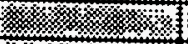 & 10 & & & & \\
\hline mokn & - & Oanatasos & O A A & & 170 & & 9520 \\
\hline - & 6 & $00 \mathrm{Ma} \times 95$ & 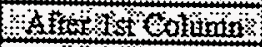 & $<1$ & 41.8 & $<$ & 89.1 \\
\hline 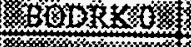 & S & 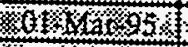 & 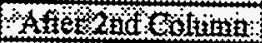 & $<$ & 41 & & 160 \\
\hline-1 & 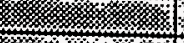 & 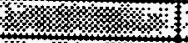 & 41\%? & & & & \\
\hline mos & S S & $02 \times 14095$ & 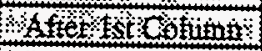 & $\leq 1$ & 35.8 & $<1$ & 84.4 \\
\hline 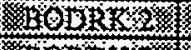 & S. & 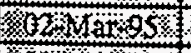 & 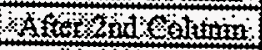 & $<$ & 39.9 & $<$ & 80.2 \\
\hline $8005 x+2$ & S & $622 x 62$ & 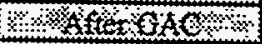 & $<1$ & 41.7 & $<$ & 78.5 \\
\hline (2) & 1) & (3) & $8 \%$ & & & & \\
\hline 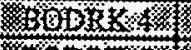 & 绽 & $03 \times 14065$ & Befare Winters & & 166 & & 9930 \\
\hline 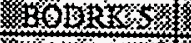 & 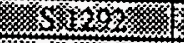 & 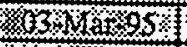 & ofiffertrifens & & 186 & & 9640 \\
\hline sop & 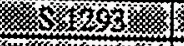 & 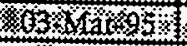 & 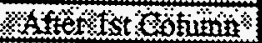 & $<1$ & 43.1 & & 177 \\
\hline 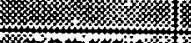 & 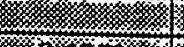 & 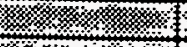 & 4 & & & & \\
\hline $130 \mathrm{dxJ} 2$ & $-853=38$ & G6sk & 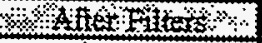 & & 169 & & 9310 \\
\hline 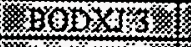 & S61559\% & (66, & 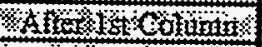 & $\leq$ & 33.4 & $<$ & 82.6 \\
\hline $390 \times 944$ & 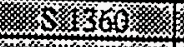 & Cos & 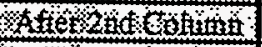 & $<1$ & 35.8 & $<$ & 87.2 \\
\hline$\sqrt[3]{2}$ & 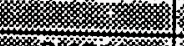 & 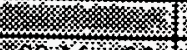 & 4 & & & & \\
\hline monoryos & S & 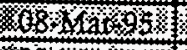 & 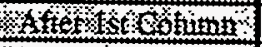 & $\leq$ & 38.5 & $<$ & 79.4 \\
\hline 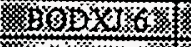 & S S 136 & $408 \%$ Márgs & 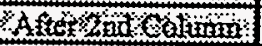 & $<$ & 40 & $<$ & 85 \\
\hline $3010 \times 17$ & 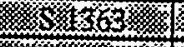 & 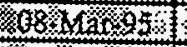 & 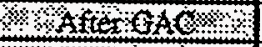 & $\leq$ & 37 & $<$ & 77.4999 \\
\hline (2) & - & 1. & 48 & & & & \\
\hline Hasoxs & 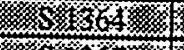 & monan & 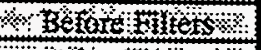 & & 185 & & 10900 \\
\hline $300 \mathrm{x}$ - & 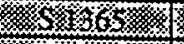 & ton & 2 Afted Filfets $/$ & & 176 & & 10700 \\
\hline 6roxorom & 3 & 10\% & 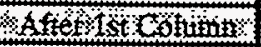 & $\leq 1$ & 41.4 & $\leq$ & 81 \\
\hline 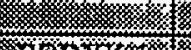 & 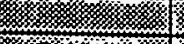 & 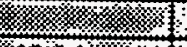 & $3 / 8 \%$ & & & & \\
\hline 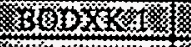 & - 3.1867, & $13 \times 10 \times 45$ & SAfteryitiess & & 167 & & 9980 \\
\hline 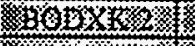 & - & THMat $\$ 95$ & 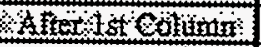 & $\leq$ & 42.4 & & 269 \\
\hline 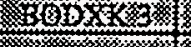 & -81369 & 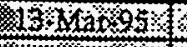 & 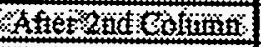 & $\leq 1$ & 35 & & 442 \\
\hline F. & $x=3$ & X) & 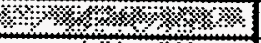 & & & & \\
\hline $540 \times x \times 4$ & SS4 S & 15/4has & $x_{f t e r}$ tst Costutiti & $\leq$ & 39.6 & & 149 \\
\hline 301 X X & 331371 & Hakaras & 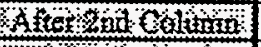 & $<$ & 38.5 & & 211 \\
\hline s. & s: & 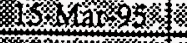 & 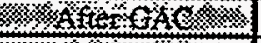 & $\leq$ & 39.2 & & 183 \\
\hline 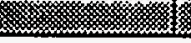 & ris & (2) & (*):-1, & & & & \\
\hline
\end{tabular}


DOE/RL-95-59

Rev. 0

Table C-23. BY-Database (Picocuries). (4 Sheets)

\begin{tabular}{|c|c|c|c|c|c|c|c|}
\hline (7) & 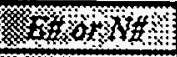 & $8 \%$ Date & $8>1$ a cation: & K & oobarow & 勧 & 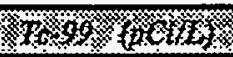 \\
\hline EOE & 3 -376: & 31716 aros & 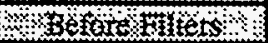 & & 147 & & 10600 \\
\hline BOEX & 4 维 & 17MMartas & 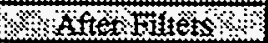 & & 150 & & 10700 \\
\hline Bas & 501378 & $8178 x a 65$ & 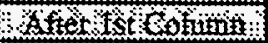 & & 36.6 & & 112 \\
\hline - & 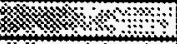 & 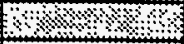 & $80 \%(0)$ & & & & \\
\hline 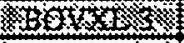 & $8 \times 699$ & 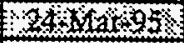 & 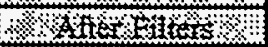 & & 187 & & 10900 \\
\hline Box & $9 \times 670$ & $244 \mathrm{Ma} \times 95$ & 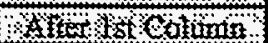 & $<$ & 40 & $<$ & 67.2 \\
\hline 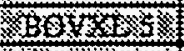 & S 61 & 24160425 & 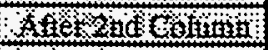 & $<$ & 40.6 & $<$ & 67.7 \\
\hline & 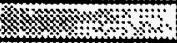 & 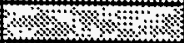 & ४७ $648 \% ४$ & & & & \\
\hline 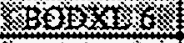 & S徒672 & 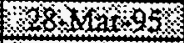 & 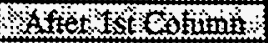 & $<$ & 37 & & 131 \\
\hline KBQEXX: & $8 / 673$ & 38 Hart95 & 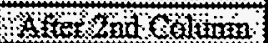 & $<$ & 37.8 & & 116 \\
\hline Bedex & 6 & $88 \times 19+95$ & 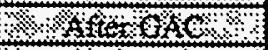 & $<$ & 37 & & 102 \\
\hline 1) & $\% \quad 4 \times 3$ & $3830 \%$ & 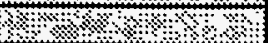 & & & & \\
\hline EOEXI & SOE675 & $830 \times 14005$ & 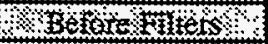 & & 169 & & 11200 \\
\hline 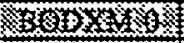 & 5676 & $300 \mathrm{Ma} \$ 25$ & 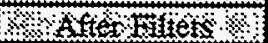 & & 163 & & 10100 \\
\hline ofogy & Silotit & 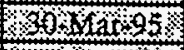 & 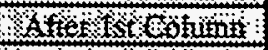 & $<$ & 36.6 & & 144 \\
\hline 1 & 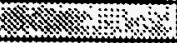 & $184 \%$ & ४ ४ ४४ $४ \checkmark 6 \%$ & & & & \\
\hline 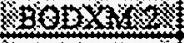 & 51678 & $65 x p=95$ & 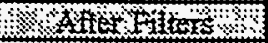 & & 157 & & 9920 \\
\hline 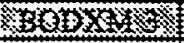 & 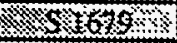 & 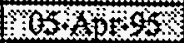 & W Y F & $<$ & 36.6 & & 206 \\
\hline 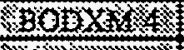 & 15689 & 6os & 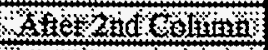 & $<$ & 37.8 & & 200 \\
\hline$\$$ & 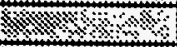 & $4 \times 8 \%$ & (४⿻ & & & & \\
\hline \&3on 23 & 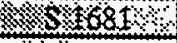 & $807 / 20453$ & 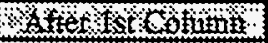 & $<$ & 41 & $<$ & 87.7 \\
\hline $300 \times 16$ & 351682 & OAXADESS & 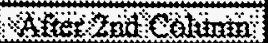 & $\overline{<}$ & 39.3 & $<$ & 89.5 \\
\hline 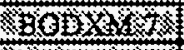 & 6,683 & 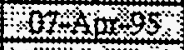 & S & $<$ & 42.4 & $<$ & 90.3 \\
\hline _ & $\quad 6$ & $8 \times 8 \%$ & ४⿻ & & & & \\
\hline 等 & 6084 & 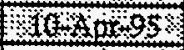 & F J & & 145 & & 10500 \\
\hline 30D $3 \times 5$ & $6 \times 685$ & 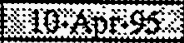 & 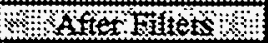 & & 165 & & 9320 \\
\hline 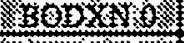 & 54686 & $13 f+x \neq+95$ & 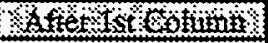 & $<$ & 39.2 & $<$ & 146 \\
\hline - & $1 \%$ & 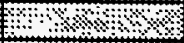 & 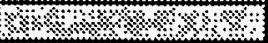 & & & & \\
\hline mop X X & 6087 & 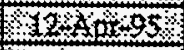 & 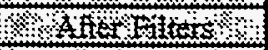 & & 170 & & 10700 \\
\hline (30) & . & $12 / \mathrm{ApH}$ GS & 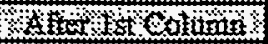 & $<$ & 41.4 & $<$ & 160 \\
\hline $309 \times 1$ & 5.689 & $132 \times a<-95$ & 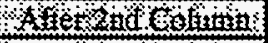 & $<$ & 42.7 & $<$ & 158 \\
\hline$\quad$ _ & $\times \quad 3 \times$ & $1 \%$ & 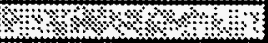 & & & & \\
\hline W6DX) & 4 t58 & $144 \times 105$ & 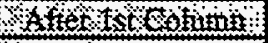 & $<$ & 38.9 & & 123 \\
\hline gabX & S 859 & $44: A p, \%\}$ & K f & $<$ & 44.1 & $<$ & 96.9 \\
\hline 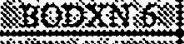 & $3 \times 6890$ & $14+1 \times 95$ & 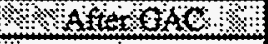 & $<$ & 38.2 & $<$ & 106 \\
\hline 1. & 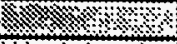 & $5+34$ & 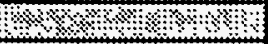 & & & & \\
\hline Bogxy & 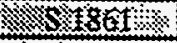 & $131+x p-95$ & o & $<$ & 34.2 & & 143 \\
\hline 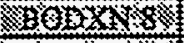 & $5 \longdiv { 8 6 2 }$ & 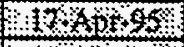 & 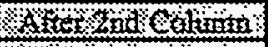 & $<$ & 39.3 & & 817 \\
\hline $302 \times 1<2$ & $5=863$ & $117+2 \times 9$ & 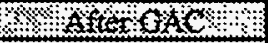 & $<$ & 41.1 & & 392 \\
\hline$\quad \ldots$ & 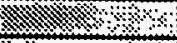 & 640 & $8 \%$ & & & & \\
\hline SopXepe & $5 \times 874$ & $81940 \times 5$ & 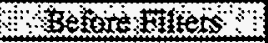 & & 169 & & 10800 \\
\hline axpl & $5: 875$ & 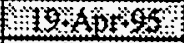 & 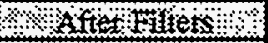 & & 172 & & 9630 \\
\hline 39oxp2 & 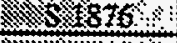 & 1904095 & 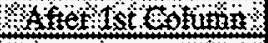 & $<$ & 41.1 & & 271 \\
\hline$\quad$ - & $\$$ & $13 \% 3 \quad 3$ & 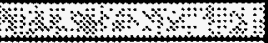 & & & & \\
\hline $8013 \times 92$ & S.58778: & $821+2045$ & 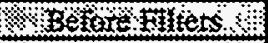 & & 161 & & 10800 \\
\hline 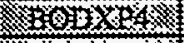 & $\begin{array}{r}1.878 \\
\end{array}$ & $2 \times 1 \times$ per 95 & 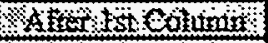 & $<$ & 43.7 & & 162 \\
\hline 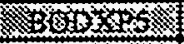 & \% & $221=A g=95$ & 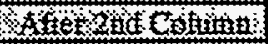 & $<$ & 40 & $<$ & 83.8 \\
\hline$\quad$ W & 18 & $14 \$ \$ \$$ & ४४४ & & & & \\
\hline ristof & $\quad 880$ & $2424 x=95$ & 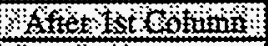 & $<$ & 36.6 & & 175 \\
\hline 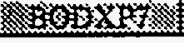 & W & 124,80295 & 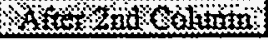 & $<$ & 40 & $<$ & 162 \\
\hline
\end{tabular}


DOE/RL-95-59

Rev. 0

Table C-23. BY-Database (pCi). (4 Sheets)

\begin{tabular}{|c|c|c|c|c|c|c|c|}
\hline molok & 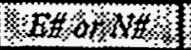 & QDates & Hotatcition & 4 & $60601306)$ & 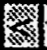 & 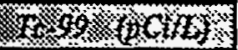 \\
\hline (3) & x & $x<A \& 0 \times 95$ & 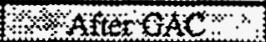 & $<$ & 45.3 & $<$ & 170 \\
\hline 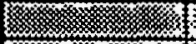 & K6/ & 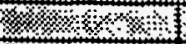 & 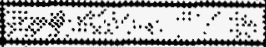 & & & & \\
\hline s.3oj & 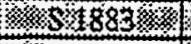 & 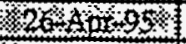 & 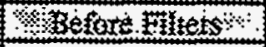 & & 157 & & 8910 \\
\hline 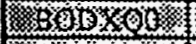 & 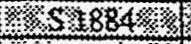 & 29640,195 & \& o After Fifies & & 166 & & 9030 \\
\hline 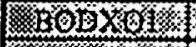 & (1) & 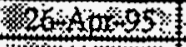 & Sxfer Tst Cofutnet & $<$ & 36.6 & & 188 \\
\hline 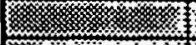 & 6/x/ & 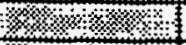 & 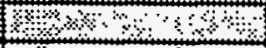 & & & & \\
\hline 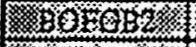 & $8 \times 52000=20$ & 28,40495 & (5) & & 178 & & 10000 \\
\hline 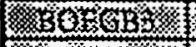 & $x<0001 \times$ & 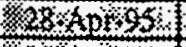 & 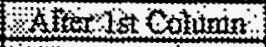 & $<$ & 38.5 & $\leq$ & 166 \\
\hline 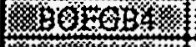 & 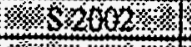 & 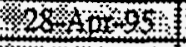 & 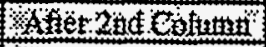 & $\leq$ & 38.1 & $<$ & 138 \\
\hline 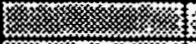 & 6x & k & (6) & & & & \\
\hline 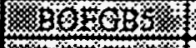 & 等 & 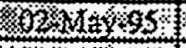 & 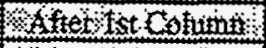 & $<1$ & 39.3 & & 190 \\
\hline 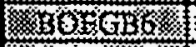 & 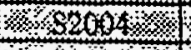 & $592314 a+425$ & 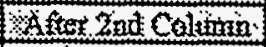 & $<$ & 42.7 & $<1$ & 69.9 \\
\hline knol & 4252005 & $62, M, 405$ & F/Aftex: $\mathrm{GXC}$ & $<$ & 36.2 & $\leq$ & 69.9 \\
\hline 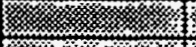 & $x</ x</ \%$ & 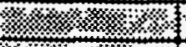 & (6) & & & & \\
\hline 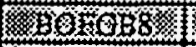 & 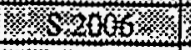 & (c) & 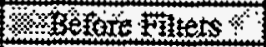 & & 202 & & 8130 \\
\hline -36 & $<452007 \%$ & 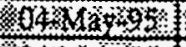 & 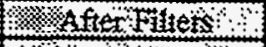 & & 181 & & 11300 \\
\hline xologos & $1 \times 28003$ & 筑 & 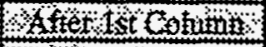 & $\leq 1$ & 42.8 & & 271 \\
\hline 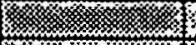 & bx/ & 药标 & 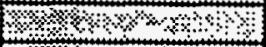 & & & & \\
\hline 组 & $4 x-3009$ & 509,1 H 35 & 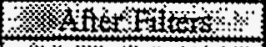 & & 163 & & 10800 \\
\hline 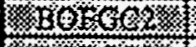 & 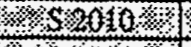 & 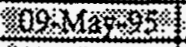 & 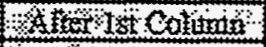 & $\leq$ & 40.4 & & 432 \\
\hline Sxing & -3201 & 309 M $4 \times 95$ & o & $\leq$ & 36.6 & $<$ & 79 \\
\hline 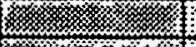 & 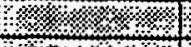 & 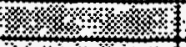 & 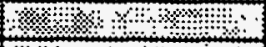 & & & & \\
\hline 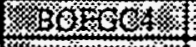 & $x \times 3=201+2$ & 3, & 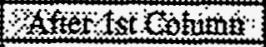 & $\leq$ & 41.3 & & 346 \\
\hline x & 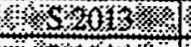 & 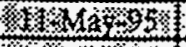 & 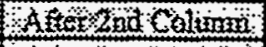 & $<$ & 37 & $<$ & 80.6 \\
\hline 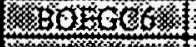 & (3) 204 & (x) & \&aftegecis & $<$ & 38.5 & $<$ & 84.3 \\
\hline 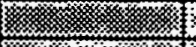 & X & 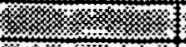 & 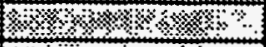 & & & & \\
\hline 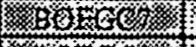 & $y-420 j x$ & 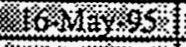 & 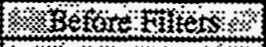 & & 197 & & 9830 \\
\hline 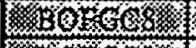 & - & 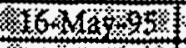 & 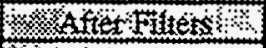 & & 150 & & 9760 \\
\hline molog & wosol & 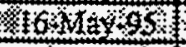 & X & $<$ & 32 & & 700 \\
\hline 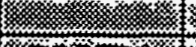 & 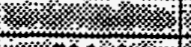 & 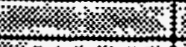 & $\gamma_{1} \times x_{2}$ & & & & \\
\hline 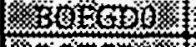 & 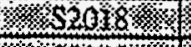 & (8) & 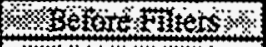 & & 177 & & 6960 \\
\hline 细 & 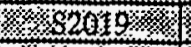 & 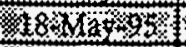 & (6 kftet Fufets & & 161 & & 8430 \\
\hline 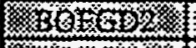 & $8 \times 20206$ & 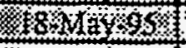 & Stetefistotofutin & $\leq$ & 43.7 & & 342 \\
\hline 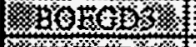 & - $3202 \mathrm{U}$ & 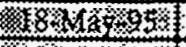 & 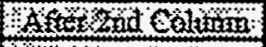 & $<$ & 35.4 & $<$ & 84.8 \\
\hline 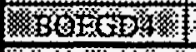 & 352022 & 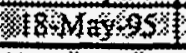 & F Affè $\mathrm{GAC}$ \% & $<1$ & 36.6 & $<$ & 106 \\
\hline$s ;$ & \% & X & 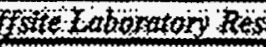 & 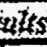 & 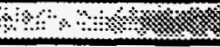 & & 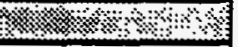 \\
\hline 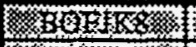 & \% & 30) & 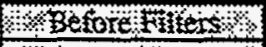 & & 168.0 & & 10500 \\
\hline X & $4.4 \%$ & 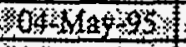 & feferifot Cotuinin: & $<$ & 10.5 & & 251.0 \\
\hline 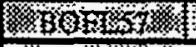 & 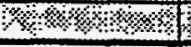 & $98+M 2 y 95$ & 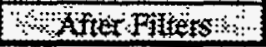 & & 147.0 & & 8590 \\
\hline 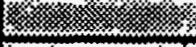 & (n) Spanto & Réstn Alitaltise & sis & & $\mathrm{PCHg}$ & & $2 C \mathrm{C}$ \\
\hline 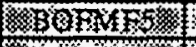 & PRegin & $200 \mathrm{May} 95$ & 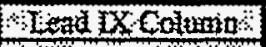 & & 8600 & & 47700 \\
\hline 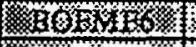 & \%Resin & $20 \times M a \times 99$ & 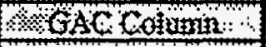 & & 2.12 & & 19.4 \\
\hline 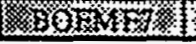 & Hasin \% & $20,1120+25$ & ( & & 1.2 & & 1600 \\
\hline
\end{tabular}




\begin{tabular}{|c|c|c|c|c|c|c|}
\hline \multicolumn{3}{|c|}{ and Clinoptilolite } & \multicolumn{4}{|c|}{ Clinoptilolite Spent Resin } \\
\hline HEIS \#: & BOFHG6 & BOFHG7 & BOF786 & BOF821 & BOFN93 & BOFN94 \\
\hline DATE : & 34816 & 34816 & 21-Mar-95 & 23-Mar-95 & 9-Jun-95 & 7-Jun-95 \\
\hline \multirow[t]{2}{*}{ LOCATION: } & As Packaged & Duplicate & Lead Clino Column & Mixed Bed Column & Bone Char Column & GAC Column \\
\hline & \multicolumn{6}{|c|}{ Units: microgram contaminant per gram resin $(u g / g)$} \\
\hline$A l$ & 18600 & 19400 & 165000 & 5420 & 733 & 501 \\
\hline As & 3.4 & 7.3 & 3.4 & 2.7 & 2.8 & 4.2 \\
\hline$B \boldsymbol{B}$ & 180 & 179 & 317 & 106 & 133 & 21.7 \\
\hline Be & 1.1 & 1.3 & 1.1 & 0.64 & 0.9 & 2 \\
\hline $\mathrm{Ca}$ & 11100 & 12500 & 19200 & 107000 & 237000 & 1050 \\
\hline $\mathrm{Cl}^{\prime}$ & & & 2.66 & 5.25 & -- & -- \\
\hline $\mathrm{Cu}$ & 1.6 & 4.8 & 2.8 & 11.6 & 27.8 & 15.2 \\
\hline HFe & 3420 & 4070 & 3840 & 2120 & 3540 & 3080 \\
\hline M $F$ & & & $\cdots$ & 2.11 & 2.74 & 2.54 \\
\hline $\mathrm{Hg}$ & -- & $\cdots$ & 0.08 & -- & 1.1 & -- \\
\hline 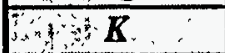 & 24000 & 22500 & 20500 & 12600 & $\cdots$ & - \\
\hline Mg & 2340 & 2570 & 2990 & 3020 & 3220 & 169 \\
\hline$M M n$ & 274 & 340 & 211 & 132 & 57.8 & 23.2 \\
\hline Na & 20800 & 20600 & 2930 & 2540 & 1730 & 93.4 \\
\hline$\therefore:$ NO3 & & & 0.26 & 2.07 & 2.98 & 7.13 \\
\hline Pb & 22.1 & 16.1 & 19.8 & 14.2 & 3.7 & 1.3 \\
\hline$\because \quad T l$ & 0.34 & 0.36 & 0.44 & 0.21 & -- & -- \\
\hline Vanadium & - & $-\cdots$ & 5.1 & 15.2 & 39.4 & 77.2 \\
\hline$Z n^{\prime}$ & 17.2 & 21.8 & 29.2 & 44.2 & 1140 & 16.6 \\
\hline
\end{tabular}


DOE/RL-95-59

Rev. 0

Table C-25. Final Resin Sample Anions/Cations 216-BY Cribs.

\begin{tabular}{|c|c|c|c|}
\hline 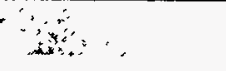 & \multicolumn{3}{|c|}{ Dowex 21K Spent Resint } \\
\hline HEIS \# : & BOFMF5 & BOFMF6 & BOFMF7 \\
\hline DATE : & 24-May-95 & 24-May-95 & 24-May-95 \\
\hline LOCATION: & Lead Column & GAC Column & Polishing Column \\
\hline \multicolumn{4}{|c|}{ Units: microgram contaminant per gram resin (ug/g) } \\
\hline$A l$ & 369 & 516 & 24.2 \\
\hline$A s$ & 1.6 & 5.8 & 1.2 \\
\hline$B a$ & 31.6 & 23 & 1.2 \\
\hline $\mathrm{Ca}$ & 481 & 1300 & 564 \\
\hline$\overline{C l}$ & 17.4 & 16.5 & 14.3 \\
\hline$C n$ & 9780 & 362 & 735 \\
\hline $\mathrm{Cr}$ & 1.9 & 3 & 3.6 \\
\hline$C u$ & - & 13.2 & 2.1 \\
\hline$F e$ & 6840 & 3270 & 659 \\
\hline $\mathrm{Hg}$ & 0.5 & 0.16 & - \\
\hline$M n$ & 2.3 & 18.1 & 0.84 \\
\hline$N a$ & 184 & 81.6 & 69.8 \\
\hline NO3 & 43.6 & 77 & 36.4 \\
\hline $\mathrm{Pb}$ & 1.3 & 3.2 & 0.39 \\
\hline Se & 2.2 & 0.72 & 3.8 \\
\hline$Z n$ & 1270 & 59.9 & 22.3 \\
\hline
\end{tabular}


DOE/RL-95-59

Rev. 0 
DOE/RL-95-59

Rev. 0

\section{APPENDIX D}

\section{WATER-LEVEL MEASUREMENTS}


DOE/RL-95-59

Rev. 0 
DOE/RL-95-59

Rev. 0

Figure D-1. 216-B-5 Reverse Well Site Water-Level Monitoring for January.

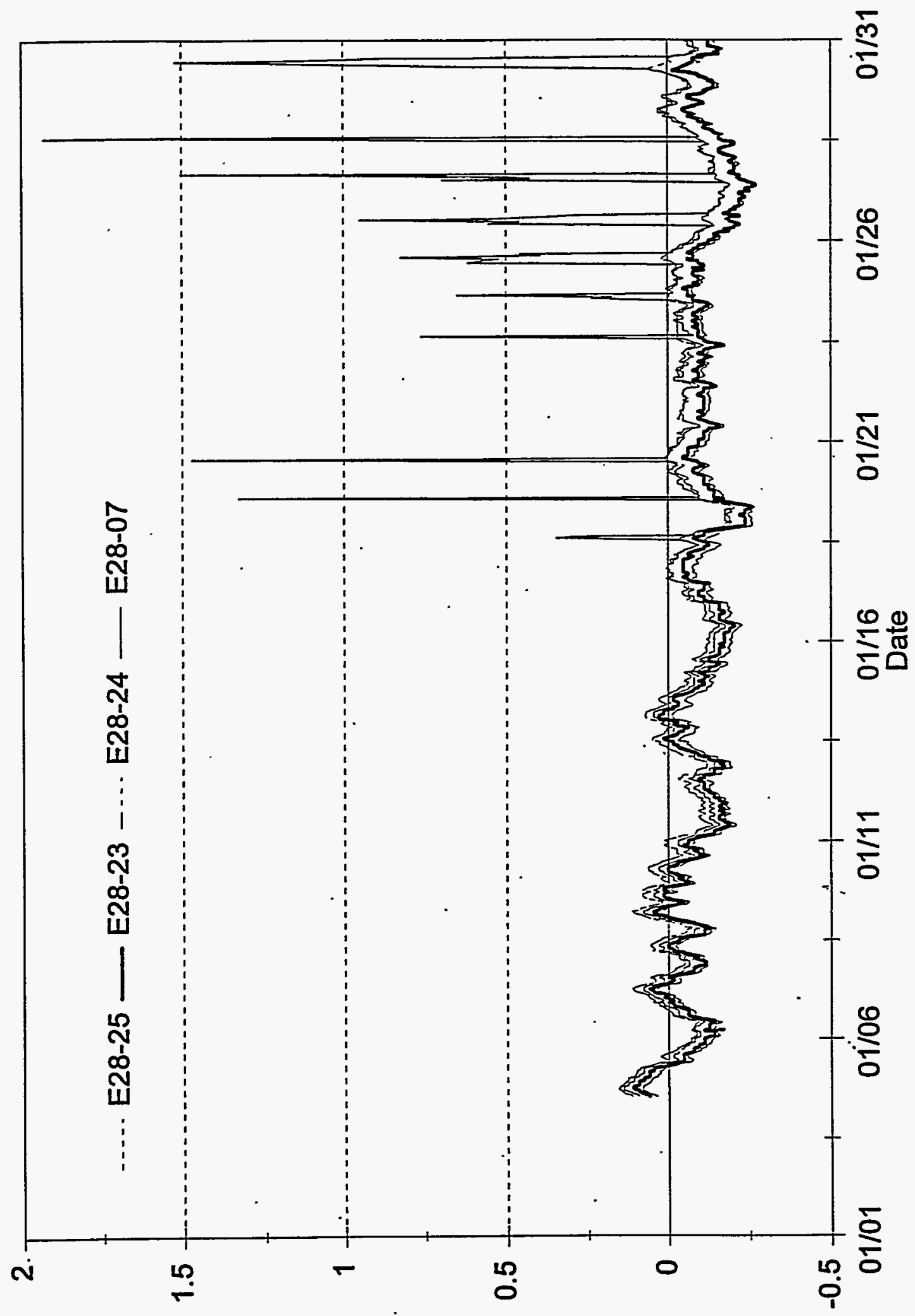

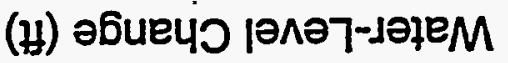


Figure D-2. 216-B-5 Reverse Well Site Water-Level Monitoring for Feburary.

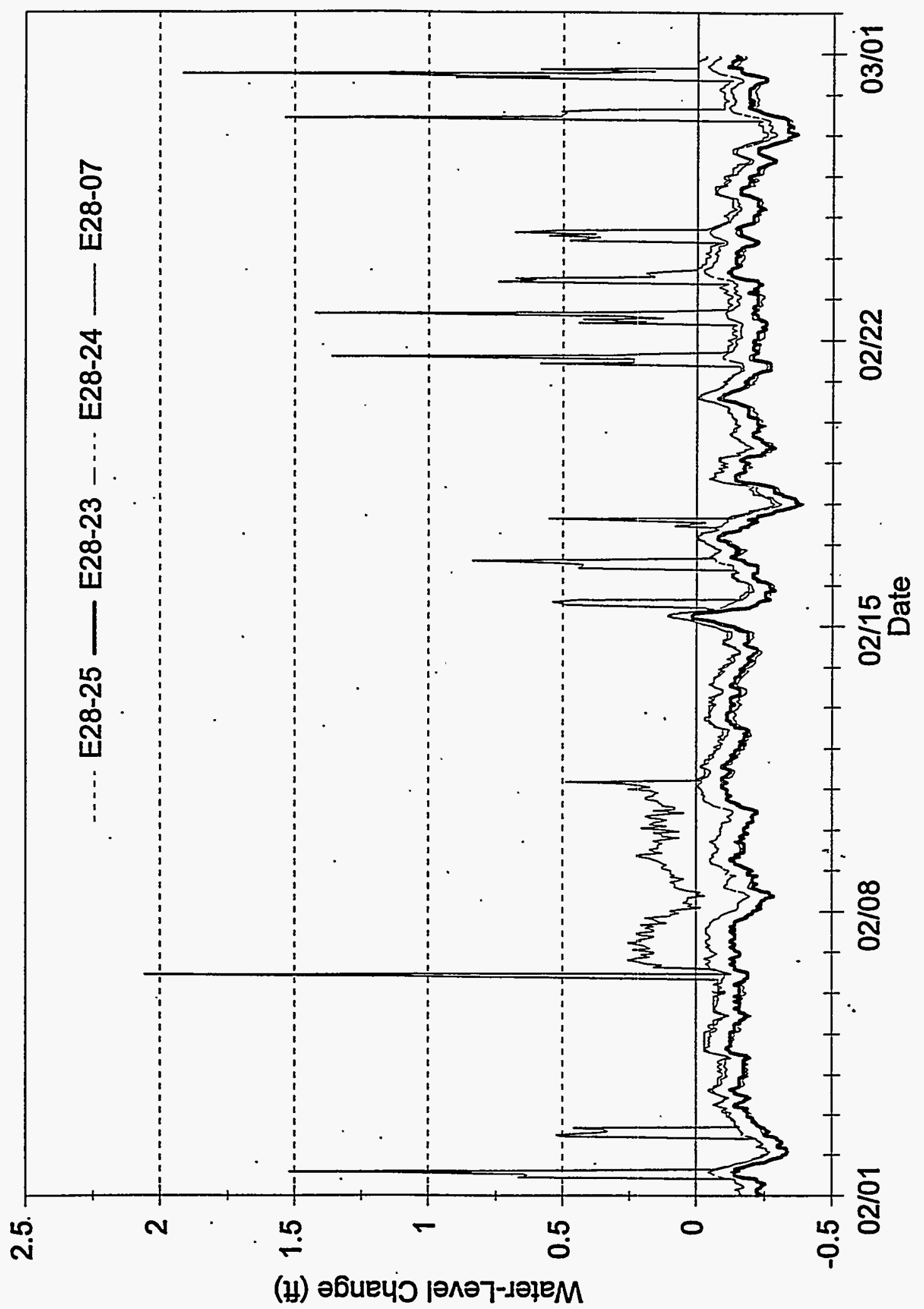


DOE/RL-95-59

Rev. 0

Figure D-3. 216-B-5 Reverse Well Site Water-Level Monitoring for March.

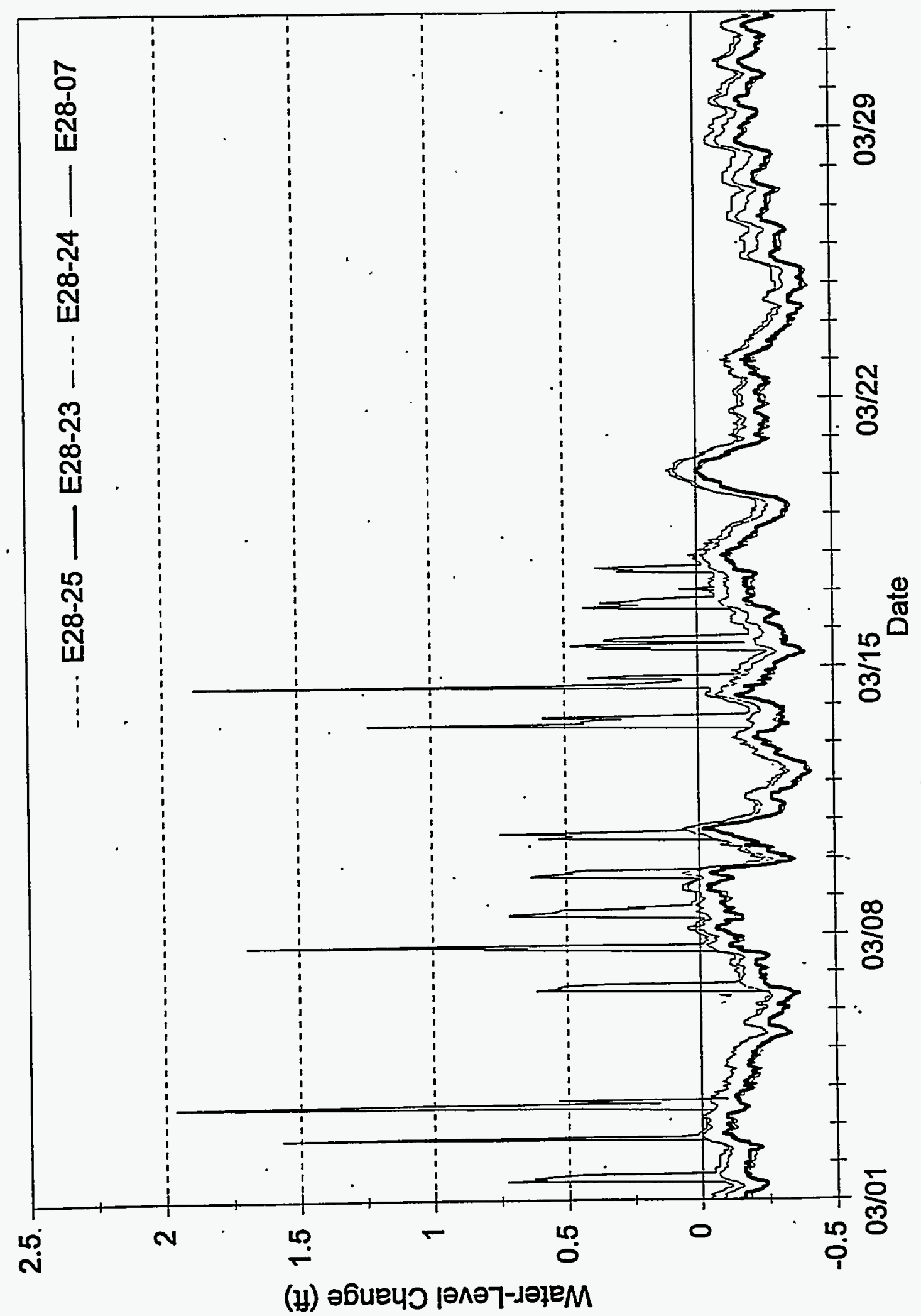


Figure D-4. 216-B-5 Reverse Well Site Water-Level Monitoring for April.

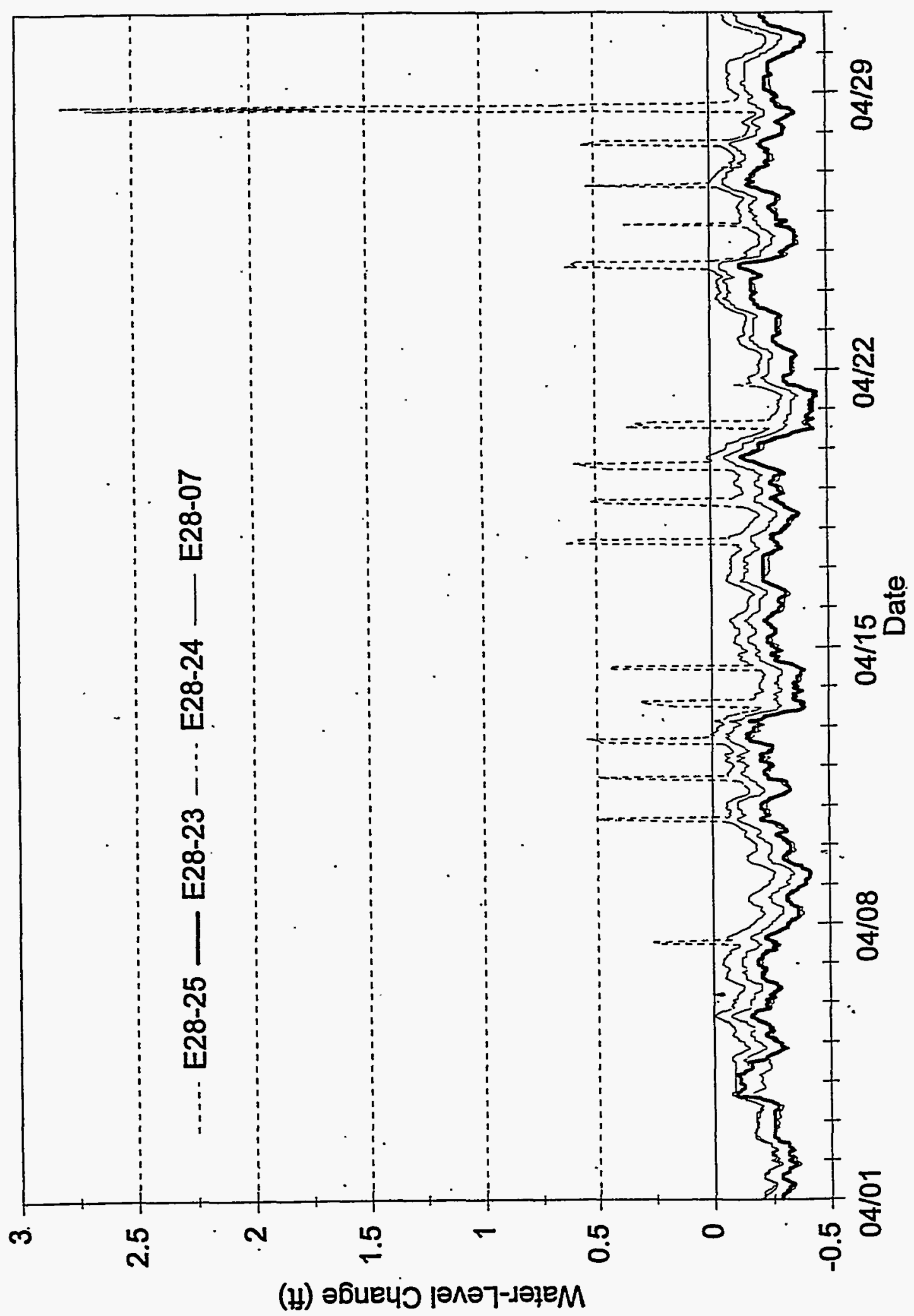


DOE/RL-95-59

Rev. 0

Figure D-5. 216-B-5 Reverse Well Site Water-Level Monitoring for May.

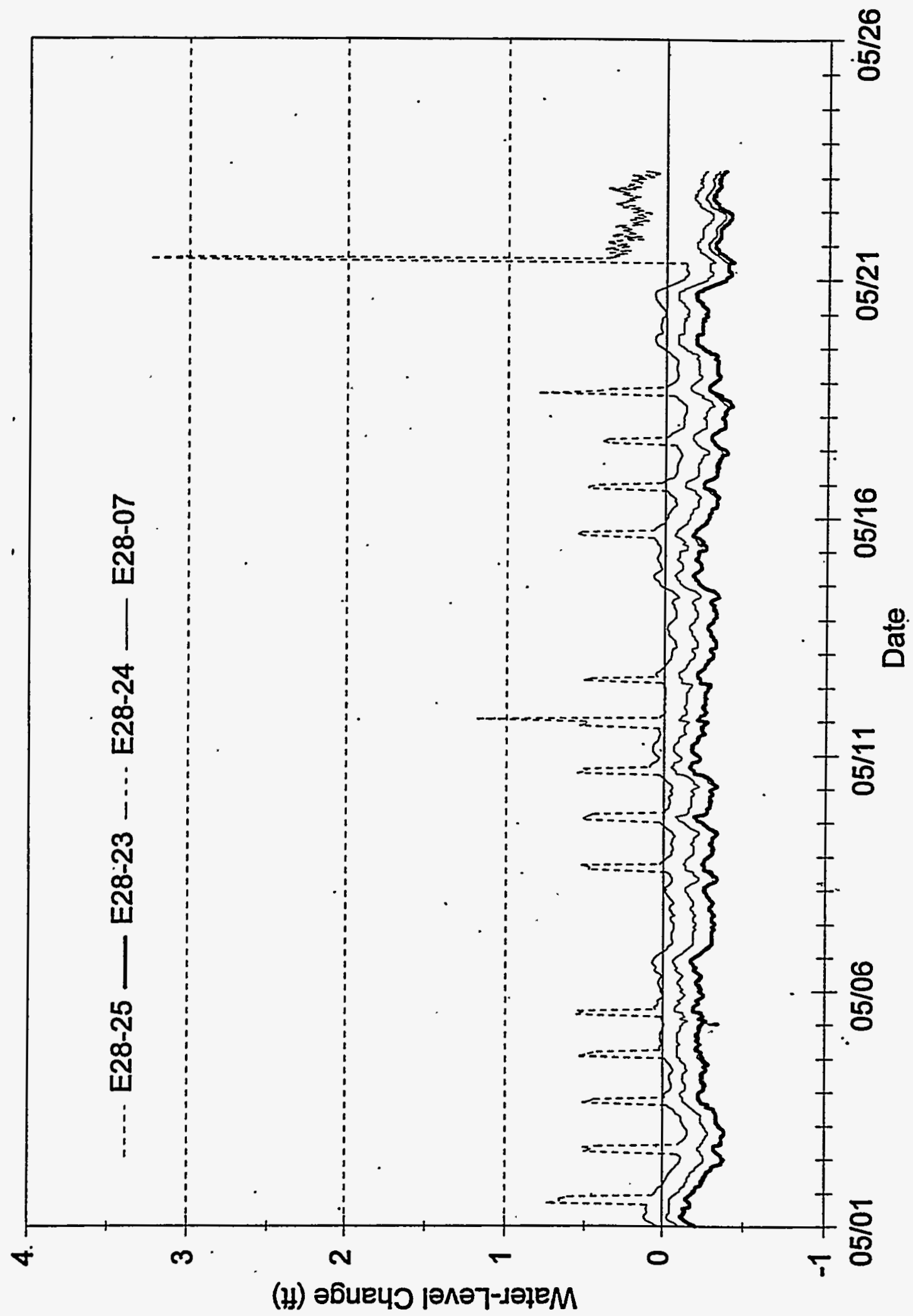


Figure D-6. 216-B-5 Reverse Well Post-Test Water-Level Monitoring.

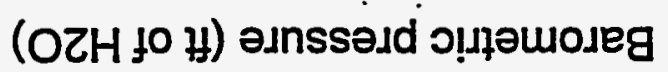

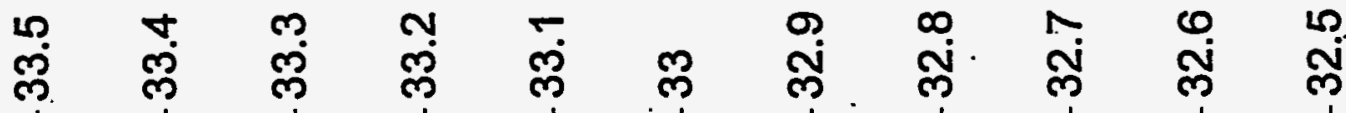

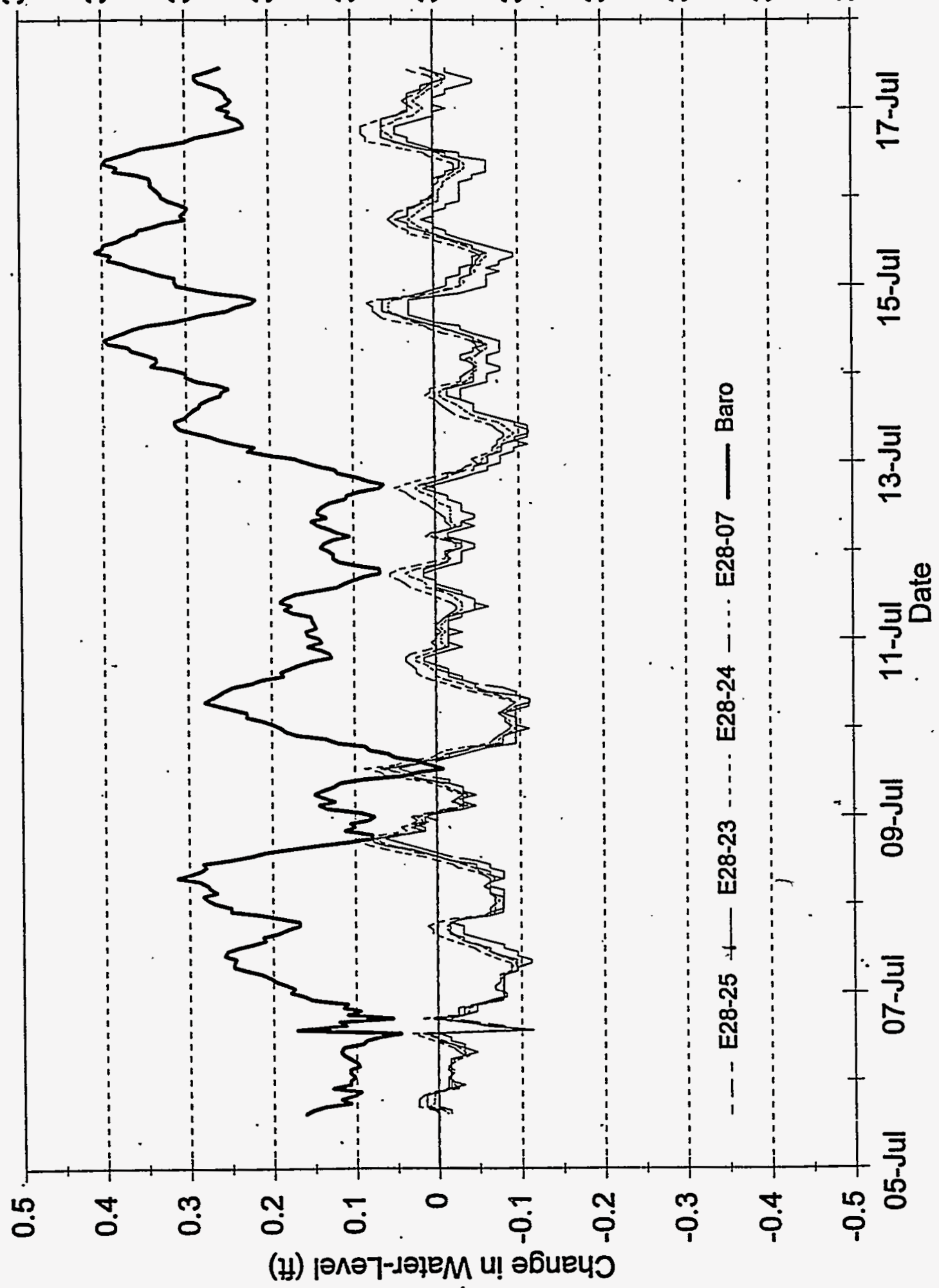


DOE/RL95-59

Rev. 0

Figure D-7. 216-BY Cribs Site Water-Level Monitoring for January.

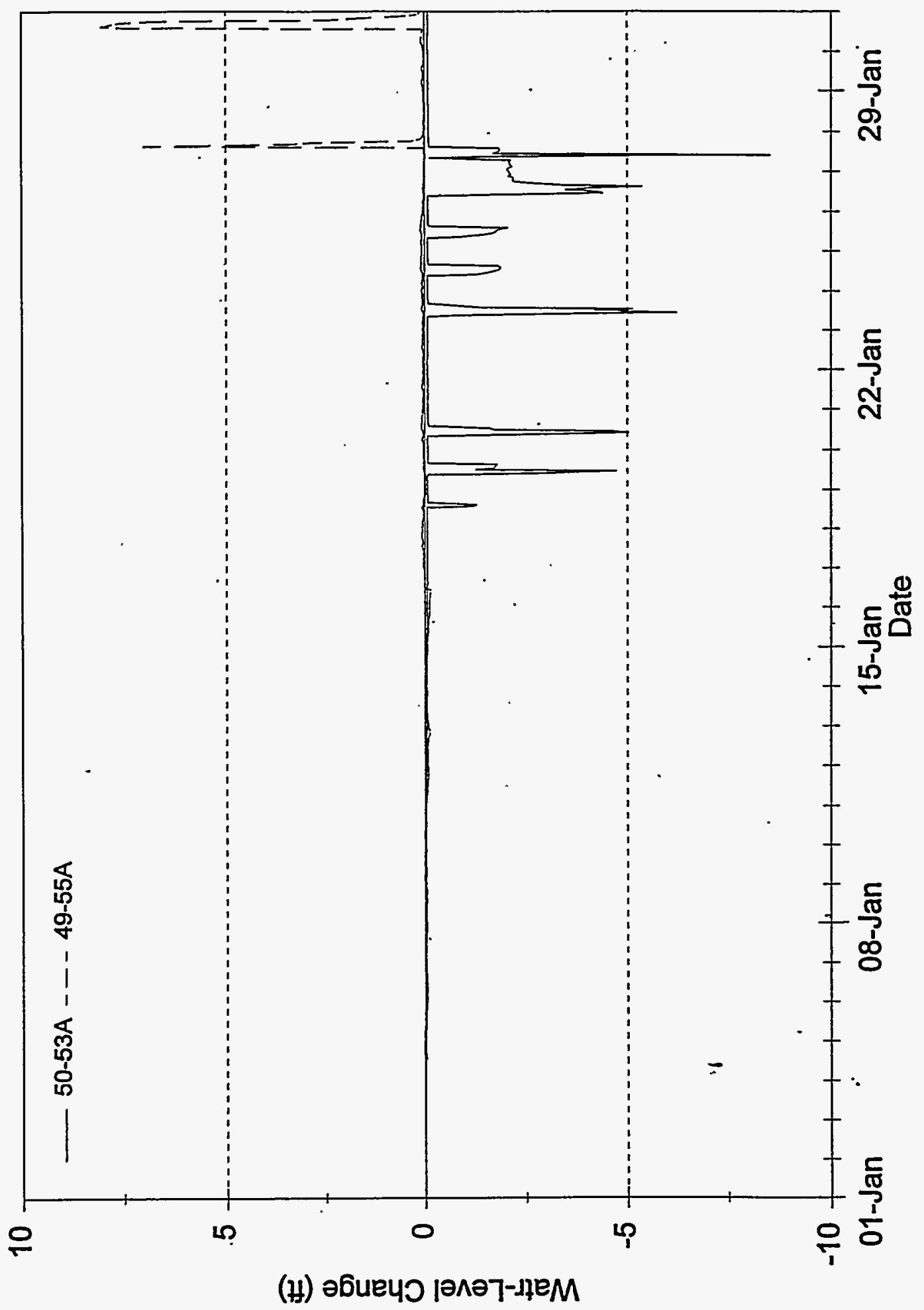


DOE/RL-95-59

Rev. 0

Figure D-8. 216-BY Cribs Site Water-Level Monitoring for February.

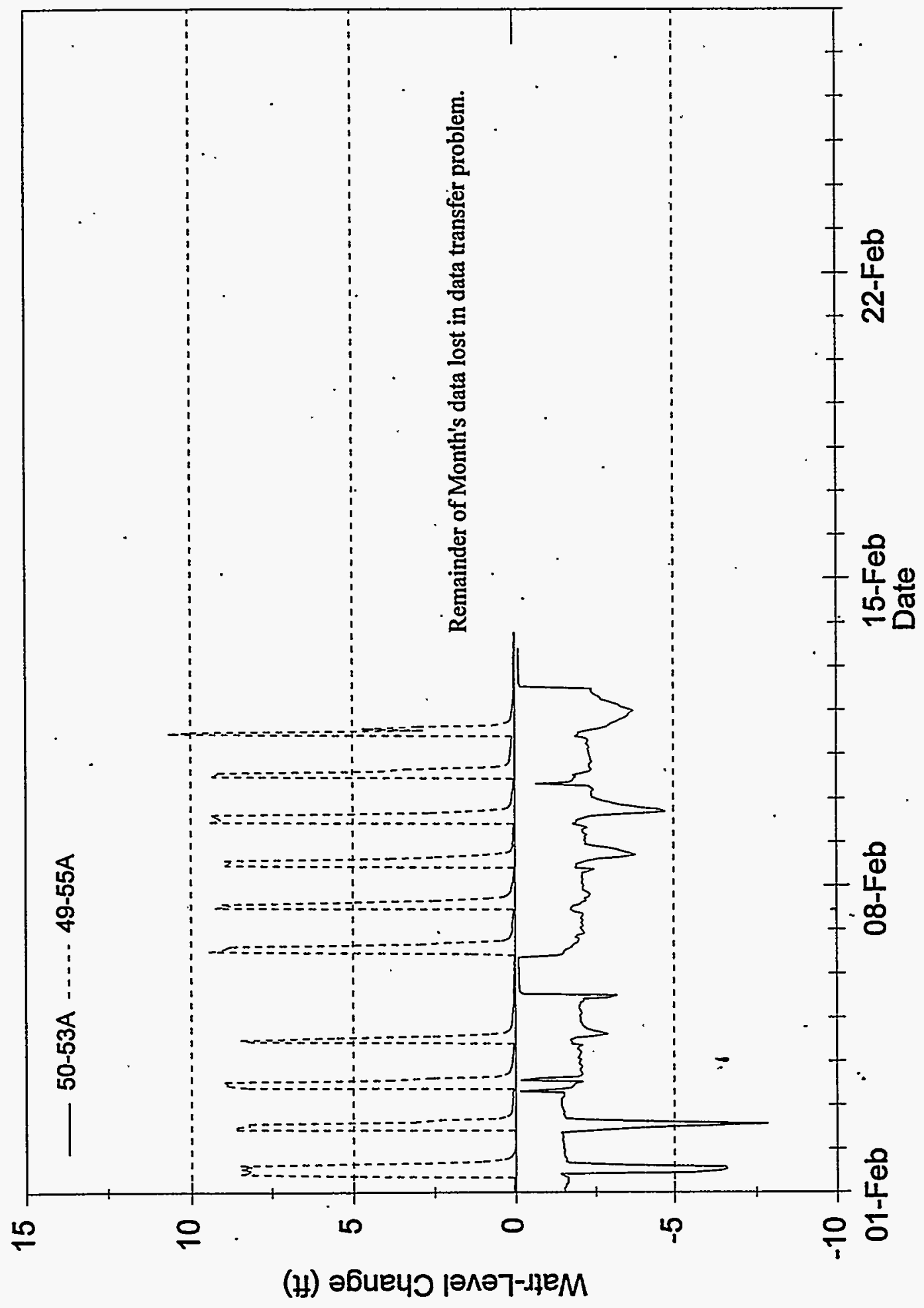


Figure D-9. 216-BY Cribs Site Water-Level Monitoring for March.

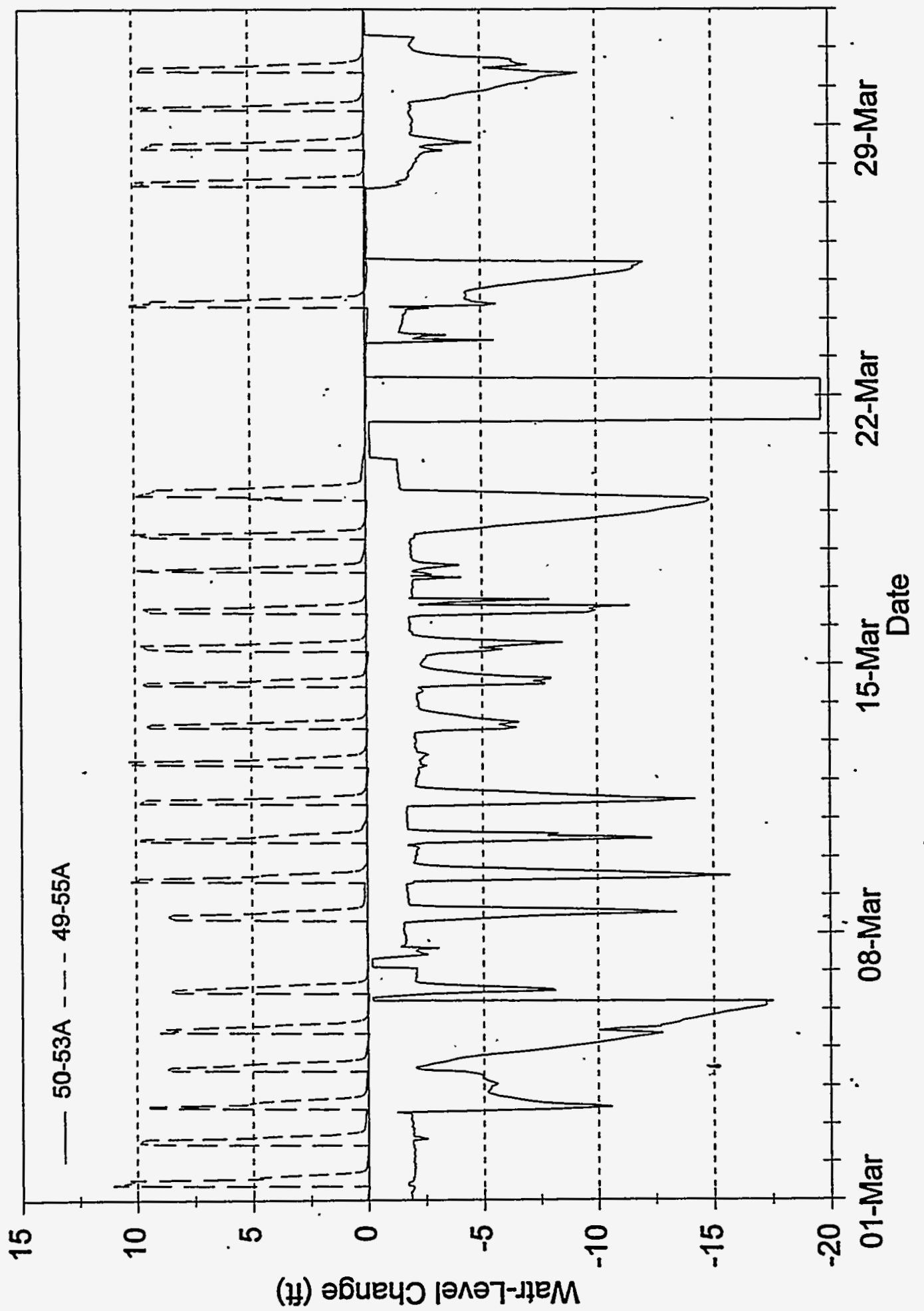


DOE/RL-95-59

Rev. 0

Figure D-10. 216-BY Cribs Site Water-Level Monitoring for April.

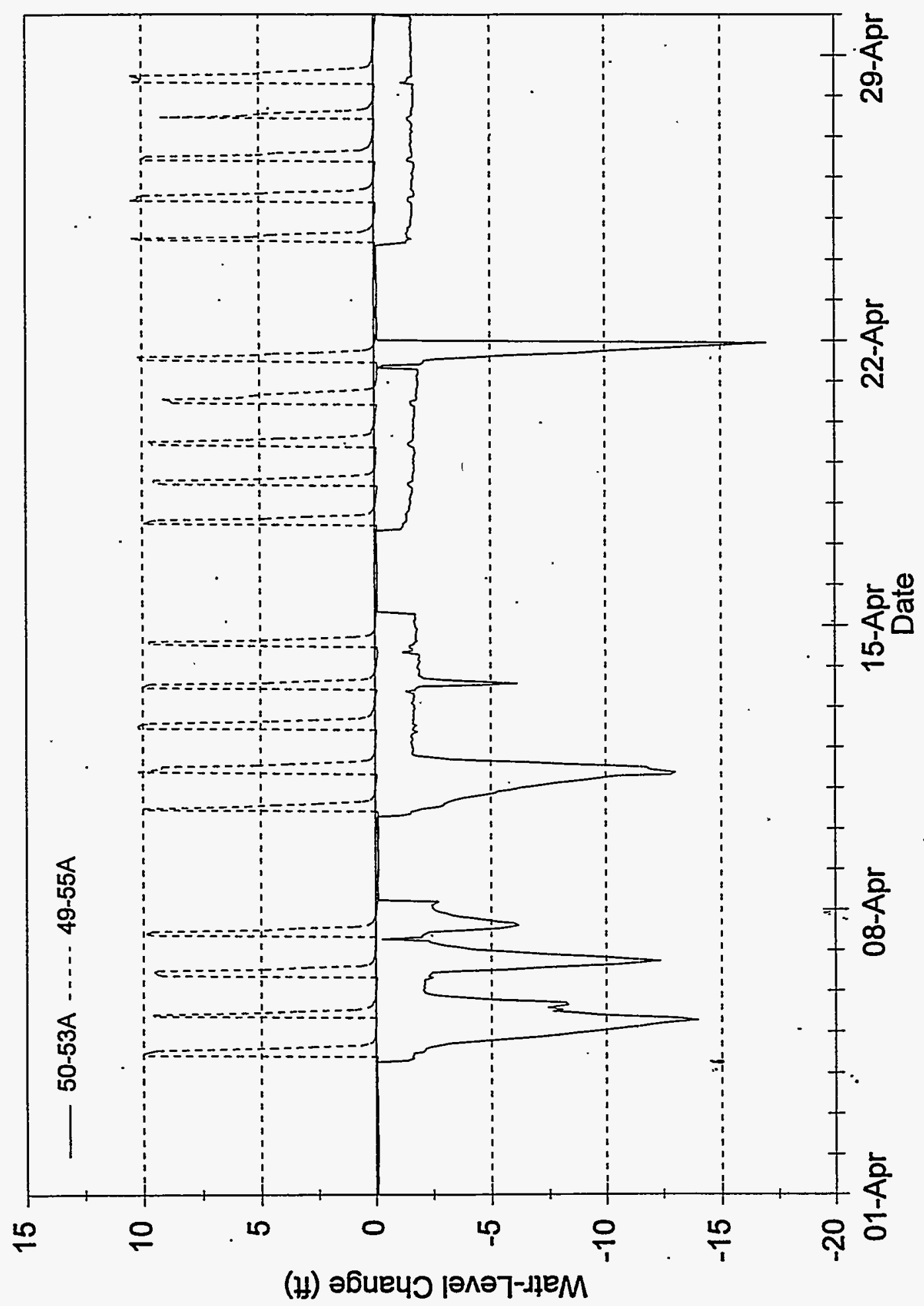


DOE/RL-95-59

Rev. 0

Figure D-11. 216-BY Cribs Site Water-Level Monitoring for May.

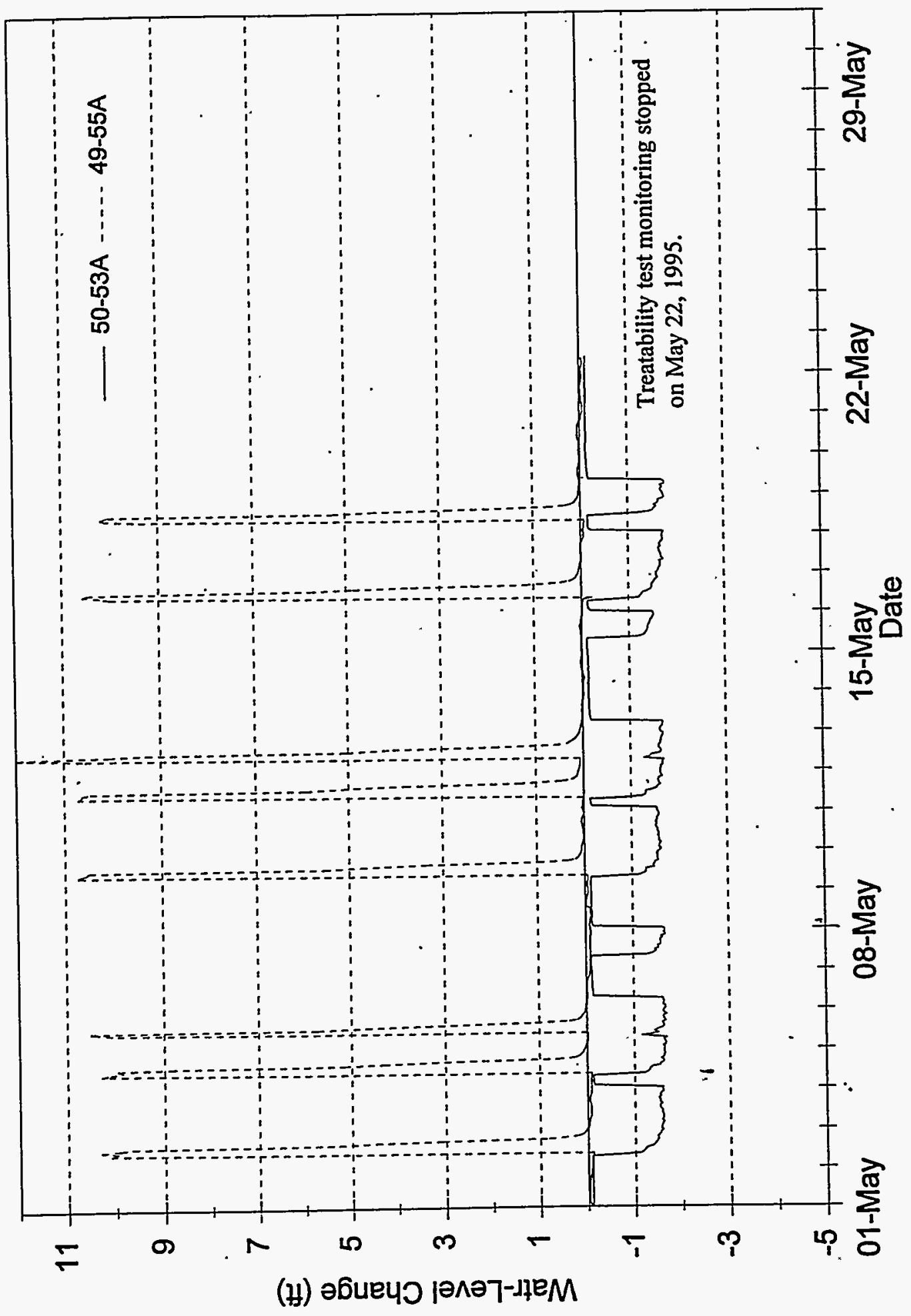


DOE/RL-95-59

Rev. 0 
Rev. 0

APPENDIX E

REPORT ON IN SITU FLOW VELOCITY MEASUREMENTS AT THE 200-BP-5 OPERABLE UNIT · 
DOE/RL-95-59

Rev. 0 
DOE/RL-95-59

Rev. 0

\section{APPENDIX E}

\section{REPORT ON IN SITU FLOW VELOCITY MEASUREMENTS AT THE 200-BP-5 OPERABLE UNIT}

To further support the hydrogeologic assessment of the 216-BY Cribs (BY-Cribs) plume, as directed in the 200 National Priorities List Agreement/Change Control Form (BHI-00203), in situ flow velocities measurements were performed in wells monitoring the plume. The wells were all located between the north end of the 200 East Area and Gable Mountain Gap. Listed in Table E-1 are the wells in which flowmeter measurements were taken. The wells measured are located in Figure E-1. The purpose of the in situ groundwater flow velocity measurements was to determine the groundwater flow rate and direction in the vicinity of the BY-Cribs plume, in and north of the 200 East Area. While measurements were collected at only 13 specific wells, the distribution of these wells allows for an interpretation of the groundwater flow rate and direction, and the factors controlling groundwater flow, across the study area.

Groundwater flow velocities were measured using a KV Associates Model 40 groundwater flowmeter. The instrument utilizes a central heat pulse source surrounded by four matched pairs of thermistors. The heat source provides a thermal pulse which is transported in the direction and the rate of groundwater flow. By collecting measurements at the top, middle, and bottom of the well screened interval, a vertical profile of groundwater flow can be obtained, and by summing the velocity vectors, a representative flow velocity can be determined for the individual screened interval.

Thirteen groundwater monitoring wells were selected for this study. The wells selected were: screened across the water table; screened using a 4- to 6-in.-diameter wire wrapped screen; and located across the study area to provide an areal distribution of measurement points. The flow measurements were obtained between May 24, 1995 and July 27, 1995. The objective was to obtain measurements at the top, middle, and bottom of each saturated screened interval; however, several wells only had sufficient saturated interval to obtain only one or two measurements. The wells measured and measurement points below water level are listed on Table E-1.

The flowmeter measurements were collected by Westinghouse Hanford Company's Groundwater Data Services organization. To obtain a measurement, the flowmeter was lowered into the well and connected to control rods, which were indexed to ensure accurate directional alignment. Once the flowmeter and rods were lowered to the desired depth, the instrument was aligned in a north-south direction which was compensated for 21 degrees of east magnetic declination. Following alignment, the groundwater was allowed to return to hydrostatic conditions for a minimum of $1 \mathrm{~h}$ before collecting measurements. Following groundwater stabilization the flowmeter was triggered and data is collected using an automated data logger.

Two data collection tests were conducted at each measurement point. The first is as described above, and a second test following rotating the instrument 180 degrees from the first test. The rotation procedure accounts for any thermistor positional bias and identifies any thermistor malfunctions. Following data collection, the flow velocity vector direction and magnitude were calculated using vector addition and instrument flow rate calibration curves. Velocity is a vector having both a direction and magnitude. The direction is expressed as a compass direction, such as north 15 degrees west, and the magnitude is expressed as a rate in feet per day. In the following discussions when the term velocity is used, both a direction and magnitude are implied. 
In situ groundwater flow velocity measurements are influenced by several factors related to well construction, well condition, and aquifer characteristics. The wells tested were selected to ensure that well construction and conditions would minimally impact flow measurements. Conditions that could adversely impact measurements are: screened zones which contain perforations rather than continuous wire wrapped screened; encrustation on the well screens; or a high-hydraulic conductivity contrast differential between the aquifer and filter pack material.

Aquifer heterogeneities or anisotropy can affect both the flow direction and rate. Aquifer heterogeneities are characterized by variable porosity, which can result in preferential flow paths through the aquifer materials. Preferential pathways may exist due to depositional environment such as in coarser main channel deposits bounded by finer grained deposits. In addition, preferential flow paths may be developed during well development or over time through the washing of fine-grained material from the aquifer.

Groundwater flow velocities are controlled by the effective porosity of the saturated sediments and the groundwater flow gradient. The effective porosity of the saturated medium describes the amount of connected pore space which will transmit water. Higher porosity results in lower flow velocity, assuming all other related factors are held constant.

Porosities for the sediments comprising the unconfined aquifer surrounding the BY-Cribs and north to the Gable Gap area are only generally known, and will vary from one location to another within the study area. Effective porosity estimates range from $10 \%$ to $30 \%$ (Graham et al. 1981). The initial flow velocity results were calculated using a representative effective porosity of $20 \%$, however, results from the 216-B-5 Reverse Well (B-5 Reverse Well) Tracer tests, discussed in Section 4.4.4, determined that a porosity of between $22 \%$ and $30 \%$ is probably more representative of the unconfined aquifer at the nearby B-5 Reverse Well site. Based on the tracer study data, groundwater flow velocities were recalculated using an effective porosity of $25 \%$ based on the tracer study data. Table E-1 presents the calculated flow velocities for both effective porosities.

In the calculation of the flow velocity magnitude resulting from the instrument readings, the effective porosity is the controlling factor external from the calibration curves. Therefore, changing the effective porosity from $20 \%$ to $25 \%$ results in a $20 \%$ reduction in velocity magnitude. Thus, with an expected variable porosity across the study area of as much as $8 \%$ (22\% to $30 \%$ ), if only the tracer test study data are used as a range, flow velocity magnitudes may vary by $27 \%$ due to uncertainty in the effective porosity of the aquifer.

The water table in the northern portion of 200 East Area and north to Gable Gap is very flat with a very low groundwater gradient of 0.00006 . Low groundwater gradients may result in low flow velocities if the aquifer is homogeneous. In the study area, water-table elevations are so similar that contouring is very difficult, and therefore determining flow direction and gradient is imprecise. This is illustrated by the June 1994 water-table elevations shown in Figure E-2. The water levels were measured over a period of days and variability of up to $0.03 \mathrm{~m}(0.1 \mathrm{ft})$ is not unexpected. Additional error is added due to uncertainty in surveying of well elevations. Errors of $0.02 \mathrm{ft}$ may be introduced if the same surveying benchmark was used and as much as $0.015 \mathrm{~m}(0.05 \mathrm{ft})$ if different benchmarks were used between wells. Therefore, in areas such as the northern portion of the 200 East Area the difference between $122.23 \mathrm{~m}(401.03 \mathrm{ft})$ and $1.22 .21 \mathrm{~m}(400.98 \mathrm{ft})$ is not considered significant.

The underlying basalt surface also controls groundwater flow in a manner analogous to a stream bed controlling water flow in a stream. Irregularities in the stream bed (such as rocks or islands) disrupts 
the smooth laminar flow of the stream resulting in variable flow velocity around and over the irregularities. The impacts of the stream bed, or in this case the underlying basalt surface, become more pronounced near the basalt surface where the irregular surface disrupts the flow the greatest. The basalt surface in the study area has been extensively eroded, and most likely a very irregular surface has developed. In addition, erosional channels or depressions may have developed in the basalt surface which also can direct groundwater flow oblique to the flow gradient direction.

The underlying basalt has also been structurally deformed by tectonic activity. A series of small anticlines and synclines have been interpreted from well logs. This is illustrated in Figure E-3, which is a bedrock geologic map of the 200 East Area and vicinity. Groundwater flow near the anticlines may be controlled by both the structural dip of the basalt surface and surface irregularities associated with erosion.

Because of the potential influences of porosity, well bore effects, and effects of the basalt surface measurements within a well were added using vector addition to determine an average flow velocity for a well. These average values are shown in Figure E-1 and listed in Table E-1.

Based on previous studies (DOE-RL 1993, WHC 1992) and a streamline analysis based on 1993 water-level data (Figure E-4), groundwater flow is generally to the north and northwest within the study area. The flow has been and is strongly influenced by wastewater discharges to the ground. These discharges have resulted in a groundwater divide in the 200 East Area which controls flow direction to the north in the northwestern portion of the 200 East Area.

The groundwater flow direction and magnitude for each well are shown in Figure E-1. In general across the study area the following may be inferred from the flow velocity measurements:

- Groundwater flow directions in the northwest portion of the 200 East Area is to the south, with magnitudes ranging from $0.13 \mathrm{~m} /$ day $(0.43 \mathrm{ft} /$ day $)$ to $0.49 \mathrm{~m} /$ day $(1.6 \mathrm{ft} /$ day).

- Groundwater flow directions northeast of the BY-Cribs flows northwest around a basalt high with a magnitude of $0.6 \mathrm{~m} /$ day $(1.9 \mathrm{ft} /$ day $)$.

- Groundwater north of the 200 East Area and south of West Lake flow northerly with a magnitude ranging from less than $0.01 \mathrm{~m} /$ day $(0.04 \mathrm{ft} /$ day $)$ to $0.34 \mathrm{~m} /$ day $(1.1 \mathrm{ft} /$ day $)$.

Groundwater velocity measurements less than $0.01 \mathrm{~m} /$ day $(0.04 \mathrm{ft} /$ day $)$ are considered less than the practical resolution of the flow meter and necessarily invalidate the flow direction and rate. There was only one location, well 699-52-54, where both flow measurement readings were below the practical resolution of the meter.

Based on the velocity meter results, groundwater flow direction, in the northwest portion of the 200 East Area, is generally to the south. Flow velocity variation was observed and is likely due to the flat gradient and aquifer heterogeneities. Flow velocities varied between 0.13 to $0.34 \mathrm{~m} /$ day (0.43 to $1.1 \mathrm{ft} / \mathrm{day}$ ). The 1993 water-table map (see Figure E-4) shows a hydrologic divide within the central portion of the 200 East Area due to past cooling water disposal activities. A streamline analysis shows that groundwater flow, in 1993, was to the northwest. Groundwater levels have been lowering with time due to decreased discharges to the soil column, and the hydrologic divide may have moved north sufficiently for groundwater flow directions to change to a more southerly 
direction. Groundwater flow in this area may be controlled by a more regional flow gradient rather than the flat local gradient.

The flow direction in the vicinity of well 299-E34-5 is to the northwest with a flow velocity of $0.6 \mathrm{~m} /$ day $(1.9 \mathrm{ft} /$ day), which was the highest measured. This higher flow velocity is supported by the water level at this well, which also is the highest in the area. The groundwater high may be due to the influence of the groundwater mound beneath B Pond to the southeast. In addition, the groundwater velocity may be influenced by the underlying basalt surface, which is only $0.9 \mathrm{~m}(3 \mathrm{ft}$ ) below the water table.

Also in this vicinity, well 299-E34-11 flows northeasterly and well 699-48-50 flows southerly, which is anomalous to well 299-E34-5. This may be due to the underlying basalt locally controlling flow at

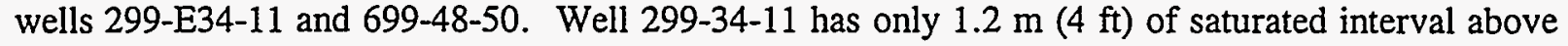

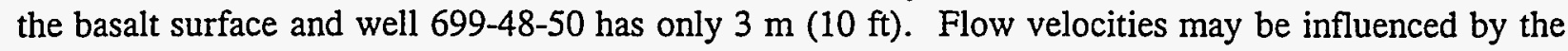
features on basalt surface such as erosional channels or depressions oblique to the general groundwater flow direction shown by well 299-E34-5. In addition, two of the three measurements collected in well 699-48-50 were below the 0.04 practical flowmeter resolution.

Flow directions heading into the Gable Gap area are consistent with a flat water table with a northerly gradient but may be partially controlled by the underlying basalt surface. Well 699-52-57 only has

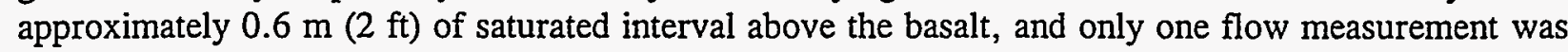
collected from this well. Two measurements were collected at well 699-52-54 and both were below the practical flowmeter resolution. This well has only approximately $0.9 \mathrm{~m}(3 \mathrm{ft})$ of saturated thickness. This well may penetrate into a small depression in the basalt surface which has only a very small flow.

The flow direction at well $699-59-58$ is southwesterly with a magnitude of $0.20 \mathrm{~m} /$ day $(0.66 \mathrm{ft} /$ day $)$. This is anomalous to the flow direction predicted from previous studies and from the wells to the

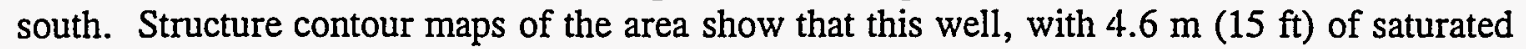
thickness above the basalt bedrock, is on the southerly dipping limb of an anticlinal structure. Erosional features on this southerly dipping limb may be controlling flow in this individual well, with the general regional flow maintaining its northerly flow direction. However, without additional velocity data this cannot be confirmed.

Well 699-60-57 is screened across two zones. The upper zone contains approximately $1.5 \mathrm{~m}(5 \mathrm{ft}$ ) of saturated screened interval, and the lower zone is screened across a section $17 \mathrm{~m}(57 \mathrm{ft})$ lower in the well. Results show that groundwater flows in opposite directions between the upper and lower screened intervals. The upper interval flows southwest and the lower interval flows northeast. This well also lies on the axis of an anticlinal structure. This could have an effect on flow directions near the basalt surface. An alternative explanation is that the two screened intervals may represent different aquifers, separated by a confining layer, which flow in opposite directions. Well logs show that a very-fine to fine sand with silt was encountered between the two screen intervals. This zone could cause semiconfined to confined conditions in the lower screened interval. Opposite flow directions between unconfined and confined aquifers have been documented at Fort Ord, California (HLA 1994). Either of the two scenarios are reasonable.

In summary, in situ groundwater flow velocity measurements provide general groundwater flow directions and velocities in areas of very low hydraulic gradient. Groundwater flow velocity measurements can be influenced by aquifer porosity, well bore effects, and the underlying basalt 
surface. Groundwater flow in the northeastern portion of the 200 East Area are to the south, at velocities ranging between 0.13 and $0.34 \mathrm{~m} /$ day $(0.43$ and $1.1 \mathrm{ft} /$ day). This is opposite to flow directions interpreted from water-table elevations collected in 1993 which show a northwesterly flow direction. This change in direction may be due to a declining water table and movement of the 200 East Area hydrologic divide to the north. Groundwater east of this area and to the north flows towards Gable Gap and is controlled by the low hydraulic gradient and locally by the underlying basalt surface.

\section{REFERENCES}

DOE-RL, 1993, 200 East Groundwater Aggregate Area Management Study Report, DOE/RL-92-19, U.S. Department of Energy, Richland Operations Office, Richland, Washington.

Graham, M.J, G.V. Last, S.R. Strait, and W.R. Brown, 1981, Hydrology of the Separations Area, RHO-ST-42, Rockwell Hanford Operations, Richland, Washington

HLA, 1994, Basewide Remedial Investigation/Feasibility Study Fort Ord, California, Harding Lawson Associates, Navato, California.

WHC, 1992, Hydrogeologic Model for the 200 East Groundwater Aggregate Area,

WHC-SD-EN-TI-019, Rev. 0, Westinghouse Hanford Company, Richland, Washington. 
Figure E-1. In Situ Velocity Flowmeter Wells in the 216-BY Cribs Plume.

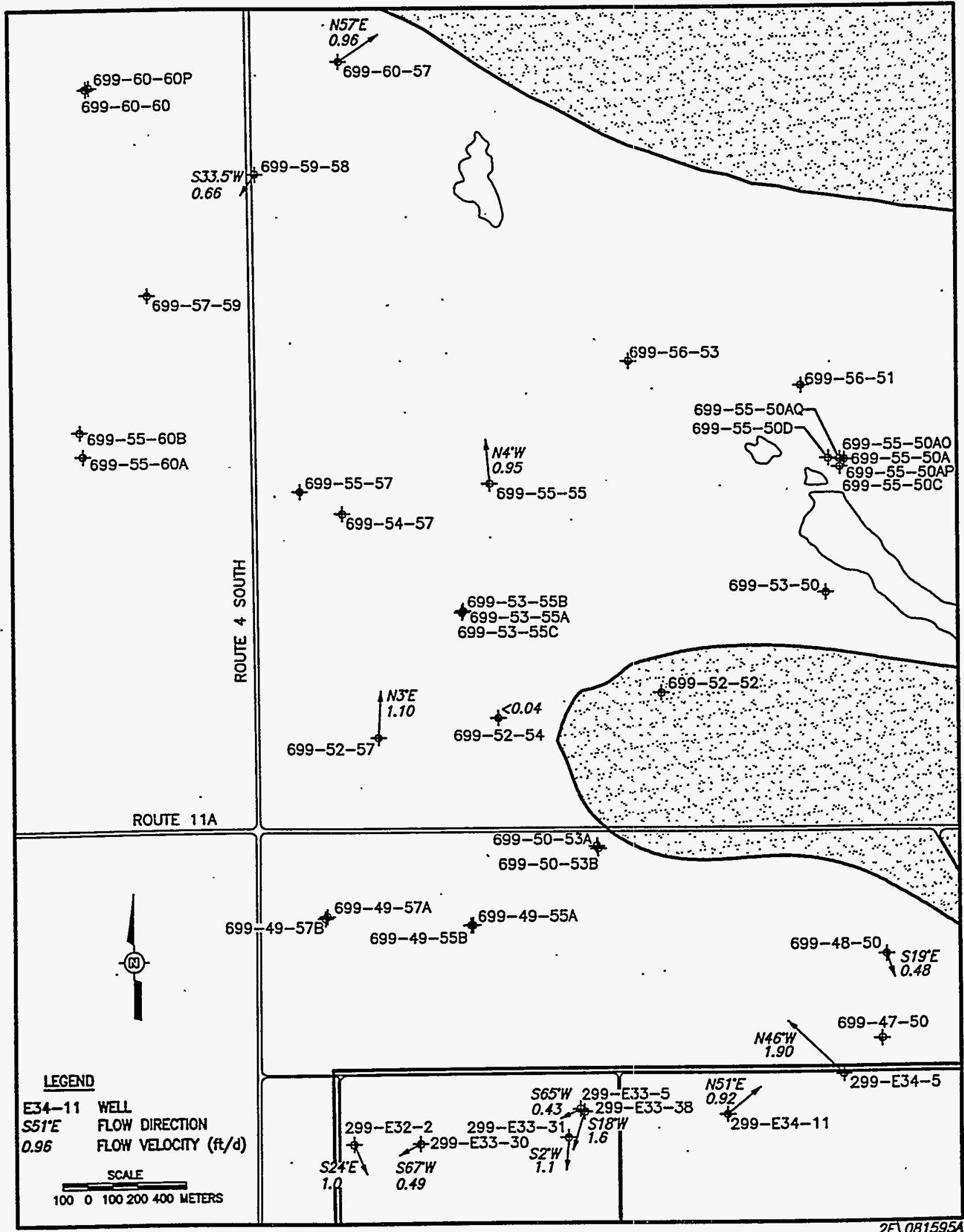




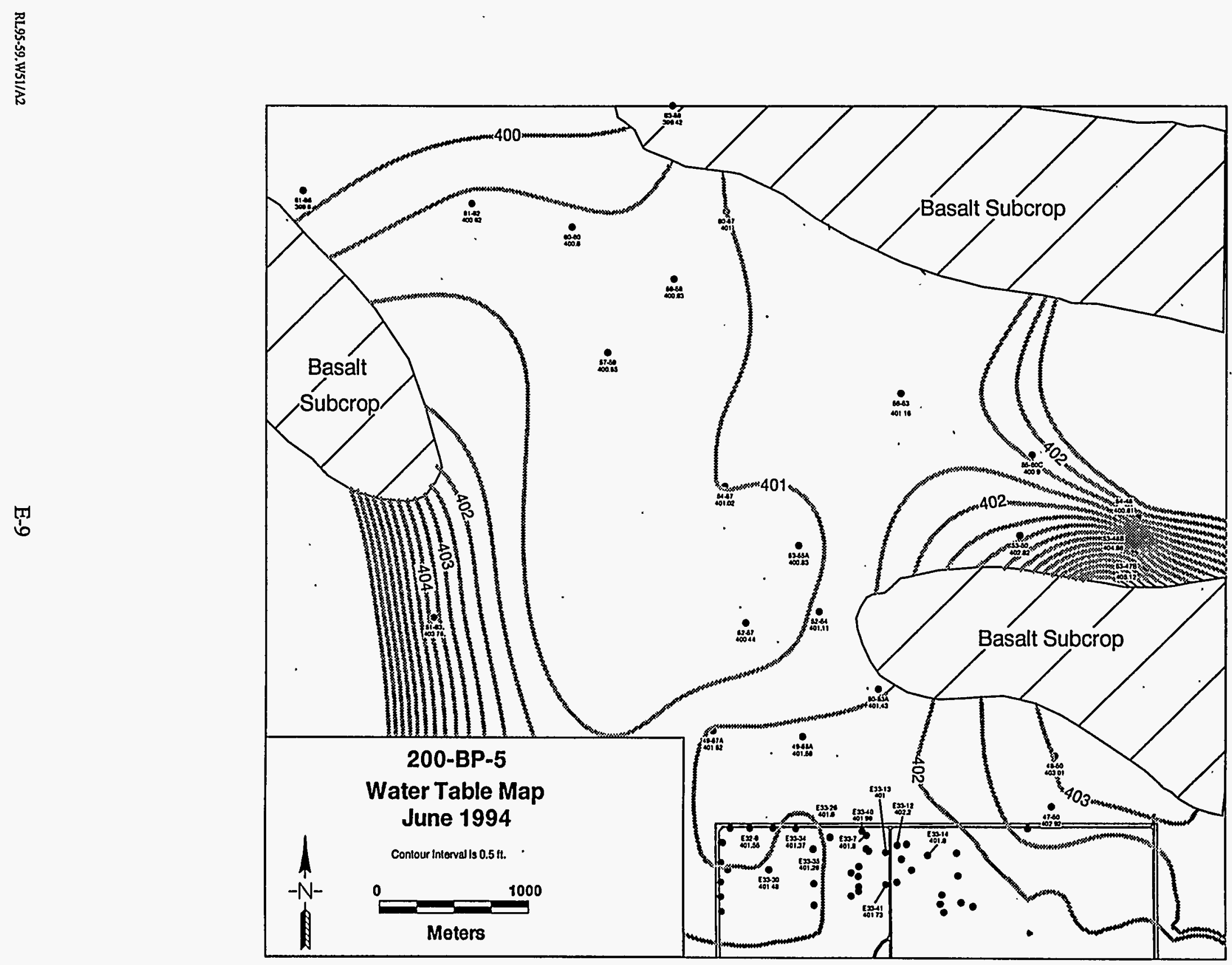

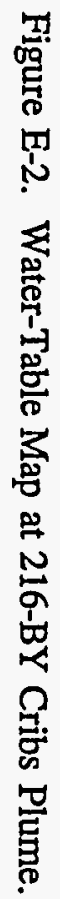

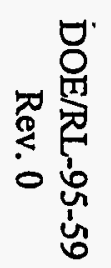




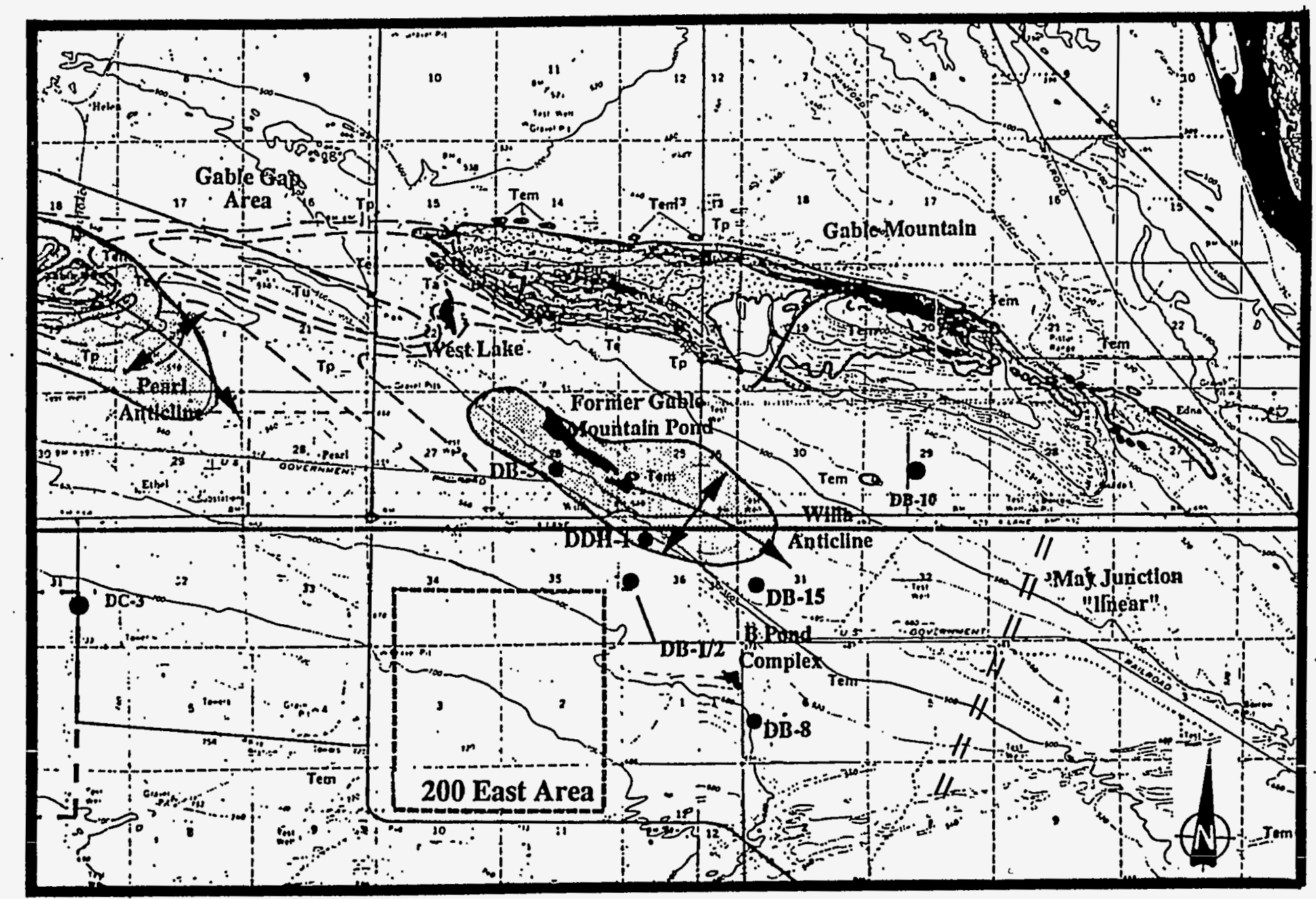

Saddle Mountains Basalt Units:

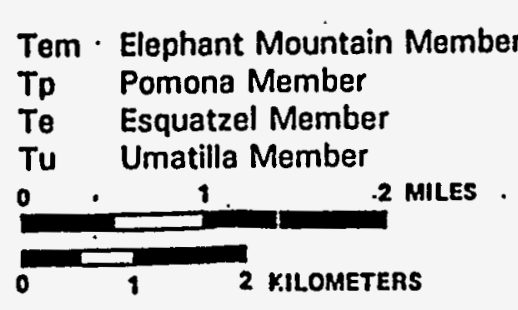

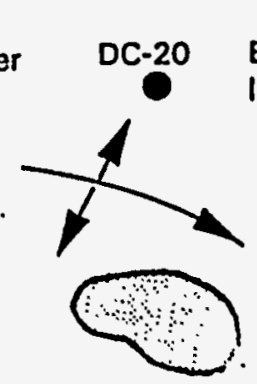

Borehole number and

location referenced in text

Anticline axis and plunge direction

Approximate area of basalt above the water table
Geologic Unit contact

Fault (ball and bar on down-thrown side) 
Figure E-4. Streamline Analysis for 200 East Area, 1993.

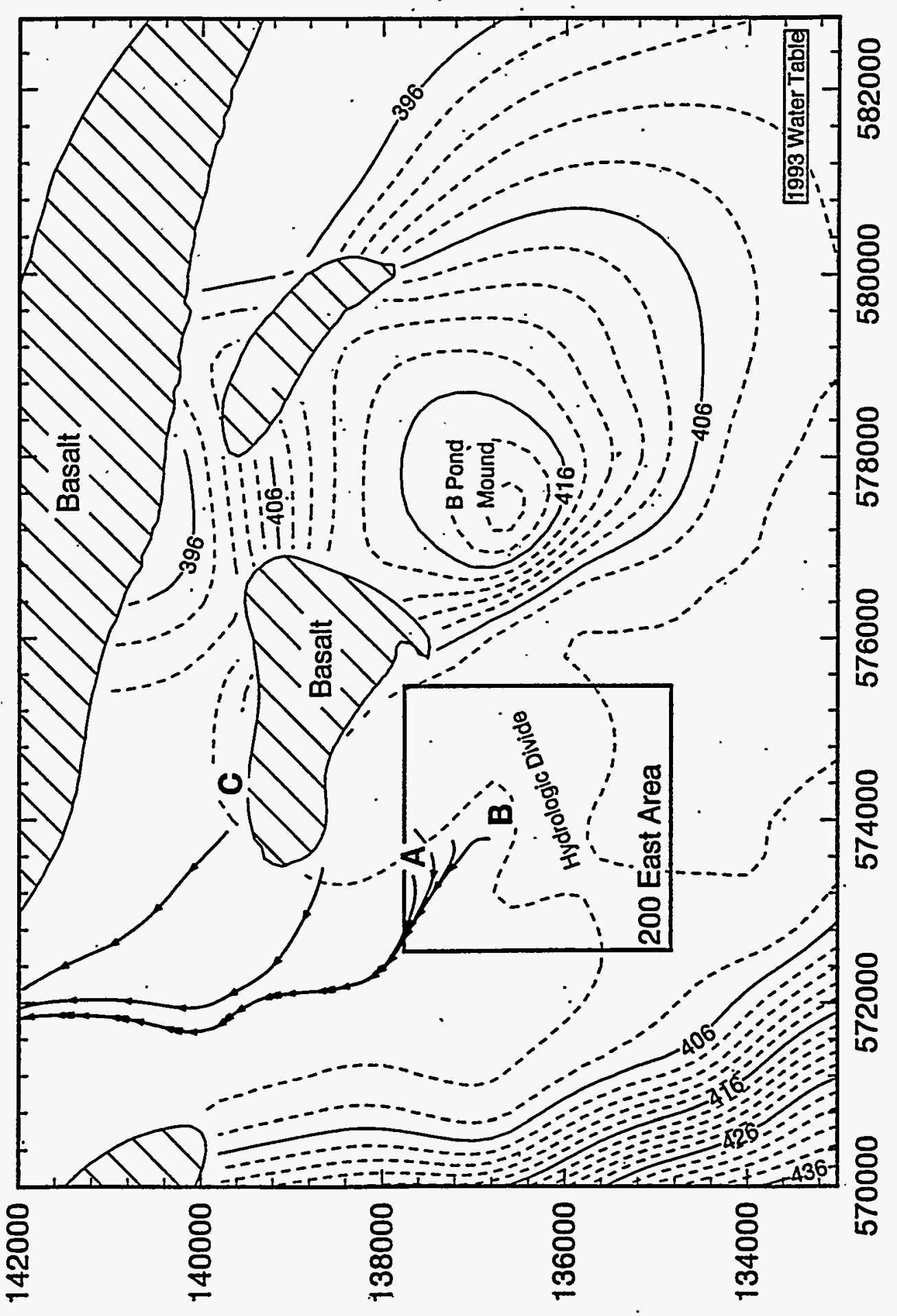


DOE/RL-95-59

Rev. 0

Table E-1. In Situ Flow Meter Results.

\begin{tabular}{|c|c|c|c|c|}
\hline \multirow{2}{*}{ Well } & \multirow{2}{*}{ DBWL (ft) } & \multicolumn{2}{|c|}{ Velocity (ft/d) } & \multirow{2}{*}{ Direction } \\
\hline & & $\phi=0.20 \%$ & $\phi=0.25 \%$ & \\
\hline \multirow{2}{*}{$\begin{array}{l}\text { 299-E32-2 } \\
\text { Average }\end{array}$} & $\begin{array}{l}3.7 \\
7.7\end{array}$ & $\begin{array}{l}0.89 \\
1.8\end{array}$ & $\begin{array}{l}0.7 \\
1.4\end{array}$ & $\begin{array}{c}\mathrm{S} 30^{\circ} \mathrm{E} \\
\mathrm{S} 34.3^{\circ} \mathrm{E}\end{array}$ \\
\hline & & & 1.0 & $\mathrm{~S} 24^{\circ} \mathrm{E}$ \\
\hline 299-E33-30 & $\begin{array}{r}4.3 \\
8.3 \\
12.3 \\
\end{array}$ & $\begin{array}{l}0.73 \\
0.66 \\
0.45 \\
\end{array}$ & $\begin{array}{l}0.58 \\
0.53 \\
0.36\end{array}$ & $\begin{array}{c}\mathrm{S} 69.9^{\circ} \mathrm{W} \\
\mathrm{S} 63^{\circ} \mathrm{W} \\
\mathrm{S} 68^{\circ} \mathrm{W}\end{array}$ \\
\hline Average & & & 0.49 & $\mathrm{~S} 67^{\circ} \mathrm{W}$ \\
\hline 299-E33-31 & $\begin{array}{l}2.9 \\
6.9 \\
8.9\end{array}$ & $\begin{array}{l}1.7 \\
2.1 \\
0.59\end{array}$ & $\begin{array}{l}1.3 \\
1.7 \\
0.47 \\
\end{array}$ & $\begin{array}{l}\mathrm{S} 22.6^{\circ} \mathrm{W} \\
\mathrm{S} 18.7^{\circ} \mathrm{E} \\
\mathrm{S} 20.0^{\circ} \mathrm{W}\end{array}$ \\
\hline Average & & & 1.1 & $\mathrm{~S} 2^{\circ} \mathrm{W}$ \\
\hline 299-E33-35 & $\begin{array}{l}2.8 \\
5.8 \\
8.8 \\
\end{array}$ & $\begin{array}{l}0.33 \\
1.2 \\
0.23\end{array}$ & $\begin{array}{l}0.27 \\
0.94 \\
0.18 \\
\end{array}$ & $\begin{array}{l}\mathrm{S} 42.2^{\circ} \mathrm{W} \\
\mathrm{S} 78.4^{\circ} \mathrm{W} \\
\mathrm{S} 21.3^{\circ} \mathrm{W}\end{array}$ \\
\hline Average & & & 0.43 & $564.5^{\circ} \mathrm{W}$ \\
\hline \multirow{2}{*}{$\begin{array}{l}\text { 299-E33-38 } \\
\text { Average }\end{array}$} & $\begin{array}{l}4.2 \\
8.2 \\
\end{array}$ & $\begin{array}{l}1.4 \\
2.4\end{array}$ & $\begin{array}{l}1.1 \\
2.0\end{array}$ & $\begin{array}{l}\mathrm{S} 23.6^{\circ} \mathrm{W} \\
\mathrm{S} 15.6^{\circ} \mathrm{W}\end{array}$ \\
\hline & & & 1.6 & $\mathrm{~S} 18.4^{\circ} \mathrm{W}$ \\
\hline 299-E34-5 & 1.4 & 2.37 & 1.9 & $\mathrm{~S} 46.6^{\circ} \mathrm{W}$ \\
\hline 299-E34-11 & $\begin{array}{l}2.0 \\
3.5 \\
\end{array}$ & $\begin{array}{l}1.2 \\
1.1\end{array}$ & $\begin{array}{l}0.96 \\
0.87\end{array}$ & $\begin{array}{l}\mathrm{N} 51.4^{\circ} \mathrm{E} \\
\mathrm{N} 51.4^{\circ} \mathrm{E}\end{array}$ \\
\hline Average & & & 0.92 & $\mathrm{~N} 51.4^{\circ} \mathrm{E}$ \\
\hline $699-48-50$ & $\begin{array}{l}1.2 \\
5.7 \\
9.7\end{array}$ & $\begin{array}{r}<0.04 \\
0.60 \\
0.04 \\
\end{array}$ & $\begin{array}{r}<0.04 \\
0.48 \\
<0.04 \\
\end{array}$ & $\begin{array}{c}\mathrm{a} \\
\mathrm{S} 18.6^{\circ} \mathrm{E} \\
\left(\mathrm{S} 52.7^{\circ} \mathrm{E}\right)^{\mathrm{a}}\end{array}$ \\
\hline Average & & & 0.48 & $\mathrm{~S} 18.6^{\circ} \mathrm{E}$ \\
\hline \multirow{2}{*}{$\begin{array}{l}699-52-54 \\
\text { Average }\end{array}$} & $\begin{array}{l}0.9 \\
1.4\end{array}$ & $\begin{array}{r}0.04 \\
<0.04 \\
\end{array}$ & $\begin{array}{l}<0.04 \\
<0.04\end{array}$ & $\begin{array}{c}\left(\mathrm{S} 46.5^{\circ} \mathrm{E}\right)^{\mathrm{a}} \\
\mathrm{a}\end{array}$ \\
\hline & & \multicolumn{2}{|c|}{ No valid value } & \\
\hline $699-52-57$ & 0.8 & 1.4 & 1.1 & $\mathrm{~N} 2.9^{\circ} \mathrm{E}$ \\
\hline $699-55-55$ & $\begin{array}{l}2.1 \\
5.1 \\
8.1\end{array}$ & $\begin{array}{l}1.5 \\
0.99 \\
1.1 \\
\end{array}$ & $\begin{array}{l}1.2 \\
0.79 \\
0.91\end{array}$ & $\begin{array}{c}\mathrm{N} 1.0^{\circ} \mathrm{E} \\
\mathrm{N} 21.7^{\circ} \mathrm{W} \\
\mathrm{N} 4.3^{\circ} \mathrm{E}\end{array}$ \\
\hline Average & & & 0.95 & $\mathrm{~N} 4.1^{\circ} \mathrm{W}$ \\
\hline
\end{tabular}


Table E-1. In Situ Flow Meter Results.

\begin{tabular}{|c|c|c|c|c|}
\hline \multirow{2}{*}{ Well } & \multirow{2}{*}{ DBWL (ft) } & \multicolumn{2}{|c|}{ Velocity (ft/d) } & \multirow{2}{*}{ Direction } \\
\cline { 3 - 5 } & & $\phi=\mathbf{0 . 2 0 \%}$ & $\phi=\mathbf{0 . 2 5 \%}$ & \\
\hline $699-59-58$ & 2.2 & 0.60 & 0.48 & $\mathrm{~S} 11.2^{\circ} \mathrm{W}$ \\
& 6.3 & 0.77 & 0.61 & $\mathrm{~S} 35.0^{\circ} \mathrm{W}$ \\
& 9.3 & 1.2 & 0.93 & $\mathrm{~S} 43.9^{\circ} \mathrm{W}$ \\
\hline \multirow{4}{*}{ Average } & & & 0.66 & $\mathrm{~S} 33.5^{\circ} \mathrm{W}$ \\
\hline $699-60-57$ & 3.0 & 2.0 & 1.6 & $\mathrm{~S} 79.3^{\circ} \mathrm{W}$ \\
& 65.5 & 0.86 & 0.69 & $\mathrm{~N} 55.6^{\circ} \mathrm{E}$ \\
& 69.5 & 1.6 & 1.2 & $\mathrm{~N} 58.1^{\circ} \mathrm{E}$ \\
\hline Average & & & $0.96^{\circ}$ & $\mathrm{N} 57.2^{\circ} \mathrm{E}$ \\
\hline
\end{tabular}

NOTES:

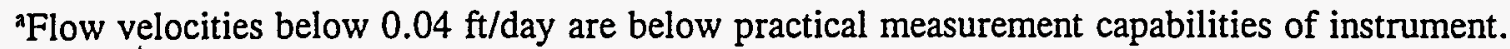
Values in parentheses are directions for velocities calculated using $0.20 \%$ porosity.

b Only the two lower flow velocities and directions were used in determining the average values. Average $=$ average value calculated using vector addition methods. NOTE: not an arithmetic average.

DBWL = depth below water level

$\phi \quad=$ effective porosity 
DOE/RL-95-59

Rev. 0 
DOE/RL-95-59

Rev. 0

APPENDIX F

AS-BUILT AND SITE MAPS FOR 200-BP-5 PUMP-AND-TREAT SITES 
DOE/RL-95-59

Rev. 0 
DOE/RL-95-59

Rev. 0

Table F-1. Treatability Test Wells Summary Table.

\begin{tabular}{|c|c|c|c|c|c|}
\hline WELI \# & DRILIED & $\begin{array}{l}\text { TOTAI } \\
\text { DEPTH }\end{array}$ & $\begin{array}{c}\text { OPEN } \\
\text { INTERVAI }\end{array}$ & DIAMETER & $\begin{array}{l}\text { TEST } \\
\text { USE }\end{array}$ \\
\hline $216-B-5$ & 1945 & $299^{\prime}$ & $240^{\prime}-299^{\prime}$ & $8 "$ & $\mathrm{~N} / \mathrm{A}$ \\
\hline 299-E28-7 & $1948 / 79$ & $338^{\prime}$ & $270^{\prime}-335^{\prime}$ & $6 "$ & $\begin{array}{l}\text { Ist } \\
\text { Injection } \\
\text { Well }\end{array}$ \\
\hline $299-E 28-23$ & 1979 & $328^{\prime}$ & $278^{\prime}-328^{\prime}$ & $4 "$ & $\begin{array}{l}\text { Exteraction } \\
\text { Well }\end{array}$ \\
\hline $299-E 28-24$ & 1980 & $327^{\prime}$ & $27^{\prime}-327^{\prime}$ & $4 "$ & $\begin{array}{l}\text { Obeservatio } \\
\mathbf{n}\end{array}$ \\
\hline $299-E 28-25$ & 1980 & $329^{\prime}$ & $279^{\prime}-329^{\prime}$ & $4 "$ & $\begin{array}{l}\text { 2nd } \\
\text { Injection } \\
\text { Well }\end{array}$ \\
\hline $699-50-53 A$ & 1955 & $159^{\prime}$ & $142^{\prime}-156^{\prime}$ & $8 "$ & $\begin{array}{l}\text { Extraction } \\
\text { Well }\end{array}$ \\
\hline $699-50-53 B$ & 1990 & $225^{\prime}$ & $215^{\prime}-225^{\prime}$ & 411 & Observation \\
\hline $699-49-55 A$ & 1961 & $141^{\prime}$ & $124^{\prime}-139$ & $6 n$ & $\begin{array}{l}\text { Injection } \\
\text { Well }\end{array}$ \\
\hline $699-49-55 B$ & 1982 & $227^{\prime}$ & $175^{\prime}-226^{\prime}$ & $6^{\prime \prime}$ & Observation \\
\hline $699-49-57 A$ & 1956 & $164^{\prime}$ & $144^{\prime}-161^{\prime}$ & $8 n$ & Observation \\
\hline $699-49-57 B$ & 1990 & $230^{\circ}$ & $219^{\prime}-230^{\prime}$ & $4 "$ & Observation \\
\hline
\end{tabular}


DOE/RL-95-59

Rev. 0

Figure F-1. 216-B-5 Reverse Well Plume.

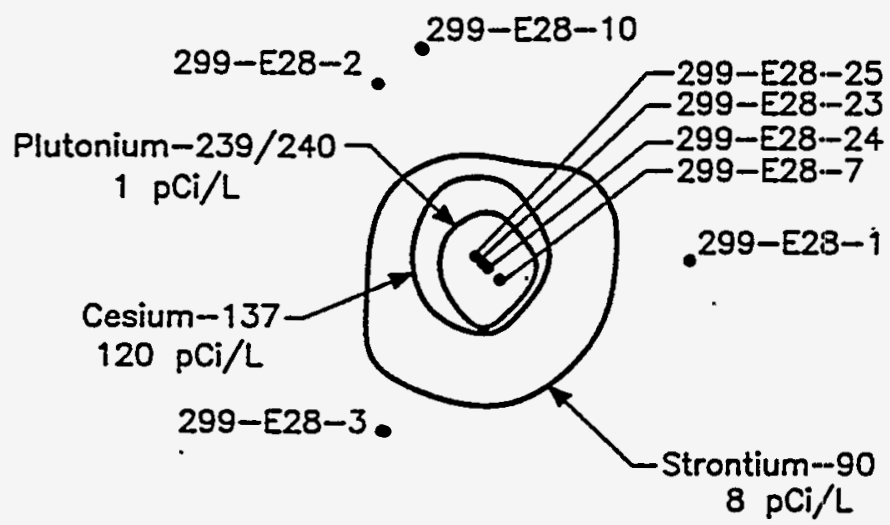

Legend

- Groundwater Monitoring Well Location

Contaminant

Drinking Water Standard Limits

IRM Concentrations Isopleth

Cesium-137..........120 pCi/L

Plutonium. .......... $1 \mathrm{pCi} / \mathrm{L}$

Strontium-90........8 $8 \mathrm{pCi} / \mathrm{L}$

Sources: Ford, 1993.

DOE-RL 1994.

mH:Lh:BP5-1 
DOE/RL-95-59

Rev. 0

Figure F-2. 200-BP-5 Location Map for the 216-B-5 Reverse Well Cluster.

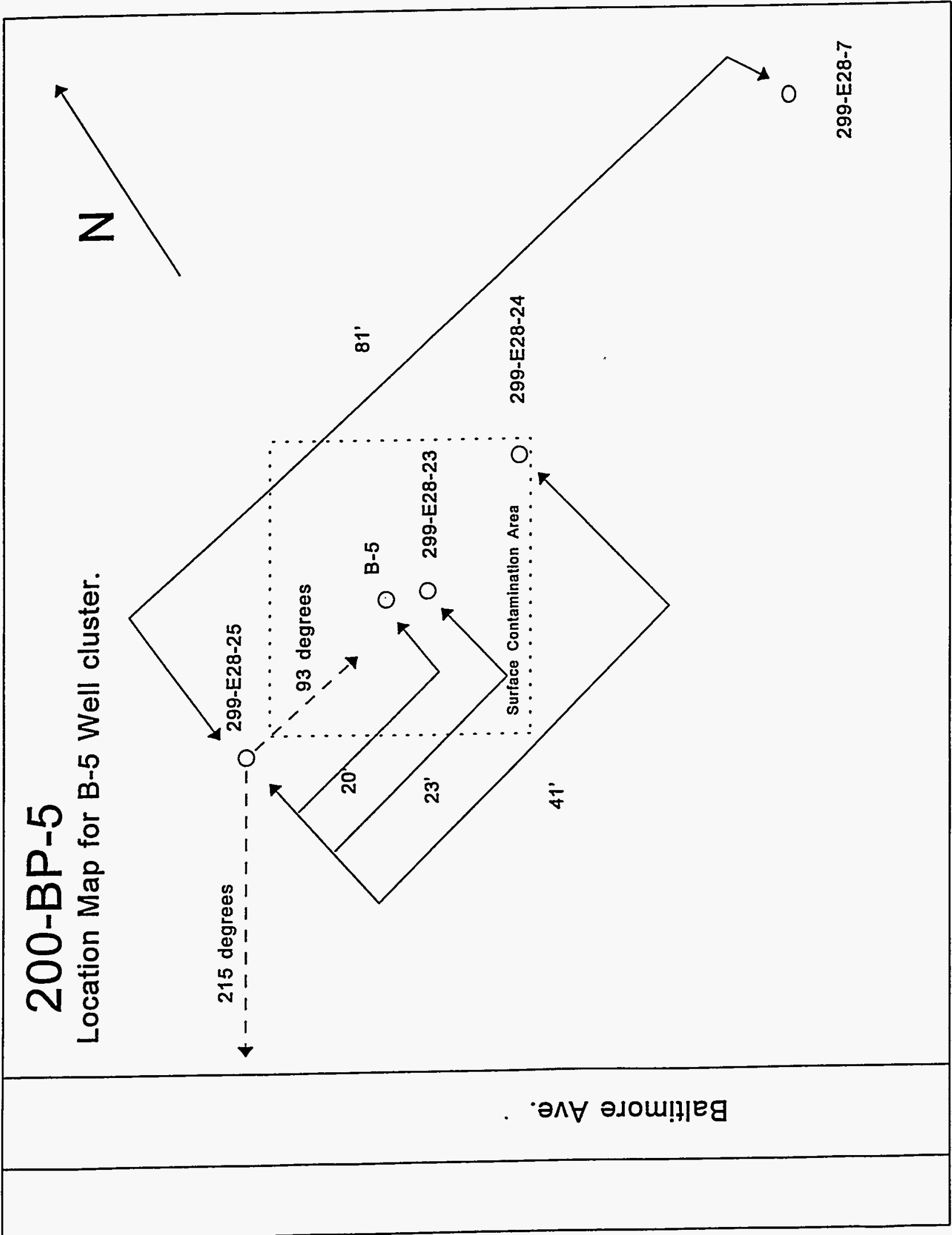




\section{Geologic Cross Section A-A'}

Ceslum $\cdot 137$

(nCl/g)

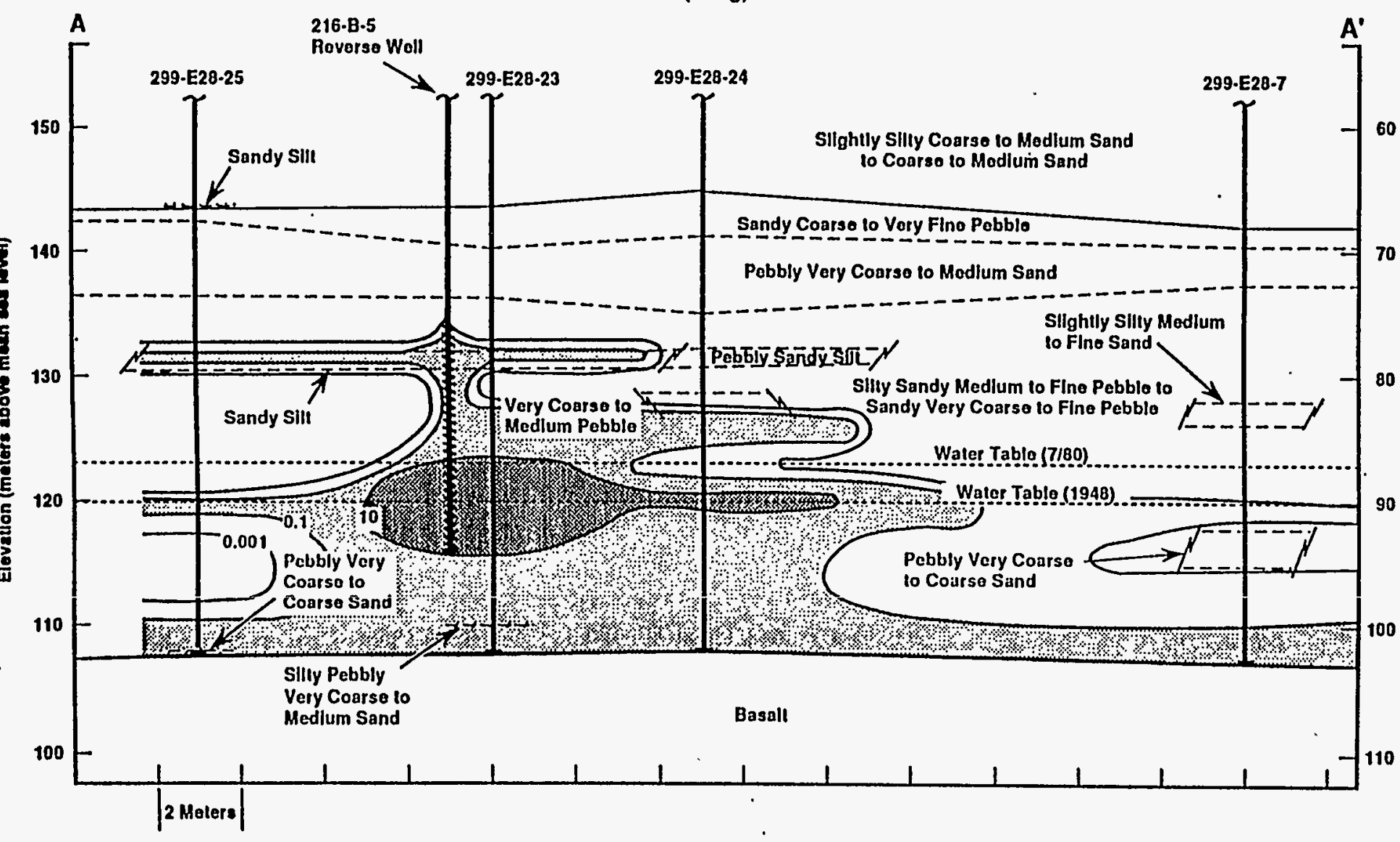




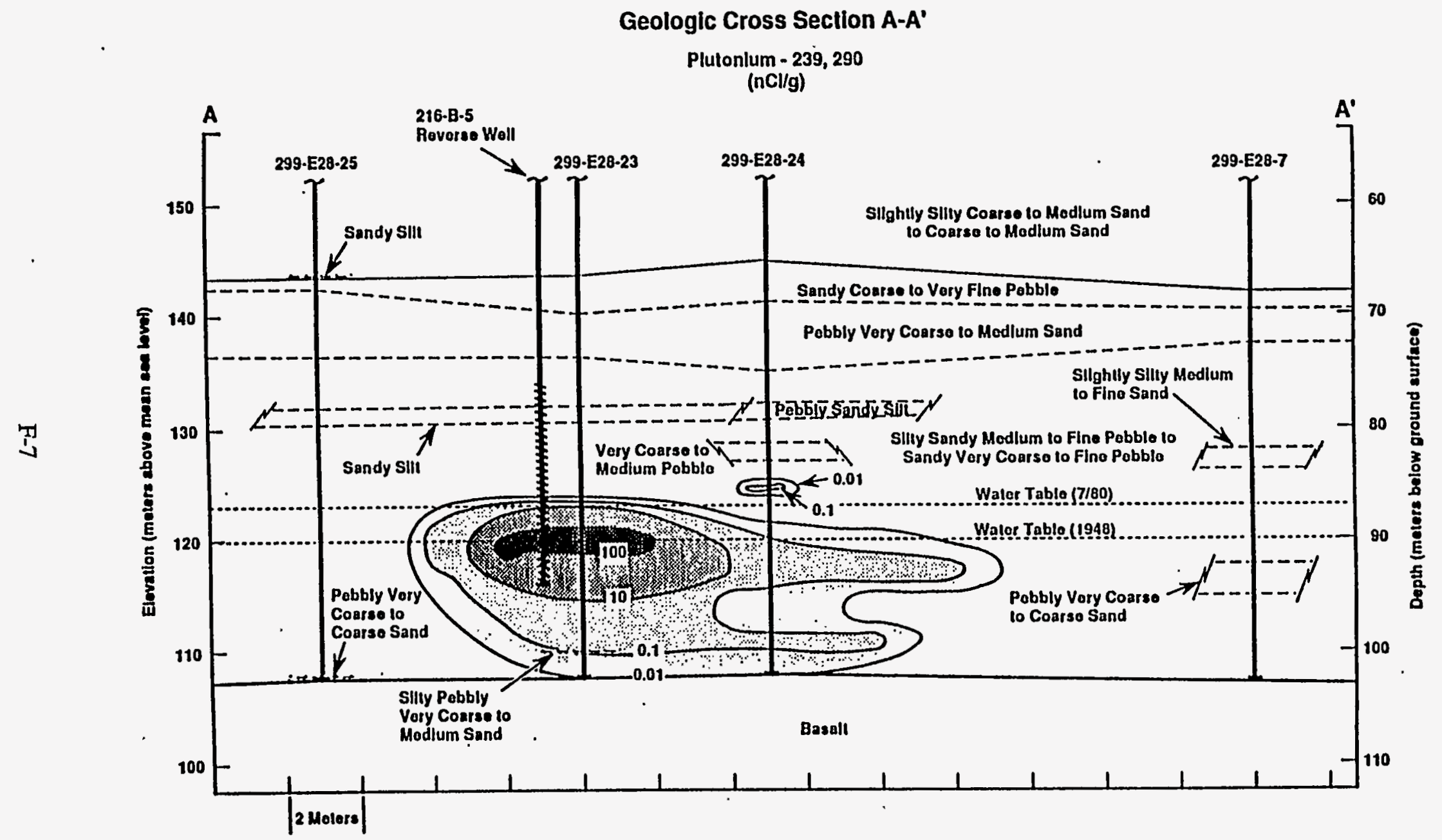


DOE/RL-95-59

Rev. 0

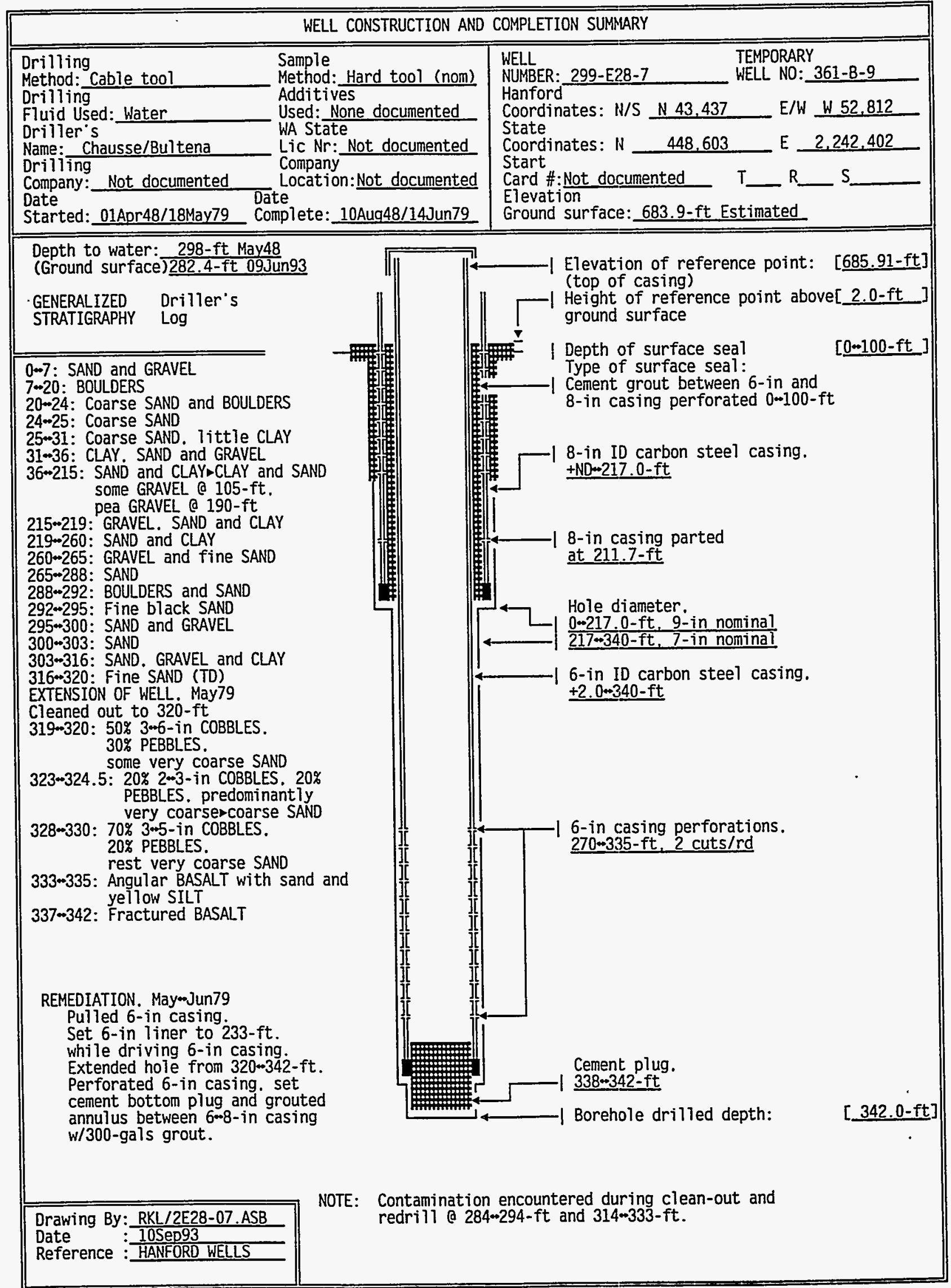


SUMMARY OF CONSTRUCTION DATA AND FIELD OBSERVATIONS RESOURCE PROTECTION WELL - 299-E28-7

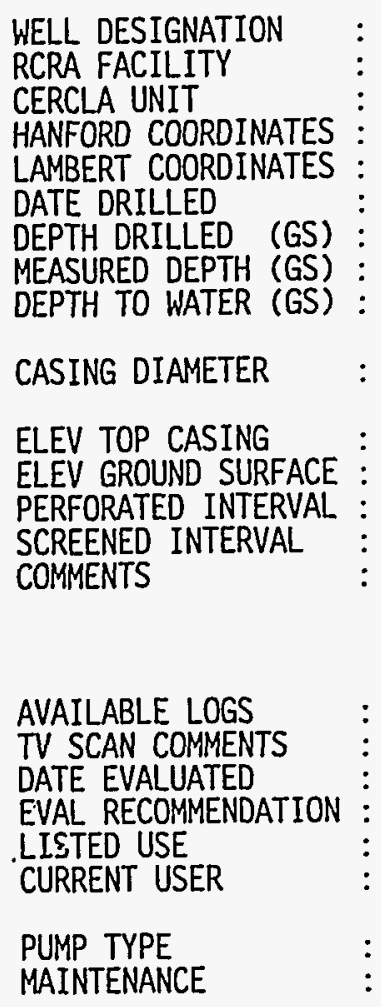

299-E28-7

Not applicable

200 Aggregate Area Management Study

$N \quad 43.437 \mathrm{~W} \quad 52.812$

$N$ 448.603 E 2.242.402 [HANCONV]

Aug48-Deepened Jun79

342.0-ft

Not documented

298-ft. May48;

282.4-ft. 09Jun93

8-in. Carbon steel. ND-217.0-ft:

$6-$ in carbon steel $+2.1 \leftrightarrow 340.0-\mathrm{ft}$

685.91-ft

683.9-ft. Estimated

270 $335-\mathrm{ft}$

Not applicable

FIELD INSPECTION, 10Aug93.

6 and 8 -in carbon steel casing. Capped and locked

2-ft pad. 4 posts, identification stamped on brass marker. Not in radiation zone.

Driller

Not applicable

Not applicabie

Not applicable

Seperations area semiannual water levels measurement, 20Apr73-09Jun93:

WHC ES\&M w/1 monitoring,

PNL sitewide sampling 93

Hydrostar 
Rev. 0

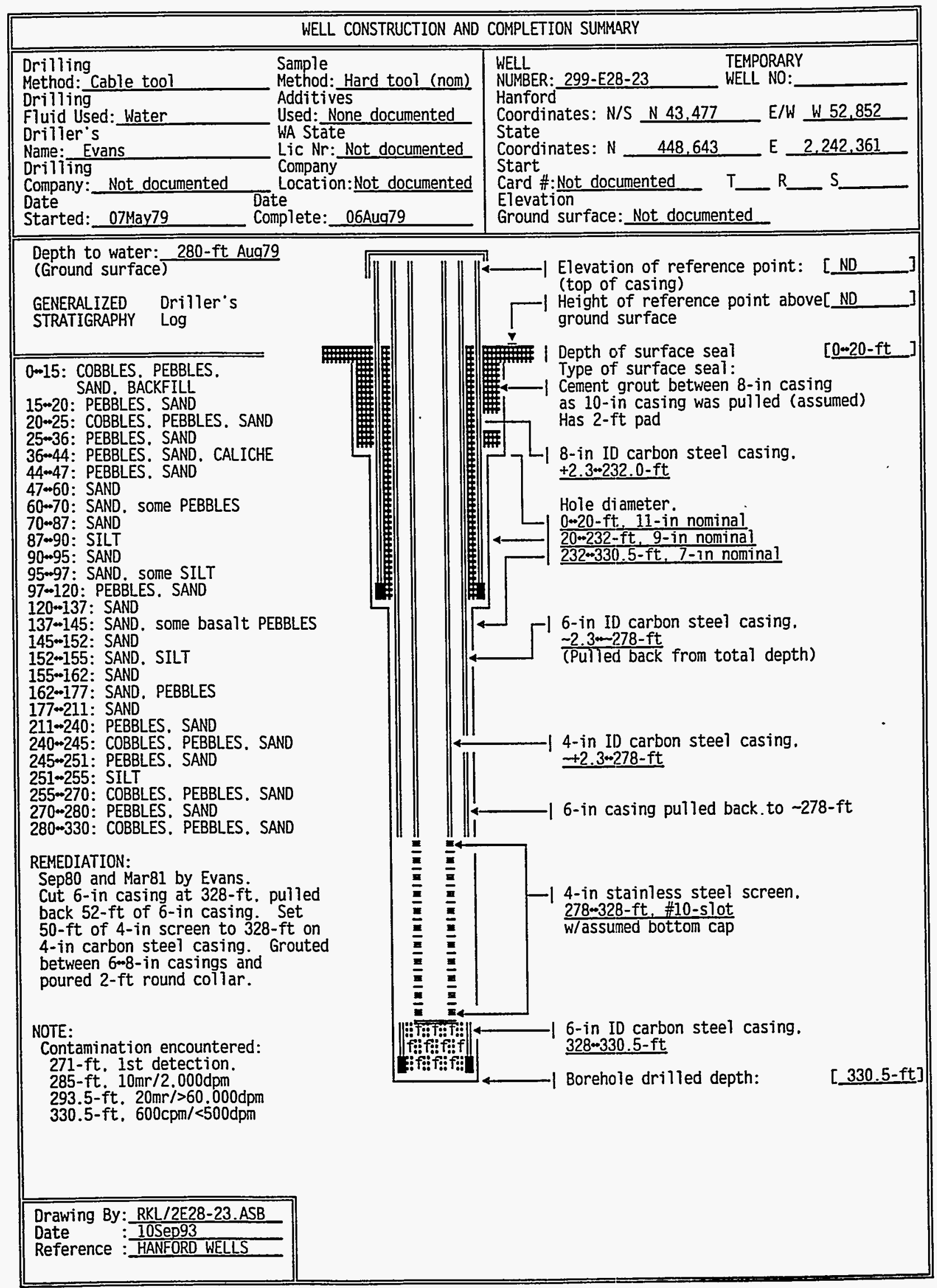




\section{DOE/RL-95-59}

Rev. 0

\section{SUMMARY OF CONSTRUCTION DATA AND FIELD OBSERVATIONS} RESOURCE PROTECTION WELL - 299-E28-23

WELL DESIGNATION
RCRA FACILITY
CERCLA UNIT
HANFORD COORDINATES
LAMBERT COORDINATES
DATE DRILLED
DEPTH DRILLED (GS)
MEASURED DEPTH (GS)
DEPTH TO WATER (GS)
CASING DIAMETER
CASING DIET

ELEV TOP CASING

ELEV GROUND SURFACE PERFORATED INTERVAL : SCREENED INTERVAL COMMENTS

\section{AVAILABLE LOGS}

TV SCAN COMMENTS

DATE EVALUATED

EVAL RECOMMENDATION :

LISTED USE

CURRENT USER

PUMP TYPE

MAINTENANCE
299-E28-23

Not applicable

200 Aggregate Area Management Study

N $43.477 \mathrm{~W} 52.852$

$N$ 448.643 E 2,242.361 [HANCONV]

Aug79-Completed Sep80 and Mar81

330.5-ft

Not documented

$280-\mathrm{ft}$. Aug79

8-in, carbon steel, $+2.3-232.0-\mathrm{ft}$ :

6 -in carbon stee] $+2.3-278.0-\mathrm{ft}$

4-in carbon stee], +2.3-278-ft

Not documented

Not documented

None

278-328-ft

FIELD INSPECTION. 240ct89.

3 carbon steel casings. 2-ft pad, no posts. capped, and locked. No permanent identification. In radiation zone.

\section{Driller, Geologist}

Not applicable

Not applicable

Not applicable

No water level measurement data,

WHC ES\&M operational sampling.

PNL sitewide sampling 93

Electric submersible 
DOE/RL-95-59

Rev. 0

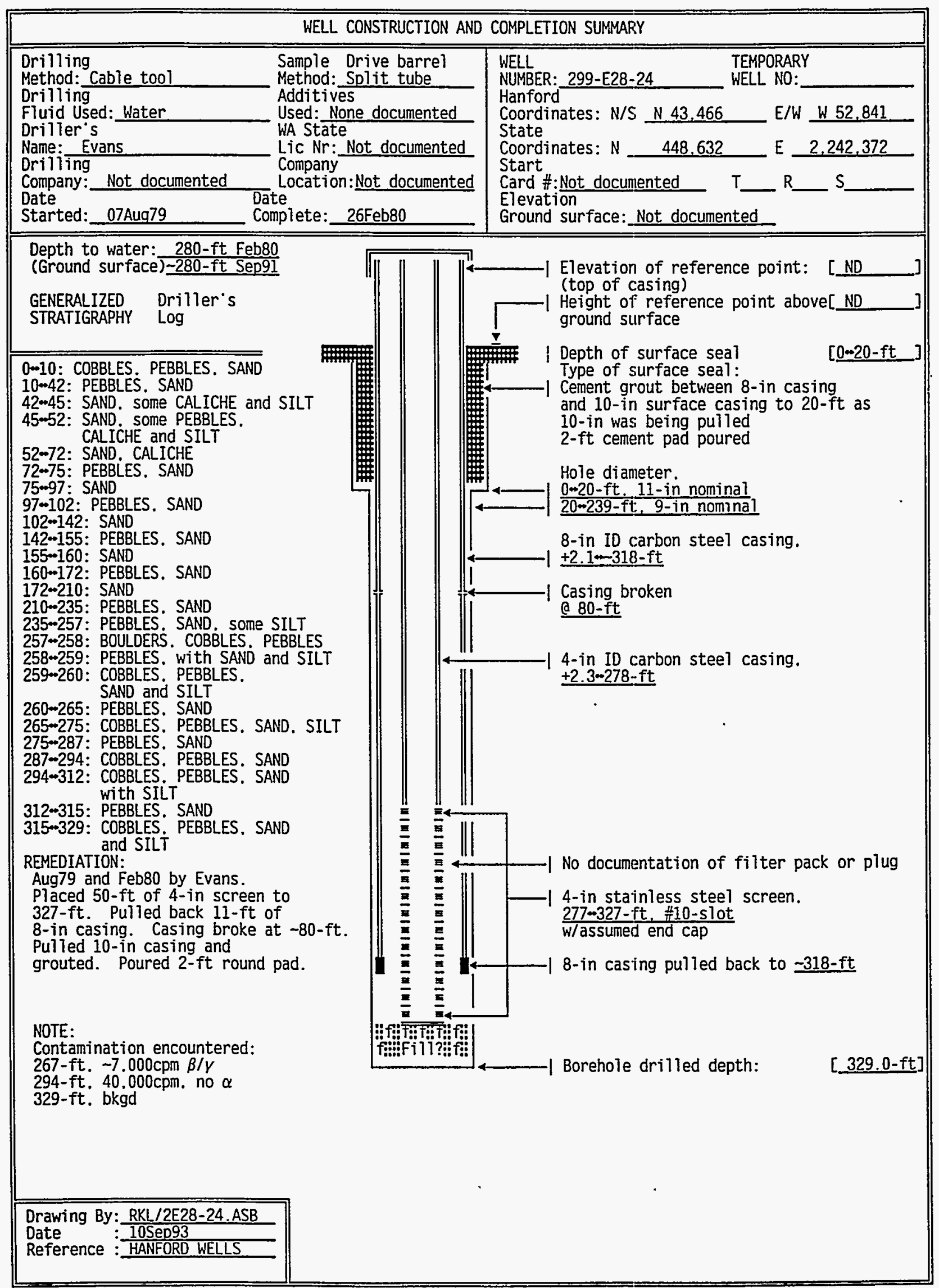


DOE/RL-95-59

Rev. 0

\section{SUMMARY OF CONSTRUCTION DATA AND FIELD OBSERVATIONS}

RESOURCE PROTECTION WELL - 299-E28-24

\begin{tabular}{l} 
WELL DESIGNATION \\
RCRA FACILITY \\
CERCLA UNIT \\
HANFORD COORDINATES \\
LAMBERT COORDINATES \\
DATE DRILLED \\
DEPTH DRILLED (GS) \\
MEASURED DEPTH (GS) \\
DEPTH TO WATER (GS) \\
CASING DIAMETER $($ TOC) \\
ELEV TOP CASING \\
ELEV GROUND SURFACE \\
PERFORATED INTERVAL \\
SCREENED INTERVAL \\
COMMENTS \\
\multicolumn{1}{|}{} \\
AVAILABLE LOGS \\
TV SCAN COMMENTS \\
DATE EVALUATED \\
EVAL RECOMMENDATION : \\
LISTED USE \\
CURRENT USER \\
PUMP TYPE \\
MAINTENANCE
\end{tabular}

\section{9-E28-24}

Not applicable 200 Aggregate Area Management Study

N $43.466 \mathrm{~W} \quad 52.841$

$N$ 448.632 E 2.242.372 [HANCONV]

Feb80-Completed Aug79 and Feb80

329.0-ft

Not documented

280-ft. Aug79.

282.9-ft. Sep91

8-in, carbon steel, +2.1-318. 0-ft:

4-in carbon steel, $+2.1 \propto 278-\mathrm{ft}$

Not documented

Not documented

None

$277-327-f t$

FIELD INSPECTION, 240ct89

2- $\mathrm{ft}$ round cement pad. Capped and locked. No posts, no permanent identification. 8-in and 4-in carbon steel casing. In radiation zone.

Driller, Geologist

Not applicable

Not applicable

Not applicable

Water levels measured (depth to water only) 06Apr90-23Sep91

PNL sitewide sampling 93

None documented 
DOE/RL-95-59

Rev. 0

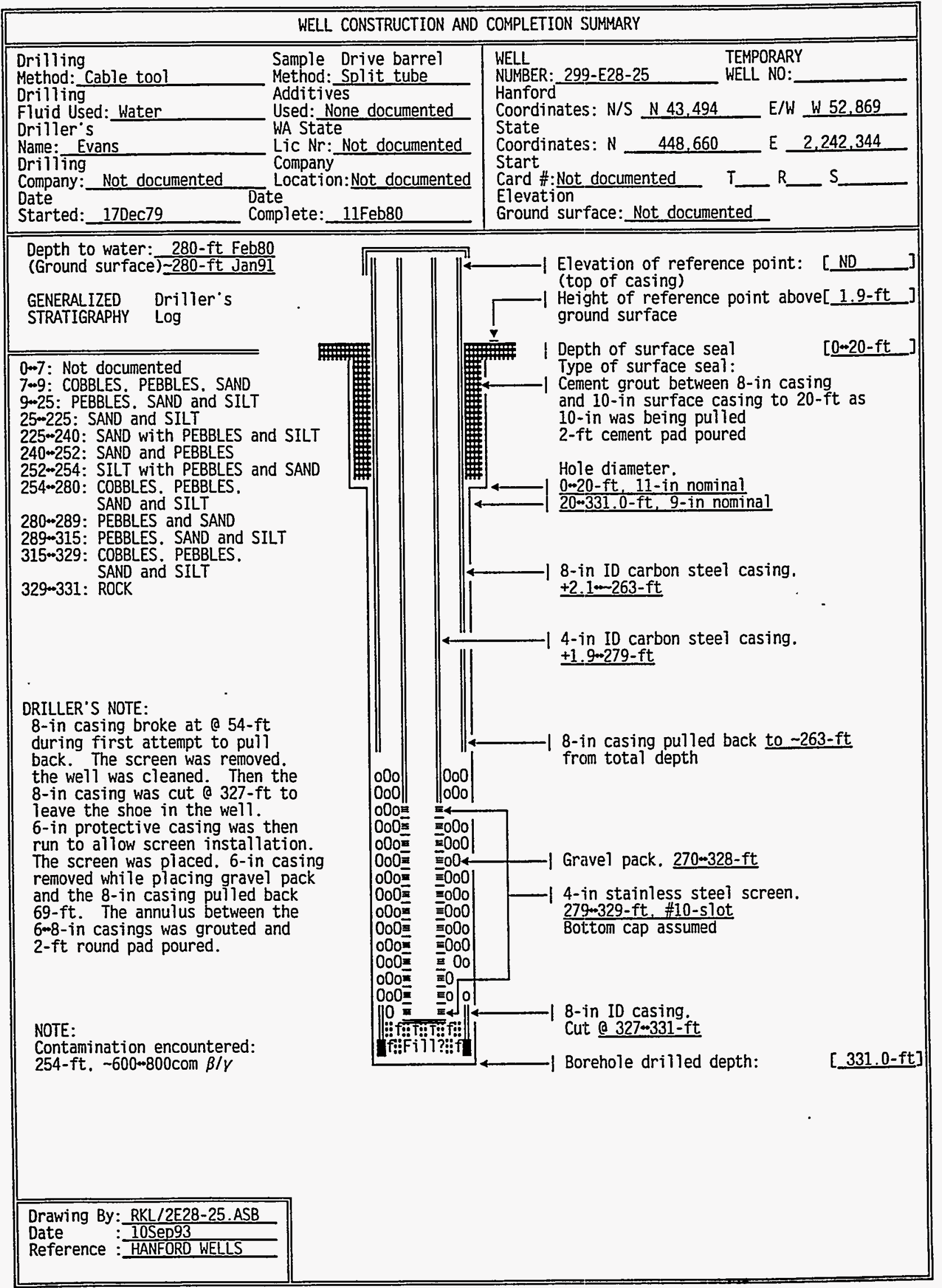


DOE/RL-95-59

Rev. 0

\section{SUMMARY OF CONSTRUCTION DATA AND FIELD OBSERVATIONS}

RESOURCE PROTECTION WELL - 299-E28-25

\begin{tabular}{|c|}
\hline $\begin{array}{l}\text { REL } \\
\text { CER } \\
\text { CER } \\
\text { HAM } \\
\text { DAT } \\
\text { DEP } \\
\text { MEA }\end{array}$ \\
\hline CASING DIAMETER \\
\hline $\begin{array}{l}\text { ELEV TOP CASING } \\
\text { ELEV GROUND SURFACE } \\
\text { PERFORATED INTERVAL } \\
\text { SCREENED INTERVAL } \\
\text { COMMENTS }\end{array}$ \\
\hline $\begin{array}{l}\text { AVAILABLE LOGS } \\
\text { TV SCAN COMMENTS } \\
\text { DATE EVALUATED } \\
\text { EVAL RECOMMENDATION } \\
\text { LISTED USE } \\
\text { CURRENT USER } \\
\text { PUMP TYPE } \\
\text { MAINTENANCE }\end{array}$ \\
\hline
\end{tabular}

299-E28-25

Not applicable

200 Aggregate Area Management Study

N 43.494 W 52.869

$N$ 448.660 E 2.242.344 [HANCONV]

Feb80

331.0-ft

Not documented

$280-\mathrm{ft}$. Feb80;

$280-\mathrm{ft}$. 31Jang1

8-in, carbon steel, $+1.9 \cdots-263.0-\mathrm{ft}$ :

$4-$ in carbon steel. $+1.9-279-\mathrm{ft}$

Not documented

Not documented

None

$279 \leftrightarrow 329-\mathrm{ft}$

FIELD INSPECTION, 240ct89

$2-\mathrm{ft}$ round cement pad. Capped and locked. No posts, no permanent identification. 8 -in and 4-in carbon steel casing. Not in radiation zone.

Driller. Geologist

Not applicable

Not applicable

Not applicable

Water levels measured (depth to water only) 23Mar90-31Jan91

PNL sitewide sampling 93

None documented 
Figure F-5. Contaminant Plumes and Location Map.

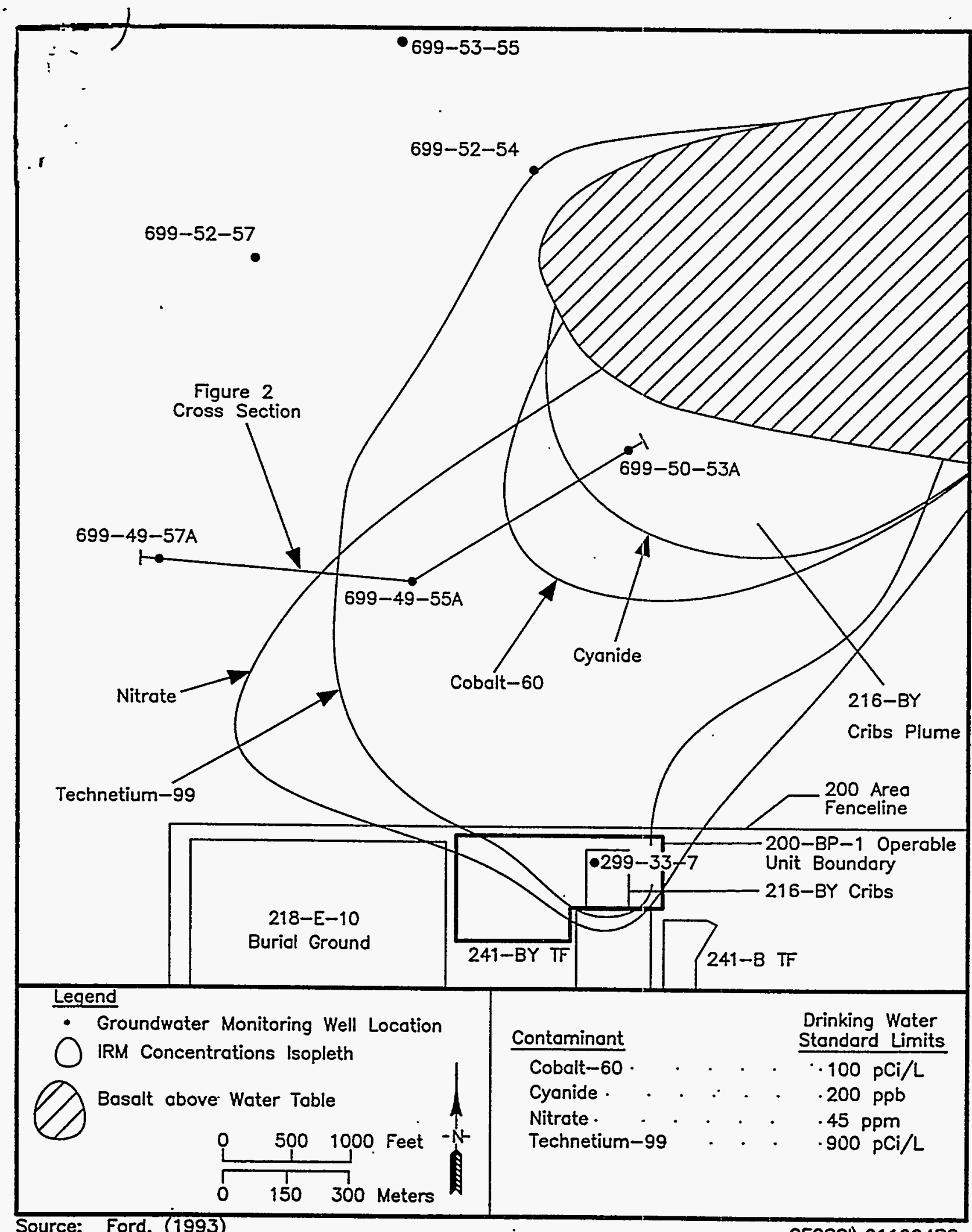


DOE/RL95-59

Rev. 0

Figure F-6. Location Map for the 216-BY Cribs.

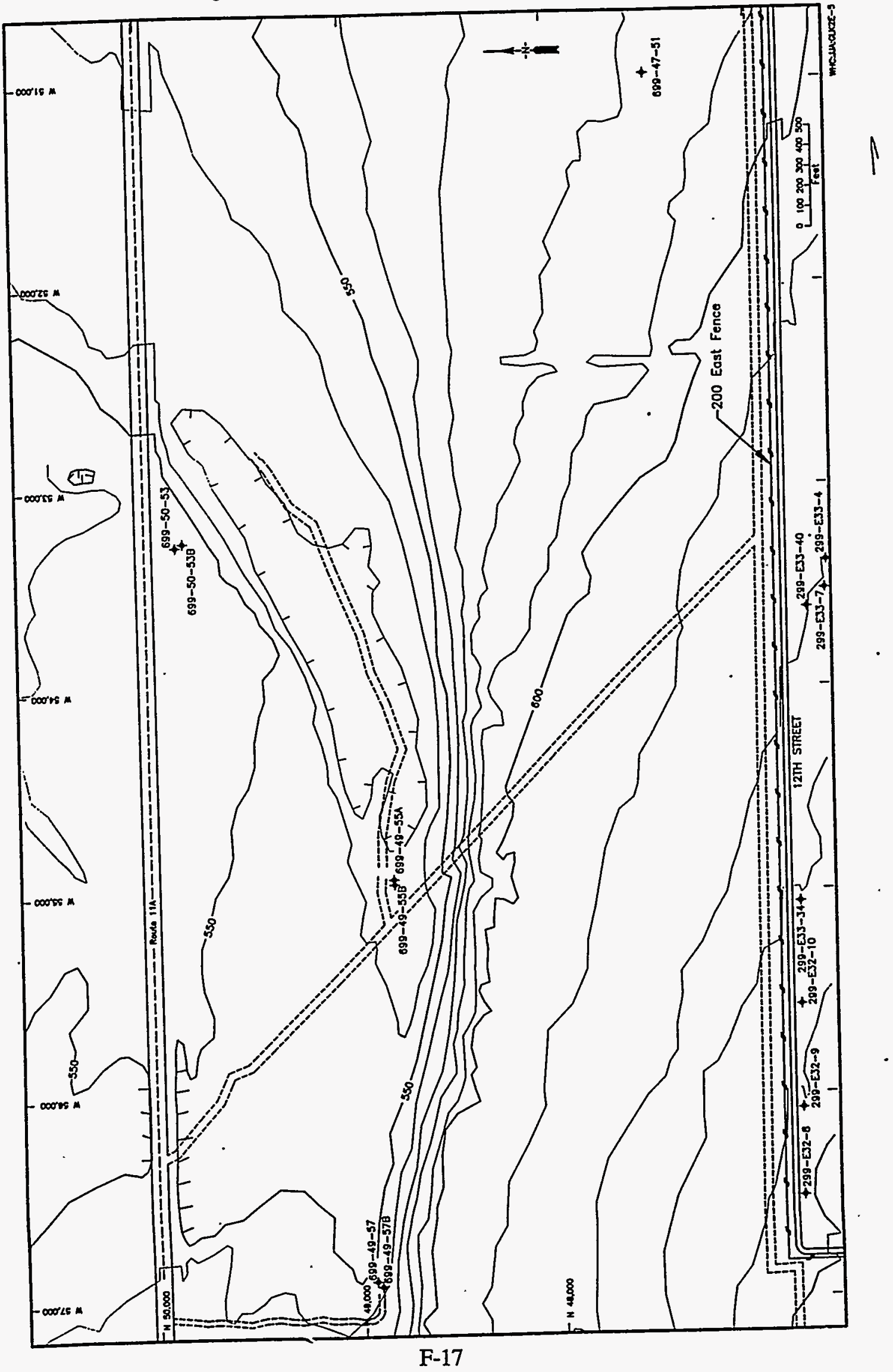


Figure F-7. Geologic Cross Section.
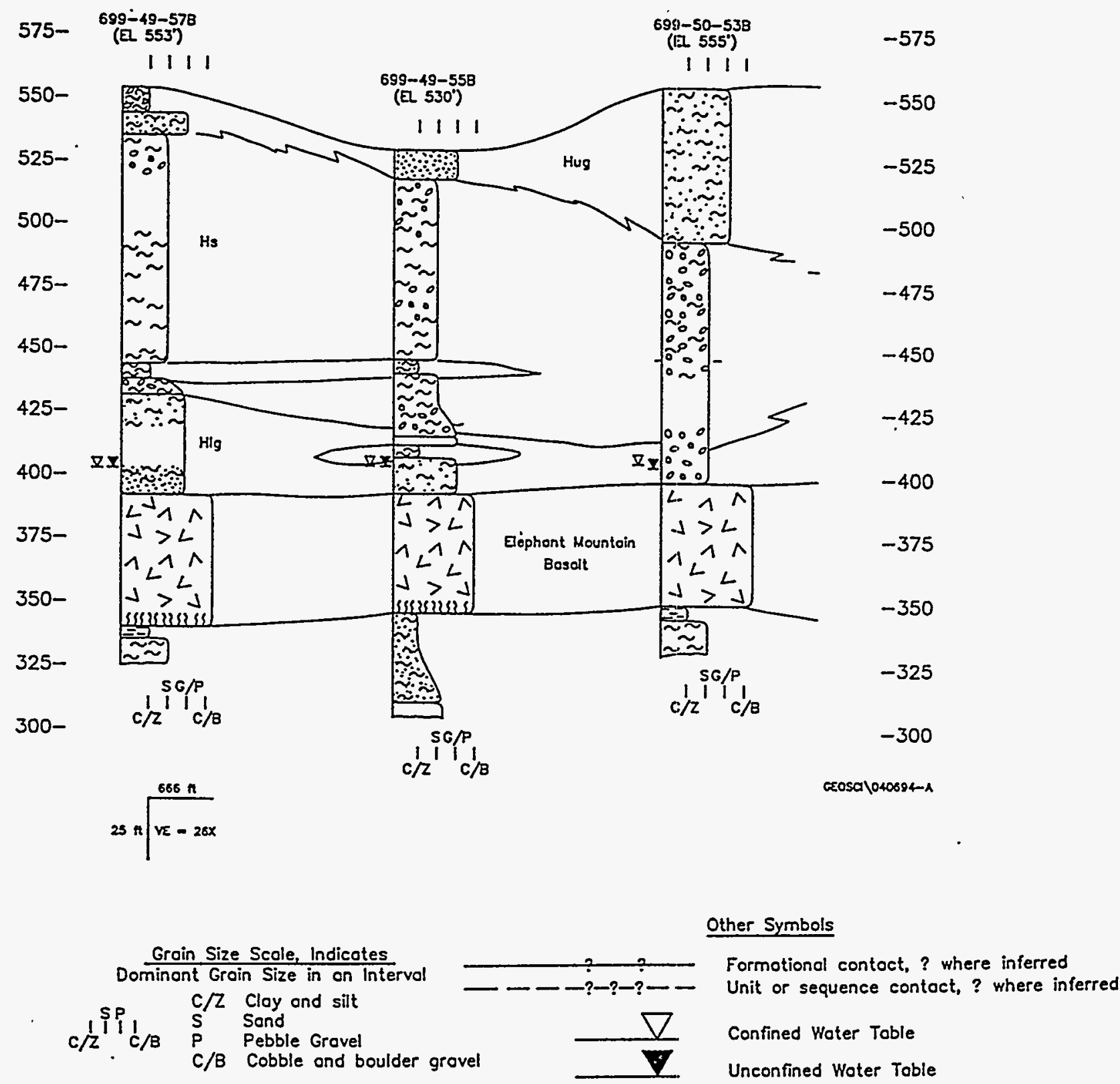

Additional Lithologic Symbols,

Includes Subordinote Lithologies

- Cloy rich

$\sim$ Silt rich

$\because \because$ Sondy

$\because: \because$ Pebble Gravel

$\therefore 0$ Cobble and Boulder

なさよ Bosolt
Strotiorophic Abbreviotions

Hun - Unclifferentioted Hanford formation

Hug - Upper grovel sequence, Honford formation

Hs - Sondy sequence, Honford formotion

Hig - Lower grovel sequence, Honford formation

EM - Elejahont Mountoin Member

RRI - Rottlesnoke Ridge Interbed

$P$ - Pornono Member 
DOE/RL-95-59

Rev. 0

As-Built Diagrams for Hells:

699-50-53A

699-50-53B

699-49-55A

699-49-55B

699-49-57A

$699-49-57 \mathrm{~B}$ 
DOE/RL-95-59

Rev. 0

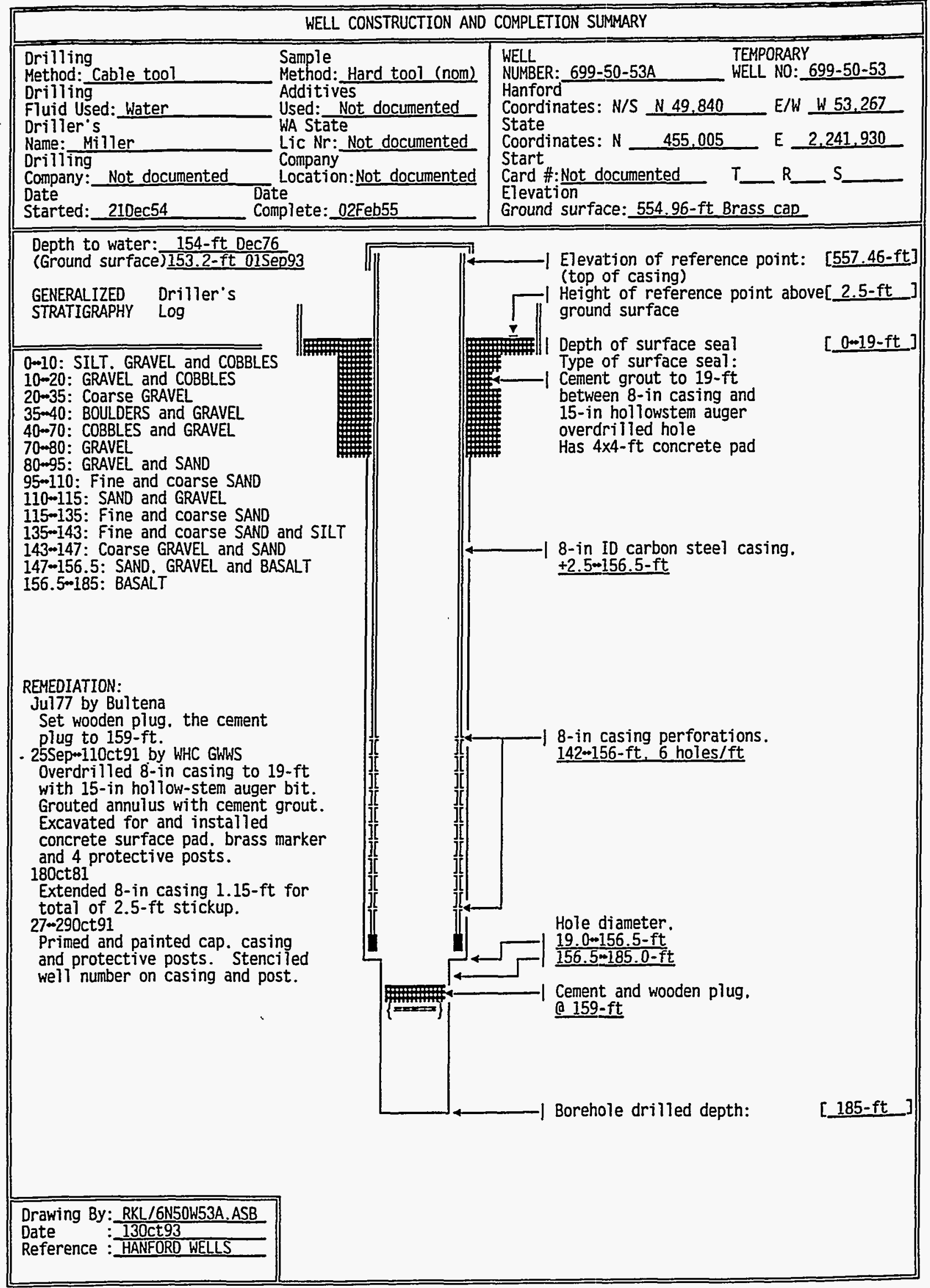


DOE/RL-95-59

Rev. 0

SUMMARY OF CONSTRUCTION DATA AND FIELD OBSERVATIONS

RESOURCE PROTECTION WELL - 699-50-53A

WELL DESIGNATION
RCRA FACILITY
CERCLA UNIT
HANFORD COORDINATES
LAMBERT COORDINATES :
DATE DRILLED
DEPTH DRILLED (GS)
MEASURED DEPTH (GS)
DEPTH TO WATER (GS)
CASING DIAMETER
ELEV TOP OF CASING
ELEV GROUND SURFACE :
PERFORATED INTERVAL :
SCREENED INTERVAL
COMMENTS

AVAILABLE LOGS

TV SCAN COMMENTS
DATE EVALUATED

EVAL RECOMMENDATION

699-50-53A

Not applicable

200-BP-1 (200 Aggregate Area Management Study)

N 49,840 W 53.267

$N 455,005 \quad E 2.241 .930$ [HANCONV]

Feb55

185-ft

162-ft, Aug90 TV

154-ft, Dec76:

153.2-ft, 01Sep93

8-in. carbon steel. $+2.5+156.5-\mathrm{ft}$

$557.46-\mathrm{ft}$.

[25Feb92-NGVD' 29)

554.96-ft. Brass cap [25Feb92-NGVD'29]

$142 \bullet 156-\mathrm{ft}$

Not applicable

FIELD INSPECTION, 110ct89.

Carbon steel casing.

No pad. capped and locked. no posts.

Identification stamped on brass marker.

FIELD INSPECTION, 060 ct92.

8-in carbon steel casing. Capped and locked

4-ft by 4 -ft concrete pad. 4 posts. Identification stamped on brass marker in pad. Not in radiation zone.

OTHER:

Driller

Depths referenced to ground surface:

Jan90:

Depth to bottom: $160-\mathrm{ft}$

Bottom of casing: 156-ft

Depth to water: $150-\mathrm{ft}$

Perforated $138+156-\mathrm{ft}$ (?). 6 cuts/rd/ft. Material flaking off caused by camera.

Casing has average scale bujld-up.

10Aug90:

Depth to bottom: $162-\mathrm{ft}$

Depth to water: $151-\mathrm{ft}$. floating debris

Casing clean. Perforated $139 \%(?)-\mathrm{ft}, 6$ cuts $\mathrm{rd} / \mathrm{ft}$. Thse visible were open.

Water murky with suspended debris. Vision obscured by possibly algae.

13 Nov 90

1. Install a 2-in void grout surface seal outside

8-in casing to approximately 18-ft. OR:

2. Perforate 3-18-ft and insta17 a 4-in liner with cement basket to approximately 20-ft. Pressure grout to 40-psi.

3. Instail protective posts and concrete pad per WAC 173-160-510 and field conditions.

4. Survey to water level measurement standards.

LISTED USE

CURRENT USER

PUMP TYPE

MAINTENANCE

REMEDIATION
$200 \mathrm{BP}-1$ quarterly water level measurement. 07Feb55\%01Sep93

: WHC ER characterization and ES\&M w/l monitoring.

PNL sitewide sampling and $w / 7$ monitoring 93

Hydrostar. intake at 156.9-ft. (top-of-casing)

: 21May90: Pulled pump. scrubbed casing and bailed debris. Considerable contamination found.

06\&11Jun90: Developed wel1 with pump to $<5$ NTU.

13Aug90: Installed pump and new cap.

: $\quad$ 25Sep91: Cleared site.

01œ020ct91: Overdrilled 8-in casing to 19-ft with 15-in hollow-stem auger. Grouted annulus with cement grout (Al powder added).

07-090ct91: Excavated for surface pad and protective posts.

110ct91: Installed 4-ft by 4 -ft surface pad. brass marker and 4 protective posts. 180ct91: Extended casing 1.15-ft for 2.50 - ft stickup.

27-290ct91: Primed and painted cap. casing and protective posts. Stenciled well number on casing and post. 
DOE/RL-95-59

Rev. 0

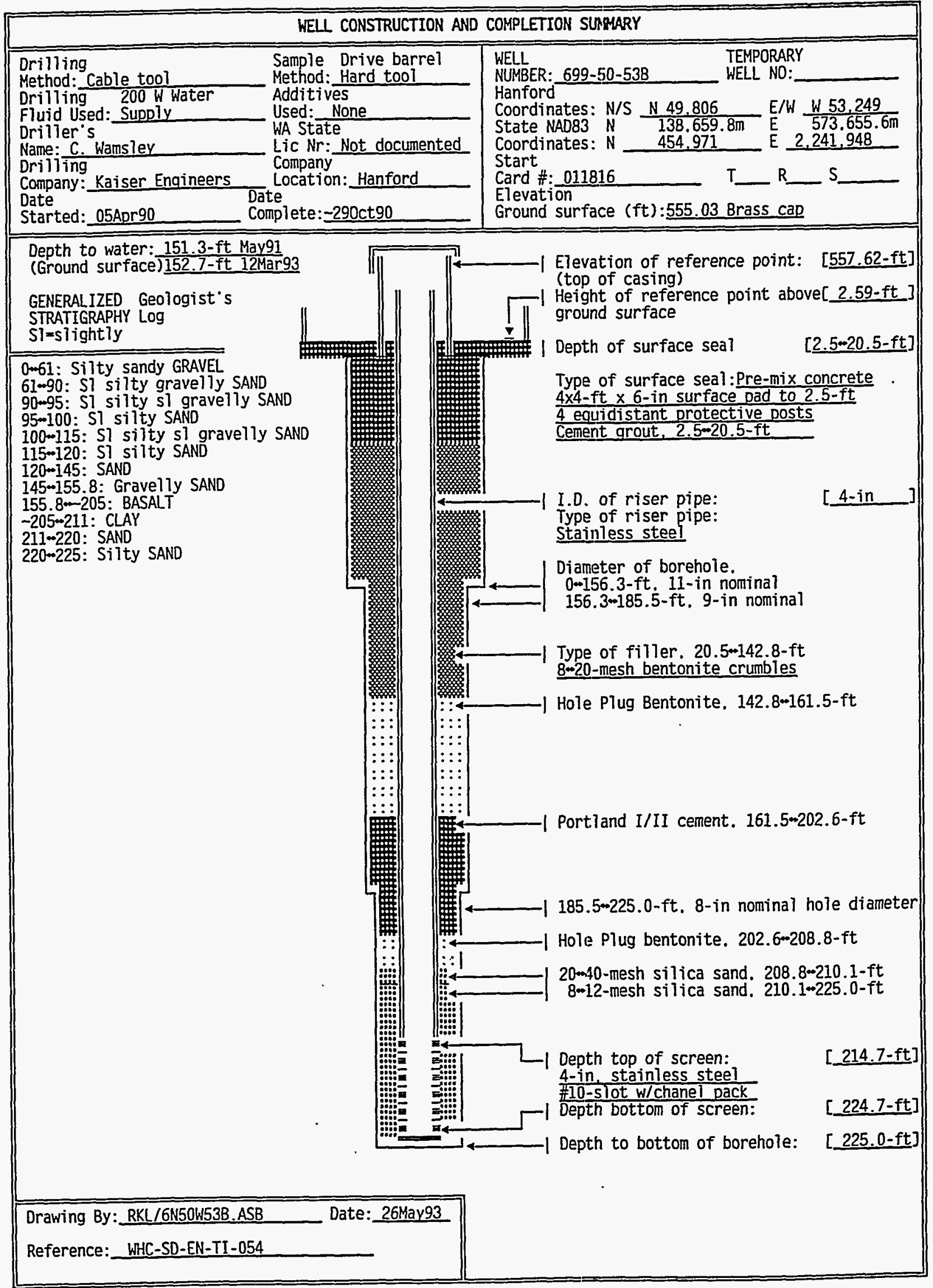


SUMMARY OF CONSTRUCTION DATA AND FIELD OBSERVATIONS RESOURCE PROTECTION WELL - 699-50-53B

WELL DESIGNATION
CERCLA UNIT
RCRA FACILITY
HANFORD COORDINATES
LAMBERT COORDINATES :
DATE DRILLED
DEPTH DRILLED (GS)
MEASURED DEPTH (GS)
DEPTH TO WATER (GS)
CASING DIAMETER
ELEV TOP CASING
ELEV GROUND SURFACE :
PERFORATED INTERVAL
SCREENED INTERVAL
COMMENTS

AVAILABLE LOGS TV SCAN COMMENTS DATE EVALUATED EVAL RECOMMENDATION : LISTED USE

PUMP TYPE MAINTENANCE
$699-50-53 B$

200-BP-1 (200 Aggregate Area Management Study) Not applicable

N 49.806

N 454.971

N $138.659 .8 \mathrm{~m}$

W 53.249

E 2.241.948

[25Jan91-200E] [HANCONV]

- Oct90

225. 0 - ft

Not documented

151.3-ft. 07May90:

152.7-ft. 12Mar93

4-in stainless steel. +0.3-214.7-ft:

6 -in stainless steel. $+2.59-0.5-\mathrm{ft}$

557.62-ft. [25Jan91-NGVD'29]

555.03-ft. Brass cap [25Jan91-NGVD 29]

Not applicable

214.7-224.7-ft. 4-in \#10-slot stainless steel w/channel pack FIELD INSPECTION, 07Mar91:

4 and 6-in stainiess steel casing.

4-ft by 4 -ft concrete pad, 4 posts, 1 removable. Capped and locked, brass cap in pad with well ID. Not in radiation zone.

OTHER:

Geologist. driller

Not applicable

Not applicable

Not applicable

200-BP-1 Quarterly water level measurement. 01Mar91-12Mar93:

Not on PNL or WHC operational water sample schedule

Hydrostar 
DOE/RL-95-59

Rev. 0

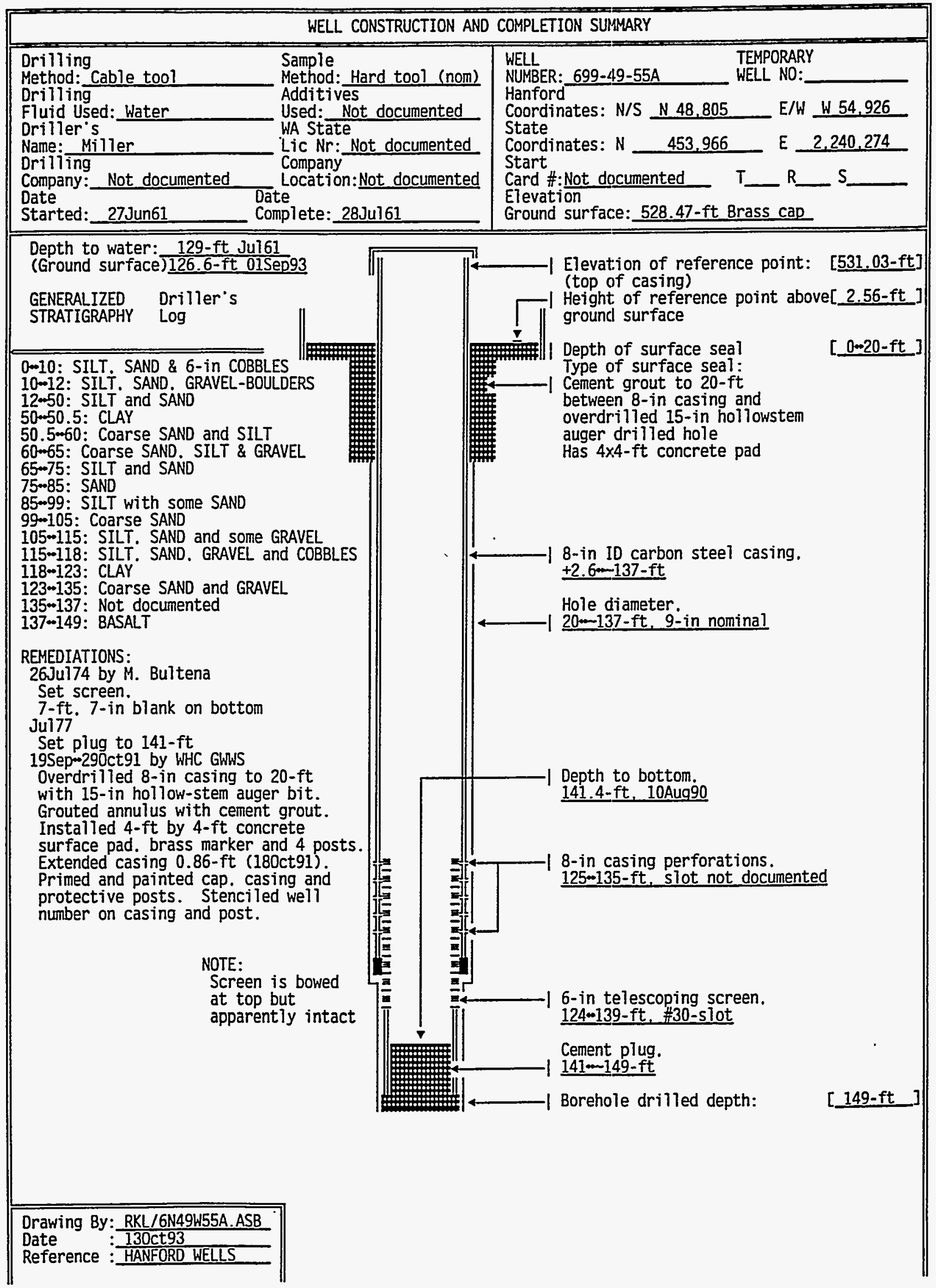


DOE/RL-95-59

Rev. 0

\section{SUMMARY OF CONSTRUCTION DATA AND FIELD OBSERVATIONS \\ RESOURCE PROTECTION WELL - 699-49-55A}

AVAILABLE LOGS

TV SCAN COMMENTS

WELL DESIGNATION
RCRA FACILITY
CERCLA UNIT
HANFORD COORDINATES
LAMBERT COORDINATES
DATE DRILLED
DEPTH DRILLED (GS)
MEASURED DEPTH (GS)
DEPTH TO WATER (GS)
CASING DIAMETER
ELEV TOP OF CASING
ELEV GROUND SURFACE
PERFORATED INTERVAL
SCREENED INTERVAL
COMMENTS

699-49-55A

Not applicable

200-BP-1 (200 Aggregate Area Management Study)

N 48.805 W 54.926

$N$ N53.966 E 2.240.274 [HANCONV]

Ju161

149-ft

141.4-ft. Aug90 TV

129-ft. JuT61:

126.6-ft. $015 e p 93$

8-in. carbon steel, $+2.56-137-\mathrm{ft}$

531.03-ft. [25Feb92-NGVD' 29]

528.47-ft. Brass cap [25Feb92-NGVD'29]

$125 \cdots 135-\mathrm{ft}$

124-139-ft. Nominal 8-in telescoping.

\#30-slot

FIELD INSPECTION. 110ct89.

Carbon steel casing.

No pad. capped and jocked, no posts.

No permanent identification.

FIELD INSPECTION, 160ct92.

8-in carbon steel casing. Capped and locked

4-ft by 4-ft concrete pad. 4 posts. Identification stamped on brass marker in pad. Not in radiation zone.

OTHER:

Driller

Depths referenced to ground surface:

Dec89:

Depth to bottom: $139-\mathrm{ft}$

Bottom of casing: $139-\mathrm{ft}$

Depth to water: $122.5-\mathrm{ft}$

Casing weathered. Screen 121-137-ft. Screen is bowed in on one side

but intact. Crud collecting on screen. Blank 137-139-ft.

10Aug90:

Depth to bottom: 141.4-ft. soft floating stuff

Depth to water: 126-ft. fioating debris

Casing clean. Screen 124-139-ft. Slots are open. screen looks good.

Water real good.

13 Nov90

DATE EVALUATED
EVAL RECOMMENDATION :

1. Install a 2-in void grout surface seal outside

8-in casing to approximately 18-ft. OR:

2. Perforate $3 \cdots 18-\mathrm{ft}$ and instal1 a 4-in liner with cement basket to approximately 20-ft. Pressure grout to 40-psi.

3. Instail protective posts and concrete pad per WAC 173-160-510 and field conditions.

4. Survey to water level measurement standards.

LISTED USE

200 BP-1 quarterly water level measurement. 14Aug61-01Sep93

WHC ES\&M ER characterization and $w / 1$ monitoring.

PNL sitewide sampling 93

Hydrostar. intake at 137.9-ft. (top-of-casing)

PUMP TYPE

MAINTENANCE

REMEDIATION
17\&19Apr90: Pulled pump. scrubbed casing and screen, bailed debris.

19\&26Jun90: Developed well by pumping to <5 NTU.

13Aug90: Installed pump.

19Sep91: Cleared site.

24Sep91: Overdrilled 8 -in casing with 15 -in auger bit to $20-\mathrm{ft}$. Grouted annulus with cement grout (Al powder added).

080ct91: Excavated for surface pad and protective posts.

110ct91: Installed 4-ft by 4-ft surface pad. brass marker and 4 protective posts. 180ct91: Extended casing 0.86-ft for total stickup of 2.52-ft.

27-290ct91: Primed and painted cap. casing and protective posts. Stenciled well number, on casing and post. 
DOE/RL-95-59

Rev. 0

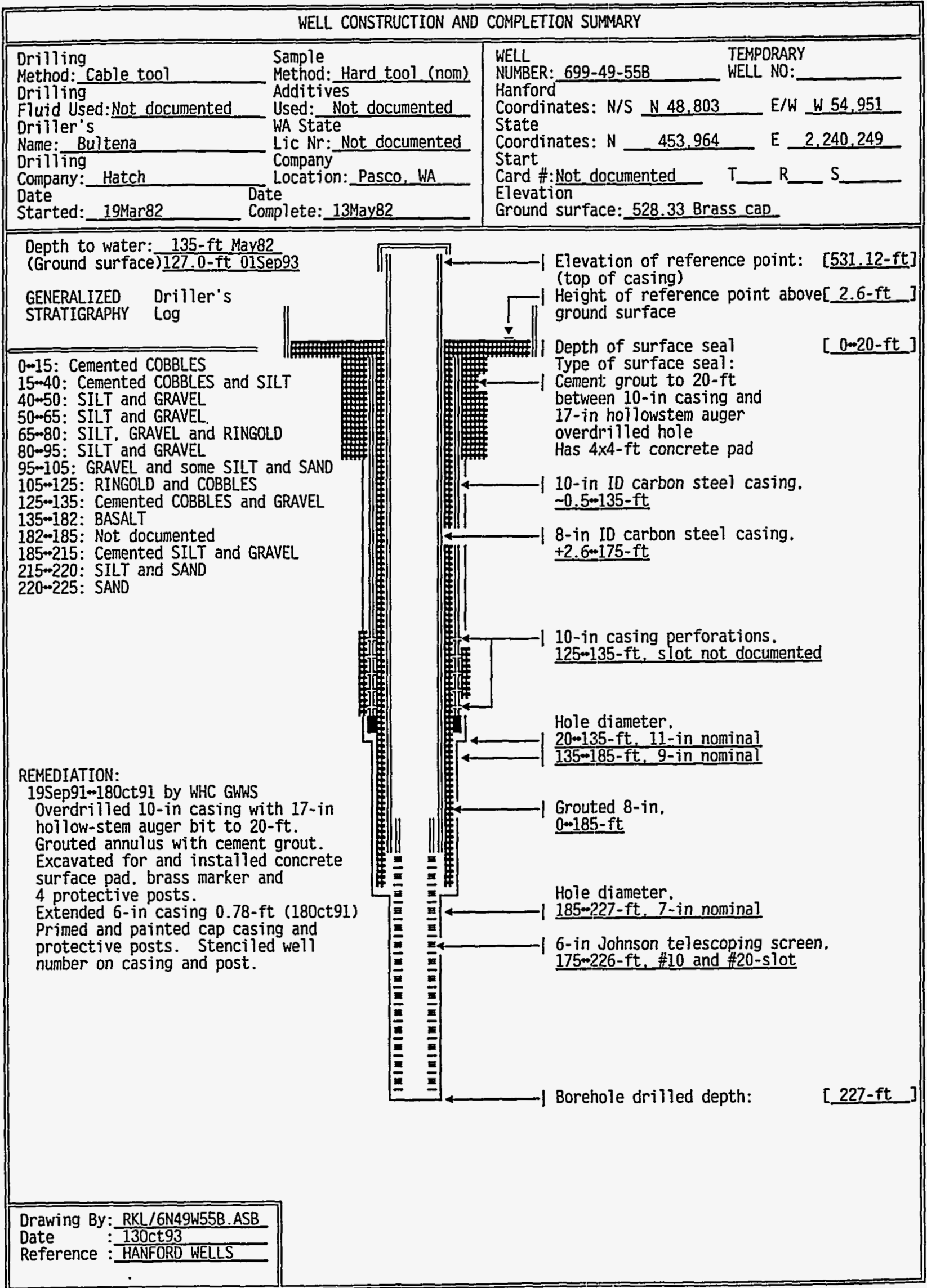


DOE/RL-95-59

Rev. 0

SUMMARY OF CONSTRUCTION DATA AND FIELD OBSERVATIONS

RESOURCE PROTECTION WELL - 699-49-55B

WELL DESIGNATION
RCRA FACILITY
CERCLA UNIT
HANFORD COORDINATES
LAMBERT COORDINATES
DATE DRILLED
DEPTH DRILLED (GS)
MEASURED DEPTH (GS)
DEPTH TO WATER (GS)
CASING DIAMETER
ELEV TOP OF CASING
ELEV GROUND SURFACE
PERFORATED INTERVAL
SCREENED INTERVAL

COMMENTS

TV SCAN COMMENTS.

DATE EVALUATED

EVAL RECOMMENDATION :

LISTED USE

CURRENT USER

PUMP TYPE

MAINTENANCE

REMEDIATION
699-49-55B

Not applicable

200-BP-1 (200 Aggregate Area Management Study)

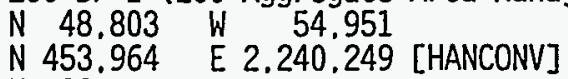

May82

227-ft

225-ft. Jun90 TV

135-ft. May82:

127.0-ft. 01Sep93

$10-$ in, carbon stee] $\sim 0.5 \cdots 135-\mathrm{ft}$;

$8-i n$. carbon steel. $+2.6+175-\mathrm{ft}$

531.12-ft. [25Feb92-NGVD' 29]

528.53-ft. Brass cap [25Feb92-NGVD'29]

None

175-226-ft. 6-in telescoping

$\# 10$ and 20-siot. Johnson.

Blank 170 - 175-ft.

: FIELD INSPECTION. 07Mar91.

Carbon steel casing, (2).

No pad, capped and locked, no posts.

No permanent identification.

FIELD INSPECTION. 160ct92.

8-in carbon steel casing. Capped and locked

4-ft by 4 -ft concrete pad, 4 posts. Identification stamped on brass marker in pad. Not in radiation zone.

OTHER:

Driller

Depths referenced to ground surface:

Jan90:

Depth to bottom: 223-ft

Depth to water: $123-\mathrm{ft}$

Top of screen $175-\mathrm{ft}$, needs scrubbing.

18Jun90:

Depth to bottom: $225-\mathrm{ft}$

Depth to water: $124.3-\mathrm{ft}$. some floating debris but fairly clean.

Casing clean. Screen $175.9+225-\mathrm{ft}$, clean. Water clear. Camera runs

were not successful in obtaining pictures until 2 weeks after development.

13 Nov90

1. Install a 2-in void grout surface seal outside

8-in casing to approximately 18-ft. OR:

2. Perforate $3=18-\mathrm{ft}$ and insta11 a 4-in liner with cement basket to approximately 20 -ft. Pressure grout to $40-p s i$.

3. Instail protective posts and concrete pad per WAC 173-160-510 and field conditions.

4. Shorten monitored interval to approximately $15-\mathrm{ft}$ by plugging back to approximately 205 -ft below ground surface.

5. Survey to water level measurement standards

$200 \mathrm{BP}-1$ quarterly water level measurement. 25May82 01 Sep93

WHC ERcharacterization and ES\&M W/1 monitoring.

PNL sitewide sampling and w/7 monitoring 93

Electric submersibie

12816Apr90: Brushed casing and screen, bailed debris.

31May90: Developed well by pumping to minimum of 9.4 NTU.

01Jun90: Attempted camera survey.

13Aug90: Installed pump.

19Sep91: Cleared site.

20-26Sep91: Overdrilled 10-in casing with 17-in auger bit to 19-ft. Grouted annulus with cement grout (Al powder added).

080ct91: Excavated for surface pad and protective posts.

110ct91: Installed 4-ft by 4-ft surface pad, brass marker and 4 protective posts.

180ct91: Extended 6-in casing $0.78-\mathrm{ft}$ for $2.52-\mathrm{ft}$ total stickup.

27-290ct91: Primed and painted cap. casing and protective posts. Stenciled number on casing and post. 
DOE/RL-95-59

Rev. 0

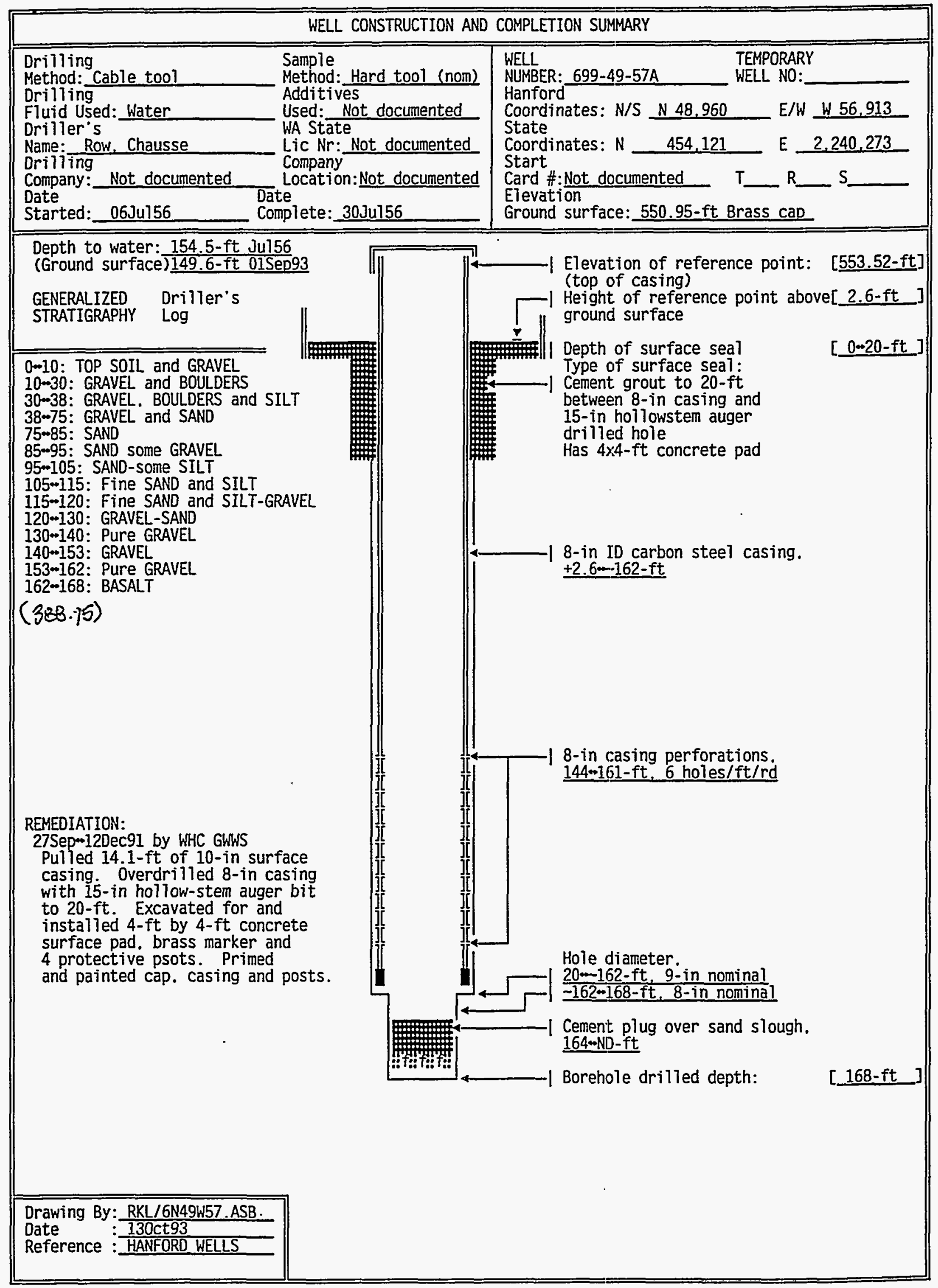




\section{SUMMARY OF CONSTRUCTION DATA AND FIELD OBSERVATIONS}

RESOURCE PROTECTION WELL - 699-49-57A

WELL DESIGNATION
RCRA FACILITY
CERCLA UNIT
HANFORD COORDINATES
LAMBERT COORDINATES
DATE DRILLED
DEPTH DRILLED (GS)
MEASURED DEPTH (GS)
DEPTH TO WATER (GS)
CASING DIAMETER
ELEV TOP OF CASING
ELEV GROUND SURFACE
PERFORATED INTERVAL
SCREENED INTERVAL
COMMENTS

AVAILABLE LOGS TV SCAN COMMENTS

DATE EVALUATED EVAL RECOMMENDATION :

\section{LISTED USE} CURRENT USER

PUMP TYPE MAINTENANCE

REMEDIATION
699-49-57A

Not applicable

200-BP-1 (200 Aggregate Area Management Study)

N 48.960 W 56.913

$N$ 454.121 E 2.240.273 [HANCONV]

Jul56

$168-\mathrm{ft}$

164.6-ft. Oct89 TV

154.5-ft, Jui56:

$149.6-\mathrm{ft}, 015 e p 93$

8-in. carbon steel. +2.57-162-ft

$553.52-\mathrm{ft}$.

$550.95-\mathrm{ft}$. Brass cap [25Feb92-NGVD'29]

$144-161-\mathrm{ft}$

Not applicable

FIELD INSPECTION. 110ct89.

Carbon steel casing.

No pad. capped and locked. no posts.

No permanent identification.

FIELD INSPECTION. 160ct92.

8 -in carbon steel casing. Capped and locked

4-ft by 4-ft concrete pad. 4 posts. Identification stamped on brass marker in pad. Not in radiation zone.

OTHER:

Driller

Nov89. depths referenced to ground surface:

Depth to bottom: $164.6-\mathrm{ft}$

Depth to water: $-148.5-\mathrm{ft}$

Perforations start at $-142-\mathrm{ft}$ and ended at $\sim 162-\mathrm{ft}$. Perforations could be

seen to bottom of casing. Well casing fairly clean of scale.

13 Nov90

1. Pull 10-in casing and install a 2 -in void grout surface seal outside 8-in casing to at least 18-ft. OR:

2. Perforate $3-18-\mathrm{ft}$ and install a 4-in liner with cement basket to approximately 20-ft. Pressure grout to 40-psi.

3. Instail protective posts and concrete pad per WAC 173-160-510 and field conditions.

4. Survey to water level measurement standards.

200 BP-1 quarterly water level measurement. 22Jun64\%01Sep93

WHC ER characterizatoin and ES\&M w/1 monitoring.

PNL sitewide sampling 93

Electric submersible

130ct89: Pulled pump.

22Nov89: Installed pump.

27Sep91: Cleared site.

11Nov91: Pulled 14.1-ft of 10-in casing.

Overdrilled 8 -in casing to 20 -ft with 15 -in hollow-stem auger bit.

12Nov91: Grouted annulus with cement grout (Al powder added).

14*15Nov91: Excavated for surface pad. annular extension and protective posts.

20Nov91: Installed 4-ft by 4-ft concrete surface pad, annular extension. brass marker and 4 protective posts.

04-05Dec91: Extended 8-in casing 0.72-ft for total of 2.5-ft stickup. Stamped casing and brass marker with well number. Removed form.

11-12Dec91: Primed and painted cap. casing and posts. 
Rev. 0

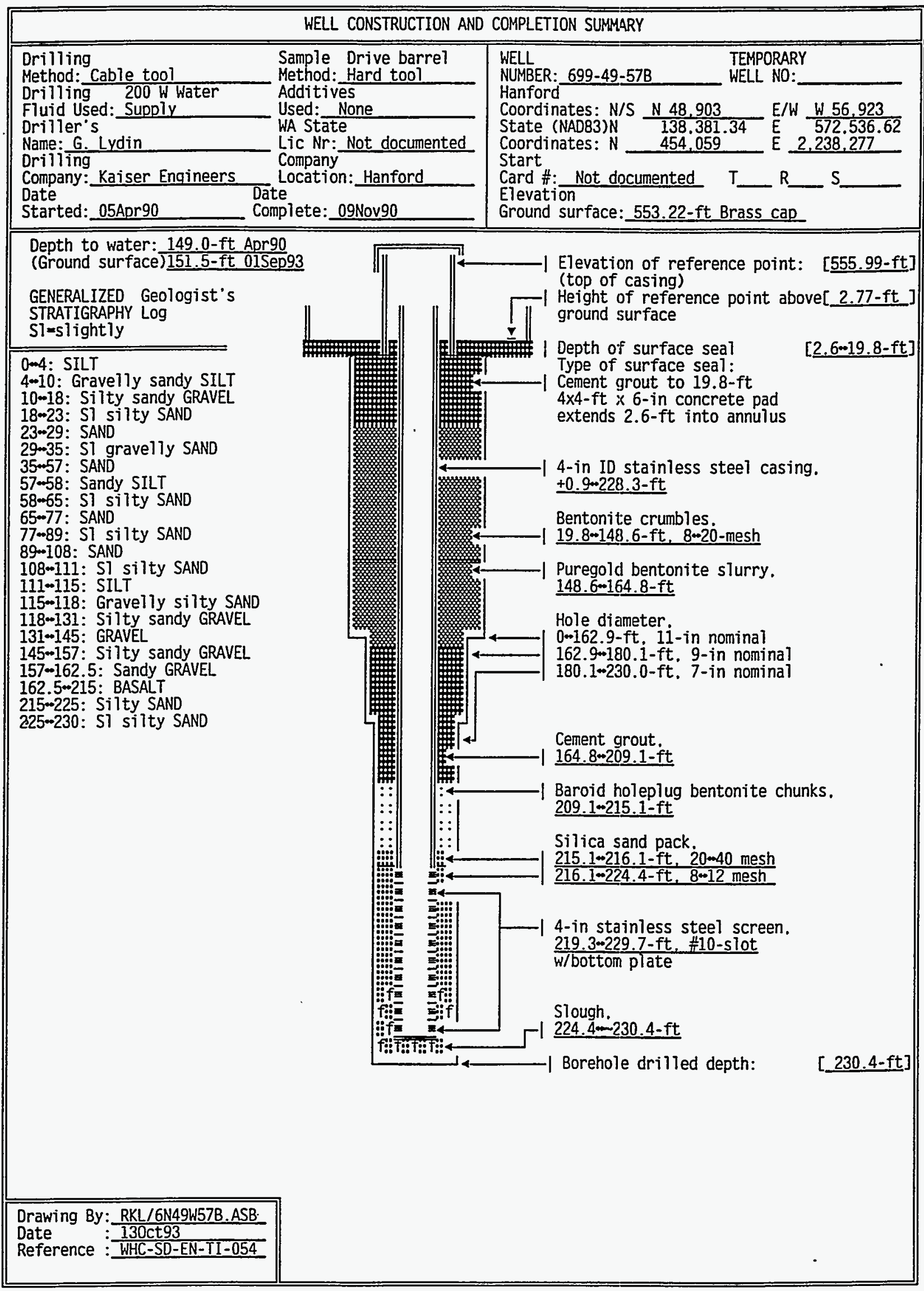


DOE/RL-95-59

Rev. 0

\section{SUMMARY OF CONSTRUCTION DATA AND FIELD OBSERVATIONS}

RESOURCE PROTECTION WELL - 699-49-57B

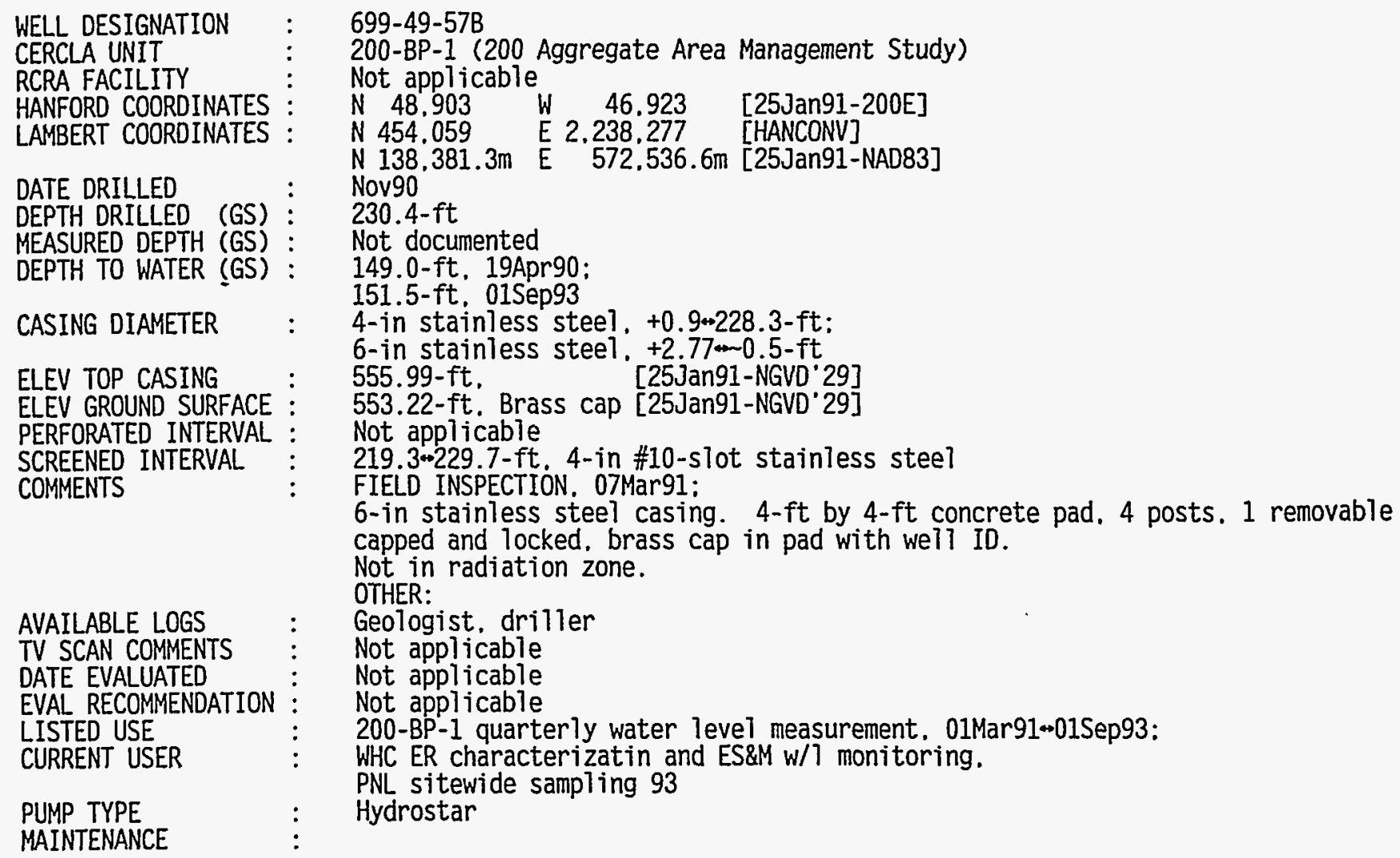


DOE/RL-95-59

Rev. 0 
Rev. 0

\section{DISTRIBUTION}

Number of Copies

ONSITE

25

M. A. Buckmaster

H4-80

G. R. Chiaramonte

H9-12

K. L. Dunks

D. B. Erb (4)

H9-10

H9-12

J. W. Green

G. L. Kasza

H9-10

K. R. Porter

H9-11

D. M. Wanek (10)

H9-12

D. M. Wanek (10)

$\mathrm{H} 0-12$

BHI Document Control (3)

H0-09

Hanford Technical Library

P8-55

Public Reading Room

$\mathrm{H} 2-53$ 